$\frac{5}{10}$
$\frac{2}{0}$
0

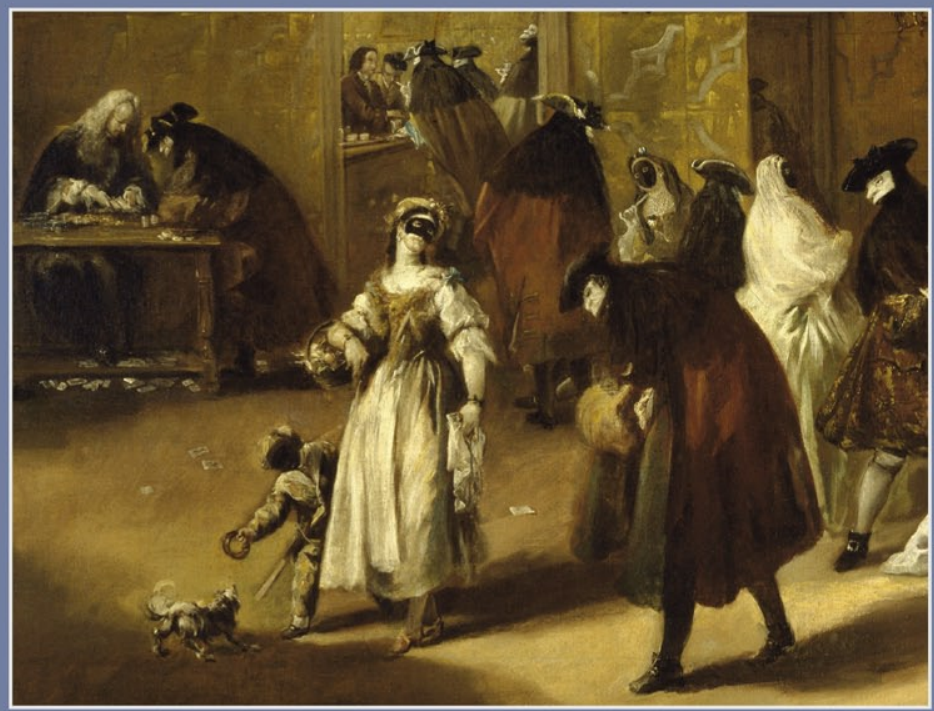

\title{
OPERA BUFFA UND SPIELKULTUR
}

EINE SPIELTHEORETISCHE UNTERSUCHUNG AM BEISPIEL DES VENEZIANISCHEN REPERTOIRES DES SPÄTEN 18. JAHRHUNDERTS

INGRID SCHRAFFL 
böhlau 
Wiener Musikwissenschaftliche Beiträge

Band 25

Herausgegeben von

Gernot Gruber 
Ingrid Schraffl

\section{OPERA BUFFA UND SPIELKULTUR}

Eine spieltheoretische Untersuchung am Beispiel des venezianischen Repertoires des späten I8. Jahrhunderts

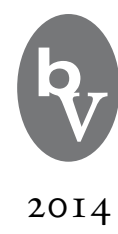

Böhlau Verlag Wien Köln Weimar 


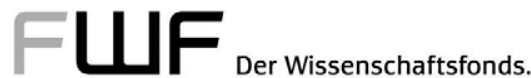

\section{Veröffentlicht mit Unterstützung des Austrian Science Fund (FWF): PUB 176-V21}

Bibliografische Information der Deutschen Nationalbibliothek:

Die Deutsche Nationalbibliothek verzeichnet diese Publikation in der Deutschen Nationalbibliografie; detaillierte bibliografische Daten sind im Internet über http://dnb.d-nb.de abrufbar.

Umschlagabbildung: Francesco Guardi, Il Ridotto, Ausschnitt (@ akg-images, Erich Lessing)

(C) 2014 by Böhlau Verlag Ges.m.b.H., Wien Köln Weimar

Wiesingerstraße 1, A-1010 Wien, www.boehlau-verlag.com

Alle Rechte vorbehalten. Dieses Werk ist urheberrechtlich geschützt.

Jede Verwertung außerhalb der engen Grenzen des Urheberrechtsgesetzes ist unzulässig.

Korrektorat: Katharina Krones, Wien

Satz: Michael Rauscher, Wien

Druck und Bindung: Theiss, St. Stefan/Lavanttal

Gedruckt auf chlor- und säurefreiem Papier

Printed in the EU

ISBN 978-3-205-79592-6 


\section{INHALT}

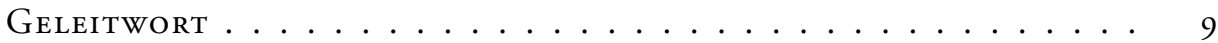

I. EINLEITUnG $\ldots \ldots \ldots \ldots \ldots \ldots \ldots \ldots \ldots \ldots \ldots \ldots \ldots$

II. Venedig als Kultur- und Opernzentrum im i 8. Jahrhundert . I3

I. Historisch-politischer Überblick . . . . . . . . . . . . . . . . . I3

2. "Il mito di Venezia" - Venedig als Vergnügungsstadt . . . . . . . . . I6

3. Venedig als Opernzentrum . . . . . . . . . . . . . . . 20

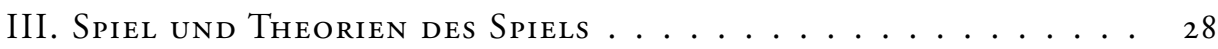

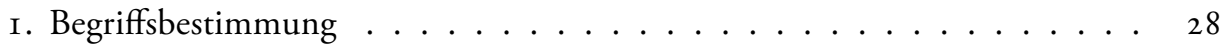

2. Theorien des Spiels . . . . . . . . . . . . . . . . . 30

2.I Historischer Überblick . . . . . . . . . . . . . . . . . . . 30

2.2 Formale Kriterien des Spiels im Vergleich . . . . . . . . . . . 4I

2.2.I Freiwilligkeit und Freiheit . . . . . . . . . . . 4 4 I

2.2.2 Handlung bzw. Beschäftigung . . . . . . . . . . . . 42

2.2 .3 Ziel in sich selbst . . . . . . . . . . . . . . . . . 44 44

2.2.4 Abgeschlossenheit und Begrenztheit in Zeit und Raum . . . . . . 47

2.2 .5 Spielregeln . . . . . . . . . . . . . . . . . 47

2.2.6 Gefühl der Spannung und Freude . . . . . . . . . . . . 48

2.2.7 Anderssein als das gewöhnliche Leben . . . . . . . . . . . . . 5 I

2.3 Gliederungsversuche . . . . . . . . . . . . . . . 55

2.4 Kunst als Spiel . . . . . . . . . . . . . . . . . . . . . . . 59

IV. Die Opera buffa im Licht der Spieltheorien . . . . . . . . . 64

I. Die Gattung Opera buffa . . . . . . . . . . . . . . . . . . . 64

2. Das Opernhaus . . . . . . . . . . . . . . . . . . . . . . . . . . 69

3. Die "Spielregeln" der Produktion . . . . . . . . . . . 78

4. Die Verwurzelung in der Commedia dell'arte . . . . . . . . . 82

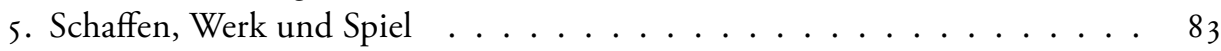

6. Die Aufführung . . . . . . . . . . . . . . . . . . . . 84

7. Das Spiel zwischen Identifikation und Distanz . . . . . . . . . . . . 89

8. Theater und Spiel als Weltmetaphern . . . . . . . . . . . . . . . 94

9. Durchkosten von Lebensmöglichkeiten und Erziehungsfunktion . . . . . 97 
ı. Musik und Spiel . . . . . . . . . . . . . . . . . . . . . . . . . 99

V. Die Gattungskonventionen der Opera buffa als „Spielregeln“ io9

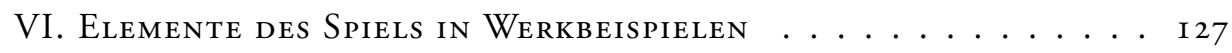

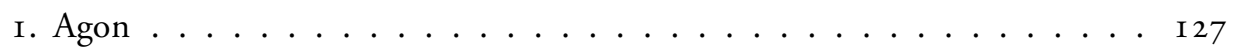

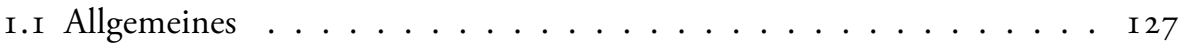

I.2 Agonale Topoi in der Opera buffa . . . . . . . . . . . I3 I

I.2.I Agon als Geschlechterkampf . . . . . . . . . . . . . I I I

I.2.2 Rivalität und Eifersucht als Auslöser für agonale Momente . . . . I34

I.2.3 Agonale Szenen . . . . . . . . . . . . . . . . . . I I37

I.2.3.I Duell- und Kampfszenen . . . . . . . . . . . . . . 138

I.2.3.2 Streitszenen . . . . . . . . . . . . . . . . I46

I.3 Gesellschaftsspiele mit agonalem Charakter . . . . . . . . . . . I54

I.4 Musikalischer Agon . . . . . . . . . . . . . . . . . . . . . I69

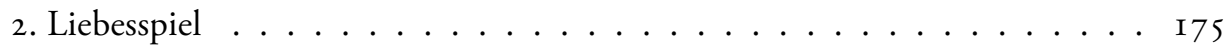

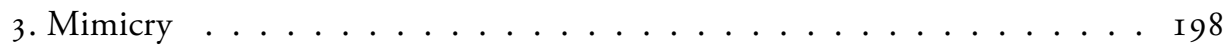

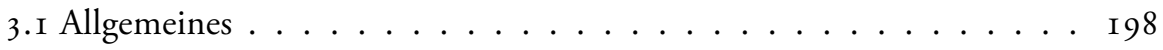

3.2 Mimicry als Nachahmungsspiel . . . . . . . . . . . . 20 I

3.3 Zwischen Nachahmung und Fiktion . . . . . . . . . 2I 2

3.4 Mimicry als Imagination . . . . . . . . . . . . 215

3.5 Mimicry als Fingiertheit: Verstellungsspiele in „La Frascatana“ . . . 228

3.6 Mimicry als Verkleidung . . . . . . . . . . . . . . 240

3.7 Exkurs: Sprachspiele . . . . . . . . . . . . . . . . . . . 247

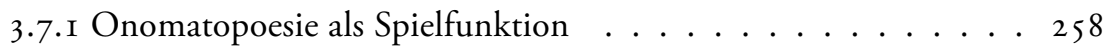

3.8 Die Burla . . . . . . . . . . . . . . . . . . . . . 262

3.9 Selbstbezüglichkeit als Spielfunktion: Die Oper in der Oper . . . . . 280

3.Io "Zerrspiegel“ als Spielfunktion . . . . . . . . . . . . 288

3.ro. I Die Zeitsatire . . . . . . . . . . . . . . 288

3.10.2 Die Parodie . . . . . . . . . . . . . . . . . 293

4. Sonderfälle: Gestaltungsspiele . . . . . . . . . . . . 302

4.I Spielendes Schaffen in "L'inutile precauzione“. . . . . . . . . . 302

4.2 Musikspiel und Tanz als ,therapeutische Spiele“ in „Li sposi in commedia“. . . . . . . . . . . . . . . 306

4.3 Jahrmarktspiele: Geschicklichkeit und Schaukunst in „Lo sposo di tre e marito di nessuna" . . . . . . . . . . . . 3I5

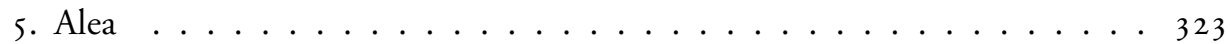

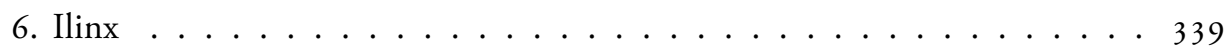




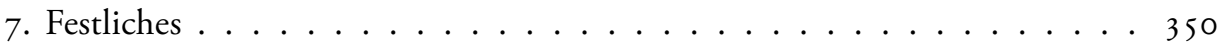

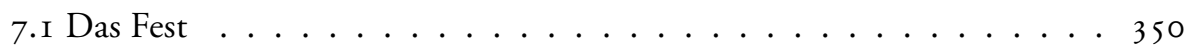

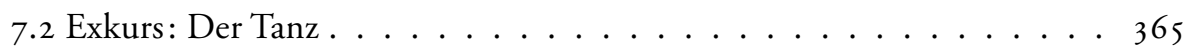

VII. Schlussbemerkungen . . . . . . . . . . . . . . . 370

ANHANG . . . . . . . . . . . . . . . . . . . 379

I. Verzeichnis der untersuchten Werke (chronologisch nach Datum der venezianischen Aufführung) . . . . . . . . . . . . . . . . 379

2. Alphabetisches Titelverzeichnis der untersuchten Werke . . . . . . . . 382

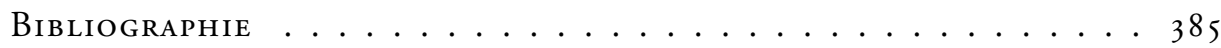

I. Primärliteratur . . . . . . . . . . . . . . . 385

I.r Libretti ....................... . . . 385

I.2 Partituren . . . . . . . . . . . . . . . . . . 387

2. Sekundärliteratur . . . . . . . . . . . . . 390

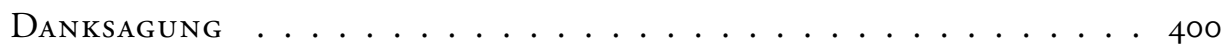

Register.......................... 4 O I 



\section{Geleitwort}

Der Blick auf die Opera buffa war in der Wissenschaft lange Zeit verzerrt und negativ getrübt: Einerseits wurden aus literarischer Perspektive Carlo Goldonis Buffa-Libretti an seinen „besseren“ reformierten Komödien gemessen, andererseits wurde von der Mozart-Forschung die italienische Buffa-Musik im Vergleich zu Mozarts Opern gering geschätzt. Erst in den letzten Jahrzehnten rückte die Opera buffa als eigenständiger Untersuchungsgegenstand in den Mittelpunkt einiger Forschungen, wodurch sich langsam das Bild von ihr zu wandeln begann. Das vorliegende Buch reiht sich in diese jüngeren Bestrebungen ein und bildet zugleich ein Beispiel für einen innovativen Forschungsansatz auf diesem Gebiet. Um das eigentliche Wesen dieser Gattung zu erfassen, wählt Ingrid Schraffl den zentralen Begriff des Spiels, der dem hohen Unterhaltungswert dieser heiteren Opernform gerecht wird.

Dieser Begriff des Spiels ist schwer fasslich und hat zu einer Vielfalt von Spieltheorien geführt. Das Problem verschärft sich beim Gegenstand der Opera buffa insofern, als hier in einem weiten Horizont von gattungsspezifischen Topoi bis hin zu Elementen des Aufführungskontextes gespielt wurde. Welche Methode aus diversen Fächern wie Anthropologie, Psychologie, Pädagogik, Kulturwissenschaft und Philosophie soll man wählen? Die Autorin gibt einen Überblick über unterschiedliche Spieltheorien und überlegt dann, welche für den Gegenstand am besten geeignet sei. Sie entscheidet sich aber nicht für eine bestimmte Theorie, um diese dann konsequent von Beispiel zu Beispiel anzuwenden. Vielmehr stellt sie den Gegenstand ins Zentrum ihrer Betrachtungen und „spielt" bei dessen Interpretation ihrerseits mit vorhandenen spieltheoretischen Ansätzen. Anders gesagt, sie greift in Anbetracht der schillernden Facettierung des Spielerischen in der Opera buffa des späten I 8. Jahrhunderts als Gattung und in deren zeitgenössischer Pflege bei jedem konkreten Fall zu einer ihr geeignet erscheinenden Theorie und deren Methode oder führt unterschiedliche theoretische Ansätze gegeneinander. Das vom Literaturwissenschaftler Stefan Matuschek betonte Charakteristikum einer „anregenden inneren Gegensätzlichkeit“ literarischer Spiele wird von Ingrid Schraffl gleichsam auf eine Metaebene der Spieltheorien projiziert und auf diese Weise zu einer eben spielerischen und doch tragenden Methode ihrer Studie. Damit entgeht sie einem drohenden Theorien-Sammelsurium. Es entsteht vielmehr ein verdichtendes Umsprechen des Gegenstandes von unterschiedlichen Seiten her, das in seiner zentripetalen Funktion letztlich doch in resümierenden Schlussbemerkungen mündet.

Ihren Ansatz wendet die Autorin exemplarisch auf das Repertoire Venedigs an, galt Venedig doch im I8. Jahrhundert als „Hauptstadt des Vergnügens“. Neben dem Kar- 
neval, der eine hohe Anziehungskraft auf Reisende aus ganz Europa ausübte, bildete die Oper einen der besonderen und bereits traditionell gewordenen Anreize an venezianischen Darbietungen. Schon um die Mitte des I7. Jahrhunderts blühte wie an keinem anderen Ort ein öffentlicher Opernbetrieb, der marktwirtschaftlich geführt wurde. „Oper“ wurde also zuerst in Venedig eine Veranstaltungsart, deren Zuschnitt sich auf zahlungskräftige Besucher richtete und nicht wie sonst primär der höfischen Repräsentation eines Fürsten diente. In der zweiten Hälfte des I 8. Jahrhunderts, als sich die Ära Venedigs als politisch bedeutsames und selbständiges Staatswesen langsam und schließlich durch die Ereignisse der französischen Revolution und die napoleonischen Kriege dem Ende zuneigte, gelangte die „Stadt des Vergnügens“ in einen irrealen, überdrehten Zustand.

Trotz der Eingrenzung der Untersuchung auf das venezianische Repertoire, weist Ingrid Schraffl - sehr zu recht - auf die Universalität der Opera buffa und ihres spielerischen Charakters hin und vermeidet somit einen auf Venedig ausgerichteten kultur- und sozialhistorischen Reduktionismus.

Gernot Gruber 
Qui si sta in allegria

Sempre in festa, sempre in gioco

Caro amico un più bel loco

No nel mondo non si dà. ${ }^{1}$

\section{EINLEITUNG}

Das Spiel fasziniert. „Es bannt, das heißt: es bezaubert.“2

Die starke Präsenz des Spiels und des Spielerischen in der Opera buffa, im dramma giocoso, scheint eine derartige Selbstverständlichkeit zu sein, dass abgesehen von beiläufigen Bemerkungen bislang keine umfassende Untersuchung zu diesem grundlegenden Aspekt der Gattung vorliegt. In diese Richtung weist in gewissem Sinne eine Studie Mary Hunters, ${ }^{3}$ die anhand der Opera buffa in Wien eine "poetics of entertainment" entwirft und die Unterhaltsamkeit dieser Gattung auf verschiedene Arten von "pleasure“

Meines Erachtens hängt der hohe Unterhaltungsfaktor der Gattung eng mit dem Aspekt des Spiels zusammen, der unter anderem als eine Ursache des besagten "pleasure" angesehen werden kann. Die Anwesenheit von Momenten des Spiels wird in dieser Untersuchung auf unterschiedlichen Ebenen sowohl der Gattung Opera buffa an sich als auch ihres Aufführungsrahmens anhand von diversen, aus verschiedenen Disziplinen stammenden Theorien des Spiels ermittelt. Die Weitläufigkeit des Spielbegriffs, der vielfältige Facetten und Erscheinungsformen umfasst, erlaubt es - unter anderem wegen seiner „anregenden inneren Gegensätzlichkeit“ viele unterschiedliche Momente der Opera buffa, von Elementen des Aufführungskontextes bis hin zu einzelnen gattungsspezifischen Topoi, auf einen einzigen Nenner zu bringen. Der Begriff des Spiels und des Spielerischen kann so als Interpretationsschlüssel des Gesamtphänomens Opera buffa verwendet werden und unter einem

1 Petrosellini/Piccinni: Le finte gemelle. Venedig 1783 (I,1).

2 Johan Huizinga: Homo ludens. Vom Ursprung der Kultur im Spiel. Hamburg 1956, S. 18 (niederländische Originalausgabe unter dem Titel Homo ludens. Proeve eener bepaling van het spel-element der cultuur. Haarlem 1938).

3 Mary Hunter: The Culture of Opera Buffa in Mozart's Vienna. Princeton 1999.

4 Dabei meint Mary Hunter unter anderem „the pleasure of the familiar" (S. 30), also die Freude am Wiedererkennen von Bekanntem, und damit verbunden "the pleasure of pervasive conventionality" (S. 31).

5 Stefan Matuschek: Literarische Spieltheorie. Von Petrarca bis zu den Brüdern Schlegel. Heidelberg 1998, S. 1. 
neuen Blickwinkel den Reiz und die besondere Beliebtheit der Gattung erklären. Dabei handelt es sich selbstverständlich um eine von vielen möglichen Sichtweisen auf die Opera buffa, die den Wert anderer Perspektiven keineswegs schmälern oder gar aufheben soll; vielmehr werden die Betrachtung und das Verständnis dieser Operngattung dadurch differenziert und um eine weitere Facette bereichert.

Ähnliches gilt meines Erachtens für die vielen unterschiedlichen Spieltheorien, die bei dieser Untersuchung berücksichtigt werden: Jede von ihnen beleuchtet unterschiedliche Aspekte des vielfältigen und vielschichtigen Phänomens des Spiels. Aus diesem Grunde werden hier möglichst viele dieser Theorien angewendet, um die spielerischen Elemente in der Opera buffa und ihrem Aufführungskontext in ihrer reichen Facettierung voll zu erfassen.

Der eben umrissene Ansatz kann an und für sich auf die gesamte Opera buffa teilweise auch auf komische Theatergattungen im Allgemeinen - bezogen werden, allerdings erfordert die Untersuchung von konkreten Werken aus praktischen Gründen eine räumliche und zeitliche Einschränkung. Venedig als „die opernreichste Stadt im I 8. Jahrhundert" ${ }^{6}$ als wichtiges Opernzentrum mit hoher Produktion sowie als Entstehungsort der eigentlichen Opera buffa ${ }^{7}$ eignet sich dabei besonders gut als „Untersuchungsraum“. Auch im Hinblick auf den Begriff des Spiels und des Spielerischen erscheint die Wahl Venedigs als Hauptstadt des Vergnügens mit seiner außerordentlich ausgeprägten Spiel- und Karnevalkultur besonders sinnvoll. Das zeitliche Untersuchungsfeld wird zweckmäßigerweise auf den Zeitraum zwischen I770 und I790 eingeschränkt, der der Blütezeit der Opera buffa nach der Etablierung der Gattungskonventionen und zugleich einer Zeit des internationalen Erfolgs der Gattung entspricht. Nicht von ungefähr bezeichnet Reinhard Wiesend die Opera buffa in diesen Jahren als „das internationale Kulturereignis schlechthin“, 8 wobei gerade Venedig als Ausgangspunkt für ihre Verbreitung fungierte.

Im Folgenden wird vor der Anwendung des Spielbegriffs auf die Opera buffa, die das zentrale Anliegen der vorliegenden Untersuchung darstellt, zunächst der historische Kontext in einem Kapitel über Venedig als Opernzentrum und Vergnügungsstätte beleuchtet und ein Überblick über die verschiedenen Theorien des Spiels geboten, um dann eine Verknüpfung der beiden Themenbereiche, nämlich des Spiels und der in Venedig aufgeführten Opere buffe, zu versuchen.

6 Reinhard Strohm: Die italienische Oper im 18. Jahrhundert. Wilhelmshaven 1979, S. 12.

7 „Die opera buffa ist in Venedig entstanden, und sie bildet zusammen mit dem Sprechtheater Goldonis vielleicht den letzten spezifisch venezianischen Beitrag zur europäischen Kultur." (Strohm, S. 251).

8 Reinhard Wiesend: Art. Opera buffa. In: Die Musik in Geschichte und Gegenwart. 2., neubearb. Ausg. hg. von Ludwig Finscher. Sachteil Bd. 7/1. Kassel u. a. 1995. Sp. 658. 


\section{Venedig als Kultur- und Opernzentrum im I8. JAHRHUNDERT}

\section{i. Historisch-politischer Überblick}

Die Geschichte Venedigs sowie die Besonderheit und Faszination dieser Stadt auf dem Meer ist in starkem Maße durch ihre einzigartige Lage geprägt. Diese ist darauf zurückzuführen, dass die Bevölkerung Venetiens sich vor den Einfällen von Hunnen, Ostgoten und Langobarden im 5. und 6. Jahrhundert auf die Laguneninseln flüchtete, wo sich nach und nach ein wichtiges Handelszentrum - das spätere Venedig - bildete. Die Lagune und die venetische Küste standen unter byzantinischer Herrschaft und blieben es - wenigstens offiziell - für lange Zeit, obwohl die Venezianer im Verlauf des 8. und 9. Jahrhunderts durch ihre wirtschaftliche und diplomatische Geschicktheit faktisch die Unabhängigkeit von Byzanz erlangten. Verwaltet wurde das damalige Venetien durch einen zunächst von der byzantinischen Regierung ernannten, später von der lokalen Bevölkerung gewählten Dux (venezianisch Doge).

Schon im 9. Jahrhundert folgte die venezianische Politik bestimmten Grundsätzen, die sich bis zum Ende der Republik, also beinahe ein Jahrtausend lang, erhielten: „Unabhängigkeit von den führenden Mächten in Ost und West, Gewinnung bzw. Erhaltung der Vorherrschaft in der Adria, Offenhaltung der Handelswege und Ausbau der eigenen Machtgrundlage",9 also vor allem der eigenen Flotte. Bereits im I I. Jahrhundert hatte sich Venedig als Seemacht im Adria-Raum behauptet, übte eine wirtschaftliche Mittlerfunktion zwischen Ost und West aus, diente als Treffpunkt zwischen byzantinischen und deutschen Händlern und hatte auch ein „Monopol für den Warenumschlag "10 inne.

Im I I. Jahrhundert wurde auch der Grundstein für die für Venedig so charakteristische republikanische Staatsform gelegt; aus dem I2. Jahrhundert stammt die berühmte venezianische Verfassung. Schon früh standen dem Dogen verschiedene Räte zur Seite, die seine Macht einschränkten. ${ }^{11}$ Zutritt zu diesen Ämtern hatte nur der Adel, allerdings konnten reiche bürgerliche Unternehmer in den Adelsstand aufsteigen und somit in die Räte aufgenommen werden. I 297 wurde der Große Rat ge-

9 Manfred Hellmann: Grundzüge der Geschichte Venedigs. Darmstadt 1976, S. 17.

10 Ebd. S. 54.

11 Als „Ende der dogalen Monarchie“ gilt das Jahr 1032 mit dem sogenannten „ersten Staatsgrundgesetz der Republik“. (Vgl. ebd. S. 36). 
schlossen und dadurch die Regierung auf die Familien beschränkt, die bis zu diesem Zeitpunkt dem Maggior Consiglio angehört hatten. Bis zum Niedergang der Republik, also rund 500 Jahre lang (I 297-1797), wurden dieselbe oligarchische Regierungsform und Konstitution beibehalten und dieselben adeligen Familien waren an der Macht, worauf unter anderem die „Stetigkeit der venezianischen Politik durch Jahrhunderte"12 zurückzuführen ist.

Durch wirtschaftliche Stärke und militärische Geschicktheit stieg die Repubblica marinara zur Großmacht auf, errang die Vorherrschaft über das gesamte östliche Mittelmeer und baute ein mächtiges Kolonialreich auf. Entscheidend für diese Entwicklungen war Venedigs Unterstützung des vierten Kreuzzugs, bei dem Konstantinopel eingenommen (I 204) und das byzantinische Reich aufgeteilt wurde. Die dadurch errungenen Stützpunkte und Kolonien im östlichen Mittelmeer ermöglichten Venedig einen beinahe uneingeschränkten Handel mit dem Osten, mussten aber auch erhalten und verteidigt werden, unter anderem gegen Genua im I3. und I4. Jahrhundert und gegen die ab dem I4. Jahrhundert vorrückenden osmanischen Türken. Durch Eroberungen auf dem Festland (Terra ferma) im I 4. und I 5 . Jahrhundert expandierte Venedig sein Kolonialreich und wurde so von einer reinen Seemacht auch zu einer Landmacht.

Im I 5. Jahrhundert erfuhr die Macht der Repubblica della Serenissima trotz der Gefährdung durch die vorstoßenden Türken und die Mailändischen Kriege ihren Höhepunkt: Nicht nur wies das venezianische Kolonialreich zu dieser Zeit seine größte Ausdehnung auf, der florierende Handel von Mittelasien bis Westeuropa und Nordafrika brachte Venedig großen Reichtum ein: Seine Einnahmen waren etwa mit denen der Großmächte England, Frankreich, Spanien vergleichbar. ${ }^{13}$

Schon im I6. Jahrhundert begann sich diese Situation allerdings zu ändern: Das Mittelmeer büßte durch die Entdeckung Amerikas seine weltwirtschaftliche Bedeutung ein, und durch die Erschließung neuer ozeanischer Schifffahrtswege verschob sich der Handel auf die atlantischen Küsten Europas. Gleichzeitig besetzten die Türken wichtige venezianische Stützpunkte im östlichen Mittelmeerraum. Die europäischen Großmächte (Frankreich, Spanien, England, Österreich) erstarkten und wurden nicht nur gefährliche wirtschaftliche Konkurrenten, sondern verbündeten sich auch gegen Venedig (Liga von Cambrai, I 508). Seitdem prägten politische Neutralität und ein geschicktes Spiel diplomatischer Allianzen Venedigs Außenpolitik.

Seit dem Angriff der Türken gegen Candia (Kreta) im Jahr i645 bis zum Frieden von Passarowitz (I7 I8), in dem der endgültige Verlust von Candia und der Morea

12 Ebd. S. 97.

13 Vgl. ebd. S. 116. 
(dem Peloponnes) bestätigt wurde, war Venedig beinahe durchgehend in verlustreiche Kriege involviert, die den Staat wirtschaftlich sehr stark in Mitleidenschaft zogen. Nach dem Frieden von Utrecht (1713) waren die venezianischen Territorien von Österreich umzingelt, so dass auch die Handelstätigkeit Venedigs weiter eingeschränkt wurde. ${ }^{14}$

Das I 8. Jahrhundert brachte eine außerordentlich lange Friedenszeit (I 7 I 8-I797) mit sich, die aber auch als politische Ohnmacht angesehen werden kann und durch einen starken Konservativismus und ein starres Festhalten an einer glorreichen Vergangenheit geprägt war. Während vom Volk und von der Mittelschicht keinerlei revolutionäre Ansätze ausgingen, waren im I8. Jahrhundert Attacken der nicht-regierenden Adeligen gegen die oligarchische Regierung an der Tagesordnung. ${ }^{15}$ Unter anderem versuchten 176I Angelo Querini und 1780 Giorgio Pisani die starre Regierungsform aufzulockern und unter Beibehaltung der republikanischen Staatsform eine Verfassungsreform einzuleiten. Darauf reagierte die oligarchische Regierung mit repressiven Maßnahmen durch die Inquisitori di Stato, ein immer häufiger eingesetztes, beinahe geheimpolizeiliches Organ. Die Politik der Oligarchen bestand in strenger Kontrolle nach innen und Neutralität und Diplomatie nach außen mit dem Ziel der Aufrechterhaltung des Status quo. Ihr reaktionärer Konservatismus hatte allerdings fatale Konsequenzen, denn die fehlende Bereitschaft zu wichtigen Änderungen - u. a. im Schiffbau, um der aufkommenden englischen Konkurrenz standzuhalten - und die ausbleibenden Reformen im wirtschaftlichen und rechtlichen Bereich - u. a. zur Auflockerung des starken Protektionismus - brachten Schifffahrt und Handel allmählich zum Untergang. Angesichts des erheblichen allgemeinen Wohlstands und allerlei Errungenschaften im Inneren der Republik wurde die Tragweite der auftauchenden Probleme weitgehend verkannt.

Die allgemeine Zufriedenheit der Bevölkerung mit ihrer Lebenssituation verhinderte auch das Wurzelfassen der inzwischen ganz Europa durchlaufenden Freiheitsbestrebungen. Im Grunde fühlten sich die Einwohner frei, denn die Freiheit war seit jeher mit der Gründung der Stadt selbst verbunden. Selbst die Französische Revolution hatte in Venedig keine besonderen Auswirkungen.

Bei der Ankunft Napoleons löste sich die Republik auf, ohne es auf einen Kampf gegen die französischen Truppen ankommen zu lassen. Die Bevölkerung beantwortete den Jakobinischen Aufruf zur Freiheit mit dem Hochruf auf „San Marco“. Das entsprach nicht nur einer politischen Treuebezeugung, sondern der Gemütslage der Bevölkerung, die anscheinend weder Grund für Unzufriedenheitsausdrücke noch für

14 Vgl. Marino Berengo: La società veneta alla fine del settecento. Florenz 1956, S. 2.

15 Vgl. ebd. S. 7. 
Aufruhr sah. Im Frieden von Campoformio (I797) wurden Venedig und Teile seiner Herrschaftsgebiete schließlich an Österreich abgetreten, um I805 nach Napoleons Sieg in Austerlitz kurzzeitig an Napoleons Königreich Italien annektiert zu werden und I 8 I 4 wieder in österreichische Hände zu fallen. ${ }^{16}$

\section{2. „Il mito di Venezia“ - Venedig als Vergnügungsstadt}

Mit dem Beginn von Venedigs politischem und wirtschaftlichem Niedergang war seine kulturelle Blüte einhergegangen, ${ }^{17}$ die bis ins I 8. Jahrhundert andauerte. Konnte Venedig nicht mehr ihr Ansehen als Handels- und Kolonialmacht aufrechterhalten, so gewann es seine Reputation als Stadt der Kunst, des Vergnügens und des luxuriösen Lebens. Besonders im I 8. Jahrhundert wurde, um die sinkende politische Bedeutung der Republik zu verschleiern, der „Venedig-Mythos“ gefördert. Europaweit präsentierte sich Venedig mit seinem prächtigen Karneval, seiner einzigartigen Dichte an Theater- und Opernhäusern, an Spielhäusern und der großen Anzahl an Festen und Feierlichkeiten als die Hauptstadt der Unterhaltungen und des Vergnügens. Als Stadt auf dem Wasser übte Venedig eine besondere Faszination aus und war aufgrund seiner Einzigartigkeit eines der beliebtesten Reiseziele der Zeit sowie eine Pflichtetappe auf der im I 8. Jahrhundert so beliebten Italienreise. ${ }^{18}$ Gerade ausländische Reisende trugen mit ihren Berichten besonders zur europaweiten Bekanntheit und Verbreitung des „Venedig-Mythos“ bei.

Die Selbstzelebrierung der Serenissima und das müßige und luxuriöse Leben ihrer Einwohner betrachtet der consigliere Giovanni Rossi rückblickend als typische Merkmale der langen Friedenszeit, die in den 80 Jahren vom Verlust der Morea bis zum Ende der Republik, also beinahe während des gesamten I 8. Jahrhunderts, in Venedig herrschte: „I Veneziani dopo la perdita della Morea, agli ozi della pace si abbandonarono. Per circa ottanta anni si visse nella città con grandissima inerzia; l'amore per la pubblica vera fortuna sommamente si è indebolito: le tendenze alla mollezza, al lusso,

16 Marino Berengo: La società veneta alla fine del settecento. Florenz 1956. Marino Berengo: Il problema politico-sociale di Venezia e della sua terraferma. In: Vittore Branca (Hg.): Storia della civiltà veneziana. Bd. 6. La civiltà veneziana del Settecento. Florenz 1960. Piero Del Negro und Paolo Preto (Hg.): Storia di Venezia. Dalle origini alla caduta della Serenissima. Bd. 8. L’ultima fase della Serenissima. Rom 1998. Manfred Hellmann: Grundzüge der Geschichte Venedigs. Darmstadt 1976. Egle Trincanato und Umberto Franzoi: Venise au fil du temps. Paris 1971, Kap. 13.

17 Vgl. Hellmann, S. 160.

18 Dass Venedig eine touristische Attraktion war, bezeugt unter anderem ein im 18. Jahrhundert in mehreren Auflagen erschienener Reiseführer von Giovanni Battista Albrizzi : Forestiere illuminato intorno le cose più rare e curiose della città di Venezia e dell'isole circonvicine. 
alla gozzoviglia immensamente si accrebbero, snervaronsi tutte le civiche virtù. Non si pensava che a grandeggiare e a sollazzarsi." 19

Diese Zurschaustellung von Üppigkeit und Überfluss und die in ein „perenne carnevale“ mündende Spiel- und Vergnügungssucht der damaligen Venezianer interpretiert Nicola Mangini dagegen als (Schutz-)Reaktion auf die schwierige politische und wirtschaftliche Situation bzw. als Nostalgie und Sehnsucht nach einer glücklichen und ruhmvollen Vergangenheit. ${ }^{20}$

Feliciano Benvenuti sieht hingegen die Fülle an Unterhaltungs- und Spielmöglichkeiten in erster Linie als politisches Machtinstrument der konservativen oligarchischen Regierung zur Erhaltung der Einheit des Staates und der Gemeinschaft. Das für eine Republik charakteristische Fehlen eines Hofes mit höfischen Vergnügungen sowie die räumliche Eigenheit der Lagunenstadt, in der sich alle hauptsächlich zu Fuß fortbewegten, lässt Benvenuti vermuten, dass es bei vielen Vergnügungen kaum zu einer Trennung der gesellschaftlichen Stände kommen konnte. Alle Gesellschaftsschichten nahmen am Karneval und an den vielen anderen Festen und Feierlichkeiten teil, die eine gezielt eingesetzte, vereinheitlichende Funktion ausübten. ${ }^{21}$

Benvenuti zählt dabei etliche öffentliche Volks-, Stadt- bzw. Nationalfeste auf wie die prunkvolle festa della Sensa, in der die symbolische Vermählung Venedigs mit dem Meer gefeiert wurde, der die fiera della Sensa, die große Himmelfahrtsmesse folgte; oder die festa del Redentore, mit einer Prozession, die über eine durch Boote gebildete Brücke über dem Canal grande zur chiesa del Redentore führte. Es handelte sich dabei um eine in ein Volksfest eingebettete religiöse Zeremonie in Erinnerung an die Befreiung von der Pest im Jahre I 577. Denselben Hintergrund - nur auf eine im I6. Jahrhundert ausgebrochene Pestepidemie bezogen - hatte die festa della Madonna della Salute. Feuerwerke, Straßentheater und andere Arten von Vorführungen

19 Giovanni Rossi: Storia delle leggi e de’ costumi veneziani. Bd. XI : BNMV. Mss. It. Cl. VII 1396 (9287), c. 231. Zit. nach Nicola Mangini: I teatri di Venezia. Mailand 1974, S. 91. Der Verlust der Morea fand 1715 statt und wurde 1718 im Frieden von Passarowitz bestätigt.

20 Vgl. Mangini: I teatri di Venezia. S. 91.

21, „...) non vi era, cioè, il piacere per il piacere ma tutto era finalizzato all'unità politica dello Stato e della comunità che lo formava. Senza distinzioni, quindi, tra piacere delle classi alte e piacere delle classi medie e del ceto popolare. Alle feste tutti partecipavano e partecipavano in eguale misura: il doge rappresentava veramente l'unità di tutti e la sua presenza alla testa dei cortei riassumeva quell'unità. Egli non era visto come un sovrano lontano e distaccato ma era uno, seppure il princeps, tra tutti i Veneziani, e così, senza che vi fosse una corte di cortigiani, i nobili partecipavano alle feste vivendole allo stesso titolo di tutti gli altri cittadini. Forse il fatto che qui non vi fossero carrozze e tutti dovessero andare a piedi poneva una condizione di inevitabile parità ;" (Feliciano Benvenuti: La città dei „piaseri“. In: Piero Del Negro und Paolo Preto (Hg.): Storia di Venezia. Dalle origini alla caduta della Serenissima. Bd. 8. Rom 1998, S. 717). 
begleiteten häufig die Stadtfeste, deren Hauptfunktion die der Selbstzelebrierung der Serenissima war und die eine "periodica rappresentazione del mito di Venezia nella vita reale“ 22 bewirkten.

Besondere Wettspiele zogen in Venedig viele Zuschauer an, unter anderem die corsi, ${ }^{23}$ die prunkvollen Regatten, der moresca-Tanz, eine Art stilisierter Schaukampf, und die forze d'Ercole genannten Menschenpyramiden. Die drei letztgenannten Spiele versinnbildlichten, genauso wie die I705 verbotenen Faustkämpfe auf den venezianischen Brücken (guerre dei pugni), den Kampf zwischen Nicolotti und Castellani, den zwei Faktionen, in die die Venezianer ursprünglich je nach Stadtteil unterteilt waren.

Den Höhepunkt aller Unterhaltungen bildete natürlich der berühmte Karneval, der mindestens drei Monate dauerte und unzählige Vergnügungen bot, die am Faschingsdonnerstag (giovedi grasso) in venezianischen „Spezialitäten“ gipfelten, wie die caccia dei tori, eine Art Stierkampf, bei dem Hunde auf alte Stiere oder Ochsen losgelassen wurden, sowie der volo dell'angelo oder volo del turco, bei dem ein Akrobat auf einem Seil vom Markusturm „hinunterflog“ bzw. sich in verschiedenen Seilkunststücken produzierte. ${ }^{24}$

Weitere Attraktionen des damals europaweit berühmten venezianischen Karnevals waren die vielen unterschiedlichen Arten von spontanen oder institutionalisierten theatralischen Vorführungen, von kleinen, improvisierten Straßenbühnen bis zu den großen Theater- oder Opernhäusern, deren Hauptsaison gerade die Karnevalszeit war. Straßenbälle (feste da ballo in campo) und vor allem das bunte Treiben der maskierten Bewohner selbst boten ebenfalls Gelegenheit zu ausgelassenem Vergnügen. ${ }^{25}$

Der Grund für die Berühmtheit Venedigs als Hauptstadt der Unterhaltungen ergab sich allerdings nicht allein aus seinen prachtvollen Festen und ausgiebigen Karneval-Feierlichkeiten. Auch im Alltag der regen und eleganten Hafen- und Handelsstadt waren Spiele und Vergnügungen allgegenwärtig. Vor allem Glücks- und Hasardspiele wurden zu jeder Saison und in allen Gesellschaftsschichten gespielt, in Wirtshäusern, botteghe da gioco und botteghe di caffe, aber auch in Theatern und Opernhäusern, die teilweise durch gesetzlich geregelte und von Unternehmern geführte Spielbanken fi-

22 Sergio Bettini: Venezia. Novara 1953. Zit. nach Bianca Tamassia Mazzarotto: Le feste veneziane. I giochi popolari, le cerimonie religiose e di governo. Florenz 1961, S. XVIII.

23, „... i Corsi per i canali, quell'antichissimo esercizio cioè che portava in giorni determinati varie imbarcazioni a raccogliersi in un sol luogo a scopo di divertimento, per poi andare, venire, cercar di superarsi, di insinuarsi nel fitto groviglio mobile, dando spettacolo di destrezza a quanti si raccoglievano sulle rive." (Tamassia Mazzarotto, S. 64).

24 Nach einem tödlichen Unfall im Jahre 1759 wurden der volo dell'angelo durch einen volo della colombina und der Akrobat durch eine große Taube aus Holz ersetzt.

$25 \mathrm{Zu}$ den vielen weiteren Festen der Republik Venedig siehe Bianca Tamassia Mazzarotto: Le feste veneziane. I giochi popolari, le cerimonie religiose e di governo. Florenz 1961. 
nanziert wurden. Glücksspiele wurden häufig auch bei prunkvollen privaten Festen und Bällen in den palazzi der Patrizier gespielt. Als regelrechte Spielhäuser fungierten in Venedig unzählige casini und ridotti, die je nach Ausrichtung zu Freudenhäusern degradierten oder aber als gehobene gesellschaftliche Treffpunkte, als literarische Salons, als Orte der galanten Konversation und der politischen Diskussion dienten, in denen auch musikalische Akademien und Bälle veranstaltet wurden, wobei das Glücksspiel eine konstante Komponente ausmachte. Die vielen casini verschafften Venedig gemeinsam mit dem öffentlichen ridotto im palazzo Dandolo a S. Moisè, dem ersten staatlichen Glücksspielhaus der westlichen Welt, den Ruf der „europäischen Hauptstadt des öffentlichen Glücksspiels“, ${ }^{26}$ zu dem wohl auch die schon seit I 522 staatlich geregelte Lotterie und das seit 1734 eingeführte Lottospiel beitrugen. Der berühmte, I638 gegründete und I774 aus sittlichen Gründen wieder geschlossene ridotto war nur zur Karnevalssaison offen - allerdings zur verlängerten Saison von Oktober bis Aschermittwoch - und konnte nur mit einer Maske betreten werden, so dass sich dort Menschen aus unterschiedlichen Gesellschaftsschichten sowie Venezianer mit Fremden vermischten. Neben den beliebten Spielen, wie faraone, bassetta, picchetto, biribiss, tressette, meneghella ${ }^{27}$ und anderen Karten-, Würfel- und Wettspielen, konnte man sich an vielen unterschiedlichen Spielorten gleichzeitig auch an den durch die Maske ermöglichten karnevalesken Identitätsspielen erfreuen.

Masken waren in Venedig nicht nur während des Karnevals gebräuchlich. Für die Adeligen war überhaupt das ganze Jahr lang beim Auftreten in der Öffentlichkeit die bautta vorgeschrieben, die typisch venezianische Maske, bestehend aus einem dunklen Umhang, dem tabarro, einer weißen Maske, der larva, die durch ihre Form auch die Stimme der maskierten Person verzerrte, einem Dreispitz (tricorno) und dem xendal, einem Spitzenschleier. Nur mit einer Maske durften auch die Theater betreten werden, die nach Taddeo Wiel die Lieblingsvergnügungsstätten der Venezianer darstellten. ${ }^{28}$ Dementsprechend hoch war im Verhältnis zur Einwohnerzahl neben einigen privaten teatrini die Anzahl der öffentlichen Theater, die jeweils auf Sprechtheater oder Oper sowie auf bestimmte Genres spezialisiert waren. Auch die starke

26 Vgl. Manfred Zollinger und Thierry Depaulis: Zwischen Allegorie und Realismus. Zur Thematisierung des Spiels in der Musik. In: Günther G. Bauer (Hg.): Homo ludens. Musik und Spiel. Bd. 10. Internationale Beiträge des Institutes für Spielforschung und Spielpädagogik an der Hochschule „Mozarteum“ Salzburg. München, Salzburg 2000, S. 45.

27 Vgl. Benvenuti, S. 724f. und Alessandro Mazzola: Giocatori e spie. Note e segnalazioni in materia di ludicità veneziana del XVIII secolo. In: Ludica. Annali di storia e civiltà del gioco. 5-6, Viella 2000, S. $266 f$.

28, „...) il teatro era lo svago prediletto dei veneziani.“ (Taddeo Wiel: I teatri musicali veneziani del settecento. Catalogo delle opere in musica rappresentate nel secolo XVIII in Venezia (1701-1800). Venedig 1897, S. LXVIII). 
Verbreitung der Theater betrachtet Benvenuti als ein Symptom für den nachlassenden militärischen Einsatz Venedigs und eine für Friedenszeiten typische Lockerung der Sitten: „I teatri (...) ebbero a Venezia una grande diffusione in concomitanza con lo svigorirsi delle pubbliche imprese militari tese alla conquista e poi alla conservazione dei mercati medio-orientali e il conseguente rilassarsi dei costumi, tipico dei periodi di pace. ${ }^{29}$

Aus den verhältnismäßig häufigeren Eingriffen der Provveditori delle Pompe, also des für die Überwachung der öffentlichen Feste zuständigen Amtes, das beispielsweise gegen das Einnehmen von Mahlzeiten in den Theatern vorging, Verordnungen zu den Kleidungssitten verabschiedete oder 1756 die Errichtung neuer Theater verbot bzw. regelte, schließt Mangini, dass während des gesamten I 8. Jahrhunderts eine Intensivierung des Theaterlebens stattgefunden haben muss. ${ }^{30}$ Laut Benvenuti waren die venezianischen Theater Orte der gesellschaftlichen Zusammenkunft, in denen unterschiedliche Stände zusammenkamen, denn die Reichen mieteten die Logen, während im Parterre das Volk saß. Die öffentlichen Theater, in denen geschäftliche wie amouröse Treffen, Konversationen, Glücksspiele und vieles mehr möglich waren, ${ }^{31}$ wurden ähnlich wie der öffentliche ridotto als auf überschaubarem Raum eingegrenzte und leicht zu überwachende Vergnügungsstätten angesehen, die ähnlich wie die prunkvollen Feste der Serenissima eine für den Staat nützliche Kontroll- und Ventilfunktion hatten.

\section{Venedig als Opernzentrum}

Schon seit den Anfängen der Oper hatte sich Venedig als eines der wichtigsten europäischen Opernzentren etabliert. Hier waren im 17. Jahrhundert die ersten öffentlichen, also von höfischen Kontexten losgelösten Opernhäuser Europas entstanden

29 Benvenuti, S. 730.

30 „In questo secolo più frequenti che in precedenza furono gli interventi delle varie magistrature, che nel quadro della situazione politico-economica (...) appaiono particolarmente preoccupate dai ,disordini“ fomentati appunto dall'intensificarsi della vita teatrale con tutti gli inconvenienti relativi. I Provveditori delle Pompe, fin dal 1711, emanano ordinanze severissime contro il lusso e gli sprechi che si vedono nei teatri." (Mangini: I teatri di Venedig. S. 95. Vgl. auch S. 97).

31 „A queste rappresentazioni assisteva in platea il popolo minuto mentre i ricchi, fossero o meno nobili, affittavano i palchi (...). Sia nella platea che nei palchi, si svolgeva poi una diversa, commedia': il teatro era un luogo di incontro dove si potevano passare ore spensierate; nei palchi si poteva fare di tutto, dalla conversazione più innocente agli incontri più peccaminosi. (...) In platea si scambiavano richiami, si avvicinavano dame e cavalieri, si davano appuntamenti non solo di affari o di gioco, ma anche di amore." (Benvenuti, S. 732). 
(I637 S. Cassiano, I639 Ss. Giovanni e Paolo, I640 S. Moisè, I64 I Teatro Novissimo etc.). Venedigs einzigartiger Dichte an Theater- und Opernhäusern entsprach ein üppiges Theater- und Opernleben, das in starkem Maße zur Bildung des „VenedigMythos" beitrug. Auch im I 8. Jahrhundert hatte Venedig eine führende Rolle in der Opernproduktion inne, die ihm allerdings Neapel streitig zu machen begann. Aus dem immer bedeutender werdenden süditalienischen Opernzentrum kamen in den vierziger Jahren commedie per musica nach Venedig, bis innerhalb weniger Jahre die Impresari der venezianischen Theater erkannten, dass es wirtschaftlich günstiger war, die beliebten komischen Opern vor Ort zu produzieren. Ab I749 begann die Anzahl der exportierten Opere buffe die der importierten Werke zu übertreffen. ${ }^{32}$ Das Jahr I749 markierte außerdem den Beginn der fruchtbaren Zusammenarbeit des berühmten Komödiendichters Carlo Goldoni mit dem Komponisten Baldassarre Galuppi, die mit ihren erfolgreichen Werken die Gattungsmerkmale der Opera buffa prägten. Die von ihnen experimentierten Formen und Muster wurden nämlich in den darauffolgenden Jahren wiederholt aufgegriffen, woraus sich regelrechte Konventionen der als Opera buffa bezeichneten Gattung entwickelten. Aus diesem Grund wird meistens Venedig als Entstehungsort der Opera buffa definiert. Gerade der Erfolg der Opera buffa bestärkte den Ruhm Venedigs als Opernzentrum: „La prestigiosa fama di Venezia, centro musicale e teatrale, era sostenuta e rinverdita dalla prepotente affermazione di un nuovo genere operistico: il ,dramma giocoso per musica' " 33

Zur besonderen Beliebtheit des komischen Genres, das in Venedig in den I77oer und I 78 oer Jahren - dem ,ventennio d'oro dell'opera comica a Venezia“34 - etwa 70 Prozent der gesamten Opernproduktion ${ }^{35}$ ausmachte, bemerkt Wolfgang Osthoff: „Die Vorherrschaft der Opera buffa um I 780 zeigt sich etwa in einer Stadt wie Venedig mit ihren öffentlichen Opernhäusern, einer Stadt, wo die Werkwahl nicht von dynastischen Wünschen und Forderungen beeinflußt war. "36 Die Loslösung von einem höfischen Kontext und die kommerziell ausgerichtete Führung der Theater beeinflussten in starkem Maße die Theateraktivität, die Spielpläne und somit auch die Verbreitung des komischen Genres. Tatsächlich standen - entsprechend den erwähnten Proportionen in der Opernproduktion - bei dreien der vier auf Oper spezialisierten Theater

32 Vgl. Giovanni Polin: „Il mondo della luna“ di Goldoni-Galuppi: uno studio sulla tradizione settecentesca. Fonti musicali italiane 13 (2008), S. $40 f$.

33 Stefano Capone: Piccinni e l'opera buffa. Modelli e varianti di un genere alla moda. Foggia 2002, S. 215.

34 Mario Armellini: Art. Livigni. In: Enciclopedia Treccani. Dizionario Biografico degli Italiani. Bd. 65, 2005. http://www.treccani.it/enciclopedia/filippo-livigni_(Dizionario_Biografico)/

35 In den 1760er Jahren machte die Opera buffa in Venedig ca. 60 Prozent der Gesamtproduktion aus.

36 Wolfgang Osthoff: Die Opera buffa. In: Wulf Arlt, Ernst Lichtenhahn und Hans Oesch (Hg.): Gattungen der Musik in Einzeldarstellungen. Gedenkschrift Leo Schrade. Bern, München 1973, S. 679. 
(Teatro Giustiniani di San Moisè, Teatro Grimani di San Samuele, Teatro Tron di San Cassiano) vorwiegend komische Opern auf dem Programm, während allein das 1755 eröffnete Teatro Grimani di San Benedetto im Zeitraum zwischen I770 und I790, abgesehen von der Herbstsaison des Jahres I77I, durchgehend Opere serie zur Aufführung brachte. ${ }^{37}$ Von den vielen in Venedig aufgeführten komischen Opern - dazu werden in dieser Statistik nicht nur Opere buffe, sondern auch Intermezzi und Farse gezählt - waren beinahe 80 Prozent eigens für Venedig produziert und lediglich 20 Prozent aus anderen, vorwiegend italienischen Städten importiert. Die Lagunenstadt war nicht nur eines der produktivsten italienischen Opernzentren, sondern diente darüber hinaus auch als „Ausgangspunkt für die Verbreitung der Stücke in Norditalien und im außeritalienischen Europa." 38

Die venezianischen Theater standen im Besitz der reichen Patrizierfamilien, die sie ursprünglich selbst geführt hatten, dann immer häufiger einem Impresario in Pacht gaben. Aufgrund der steigenden finanziellen Schwierigkeiten ging das Eigentum der Theater in der zweiten Hälfte des I 8. Jahrhunderts immer mehr an Gesellschaften mit mehreren Trägern über. Als vielleicht bemerkenswertestes Beispiel lässt sich die Familie Grimani nennen, die I766 in einer finanziellen Notlage zwei von ihren insgesamt drei Theatern abgeben musste, nämlich das S. Benedetto und kurz darauf das S. Samuele, während sie nur noch das Teatro San Giovanni Grisostomo behalten konnte. Das S. Benedetto wurde an die Besitzer der Logen übereignet, die eine „nobile società proprietaria“" gründeten, 39 und Ähnliches geschah mit dem S. Samuele, für das ab I770 die „Eccellentissima Società del Teatro di San Samuele“ als Inhaber belegt ist. ${ }^{40}$ Dieses Ereignis bildete einen bedeutenden Einschnitt im venezianischen Opernleben, Mangini spricht sogar von der „fine di un'epoca“, vom Ende des „teatro de casada“ und dem allmählichen Übergang zu „forme societarie“, die vor dem Hintergrund der schwierigen wirtschaftlichen Situation geeigneter waren, die finanzielle Belastung einer Theaterführung zu übernehmen. ${ }^{41}$ Mangini interpretiert diesen Übergang als Verbürgerlichung des Theaters, denn die Entscheidungen der Eigentümer und Verwalter seien nicht mehr durch die Prestige-Motivationen der Patrizier geprägt, sondern durch kommerzielles Kalkül. ${ }^{42}$

37 Die Opernsaisonen waren in Venedig die Karneval-, die Herbstsaison und die Fiera dell'Ascensione (Himmelfahrtsmesse). Bei Letzterer durften allerdings lediglich Opere serie aufgeführt werden.

38 Wiesend: Art. Opera buffa. In: MGG. Sp. 657.

39 Vgl. Francesco Passadore und Franco Rossi: Il Teatro San Benedetto di Venezia. Cronologia degli spettacoli 1755-1810. Venedig 2003, S. IX.

40 Vgl. Mangini: I teatri di Venezia. S. 130.

41 Vgl. ebd. S. $129 f$.

42 „Tutti segni che sottolineano, in generale, una diminuita disponibilità finanziaria, e di conseguenza il 
Nichtsdestotrotz oder gerade deswegen intensivierte sich die Aktivität der venezianischen Theater in den I770er Jahren und die Produktion der im Vergleich zu den Opere serie weniger aufwendigen Opere buffe stieg deutlich an. Das produktivste Opernhaus dieser Zeit war das kleine Teatro Giustiniani di San Moisè im Besitz der Familie Giustiniani, das Buffa-Theater schlechthin, dessen geringe Ausmaße und anmutiger Anblick häufig mit der intimen Atmosphäre und der guten Akustik in Verbindung gebracht und mit einer „sala di conversazione“ verglichen wurden. ${ }^{43}$ Wenige Jahre nach seiner Schließung (I 8 I 8) beschreibt Giovanni Rossi das S. Moisè folgendermaßen: „Era il più grazioso teatrino ch'immaginar si potesse, capace di settecento spettatori, al più, piccolo in vero, con palchetti angusti, ma interamente di gaio aspetto. Tutto vi faceva con poco bella comparsa: niente perdevasi della declamazione e della musica: voci discrete diventavano sufficienti; a proporzione era necessariamente formata l'orchestra. “44 Die durch die Größe des Theaters erleichterte Kommunikation unter den Zuschauern einerseits sowie zwischen Bühne und Publikum andererseits - in einem Brief aus dem Jahr 1755 sprach Gasparo Gozzi von einem „continuo dialogo fra i palchi e i recitanti“ ${ }^{45}$ - dürfte einer der Gründe für den Erfolg dieses Opernhauses gewesen sein. Nicht zu unterschätzen ist aber auch der Beitrag des äußerst produktiven Buffa-Librettisten Giovanni Bertati, der von I 772 bis 1787 das Teatro San Moisè leitete, ${ }^{46}$ für das er in diesem Zeitraum über 40 Libretti schrieb.

Das Teatro Grimani di San Samuele behauptete sich ab I747, als es nach einem Brand wieder auf- und ausgebaut wurde, als „il maggior teatro d'opera buffa“, 47 konnte aber keine so markante Kontinuität in der Buffa-Produktion verzeichnen wie das S. Moisè. Unterbrechungen fanden zunächst augrund der plötzlichen finanziellen Krise der Familie Grimani vor dem Besitzwechsel statt, dann als 1772 im S. Samu-

prevalere nei rapporti di gestione del calcolo economico più che delle motivazioni di prestigio. (...) il teatro (...) s'simborghesisce' perdendo del tutto quel po' d'alone mecenatesco e principesco che gli era pur rimasto attorno per molto tempo dopo esser diventato uno spettacolo pubblico." (Ebd. S. 92).

43 Giovanni Rossi bezeichnet das S. Moisè als ein „,teatrino' sempre pieno di gente, ove contava però anche il gusto di poter distinguere tutti da qualsiasi punto, e parlarsi, proprio come in una sala da conversazione." (Rossi. Zit. nach Maria Giovanna Miggiani : Il teatro di San Moisè (1793-1818). Bollettino del centro Rossiniano di Studi. Anno XXX (1990) Nr. 1-3. Hg. von der Fondazione Rossini Pesaro. Urbino 1991, S. 5).

44 Ebd. Die übliche Besetzung des venezianischen Orchesters, der von Galuppi geprägten „orchestra di Buranello", bestand aus 12 Geigen, 6 Bratschen, 4 Celli, 5 violoni, 4 Oboen und Flöten, 4 Hörnern und Trompeten. (Vgl. Christine Villinger: Mi vuoi tu corbellar. Die opere buffe von Giovanni Paisiello. (Mainzer Studien zur Musikwissenschaft 40), Tutzing 2000, S. 83).

45 Opere di Gasparo Gozzi. Bd. 2. Mailand 1832, S. 480.

46 Miggiani, S. 8.

47 „In questo primo ventennio dopo la rifabbrica il S. Samuele s'impose (...) come il maggior teatro d'opera buffa." (Mangini: I teatri di Venezia. S. 128) 
ele eine französische Schauspieltruppe gastierte, schließlich als von der Herbstsaison I 787 bis zur Karnevalsaison 1792 die Produktion auf Opere serie umgestellt wurde. Dieser Richtungswechsel am Teatro S. Samuele war für die vorübergehende Umkehrung der Buffa-Seria-Proportionen im venezianischen Repertoire ausschlaggebend. Nachdem im Mai des Jahres I792 das auf Opera seria spezialisierte Teatro La Fenice eröffnet wurde, widmete sich das S. Samuele wieder dem komischen Genre, das nach einer kurz andauernden Seria-Mode in den darauffolgenden Jahren wieder einen Aufschwung erfuhr.

Unter der Konkurrenz mit diesen beiden auf Opera buffa spezialisierten Häusern andere Theater wie das große San Giovanni Grisostomo, das Sant'Angelo oder das San Benedetto brachten nur in vereinzelten Fällen Opere buffe auf die Bühne ${ }^{48}$ - litt das Teatro Tron di San Cassiano unter anderem wegen seiner isolierten, entlegenen Position „al di là delle acque“ direkt neben der verrufenen „contrada de le Carampane“ ${ }^{49}$ einem armseligen Prostituiertenviertel. Die größten Unruhen, gegen die die Inquisitori di Stato vorgehen mussten, fanden in diesem Opernhaus statt. Über Bankette (cene) und Prostitution in den Logen berichtet unter anderem Casanova, ein Spitzel der Inquisitori im Jahr I 776. ${ }^{50}$ In früheren Zeiten wurde das Theater direkt von den Eigentümern, der Familie Tron verwaltet, bis es aus finanzieller Not mehrere Jahre lang (I755-I762) geschlossen blieb. Nach seinem Umbau im Jahr 1763 versuchte man, mit unterschiedlichen Genres Publikum anzulocken, musste aber schließlich aus wirtschaftlichen Gründen vor allem auf die niedrigeren Farse, Intermezzi und Komödien zurückgreifen, die beim Publikum aus dieser Gegend am besten ankamen. ${ }^{51}$ Opere buffe wurden im untersuchten Zeitraum in den Jahren I775-1777 unter dem daraufhin inhaftierten Impresario Giuseppe Pietro Pisoni aufgeführt, sowie später ab I787. Abgesehen von diesen Zeiträumen wurden in den I770er Jahren am S. Cassiano vor allem Farse mit gesprochenem Text und gesungenen Arien von der

48 Beim Teatro San Giovanni Grisostomo der Familie Grimani standen nur von 1778 bis 1780 Opere buffe auf dem Spielplan, sonst wurden dort in den 1770er und 1780er Jahren hauptsächlich Sprechtheaterstücke aufgeführt. Ähnliches gilt für das Teatro Sant'Angelo und das Opera-seria-Theater San Benedetto, in denen im untersuchten Zeitraum nur jeweils zwei Opere buffe aufgeführt wurden. Die kleinen privaten Theater wie das des Conte Alessandro Pepoli spielten, was die Opera buffa betrifft, kaum eine Rolle.

49 Vgl. Nicola Mangini: Sulla diffusione dell'opera comica nei teatri veneziani. In: Maria Teresa Muraro (Hg.): Venezia e il melodramma nel settecento. Bd. 1. Florenz 1978 (Studi di musica veneta 6), S. 182.

50 „Donne di mala vita e giovinotti prostituiti commettono ne’ palchi in quarto ordine que’ delitti che il governo, soffrendoli, vuole almeno che non sieno esposti all'altrui vista. Ciò avviene dopo l'opera." (Giacomo Casanova: Storia della mia vita. Hg. von Piero Chiara. Mailand 1965, Bd. 7, S. 76. Zit. nach Mangini: I teatri di Venezia. S. 102).

51 Vgl. Mangini: Sulla diffusione dell'opera comica nei teatri veneziani. S. 182. 
Compagnia de' Comici aufgeführt, in den I780ern dagegen vorwiegend von Sängern dargebotene, sich kaum von zweiaktigen Opere buffe unterscheidende Intermezzi mit gesungenen Rezitativen.

$\mathrm{Zu}$ bemerken ist dabei, dass zu dieser Zeit in Venedig die größtenteils aus Rom importierten Intermezzi im Gegensatz zu ihrer Herkunftsstadt meistens nicht als Zwischenspiele, sondern als abendfüllende Werke verwendet wurden, während zwischen den Akten einer Oper in der Regel balli aufgeführt wurden. Angesichts der verwirrenden Vielfalt der Gattungsbezeichnungen muss bemerkt werden, dass oft für ein und dasselbe Werk unterschiedliche Termini verwendet wurden, deshalb wird in dieser Arbeit nur bedingt zwischen dramma giocoso per musica, der gängigsten Bezeichnung auf den gedruckten Libretti, opera buffa und intermezzo, intermezzo giocoso bzw. intermezzi in musica und der seltenen, in Venedig erst Ende der $1780 e r$ Jahre aufkommenden Bezeichnung commedia per musica unterschieden, zumal keine relevanten Unterschiede festzustellen sind, vor allem nicht im Hinblick auf den spielerischen Aspekt. Letzteres gilt an sich auch für die fars $a^{52}$ auf die aber in der Werkanalyse nicht weiter eingegangen wird, weil sie aufgrund der meist nur gesprochenen Dialoge einer gesonderten Kategorie zugeordnet wird. Sowohl die Komponisten der Zwischenaktballette als auch die Farsa-Komponisten werden in den Libretti selten genannt und scheinen sich oft von denen der untersuchten komischen Opern zu unterscheiden.

Unter den Letzteren ist besonders Giovanni Bertati zu nennen, der nach Goldonis prägendem Beitrag ab Anfang der I77oer Jahre als Leiter des S. Moisè eine führende Position in der venezianischen Librettodichtung einnahm. Die übrigen Textdichter scheinen zwischen den Theatern gewechselt zu haben - bzw. schon vorhandene Libretti wurden neu vertont -, denn die Namen Filippo Livigni, Carlo Goldoni, Pietro Chiari, Tommaso Grandi, Lorenzo Da Ponte, Giuseppe Petrosellini, Giuseppe Palomba, Giambattista Lorenzi, u. a. erscheinen in den I770er und I780er Jahren auf den Spielplänen verschiedener Opernhäuser.

Während unter den Librettisten viele Venezianer zu finden sind, stammt die Musik häufig von Komponisten aus der neapolitanischen Schule. Der mit Abstand produktivste Komponist war in Venedig in den I770er und I78oer Jahren Pasquale Anfossi, sehr häufig wurden an verschiedenen Theatern auch Opere buffe von weiteren „Neapolitanern" wie Giovanni Paisiello, Domenico Cimarosa, Gennaro Astarita, Pietro Guglielmi, Michele Mortellari, Niccolò Piccinni, Giovanni Valentini aufgeführt, so-

52 Die Rede ist hier von der zweiaktigen venezianischen Farsa der 1770er Jahre mit Prosatexten und nicht von der einaktigen Farsa der Jahrhundertwende. Zu den unterschiedlichen Farsa-Typen siehe Roberto Verti: Indizi su repertorio, geografia e milieu delle farse per musica. In: Maria Teresa Muraro und David Bryant (Hg.) : I vicini di Mozart. Bd. 2. Florenz 1989, S. 597-624. 
wie von den „Römern“ Giacomo Rust und Felice Alessandri. Unter den norditalienischen Komponisten hebt sich besonders Giuseppe Gazzaniga ab, dessen Zusammenarbeit mit Giovanni Bertati an jene von Goldoni und Galuppi erinnert, die zwar beide noch lebten, aber kaum mehr für Venedig produzierten. ${ }^{53}$ Norditalienische Autoren von Opere buffe waren außerdem Giuseppe Sarti und Francesco Bianchi, ein einziges Werk stammt von Luigi Cherubini und eines von Antonio Salieri. Ausländische Komponisten sind kaum vertreten, lediglich von Vicente Martín y Soler, Joseph Schuster und Johann Gottlieb Naumann sind in Venedig vereinzelt Opern aufgeführt worden.

Viele dieser Autoren schrieben ihre Opere buffe eigens für Venedig, von anderen wurden nur für andere Städte verfasste Werke in die immer nach Neuigkeiten Ausschau haltende Lagunenstadt importiert. In die Betrachtung fällt in dieser Arbeit das gesamte Opera-buffa-Repertoire ${ }^{54}$ des Zeitraums I770-I790 und nicht nur die eigens für Venedig komponierten Opern, die allerdings den Großteil des Repertoires ausmachen. Es handelt sich um eine Zeit des intensivierten Opernlebens, in der auch „Kriege“ unter den Theatern geführt wurden, die vor allem auf der Konkurrenz im „accaparramento dei cantanti di maggior fama“ beruhten. ${ }^{55}$ Die erwähnte neue Ausrichtung des Teatro San Samuele, das ab 1787 Opere serie zur Aufführung brachte, entfachte einen ,regelrechten Theaterkrieg, der die Venezianer in den Jahren 1787 bis I 792 in Samuelisti und Benedettisti entzweite “. ${ }^{56}$ Das Unterhaltungsprogramm der im Untergang begriffenen Republik wurde immer kommerzieller und als sich der Staat auflöste, arbeitete die Unterhaltungsmaschinerie weiter. Um die Jahrhundertwende verbreitete sich besonders die Gattung der (meist einaktigen) Farsa, die als „una sorta di surrogato dell'opera", 57 als billig und minderwertig hingestellt wird. Erst nach I 8 I 4 begannen zweiaktige Opern wieder zu überwiegen und die Anzahl der aufgeführten Farse ging zurück. ${ }^{58}$ In der Zwischenzeit hatte Napoleon mehrere Theater und Opernhäuser schließen lassen, um eine gewisse Proportion zwischen der Anzahl der Theater und der Einwohnerzahl der Stadt herzustellen. ${ }^{59}$ Der Karneval war inzwischen von den Besatzungsmächten abgeschafft worden, um Unruhen zu vermeiden.

53 Goldoni lebte seit 1762 in Paris und Galuppi schrieb 1773 seine letzte Oper und widmete sich dann vorwiegend der Kirchenmusik.

54 Die Werkauswahl für die konkrete Werkanalyse erfolgte nach dem Kriterium der Erhaltung und Auffindbarkeit der Partituren.

55 Mangini: I teatri di Venezia. S. 95.

56 Arnold Jacobshagen: Opera semiseria. Gattungskonvergenz und Kulturtransfer im Musiktheater. (Archiv für Musikwissenschaft, Beiheft 57), Stuttgart 2005, S. 106.

57 Verti, S. 604.

58 Vgl. Miggiani, S. 13ff.

59 Vgl. Passadore u. Rossi, S. XXIV. 
Das allgemein als eine „Blütezeit der Spielkultur“60 angesehene I 8. Jahrhundert ging zu Ende und im 19. Jahrhundert, in dem von Venedig ein trostloses Bild überliefert wird, ${ }^{61}$ trat „in fast allen Manifestationen der Kultur der Spielfaktor stark in den Hintergrund." 62

Nach diesem Überblick über den historischen Kontext der zu behandelnden Gattung folgt nun eine intensive Auseinandersetzung mit dem Begriff des Spiels und mit den Theorien des Spiels, um in Folge eine unübliche Annäherung der beiden Bereiche, zunächst auf einer allgemeinen und theoretischen Ebene, dann anhand von praktischen Werkbeispielen, vorzunehmen.

60 „Die Kultur des zu Ende gehenden 18. Jahrhunderts wurde nicht nur geprägt von Meisterleistungen auf dem Gebiet der Musik, Literatur und Künste, sondern war auch eine Blütezeit der Spielkultur. Adel, Bürger und Bauern hatten gleichermaßen Anteil an dieser Entwicklung. Alle Arten spielerischer Unterhaltung waren große Mode. Bücher mit Spielanleitungen erreichten immer größere Auflagen, Spielzimmer und Spielmöbel waren kein Luxus mehr, kurz, ein nicht geringer Anteil des Alltags, vor allem aber die Sonn- und Feiertage waren dem Spiel gewidmet." (Günther G. Bauer: Spielleidenschaft. In: Gernot Gruber und Joachim Brügge (Hg.): Das Mozart-Lexikon. Laaber 2005, S. 783).

61 „Alla Venezia settecentesca (...) succede, ben si sa, quella ottocentesca: scoronata, umiliata, desolata; rassegnata a sprofondare a poco a poco nella laguna." (Diego Valeri: Il mito del Settecento veneziano. In: Vittore Branca (Hg.): Storia della civiltà veneziana. Bd. 3. Dall'età barocca all'Italia contemporanea. Florenz 1979, S. 129.

62 Huizinga, S. 185. 


\section{Spiel und Theorien des Spiels}

\section{BEgRIFFSBESTIMMUNG}

Angesichts der Bedeutungsvielfalt des Wortes „Spiel“ und seiner nahezu unbegrenzten Anwendungsmöglichkeiten ${ }^{63}$ ergibt sich hier die Notwendigkeit, den im alltäglichen Sprachgebrauch gängigen Begriff - von Wittgenstein zu Recht als „Begriff mit verschwommenen Rändern" bezeichnet ${ }^{64}$ - zu umreißen. Im Allgemeinen wird Spiel definiert als „Verhaltensbereich bei Mensch und Tier, in dem die spielerische Aktivität eigenen, von allem anderen Verhalten abgegrenzten Regeln folgt, sich frei von äußerer Zwecksetzung oder Zwang vollzieht und damit für den Menschen einen Bereich der Freiheit und Offenheit individuellen Handelns erschließt." 65 Darüber hinaus wird häufig betont, dass es sich um eine Tätigkeit handelt, die aus Freude an ihr selbst ausgeübt wird.

Von einigem Interesse mag zunächst die etymologische Berücksichtigung sein. Bezeichnenderweise lassen sich weder frühere Sprachwurzeln noch indogermanische Verwandtschaften für das alt- und mittelhochdeutsche spil (Verb ahd. spilon und mhd. spiln) finden. Dasselbe gilt für das lateinische ludus (Verb ludere). Das legt die Vermutung nahe, dass es sich um eine so grundlegende Tätigkeit handelt, dass unter Verzicht auf Ab- bzw. Herleitungen ein eigenständiges Lexem geprägt wurde. ${ }^{66}$ Die ersten aufgezeigten Bedeutungen des deutschen und lateinischen Wortes deuten auf das Tanzen oder jedenfalls auf eine tänzerische Bewegung (auch auf Licht, Schatten und andere Elemente bezogen) hin, bevor sich daraus die später grundlegende Bedeutung des Spielens entwickelte. Das lateinische ludus nahm dann sehr bald die Bedeutung von Schauspiel und parallel dazu Wettkampf (griechisch agòn) an, bevor sich die Bedeutungen von Kurzweil und Spaß dazugesellten, die dieses Wort mit iocus

63 „Eindrucksvoll wird dies im Grimmschen Wörterbuch vorgeführt. Für das Substantiv ,Spiel‘ verzeichnet es unter 23 Bedeutungsvarianten insgesamt 132, für das Verb ,spielen' unter 22 Varianten insgesamt 215 verschiedene Verwendungsmöglichkeiten." (Matuschek, S. 4).

64 Ludwig Wittgenstein: Philosophische Untersuchungen. Frankfurt a. M. 1977, S. 60.

65 Art. Spiel. In: Brockhaus. Die Enzyklopädie. Leipzig, Mannheim 1998 (20. Aufl.), S. 583.

66 Huizinga bemerkt dazu: „Man kann zwar im Deutschen, ein Spiel treiben“ und im Holländischen ,een spelletje doen', das eigentlich zugehörige Zeitwort aber ist Spielen selbst. Man spielt ein Spiel. Mit anderen Worten: um die Art der Tätigkeit auszudrücken, muß der im Substantiv enthaltene Begriff wiederholt werden, um das Verbum zu bezeichnen. Das bedeutet allem Anschein nach, daß die Handlung von so besonderer und selbständiger Art ist, daß sie aus den gewöhnlichen Arten von Betätigungen herausfällt: Spielen ist kein Tun im gewöhnlichen Sinne." (Huizinga, S. 43). 
(= Scherz, Spaß, dann auch Spiel und Zeitvertreib, aber auch Spott) teilt. Die aus dem gesprochenen Volkslatein abgeleiteten romanischen Sprachen haben ludus als zu hochsprachlich aufgegeben und das Wort für den Spielbegriff aus dem volkstümlicheren mittelalterlichen jocus abgeleitet (vgl. italienisch gioco, französisch jeu, spanisch juego, portugiesisch jogo, rumänisch joc).

Im Englischen wird sprachlich unterschieden zwischen play und game, während im Deutschen mit dem Wort „Spiel“ beides gemeint sein kann. Das Spiel in der Bedeutung von game ist meistens durch ein Regelsystem organisiert, das auch dessen Ausgang bestimmt, und zwar als Gewinn bzw. Sieg oder Verlust bzw. Niederlage oder auch als Unentschieden. Dazu zählen Gesellschaftsspiele (z. B. Kartenspiele, Brettspiele), Glücksspiele, aber auch (sportliche) Wettkämpfe und Ballspiele. Das Spiel im Sinn von play kann im Deutschen wiederum in verschiedene Bedeutungsfelder unterteilt werden: Eines, das für die vorliegende Untersuchung von nicht geringer Bedeutung ist, ist das Spiel als Theaterstück, als schauspielerische Vorführung, als Darstellung, als Gestik und Mimik. Mit „spielen“ ist dabei „schauspielerisch darstellen“, oder genereller ausgedrückt „so tun als ob“ gemeint. Ein zweites, für diese Arbeit ebenfalls relevantes Bedeutungsfeld ist das der musikalischen Darbietung, des Spielens eines Instruments. ${ }^{67}$ Eine weitere grundlegende Bedeutung ist die des Spiels als lebhafte, leichte, harmonische Bewegung (Wellenspiel, Farbenspiel). Damit verbunden ist auch die Bedeutung des Verbs „spielen“ als „schimmern, schillern“. ${ }^{6}$

67 Für das Theater-Spielen und Musik-Spielen wird nur im Deutschen, im Englischen und Französischen das Wort "Spiel“ (play, jeu) verwendet, während im Italienischen und Spanischen spezifische Termini gebraucht werden (recitare, suonare; recitar, tocar).

Dazu Huizinga: „Musizieren trägt von vornherein beinahe alle formalen Merkmale des Spiels an sich (...). An sich wäre es vollkommen begreiflich, wenn man alle Musik unter Spiel einbezöge. Zieht man jedoch in Betracht, daß Spielen als Musizieren niemals auf Singen angewendet wird und lediglich in einigen Sprachen gebräuchlich zu sein scheint, dann wird es wahrscheinlicher sein, daß hier das verbindende Moment zwischen Spiel und instrumentaler Technik in dem Begriff der raschen, behenden und geordnet verlaufenden Bewegung zu suchen ist." (Huizinga, S. 48).

Moritz Lazarus, der Spiel als Bewegung definiert, vermutet, dass der Grund für den Gebrauch des Wortes „spielen“ für den musikalischen Vortrag in der Sichtbarkeit der Bewegung liegt. Vgl. Moritz Lazarus: Über die Reize des Spiels. Berlin 1883, S. 23. Zit. nach Scheuerl: Theorien des Spiels. S. 66.

68 Art. spielen. In: Renate Wahrig-Burfeind (Hg.): Wahrig. Deutsches Wörterbuch. Gütersloh, München 2006 (8. Auflage), S. 1386. 


\section{Theorien des Spiels}

Da es sich beim Spielen um eine grundlegende Tätigkeit des Menschen handelt, kann es nicht verwundern, dass Überlegungen dazu sehr früh angestellt wurden und dass im Laufe der Geschichte regelrechte Theorien dazu entstanden.

\section{I Historischer Überblick}

Aion pais esti paizon, pesseuon.

Dieses Fragment von Heraklit wird von Stefan Matuschek als „der älteste Zeuge für die Verführungskraft des Spielbegriffs“69 bezeichnet. Seine übliche Übersetzung lautet „Der Weltlauf ist ein Kind, das spielt, hin und her die Spielsteine setzt.“ In dieser Interpretation (aion kann jedoch auch Zeit, Lebenszeit oder Ewigkeit bedeuten ${ }^{70}$ ) bildet das Fragment die Keimzelle für spätere Theorien, die den Spielbegriff als Weltmetapher verwenden: In erster Linie ist dabei an Eugen Finks „Spiel als Weltsymbol“71 zu denken, in dem das Spiel zur philosophischen Weltformel erhoben wird, aber auch an die These zweier Biochemiker, Manfred Eigen und Ruthild Winkler, die folgendermaßen lautet: „Alles Geschehen in unserer Welt gleicht einem großen Spiel. (...) Wir sehen das Spiel als das Naturphänomen, das in seiner Dichotomie von Zufall und Notwendigkeit allem Geschehen zugrunde liegt." ${ }^{22}$ Dass sich der Spielbegriff als universelle Erklärung der Welt eignet, scheint an seiner facettenreichen Semantik und seiner suggestiven Kraft zu liegen. Matuschek nennt den Begriff des Spiels den „erfolgreichsten natursprachlichen Vorschlag für eine Weltformel“".73 Eine ähnliche Verwendung ist in einer häufig zitierten Passage aus Platons Gesetzen zu finden : „Man muß Ernst machen mit dem Ernsten, und es ist Gott, der alles seligen Ernstes wert ist, der Mensch aber ist dazu gemacht, ein Spielzeug Gottes zu sein, und das ist wirklich das Beste an ihm. So muß denn jedermann, ein Mann so gut wie eine Frau, dieser Weise folgend und die schönsten Spiele spielend das Leben leben. (...) Spielend muß es gelebt werden, gewisse Spiele spielend, opfernd, singend und tanzend, um die Götter gnädig zu stimmen."74 Hier werden die Menschen als Spielzeug Gottes erklärt, wobei der Spielbegriff pejorativ verwendet wird, um die Minderwertigkeit der

69 Matuschek, S. 6.

70 Vgl. ebd. S. 5.

71 Eugen Fink: Spiel als Weltsymbol. Stuttgart 1960.

72 Manfred Eigen und Ruthild Winkler: Das Spiel. Naturgesetze steuern den Zufall. München 1975, S.11.

73 Vgl. Matuschek, S. $4 f$.

74 Platon: Leges VII 803 CD. Zit. nach Huizinga, S. 26. 
Menschen gegenüber dem göttlichen Ernst darzustellen. Den Menschen wird hierbei eine "Spieler-Natur“ zugeschrieben, die besonders im 20. Jahrhundert in positiver Konnotation wieder aufgegriffen wird, vor allem in der Theorie des niederländischen Kulturhistorikers Johan Huizinga.

In der Antike taucht die erste detaillierte Behandlung des Spielbegriffs in einer organischen Theorie erstmals in Aristoteles' Politik VII ${ }^{75}$ auf, innerhalb der Diskussion um Arbeit und Muße. Das Spiel dient nach Aristoteles der Erholung von der Arbeit, wird aber streng vom Begriff der Muße unterschieden, obwohl beide als Tätigkeit definiert sind, in der „man nichts weiter sucht als die Tätigkeit selbst“ ${ }^{76}$ Der Unterschied zwischen Muße und Spiel scheint für Aristoteles darin zu liegen, dass „die Muße in ihrem Zweck autonom“ ist, während das Spiel „von vorausliegender Ermüdung“ abhängt. ${ }^{77}$ Mit dem Thema „Selbstzweck versus Fremdzweck“ eröffnet Aristoteles eine der Hauptfragen um den Spielbegriff, die später, vor allem im 20. Jahrhundert, von Spieltheoretikern aus verschiedenen Disziplinen erörtert wurde.

Nach Aristoteles scheint die theoretische Auseinandersetzung mit dem Spiel viele Jahrhunderte lang ad acta gelegt worden zu sein. Im Mittelalter haben Theoretiker und Gelehrte im Allgemeinen eine sehr negative Einstellung gegenüber dem Spiel bzw. jeglicher Art von Vergnügen und Freude. Augustinus sieht in den Spielen „nichts Nützliches und Heilsames. Sie lenken nur den Geist ab und dienen zur Verschwendung der Zeit, die auf das Lernen verwandt werden sollte. Sehr oft sind sie für die Kinder die Ursachen zu zahlreichen Sünden. “78

75 „Denn die Muße (...) ist der Angelpunkt, um den sich alles dreht. Denn wenn auch beides sein muss, so ist doch das Leben in Muße dem Leben der Arbeit vorzuziehen, und das ist die Hauptfrage, mit welcher Art Tätigkeit man die Muße auszufüllen hat. Man wird doch wohl nicht behaupten wollen, dass man sie auf eitles Spiel verwenden müsse. Dann wäre ja das Spiel der Zweck unseres Daseins. Wenn das aber unmöglich ist, und man des Spieles vielmehr bei der Arbeit pflegen soll - denn der Müde braucht Erholung, und das Spiel ist der Erholung wegen, und die Arbeit geschieht mit Mühe und Anstrengung nun, so folgt, dass man dem Spiele nur mit Beobachtung der rechten Zeit seiner Anwendung Raum geben darf, indem man es wie eine Medizin gebraucht. Denn eine solche Bewegung der Seele ist Ausspannung und wegen der damit verbundenen Lust Erholung. Die Muße dagegen scheint Lust, wahres Glück und seliges Leben in sich selbst zu tragen. Das ist aber nicht Anteil derer, die arbeiten, sondern derer, die feiern. Denn wer arbeitet, arbeitet für ein Ziel, das er noch nicht erreicht hat, das wahre Glück aber ist selbst Ziel und bringt, wie allen feststeht, nicht Scherz, sondern Lust." (Aristoteles: Politik VII. Zit. nach Stepina: Clemens Stepina: Systematische Handlungstheorie. Wien 2007, S. 485).

76 Aristoteles: Die Nikomachische Ethik. Zit. nach Matuschek, S. 29.

77 Vgl. Matuschek, S. 31. „Er [Aristoteles] argumentiert dabei mit solchem Nachdruck, daß man einen wenngleich unausgesprochenen, so doch genau visierten Gegner vermuten darf. Die neuere Aristoteles-Forschung sieht die Stelle in Platons Gesetzen dafür an, die von der Spiel-Natur des Menschen spricht." (Matuschek, S. 29).

78 Zit. nach Giovanni Antonio Colozza: Psychologie und Pädagogik des Kinderspiels. Altenburg 1900, 
Früher hat hingegen Quintilian nicht nur das Verb ludere (anknüpfend an Aristoteles' Begriff der eutrapelia, der Wortgewandtheit) für das rhetorisch-literarische Spiel verwendet - wobei einerseits der Einsatz bestimmter rhetorischer Figuren, andererseits die Souveränität im Umgang mit der Sprache gemeint sind -, sondern auch (aus der pädagogischen Perspektive) das Lernen in spielerischer Form gefordert.

In denselben zwei Bedeutungen taucht der Spielbegriff im I 5. und I 6. Jahrhundert wieder auf: bei den Humanisten Lorenzo Valla und Erasmus von Rotterdam. Letzterer verbindet die beiden genannten Verwendungen des Spielbegriffs miteinander und setzt sie in „ein zum spielenden Lernen unterhaltsames Lateinbuch"79 um, das nicht nur die lateinische Sprache lehrt, sondern auch die (rhetorische) Kunst der Wortverdrehung, in deren Zusammenhang häufig der Begriff des Spiels erscheint.

Im Zeichen von Ambivalenz und Doppelsinn steht auch Rabelais' Roman Gargantua et Pantagruel, in dessen Prolog ein Ballspiel (jeu de paulme) allegorisch erwähnt wird, wobei der „Richtungswechsel des Balls“ als Metapher für „die Mehrsinnigkeit des Textes" 80 steht.

Im I6. Jahrhundert erscheinen vor allem in Italien verschiedene Dialoge, Sammlungen und Traktate über das Spiel, was ein wachsendes theoretisches Interesse und eine positivere Haltung dem Spiel gegenüber vermuten lässt.

In Bologna erscheint I 55 I eine der Caterina de’ Medici gewidmete Spielsammlung von Innocentio Ringhieri: Cento giuochi liberali, et d'ingegno. Wenige Jahre später wurde in Venedig ein Traktat über das Ballspiel gedruckt (Antonio Scaino: Trattato del Giuoco della Palla. I 555 ).

Girolamo Bargaglis Dialogo dé giuochi (in den I $560 e r$ Jahren entstanden, zwischen I 572 und I 609 gedruckt) ist ein Handbuch mit praktischen Spielanleitungen, enthält allerdings auch einige theoretische Gedanken zum Thema Spiel. Es handelt sich um einen fiktiven Dialog, der zwischen einem ehemaligen Mitglied der Accademia degli Intronati in Siena und jüngeren Männern stattfindet, die die aufgrund von Krieg und Belagerung der Stadt geschlossene Akademie wieder beleben wollen und sich beim Alten erkundigen, welche Spiele vor den Kriegen in der Accademia gespielt wurden. Offensichtlich wurden in den Akademien neben der Beschäftigung mit Literatur, Kunst und Wissenschaft auch Spiele gespielt, vor allem literarische Gesellschaftsspiele. Bezeugt wird dies (wenigstens für Frankreich) vom Dictionnaire de l'Académie Françoise, dessen zweite Definition des Begriffs académie folgendermaßen lautet: „un lieu

S. 110 (italienische Originalausgabe unter dem Titel Il giuoco nella psicologia e nella pedagogia. Turin 1895).

79 Vgl. Matuschek, S. 69.

80 Vgl. ebd. S. 86 
où l'on donne publiquement à joüer“ ${ }^{81}$ Matuschek weist sogar darauf hin, dass „in Frankreich im I7. Jahrhundert académie zum Modewort für die öffentlichen Orte des Glücks-, Karten- und Billardspiels" ${ }^{82}$ geworden war.

Bargagli definiert das „akademische“ Spiel ${ }^{83}$ als „eine gesellige Runde, die nach immer neu vorgeschlagenen und verabredeten Regeln vergnügliche Reihum-Konversation, mitunter auch kleine gestische Übungen treibt. "84 Die Kriterien des Spiels sind dabei Geselligkeit, Vergnügen und Unterhaltung, Dynamik und Regelhaftigkeit. Eine ähnliche Definition enthalten die Trattenimenti (vor I 569 entstanden, I 587 erstmals veröffentlicht), die Girolamo Bargaglis Bruder Scipione etwa zur selben Zeit verfasste. Hier wird Spiel (im Sinne von „Gespräch, Geselligkeit und Vergnügen“85) als Heilmittel gegen Schwermut und Melancholie empfohlen.

Anders verhält es sich in Sperone Speronis Apologia dei Dialoghi ( I 574): Um seine Dialoge vor der Inquisition zu verteidigen, argumentiert er mit dem Begriff des Spiels. Dafür holt er weit aus: Die Lebenszeit unterteile sich in Wachen und Schlafen, das Wachen wiederum in Arbeit und Muße. Muße sei Erholung von der Arbeit, dafür gebe es verschiedene Möglichkeiten: Eine davon sei die schriftstellerische Tätigkeit („scrivere a giuoco“), denn Nachahmung sei Spiel („imitare è giuocare“). Die Nachahmung sei nicht nur für den Schriftsteller, sondern auch für den Leser ein vergnügliches Spiel („parimenti diletta molto il lettore e lo scrittore del dialogo, e è un bel giuoco di tutti e due“). ${ }^{86}$ Speroni verbindet also im Gegensatz zu Aristoteles den Spielbegriff mit dem der Muße und wendet ihn literaturtheoretisch an. Meines Wissens handelt es sich dabei um die erste explizite Definition von schriftstellerischem Schaffen und ästhetischem Genuss als Spiel.

Die Gleichsetzung von Spiel und Muße ist wenige Jahre später in einem Dialog über das Spiel von Torquato Tasso Il Gonzaga secondo overo del giuoco (I 58 I /82, überarbeitet I 587) zu finden. Es handelt sich hier um eine „als Gespräch inszenierte Ab-

81 Le Dictionnaire de l'Académie Françoise, dedié au Roy. Tome premier. Paris 1694, S. 6. Zit. nach Matuschek, S. 118.

82 Matuschek, S. 119.

83 „Or considerando che cosa sia questo giuoco, secondo ch'io sentii una volta dire da un dotto Intronato sopra ciò, per ischerzo filosofando, e' pare che dire non si possa altro che una festevole azzione d'una lieta e amorosa brigata, dove sopra una piacevole od ingegnosa proposta fatta da uno, come autore e guida di tale azzione, tutti gli altri facciano o dicano alcuna cosa l'un dall'altro diversamente, e questo a fin di diletto e d'intertenimento." (Girolamo Bargagli: Dialogo de' giuochi che nelle vegghie sanesi si usano di fare. Hg. von Patrizia D’Incalci Ermini. Siena 1982, S. 69. Zit nach Matuschek, S. 120).

84 Matuschek, S. 120.

85 Vgl. ebd. S. 128.

86 Ebd. S. $97 f$. 
handlung über das Spiel“", 87 in dem der schon in Aristoteles' Poetik theoretisierte Zusammenhang zwischen Nachahmung und Vergnügen mit der Natur des Spiels in Verbindung gebracht wird. Der Spielbegriff dient hier außerdem als Lebensmetapher, denn er wird als Konflikt zwischen zwei Gegenpolen, als „contesa di fortuna e d'ingegno" beschrieben. ${ }^{88}$ Diese Auffassung von Spiel als ein Gegensätze umschließendes Prinzip (coincidentia oppositorum) wird in späteren Theorien immer wieder auftauchen: Schiller definiert den Spieltrieb als die Verbindung zwischen Formtrieb und sinnlichem Trieb, die schon erwähnte Theorie von Eigen und Winkler betrachtet das Spiel als Grundprinzip in einer von Zufall und Naturgesetzen beherrschten Welt, ${ }^{89}$ Sutton-Smith sieht im Spiel das symbolische Durchleben von verschiedenen, vom Alltagsleben abstrahierten Antithesen. ${ }^{90}$

Von einer „dispute agréable “91 als Spiel spricht im 17. Jahrhundert Charles Sorel in seiner Maison des jeux (I642). Er bezieht sich allerdings so wie die Brüder Bargagli im I6. Jahrhundert auf die sogenannten jeux de conversation, die sein Spiel-Ideal darstellen, denn in ihnen verbindet sich "das heitere Vergnügen mit dem ernsten Bildungsanspruch". ${ }^{92}$ Das Spiel wird hier nicht nur wie bei Aristoteles als Erholung („,récréation“) gesehen, sondern durch die Betonung seines Bildungswerts auch mit dem höheren Begriff der Muße in Zusammenhang gebracht. Darüber hinaus behauptet Sorel in der der Neuauflage von I658 vorangestellten Widmung: „Le Ieu \& la feinte estant mesme chose. "93 Damit ist der Begriff der Fiktion, des „als ob“ in die Diskussion um das Spiel eingebracht, ein Begriff, der in vielen Spieltheorien des 20. Jahrhunderts eine wesentliche Rolle spielen wird.

Gegen Ende des 17. Jahrhunderts beginnt mit John Lockes Some thoughts concerning education (1693) eine gründlichere Auseinandersetzung mit dem Spiel in Zusammenhang mit Fragen der Erziehung. Seine durch den ausgiebigen Gebrauch

87 Ebd. S. 106.

88 „- Ditemi dunque, o signor Annibale: che cosa è giuoco? - Una contesa di fortuna e d'ingegno fra due e fra più. (...) - Dunque la vita è un giuoco, o signor Annibale." (Torquato Tasso: Il Gonzaga secondo overo del giuoco. In: Ders.: Dialoghi. Hg. von Ezio Raimondi. Florenz 1958, S. 462f. Zit. nach Matuschek, S. 107).

89 „Das Spiel selber ist weder mit dem Satz seiner Regeln noch mit der Kette von Zufällen, die seinen Ablauf individuell gestalten, identisch. Es ist weder das eine noch das andere, weil es beides zugleich ist." (Eigen u. Winkler, S. 11).

90 Vgl. Brian Sutton-Smith: Games, the Socialization of Conflict. Deutsche Übersetzung im Kongressbericht anlässlich der XX. Olympischen Spiele in München 1972: Sport in unserer Welt. Chancen und Probleme. Berlin, u. a. 1973, S. 78-84. In: Hans Scheuerl: Theorien des Spiels. Weinheim, Basel 1975, S. 123-130.

91 Charles Sorel: Maison des jeux. Hg. von Daniel A. Gajda. Genf 1977, S. 387. Zit. nach Matuschek, S. 135.

92 Matuschek, S. 135.

93 Zit. nach Matuschek, S. 137. 
des Spiels charakterisierte, „natürliche“ Erziehungsmethode gibt gemeinsam mit Jean-Jacques Rousseaus Erziehungsroman Emile ou de l'éducation (I762) einen bedeutenden Impuls für eine Aufwertung des Spiels und für die philanthropistische Erziehungsreform der zweiten Hälfte des i 8. Jahrhunderts. Der Erfahrungs- und Übungswert des Kinderspiels wird dabei in seiner vollen Bedeutung erkannt und zu pädagogischen Zwecken genutzt.

Ganz im Sinne dieser pragmatisch geprägten Haltung stehen die Definitionen der zeitgenössischen Wörterbücher und Lexika:

„Spiel, Ludus, überhaupt ein thun, so zur belustigung und zeitvertreib angesehen. (...) Ins besondre werden spiele genennet solche handlungen, die für sich keinen zweck haben. Und allein erfunden worden, den leib in einer bekommlichen bewegung zu unterhalten, oder den gemüth eine ergötzlichkeit, nach verrichteter arbeit, zu verschaffen. “94

„Spiel (...) Eigentlich, freye Bewegung (...). In engerer und theils figürlicher Bedeutung ist das Spiel eine Bewegung und Beschäftigung, welche aus keiner andern Absicht als zum Zeitvertreibe oder zur Ergetzung des Gemüthes unternommen wird."

Bei diesen Definitionen fällt die Häufigkeit des Terminus „Bewegung“ auf. In diesem Zusammenhang ist einerseits die Etymologie des Wortes erwähnenswert, denn ursprünglich hatte Spiel die Bedeutung einer „tänzerischen Bewegung “,96 andererseits ist zu bemerken, dass verschiedene spätere Theorien (Lazarus, Buytendijk, Fink, Scheuerl) gerade auf der Definition von Spiel als Bewegung basieren.

Der im I 8. Jahrhundert gebräuchliche pragmatisch-funktionale Spielbegriff tritt gleichzeitig mit dem Niedergang der philanthropischen Erziehungsbewegung um I 800 in den Hintergrund, während sich das Interesse auf den „Begriff eines sublimierten ,ästhetischen Spiels “"97 verlagert.

Dieser abstrakte philosophische Spielbegriff taucht zunächst in Immanuel Kants Kritik der Urteilskraft (I790) auf. Hier wird das "freie Spiel der Erkenntniskräfte“

94 Johann Theodor Jablonski: Allgemeines Lexicon der Kunst und Wissenschaften. Neue, um die Helfte vermehrte, und durchgehends verbesserte Auflage. Königsberg, Leipzig 1748, S. 1106. Zit. nach Matuschek, S. 196.

95 Johann Christoph Adelung: Grammatisch-kritisches Wörterbuch der Hochdeutschen Mundart, mit beständiger Vergleichung der übrigen Mundarten, besonders aber der Oberdeutschen. Vierter Theil. Zweyte vermehrte und verbesserte Ausgabe. Leipzig 1801, Sp. 197. Zit. nach Matuschek, S. 196.

96 Vgl. Duden Etymologie. Herkunftswörterbuch der deutschen Sprache. Mannheim 1963, S. 659.

97 Vgl. Heinrich Kaulen: Spielmethoden ohne Spieltheorie? Zur Geschichte und aktuellen Konjunktur des Spielbegriffs in der Literaturdidaktik. In: Thomas Anz und Heinrich Kaulen (Hg.): Literatur als Spiel. Evolutionsbiologische, ästhetische und pädagogische Konzepte. Berlin 2009, S. 582. 
(Einbildungskraft und Verstand) zur theoretischen Begründung des durch Interesselosigkeit und Zwecklosigkeit (,interesseloses Wohlgefallen“) charakterisierten ästhetischen Gemütszustandes herangezogen. Seitdem wird das Spiel als philosophischästhetisches Paradigma verwendet. Auf Kant bezieht sich auch Friedrich Schillers im Bezug auf das Spiel häufig zitierte Theorie. ${ }^{98}$ In seinen Briefen Über die ästhetische Erziehung des Menschen definiert Schiller nämlich den Spieltrieb als die Verbindung zwischen dem sinnlichen Trieb und dem Formtrieb des Menschen. Gegenstand des Spieltriebs ist nach Schiller die Schönheit im weitesten Sinn: Der Mensch soll mit der Schönheit spielen und sich am ästhetischen Schein freuen, denn er ,ist nur da ganz Mensch, wo er spielt." 99

Die Kluft zwischen diesem abstrakten philosophischen Spielbegriff und dem sonst im I 8. Jahrhundert diskutierten Kinderspiel versucht Schiller selbst zu überbrücken, indem er ein mehrstufiges Modell konstruiert: Auf der untersten Stufe befindet sich das "physische Spiel“, die "freie Bewegung“, die beim Tier und beim Menschen nur bei Freiheit von sinnlichen Bedürfnissen stattfinden kann. Der nächsten Stufe ist das „Phantasiespiel“ zugeordnet, das „Spiel der freien Ideenfolge“, das Spiel der Einbildungskraft, das Schiller immer noch als "materielles Spiel“ bezeichnet. Von diesem bis zum „ästhetischen Spiel“, zum „Spiel mit der Schönheit“ und zum „ästhetischen Zustand“ bleibt trotzdem eine Kluft offen: ,einen Sprung muß man es nennen, weil sich eine ganz neue Kraft hier in Handlung setzt. "100

Zwischen dem konkreten Spiel von Mensch und Tier und dem Spiel als philosophisch-ästhetischem Begriff öffnet sich ein Spannungsraum, in dem die meisten späteren Spieltheorien angesiedelt sind.

In Schillers Beschreibung des "physischen Spiels“ ist ein Gedanke enthalten, der die Grundlage für spätere Theorien bildet, die unter dem Begriff „Überschusstheorien“ subsumierbar sind. Schiller schreibt: „Das Tier arbeitet, wenn ein Mangel die Triebfeder seiner Tätigkeit ist, und es spielt, wenn der Reichtum der Kraft, wenn das überflüssige Leben sich selbst zur Tätigkeit stachelt. "101 Um die Mitte des I9. Jahrhunderts knüpft der Evolutionstheoretiker Herbert Spencer an Schillers Idee seine Theorie an, die das Spiel der Menschen und der Tiere als „Sekundärbetätigung bei

98 Zur Verbindung zwischen Kants und Schillers Theorie in Bezug auf den Spielbegriff siehe Matuschek Kapitel 8, S. 183-214, sowie Tanja Wetzel: Art. Spiel. In: Karlheinz Barck u. a. (Hg.): Ästhetische Grundbegriffe. Bd. 5. Stuttgart 2010, S. 577-618.

99 Friedrich Schiller: Fünfzehnter Brief. In: Über die ästhetische Erziehung des Menschen in einer Reihe von Briefen. (1793-94). Zit. nach Scheuerl: Theorien des Spiels. S. 37.

100 Schiller: Siebenundzwanzigster Brief. Zit. nach Scheuerl: Theorien des Spiels. S. 40

101 Ebd. S. 39f. 
Kraftüberschuss“ („surplus of vigour") ${ }^{102}$ erklärt. Spencers Theorie bildet den Ausgangspunkt sowohl für die spätere Verhaltensforschung als auch für die sogenannte Kompensationstheorie, die beide vom Begriff des animal ludens ausgehen.

Die vergleichende Verhaltensforschung untersucht das Spielverhalten der ,intelligenten Säugetiere" 103 (vor allem der Affen) im Vergleich zu dem der Menschen (vor allem der Kinder) und stellt von der Grundhaltung her eine ähnliche Neugier, einen ähnlichen Gesichtsausdruck („play face“ ${ }^{104}$ ) und dieselbe implizite metakommunikative Mitteilung (,message: this is play “105) fest. Die letztgenannte Erkenntnis stammt von Gregory Bateson. Anhand des tierischen Verhaltens stellt er bei Handlungen, die „als Spiel“ gemeint sind, die non-verbale Mitteilung „Dies ist ein Spiel“ fest, die er folgendermaßen erklärt und umschreibt: „Diese Handlungen, in die wir jetzt verwickelt sind, bezeichnen nicht, was jene Handlungen, für die sie stehen, bezeichnen würden. "106 So leuchtet dem Beobachter von kämpfenden Affen sofort ein, ob sie im Ernst oder nur zum Spaß kämpfen. Dabei bilden nach Bateson „theatralisches Spiel, Bluff, spielerische Drohung und Necken einen einzigen Gesamtkomplex von Phänomenen. “107 Die „Besonderheiten des Spiels“ sind nach Batesons Theorie „(a) daß die im Spiel ausgetauschten Mitteilungen oder Signale in gewissem Sinne unwahr oder nicht gemeint sind; und (b) daß das, was mit diesen Signalen bezeichnet wird, nicht existiert. "108

Gegen Ende des I9. Jahrhunderts wird Spencers Kraftüberschusstheorie zu einer Kompensationstheorie weiterentwickelt. In ihrem Mittelpunkt stehen die Funktionen des Spiels, nämlich die Ergänzung der Arbeit und die Erholung von ihr, die kathartische Funktion und vor allem die Übung im Sinne einer Vorbereitung für das Erwachsenendasein („Einübungstheorie“). In diesem Zusammenhang ist Moritz Lazarus, aber vor allem Karl Groos zu nennen, der aus evolutionstheoretischer Sicht besonders umfangreiche Untersuchungen zum Spiel der Menschen und der Tiere durchführte. ${ }^{109}$

102 Vgl. Herbert Spencer: The Principles of Psychology. London 1855. Zit. nach Scheuerl: Theorien des Spiels. S. $55 \mathrm{f}$.

103 Vgl. Stepina, S. 329.

104 Vgl. Suzanne Chevalier-Skolnikoff: Ontogenesis of the play face among stumptail monkeys. In: Jerome S. Bruner, Alison Jolly und Kathy Sylva (Hg.): Play - its role in development and evolution. New York 1976, S. 140-195.

105 Gregory Bateson: Eine Theorie des Spiels und der Phantasie (1955). In: Uri Rapp: Rolle. Interaktion. Spiel. Eine Einführung in die Theatersoziologie. Wien, Köln, Weimar 1993.

106 Ebd. S. 115.

107 Ebd. S. 117.

108 Ebd. S. 119.

109 Vgl. Karl Groos: Die Spiele der Tiere. Jena 1896 und Die Spiele der Menschen. Jena 1899. 
Als Weiterführung dieser funktionsorientierten Spielbetrachtung kann Sigmund Freuds Theorie gesehen werden, in der das Spiel der Kinder als Bewältigung einer gelebten Situation verstanden wird (Jenseits des Lustprinzips, I920). Diese Idee übernimmt später Brian Sutton-Smith, nach dessen Theorie das Spiel der Konflikt- und Lebensbewältigung dient. An diese Ansicht knüpft zu Beginn des 2 I. Jahrhunderts gewissermaßen auch Clemens Stepina an, der die einzige Möglichkeit einer Spieltheorie im Rahmen einer Handlungstheorie sieht; er definiert Spiel nämlich als „das selbstreflexive und darin handlungs-, geschichts- und gesellschaftsbildende Medium des Menschen“."110

Von der pragmatisch-funktionsorientierten Evolutionsbiologie gehen auch die anthropologisch ausgerichteten Spieltheorien aus, die sich aber von den eben beschriebenen Theorien dadurch unterscheiden, dass sie sich nicht schwerpunktmäßig mit den Funktionen des Spiels beschäftigen, sondern eine möglichst allgemeine strukturelle Definition von Spiel zu treffen versuchen. Die anthropologischen Theorien sehen im Allgemeinen das Spiel als Inbegriff menschlichen Handelns. In ihrem Mittelpunkt steht der homo ludens. Dieser Begriff ist gleichzeitig der Titel des wohl bedeutendsten Werks zum Thema des Spiels aus anthropologischer Sicht, auf das alle späteren Theoretiker Bezug nehmen. In Homo ludens stellt nämlich Johan Huizinga in den I93oer Jahren die These des Spiels als Ursprung der Kultur auf und zeigt, wie das Spiel bzw. Elemente des Spiels in den verschiedensten Bereichen der menschlichen Kultur erscheinen, wie Recht, Krieg, Wissen, Dichtung, Philosophie und Kunst. Huizingas allumfassende Theorie wurde wegen der ihr zugrunde liegenden Denkweise als zu teleologisch kritisiert. Eine weitere Kritik stammt von Uri Rapp, der Huizinga die Vermischung von Spielgeist und Spielstruktur vorwirft, die der Hegel-Schüler Julius Schaller schon Mitte des I9. Jahrhunderts festgestellt hatte, als er zwischen dem Spiel als „eigenthümlichem Gemüthszustand“ und als „besonderer Tätigkeit“ unterschied. ${ }^{11}$ Karl Eibl hingegen hat Anfang des 2 I. Jahrhunderts Huizingas These des Ursprungs der Kultur im Spiel evolutionsbiologisch bestätigt: „Im Spiel werden die Verhaltensprogramme von vitalen Handlungszwecken abgelöst. "112 Beim Spiel handle es sich um „die entwicklungsgeschichtlich früheste Form des Entkoppelns“, 113 die „vom Menschen genutzt wird zur Konstruktion unterschiedlicher kontingenter Kulturen". 114

110 Stepina, S. 326.

111 Schaller, S. 4f. Zit. nach Scheuerl: Theorien des Spiels. S. 58.

112 Karl Eibl: Vom Ursprung der Kultur im Spiel. Ein evolutionsbiologischer Zugang. In: Thomas Anz und Heinrich Kaulen (Hg.): Literatur als Spiel. S. 15.

113 Ebd.

114 Ebd. S. 19. 
In die anthropologische Strömung kann auch der Verhaltensforscher Frederik Jacobus Johannes Buytendijk eingereiht werden, der kurz vor Huizinga eine für die Spieltheorie wichtige Beschreibung der Struktur des Spiels als besondere Dynamik, nämlich die einer „,hin' und ,zurück' gerichteten Bewegung“, ${ }^{115}$ geliefert hat.

Roger Caillois' Spieltheorie (Les jeux et les hommes, 1958) bildet noch immer eine Grundlage für aktuelle Spieldiskussionen: In seiner Definition von Spiel hält Caillois sich eng an Huizinga, entwirft aber darüber hinaus anhand von anthropologischen Kategorien eine allgemeine Klassifikation der Spiele. ${ }^{116}$

Eine ebenfalls bedeutende Spieltheorie stammt von Hans Scheuerl, der von der Pädagogik ausgehend verschiedene Aspekte aus unterschiedlichen Theorien zusammenfasst und sie zu teilweise neuen, differenzierteren Kriterien des Spiels erweitert. ${ }^{117}$ Scheuerl schafft so einen Spagat zwischen pädagogischen, auf das konkrete Spiel der Kinder bezogenen Theorien und der abstrakten Ebene der anthropologischen Spieltheorien.

Den höchsten Abstraktionsgrad erreicht der Begriff des Spiels in den philosophischen Theorien, die eine Ontologie des Spiels entwerfen. Das Spiel wird in diesen Theorien als existentielles Grundphänomen und als Kategorie des Seins interpretiert. Von Heraklits Fragment ausgehend verwendet Nietzsche das Spiel als Metapher für den Lauf der Welt, den er mit dem Spiel eines Kindes bzw. eines Künstlers vergleicht: „Ein Werden und Vergehen, ein Bauen und Zerstören, ohne jede moralische Zurechnung, in ewig gleicher Unschuld hat in dieser Welt allein das Spiel des Künstlers und des Kindes. Und so, wie das Kind und der Künstler spielt, spielt das ewig lebendige Feuer, baut auf und zerstört, in Unschuld - und dieses Spiel spielt der Aeon mit sich." 118

Nietzsches Begriff des universalen Weltspiels wurde später von Heidegger übernommen, auf dessen Konzept wiederum Eugen Fink seine philosophisch-spekulative Spieltheorie (Spiel als Weltsymbol) aufbaute, die darauf hinausläuft, aufzuzeigen, dass das Spiel gewissermaßen eine Spiegelung des Seins enthält und aufgrund dieser Entsprechung als „spekulative Weltmetapher"119 verstanden werden kann, durch die die Wirklichkeit gleichnishaft erklärt wird. Das ganze Leben ist nur ein Spiel. Fink zieht

115 Frederik Jacobus Johannes Buytendijk: Wesen und Sinn des Spiels. Das Spielen des Menschen und der Tiere als Erscheinungsform der Lebenstriebe. Berlin 1933, S. 36.

116 Siehe Kapitel „Gliederungsversuche“.

117 Details seiner strukturellen Spielbetrachtung im nächsten Kapitel.

118 Friedrich Nietzsche: Die Philosophie im tragischen Zeitalter der Griechen. In: Ders.: Sämtliche Werke. Kritische Studienausgabe in 15 Bänden. Berlin, New York 1980, Bd. 1, S. 830f. Zit. nach Thomas Anz: Literatur und Lust. Glück und Unglück beim Lesen. München 1998, S. 50.

119 Eugen Fink: Oase des Glücks. Gedanken zu einer Ontologie des Spiels. Freiburg 1957, S. 50. 
den Gedanken so lange durch, bis er zu dem Schluss kommt: „Alles Seiende ist kosmisches Spielzeug, aber auch alle Spieler sind selber nur gespielt. Die Erscheinung ist Maske hinter der ,niemand', hinter der nichts ist - als eben das Nichts. "120

Einen ontologischen bzw. ontologisierenden Anspruch erhebt auch Gadamers hermeneutische ästhetische Theorie, die die Erfahrung von Kunst durch die anthropologischen Begriffe Spiel, Symbol und Fest erklärt. ${ }^{121}$ „Das Spiel charakterisiert (...) auf paradigmatische Weise die Seinsbestimmung des Kunstwerks“ und dient seiner „ontologischen Explikation“. ${ }^{122}$ Der Vollständigkeit halber sei hier auch Jacques Derrida erwähnt, der den Begriff des Spiels mit dem dekonstruktiven Verfahren in Bezug auf die Bedeutungen von Texten bzw. allgemein von Kunstwerken in Zusammenhang bringt. ${ }^{123}$

Eine regelrechte „Weltformel“ umrahmt dagegen die schon erwähnte ontologische Theorie von Eigen und Winkler, die das Spiel als schöpferisches Organisationsprinzip der Natur deuten. Schon der Titel ihres Buches verrät ihre Sichtweise der Welt als Spiel zwischen Naturgesetzen und Zufall.

Naturgesetz und Zufall spielen auch in der mathematischen Spieltheorie eine grundlegende Rolle. Diese Disziplin entsteht unabhängig von den beschriebenen (nicht-mathematischen) Spieltheorien in den I940er Jahren mit dem Erscheinen des Buches Theory of Games and Economic Behavior von John von Neumann und Oskar Morgenstern. ${ }^{124}$ Die mathematische Spieltheorie modelliert die unterschiedlichsten Situationen, vor allem Konfliktsituationen, als Spiel, um ihre Mechanismen (beispielsweise Entscheidungsverhalten) zu erklären und vorherzusehen und um optimale Lösungen zu finden. Ausgehend vom Bereich der Wirtschaftswissenschaft wuchs die Zahl der Anwendungsbereiche der mathematischen Spieltheorie in weiterer Folge

120 Fink: Spiel als Weltsymbol. S. 242.

121 Hans-Georg Gadamer: Die Aktualität des Schönen. Stuttgart 1977.

122 Vgl. Tanja Wetzel: Art. Spiel. In: Karlheinz Barck u. a. (Hg.): Ästhetische Grundbegriffe. Bd. 5, S. $605 f$.

123 Gadamers und Derridas Theorien werden von Ruth Sonderegger in Für eine Ästhetik des Spiels (Frankfurt a. M. 2000) einander gegenübergestellt. Hier wird aufgrund der heftigen kritischen Reaktionen (besonders in Peter Brandes: Das Spiel der Bedeutungen im Prozess der Lektüre. Überlegungen zu einer Literaturtheorie des Spiels. In: Thomas Anz und Heinrich Kaulen (Hg.): Literatur als Spiel. S. 115-134) auf dieses Werk von einer weiteren Auseinandersetzung damit abgesehen.

124 Eine mathematische Spieltheorie hatte eigentlich schon Antoine-Augustin Cournot um die Mitte des 19. Jahrhunderts als Weiterentwicklung der Wahrscheinlichkeitsrechnung gegründet. Verwunderlich ist, dass diese Theorie erst 100 Jahre später wieder aufgenommen wurde, und zwar als Weiterentwicklung der mathematischen Analyse. Weiter ausgebaut wurde die Theorie durch John Nash, János Harsányi und Richard Selten als dissuasive strategies und schließlich als mechanism design theory. 
deutlich an (Rechtswissenschaften, Politikwissenschaft, Soziologie, Psychologie, Informatik, Biologie).

\subsection{Formale Kriterien des Spiels im Vergleich}

Johan Huizingas vielzitierte Definition des Spiels, die 1938 in seinem Werk Homo ludens erschien und immer noch ihre Gültigkeit bewahrt, soll nun als Ausgangspunkt für die Erörterung verschiedener Spieltheorien dienen:

Spiel ist eine freiwillige Handlung oder Beschäftigung, die innerhalb gewisser festgesetzter Grenzen von Zeit und Raum nach freiwillig angenommenen, aber unbedingt bindenden Regeln verrichtet wird, ihr Ziel in sich selber hat und begleitet wird von einem Gefühl der Spannung und Freude und einem Bewußtsein des „Andersseins“ als das „gewöhnliche Leben". ${ }^{125}$

In dieser Definition sind schon die für Huizinga wesentlichen formalen Kriterien für das Spiel enthalten, die nun in einzelnen Unterkapiteln besprochen werden.

\subsection{Freiwilligkeit und Freiheit}

Als erste Eigenschaft des Spiels erscheint in Huizingas Definition der Begriff der Freiwilligkeit. An einer anderen Stelle definiert Huizinga das Spielen als ein „überflüssiges " Handeln, das im Gegensatz zur Arbeit in der Freizeit erfolgt. ${ }^{126}$ Damit wird die Freiheit des Spiels von Notwendigkeit und Zwang zum Ausdruck gebracht und somit das Spiel von der Arbeit abgegrenzt. Roger Caillois übernimmt Huizingas Definition und bezeichnet das Spiel ebenfalls als eine „freie Tätigkeit“, denn „man spielt nur, wenn man will, wann man will und solange man will." ${ }^{127}$ Scheuerl äußert sich etwas differenzierter zu dieser ,Freiheit' und behauptet, das Spiel sei „von der Arbeit, vom Kampfe ums Dasein, von der Not und der Sorge, vom Ernst und den objektiven Wertund Zweckordnungen abgehoben“128 und deswegen „frei vom Zwang ungebärdig drängender Triebe, frei von den gebieterischen Nötigungen des Instinkts“, „frei von

125 Huizinga, S. 34.

126 Vgl. ebd. S. 15.

127 Roger Caillois: Die Spiele und die Menschen. Maske und Rausch. Stuttgart 1960, S. 14 (französische Originalausgabe unter dem Titel Les jeux et les hommes. Paris 1958).

128 Hans Scheuerl: Das Spiel. Untersuchungen über sein Wesen, seine pädagogischen Möglichkeiten und Grenzen. Bd. 1. Weinheim, Basel 1979, überarbeitete Neuausgabe 1990, S. 67. 
den Bedürfnissen des Daseinskampfs, von der Not der Sich-Wehrens"..129 Scheuerl zitiert in diesem Zusammenhang unter anderem den Psychotherapeuten und Psychiater Gustav Bally, der das Spiel als „die Bewegung der Freiheit"130 schlechthin definiert und behauptet, Spiel könne sogar beim Tier nur dann auftreten, wenn die „instinktiven Nötigungen eine Lockerung erfahren“, das „Feld“ entspannt und die Instinktziele „an den fernsten Horizont verwiesen“131 sind. Nach Scheuerl ist die „Freiheit von unmittelbarer Notdurft und Sorge" die Voraussetzung für den idealen Zustand beim Spiel des Kindes bis hin zum musikalischen oder dramatischen Spiel des Künstlers, nämlich der einer „selbst- und weltvergessenen Hingabe“. ${ }^{132}$

Ballys Gedanke erinnert an Schillers Beschreibung des „physischen Spiels“ der Tiere: „Wenn den Löwen kein Hunger nagt und kein Raubtier zum Kampf herausfordert, so erschafft sich die müßige Stärke selbst einen Gegenstand; mit mutvollem Gebrüll erfüllt er die hallende Wüste (...). Unleugbar ist in diesen Bewegungen Freiheit, aber nicht Freiheit von dem Bedürfnis überhaupt, bloß von einem bestimmten, einem äußeren Bedürfnis. "133 Die Idee, dass Spiel nur bei Freiheit von lebensnotwendigen Bedürfnissen stattfinden kann, stammt also schon von Schiller, während die Freiwilligkeit des Spiels und die damit verbundene Abgrenzung von der mit Zwang verbundenen Arbeit noch früher, nämlich schon von Rousseau in seinem Erziehungsroman Emile ou de l'éducation (I762) erwähnt werden: „Übrigens muß man immer bedenken, daß dies alles nichts anderes ist und sein soll als Spiel, leichte und freiwillige Leitung der Bewegungen, die die Natur von ihnen [von den Kindern] fordert, eine Kunst, ihre Vergnügungen zu variieren, um sie ihnen angenehmer zu machen, ohne daß jemals der mindeste Zwang sie in Arbeit verkehrte." ${ }^{34}$

\subsubsection{Handlung bzw. Beschäftigung}

Wie fast alle anderen Spieltheoretiker definiert Huizinga Spiel als Handlung oder Beschäftigung; oft wird auch der Terminus „Tätigkeit“ verwendet, mit dem sich Scheuerl aber nicht zufriedengibt. Er behauptet nämlich, „daß ein Spiel nicht lediglich als Tätigkeit definiert werden kann, auch nicht als eine psychische Verhaltensweise, sondern allenfalls als ein Tätigkeitsfeld, auf dem Bewegungsabläufe erzeugt und in

129 Ebd. S. 69.

130 Gustav Bally: Vom Ursprung und von den Grenzen der Freiheit. Basel 1945, S. 7. Zit. nach Scheuerl: Theorien des Spiels. S. 68.

131 Ebd. S. 5 und 73. Zit nach Scheuerl: Das Spiel. S. 68f.

132 Scheuerl: Das Spiel. S. 67.

133 Schiller: Siebenundzwanzigster Brief. Zit. nach Scheuerl: Theorien des Spiels. S. 39.

134 Jean-Jacques Rousseau: Emile ou de l'éducation (1762). Zit. nach Scheuerl: Theorien des Spiels. S. 21. 
Gang gehalten werden, in die zwar als Einzelmomente auch Tätigkeiten, Aktionen und Interaktionen, Erwartungshaltungen und Reaktionen usw. einfließen, die aber insgesamt nicht im Oberbegriff Tätigkeit angemessen aufgehen. "135 Scheuerl definiert Spiel hingegen als „Bewegungsform von besonderer Ablaufsgestalt“, als „spezielle Dynamik“ und als „ein entspanntes und doch in sich variables, immer wieder neues, nie genau vorhersehbares, in Grenzen hin- und herspielendes Geschehen “. ${ }^{136}$ Hinter diesen Begriffen schimmern Theorien aus der Vergangenheit durch, beispielsweise die des Philosophen und Psychologen Moritz Lazarus, der schon I 883 die dynamische Struktur des Spiels „entdeckt“, das er als eine „leichte, schwankende, ziellos schwebende, in sich selbst vergnügte Thätigkeit" ${ }^{137}$ beschreibt. Er vergleicht sie mit dem „Wechsel der kaleidoskopischen Farben und Formen“ und stellt die später von verschiedenen Theoretikern wieder aufgenommene These auf, dass Spiel Bewegung sei. Frederik Buytendijk spricht ein halbes Jahrhundert später von der „Dynamik des Spielens“ als „eine Hin- und Herbewegung“, ${ }^{138}$ um die Mitte des 20. Jahrhundert beschreibt Gustav Bally das Spiel als „stehende Bewegung“139 und Eugen Fink als „in sich bewegtes Dasein“, ${ }^{140}$ während Gadamer direkt Buytendijks Begriff der Hinund Herbewegung übernimmt und das Spiel weder als Betätigung noch als Gemütsverfassung, sondern als „Vollzug der Bewegung als solcher“ definiert. ${ }^{141}$ Entschieden gegen all diese Theoretiker äußert sich zu Beginn des 2 I. Jahrhundert Clemens Stepina: „Dass menschliches Handlungsspiel beweglich, ein Hin und Her innerhalb eines Spannungszustands sein soll, ist eine - althergebrachte - Hypothese, die so ungenau ist, dass in Folge der Gegenstand des Spielens, das spezifische Spielphänomen, ebenso wenig definiert (...) werden kann."142 Stepina betrachtet das Spiel aus einer pragmatischeren, funktionsorientierten Perspektive und sieht es als „Medium zur Erprobung neuer Handlungsformen“ und somit als „das selbstreflexive und darin handlungs-, geschichts- und gesellschaftsbildende Medium des Menschen". ${ }^{143}$ Stepinas Sichtweise beruht auf der Annahme, „dass es das Spiel an sich (...) nicht geben

135 Scheuerl: Theorien des Spiels. S. 200f.

136 Ebd. S. $201 f$.

137 Vgl. Lazarus: Über die Reize des Spiels. Zit. nach Scheuerl: Theorien des Spiels. S. $65 f$.

138 Vgl. Buytendijk, S. 118.

139 Zit. nach Scheuerl: Das Spiel. S. 88.

140 Fink: Oase des Glücks. S. 20.

141 „Die Bewegung des Hin und Her ist für die Wesenbestimmung so zentral, daß es gleichgültig ist, wer oder was diese Bewegung ausführt. (...) Das Spiel ist Vollzug der Bewegung als solcher." (HansGeorg Gadamer: Wahrheit und Methode. Grundzüge einer philosophischen Hermeneutik. Tübingen 1960, S. 99).

142 Stepina, S. 311.

143 Ebd. S. 326. 
kann ", 144 was eine vollständige Inkompatibilität mit den meisten Spieltheorien aus anthropologischer und philosophischer Perspektive (Buytendijk, Huizinga, Caillois, Scheuerl, Fink, Gadamer) in sich birgt.

\subsubsection{Ziel in sich selbst}

Durch die Aussage, das Spiel habe sein Ziel ,in sich selber“ nimmt Huizinga eine klare Position innerhalb der Diskussion über die Selbstzwecklichkeit bzw. Fremdzwecklichkeit des Spiels ein.

Aristoteles hatte das Spiel genauso wie die Arbeit als fremdzwecklich definiert, denn es diene der Erholung (von der Arbeit) und solle „wie eine Medizin“ gebraucht werden. Die Muße dagegen sei selbstzwecklich und bedeute primär „das Enthobensein von den Geschäften des Alltags“, „philosophische Kontemplation“ und „Musik“. ${ }^{145}$

Stepina sieht im Spielbegriff der von ihm als neoaristotelisch definierten Spieltheoretiker schlicht und einfach eine „Säkularisierung des Aristotelischen Mußebegriffs“ bzw. „einen semantisch modernisierten Muße-Begriff, der - wie bei Aristoteles - im schroffen Gegensatz zum Begriff der Arbeit steht. "'146 Damit sind wohl in erster Linie die anthropologischen Spieltheorien gemeint, die als erstes Wesenskriterium des Spiels die Freiheit von äußerlichen Ziel- und Zwecksetzungen hinstellen, sowie Eugen Finks Theorie, die Huizingas These des „Ziels in sich selbst“ bestätigt, aber auch versucht, missverständliche Interpretationen dieser These aus dem Weg zu räumen: „Man sagt oft, Spiel sei ein ,zweckloses', ,zweckfreies' Tun und Handeln. Das trifft nicht zu. Es ist als Gesamthandlung zweckhaft bestimmt (...). Aber der immanente Spielzweck ist nicht, wie die Zwecke der übrigen menschlichen Handlungen hin entworfen. Die Spielhandlung hat nur interne, keine sie überschreitenden Zwecke." ${ }^{147}$

Eine noch differenziertere Betrachtung versucht Karl Bühler: ${ }^{148},(\ldots)$ bleibt ein Wort über die sogenannte ,Selbstzwecklichkeit' des Spieles zu sagen. Selbstzweck, selbstzweckliche Tätigkeit im strengen Wortsinn gibt es ebensowenig wie es Selbstursachen (causae sui) gibt; Zweck und Mittel gehören begrifflich ebenso denknotwendig zusammen und sind ebenso denknotwendig zwei wie Wirkung und Ursache. (...)

144 Ebd.

145 Ebd. S. 298.

146 Ebd. S. 299.

147 Fink: Oase des Glücks. S. 23.

148 Seine Definition von Spiel lautet folgendermaßen: „Eine Tätigkeit, die mit Funktionslust ausgestattet ist und von dieser Funktionslust direkt oder um ihretwillen aufrecht erhalten wird, wollen wir Spiel nennen." Karl Bühler: Die Krise der Psychologie. Jena 1927. Zit. nach Scheuerl: Theorien des Spiels. S. 97. 
Wer am Spiel die Tätigkeit und die Lust als zwei Bestandteile (Momente) betrachtet, darf die Tätigkeit, weil sie zur Erzeugung der Lust da ist, nicht als Selbstzweck bezeichnen, wer dagegen Tätigkeit und Lust als Einheit betrachtet, darf es." 149

Die meisten Theorien des I 8. und I9. Jahrhunderts schreiben dem Spiel nicht nur den Zweck der Erzeugung von Lust zu, sondern vor allem den der Erholung, und führen somit die aristotelische These ${ }^{150}$ der Fremdzwecklichkeit des Spiels weiter. Im Zeitalter der Aufklärung wird das kindliche Spiel als Naturrecht des Kindes ${ }^{151}$ anerkannt und mit seinem Übungswert und seiner Erholungsfunktion gerechtfertigt. John Locke führt Ende des I7. Jahrhunderts die erleichternde und erholsame Wirkung des Spiels auf das Prinzip der Abwechslung zurück: „Denn Erholung heißt nicht müßig sein, sondern den ermüdenden Teil durch Wechsel der Betätigung Erleichterung verschaffen. "152 Ebenso argumentiert der deutsche philanthropische Pädagoge Johann Christoph Friedrich Guts Muths: „Erholung ist der rechtmäßige Zweck bei allem Spiel. Erholung ist Bedürfnis so wie Schlaf. Sie gründet immer auf Abwechslung der Beschäftigungen." 153

Über den erzieherischen Wert des Spiels hatte schon Platon in den „Gesetzen“154 gesprochen, im I 8. Jahrhundert wird der Übungswert des Spiels so explizit wie nie zuvor dargestellt: Das Spiel schule die Sinne und forme den Charakter und sei von natürlichem Frohsinn begleitet, wie Rousseau in seinem Erziehungsroman Emile ou de l'éducation ausführt. ${ }^{155}$ Nach Guts Muths ist Spiel „Übung für Beobachtungsgeist, Gedächtnis, Aufmerksamkeit, Phantasie, Verstand, etc. "156

Als die Gegner der Philanthropisten die früher verbreitete Dichotomie von Spiel und Arbeit wiederaufgriffen, verschärfte sich die Idee der Fremdzwecklichkeit des

149 Ebd.

150 „(...) denn der Müde braucht Erholung, und das Spiel ist der Erholung wegen, und die Arbeit geschieht mit Mühe und Anstrengung - nun, so folgt, dass man dem Spiele nur mit Beobachtung der rechten Zeit seiner Anwendung Raum geben darf, indem man es wie eine Medizin gebraucht. Denn eine solche Bewegung der Seele ist Ausspannung und wegen der damit verbundenen Lust Erholung." (Aristoteles Politik VII. Zit. nach. Stepina, S. 485).

151 Vgl. ebd. S. 13.

152 John Locke: $\$ 206$ aus Some thoughts concerning education (1693). Zit. Nach Scheuerl: Theorien des Spiels. S. 20.

153 Johann Christoph Friedrich Guts Muths: Spiele zur Erholung und Übung des Körpers und Geistes für die Jugend, ihre Erzieher und alle Freunde unschuldiger Jugendfreuden. Schnepfenthal 1796. Zit. nach Scheuerl: Theorien des Spiels. S. 28.

154 „Sokrates: ,Wie wir also zu Anfang gesagt haben, müssen sich die Kinder in den ersten Jahren durch Spiele und ehrbare Scherze gewöhnen, denn wenn sie unter nicht ehrbaren Scherzen aufwachsen, so können sie später niemals gute Männer werden." Zit. nach Colozza, S. 104.

155 Vgl. Rousseau: Emile ou de l'éducation. Zit. nach Scheuerl: Theorien des Spiels. S. 21-23.

156 Zit. nach Scheuerl: Theorien des Spiels. S. 29. 
Spiels. Schon zu Beginn des 19. Jahrhunderts schreibt Kant, das Kind solle in erster Linie lernen und arbeiten, zur Erholung dürfe es auch spielen. Erwünscht ist allerdings "nicht nur ein bloßes Spiel, sondern es muss auch ein Spiel mit einem Endzweck sein." 157

Den schon im I 8. Jahrhundert vorherrschenden Begriff des Spiels als Übung übernimmt und erweitert Karl Groos, der in seiner besonders umfangreichen Spieltheorie aus evolutionsbiologischer Sicht dem Spiel bei jungen Menschen und Tieren den biologischen Zweck der Vorbereitung auf das Erwachsenendasein (Einübung, Selbstausbildung) zuweist. Beim erwachsenen Menschen hat das Spiel die Funktion der „Ergänzung“", die Groos als Ausgleich zur Arbeit beschreibt, sowie der „Erholung“ und „Befreiung von dem Druck und Zwang des Ernstlebens"158 (kathartische Funktion). Groos spricht auch vom „spielenden Durchkosten von Lebensmöglichkeiten“. ${ }^{159}$ Das Spiel ist seiner Meinung nach also nicht selbstzwecklich, sondern dient, wie auch Freud feststellt, der Lebensbewältigung.

Diese Ansicht teilt auch der Kulturtheoretiker Sutton-Smith, der in seiner Spieltheorie den Schwerpunkt auf die Funktion der Konfliktbewältigung legt: Kulturelle Alltagsthemen werden im Spiel reflektiert, dabei wird ein Repertoire von Handlungsund Reaktionsweisen entwickelt, aus dem dann im „Ernstfall“ zur Lösung von Krisen und Konflikten geschöpft werden kann. Spielen ist also ein Erkenntnisprozess, ein „Prozeß des Abstrahierens und Begreifens kultureller Krisenpunkte, in dem man ihnen die Form spielerischer Antithesen verleiht. " ${ }^{160}$ Sutton-Smith zählt eine Reihe von Antithesen auf, die im Spiel symbolisch dargestellt und erlebt werden: Die übergeordnete Antithese lautet „Ordnung - Anarchie“, darauf folgen „Annäherung - Vermeidung" und „Erfolg - Versagen“ sowie Ableitungen davon.

Stepina knüpft an Sutton-Smiths Spieltheorie an und weist darauf hin, dass „die Selbstzwecklichkeit des Spiels nie eine Zwecklosigkeit bedeuten kann. Denn Spiel ist immer ein Spiel im ganz konkreten, das heißt in den sozioökonomischen wie solidarischen Strukturen der Gesellschaft vorzufindenden, Leben, und dieses trägt seinen Zweck, nämlich das Leben in spielerischer Sinnhaftigkeit zu führen, in sich. Das Spiel ist also das selbstreflexive und darin handlungs-, geschichts- und gesellschaftsbildende Medium des Menschen." 161

Der Literaturwissenschaftler Thomas Anz, der eine Parallelisierung zwischen Literatur und Spiel versucht, sieht keinen Widerspruch in der Gleichzeitigkeit von Selbst-

157 Vgl. Colozza, S. 130.

158 Vgl. Karl Groos: Das Spiel. Zwei Vorträge. Jena 1922. Zit. nach Scheuerl: Theorien des Spiels. S. 72.

159 Ebd.

160 Vgl. Brian Sutton-Smith. Zit. nach Scheuerl: Theorien des Spiels. S. 125.

161 Stepina, S. 326. 
und Fremdzwecklichkeit des Spiels. Er erwähnt in Bezug auf das Spiel den von Mihaly Csikszentmihalyi geprägten Begriff der „autotelischen Aktivität"162 - einer Tätigkeit, die ihr Ziel bzw. ihren Zweck (griech. telos) in sich selbst (griech. auto = eigen, selbst) hat und durch die von ihr hergestellte intensive Freude intrinsisch motiviert ist - und schreibt: „Lust am Spiel und biologische oder auch pädagogische Nützlichkeit des Spiels sind kein Widerspruch, sondern aufeinander angewiesen. (...) Die ,Natur' und die pädagogische Kultur bedienen sich gleichsam einer List, indem sie Tätigkeiten, die dem Überleben oder der Ausbildung kulturell erwünschter Fähigkeiten förderlich sind, mit Lust prämieren und dabei die auf diese Weise motivierten Spieler vergessen lassen können, dass sie mit ihrem Aufwand an Energie etwas für sich Vorteilhaftes tun. "163

\subsubsection{Abgeschlossenheit und Begrenztheit in Zeit und Raum}

Ein weiteres formales Kriterium des Spiels ist nach Huizinga die Abgeschlossenheit und Begrenztheit in Zeit und Raum: Durch zeitliche und räumliche Abgrenzung wird eine eigene Welt (siehe 2.2.7) geschaffen, in der eigene Regeln (siehe 2.2.5) herrschen.

Auf eine ähnliche Art äußert sich Calliois: „Das Spiel ist (...) eine abgetrennte und sorgfältig von dem übrigen Dasein isolierte Beschäftigung und findet im Allgemeinen in räumlich und zeitlich genau festgelegten Grenzen statt. “Die „Domäne des Spiels“ beschreibt er als „eine reservierte, geschlossene oder geschützte Welt". ${ }^{164}$ Scheuerl schließt sich im Wesentlichen dieser These an und nennt als Wesensmerkmale des Spiels „Bündigkeit, Eigengesetzlichkeit und Geschlossenheit“. 165

\subsubsection{Spielregeln}

Eine abgrenzende Funktion haben auch die Spielregeln. Friedrich Georg Jünger schreibt dazu: „Spielregeln sind die Grenzen eines Spiels. Ihre Verletzung ist zugleich Verletzung der Spielgrenzen und führt zur Schädigung und Aufhebung des Spiels. (...) Die Bindung an Spielregeln wird frei übernommen und kann nicht erzwungen werden. " 166 Das schon erwähnte Kriterium der Freiwilligkeit des Spiels hängt also mit dem Akzeptieren von Spielregeln zusammen.

162 Vgl. Mihaly Csikszentmihalyi: Das flow-Erlebnis. Stuttgart 1985.

163 Thomas Anz und Heinrich Kaulen: Vom Nutzen und Nachteil des Spiel-Begriffs für die Wissenschaften. In: Thomas Anz: Literatur als Spiel. S. 3.

164 Caillois, S. 13.

165 Scheuerl. Das Spiel. S. 93.

166 Friedrich Georg Jünger: Die Spiele. Ein Schlüssel zu ihrer Bedeutung. Frankfurt a. M. 1953, S. $99 f$. 
Huizinga spricht von einem „genau umschriebenen Kodex von Spielregeln in striktem System mit zwingender Gültigkeit aber endloser Variationsmöglichkeit“. ${ }^{167}$ Caillois unterscheidet seinerseits zwischen geregelten und fiktiven Spielen. Im ersten Fall ist Spiel „eine geregelte Betätigung, die Konventionen unterworfen ist, welche die üblichen Gesetze aufheben und für den Augenblick eine neue, alleingültige Gesetzgebung einführen." 168 Interessant ist dabei, dass der Spieler einerseits im Spiel eine meist angenehme oder sogar lustvolle Befreiung von den Regeln des „Ernstlebens“ erfährt, andererseits ein anderes Regelsystem akzeptieren muss, um spielen zu können. Fink bemerkt dazu, dass beim Spiel oft "gerade die Gebundenheit an eine schon geltende Spielregel lustvoll und positiv erlebt" ${ }^{169}$ wird.

Sowohl Huizinga als auch Caillois erläutern im Zusammenhang mit den Spielregeln die Phänomene des Falschspielers und des Spielverderbers: „Der Falschspieler, der die Regeln verletzt, heuchelt doch zumindest, sie zu respektieren. Er stellt sie nicht in Abrede, er mißbraucht lediglich die Loyalität der übrigen Spieler." ${ }^{170}$ Der Spielverderber hingegen widersetzt oder entzieht sich den Regeln. Er enthüllt dadurch die Relativität der Spielwelt und nimmt dem Spiel die Illusion. ${ }^{171}$

Aus dem Vorhandensein von Regeln ergibt sich nach Huizinga eine weitere Aussage über das Spiel, nämlich: „Es schafft Ordnung, ja es ist Ordnung. “172 Jean Château spricht in Bezug auf das Spiel der Kinder vom „amour de l'ordre“, der die Welt der Spiele beherrsche. ${ }^{173}$ Den Begriff der Ordnung erwähnt auch Sutton-Smith, der als Kriterien für die Definition von Spiel das Vorhandensein von Regeln, den „Gegensatz der Kräfte“ und den ungewissen Ausgang nennt. ${ }^{174}$ Mit „Gegensatz der Kräfte“ meint Sutton-Smith vom Alltagsleben abstrahierte Antithesen, die im Spiel symbolisch und probeartig erfahren werden. ${ }^{175}$ Die übergeordnete Antithese lautet „Ordnung - Anarchie“.

\subsubsection{Gefühl der Spannung und Freude}

In Huizingas Definition von Spiel ist generell von einem „Gefühl der Spannung und Freude“ die Rede. Als Ursache für das Gefühl der Spannung gilt unter anderem die

\footnotetext{
167 Huizinga, S. 132.

168 Caillois, S. 16.

169 Fink: Oase des Glücks. S. 31.

170 Ebd. S. 13.

171 Vgl. Huizinga, S. 18f.

172 Ebd. S. 17.

173 Vgl. Scheuerl: Theorien des Spiels. S. 78.

174 Vgl. ebd. S. 128.

175 Vgl. 2.2.3.
} 
Ungewissheit des Ausgangs, die Caillois als eines der Hauptkriterien für das Spiel nennt, denn „ein im voraus bekannter Ablauf ohne Möglichkeit des Irrtums oder der Überraschung, der eindeutig zu einem unvermeidlichen Resultat führt, wäre mit dem Wesen des Spiels unvereinbar. Es bedarf einer beständigen, nicht voraussehbaren Erneuerung der Situation."176

Zum „Gefühl der Freude“ ist zu bemerken, dass in jeder Spieldefinition oder Spieltheorie Begriffe wie Fröhlichkeit, Vergnügen, Spaß und Freude vorkommen. Groos, der das Spiel unter anderem als Katharsis betrachtet, denn es befreie „von dem Druck und Zwang des Ernstlebens“, ${ }^{177}$ zählt in diesem Zusammenhang „entladende“ Gefühle auf, die beim Spiel häufig auftreten bzw. entstehen, nämlich „Gefühle der Spannung, des Wetteifers, der triumphierenden Freude am Können, des Sieges über andere, des Zusammenhaltens mit der Partei, des harmlosen Lachens über Zufall und Ungeschicklichkeit“. ${ }^{178}$ Groos nennt neben der Einübungsfunktion gerade die Lust als Bestimmung des Spiels: „Wo eine Thätigkeit rein um der Lust an der Thätigkeit selbst willen stattfindet, da ist ein Spiel vorhanden. " ${ }^{179}$ Von der Lust als Motivation und intrinsische Belohnung des Spiels geht über ein Jahrhundert später auch der Evolutionsbiologe Karl Eibl aus. ${ }^{180}$ Auch Nicht-Biologen wie der Literaturwissenschaftler Thomas Anz sehen heutzutage Lust und Vergnügen nicht lediglich als Begleiterscheinungen des Spielens an, sondern als vorrangige Motivation dafür. ${ }^{181}$

Als Heiterkeit hatte Schaller im I9. Jahrhundert den geistigen Zustand des spielenden Menschen definiert; auch wenn man beim Spielen ernst ist, handle es sich immer noch um einen „heitern Ernst“. ${ }^{182}$ William Stern führt diesen Gedanken weiter und stellt fest, dass „zwischen den beiden Grenzphasen des rein spielerischen und des absolut ernsthaften Verhaltens eine unendliche Skala von Verhaltensweisen liegt, die Spielhaftes und Ernsthaftes in eins verschmolzen enthalten ": Diese definiert er als „Ernstspiele“ ${ }^{183}$. Stern nennt mehrere Beispiele dafür, darunter - für unseren Bereich besonders interessant - das des Schauspielers, der während der Darbietung Affekte von höchster Intensität durchlebt, die doch nur als „halb ernst“ bezeich-

176 Vgl. Caillois, S. 14.

177 Vgl. Groos: Das Spiel. Zit. nach Scheuerl: Theorien des Spiels. S. 72.

178 Ebd.

179 Groos: Die Spiele der Menschen. S. 7. Zit. nach Anz: Literatur und Lust. S. 58.

180 Vgl. Eibl: Vom Ursprung der Kultur im Spiel. Ein evolutionsbiologischer Zugang. In: Thomas Anz und Heinrich Kaulen (Hg.): Literatur als Spiel. S. 11-25.

181 Vgl. Thomas Anz: Spiel. In: Jan-Dirk Müller (Hg.): Reallexikon der deutschen Literaturwissenschaft. Bd. 3. Berlin, New York 2003, S. 469-472.

182 Zit. nach Scheuerl: Theorien des Spiels. S. 59.

183 William Stern: Ernstspiel als Verhalten und Erlebnis. In: Zeitschrift für pädagogische Psychologie. 30. Jg., Leipzig 1929. Zit. nach Scheuerl: Theorien des Spiels. S. $100 \mathrm{f}$. 
net werden können, weil sie eben nur gespielt sind. Dieser „halbe Ernst“ entspricht prinzipiell Schallers Begriff des „heiteren Ernstes“. Bedenklich fügt Schaller hinzu: Wer das Spiel zu seinem Beruf macht, dem geht „die eigenthümliche Heiterkeit des wirklich Spielenden"184 verloren. Allgemeiner ausgedrückt, die heitere Stimmung des Spiels verschwindet, wenn beim Spiel die Absicht auf Gewinn das Hauptinteresse ausmacht.

Huizingas erweiterte Definition von Spiel enthält einen ähnlichen Gedanken: Spiel ist „eine freie Handlung, (...) an die kein materielles Interesse geknüpft ist und mit der kein Nutzen erworben wird. "185 Caillois kritisiert Huizingas Aussage, denn sie würde jede Form von Wett- und Glücksspiel ausschließen. Bei dieser Art von Spiel findet laut Caillois zwar keine Güterproduktion, jedoch eine „Verschiebung des Eigentums“ statt. ${ }^{186}$ Seine überarbeitete und dennoch nicht unproblematische Definition lautet folgendermaßen: „Das Spiel ist (...) eine unproduktive Betätigung, die weder Güter noch Reichtum noch sonst ein neues Element erschafft und die, abgesehen von einer Verschiebung des Eigentums innerhalb des Spielerkreises, bei einer Situation endet, die identisch ist mit der zu Beginn des Spiels. "187 Indirekt wird durch diese Aussage eine Abgrenzung des Spiels vom Begriff der Arbeit versucht. Es handelt sich dabei um ein klassisches Gegensatzpaar (Spiel versus Arbeit), auf dem schon Aristoteles' Gedanken basiert waren. Skeptisch gegenüber jedem theoretischen Abgrenzungsversuch zwischen Spiel und Arbeit zeigt sich Stepina. Er behauptet, dass „erst gesellschaftliche Konvention definiert, was Spiel und was Arbeit ist." 188

Schallers oben erwähnter Gedanke verknüpft die Spiel-Arbeit-Problematik mit einem zweiten klassischen Gegensatzpaar, nämlich der Spiel-Ernst-Antithese. Huizinga kapituliert vor dem Versuch eine Demarkationslinie zu definieren und spricht von einer „verwirrenden Unauflösbarkeit des Problems Spiel oder Ernst“. ${ }^{189}$ Diesbezüglich schreibt er: „Der Gegensatz Spiel - Ernst bleibt stets schwebend. Die Minderwertigkeit des Spiels hat ihre Grenze im Mehrwert des Ernsts. Das Spiel schlägt in Ernst um, der Ernst in Spiel." 190

Gregory Bateson, der das Spielverhalten sowohl der Menschen als auch der Tiere durch die implizite metakommunikative Mitteilung „Dies ist ein Spiel“ charakterisiert sieht, entdeckt bei komplexeren Formen des Spiels eine gewisse Labilität, die sich

184 Schaller, S. 4ff. Zit. nach Scheuerl, S. 59.

185 Huizinga, S. 20.

186 Vgl. Caillois, S. $11 \mathrm{f}$.

187 Ebd. S. 16.

188 Stepina, S. 313.

189 Huizinga, S. 200.

190 Vgl. Huizinga, S. 16. 
dadurch äußert, dass in diesen Fällen das Spiel nicht so sehr „auf der Prämisse ,Dies ist ein Spiel' gegründet ist, sondern sich eher um die Frage ,Ist das Spiel?" dreht". ${ }^{191}$

Scheuerl bemerkt, dass unabhängig von der Perspektive, aus welcher das Spiel betrachtet wird, immer eine Ambivalenz festgestellt wird. Diesen Begriff erweitert er zu einem Wesensmerkmal des Spiels, das er als „labile Ambivalenz"192 bezeichnet, und das mit der Definition von Spiel als „Hin- und Herbewegung“ in Verbindung steht. Nach Scheuerl kann also nicht nur die (psychische) Haltung des Spielers ambivalent sein - denn „das Spiel kann vom Spieler ,unernst‘, ,leichtsinnig“ (...) betrieben werden oder ihn auch mit heiligem Ernst erfüllen"193 "schwebend“ und ambivalent, denn „Spielen ist immer ein ,Spielen - zwischen“."194 Dabei beruft sich Scheuerl auf Schillers Spieltheorie, in der der Spieltrieb eine Vermittlerrolle zwischen „Stofftrieb“ (Sinnlichkeit, Leben) und „Formtrieb“ (Gestalt) einnimmt. „Dem Stofftrieb wie dem Formtrieb ist es mit ihren Forderungen ernst" ${ }^{195}$, zitiert Scheuerl Schiller und fügt hinzu: „Spiel aber stellt das Gleichgewicht her und hebt jeden einseitigen Ernst auf.“ 196 „Durch Entgegensetzung zweier sich widerstreitender Eindeutigkeitstendenzen“ entsteht nach Scheuerl eine „Ambivalenz und damit jener Spannungsraum, in dem kein nachfolgender Moment aus dem vorigen ganz prognostizierbar ist, und damit der abenteuerliche, scheinbar determinationsfreie Variationsreichtum des Spiels. " 197 In dieser Ambivalenz liegt nach Scheuerl unter anderem die Faszination des Spiels.

\subsubsection{Anderssein als das gewöhnliche Leben}

Eine gewisse Ambivalenz im Spiel - allerdings aus einer anderen Perspektive - bemerkt auch Eugen Fink, der Folgendes dazu schreibt: „Die philosophische Frage würde dann abzielen auf die Seinsverfassung des Menschenspiels, auf die besondere Art, wie das Spiel seiend ist; denn das fällt ja sogleich auf, daß es nicht, ist' wie sonst die ernsthaften Lebensvollzüge des Menschen, - daß es ein beschwingtes ,Tun als ob ist, einen eigentümlichen ,Schein', eine merkwürdige Sphäre von ,Unwirklichkeit' in sich enthält. Das Spiel - als ein seltsames Ineinander von ,Sein' und ,Schein “ - ist

191 Gregory Bateson: Eine Theorie des Spiels und der Phantasie. Zit. nach Rapp: Rolle. Interaktion. Spiel. S. 118.

192 Scheuerl: Theorien des Spiels. S. 204.

193 Scheuerl: Das Spiel. S. 89.

194 Ebd. S. 90.

195 Schiller: Fünfzehnter Brief. Zit. nach Scheuerl: Das Spiel. S. 85.

196 Scheuerl: Das Spiel. S. 85.

197 Scheuerl: Theorien des Spiels. S. 205. 
gleichsam ein scheinendes Sein und ein seiender Schein. Eine ontologische Durchklärung des Spieles erfordert einen nicht leicht zu gewinnenden Einblick in das ,Zusammenspiel" von Sein und Schein." 198

Damit berührt Fink einerseits durch die Begriffe „Sein“ und „Schein“ ein fundamentales philosophisches Problem, andererseits spricht er eine Charakteristik des Spiels an, die im Prinzip dem in Huizingas Definition des Spiels auf eine simplere Art formulierten Merkmal des „Andersseins“ als das „gewöhnliche Leben“ entspricht.

$\mathrm{Zu}$ diesem Thema hatte schon Schaller im I9. Jahrhundert festgestellt, dass sich der Mensch beim Spiel „aus dem Ernste des geistigen Lebens herauszieht“ und sich eine besondere Sphäre schafft, in der er „die Wechselfälle des Glücks, die Gefahren und Schwierigkeiten“ zwar intensiv erlebt, dabei aber weiß, dass sie „im Vergleich zu den ernsten Gefahren doch nur Scheingefahren“ sind. ${ }^{199}$

Edouard Claparède hatte Anfang des 20. Jahrhundert von der Domäne des Spiels als ein „paradis du comme si“200 gesprochen. Etwa zur selben Zeit hatte Freud bemerkt: „Jedes spielende Kind benimmt sich wie ein Dichter, indem es sich eine eigene Welt erschafft oder, richtiger gesagt, die Dinge seiner Welt in eine neue, ihm gefällige Ordnung versetzt. “201 Seine treffende Schlussfolgerung daraus war: „Der Gegensatz von Spiel ist nicht Ernst, sondern - Wirklichkeit. "202 Heutzutage ist es in der Psychologie selbstverständlich, die Schaffung einer „zweiten Realitätsebene“ als typisches Merkmal des Spiels zu betrachten. ${ }^{203}$

Huizinga stellt in der beim Spiel stattfindenden ,zeitweiligen Aufhebung der ,gewöhnlichen Welt““ eine „Aufhebung aller Schwere des Lebens, Denkens, Handelns“204 fest, von der auch Fink spricht, wenn er die Wirkung der Spielwelt als „des ,Lebens Leichtwerden““”, als „Lösung von den Gewichten der Daseinslast“205 beschreibt und das Spiel für den Erwachsenen als eine „Oase angekommenen Glücks“ bezeichnet. Dazu schreibt Fink: „Spielend sind wir für eine Weile entlassen aus dem Lebensge-

198 Fink: Spiel als Weltsymbol. S. 32.

199 Vgl. Scheuerl: Theorien des Spiels. S. 61.

200 Edouard Claparède: Psychologie de l'enfant et pédagogie expérimentale. Genf 1915, S. 449. Zit. nach Scheuerl: Das Spiel. S. 80.

201 Sigmund Freud: Der Dichter und das Phantasieren. In: Ders. Studienausgabe. Bd. 10. Bildende Kunst und Literatur. Frankfurt a. M. 2000, S. 171. Zit. nach Nicola Gess: „Magisches Denken“ im Kinderspiel. In: Thomas Anz und Heinrich Kaulen (Hg.) : Literatur als Spiel. S. 301.

202 Sigmund Freud: Der Dichter und das Phantasieren. In: Ders. Gesammelte Werke. Bd. 7. Hg. von Anna Freud. London 1955, S. 214. Zit. nach Peter Brandes in: Thomas Anz und Heinrich Kaulen (Hg.): Literatur als Spiel. S. 116.

203 Vgl. Rolf Oerter: Psychologie des Spiels. Weinheim 1997, S. $293 \mathrm{f}$.

204 Huizinga, S. 78.

205 Fink: Oase des Glücks. S. 38. 
triebe - wie versetzt auf einen anderen Stern, wo das Leben leichter, schwebender, glückender scheint. (...) Das reine Selbstgenügen (...) läßt im Spiel eine Möglichkeit des menschlichen Aufenthalts in der Zeit aufscheinen, wo sie nicht das Reißende und Forttreibende hat, vielmehr Verweilen gewährt, gleichsam ein Lichtblick der Ewigkeit ist. (...) Das Spiel schenkt Gegenwart."206

Dieses Gefühl der Zeitenthobenheit stellen verschiedene Spieltheoretiker fest, beispielsweise Gadamer, der von einer „spezifischen Art des Verweilens“ spricht, sowie Scheuerl, der als Wesensmerkmal des Spiels das „Moment der Gegenwärtigkeit“207 nennt.

Fink erwähnt eine nicht nur zeitliche, sondern allgemeine „Enthebung aus der reellen Weltwirklichkeit, die bis zur Entrückung, bis zur Verzauberung gehen kann “. ${ }^{208}$ Der Zauber dieser abgeschlossenen, imaginären Sphäre klingt auch sowohl in Claparèdes Wortwahl („paradis“) als auch in Finks Titel „Oase des Glücks“ an.

Huizinga beschreibt die Stimmung beim Spiel als „Entrücktheit und Begeisterung “209 und spricht an der Stelle, wo er auf den „ästhetischen Faktor“ des Spiels aufmerksam macht, ebenfalls von Bezauberung: „Der ästhetische Faktor ist vielleicht identisch mit dem Drang, eine geordnete Form zu schaffen, die das Spiel in allen seinen Gestalten belebt. Die Wörter, mit denen wir Elemente des Spiels benennen können, gehören zum größten Teil in den Bereich des Ästhetischen. Es sind Wörter, mit denen wir auch Wirkungen der Schönheit zu bezeichnen suchen: Spannung, Gleichgewicht, Auswägen, Ablösung, Kontrast, Variation, Bindung und Lösung, Auflösung. Das Spiel bindet und löst. Es fesselt. Es bannt, das heißt: es bezaubert. "210 Über das „ästhetische Genießen “ äußert sich interessanterweise auch gerade ein Theoretiker wie Groos, der das Spiel in erster Linie aus biologischer und funktionsorientierter Sicht betrachtet. Er bezeichnet dieses „ästhetische Genießen“ als „die höchste und feinste Form des Spiels“, ${ }^{211}$ wobei ein gefühlsreiches „inneres Miterleben“, ein „Hineingerissenwerden in die dargestellten Begebenheiten“ stattfindet, das „uns eine ideale Bereicherung unseres Daseins bietet“. ${ }^{212}$ Somit findet Groos auch auf der ästhetischen Ebene eine Bestätigung seiner Kompensationstheorie und nimmt gewissermaßen Gadamers Idee des mitspielenden, innerlich teilnehmenden Zuschauers bzw. Kunstbetrachters vorweg.

206 Ebd. S. 23f.

207 Scheuerl: Das Spiel. S. 95.

208 Fink: Oase des Glücks. S. 39.

209 Huizinga, S. 129.

210 Ebd. S. 18.

211 Scheuerl: Theorien des Spiels. S. 67.

212 Ebd. S. 72. 
Groos hatte vom „spielenden Durchkosten von Lebensmöglichkeiten“ in der "Scheinwelt des Spiels" gesprochen; ein ähnlicher Ansatz ist bei Konrad Lange zu finden, der behauptet, man setze sich im Spiel und in der Kunst „fingierte Ernstzwecke“, „um fehlende Erlebnismöglichkeiten zu ergänzen“. ${ }^{213}$ Lange sieht in der Kunst „ein gesteigertes und verfeinertes, dem Bedürfnis des Erwachsenen angepaßtes Illusionsspiel.“" ${ }^{14}$ In seiner Schrift „Die bewußte Selbsttäuschung als Kern des künstlerischen Genusses“ stellt Lange fest, dass „illusionsstörende Momente“ die Selbsttäuschung bewusst machen und damit ein in Spiel und Kunst charakteristisches „Hin- und Heroszillieren zwischen Schein und Wirklichkeit“215 erzeugen. Damit wird Huizingas Aussage, dass zur Definition des Spiels Begriffe aus der Ästhetik verwendet werden, bestätigt.

Fink dagegen spricht in Bezug auf das Spiel nicht von einer Pendelbewegung, sondern von einem „seltsamen Ineinander von ,Sein“ und ,Schein “ "im Sinne eines „scheinenden Seins und seienden Scheins“, denn in der Welt des Spiels kommen „Dinge, die unleugbar selber etwas Wirkliches sind und doch in sich ein Moment von ,Unwirklichkeit" enthalten", ${ }^{216}$ vor. Um seine Idee zu veranschaulichen, führt Fink das Beispiel einer Pappel an, die sich auf einer schimmernden Wasserfläche spiegelt. Fink nennt diese "Abbilder" von etwas Wirklichem - damit meint er nicht nur Spiegelbilder, sondern beispielsweise auch Schatten - „eine eigenständige Sorte von Seiendem“. Spielen ist nach Fink also „ein wirkliches Verhalten, das gleichsam in sich eine ,Spiegelung', das spielweltliche Verhalten gemäß der Rollen, befaßt." 217

Fink versucht, diese für die „Spielwelt" charakteristische „Sphäre des Scheins“ näher zu bestimmen und bemerkt, dass dieser „Schein“ „,mitunter eine stärkere erlebnishafte Realität und Eindruckskraft als die massiven Alltagsdinge in ihrer abgenutzten Gewöhnlichkeit" ${ }^{\text {"218 }}$ besitzt.

Schon Schiller hat von der „Freude am Schein“ gesprochen und erläuternd hinzugefügt: „Es versteht sich von selbst, daß hier nur von dem ästhetischen Schein die Rede ist, den man von der Wirklichkeit und Wahrheit unterscheidet, nicht von dem logischen, den man mit derselben verwechselt - den man folglich liebt, weil er Schein ist, und nicht, weil man ihn für etwas Besseres hält. Nur der erste ist Spiel,

213 Scheuerl: Das Spiel. S. 79.

214 Konrad Lange: Das Wesen der Kunst. Bd. 2. Berlin 1901, S. 24. Zit. nach Scheuerl: Das Spiel. S. 79.

215 Zit. nach Scheuerl: Das Spiel. S. 79.

216 Fink: Oase des Glücks. S. 46.

217 Ebd. S. 47.

218 Ebd. S. 44. 
da der letzte bloß Betrug ist."219 Auch Scheuerl nennt als Merkmal des Spiels das "Moment der Scheinhaftigkeit“ und stützt sich auf Schillers Unterscheidung: Was Schiller als „logischen Schein“ bezeichnet, nennt Scheuerl „Illusion“, „als-ob“ bzw. „Zu-sein-Scheinen“, während er den „ästhetischen“ oder „reinen Schein“ als „ein im ,Feld der Erscheinungen“ und nur hier offenbar Werdendes“ umschreibt. Beide Arten des Scheins können nach Scheuerl im Spiel vorkommen. Die erstgenannte Art („Illusion“) gehört allerdings nicht zum Wesen des Spiels, „sondern tritt nur in manchen Fällen als Akzidenz hinzu“, ${ }^{220}$ nämlich in den Spielen, die Caillois „fiktive Spiele“ nennt und die er den „geregelten Spielen“ gegenüberstellt. ${ }^{221}$

\subsection{Gliederungsversuche}

Bisher wurden allgemeine Kriterien für die Wesensbestimmung des menschlichen Spiels erörtert. Schon relativ früh suchte man nach Einteilungsmöglichkeiten für die vielfältigen Erscheinungsformen des Spiels, wobei die Gliederungen zunächst ziemlich einfach ausfielen. Im I 8. Jahrhundert unterscheidet Guts Muths beispielsweise zwischen „Bewegungsspielen“ und „sitzenden oder Ruhespielen“ bzw. zwischen „geselligen “ und „einsamen“ Spielen, während im I9. Jahrhundert, angefangen von Friedrich Fröbel, ${ }^{222}$ differenziertere, vor allem auf das Spiel der Kinder bezogene Gliederungen entstanden, die die Einteilungsprinzipien des vorhergehenden Jahrhunderts übernahmen und erweiterten. Colozzas noch rein pädagogisch orientierte Klassifikation der Spiele scheint für Groos als Anregung gedient zu haben, denn er übernahm die Spielkategorien der Nachahmungs- und der Kampfspiele und fügte ihnen die Klassen des spielenden Experimentierens, der sozialen Spiele und sogar der Liebesspiele hinzu. ${ }^{223}$ Später verwendeten Pädagogen und Psychologen Lebensalter und psychologische Entwicklungsstufen (besonders Jean Piaget und Charlotte Bühler) oder das verwendete Spielmaterial ${ }^{224}$ als Gliederungskriterien. Die Palette reicht bis zu höchst komplexen Gliederungen, wie beispielsweise jene von Jean Château, dessen Grundunterteilung in geregelte und nicht-geregelte Spiele sich je nach Art der Aktivität

219 Schiller: Sechsundzwanzigster Brief. Zit. nach Scheuerl: Theorien des Spiels. S. 39.

220 Scheuerl: Das Spiel. S. 81.

221 Caillois, S. $15 f$.

222 Friedrich Wilhelm August Fröbel: Die Menschenerziehung, die Erziehungs-, Unterrichts- und Lehrkunst, angestrebt in der allgemeinen deutschen Erziehungsanstalt zu Keilhau. Bd. 1. Keilhau-Leipzig 1826.

223 Vgl. Karl Groos: Die Spiele der Menschen. Jena 1899

224 Garvey unterteilt die Kinderspiele beispielsweise nach den folgenden „Spielgegenständen“: Bewegung, Objekte, Sprache, soziales Material, Regeln, Ritualisierung. (Vgl. Catherine Garvey: Spielen. Stuttgart 1978 [englische Originalausgabe unter dem Titel Play. London 1977]). 
und der "geistigen Spielgesetze“225 in viele weitere Unterteilungen verzweigt. Hans Scheuerl gibt sich dagegen mit keinem noch so ausgeklügelten Gliederungsversuch zufrieden und stellt Folgendes fest: „So bleiben alle bisherigen Gliederungsversuche nach irgend einer Seite hin unbefriedigend. Denn sie versuchen nichts Geringeres, als die Gesamtheit des Lebens selbst in ein System zu bringen. Heterogenste Erscheinungen, deren einziger Vergleichspunkt darin besteht, daß an irgend einer Stelle in ihnen das Urphänomen Spiel zum Aufleuchten kommt, widersetzen sich offenbar jeder Systematisierung und Klassifizierung. "226 Folglich bleibt seine Gliederung in Bewegungsspiele, Leistungsspiele, Spiele mit Darstellungscharakter und Spiele mit Schaffenscharakter absichtlich unvollkommen.

Diese schon im I 9. Jahrhundert festgestellte Schwierigkeit oder gar Unmöglichkeit, die vielfältigen Erscheinungsformen des Spiels in eine allumfassende und streng bestimmte Systematik zu bringen, ${ }^{227}$ wird unter anderem aus einer Äußerung Ludwig Wittgensteins ersichtlich, der das Augenmerk auf das komplexe Netz von Ähnlichkeiten zwischen den unterschiedlichen Spielen legt:

„Betrachte z. B. einmal die Vorgänge, die wir ,Spiele‘ nennen. Ich meine Brettspiele, Kartenspiele, Ballspiele, Kampfspiele, usw. Was ist allen diesen gemeinsam? - Sag nicht: ,Es muß ihnen etwas gemeinsam sein, sonst hießen sie nicht ,Spiele“ - sondern schau, ob ihnen allen etwas gemeinsam ist. - Denn wenn du sie anschaust, wirst du

225 Vgl. Scheuerl: Das Spiel. Bd. 1. Weinheim, Basel 1979, S. 141.

I. Jeux non réglés:

a) Jeux de l'intelligence concrète:

1. Funktionsspiele

2. Hedonistische Spiele

3. Erforschungsspiele

b) Jeux d'affirmation inférieure de soi

1. Jeux de désordre

2. Jeux d'emportement (Spiele des Hingerissenseins, Entladungsspiele)

II. Jeux réglés

a) Jeux du groupe segmentaire

1. Nachahmungs- und Illusionsspiele

2. Jeux de travail

3. Abstrakte Spiele: Künstlich geregelte Spiele

b) Jeux de coopération

1. Mannschaftswettkämpfe mit oder ohne Spielfelder

2. Jeux à régulation stricte:

a) Tänze

b) Zeremonien

226 Scheuerl: Das Spiel. S. 142.

227 Groos meint beispielsweise, „daß eine vollkommene Systematisierung fast überall nur ein logisches Ideal ist und bleiben wird." (Groos: Die Spiele der Menschen. S. 3). 
zwar nicht etwas sehen, was allen gemeinsam wäre, aber du wirst Ähnlichkeiten, Verwandtschaften sehen, und zwar eine ganze Reihe. Wie gesagt: denk nicht, sondern schau! - Schau z. B. die Brettspiele an, mit ihren mannigfachen Verwandtschaften. Nun geh zu den Kartenspielen über: hier findest du viele Entsprechungen mit jener ersten Klasse, aber viele gemeinsame Züge verschwinden, andere treten auf. Wenn wir nun zu den Ballspielen übergehen, so bleibt manches Gemeinsame erhalten, aber vieles geht verloren. - Sind sie alle ,unterhaltend"? Vergleiche Schach mit dem Mühlfahren. Oder gibt es überall ein Gewinnen und Verlieren, oder eine Konkurrenz der Spielenden? Denk an die Patiencen. In den Ballspielen gibt es Gewinnen und Verlieren; aber wenn ein Kind den Ball an die Wand wirft und wieder auffängt, so ist dieser Zug verschwunden. Schau, welche Rolle Geschick und Glück spielen. Und wie verschieden ist Geschick im Schachspiel und Geschick im Tennisspiel. Denk nun an die Reigenspiele: Hier ist das Element der Unterhaltung, aber wie viele der anderen Charakterzüge sind verschwunden! Und so können wir durch die vielen, vielen anderen Gruppen von Spielen gehen. Ähnlichkeiten auftauchen und verschwinden sehen.

Und das Ergebnis dieser Betrachtung lautet nun: Wir sehen ein kompliziertes Netz von Ähnlichkeiten, die einander übergreifen und kreuzen. Ähnlichkeiten im Großen und Kleinen.

Ich kann diese Ähnlichkeiten nicht besser charakterisieren als durch das Wort ,Familienähnlichkeiten'; denn so übergreifen und kreuzen sich die verschiedenen Ähnlichkeiten, die zwischen den Gliedern einer Familie bestehen: Wuchs, Gesichtszüge, Augenfarbe, Gang, Temperament, etc. etc. - Und ich werde sagen: die Spiele bilden eine Familie (...).“228

Anknüpfend an Wittgensteins Begriff der „Familienähnlichkeiten“ teilt Rainer Buland die Spiele in folgende „Familien“ ein: „Zug um Zug-Spiele“, „Einsatz-Spiele“, „Bewegungsfreiheits-Spiele“, „Gestaltungs-Spiele“ und Mischformen dieser Spielarten. Das entscheidende Kriterium zur Abgrenzung der Spiele von rein spielerischen bzw. lose mit dem Spiel in Verbindung stehenden Tätigkeiten besteht nach Buland in der Entscheidungsfreiheit des Spielers innerhalb des Spiels. ${ }^{229}$

Von den meisten dieser Gliederungsversuche hebt sich Caillois' auf anthropologischer Grundlage beruhende Klassifikation der Spiele ab. Er teilt die Spiele in vier anthropologische Grundkategorien ein, nämlich agôn, alea, mimicry und illinx. Bei der ersten Gruppe von Spielen handelt es sich um einen Wettkampf, in dem „eine

228 Wittgenstein: Philosophische Untersuchungen. S. $56 f$.

229 Vgl. Rainer Buland: Die Einteilung der Spiele nach ihren Freiheitsaspekten. In: Günther G. Bauer (Hg.): Homo ludens. Lotto und Lotterie. Bd. 7. Internationale Beiträge des Institutes für Spielforschung und Spielpädagogik an der Hochschule „Mozarteum“ Salzburg. München, Salzburg 1997, S. $270 \mathrm{ff}$. 
künstliche Gleichheit der Chancen geschaffen wird, damit sich die Wettkämpfer unter idealen Bedingungen miteinander messen können. “230 Der "Wille zum Sieg“ bildet dabei den Antrieb dieser Art von Spielen. Die zweite Gruppe (alea, lat. Würfelspiel) bezeichnet Spiele, „die ganz im Gegensatz zu den agonalen Spielen auf einer Entscheidung basieren, die nicht vom Spieler abhängig ist und auf die er nicht den geringsten Einfluß hat (...) Genauer gesagt wird hier der Sieg nur durch das Schicksal bewirkt. “231 Es handelt sich also um Glücksspiele, deren ,Triebfeder" gerade die „Willkür des Zufalls" ist. Auch bei diesen Spielen, die vorwiegend von Erwachsenen gespielt werden, bildet die künstlich geschaffene Chancengleichheit die Ausgangslage. Die dritte Gruppe von Spielen, für die Caillois den englischen Terminus mimicry wählt, basiert auf „dem Hang des Menschen, sich zu verstellen, zu verkleiden, eine Maske zu tragen, eine Persönlichkeit darzustellen. "232 Für die letzte Kategorie von Spielen verwendet Caillois den Begriff ilinx (griech. Wasserstrudel) und meint damit jene Spiele, „die auf dem Begehren nach Rausch beruhen und deren Reiz darin besteht, für einen Augenblick die Stabilität der Wahrnehmung zu stören. "233 Durch Geschwindigkeit und/oder Drehbewegung wird ein „tranceartiger Betäubungszustand“234 erreicht, ein Schwindelgefühl, eine Verwirrung, eine Ekstase.

Diese vier Grundkategorien, die in der Realität auch kombiniert auftreten können, bilden den Rahmen für eine Klassifikation der Spiele. Innerhalb jeder Kategorie ordnet Caillois die anfallenden Beispiele wiederum nach zu- bzw. abnehmender paidia, einem Prinzip, für dessen Beschreibung Caillois die Begriffe der „unkontrollierten Phantasie, der „freien Improvisation“, der „unbekümmerten Lebensfreude“ und der „anarchischen und launenhaften Natur" verwendet, und nach zu- bzw. abnehmendem ludus, gewissermaßen dem Gegenprinzip dazu, das er in „willkürlichen, gebieterischen und absichtlich hemmenden Konventionen“ und „schwierigen Hindernissen“ verwirklicht sieht, die „Anstrengung, Geduld oder Geschicklichkeit und Erfindungsgabe" erfordern. ${ }^{235}$

230 Caillois, S. 21.

231 Ebd. S. 24.

232 Ebd. S. 28.

233 Ebd. S. 32.

234 Ebd.

235 Ebd. S. 20. 
Verteilung der Spiele

\begin{tabular}{|c|c|c|c|c|}
\hline & $\begin{array}{c}\text { AGON } \\
\text { (Wettkampf) }\end{array}$ & $\begin{array}{c}\text { ALEA } \\
\text { (Chance) }\end{array}$ & $\begin{array}{c}\text { MIMICRY } \\
\text { (Verkleidung) }\end{array}$ & $\begin{array}{c}\text { ILINX } \\
\text { (Rausch) }\end{array}$ \\
\hline $\begin{array}{l}\text { PAIDIA } \\
\text { Lärm } \\
\text { Bewegung } \\
\text { Unbändiges } \\
\text { Gelächter }\end{array}$ & $\begin{array}{l}\text { Nichtgeregelter } \\
\text { Wettlauf, Kampf, } \\
\text { usw. } \\
\text { Athletik }\end{array}$ & $\begin{array}{l}\text { Auszählspiele } \\
\text { „Zahl oder Adler“ }\end{array}$ & $\begin{array}{l}\text { Kindliche Nach- } \\
\text { ahmung } \\
\text { Illusionsspiele } \\
\text { Puppe, Rüstung } \\
\text { Maske } \\
\text { Travestie }\end{array}$ & $\begin{array}{l}\text { Kindliche Drehspiele } \\
\text { Zirkus } \\
\text { Schaukel } \\
\text { Walzer }\end{array}$ \\
\hline $\begin{array}{l}\text { Drachen } \\
\text { Grillenspiel } \\
\text { Patiencen }\end{array}$ & $\begin{array}{l}\text { Boxen, Billard, } \\
\text { Fechten, Dame- } \\
\text { spiel, Fußball, } \\
\text { Schach }\end{array}$ & $\begin{array}{l}\text { Wette } \\
\text { Roulette }\end{array}$ & & $\begin{array}{l}\text { „volador" } \\
\text { Jahrmarktsattrakti- } \\
\text { onen }\end{array}$ \\
\hline $\begin{array}{l}\text { Kreuzworträtsel } \\
\text { LUDUS }\end{array}$ & $\begin{array}{l}\text { Sportwettkämpfe } \\
\text { im allgemeinen }\end{array}$ & $\begin{array}{l}\text { Einfache Lotterie } \\
\text { Zusammen- } \\
\text { gesetzte Lotterie } \\
\text { Lotterie auf Bu- } \\
\text { chung }\end{array}$ & $\begin{array}{l}\text { Theater } \\
\text { Schaukünste im } \\
\text { allgemeinen }\end{array}$ & $\begin{array}{l}\text { Alpinismus } \\
\text { Kunstsprünge }\end{array}$ \\
\hline
\end{tabular}

Anmerkung: In jeder senkrechten Rubrik sind die Spiele annähernd so angeordnet, daß das Element paidia ständig abnimmt, während das Element ludus ständig wächst.

Quelle: Roger Caillois: Die Spiele und die Menschen. Maske und Rausch. Stuttgart 1960, S. 46.

\subsection{Kunst als Spiel}

Bemerkenswert und für unser Anliegen interessant ist die Selbstverständlichkeit, mit der Caillois Theater und „Schaukünste im allgemeinen“ als Spiele einstuft. Er schreibt ausdrücklich: „Natürlich gehören mit vollem Recht auch die Theateraufführungen und die Interpretationen dramatischer Werke in diese Gruppe. "236 Erwähnenswert sind in diesem Zusammenhang Huizingas Gedanken zum Verhältnis zwischen Kunst und Spiel: Er sieht nämlich in den musischen Künsten Poesie, Musik und Tanz eine deutlichere Verbindung zum Spiel als in den plastischen Künsten ${ }^{237}$ und spricht von „den ausgesprochenen Spielqualitäten des Musischen “. ${ }^{238}$ Er unterstützt diese Behauptung mir folgender Erklärung: „In den musischen Künsten besteht die tatsächliche ästhetische Aktivierung darin, daß das Kunstwerk ausgeführt wird. (...) Die musische Kunst ist Handlung und wird als Handlung in der Ausführung jedesmal von neuem genossen. (...) Diese Handlung selbst aber, in der die musische Kunst erlebt wird, ist ein Spiel zu nennen. "239

236 Caillois, S. 30.

237 Vgl. Huizinga, S. 159.

238 Ebd. S. 160.

239 Ebd. 
Auch zu den einzelnen musischen Künsten äußert sich Huizinga: Dichtung ist für ihn ,in der Spielsphäre (...) zu Haus“, denn „Poiesis ist eine Spielfunktion. Sie geht in einem Spielraum des Geistes vor sich, in einer eigenen Welt, die der Geist sich schafft. Dort haben die Dinge ein anderes Gesicht als im ,gewöhnlichen Leben“ und sind durch andere Bande als logische aneinander gebunden. "240 Dabei ist das Drama das einzige Gebiet der Dichtung, das durch „seine Eigenschaft, Handlung zu sein“, einen „festen Zusammenhang mit dem Spiel“ hat. ${ }^{241}$

Zwischen Musik und Spiel sieht Huizinga eine besonders tiefe Wesensbeziehung, denn „die wesentliche Art aller musikalischen Aktivität ist ein Spielen“. ${ }^{242}$ Die Musik bezeichnet Huizinga als die „reinste und höchste Manifestation der menschlichen Facultas ludendi“243 und zu ihrer Zwillingskunst, dem Tanz, bemerkt er, dass es sich um „eine der reinsten und vollkommensten Formen des Spiels“ handelt. ${ }^{244}$

Ein expliziter Versuch, Kunst allgemein als Spiel zu betrachten, stammt von Schaller, der den Spieler mit dem schaffenden Künstler gleichsetzt. Der Unterschied liegt seiner Meinung nach darin, dass beim Spiel das Ergebnis sich „nicht von der subjectiven Thätigkeit des Spielers loslöst“ und im Gegensatz zum Kunstwerk „keine objektive, selbständige Bedeutung erhält". ${ }^{245}$ Das Resultat der Kunst ist, anders als beim Spiel, ein „Werk, das über sein Werden hinaus Bestand“ behält. ${ }^{246}$

Im I9. Jahrhundert macht sich auch Moritz Lazarus Gedanken über den Zusammenhang zwischen Spiel und Kunst und bemerkt dazu, dass „das musikalische und poetische Werk dem Spiele darin verwandt ist, daß es wie ein Spiel eben in der Darstellung und Vorführung vorüberrauscht. Komponieren und dichten ist nicht spielen, wie darstellen und vortragen es ist. “247 Diese Unterscheidung vom künstlerischen Schaffen als „Nicht-Spiel“ und Aufführung als Spiel zieht sich durch verschiedene Theorien.

Groos, der das ästhetische Genießen als „die höchste und feinste Form des Spiels“248 betrachtet, behauptet beispielsweise, das künstlerische Schaffen sei vom Spiel weiter entfernt, weil es bestimmte Zwecke verfolge. ${ }^{249}$ Auch Scheuerl teilt im Wesentlichen

240 Ebd. S 118. In Huizingas Aussage steckt implizit der Gedanke der Autonomie von Spiel und Poesie bzw. Kunst, der durch die für beide Bereiche charakteristische „Schaffung einer eigenen Welt“ begründet wird.

241 Vgl. ebd. S. 140.

242 Ebd. S. 157.

243 Ebd. S. 179.

244 Vgl. ebd. S. 159.

245 Schaller, S. 4ff. Zit. nach Scheuerl: Theorien des Spiels, S. 60.

246 Zit. nach Scheuerl: Das Spiel. S. 96.

247 Lazarus: Über die Reize des Spiels. S. 23. Zit. nach Scheuerl: Theorien des Spiels. S. 66.

248 Scheuerl: Theorien des Spiels. S. 67.

249 Vgl. Scheuerl: Das Spiel. S. 97. 
diese Meinung und stellt folgende These auf: „Allein die Aufführung, die Improvisation und die im ästhetischen ,Genuß` erfahrene Wirkung der Kunst sind mit dem

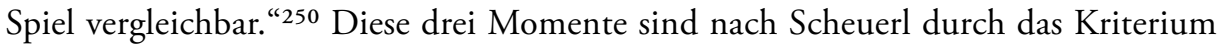
der „zeitenthobenen Gegenwärtigkeit“ mit dem Spiel verbunden. ${ }^{251}$

Nichtsdestotrotz schreibt Scheuerl ein ganzes Kapitel über Spiele mit Schaffenscharakter, in dem er unter anderem über Spielphasen im Schaffensprozess spricht, die in Form eines „,irtuellen Spielens mit den vorweggenommenen Wirkungen des erstrebten Werks" ${ }^{252}$ stattfinden. Wenn im Schaffensprozess Spiel- und Schaffensphasen grenzenlos ineinander übergehen, handelt es sich nach Scheuerl um ein „spielendes Schaffen“, dessen Gipfel die „Inspiration“ ist. ${ }^{253}$ Als ein „schaffendes Spielen“ dagegen kann man im Bereich der Kunst die Improvisation auffassen. Scheuerl wagt die Behauptung, „daß der Schöpfer eines Werks im Grunde Handlanger des Spielers sei. (...) Was der Spieler nicht improvisieren kann, das nimmt ihm der Komponist durch vorbereitende Arbeit ab. "254 "Schaffen im Dienste des Spiels“ geschieht nach Scheuerl prinzipiell außerhalb der Spielwelt, aber „den im Schaffensprozess vereinten Gegensatz von Schaffen und Spielen im Gleichgewicht zu halten, könnte selber wieder als ein Spiel auf höherer Ebene aufgefaßt werden. “255

Ein eigenes Kapitel widmet Scheuerl den Spielen mit Darstellungscharakter, von denen das Spiel mit verteilten Rollen und zusätzlich das Auseinandertreten von Darstellern und Zuschauern (wie beim Theater) eine spezielle Unterform bildet. Die Rolle, die im letzteren Fall die Zuschauer spielen, beschreibt er folgendermaßen: „Der Zuschauer spielt zwar nicht mit, aber er spielt (virtuell) doch sein eigenes Spiel. Auch wenn er nicht in die Darstellung selbst eingreift, so muß er doch für sich in der Ebene des Scheins alle Bilder reproduktiv noch einmal erzeugen, (...) muß alle Bewegungen innerlich noch einmal vollziehen (...). Bringen die Spieler improvisierend oder streng nachschaffend eine objektive Form mit allen ihren Gehalten zur Wirkung, so beginnen die Zuschauer nun, mit dieser Wirkung zu spielen. Vom Tun der Schauspieler, das harte Arbeit sein kann, abstrahieren sie das, was Spiel ist: Das reine Geschehen. Diese Abstraktion selbst kann wie das Lesen eines Buches ebenfalls harte Arbeit sein. Was sie aber erzeugt, ist ein reines, in sich unendliches Schweben von Bildern." 256

250 Ebd. S. 98.

251 Vgl. ebd. S. 99.

252 Ebd. S. 156.

253 Vgl. ebd. S. 153.

254 Ebd. S. 151.

255 Ebd. S. 153.

256 Ebd. S 149f. 
Gadamer, der die Erfahrung von Kunst durch die anthropologischen Begriffe Spiel, Symbol und Fest umschreibt, sagt etwas Ähnliches über die „Aktivität“ des Zuschauers eines Spiels aus, nämlich dass „Spielen immer ein Mitspielen verlangt. Selbst der Zuschauer (...) kann gar nicht anders. Wenn er wirklich ,mitgeht', ist das nichts anderes als die participatio, die innere Teilnahme an dieser sich wiederholenden Bewegung. (...) Der Zuschauer ist offenkundig mehr als ein bloßer Beobachter, der sieht, was vor sich geht, sondern ist als einer, der am Spiel ,teilnimmt', ein Teil von ihm. "257

Die Partizipation der Zuschauer sieht auch Caillois als Spiel und teilt sie der Kategorie mimicry zu, weil hier eine Form der Mimesis ${ }^{258}$ und der Verstellung stattfindet. ${ }^{259}$ Dieser Identifikationsvorgang bzw. -zustand ist allerdings Teil des „ästhetischen Genießens“, das schon Groos als Spiel bezeichnet hat. Denselben Gedankenschritt vollzieht Gadamer und thematisiert ihn folgendermaßen: „Die Einführung des Begriffes des Spieles hatte gerade die Pointe, zu zeigen, daß jeder bei einem Spiel Mitspieler ist. Das soll auch für das Spiel der Kunst gelten, daß es hier prinzipiell keine Trennung zwischen dem eigentlichen Werkgebilde der Kunst und dem, von dem dieses Werkgebilde erfahren wird, gibt." 260

Rapp nennt als erste Eigenschaft der Spielstruktur die Simulation ${ }^{261}$ und bezeichnet das menschliche Spiel als „Spiel mit Symbolen“ ${ }^{262}$ „Kunst wäre dann (...) eine Weise des Spiels, die sowohl dem Schöpfer die Parameter für sein Wirken bereitstellt, wie auch dem Empfänger das Erleben des Werkes in Spielform ermöglicht." 263 Rapp spricht im Falle des Theaters von einem „mimetischen Spiel“ vonseiten des Publikums und spielt dabei mit der Doppelbedeutung des Wortes, Vorstellung': „Die Schauspieler (und die hinter ihnen wirkenden Autoren und Regisseure) sind Hersteller einer Darstellung (presentation), die als vollzogene Vorstellung (performance) zur Vorstellung im Bewußtsein der Zuschauer wird. Die Zuschauer spielen ein mimetisches Spiel, in dem die Darsteller als ihre Stellvertreter fungieren; es bildet sich eine symbolische Interaktion." 264

Rapp kritisiert an Huizingas Spieltheorie die fehlende Differenzierung zwischen Spielgeist und Spieltätigkeit und schlägt für das Theater (als Spiel) folgendes Modell

257 Gadamer: Die Aktualität des Schönen. S. 31.

258 An dieser Stelle sei kurz daran erinnert, dass schon im 16. Jahrhundert Sperone Speroni, wenn auch nicht in einer umfassenden organischen Theorie, nicht nur die Nachahmung, sondern auch das Verfassen und die Lektüre eines Dialogs als Spiel definiert hat. (Vgl. Kapitel „Historischer Überblick“).

259 Vgl. Caillois, S. 30.

260 Gadamer: Die Aktualität des Schönen. S. 37.

261 Vgl. Rapp: Rolle, Interaktion, Spiel. S. 98.

262 Vgl. ebd. S. 100.

263 Ebd.

264 Ebd. S. $101 f$. 
vor: „In Veranstaltungen (Vorstellungen) spielen die Zuschauer ein mimetisches Spiel im Sinne des Spielgeistes, und die Schauspieler erhalten die Spielstruktur. (Ob Schauspieler wie auch andere ausführende Künstler bei ihrer Arbeit auch den Spielgeist erleben, wäre dann eine rein empirische Frage, von Fall zu Fall zu beantworten.) “265

Diese Formulierung entspricht im Großen und Ganzen dem Modell, das mir im Hinblick auf eine Betrachtung der Opera buffa unter dem Aspekt des Spiels vorschwebt. 


\section{Die Opera buffa im Licht der Spieltheorien}

In den folgenden Ausführungen soll anhand des venezianischen Repertoires im Zeitraum von 1770 bis 1790 eine Betrachtung der Opera buffa vom Blickwinkel des Spiels aus versucht werden. Ausgangspunkt dieser Untersuchung ist die Idee, dass die Opera buffa sowohl als Gattung als auch als Veranstaltung eine Fülle von spielhaften Momenten beinhaltet, die unter anderem den Reiz und den Erfolg dieses Genres ausgemacht haben könnten.

\section{Die Gattung Opera buffa}

Verschiedene Aspekte der Opera buffa können mit dem Begriff des Spiels in Verbindung gebracht werden. In erster Linie ist diesbezüglich die gemeinsame Grundstimmung zu nennen, die gewissermaßen die Basis für diesen Annäherungsversuch bildet. Schon der Terminus buffo ${ }^{266}$ gibt darüber Aufschluss, dass es sich um eine komische Operngattung handelt, in der Heiterkeit und Fröhlichkeit die vorherrschenden Stimmungen sind, dieselben, die häufig mit dem Spielbegriff assoziiert werden. Es verwundert also nicht, dass der zeitgenössische Komponist und Theoretiker Vincenzo Manfredini in seinem Traktat (Regole armoniche o sieno precetti ragionati per apprendere la musica) im Kapitel „Dello stile buffo“ der Opera buffa den Zweck „divertire e muovere al riso“267, wörtlich „vergnügen und zum Lachen bewegen“, zuschreibt. Ähnliches stellen Matteo Borsa („lo scopo è di commover soltanto lo spirito alla letizia“" ${ }^{268}$ ) und Giovanni Francesco Zulatti fest: „Lo stile vario, grazioso, piccante della Frascatana del Paisiello, del Convitto di Cimarosa, e di varie altre Opere buffe graziosissime risveglia al più melanconico l'allegrezza e il diletto." ${ }^{269}$ Die hier genannten Stimmungen der letizia, diletto, allegrezza sowie das von Zulatti mit Nachdruck verwendete Adjektiv grazioso entsprechen den mit dem Spiel üblicherweise assoziierten Begriffen: Freude, Vergnügen, „Fröhlichkeit und Anmut“. ${ }^{270}$

266 Buffo bedeutet komisch, lustig, fröhlich, lächerlich.

267 Vincenzo Manfredini: Dello stile buffo. In: Ders.: Regole armoniche o sieno precetti ragionati per apprendere la musica. 2. Ausgabe, Venedig 1797, S. 131.

268 Matteo Borsa: Saggio filosofico sopra la musica imitativa teatrale. In: Opuscoli scelti sulle scienze e sulle arti. Bd. 4. Mailand 1781, S. 218.

269 Giovanni Francesco Zulatti: Della forza della musica nelle passioni, nei costumi, e nelle malattie, e dell'uso medico del ballo. Discorso. Venedig 1787, S. 29.

270 Huizinga, S. 14. 
Freilich handelt es sich bei der Feststellung einer heiteren Grundstimmung lediglich um eine allgemeine Tendenz, denn genauso wie das Spielen auch bei einer ernsten oder wenigstens halbernsten Grundhaltung möglich ist, ist auch das Lustspiel, wie jede komische Theatergattung, nicht kontinuierlich komisch, sondern kann durchaus auch Ernst bzw. andere Facetten enthalten. Gururaja S. Amur nennt die „Gleichsetzung der Komödie mit dem Komischen“ sogar einen „Irrtum“ und meint Folgendes dazu: „Der Glaube, ,die Komödie habe es mit der leichteren Seite des Lebens' zu tun, läßt uns häufig die Tatsache übersehen, daß der ,Ernst' nicht aus der Komödie ausgeschlossen ist.“ „Zwar hat es die Komödie eng mit dem Komischen und dem Lachen zu tun; wie dargelegt, hat sie es doch mit weit mehr zu tun. Auch ist die Reichweite der Komödie nicht allein auf das Komische beschränkt. Das Komische, das Ernste, das Spielerische, das Phantastische, das Heitere, das Satirische und das Normale finden sich alle Seite an Seite in der Komödie. “271 Amurs Hauptanliegen besteht darin, die Möglichkeit einer Umschreibung eines ,undefinierbaren, unfaßbaren, aber belebenden Geist" der Komödie zu ergründen, der eine gewisse Ähnlichkeit mit dem von den Spieltheoretikern etwas vage definierten „Spielgeist“ aufweist.

Eine Analogie scheint außerdem generell zwischen der Gegenüberstellung von Opera buffa und Opera seria und dem in Spieltheorien immer wieder erörterten Gegensatzpaar Spiel-Ernst zu bestehen. Zu diesem Thema ist es interessant, zu bemerken, dass die Opera buffa im I 8. Jahrhundert meistens als dramma giocoso bezeichnet wurde. Giocoso bedeutet wörtlich spielhaft, spielerisch, aber auch scherzhaft, komisch, burlesk, und wurde, wenigstens in Bezug auf die Oper, offensichtlich als Synonym von buffo verwendet. Auch im sprachlichen Gebrauch wird also eine Integration der allgemeinen Auffassung von Spiel als Belustigung und Vergnügung bzw. eine Gleichsetzung von spielhaft/spielerisch und heiter/lustig unterstellt, wodurch eine Assoziation zwischen Opera buffa und Spiel nahegelegt wird. Wahrscheinlich hängt diese sprachliche Synonymie gerade mit der gemeinsamen Grundstimmung der Heiterkeit im Spiel und in der Opera buffa zusammen. Einem ähnlichen Gedankengang scheint auch Rainer Warning nachzugehen, wenn er von einer „Affinität zwischen Lust am Komischen und Lust am Spiel“272 spricht. Helmuth Plessner definiert diese gemeinsame Lust als „die besondere Lust am Schwebezustand des Spielens, an der Labilität eines Gleichgewichts, das eigentlich kein Gleichgewicht ist (...), Lust an et-

271 Gururaja S. Amur: Der Geist der Komödie. In: Reinhold Grimm und Klaus L. Berghahn (Hg.): Wesen und Formen des Komischen im Drama. Darmstadt 1975, S. 282 und 300.

272 Rainer Warning: Elemente einer Pragmasemiotik der Komödie. In: Ders. und Wolfgang Preisendanz (Hg.): Das Komische. (Poetik und Hermeneutik VII) München 1976, S. 316. Zit nach Wolfgang Matzat: Dramenstruktur und Zuschauerrolle. Theater in der französischen Klassik. München 1982, S. 54 . 
was Mehrdeutigem, das sich dem eindeutigen Entweder-Oder der Wirklichkeit nicht fügt. "273 Plessner geht sogar so weit, das Spielen als Anlass des Lachens zu sehen, ${ }^{274}$ denn „Spielen macht Freude, weil es uns erleichtert, den alltäglichen Druck von uns nimmt und den aufgestauten Bewegungsdrang, dem (in der Jugend besonders starken) Drang nach Betätigung der Einbildungskraft freie Bahn schafft. "275 Die entladende Funktion des Spielens äußert sich nach Plessner unter anderem gerade im erleichternden Lachen. Dieselbe These vertritt Groos, wenn er unter den beim Spiel entstehenden kathartisch-entladenden Gefühlen auch das „harmlose Lachen über Zufall und Ungeschicklichkeit“276 zählt, eine Aussage, die ebenso gut als Feststellung über das Grundwesen der Komödie tauglich wäre.

Eine Gemeinsamkeit zwischen komischen Theatergattungen im Allgemeinen, zu denen man auch die Opera buffa zählen kann, und dem Spiel kann man in der Theorie der literarischen Komik finden, die sich besonders mit der Frage nach dem auslösenden Moment des Lachens beschäftigt. Dieter Lamping schreibt dazu: „Die klassische Antwort auf diese Frage lautet: Was uns lachen macht (oder machen soll), muß harmlos sein. (...) Daß der komische Gegenstand harmlos sei, ist eine der ältesten Annahmen der Komik-Theorie; und zugleich die, die am nachhaltigsten gewirkt hat. Die Geschichte dieser Ansicht reicht zurück bis zu Aristoteles. "277 Diese Harmlosigkeit, für Andràs Horn „eine notwendige Bedingung des Komischen“,278 umschreibt Lamping mit den Adjektiven „klein“, „unbedeutend“, „unwichtig“ und „unschädlich“. ${ }^{279}$ Diese Konnotation der Harmlosigkeit ist nicht nur jeder komischen Theatergattung, darunter auch das Buffa-Libretto, eigen, sondern auch dem Spiel, das als „folgenlos“, weil „probeartig“280, definiert wird, in dem gefährliche Situationen „im Vergleich zu den ernsten Gefahren doch nur Scheingefahren“ sind ${ }^{281}$ und das als „bloßes Spiel“ auch die abwertende Facette des Unwichtigen, Leichten und Unernsten erhält. Rainer Warnings Aussage, das Hauptmerkmal der komischen Handlung in der

273 Helmuth Plessner: Lachen und Weinen. Eine Untersuchung der Grenzen menschlichen Verhaltens. (1941). In: Ders.: Gesammelte Schriften VII. Ausdruck und menschliche Natur. Hg. von Günter Dux, Odo Marquard und Elisabeth Ströker. Frankfurt a. M. 1982, S. 289.

274 Vgl. ebd. S. $285 \mathrm{ff}$.

275 Ebd. S. 289.

276 Vgl. Groos: Das Spiel. Zit. nach Scheuerl: Theorien des Spiels. S. 72.

277 Dieter Lamping: Ist Komik harmlos? Zu einer Theorie der literarischen Komik und der komischen Literatur. In: Literatur für Leser, 1994, S. 53.

278 Andràs Horn: Das Komische im Spiegel der Literatur. Versuch einer systematischen Einführung. Würzburg 1988, S. 42. Zit. nach Lamping, S. 54.

279 Lamping, S. 53.

280 Vgl. Rapp: Rolle, Interaktion, Spiel. S. 103f.

281 Schaller, zit. nach Scheuerl: Theorien des Spiels. S. 61. 
Komödie sei „ihre Konsequenzlosigkeit, ihre Nichtigkeit“,282 könnte genauso gut für das Spiel zutreffen. ${ }^{283}$

„Die Minderwertigkeit des Spiels“, 284 eine weit verbreitete Auffassung, die auf der Unernsthaftigkeit des Spiels beruht, hat ihr Pendant in der allgemeinen Beurteilung der komischen literarischen Gattungen, wie Fritz Martini erläutert: „Diese Minderwertung des Komischen gegenüber dem Tragischen, von Komödie oder Lustspiel gegenüber der Tragödie und dem ernsten Schauspiel hat eine lange Geschichte, die schon bei Aristoteles einsetzt und vor allem durch die humanistische Poetik soziologisch und poetologisch mit geradezu dogmatischer Geltung befestigt wurde. (...) Die humanistische Poetik hatte bestimmt, daß das Komische und die Komödie im motivlichen, soziologischen wie sprachlichen Sinne an das Niedere und Niedrige gebunden seien." ${ }^{285}$ Die Abwertung der komischen im Vergleich zu den ernsten Gattungen betrifft auch die Oper des I8. Jahrhunderts. Das schriftliche Urteil der Gelehrten über die Opera buffa war generell negativ, denn sie wurde vorwiegend als literarische Gattung betrachtet und konnte als solche ihren poetischen Ansprüchen nicht genügen. Im Allgemeinen wurde die Opera buffa im Verhältnis zur Seria in zeitgenössischen italienischen Traktaten wenig behandelt, weil sie als ein niedrigeres Genre bei den Theoretikern kaum Beachtung fand. Wenn sie überhaupt explizit erwähnt wurde, dann wurde sie heftiger Kritik unterworfen, wie es beispielsweise in

282 Warning: Elemente einer Pragmasemiotik der Komödie. In: Ders. u. Preisendanz (Hg.): Das Komische. S. 285. Zit nach Lamping, S. 55.

283 Viele Theorien definieren das Komische als Normabweichung, als „Diskrepanz zwischen Erwartung und Erfüllung" (vgl. Otto Rommel: Die wissenschaftliche Bemühungen um die Analyse des Komischen. In: Grimm u. Berghahn (Hg.): Wesen und Formen des Komischen im Drama. S. 1-38. Die meisten auf diesem Inkongruenzkriterium beruhenden Theorien des Komischen berufen sich auf Henri Bergsons Aufsatz Le rire. Essai sur la signification du comique. Paris 1900). Wolfgang Iser führt diese Kontrasttheorie gewissermaßen weiter und erläutert seine Definition des Komischen als „Kipp-Phänomen“ folgendermaßen: „Geht man davon aus, daß die im Komischen zusammengeschlossenen Positionen sich wechselseitig negieren, zumindest aber in Frage stellen, so bewirkt dieses Verhältnis ein wechselseitiges Zusammenbrechen dieser Positionen. Jede Position läßt die andere kippen. Daraus folgt zunächst die Instabilität komischer Verhältnisse, nicht zuletzt, weil das Kollabieren der einen Position nicht notwendigerweise die andere triumphieren läßt, sondern diese in die Kettenreaktion ständigen Umkippens einbezieht." (Wolfgang Iser: Das Komische: ein Kipp-Phänomen. In: Preisendanz u. Warning (Hg.) : Das Komische. S. 399) Diese Beschreibung der „Instabilität komischer Verhältnisse“ weist eine gewisse Ähnlichkeit mit einem von Scheuerl festgestellten Wesensmerkmal des Spiels, nämlich dem der „labilen Ambivalenz“ auf, mit der die ständige Möglichkeit des „Kippens“, die einige Spieltheoretiker als Hin- und Herbewegung (Buytendijk) definiert haben, einhergeht.

284 Huizinga, S. 16.

285 Fritz Martini: Johann Elias Schlegel: Die stumme Schönheit. Spiel und Sprache im Lustspiel. Mit einem Anhang: „Einige Überlegungen zur Poetik des Lustspiels“. In: Grimm u. Berghahn (Hg.): Wesen und Formen des Komischen im Drama. S. 338. 
Manfredinis Traktat der Fall ist, dessen Kapitel „Dello stile buffo“ einzig und allein aus einer Aufzählung der „difetti“ der Opera buffa und ihres Produktionssystems besteht. Eine negative Beurteilung findet man auch bei Saverio Mattei, der (wie es häufig geschah) nicht nur den Sängern die Schuld am „gusto corrottissimo“ zuschreibt, sondern auch den „maestri, giacchè costoro hanno guastato il loro stile non per imperizia, ma per debolezza di compiacere i cantanti“. ${ }^{286}$ Der einzige „Vorteil“, der der Buffa im Vergleich zur Seria zugestanden wird, liegt in ihrer Natürlichkeit und in der "Wahrheit“ des Ausdrucks. So schreibt beispielsweise der venezianische Literat Francesco Algarotti : „(...) gl'Intermezzi, e le Operette buffe, dove la qualità principalissima dell'espressione domina assai meglio, che in qualunque altro componimento che sia." Er schiebt die Verantwortung für die schlechte Qualität der Stücke auf die „cantanti mediocrissimi“ und sieht in der „verità“ den Grund für die Beliebtheit dieser eher niedrigen („plebea“) Gattung: „Da qualunque causa ciò venga, a cagione appunto della verità che in se contiene, ha la voga e trionfa un tal genere di musica, benchè riputata plebea. " 287 Ähnlich argumentiert Arteaga, der der Opera buffa immerhin einige Qualitäten, nämlich „maggiore verità di natura e varietà di espressione“, ${ }^{288}$ beimisst; das gelte aber nur in der Theorie, denn in der Praxis sei die Opera buffa das gröbste, verschrobenste und geschmackloseste Ding dieser Welt („non havvi al mondo cosa più sguajata, più bislacca, più senza gusto di questa“289). Eine Diskrepanz zeigt sich auch in Francesco Galeazzis Urteil, der die Opera buffa zwar als reformbedürftig und ihren Inhalt als geistlos und abgeschmackt bezeichnet, gleichzeitig aber die Musik vieler Buffa-Komponisten, wie Paisiello, Cimarosa und Sarti, in höchsten Tönen lobt. ${ }^{290}$

286 Saverio Mattei : Elogio del Jommelli ossia Il progresso della poesia, e musica teatrale. In: Ders.: Memorie per servire alla vita del Metastasio. Colle, Martini, 1785. Zit. nach Kipper, S. 39.

287 Francesco Algarotti: Saggio sopra l'opera in musica. Livorno 1763, S. 38. Zit. nach Kipper, S. 39.

288 Stefano Arteaga: Le rivoluzioni del teatro musicale italiano dalla sua origine fino al presente. 2. Ausgabe, Venedig 1785, Bd. 3, S. 139f. An einer anderen Stelle spricht Arteaga von der „decadenza attuale dell'Opera“. Die „korrupte“ Situation der Opera buffa beschreibt Arteaga anschließend durch den Vergleich mit der „statua di Glauco“, die am Meeresufer steht und durch die Wellen derart entstellt wurde, dass sie zu einem unförmigen Felsen geworden ist. Schließlich folgt zur Veranschaulichung der konkreten Mängel der Opera buffa ein fiktives discorso eines Impresario, der an einen imaginären Librettisten unzählige Forderungen und Regeln zur Anfertigung eines neuen Librettos stellt. (Vgl. S. 140-150).

289 Arteaga, Bd. 3, S. 140.

290 „Tale è la Condotta nello stile serio; quanto al Buffo egli è così vario, come bizzarre sono le parole: e siccome queste pure sono al presente insulse, e per lo più prive di alcun senso, così non saprei qui che regola dare, fino a tanto che sorga qualche bel genio, e riformi il Teatro Buffo (...). La nostra mancanza vien però abbondantemente supplita da' scritti di tanti valentissimi Maestri, che girano per le mani di tutti, come di un Paisiello, di un Cimarosa, di un Sarti ec. sopra le cui egregie composizioni 
Doch genauso wie die allgemeine Auffassung vom Spiel ambivalent „zwischen Verlockung und Unwürdigkeit ", ${ }^{291}$ zwischen einem positiv konnotierten Spielbegriff als eine Tätigkeit, die Freude und Vergnügen bringt und mit Leichtigkeit und Harmonie assoziiert wird, und einer negativen Deutung des Spiels als leichtsinniges, also unvernünftiges Tun schwankt, das mit dem pejorativen Begriff der Spielerei in Verbindung steht, so teilten sich die Urteile der Zeitgenossen über die Opera buffa: Trotz des schlechten Ansehens bei den Gelehrten erfreute sich die Opera buffa in der zweiten Hälfte des I 8. Jahrhunderts besonders großer Beliebtheit ${ }^{292}$ und verbreitete sich aufgrund ihres großen Erfolgs über ganz Europa. Genauso wie das Spiel befand sich also die Opera buffa in einer Ambivalenz „zwischen Verlockung und Unwürdigkeit“, genauso wie es beim Spiel der Fall ist, rief sie Verachtung und Kritik hervor und übte gleichzeitig eine unwiderstehliche Faszination aus.

Doch was war es, das das Opera-buffa-Publikum so sehr bezauberte und so zahlreich ins Opernhaus lockte?

2. Das Opernhaus

$$
\begin{array}{r}
\text { Ad ogni istante } \\
\text { Passar di loggia in loggia, } \\
\text { Guardare or da una parte, or da quell'altra, } \\
\text { Ridere, cicalar, far all'amore, } \\
\text { E parlar d'interessi anche tal volta, } \\
\text { L'Opera così affè, che non si ascolta. }{ }^{293}
\end{array}
$$

Beim Versuch, die Faszination nachzuvollziehen, die von der Opera buffa ausging, sollte man den Blick nicht allein auf die einzelnen Stücke richten, sondern auf den gesamten Kontext, in dem eine Opernaufführung stattfand.

Die venezianischen Theater des I 8. Jahrhunderts galten als "luogo di piacere“ sowie als „luogo di ritrovo“, und die Opernaufführung war unter Umständen bloß

troverà il principiante di che maggiormente istruirsi." (Francesco Galeazzi: Elementi teorico-pratici di musica con un saggio sopra l'arte di suonare il violino. Rom 1791-1796, Bd. 2, S. 301f.).

291 Vgl. Matuschek, S. 43.

292 Die besondere Beliebtheit der niedrigen und einfachen Opera buffa im Vergleich zur Seria stellt Francesco Milizia fest: „(...) quegl'intermezzi in Musica, e quell'operette buffe, le quali piacciono più dell'eroiche chè la Musica è in quelle più semplice, ed esprime meglio l'argomento del tutto e delle parti. A queste Operette si pone più semplicità, perchè si ha ordinariamente da fare con caratteri mediocrissimi, ai quali non si possono far eseguire tutti i segreti dell'arte, ed i tesori della scienza." (Francesco Milizia: Trattato completo, formale e materiale del teatro. Venedig 1794, S. 57f.)

293 Bertati/Alessandri: La novità. Venedig 1775 (I,7). 
„occasione per il gusto del ritrovarsi insieme“. ${ }^{294}$ In den venezianischen Opernhäusern traf sich - im Gegensatz zu den „teatri di commedia“, die laut Wiel eher niedrigere Bevölkerungsschichten anzogen - ein „pubblico scelto ed elegante“,295 das sich vergnügen, feiern, sich zeigen und „dabei sein“ wollte. Welches Ausmaß die Aktivitäten im Zuschauerraum im Vergleich zur auf der Bühne aufgeführten Oper einnahmen, beschreibt in ironisch-kritischem Ton Francesco Milizia: „Sarà dunque l'Opera il capo d'opera degli spettacoli, il non plus ultra del diletto e dell'utile. Entriamo a vederla. Ecco un vastissimo pozzo, la cui aja è rigata di gente; chi discorre, chi gira il capo in qua e in là, chi legge, chi sbaviglia, e v'è anche chi dorme. Il contorno è in gran parte da fondo in cima tutto bucato di cellette, e in ciascuna è annicchiata almeno una donna circondata da un ronzio d'uomini armati tutti di telescopi, che servono loro come di bussola per saltare da cella in cella, cicalando, mangiando, giuocando. E l'Opera, la grand'Opera dov'è ? Colà in fondo (...). "296 Ein Opernabend hatte also auch eine soziale Funktion als mondäne Zusammenkunft einer feierfreudigen Gesellschaft. Der „gemeinschaftsstiftende“297 Charakter und die Verbindung mit dem Begriff des Festes, die Fink und andere Theoretiker in Zusammenhang mit dem Spiel bemerken, ${ }^{298}$ sind Merkmale, die auch auf die Opera buffa und auf die gesamte Veranstaltung des Opernabends zutreffen.

Generell eignet sich das Opernhaus besonders dazu, als „Spielraum“ angesehen zu werden: Als spezielles Gebäude, das „das Theaterereignis auf sichtbare Weise aus der Alltagswirklichkeit ausgrenzt“, ${ }^{299}$ in dem sich ein spielfreudiges Publikum zum Vergnügen zusammenfindet, um der Aufführung einer heiteren Oper beizuwohnen, entspricht es, vielleicht sogar mehr als es bei anderen, „eigentlicheren“ Arten des Spiels der Fall ist, Caillois’ Definition der „Domäne des Spiels“ als „einer reservierten, geschlossenen oder geschützten Welt“300 bzw. dem von Huizinga theoretisierten Kriterium der Abgeschlossenheit und Begrenztheit in Zeit und Raum, denn außer dem Raum war auch die Zeit, die man darin verbrachte, auf einen Abend bzw. auf vier oder fünf Stunden begrenzt. ${ }^{301}$ Huizingas Bestimmung eines „Spielplatzes“ als „geweihter Boden, abgesondertes, umzäuntes, geheiligtes Gebiet, in dem besondere

294 Vgl. Benvenuti, S. 732.

295 Vgl. Wiel, S. XLIXf.

296 Milizia, S. $39 f$.

297 Fink: Oase des Glücks. S. 41.

298 Huizinga schreibt beispielsweise: „Das menschliche Spiel gehört doch jedenfalls in all seinen höheren Formen, in denen es etwas bedeutet oder etwas feiert, der Sphäre des Festes (...) an." (Huizinga, S. 16).

299 Matzat, S. 40.

300 Caillois, S. 13.

301 Vgl. Benvenuti, S. 732. 
eigene Regeln herrschen“ und seine allgemeine Definition der Spielräume als „zeitweilige Welten innerhalb der gewöhnlichen Welt, die zur Ausführung einer in sich abgeschlossenen Handlung dienen ", ${ }^{302}$ trifft auch für das Theater- oder Opernhaus zu.

Genauso wie es beim Spiel der Fall ist, das aus „Freude an ihm selbst“ und in unbeschwerter und sorgloser Stimmung (Scheuerl: „Freiheit von unmittelbarer Notdurft und Sorge") betrieben wird, war das Hauptziel eines solchen Opernbesuchs offensichtlich die Unterhaltung in jeder Hinsicht, und diese scheint in engem Zusammenhang mit der spielerischen Atmosphäre der gesamten Veranstaltung zu stehen.

Die Stimmung im „Spielraum Opernhaus“ war im Allgemeinen, nicht zuletzt auch aufgrund des Inhalts und der Musik des dramma giocoso, leicht, heiter und vergnügt, ja zeitweise wohl auch sehr ausgelassen, wenn - wie unter anderen Wiel berichtet - das Publikum durch lärmenden Applaus und laute Zurufe, Blumen, Sonette ${ }^{303}$ oder sogar durch Stürmung der Bühne seine Lieblingssänger feierte oder durch Pfiffe, Schreie und "grandinate di pomidoro" ${ }^{304}$ sein Missgefallen ausdrückte. (Der Lärm wurde teilweise durch Claqueure - meistens die protettori der Sängerinnen - bewusst lenkend organisiert, die gewissermaßen mit den Falschspielern im Spiel verglichen werden könnten.) Über den Lärm, der auch während der Vorstellung im Opernhaus herrschte, und über den in Italien üblichen Starkult berichten ausländische Reisende. Charles Burney schreibt beispielsweise: „The noise here during the performance was abominable, except while two or three airs and a duet were singing, with which every one was in raptures. "305 Der Lärm, über den Burney so entsetzt berichtet, ist darauf zurückzuführen, dass auch während der Vorführung Konversation gemacht und geflirtet wurde, Geschäfte abgeschlossen und Erfrischungen zu sich genommen wurden. Letzteres wird unter anderem durch die Bezeichnung aria del sorbetto bezeugt: Es handelte sich dabei um eine Arie, die von Nebenfiguren gesungen wurde und wenig Aufmerksamkeit auf sich lenkte, so dass man dabei ein Sorbet schlürfen konnte.

302 Huizinga, S. 17.

303 Es war damals Mode, Lob in Form von Gedichten, eben in Sonetten, zu „verpacken“ und zu verschenken. Arteaga zitiert diesbezüglich den Bericht bzw. Kommentar eines französchen Autors, eines gewissen Thomas: „Sono in materia di lodi la moneta corrente del paese. Ogn'uno la vende, la dona, la compra, o la riceve. Di tali generi di lodi ve ne sono per tutti gli uomini, e per tutti gli eventi. Si lodano con sonetti un villano, un principe, un poeta, un frate, una dama, e un sarto. Tali sonetti estremamente ripetuti ed eternamente obbliati cadono gli uni sugli altri, come la polvere sopra le strade ove si cammina senza che tali elogj facciano nè piccoli nè grandi più di quello che sono coloro che gli fanno e che gli ricevono, e si riducono ad una moda, come è una moda, un saluto, una riverenza." (Arteaga, Bd. 3, S. 97f.).

304 Vgl. Wiel, S. LXVIII.

305 Charles Burney: The Present State of Music in France and Italy. London 1771, S. 81. 
Auch Spiele im engeren Sinne beeinflussten die „Spielatmosphäre“ des Opernhauses: Man spielte nämlich sowohl in den Logen als auch in eigenen Spielsälen Spiele, vor allem Karten- und Glücksspiele, die in nicht geringem Maße der Finanzierung des Theater- bzw. Opernbetriebs dienten. ${ }^{306}$ Manfred Zollinger bemerkt zu dieser Beziehung zwischen Theater und Glücksspiel, die in Italien ihren Ursprung hatte: „Wird schon die soziale Funktion des Theaters aus der Verbindung von Konversation, Spiel und Bühnengeschehen deutlich, so gewinnt sie durch die Einführung und kommerzielle Nutzung der Glücksspiele (Bassette und Pharao) eine zusätzliche Qualität." 307 Verschiedene zeitgenössische Reiseberichte ${ }^{308}$ bezeugen, dass das Kartenspiel ${ }^{309}$ in italienischen Theatern während der Vorstellung üblich war. Um nur ein Beispiel zu nennen, schreibt Charles Burney über das Regio Ducal Teatro in Mailand: „Across the gallery of communication is a complete room to every box, with a fire-place in it, and all the conveniences of refreshments and cards. In the fourth row is a pharo table, on each side of the house, which is used during the performance of the opera." 310 Dass die Zuschauer Glücksspiele spielten, Konversation betrieben und zum „sehen und gesehen werden “ in die Oper gingen, erwähnt - in verachtendem Ton - auch Arteaga, der in seinem Traktat Le rivoluzioni del teatro musicale italiano dalla sua origine fino al presente das Publikum in fünf Kategorien unterteilt. Die erste und vermutlich auch am stärksten vertretene Kategorie ist die des uomo di mondo. Diesen verabscheut Arteaga, denn er geht nicht in die Oper, um die Aufführung zu genießen, sondern nur „perchè ci vanno gli altri“, also aus Konformismus. Seine Aktivität ist dementsprechend „adocchiare per essere adocchiati, aggirarsi da scioperati da palchetto in palchetto, scoprir nelle regioni della galanterìa paesi non per anco tentati, spiar in aria di somma importanza i segreti movimenti d'Irene o di Nice verso Celadone o Silvandro, riempire l'intervallo di quelle ore lunghissime con isquisita e deliziosa mormorazione, oppure col gioco (quella occupazione insipida ritrovata dall'ozio e dall'avarizia per consolar tutte le anime vuote, che non sanno che farsi della propria esistenza). “311

306 Vgl. Manfred Zollinger: Der „König der Spiele“ im Theater des 18. Jahrhunderts. In: Ludica. Annali di storia e civiltà del gioco. 2. Viella 1996, S. 237-250.

307 Ebd. S. 240.

308 Vgl. Hunter, S. 27.

309 Das Kartenspiel während der Vorstellung war wohl selbstverständlich, denn beispielsweise im Nuovo Teatro Regio in Turin war „die Türe der königlichen Loge (...) verspiegelt und erlaubte den Spielern, die der Bühne den Rücken kehrten, die Aufführung zu sehen." (Zollinger: Der „König der Spiele“ im Theater des 18. Jahrhunderts. S. 241).

310 Burney, S. 81.

311 Arteaga, S. 2f. Die übrigen Kategorien sind die des politico, der böswilliger ist als der uomo di mondo und den Opernbesuch als „nuovo ramo di commercio“ nützt, um private Geschäfte abzuschließen, und die Oper als Vergnügung sieht, die dem Volk geboten wird, damit es besser beherrscht und 
Was Arteaga eindeutig negativ beurteilt, nämlich die Frivolität und Müßigkeit der Zuschauerkategorie der gente di mondo, könnte auch ins Positive gekippt werden und als die spielhafte Leichtigkeit des homo ludens und die Muße des ästhetisch genießenden Menschen interpretiert werden, als die spielerische Haltung eines festlich gestimmten Publikums, das mit dem Ziel eines anspruchsvollen Vergnügens in die Oper ging.

Jablonskis zeitgenössische Definition des Spiels könnte in diesem Sinne genauso gut für einen Opernbesuch gelten: „Spiel, Ludus, überhaupt ein thun, so zur belustigung und zeitvertreib angesehen. (...) Ins besondre werden spiele genennet solche handlungen, die für sich keinen zweck haben. Und allein erfunden worden, (...) den gemüth eine ergötzlichkeit, nach verrichteter arbeit, zu verschaffen." ${ }^{12}$ Die Frage, ob man wirklich in die Oper ging, um sich von der Arbeit zu erholen, muss offen bleiben. Für den venezianischen Adel des I8. Jahrhunderts und die dem Adel nacheifernde Bourgeoisie scheinen die verschiedenen mondänen Vergnügungsmöglichkeiten eher die Hauptbeschäftigung gewesen zu sein. Allerdings muss man bedenken, dass in Venedig die Adeligen auch im Handel tätig waren und dass die reichen Bürger gerade durch den Handel ihr Vermögen (und folglich auch die finanzielle Möglichkeit, z. B. eine Loge zu mieten) erworben hatten.

Die Dichte an Vergnügungsmöglichkeiten, die Venedig bot, wird in zeitgenössischen Berichten von ausländischen Reisenden besonders betont. Beispielsweise findet man im anonym erschienenen Amours and Adventures of Two English Gentlemen in Italy (1795) folgende Bemerkung in Bezug auf den venezianischen Karneval: „Every night is spent at Comedies, Operas or at some noble Venetian's House, who gives a Ball. By this you may imagine the scene of intermixt pleasure, jumbled together without any regulation. “" ${ }^{13}$ Bemerkenswert ist dabei, dass die in Venedig besonders ausgeprägte Karnevalkultur in engem Zusammenhang mit dem Opernbetrieb stand, dessen Hauptsaison eben die Karnevalzeit war, deren Beginn und Ende gerade (so wie auch in anderen italienischen Städten) durch die Eröffnung und Schließung der Theater angekündigt wurde. ${ }^{314}$ Der Zusammenhang zwischen Oper und Karneval ging allerdings weit über die zeitliche Übereinstimmung hinaus: Über „alle karnevales-

unterdrückt werden kann; der erudito, der zwar um allerlei Fakten und Zahlen weiß, aber nichts von Kunst versteht, der uomo di gusto, der Einzige, der durch Sensibilität und Geschmack die Schönheit der Oper wirklich genießen und schätzen kann, und der filosofo, der alles, selbst einen Opernbesuch, auf abstrakte Prinzipien zurückführt.

312 Johann Theodor Jablonski: Allgemeines Lexicon der Kunst und Wissenschaften. Neue, um die Helfte vermehrte, und durchgehends verbesserte Auflage. Königsberg und Leipzig 1748, S. 1106. Zit. nach Matuschek, S. 196.

313 Zit. nach Martha Feldman: Opera and Sovereignty. Chicago 2007, S. 145.

314 „Periodicals and travelers repeatedly affirm that the opening and closing of theaters heralded the coming and going of Carnival." (Vgl. Feldman, S. 145). 
ken Formen“ sagt Bachtin Folgendes: „Von ihrem anschaulichen, konkret-sinnlichen Charakter her und durch ein starkes spielerisches Element stehen sie künstlerischbildhaften Formen, besonders dem Theater, nahe. " ${ }^{15}$ Das verbindende Element zwischen Theater und Karneval ist also nach Bachtin gerade das spielerische Moment. Die Gemeinsamkeit zwischen Theater, Karneval und Spiel haben auch Huizinga in der „zeitweiligen Aufhebung der gewöhnlichen Welt" ${ }^{16}$ und Caillois in der SpielKategorie der „Maske“ festgestellt. Bachtin fügt hinzu: „So spielt im Karneval das Leben selbst; das Spiel jedoch wird auf Zeit zum eigentlichen Leben. Das ist das Wesen des Karnevals, seine besondere Existenzform. "317 Die Ambivalenz besteht also nach Bachtin darin, dass beim Karneval aufgrund seiner langen Dauer dieser besondere Zustand des Spiels zum „eigentlichen Leben“ wird.

In Venedig wurde diese Ambivalenz zusätzlich durch das Tragen von Masken auch außerhalb des Karnevals verstärkt, denn den Adeligen war in der Öffentlichkeit das ganze Jahr lang das Tragen der bautta vorgeschrieben und nach einem Gesetz, ${ }^{318}$ das die Kleidungssitten in den Theatern regelte, mussten nicht nur die Adeligen, sondern auch "tutte le persone di civil condizione“ im Opernhaus eine Maske tragen. Ausländer waren von dieser Vorschrift ausdrücklich ausgenommen. Die Damen durften ohne Maske zwar das Theater, aber nicht das Parterre betreten und mussten in dem Fall den „abito nero ch'è loro dalle leggi assegnato “319 tragen. Am Eingang des Theaters kontrollierte (laut Wiel) eine maskierte Person gemeinsam mit dem Theaterdirektor, dass alle Gäste eine Maske trugen. ${ }^{320}$ Aus einem Bericht vom 30. Mai 1777 eines Spions der Inquisitori di Stato, unter deren direkten Aufsicht die Theater standen, ${ }^{321}$ geht hervor, dass viele Frauen nach der Kontrolle am Eingang ihre Maske wieder auszogen. ${ }^{322}$

315 Michail Bachtin: Rabelais und seine Welt. (1965). Hg. und mit einem Vorwort versehen von Renate Lachmann. Frankfurt am Main 1987, S. 56.

316 Huizinga, S. 20.

317 Ebd.

318 Vgl. Wiel, S. LVIII: „Che li N. N. H. H. non possono entrare nelli Teatri, e molto meno in Platea, se non che in maschera, e col bauttino (specie di rocchetto) adattato al viso; che similmente le Dame non debbono portarsi senza Maschera, e solo le verrà permesso d'andar senza, allora quando anderanno vestite col loro abito, vale a dire di nero, restandogli vietato l'entrar con quello in Platea; finalmente che lo stesso s'intenderà anche di tutte le persone di civil condizione, eccettuato le forestiere." (Arch. Di St. Inquisit. Di St. Busta 914, ohne Datum).

319 Gesetz (legge) vom 20. Dezember 1776. Zit. nach Wiel, S. LIX.

320 In diesem Zusammenhang ist es interessant, zu bemerken, dass die italienische Bezeichnung für Platzanweiser noch heute maschera ist und offensichtlich auf der Tatsache beruht, dass die Platzanweiser im Theater Masken trugen.

$321 \mathrm{Vgl}$. Wiel, S. LII.

322 Vgl. Wiel, S. LIXf. „Generalmente si è capito che le Dame, quali entravano alla porta del teatro non 
Die Maskierung bei öffentlichen Festen, im ridotto, im Theater und in den botteghe da gioco, in denen den Gästen sogar Masken zur Verfügung gestellt wurden, ${ }^{323}$ erweist sich als ein zusätzliches „Spielelement“, das die Theatralität und die spielerische Haltung der mondänen Gesellschaft des I8. Jahrhunderts, die sich schon durch den Gebrauch von Perücken, ${ }^{324}$ Puder, Schminke, Mouche etc. äußerte, verstärkt zum Ausdruck brachte.

Das maskierte und herausgeputzte Publikum genoss also das Spiel, das auf der Bühne vorgeführt wurde, und spielte gleichzeitig auch sein eigenes karnevaleskes Rollen- und Darstellungsspiel. Im Inneren des Opernhauses kam es so zu einer Art Spiegelung zwischen der Welt, die auf der Bühne dargestellt wurde, und der realen Welt im Bereich des Zuschauerraums.

Eine detailliertere Behandlung des Themas „Theatergleichnis“ wird in einem späteren Kapitel vorgenommen, zunächst folgen einige weitere theoretische Gedanken zur Opernveranstaltung als „Spiel“.

Innerhalb des Spielraums „Opernhaus“ sichtbar und direkt am Ereignis der Aufführung beteiligt sind die Ausführenden und das Publikum, aber um das Ganze zu ermöglichen, stehen Autoren und „Produzenten“ (Impresario, capocomico etc.) dahinter, die das gesamte „Spiel“ inhaltlich sowie organisatorisch vorbereiten. Es sei hier kurz an Scheuerls Behauptung erinnert, „daß der Schöpfer eines Werks im Grunde Handlanger des Spielers sei. (...) Was der Spieler nicht improvisieren kann, das nimmt ihm der Komponist durch vorbereitende Arbeit ab." ${ }^{25}$ Ähnlich wie der „Master" bei heutigen Rollenspielen haben die Autoren den Überblick, planen die Handlung und die dazugehörige Musik und „berechnen“ die Wirkung des Ganzen. ${ }^{326}$ Es ist ihre Vorbereitung, die die Spielaktivität der Interpreten und den Spielgeist der Zuschauer überhaupt ermöglicht. Den Vorgaben der Autoren folgend führen die Interpreten die eigentliche Spieltätigkeit aus: Die Orchestermusiker spielen im Sinne von „Musik

mascherate, avvisate dal portinaro a dover mascherarsi, restavano sorprese come fosse una istantanea novità : si coprivano colla Bavuta e molte in forma ridicola. Si è poi osservato che molte Dame, dopo essere state avvisate la prima volta, facevansi portar dal barcarolo la bavuta e la maschera, che nell'atrio si mascheravano colla bavuta in testa sopra il conzier (acconciatura del capo) e i pennacchi; che passata la porta, prima d'entrar in palco se la levavano, da riportar in barca; così che nei palchi restavano senza bavuta e senza maschera, col solo conzier."

323 Vgl. Mazzola, S. 266-268.

324 Huizinga schreibt dazu: „In den jüngeren Epochen der europäischen Kultur läßt sich kaum ein Element finden, das so sehr den spielhaften Kulturimpuls erkennen läßt wie die Perücke." (Huizinga, S. 175).

325 Ebd. S. 151.

326 Scheuerl spricht vom „virtuellen Spielen mit den vorweggenommenen Wirkungen des erstrebten Werks." (Vgl. Scheuerl: Das Spiel. S. 156). 
machen" auf einem Instrument, während die Sänger die eigentlichen Träger des Theaterspiels sind. Sie stellen singend eine Handlung dar, was als eine besondere Form der „Spiele mit Darstellungscharakter“327 gelten kann. Alle Spieltheoretiker sind sich darüber einig, dass es sich beim Theaterspiel um eine Grundart des Spiels handelt: Nicht nur Caillois bestätigt dies durch seine Spielkategorie der Maske bzw. der Verkleidung (mimicry), der er ausdrücklich das Theaterspiel zuordnet, ${ }^{328}$ sondern auch Huizinga beschreibt das Drama als das einzige Gebiet der Dichtung, das einen engen Zusammenhang mit dem Spiel aufweist, denn „das Drama heißt ein Spiel, es wird gespielt.“"329

Dagegen könnte man einwenden, dass für die Berufssänger der Opera buffa das Schauspielen eine regelrechte Arbeit war und somit mit Verpflichtungen einherging, was mit dem Kriterium der Freiheit und Freiwilligkeit des Spiels nicht vereinbar wäre. Dass ihr Ziel der wirtschaftliche Gewinn war, würde ebenfalls gegen die Spiel-Kriterien, vor allem gegen das Kriterium des „Ziels in sich selbst“ sprechen. Wenn man Spiel und Arbeit als sich gegenseitig ausschließende Kategorien versteht und sich an Huizingas Definition des Spiels als „eine freie Handlung, (...) an die kein materielles Interesse geknüpft ist und mit der kein Nutzen erworben wird," ${ }^{330}$ hält, dann kann die Tätigkeit von Berufsschauspielern und -sängern keineswegs als Spiel angesehen werden. ${ }^{331}$

Dieser Einwand verliert allerdings seine Gültigkeit, wenn man Gadamers Theorie folgend die Veranstaltung „Opernabend“ in ihrer Gesamtheit als „Spiel“ („das Spiel selbst ist das Ganze aus Spielern und Zuschauern“332) oder zumindest als ein von spielhaften Momenten durchtränktes Ereignis betrachtet, denn durch die Trennung des „Spielgeistes“ von der „Spielaktivität“ werden auch die Eigenschaften des Spiels aufgeteilt: Der wirtschaftliche Gewinn ist lediglich das Ziel der am Produktionssystem Beteiligten, nämlich Autoren (Librettist und Komponist), Ausführende (Sänger und Orchestermusiker) sowie „Organisatoren“ (Impresario, capocomico, direttore di scena) und Kostüm- und Bühnenbildner etc., ${ }^{333}$ die alle darauf hinarbeiten, dass das Publi-

327 Vgl. ebd. S. 148.

328 Vgl. Caillois, S. 30.

329 Vgl. Huizinga, S. 140.

330 Ebd. S. 20.

$331 \mathrm{Zu}$ diesem Einwand äußert sich Caillois folgendermaßen: „Derjenige, der aus der Spieltätigkeit seinen Beruf macht, ändert das Wesen des Spiels in keiner Weise. Gewiß, er selbst spielt nicht, er übt seinen Beruf aus. Das Wesen des Wettbewerbs und das des Schauspiels werden kaum davon betroffen, wenn die Athleten oder die Kommödianten Berufsmenschen sind, die gegen Lohn spielen, und nicht Amateure, die sich nichts als ein Vergnügen versprechen. Der Unterschied betrifft nur sie selbst." (Caillois, S. 54).

332 Gadamer. Wahrheit und Methode. S. 105.

333 In Calzabigis „L’opera seria“ zählt der Maestro di Cappella Sospiro die an einer Opernproduktion 
kums „den Spielgeist erlebt“", sich in eine leichte, ${ }^{334}$ spielerische, vergnügte Stimmung versetzt fühlt, in der es frei ,von der Arbeit, vom Kampfe ums Dasein, von der Not und der Sorge (...)“335 sich „aus dem Ernste des geistigen Lebens herauszieht“336, wo-

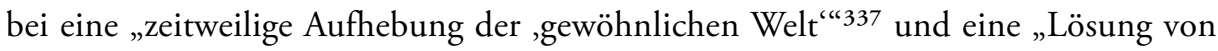
den Gewichten der Daseinslast “338 stattfindet. Ziel des Publikums ist dabei natürlich nicht der wirtschaftliche Gewinn, sondern das „Spiel“ als unterhaltende Beschäftigung, was zu Huizingas Kriterium des „Ziels in sich selbst“ zurückführt, denn - wie Johann Elias Schlegel erwähnt - ,alles Vergnügen gehört zu den Sachen, die man um ihrer selbst willen sucht." 339

Spiel findet im "Spielraum Opernhaus“ nicht nur in der besonderen Aufteilung von Spieltätigkeit und -geist statt, sondern auch auf verschiedenen Ebenen mit teilweise unterschiedlichen Bedeutungsfacetten des Spielbegriffs. Je nach Bereich gelten somit auch spezifische „Spielregeln“, die die mit dem Spiel verbundene Ordnung ${ }^{340}$ herbeiführen, beispielsweise:

a) Regeln und Hierarchien innerhalb des Produktionssystems

b) Konventionen im Komponieren einer Opera buffa, Regelpoetik der Gattung

c) Konventionen der Aufführungspraxis in Musik und Schauspiel (Interpretationsstil, Verzierungsarten etc.)

d) „Konventionen, die den Rahmen der Aufführung (mit Publikum) als Ganzes bestimmen

(...) und die eine ,Verschwörung ${ }^{`}(.$.$) bedeuten. { }^{341}$

beteiligten Personen auf: „Musici, Ballerini, / E Poeti, e Maestri, e Sonatori, / Ingegneri, e Pittori, / Suggeritori, Affittapalchi, e Sarti, / Paggi, Smoccolalumi, Tirascene, / Comparse, Legnajoli, Macchinisti, / E Magnani, e Copisti ..." (Ranieri de' Calzabigi/Florian Gassmann: L'opera seria. Wien 1769. Scena ultima).

334 Zur eigentümlichen Leichtigkeit des Spiels schreibt Gadamer: „Zum Spiel gehört, daß die Bewegung nicht nur ohne Zweck und Absicht, sondern auch ohne Anstrengung ist. Es geht wie von selbst. Die Leichtigkeit des Spiels, die natürlich kein wirkliches Fehlen von Anstrengung zu sein braucht, sondern phänomenologisch allein das Fehlen der Angestrengtheit meint, wird subjektiv als Entlastung erfahren." (Gadamer: Wahrheit und Methode. S. 100).

335 Scheuerl: Das Spiel. S. 67.

336 Vgl. Schaller. Zit. nach Scheuerl: Theorien des Spiels. S. 61.

337 Huizinga, S. 78.

338 Fink: Oase des Glücks. S. 38.

339 Johann von Antoniewicz (Hg.): Johann Elias Schlegels ästhetische und dramaturgische Schriften. Heilbronn 1887, S. 134f. Zit nach Fritz Martini, S. 311.

340 Vgl. Kapitel „Spiel und Theorien des Spiels“.

341 Rapp: Handeln und Zuschauen. Untersuchungen über den theatersoziologischen Aspekt in der menschlichen Interaktion. Darmstadt 1973, S. 213. Erika Fischer-Lichte und Jens Roselt schreiben dazu: „Die Kommunikationsbedingungen einer Aufführung werden so als Regeln eines Spiels bestimmt, 
e) Verhaltenskodex des Publikums (darunter Kleidungsvorschriften)

f) Spielregeln der im Theater gespielten Karten- bzw. Glücksspiele

Es werden nun die „Spielregeln“ der Opera-buffa-Produktion und, zu einem späteren Zeitpunkt, die Gattungskonventionen der Buffa näher behandelt. Die detaillierte Beschäftigung mit den übrigen „Spielregeln“ würde den Rahmen und den Opera-buffaSchwerpunkt dieser Arbeit sprengen.

\section{Die „Spielregeln“ Der Produktion}

Das oberste Prinzip war im gesamten italienischen Opernbetrieb des I 8. Jahrhunderts die Unterhaltung des Publikums, nach dessen Geschmack sich alle am Produktionssystem beteiligten Personen richten mussten. ${ }^{342}$ Der Erfolg jeder einzelnen Aufführung wie auch jedes Stücks hing in starkem Maße von der „Performance“ der Sänger ab. Folglich wurde bei der Herstellung einer Opera buffa (unter Beachtung der gattungsspezifischen Konventionen) besondere Rücksicht auf die Bedürfnisse der compagnia (Rollen, Hierarchie, Stimmlagen, Fähigkeiten und Wünsche der Sänger) genommen. Über die „Machtposition“ der Sänger innerhalb des Produktionssystems schreibt Martha Feldman: "The solo singers had more pull and prestige than any of the other figures involved in an opera's preparation, (...) and considerably more than its authors. Better paid than anyone else because (ideally) they could draw crowds and steal the show, singers ruled over the performative event. "3433 Auch unter den Sängern galt eine strenge Hierarchie: Seria-Sänger erhielten generell höhere Gagen als BuffaSänger. In beiden Gattungen genossen die prime donne und primi uomini besondere Vorteile, sie spielten die Hauptrollen, bekamen die meisten und die schönsten Arien

die zwischen allen Teilnehmern - Akteuren und Zuschauern - ausgehandelt werden." (Erika FischerLichte und Jens Roselt: Theorien des Performativen. S. 239). Es handelt sich dabei im Allgemeinen um die „gemeinsame Verabredung des ,als-ob“" (Arno Paul: Theaterwissenschaft als Lehre vom theatralischen Handeln. In: Kölner Zeitschrift für Soziologie und Sozialpsychologie 23, 1 (1971), S. 186. Zit nach Matzat, S. 39f.) sowie einzelne Elemente wie beispielsweise das Beiseitesprechen.

342 Dies bezeugen viele zeitgenössische Quellen, beispielsweise folgende Bemerkung von Carlo Goldoni: „Io non ho fatto altro studio che quello di piacere all'universale, far correre la gente al teatro e rendere del profitto a chi mi paga le opere mie, avendo molto maggior piacere allorch'io sento battere le mani ad un attore d'una mia tragedia, di quello io abbia nel sentir lodar la medesima." (Zit. nach Giovanni Polin: Introduzione. In: Carlo Goldoni: Drammi comici per musica (1748-1751). Hg. von Silvia Urbani. Venedig 2007, S. 11).

343 Feldman, S. 18. 
sowie die beste Position auf der Bühne, nämlich die rechte Seite, ${ }^{344}$ während sich die seconde und terze parti mit Nebenrollen (häufig Dienerrollen), wenigen Auftritten und weniger anspruchsvollen Arien begnügen mussten. ${ }^{345}$ Die ungeschriebene, aber sowohl in der Oper als auch im Sprechtheater geltende „Regel“, dass die prime donne und primi uomini unter keinen Umständen auf die ihnen zustehende Rolle und Position verzichten, beschreibt Goldoni im Vorwort zur venezianischen Edition seiner Werke: „La regola la più ridicola delle altre, e che mi ha più disgustato, è questa: Le prime Donne, i primi Amorosi, non cedono le prime parti a nessuno. Sieno vecchi, cadenti, non lasciano di rappresentare le parti di giovani amanti, di semplici giovanette, e che la Commedia precipiti, e che il Teatro perisca, piuttosto di perdere il loro posto. Questo non è ancor tutto. Se la prima donna è di carattere dolce, inclinata al patetico, e che la prima parte di una Commedia o di un'Opera sia di un personaggio collerico, trasportato, furioso, la prima Attrice preferisce di rendersi odiosa al pubblico, piuttosto che cedere ad una seconda la parte che meglio le converrebbe. Gli uomini fanno lo stesso, e quegli che si è acquistato del credito nel rappresentare un Bruto, un Cicerone, un Sansone, lo perde affatto volendo sostenere il carattere di un Don Gelsomino, di un Cicisbeo affettato, di un Discolo, di un Prodigo o di un Amoroso. $\mathrm{Ma}$ (dissi io allora) chi facesse un Componimento nuovo, e lo desse ai Comici, e li pregasse di arrendersi alla distribuzione delle parti? ... Non signore (m'interruppe il Casali), voi non fareste niente. Voi riuscireste a far cedere i Comici in tutti gli altri articoli delle loro regole; ma in questo non lo sperate. " 346

Auch für die Entsprechung zwischen Rollen und Stimmfächern galten ungeschriebene Regeln. ${ }^{347}$ Im Allgemeinen unterteilte man die Personen in personaggi seri, di mezzo carattere, buffi und buffi caricati, wobei jeder Sänger auf einen bestimmten Rollencharakter spezialisiert war.

Nach Arteagas fiktivem discorso, in dem ein Impresario einem Dichter den Auftrag für ein neues Libretto erteilt, zu urteilen, zeigte sich der Impresario einerseits in Bezug auf Wünsche und Forderungen der virtuosi entgegenkommend, ließ jedoch im Gegenzug den Autoren des Dramas keinerlei Freiheit, sondern entschied mit der Be-

344 Vgl. Dene Barnett: Die Schauspielkunst in der Oper des 18. Jahrhunderts. In: Hamburger Jahrbuch für Musikwissenschaft. 3, 1978, S. 301 : „Eine andere Grundregel verdeutlichte die Rangunterschiede zwischen den Charakteren: hochgestellte Persönlichkeiten und Damen standen rechts von niederen Personen."

345 In „La moglie capricciosa“ (Venedig 1785) macht die fiktive Sängerin Rosina (Rosina, seconda buffa del teatro di Livorno) in diesem Zusammenhang darauf aufmerksam, dass „I trilli e le cadenze, (...) / Solo alla prima donna / Spettano espressamente; / Io son seconda, e canto debolmente."

346 Carlo Goldoni: Il teatro comico. Memorie italiane. Hg. von Guido Davico Bonino. Mailand 1983, S. $167 f$.

347 Siehe Kapitel „Die Gattungskonventionen der Opera buffa als ,Spielregeln““. 
gründung „siccome trattasi del mio guadagno o della mia perdita“348 despotisch über Charakter des Stücks, Stoff, Anzahl der cangiamenti di scena, Bühnenbild, "Menge“ der Rezitative, Länge der Akte und Anzahl der Arien und Ensembles. ${ }^{349}$ Librettist und Komponist befanden sich auf einer niedrigen Stufe der Hierarchie des Produktionssystems und alle an der Produktion Beteiligten waren dem Geschmack und den Wünschen des Publikums unterworfen.

Wie sehr dies der Fall war, und was für eine starke Geltung die sogenannten convenienze teatrali hatten, lässt sich beispielsweise in Libretto-Vorwörtern der Impresari feststellen. In den venezianischen Libretti der I770er und I780er Jahre gehen wenige Vorwörter über die formelle Huldigungsrede an einen gegebenenfalls vorhandenen Widmungsträger bzw. an die Damen oder an das Publikum mit dem Hinweis auf die kurze Zeit, die zur Vorbereitung der Oper zur Verfügung stand, hinaus. Im Vorwort zu „La statua matematica“ (Venedig, Teatro San Moisè, I78 I) dagegen wendet sich der Impresario an das Publikum, um zu erklären und zu rechtfertigen, warum es zu Abweichungen gegenüber bestimmten convenienze teatrali gekommen ist. Er beginnt mit der Aufzählung der Umstände, über die sich das Publikum wundern wird, nämlich dass in dieser Oper eine vortreffliche prima buffa (Anna Morichelli ${ }^{350}$ ) erst am Ende des zweiten Aktes auftritt, dass sie eine Rolle singt, die weder ihrem Können noch dem Rollentypus entspricht, in dem sie üblicherweise erfolgreich gewesen war. Der Grund dafür war anscheinend, dass das Publikum den Wunsch geäußert hatte, diese Sängerin zu hören, nachdem allerdings schon eine andere berühmte prima buffa (Celeste Coltellini) engagiert worden war, die auch schon ihre Partie einstudiert hatte. Um das Publikum nicht zu enttäuschen, wurde eine Kompromisslösung gefunden und eine neue Rolle in die schon fast fertiggestellte Oper eingefügt, die erst gegen Ende des Dramas erscheint. Der Impresario betont ausdrücklich, dass diese unkonventionelle Lösung nur ersinnt wurde, um dem Geschmack und dem Wunsch des Publikums entgegenzukommen, woran ersichtlich wird, wie sehr man sich bemühte, es dem Publikum recht zu machen. ${ }^{351}$

348 Arteaga, Bd. 3, S. 143.

349 Vgl. Arteaga, Bd. 3, S. $143 \mathrm{ff}$.

350 Anna Morichelli war laut Mangini nicht nur eine beliebte Sängerin, sondern sogar „la beniamina del pubblico del S. Moisè“. (Mangini: I teatri di Venezia. S. 109).

351 Vorwort zu „La statua matematica“ von Giovanni Bertati und Giovanni Valentini (1781): „Al rispettabile publico che onora il Teatro Giustiniani in S. Moisè: Sembrerà strano a chi non è informato il vedere, che una bravissima Cantatrice, che con tanto applauso ha sostenuto fin ora la Parte di prima Buffa in questo Teatro, abbia in quest'Opera da comparire solo verso la fine dell'Atto Secondo, ed abbia una Parte, che non conviene al suo merito, e rappresenti un Carattere diverso da quelli in cui si è fin'ad ora distinta.

Un accidente impensato fu quello, che aprì l'adito di approfittarsi di questa celebre Virtuosa anche 
An diesem Vorwort ist auch zu sehen, dass man bei der Produktion einer Oper sehr pragmatisch vorging: Die Opern wurden ausdrücklich für eine bestimmte Aufführungssituation komponiert, meistens wurde den Sängern ihre Partie sogar regelrecht „auf den Leib“ geschrieben. Goldoni beschreibt diese Praxis im Vorwort zur venezianischen Edition seiner Werke als eine regola der Produktion und als ein sicheres Mittel zum Erfolg eines Stücks. ${ }^{352}$ Für die verschiedenen Wiederaufführungen ein und derselben Oper wurden zur Anpassung an die Bedingungen des jeweiligen Aufführungsortes häufig verschiedene Versionen erstellt. Aufgrund von Besetzung, „Extra-Wünschen“ der Sänger etc. wurden ganze Rollen, Szenen, Dialoge und besonders einzelne Arien, gestrichen, ausgetauscht oder hinzugefügt, wobei sich durchaus Verschiebungen in der Dramaturgie eines Werkes ergaben. ${ }^{353}$

Nach der Leichtigkeit, mit der sie die Opern bearbeiteten und veränderten, nach der chamäleonartigen Flexibilität, mit der sie ihre Werke an die jeweiligen Bedingungen anpassten, nach der Leichtfertigkeit, mit der sie eine Rolle oder sogar einen ganzen Akt ohne Ersatz und ohne Umarbeitung der restlichen Teile eliminierten, nach der Schnelligkeit, mit der sie eine Oper komponierten, zu urteilen, wurde von den Autoren vermutlich eine lockere und „spielerische“ Haltung verlangt. Dafür bedien-

per il Carnevale; e l'Impresa di buona voglia acconsentì al desiderio che si manifestava nel Publico, ch'Ella continuasse sù queste Scene. Ma questo accidente seguì in tempo che già provveduto era il Teatro d'un'altra prima Buffa, che con molto merito sostenne un tal posto in altri Teatri di Città Capitali: che il Dramma era già scritto: che la Musica era quasi per intiero composta: e che le Parti erano state ai rispettivi Attori distribuite. La mancanza del tempo non permetteva di far comporre un nuovo Libro, e di farlo mettere in Musica; e giustissime convenienze toglievano affatto l'arbitrio di levar la Parte dalle mani, a chi l'aveva già avuta, e studiata. Insuperabili essendo tutte le difficoltà, che s'incontravano, altro espediente non restava per soddisfare al genio del Publico, che quello d'introdurre com'era possibile la Sig. Morichelli in quest'Opera, e come si è fatto, col di lei suggerimento: così Essa volontariamente contentandosi riguardo alla Parte, e cos̀̀ espressamente desiderando per il Carattere e per le Arie."

352 „Bisognerebbe dunque (ripresi a dire) comporre un'Opera precisamente adattata ai caratteri personali di quei che devono rappresentarla. Oh! sì (rispose), sì certamente, se un Autore volesse a ciò suggettarsi, sarebbe quasi certo della riuscita. In fatti il Casali avea gran ragioni di così parlarmi. L'ho provato in seguito per esperienza. (...) Tutte le opere teatrali che ho poi composte, le ho scritte per quelle persone ch'io conosceva, col carattere sotto gli occhi di quegli Attori che dovevano rappresentarle, e ciò, cred'io, ha molto contribuito alla buona riuscita de' miei componimenti, e tanto mo sono in questa regola abituato, che trovato l'argomento di una Commedia, non disegnava da prima $\mathrm{i}$ Personaggi, per poi cercare gli Attori, ma cominciava ad esaminare gli Attori, per poscia immaginare i caratteri degl'Interlocutori." (Goldoni: Il teatro comico. Memorie italiane. S. 168).

353 Von den zeitgenössischen Gelehrten wurde diese Praxis stark kritisiert. Arteaga macht sie beispielsweise unter anderem für die „decadenza dell'opera“ verantwortlich und schimpft über „l'uso corrente d'Italia che è quello di strozzare i drammi (...), levando via a capriccio il più bello per inserire in sua vece arie e duetti fatti da qualche versificator dozzinale." (Arteaga, S. 141). 
ten sie sich schon vorhandener Stücke und bewährter Muster in Dramaturgie und Musik und schufen (teilweise pasticcio-artige) Werke, die in erster Linie unterhalten und erheitern und den Geschmack des Publikums befriedigen sollten.

Das Reservoir, aus dem die Autoren schöpften, bestand vorwiegend aus dem BuffaRepertoire der vergangenen Jahrzehnte, aber auch aus dem italienischen und französischen Sprechtheater, aus der Commedia dell'arte und aus der Opera seria. (Besonders häufig wurden Libretti und Komödien des venezianischen Dichters Carlo Goldoni als Vorlage verwendet.) Übernommen wurden nicht nur „konkrete“ Versatzstücke wie z. B. erfolgreiche Arien, ${ }^{354}$ sondern vor allem bewährte Muster besonders im Hinblick auf dramatische Motive, Personentypen und -konstellationen, Handlungsschemata und -mechanismen, Situationen und dazugehörige Arien- und Ensembletypen. Es handelte sich dabei um eher schematische und deswegen leicht austauschbare Versatzstücke, die immer wieder verwendet wurden und dadurch zu regelrechten Topoi geworden waren.

Dieses „Netzwerk von Mustern“ war dem Großteil des Publikums wahrscheinlich sehr vertraut und konnte einerseits für die Autoren als Reservoir, andererseits für alle an Produktion und Rezeption der Opera buffa beteiligten Personengruppen als Bezugssystem und gemeinsame Basis für ein wirksames Kommunikationssystem dienen.

Mary Hunter spricht in diesem Zusammenhang von einer „elaborate theatrical conversation involving composers, librettists, performers, and audiences “ 355 und über das sich daraus ergebende intertextuelle Spiel bzw. Assoziationsspiel äußert sie sich folgendermaßen: "The ,game' aspect of these works is probably most relevant to the network of particular associations that a single work might have triggered in a specific audience." 356

\section{Die Verwurzelung in der Commedia dellóate}

Der Usus, bewährte Muster immer wieder neu miteinander zu kombinieren, stammte aus der Commedia dell'arte. Auf der Basis eines canovaccio, der Angaben über Rollen, Requisiten, Abfolge der Szenen enthielt, improvisierten die Schauspieler ein Stück, wobei sie regelrechte Versatzstücke verwendeten: von formelhaften Satzanfängen bis zu fertigen Monologen, von typischen lazzi bis zu stereotypen Szenen, die

354 Die Sänger nahmen ihre Lieblingsarien mit, um sie auch in andere Opern einzufügen. Man nannte solche Arien bezeichnenderweise arie di baule, also „Reisekofferarien“. Die Praxis, bewährte Arien und Ensembles in eine „fremde“ Oper einzulegen, war generell sehr verbreitet.

355 Hunter, S. 4.

356 Ebd. S. 34. 
die Schauspieler sammelten und in eigenen zibaldoni schriftlich festhielten. Nicht wenige dieser Versatzstücke wurden auch in die Opera buffa übernommen und an die Bedingungen der Gattung Oper angepasst. Nicht nur der Inhalt und die „Organisation" des Materials in der Opera buffa, sondern auch die gesamte Einstellung innerhalb des Opernbetriebs hatten ihre Wurzeln in der Commedia dell'arte: Was über die commedianti folgendermaßen zusammengefasst worden ist - „Diese Schauspieler, die den größtmöglichen Erfolg suchten, (...) griffen auf erprobte Arten des Spiels und der Aufführung zurück und gestalteten die Aufführungen effektreich nach ihrem Gutdünken. “" ${ }^{557}$-, wirkte auch in der Opera buffa nach. Das Selbstverständnis der Buffa-Sänger, sich am Schaffensprozess mitzubeteiligen, sowohl aktiv mit eigenen Vorschlägen, Wünschen oder Forderungen, als auch passiv in der Praxis der „maßgeschneiderten Rolle“, kam wohl aus der Commedia dell'arte, in der die Rolle der Ausführenden mit der des Dramaturgen zusammenfiel.

\section{Schaffen, Werk und Spiel}

Der Umgang mit dem Werk Opera buffa, das aus stereotypen, austauschbaren Versatzstücken nach pragmatischen Kriterien, nämlich in erster Linie nach Wirkungskriterien, zusammengestellt und für jede Aufführungssituation wieder verändert wurde, ist ebenfalls in der Praxis der Commedia dell'arte verwurzelt. Diese Einstellung gegenüber dem Werk kann im Verhältnis zum schon ab dem I9. Jahrhundert üblicheren ernsten, emphatischen Werkbegriff durchaus als „spielerisch“ bezeichnet werden. Der Schaffensprozess selbst gilt im Allgemeinen nicht als Spiel, ${ }^{358}$ kann aber als solches angesehen werden, wenn man das Komponieren im Sinne von com-ponere, also Zusammensetzen von Versatzstücken, als eine Art Kombinationsspiel sehen möchte: Die Autoren verfügen über einen Fundus an Topoi und konventionellen Elementen sowie an konkreten Stücken, die ihnen als Muster dienen; aus diesem „Baukasten“ schöpfen sie „Bausteine“, aus denen sie durch Aneinanderreihung, Verschachtelung, Einfügung und anderen Kombinationsmöglichkeiten ganze Stücke konstruieren können.

Eine allgemeine Analogie zwischen Kunst und Spiel auf abstrakter Ebene stellt Scheuerl fest: „Spiel und Kunst gehorchen im rein formalen Wechselverhältnis zwischen Form und Ablauf prinzipiell den gleichen Strukturgesetzen: Allemal wird ein

357 Wolfram Krömer: Art. Commedia dell'arte. In: Die Musik in Geschichte und Gegenwart. 2., neubearb. Ausg. hg. von Ludwig Finscher. Sachteil Bd. 2/2, Kassel u. a. 1995. Sp. 955.

358 Vgl. Kapitel „Spiel und Theorien des Spiels“. 
objektives Formgerüst vorgefunden oder improvisiert, und allemal wird innerhalb dieses Gerüstes ein gegenwärtiges, in sich unendliches Spiel von Wirkungen, denen man sich zeitenthoben hingibt, erzeugt." 359 Scheuerls „Formgerüst“ würde im Falle der Opera buffa den von den Autoren „,vorgefundenen“, vor allem „makrostrukturellen“ Konventionen entsprechen, innerhalb deren das „dramaturgische Spiel“ stattfinden würde. Die Möglichkeit des „improvisierten Formgerüsts“ ist dagegen in der Opera buffa nicht vorhanden.

An einer anderen Stelle spricht Scheuerl von der Improvisation im Bereich der Kunst und fasst sie als „schaffendes Spielen“ auf, weil das Schaffen während des Spiels, also innerhalb der Spielwelt stattfindet. ${ }^{360}$ Selbstverständlich erfolgt dagegen bei der Opera buffa das Schaffen vor dem Spielanfang und daher außerhalb der Spielwelt, allerdings ist der lockere Umgang mit dem Werk und seine kurzfristige Veränderbarkeit nicht allzu weit entfernt vom Schaffen innerhalb des improvisierten Theaters, das ebenfalls auf vorbereitenden Abmachungen (Wahl des soggetto, Rollenverteilung etc.) außerhalb der Spielwelt beruht.

Darüber hinaus könnte Scheuerls Begriff des „spielerischen Schaffens“ im Sinne einer Souveränität ${ }^{361}$ im Umgang mit den Versatzstücken, in der Beherrschung des Handwerks und der Konvention als eine zusätzliche „spielhafte“ Facette des Schaffens einer Opera buffa sowie als eine weitere Gemeinsamkeit zwischen Commediadell'arte-Schauspielern, deren dramaturgische Entscheidungen auf Erfahrung basierten, und Buffa-Autoren, die sich ebenfalls pragmatisch nach der jeweiligen Situation richteten, gelten.

\section{Die Aufführung}

Beim Vergleich zwischen Kunst und Spiel hatte Julius Schaller festgestellt, dass der Unterschied im Werk liegt, denn das Ergebnis der Kunst ist, im Gegensatz zum Spiel, ein „Werk, das über sein Werden hinaus Bestand“ behält. ${ }^{362}$ Wenn man im Falle der Opera buffa bedenkt, wie sehr der Fokus auf die Aufführung, lo spettacolo, gerichtet war und wie wenig das Werk als schriftlich fixiertes Ganzes wert war und in seiner Einheit „respektiert“ wurde, dann tendiert man dazu, die einzelne Aufführung als

359 Scheuerl. Das Spiel. S. $104 \mathrm{f}$.

360 Vgl. Scheuerl. Das Spiel. S. 153.

361 Vgl. Matuschek, S. 10: „Das schöpferische Vermögen ist die Souveränität, mit etwas zu spielen. Spiel bedeutet hier das freie Verfügen, die auktoriale Willkür, die sich gleichwohl im Rahmen selbstgewählter oder (etwa gattungs-)konventionell vorgegebener Regeln hält."

362 Schaller. S. 4ff. Zit. nach Scheuerl: Das Spiel. S. 96. 
das eigentliche Werk zu betrachten. Die Aufführung hat wiederum mit dem Spiel das Ereignishafte und die Flüchtigkeit gemeinsam, was zu Huizingas grundsätzlicher Feststellung über die Vergleichbarkeit von musischen Künsten und Spiel zurückführt: „In den musischen Künsten besteht die tatsächliche ästhetische Aktivierung darin, daß das Kunstwerk ausgeführt wird. Es ist zwar vorher verfaßt, eingeübt oder niedergeschrieben, lebendig wird es jedoch erst durch das Ausführen, die Aufführung, das Zugehörbringen, die Darstellung - durch die Productio in dem buchstäblichen Sinne, den das Wort im Englischen noch bewahrt hat. Die musische Kunst ist Handlung und wird als Handlung in der Ausführung jedesmal von neuem genossen. (...) Diese Handlung selbst aber, in der die musische Kunst erlebt wird, ist ein Spiel zu nennen. “363

Schon im I9. Jahrhundert hatte Moritz Lazarus bemerkt, dass „das musikalische und poetische Werk dem Spiele darin verwandt ist, daß es wie ein Spiel eben in der Darstellung und Vorführung vorüberrauscht. “364

Auch in der Untersuchung der Spielaspekte eines „Opernabends“ als Ganzes steht dementsprechend die Aufführung im Mittelpunkt des Interesses.

In Bezug auf die Aufführung eines Theaterstücks schreibt der Theatersoziologe Uri Rapp: „Jede Theateraufführung, als einmaliges Ereignis, ist eine Enklave (...) innerhalb der Alltagswelt. “365 In diesem Zusammenhang verwendet Rapp den Begriff der „lebendigen Gegenwärtigkeit“"366 und behauptet außerdem: „Die Alltagszeit wird als suspendiert erlebt, während die Aufführung ihre eigene Zeitdauer hat.“"367

Alle diese Bemerkungen sind den in Bezug auf das Spiel festgestellten Kriterien erstaunlichähnlich:Scheuerl nennt das, Merkmal der zeitentrückten Gegenwärtigkeit“368 als eines der sechs Grundkriterien für das Spiel, und dieses Gefühl der Zeitenthobenheit steht in enger Verbindung mit der von Fink in Bezug auf das Spiel theoretisierten „Enthebung aus der reellen Weltwirklichkeit“. ${ }^{369}$ Der Zusammenhang zwischen dem von Huizinga genannten Merkmal der „zeitweiligen Aufhebung der ,gewöhnlichen Welt “" ${ }^{370}$ und dem der „zeitenthobenen Gegenwärtigkeit“" ${ }^{371}$ gilt also offensichtlich sowohl für das Spiel als auch für die Theater- oder Opernaufführung.

363 Huizinga, S. 160.

364 Lazarus, S. 23. Zit. nach Scheuerl: Theorien des Spiels. S. 66.

365 Rapp: Handeln und Zuschauen. S. 49.

366 Ebd.

367 Ebd. S. 202.

368 Scheuerl: Theorien des Spiels. S. 206.

369 Ebd. S. 39.

370 Huizinga, S. 78.

371 Scheuerl: Das Spiel. S. 99. 
Mit Huizingas Kriterien des „Andersseins“ als das „gewöhnliche Leben“ und der Abgeschlossenheit in Zeit und Raum, die die Welt des Spiels kennzeichnen, in der andere Regeln als im „gewöhnlichen Leben“ gelten, hängt nach der Meinung mehrerer Spieltheoretiker auch eine charakteristische „Sphäre des Scheins“ zusammen. Nach Fink handelt es sich innerhalb der Spielwelt um „Dinge, die unleugbar selber etwas Wirkliches sind und doch in sich ein Moment von ,Unwirklichkeit" enthalten “, 372 eine Definition, die auch auf das Theater zutrifft, wenn man bedenkt, dass die aufgeführte Handlung zwar fiktiv ist, jedoch „real“ dargestellt, d. h. in der Wirklichkeit als Darstellung „realisiert“ wird. In diesem Zusammenhang ist Winnicotts psychoanalytische Sichtweise in Bezug auf das Spiel interessant: „Der Spielbereich ist nicht Teil der intrapsychischen Realität. Er liegt außerhalb des Individuums, ist aber auch nicht Teil der äußeren Welt. In diesen Spielbereich bezieht das Kind Objekte und Phänomene aus der äußeren Realität ein und verwendet sie für Vorstellungen aus der inneren, persönlichen Realität. "373 Nach Winnicott findet das Spiel also in einem intermediären Bereich statt, der die innere, subjektive Welt mit der äußeren Realität verbindet. In demselben „Spielraum“ spielt sich „kulturelles Erleben“ ab, das sich direkt aus dem Spielen entwickelt. ${ }^{374}$ Diese These weist eine erstaunliche Ähnlichkeit zur Theorie von Huizinga auf, der im Spiel den Ursprung der Kultur sieht.

Winnicott verbindet die Idee dieses schöpferischen Zwischenbereichs mit dem Begriff der Illusion, ${ }^{375}$ ein Zustand, der „dem Kleinkind zugebilligt wird und im Leben des Erwachsenen einen bedeutsamen Anteil an Kunst und Religion hat. Und doch“ fährt Winnicott fort - „sehen wir es als Zeichen seelischer und geistiger Störung an, wenn ein Erwachsener zu große Ansprüche an die Glaubensbereitschaft seiner Mitmenschen stellt und sie dazu zwingen will, eine Illusion zu teilen, die nicht ihre ist." ${ }^{376}$ Ist der Bezug bzw. die Grenze zwischen Illusion und Realität für die Mitmenschen nicht mehr nachvollziehbar, so beginnt der Zustand der Illusion pathologische Züge aufzuweisen.

372 Fink: Oase des Glücks. S. 46.

373 Donald W. Winnicott: Vom Spiel zur Kreativität. Stuttgart 1985, S. 63 (englische Originalausgabe unter dem Titel Playing and Reality. London 1971).

374 „Kulturelles Erleben ist lokalisiert in einem schöpferischen Spannungsbereich (oder potentiellen Raum) zwischen Individuum und Umwelt (...). Dasselbe gilt für das Spielen. Kulturelles Erleben beginnt mit dem kreativen Leben, das sich zuerst als Spiel manifestiert.“ (Winnicott, S. 116).

375 „Der intermediäre Bereich, von dem ich hier spreche, ist jener Bereich, der dem Kind zwischen primärer Kreativität und auf Realitätsprüfung beruhender, objektiver Wahrnehmung zugestanden wird. Die Übergangsphänomene repräsentieren die frühen Stadien des Gebrauchs der Illusion, ohne den ein menschliches Wesen keinen Sinn in der Beziehung zu einem Objekt finden kann, das von anderen als Objekt wahrgenommen wird, das außerhalb des Kindes steht." (Winnicott, S. 21f.).

376 Winnicott, S. 12. 
Winnicotts Idee eines intermediären Bereichs, in dem sowohl Spiel als auch kulturelles Erleben stattfinden, das aber auch eine gewisse Nähe zur Verrücktheit aufweisen kann, erinnert an Paul Klees Begriff der „Zwischenwelten“, 377 die seiner Ansicht nach in erster Linie für Kinder, Künstler und Verrückte zugänglich sind.

Vom Begriff der „Zwischenwelten“ sind wiederum die „zeitweiligen Welten innerhalb der gewöhnlichen Welt “, ${ }^{378}$ von denen Huizinga in Bezug auf das Spiel gesprochen hatte, nicht allzu weit entfernt. In Huizingas Formulierung wird die zeitliche Begrenzung hervorgehoben, die in seiner Theorie eines der Wesenskriterien des Spiels darstellt (und vielleicht auch zur Unterscheidung zwischen „gesundem“ und pathologischem Verhalten beiträgt).

Der italienische Philosoph Alfonso Iacono geht so weit, zu behaupten, das Leben in Zwischenwelten sei der normale Zustand des Menschen. Diesbezüglich verwendet er die Metapher des Fensters, das zugleich den Ausblick auf eine andere Welt gestattet, ohne dabei die Wahrnehmung des Rahmens zu verhindern. ${ }^{379}$ Um den Eintritt in eine Zwischenwelt bzw. Illusion im Sinne des Spiels und der Kunst zu charakterisieren, übernimmt Iacono eine (eigentlich auf die Poesie bezogene) Formulierung von Samuel Taylor Coleridge, nämlich die der „willing suspension of disbelief for the moment“, 380 die das Wesentliche auf den Punkt bringt: Die Aufhebung der Realitätsprüfung, die meines Erachtens für jede Art von Illusion charakteristisch ist, die zeitliche Begrenzung derselben sowie die Intentionalität des Vorgangs. Die beiden letzteren Kriterien gelten nicht uneingeschränkt. Der Eintritt in eine Illusion kann auch unbewusst und unwillkürlich stattfinden und zeitlich unbegrenzt sein, in diesem Fall nimmt der Terminus Illusion die Bedeutungsfacette der Täuschung an. Im Falle des Spiels und der Kunst aber geschieht der Eintritt in eine Illusion bzw. in eine Zwischenwelt in der Regel auf

377 „Ich sage es oft, aber es wird manchmal nicht ernst genug genommen, daß sich uns Welten geöffnet haben und öffnen, die auch der Natur angehören, aber in die nicht alle Menschen hineinblicken, vielleicht wirklich nur die Kinder, die Verrückten, die Primitiven. (...) Zwischenwelt nenne ich sie, da ich sie zwischen den unseren Sinnen äußerlich wahrnehmbaren Welten spüre und innerlich so aufnehmen kann, daß ich sie in Entsprechungen nach außen projizieren kann. Dorthin vermögen die Kinder, die Verrückten, die Primitiven noch oder wieder zu blicken. Und was diese sehen und bilden, ist für mich die kostbarste Bestätigung. Denn wir sehen alle das gleiche, wenn auch von verschiedenen Seiten. Es ist im ganzen und einzelnen das gleiche, über den ganzen Planeten, keine Phantasterei, sondern Tatsache um Tatsache." (Lothar Schreyer: Erinnerungen an Sturm und Bauhaus. München 1956, S. 171).

378 Huizinga, S. 17.

379 „Normalmente noi viviamo in mondi intermedi. Quando ci immergiamo in un mondo di senso non abbandoniamo gli altri mondi: è come se li percepissimo con la coda dell'occhio, poco al di là della cornice." (Alfonso M. Iacono: Lillusione e il sostituto. Mailand 2010, S. 71).

380 Samuel Taylor Coleridge: Biographia literaria (1817) ch. 14. In: Samuel Taylor Coleridge. Hg. von H. J. Jackson. Oxford 1985, S. 314. Zit. nach Iacono, S. 75. 
eine bewusste Art. Im Bereich des Spiels wird dieser Vorgang, wie von Bateson theoretisiert, durch die metakommunikative Mitteilung „Dies ist ein Spiel“ signalisiert. Es herrscht zwischen den Spielgefährten also nicht nur das Bewusstsein, sondern auch eine Art Vereinbarung über den Eintritt in die Welt des Spiels. Ähnliches gilt auch für die Illusion in der Kunst: Gerade am Beispiel des Theaters kann sehr klar gezeigt werden, dass der Zuschauer sich bewusst und willkürlich in den Zustand der Illusion begibt, aus dem er jederzeit leicht wieder heraustreten kann.

Wie eng der Eintritt in eine Illusion mit dem Begriff des Spiels in Zusammenhang steht, ergibt sich schon aus dem Terminus selbst, der vom Lateinischen illudere stammt („hinspielen, spielend hinwerfen“ bzw. „sein Spiel treiben, verspotten“ oder „täuschen“), dessen Wurzel in + ludere wörtlich als „in ein Spiel eintreten“verstanden werden könnte. Es erscheint also nicht gerade abwegig, Zwischenwelten, Illusion und Scheinhaftigkeit als gemeinsame Nenner zwischen Spiel und Theater zu bezeichnen.

Finks Bemerkung, der für die Spielwelt charakteristische „Schein“ besitze „mitunter eine stärkere erlebnishafte Realität und Eindruckskraft als die massiven Alltagsdinge in ihrer abgenutzten Gewöhnlichkeit“,381 kann unverändert auf das Theater übertragen werden, denn ,sobald die Realität des Alltags, und sei sie noch so gewöhnlich oder vertraut, Teil einer Repräsentation oder Fiktion (...) wird, verliert sie den Charakter des Alltäglichen, denn eine dargestellte ist nicht mehr eine reale Alltäglichkeit. “382 Die Loslösung aus ihrem gewöhnlichen Kontext und die Darstellung auf der Bühne verleihen einer alltäglichen Situation den Charakter des Besonderen, des Nicht-Alltäglichen, sowie eine ästhetische Funktion. Dies ist auf die durch die Dekontextualisierung entstandene Distanz zurückzuführen, die Rapp als „die Kategorie, die das Ästhetische erst ausmacht", 383 definiert.

Eine ambivalente, aber umso spielerische Note kommt hinzu, wenn das nichtalltägliche Fiktive, in Huizingas Worten das „Anderssein als das gewöhnliche Leben“, zum Alltag wird. Das gilt nämlich nicht nur für Berufsschauspieler oder -opernsänger, für die das „so tun als ob“ zum Alltag und zum „gewöhnlichen Leben“ gehört, sondern möglicherweise auch für das Publikum, das im Venedig des I8. Jahrhunderts besonders häufig mit Fiktion und Maske konfrontiert war, einerseits durch den regelmäßigen und häufigen Theater- und Opernbesuch - man denke nur daran, dass die Theaterlogen (saisonweise) gemietet oder sogar gekauft wurden -, andererseits durch die in Venedig besonders stark ausgeprägte Festkultur, die im Karneval gip-

381 Fink: Oase des Glücks. S. 44.

382 Winfried Nöth: Handbuch der Semiotik. Stuttgart-Weimar, 1985, 2. Auflage 2000, S. 520.

383 Rapp: Handeln und Zuschauen. S. 57. Vgl. dazu auch Edward Bullough: Psychical Distance as a Factor in Art and an Aesthetic Principle. In: Ders.: Aesthetics. London 1957. 
felte, den man mindestens drei Monate pro Jahr, oft schon von Oktober bis zum Aschermittwoch, ${ }^{384}$ feierte. Die Regelung, nach der die Adeligen auch außerhalb der Karnevalszeit zu offiziellen Anlässen sowie in der „zona del gioco“385 eine Maske tragen mussten, mutet wie eine „Erweiterung“ des Karnevals an. Es ist wohl nicht übertrieben, zu sagen, dass die Grenzen zwischen dem „gewöhnlichen Leben“ und der "Spielsphäre“ in Venedig etwas „verwischt" waren und dass der Alltag, wenigstens in der Karnevalsaison, ein besonders spielerischer war. Wahrscheinlich war man ein ständiges Hin-und-Her-Wechseln bzw. Kippen zwischen „gewöhnlicher Welt" und "Spielwelt" gewohnt, was sowohl dem formalen Kriterium der "labilen Ambivalenz“ des Spiels (Scheuerl) als auch dem der charakteristischen „Hin- und Herbewegung“ (Buytendijk, Gadamer, Scheuerl) entsprechen würde.

\section{Das Spiel zwischen Identifikation und Distanz}

Im Opernhaus des I8. Jahrhunderts äußerte sich dieses Hin- und Herpendeln zwischen Spielwelt und Realität unter anderem auch darin, dass die Aufmerksamkeit der Zuschauer zwischen dem Geschehen auf der Bühne und den vielen Ablenkungen im Zuschauerraum hin und her wechselte, wovon einige zeitgenössische Berichte zeugen. Mary Hunter und Martha Feldman bezeichnen dieses Phänomen als „intermittent attention“.386 "Intermittent" ist ein sehr treffender Ausdruck, wenn man ihn ausschließlich auf die Aufmerksamkeit bezieht, die auf das Bühnengeschehen gerichtet war; eigentlich war aber die „attention“ an sich kontinuierlich, nur wechselte sie eben zwischen der Bühne und dem „von Spiel durchtränkten“ Zuschauerraum. Besonders während der Rezitative oder der Arien der Nebenfiguren war das Publikum eher mit sich selbst beschäftigt, d.h. mit Konversation, Flirt, Kartenspiel und Erfrischungen, aber während der Arien, vor allem denen der Hauptrollen, und Ensembles unterbrach man alle übrigen Beschäftigungen, um mit höchster Aufmerksamkeit der Darbietung zu folgen. ${ }^{387}$

Martha Feldman beschreibt die Zuschauer der Opera seria als ,actors in a kind of ritual that, like many religious and civic rituals, requires an intuitive sensory familiarity with formal and semantic cues, allowing participants to tune in and out without missing the prime vertices of the event. "388 Ähnliches gilt auch für die Opera buffa.

384 Vgl. Benvenuti, S. 725 (Il „periodo di carnevale (...) era molto più lungo di quello attuale cominciando talora in ottobre per finire al mercoledì delle ceneri.").

385 Vgl. Mazzola, S. 268.

386 Vgl. Hunter, S. 20 und Feldman, S. 18.

387 Vgl. Wiel, S. XXXIIIf. und Burney, S. 81.

388 Feldman, S. 13. 
Die participatio des Publikums pendelte dabei also zwischen Teilnahme an der dargestellten Handlung auf der Bühne und Teilnahme an den restlichen (Spiel-)Aktivitäten sowie an der Interaktion mit den anderen Zuschauern - je nachdem, was seine Aufmerksamkeit gerade am meisten anzog -, denn das Ziel war der maximale Genuss und das maximale Vergnügen.

Nicht nur die Abwechslung der Aufmerksamkeit des Publikums zwischen Bühne und Zuschauerraum führt Momente der Identifikation bzw. der Distanz zum einen oder anderen „Spielraum“ herbei, sondern auch die Teilnahme am Bühnengeschehen ist durch eine Ambivalenz zwischen der vollkommenen empathischen Versenkung (Burney: „every one was in raptures“) und einer distanzierten Haltung geprägt, die auf alle an der Aufführung beteiligten Personengruppen erweitert werden bzw. generell als Eigenschaft der conditio humana gelten kann. Am Beispiel des Schauspielers ist dieses Thema schon im I8. Jahrhundert vor allem in Frankreich heftig diskutiert worden: Es ging in erster Linie um die Frage, ob der Schauspieler, um das Publikum zu berühren, sich so vollkommen mit der von ihm gespielten Rolle identifizieren muss, dass er während des Spiels sich selbst und das Bewusstsein der Fiktivität der Rolle „verliert“, oder ob er eine emotionale Distanz bewahren sollte. Letztere Meinung wurde besonders von Denis Diderot vertreten, der in seinem berühmten Aufsatz Paradoxe sur le comédien die These aufstellte „pour émouvoir il ne faut pas être ému!“, ${ }^{389}$ während Jean-Baptiste Du Bos und andere dem vollständigen Aufgehen in der Rolle eine stärkere Ausdruckskraft zuschrieben. ${ }^{390}$ Inzwischen tendieren die meisten Theorien zur Feststellung, dass beide Haltungen zusammengehören ${ }^{391}$ und (auch außerhalb des Theaters) in jedem Menschen grundsätzlich vorhanden sind. Rapp schreibt dazu: „Die spezifische Hinwendung des Subjekts (...) besteht aus einem spezifischen Ineinanderspielen von Distanzierung und Perspektivengebundenheit, deren Ursprünge der anthropologischen Verfassung des Menschen entstammen, und die in jedem menschlichen Schaffensbereich auf verschiedene Weise sich überlagern. “392 Genauso wie der Schauspieler auch in der totalen Identifikation mit der von ihm gespielten Rolle immer auch ein Mindestmaß an Bewusstsein um Fiktion und Realität behält - wie beim Fensterausblick aus den Augenwinkeln auch der Rahmen wahrgenommen wird -, befindet sich auch der Zuschauer, wenn auch auf eine passivere Art und Weise, in einer "labilen Ambivalenz"

389 Denis Diderot: Paradoxe sur le comédien. Zit. nach Rapp: Handeln und Zuschauen. S. 220.

390 „C'est que les hommes qui sont eux-mêmes touchés nous touchent sans peine. Les acteurs dont je parle sont émus véritablement et cela leur donne le droit de nous émouvoir (...)." (Jean-Baptiste Du Bos: Refléxions critiques sur la poésie et sur la peinture. 1. Teil, S. 14. Zit nach Alberto Beniscelli: Naturale e artificiale in scena nel secondo settecento. Rom 1997, S. 19).

391 Vgl. Rapp: Handeln und Zuschauen. S. 221.

392 Ebd. S. 50. 
zwischen Identifikation und Distanz, denn „er steht in der Illusion, ist von ihr ergriffen und mitgerissen“, ist sich dabei aber ,jederzeit der Illusionshaftigkeit des Geschehens bewußt, steht in Distanz nicht nur zum Schauspiel und zur Bühne, sondern auch zu sich als Miterlebenden (...); er weiß um die Scheinhaftigkeit der Aufführung und genießt gerade deshalb das Spiel als Spiel (...".393 Rapp bezeichnet dieses „Doppelbewußtsein“, diese „Meta-Ebene des distanzierten Miterlebens“ als „In-lusion“.394

Obwohl die Haltungen der Identifikation und Distanz prinzipiell gleichzeitig vorhanden sind, dominiert meistens einer der beiden Pole, was nicht nur von der subjektiven Befindlichkeit des einzelnen Zuschauers abhängt, sondern auch von den Mitteln, die in dem jeweiligen Stück verwendet werden. Wolfgang Matzat spricht von einer „dramatischen“ und einer „theatralischen Perspektive“: Im ersten Fall dominiert die Identifikationshaltung, eine „fiktionsimmanente Perspektive“. Hinsichtlich der Mittel des „dramatischen Theaters“ schreibt Matzat: „Die Wahrscheinlichkeit wird daher zu einem der Axiome dramatisch orientierter Gattungspoetiken, da durch jeden Verstoß gegen diese Regel die immanente Sinnhaftigkeit bedroht wird. (...) Der Schauspieler darf nicht zeigen, daß er spielt, und der Zuschauer wird als abwesend gedacht, d.h. das dramatische Theater setzt gleichsam eine Verleugnung der Theatersituation voraus." 395 Der Spannungsreiz dieser Perspektive besteht in der empathischen Teilnahme, im identifikatorischen Miterleben.

In der "theatralischen Perspektive“ dagegen überwiegt das Bewusstsein um den Kontext der Theatersituation und somit die Fiktivität des Bühnengeschehens, zu dem der Zuschauer also eine gewisse Distanz empfindet. Das Bewusstsein, dass es sich um ein Spiel handelt, kann durch verschiedene Mittel, beispielsweise Illusionsdurchbrechung, Thematisierung des Theaterspiels oder „Spiel im Spiel“, hervorgerufen werden, die in einem späteren Kapitel detailliert behandelt werden. Der Spannungsreiz besteht im Fall der „theatralischen Perspektive“ im distanzierten „intellektuell-ästhetischen Vergnügen“ am Spiel, im Durchschauen der Theatersituation und in der „heiteren Unbetroffenheit und Überlegenheit“. ${ }^{396}$ Die letztere Perspektive ist typisch für die Komödie bzw. für komische Theatergattungen, „denn es entspricht dem Lustspiel, daß das, was den dargestellten Figuren zugemutet wird, für den Zuschauer in der Distanz des Spielhaften, damit des ästhetischen Scheins bleibt. " ${ }^{397}$ Allerdings hat nach

393 Rapp: Handeln und Zuschauen. S. $75 \mathrm{f}$.

394 Ebd. S. 76. Über die Angemessenheit dieser Wortprägung kann man sicher diskutieren, denn der Unterschied zwischen den Termini Illusion und In-lusion liegt eigentlich allein in der Assimilation der Konsonantengruppe $n$ - $l$, welche aber die Bedeutung des Wortes nicht verändert.

395 Matzat, S. 37.

396 Vgl. Martini, S. 346.

397 Martini, S. 316. 
Matzat „die theatralische Perspektive im allgemeinen ein gewisses Maß an dramatischer Vergegenwärtigung zur Voraussetzung“, 398 so kommt es zu einem „simultan dialektischen Wechselspiel zwischen Betroffenheit und Distanzierung“, das Martini als „strukturelles Grundprinzip“ der Komödie definiert. ${ }^{399}$

Die Teilnahme an der vorgeführten Handlung und das gleichzeitige Bewusstsein ihrer Fiktivität bzw. das Hin- und Herpendeln zwischen diesen beiden Haltungen ist nicht nur eine allgemeine Grundbedingung des Theaters, sondern auch des Spiels. Die Gleichzeitigkeit vom „In-der-Spielwelt-sein“ und dem Bewusstsein, dass es sich nur um ein Spiel handelt, ist nach Fink eine Grundbedingung des Spiels, denn „nur wo das Imaginäre als solches gewußt und offen eingestanden ist, kann man strenggenommen von einem Spiel reden“. ${ }^{400}$ Das „Doppelbewusstsein“, das Huizinga auch als „Einheit und Untrennbarkeit von Glauben und Nichtglauben " 401 versteht, kann also als ein weiteres gemeinsames Merkmal sowohl für das Spiel als auch für das Theater gelten.

Dass dieses „Doppelbewusstsein“ prinzipiell eine Charakteristik aller an einer Aufführungssituation beteiligten Personengruppen ist, hängt mit der Tatsache zusammen, dass das Rollenspiel - unabhängig davon, ob es bewusst oder unbewusst betrieben wird - zum Grundverhalten des Menschen gehört und somit nicht nur auf der Bühne, sondern auch „in der sozialen Wirklichkeit vorfindbar“ ist. ${ }^{402}$ Das Rollenspiel beruht auf der menschlichen „Fähigkeit, die Perspektiven verschiedener Rollen, real oder imaginativ, sich zu eigen zu machen“, also auf das menschliche Einfühlungsvermögen in fremde Rollen, und enthält gleichzeitig auch ein gewisses „Abstandnehmen von sich“. ${ }^{403}$ Für unser Anliegen ist dabei interessant, dass Rapp in dieser auch im Alltagsleben vorhandenen Rollenübernahme einen „spezifischen Spielcharakter“ ${ }^{404}$ sieht (eine Rolle spielen) und dass dabei eine für das Spiel typische Ambivalenz herrscht zwischen Identifikation mit der Rolle und dem distanzierenden Bewusstsein, dass es sich nur um ein Rollenspiel handelt.

Bei der „alternierenden Aufmerksamkeit“ des Zuschauers des I8. Jahrhunderts, der in Venedig überdies maskiert war, ist dieses „Doppelbewusstsein“ noch etwas komplexer, denn außer dem „mimetischen Spiel“, ${ }^{405}$ der imaginativen Einfühlung in

398 Matzat, S. 45.

399 Vgl. Martini, S. 347 und 364.

400 Fink: Grundphänomene des menschlichen Daseins. Freiburg, München 1979, S. 401.

401 Huizinga, S. 31.

402 Vgl. Rapp: Handeln und Zuschauen. S. 91.

403 Ebd. S. 54.

404 Ebd. S. 222.

405 Vgl. Rapp: Rolle, Interaktion, Spiel. S. 103. Dieses „mimetische Spiel“ hatte Scheuerl folgendermaßen beschrieben: „Der Zuschauer spielt zwar nicht mit, aber er spielt (virtuell) doch sein eigenes Spiel. Auch wenn er nicht in die Darstellung selbst eingreift, so muß er doch für sich in der Ebene des Scheins alle 
die Rollen, die ihm auf der Bühne vorgespielt werden, kann er, wenn seine Aufmerksamkeit auf den Zuschauerraum gerichtet ist, auch ein reales Rollenspiel spielen, das wiederum durch das gleichzeitige Vorhandensein von Identifikation mit der gespielten Rolle und Distanz zur Rolle und zu sich selbst im Bewusstsein über die Fiktivität dieser Rolle, geprägt ist.

Dieses „doppelte Hin- und Herpendeln“, dem eine Art „multiple Ambivalenz“ innewohnt, besitzt eine besonders spielerische Qualität und hängt eng mit dem ästhetischen Genießen zusammen, das beispielsweise Groos als „die höchste und feinste Form des Spiels “ ${ }^{406}$ bezeichnet. Groos meint dabei ein gefühlsreiches „inneres Miterleben“, ein "Hineingerissenwerden in die dargestellten Begebenheiten“" ${ }^{407}$ Sein Begriff des ästhetischen Genießens deckt sich also mit dem der Einfühlung als totale Identifikation. Dabei bleibt die „distanzierende“ Qualität des ästhetischen Genießens unbeachtet, obwohl sie eine ebenso wichtige Rolle spielt. An einer anderen Stelle wurde schon Rapp zitiert, der Distanzierung als „die Kategorie, die das Ästhetische erst ausmacht ", ${ }^{408}$ definiert. Der ästhetische Genuss liegt nicht nur im empathischen Miterleben, sondern besonders auch in der Betrachtung aus einer Distanz und im Genießen des Spiels als Spiel, vor allem aber wahrscheinlich gerade im spielerischen Hin und Her zwischen den beiden Haltungen, das Fritz Martini als „simultan dialektisches Wechselspiel zwischen Betroffenheit und Distanzierung" bezeichnet. Charakteristisch ist also die "labile Ambivalenz" zwischen Identifikation und Distanz, die Rapp folgendermaßen erklärt: „Distanz ist nicht ein Zustand, sondern eine immerwährend zu vollziehende, an sich äußerst prekäre Haltung, der ständig die Gefahr droht, in Bindung und Befangenheit zurückzufallen. " ${ }^{009}$ Gleichzeitig soll bemerkt werden, dass Distanz - nach Plessner eine Grundbedingung der „Sphäre des Menschen“ ${ }^{410}$ - auch eine grundsätzliche Eigenschaft der „Zuschauerfunktion“ ist ${ }^{411}$ und dass so wie das Rollenspiel auch der „Zustand des Zuschauens“ im Alltag immer wieder anzutreffen

Bilder reproduktiv noch einmal erzeugen, (...) muß alle Bewegungen innerlich noch einmal vollziehen (...). Bringen die Spieler improvisierend oder streng nachschaffend eine objektive Form mit allen ihren Gehalten zur Wirkung, so beginnen die Zuschauer nun, mit dieser Wirkung zu spielen. Vom Tun der Schauspieler, das harte Arbeit sein kann, abstrahieren sie das, was Spiel ist: Das reine Geschehen. Diese Abstraktion selbst kann wie das Lesen eines Buches ebenfalls harte Arbeit sein. Was sie aber erzeugt, ist ein reines, in sich unendliches Schweben von Bildern." (Scheuerl: Das Spiel. S. 149f.).

406 Scheuerl: Theorien des Spiels. S. 67.

407 Ebd. S. 72.

408 Rapp: Handeln und Zuschauen. S. 57.

409 Ebd. S. 50.

410 Plessner spricht von der „exzentrischen Position“ als anthropologische Grundlage des menschlichen Daseins. (Vgl. Plessner: Lachen und Weinen. S. 236ff.).

411 Vgl. ebd. S. 51. 
ist. Genau diese Tatsache, nämlich dass sowohl Rollenspiel als auch Zuschauen typische Phänomene des Theaters sind, aber auch im "gewöhnlichen Leben“ vorkommen, bildet die Grundlage für das Theatergleichnis.

\section{Theater und Spiel als Weltmetaphern}

Gran teatro è questo mondo

Pien di popol misto, e vario;

Ecco; tirasi il Sipario;

La Commedia è bella affè.

Ogni Attor da cima a fondo

Corre, e inonda la gran Scena;

La fortuna è che comparte

A ciascun la propria parte.

Uno gode, uno s'affanna.

Un riposa, un s'affatica,

Io frattanto, e cosa fò?

Sopra una sedia

Dal mio palchetto

Questa Commedia

Coll'occhialetto

Guardo ridendo,

Nè me la prendo;

Ma sol le mani

Battendo vò. ${ }^{412}$

Das Theatergleichnis, das vor allem mit dem I7. Jahrhundert in Verbindung gebracht wird, blickt in Wirklichkeit auf eine lange Tradition zurück. Schon in der Antike belegt, erscheint es ab der zweiten Hälfte des I6. Jahrhundert in verstärktem Maße. Um nur einige Beispiele herauszugreifen, kann Torquato Tassos Wort „La vita nostra è somigliante a la comedia o pur a la tragedia“ zitiert werden oder die im Prolog des Amfiparnasso von Orazio Vecchi (Venedig I 597) enthaltene Ankündigung: „La città dove si rappresenta / quest'opera è'l gran teatro / del mondo “. ${ }^{413}$ Im I7. Jahrhundert -

412 Giovanni de Gamerra/Antonio Salieri: La finta scema. Wien 1775 (II,8) Aria Argante.

413 Zit. nach Mercedes Viale Ferrero: Luogo teatrale e spazio scenico. In: Storia dell'opera italiana. Bd. 5. La spettacolarità. Turin 1988, S. 45. 
man denke besonders an El gran teatro del mundo von Calderón de la Barca - erfreute sich diese Theatermetapher besonders großer Beliebtheit. Dabei wird die Welt mit einer großen Bühne bzw. mit einem Theater verglichen, die Rollen, die die Menschen spielen, werden als Theaterrollen, einzelne Situationen als Theaterszenen und das ganze Leben als Theaterveranstaltung gesehen.

Die Gleichsetzung von Welt und Theater wird von Theatersoziologen dadurch gerechtfertigt, dass eine „affinité frappante entre la société et le théâtre“ ${ }^{414}$ herrscht. Diese Affinität hängt mit der Tatsache zusammen, dass Theater „in sich selbst ein Abbild und Symbol menschlicher Interaktion ist". 415 Matzat erläutert dies folgendermaßen: „Was das Theatergleichnis ermöglicht, ist die Affinität zwischen Theaterrolle und gesellschaftlichen Handlungsmustern, Verhaltensweisen und Ausdrucksformen. Durch die Vereinbarung des Als-ob werden diese Formen gesellschaftlichen Verhaltens einem Abstraktionsprozess unterworfen und können damit die konstitutiven Elemente der Theaterrolle bilden. (...) Typisierte Verhaltensweisen werden im Theater also zur Basis eines Rollenentwurfs mit symbolischer Funktion. " ${ }^{16}$ Der besagte Abstraktions- bzw. Stilisierungsprozess beruht auf einer Distanzierung, die eine lustvolle - weil unbetroffene - ästhetische Betrachtung ermöglicht.

Die Komödie eignet sich besonders für eine solche distanzierte Betrachtung der Welt als Theaterbühne, denn sie „hat es mit dem Leben in seiner Ganzheit zu tun“.417 Selbst ein großer Komödiendichter wie Carlo Goldoni bezeichnet ,il Mondo e il Teatro" als die beiden „Bücher“, aus denen er das Komödiendichten erlernt und den Stoff für seine Stücke geschöpft hat. ${ }^{418}$ Die für die Komödie typische Nähe zum Leben und zu den (gewöhnlichen) Menschen ist von vielen Theaterwissenschaftlern bekräftigt worden, unter anderen von Fritz Martini, der sich diesbezüglich folgendermaßen ausdrückt: „Die Konflikte des Lustspiels sind Konflikte unter Menschen innerhalb der von ihnen geschaffenen und verwirrten Zuständen; Menschen verschulden sie, Menschen können sie auch wieder ausgleichen und entwirren. (...) Die einzige außermenschliche Macht, welche das Lustspiel in sich aufzunehmen vermag und auch geradezu ausbeutet, ist der Zufall. Denn in ihm wohnt die Qualität des Unerwarteten

414 Georges Gurvitch: Sociologie du théâtre. Zit. nach Rapp: Handeln und Zuschauen. S. 31.

415 Rapp: Handeln und Zuschauen. S. 31.

416 Matzat, S. $42 \mathrm{f}$.

417 Amur, S. 283.

418 Vgl. Carlo Goldoni: Prefazione dell'Autore alla prima raccolta delle commedie del 1750: „I due libri su’ quali ho più meditato, e di cui non mi pentirò mai di essermi servito, furono il Mondo e il Teatro. Il primo mi mostra tanti e poi tanti vari caratteri di persone, me li dipinge così al naturale, che paion fatti apposta per somministrarmi abbondantissimi argomenti di graziose e istruttive Commedie." (Carlo Goldoni: Memorie. Con un'appendice di scritti goldoniani. Übers. von Eugenio Levi, hg. von Guido Davico Bonino. Turin 1967, S. 628f.). 
und Unberechenbaren (...). Er ist dann das Spielelement, das gleichsam das Leben selbst zur Verfügung stellt und mit dem es seine Überraschungen produziert und zurücknimmt. " 419 Die fundamentale Rolle des Zufalls, der im Leben der Menschen „mitspielt" bzw. mit dem Leben der Menschen spielt, wird in folgender Definition der Komödie zum Ausdruck gebracht:

„Comedy is an amusing, relatively discontinuous action concerning succes and failure in social relations and culminating in a judgement whereby the ,divine average triumphs over the exceptional or peculiar. The movements towards success and failure are arranged in a pattern of inevitability and chance: the freedom of the will is not stressed. The total work, therefore, presents life as a product of natural law and erratic fortune. " ${ }^{220}$ Der letzte Satz dieser Definition weist eine erstaunliche Ähnlichkeit mit der These der Biochemiker-Spieltheoretiker Manfred Eigen und Ruthild Winkler auf, die die Welt als Spiel zwischen Naturgesetz und Zufall sehen. ${ }^{421}$ Das in der Komödie dargestellte Leben (im Sinne McColloms) scheint also nach denselben Prinzipien organisiert zu sein wie die reale Welt (im Sinn von Eigen und Winkler). Letztere erklären das Verhältnis zwischen den beiden Prinzipien, nämlich Zufall und Naturgesetz, mit dem Begriff des Spiels, das somit als universelles Organisationsprinzip und - genauso wie das Theater - als Metapher für die Welt, oder besser für die „Funktionsweise“ der Welt, dient. Eine weitere Gemeinsamkeit zwischen Theater und Spiel besteht also in ihrer Tauglichkeit als Weltmetapher. Die umfassendste Theorie, die den Spielbegriff als Weltmetapher verwendet, stammt allerdings nicht von Eigen und Winkler, sondern von Eugen Fink („Spiel als Weltsymbol“).422 Die schon bei Heraklit und Platon in Ansätzen vorhandene These, die Welt gleiche einem großen Spiel, beruht genauso wie das Theatergleichnis auf der Tatsache, dass im Spiel ebenso wie im Theater eine symbolische Darstellung bzw. eine Spiegelung der Welt möglich ist. Finks Definition des Spiels als ,eine darstellende Symbol-Handlung der sich darin selbstdeutenden menschlichen Existenz “ ${ }^{223}$ kann gleichermaßen für das Theater gelten. Eine Spiegelung gestattet immer die Möglichkeit einer Umkehrung: Fink selbst betrachtet das Spiel als „spekulative Weltmetapher“, ${ }^{424}$ d.h. das Spiel spiegelt die

419 Martini, S. 350.

420 William McCollom: The Divine Average. A View of Comedy. Cleveland, London 1971, S. 7. Zit. nach Grimm u. Berghahn (Hg.): Wesen und Formen des Komischen im Drama. S. XII.

421 Ihre These lautet wörtlich: „Alles Geschehen in unserer Welt gleicht einem großen Spiel. (...) Wir sehen das Spiel als das Naturphänomen, das in seiner Dichotomie von Zufall und Notwendigkeit allem Geschehen zugrunde liegt." (Eigen u. Winkler, S.11).

$422 \mathrm{Vgl}$. Kapitel „Spiel und Theorien des Spiels“.

423 Fink: Oase des Glücks. S. 40.

424 Ebd. S. 50. 
Welt und aus dieser Spiegelung können wiederum Rückschlüsse auf die Wirklichkeit gezogen werden. Das Spiel kann also nach Fink als gleichnishafte Erklärung der Welt dienen. Ähnliches kann aber auch über das Theater gesagt werden, da es dieselbe „Spiegelfunktion“ besitzt. In beiden Fällen wird durch Distanzierung eine Abstraktion erreicht, die dem Spieler bzw. dem Zuschauer Überblick und Klarheit sowie ästhetischen Genuss verschaffen kann.

\section{Durchiosten von Lebensmöglichieiten und ERZIEHUNGSFUNKTION}

Eine weitere mit dieser symbolischen Qualität verbundene Analogie zwischen Theater und Spiel besteht auch in der beiden Phänomenen zugeschriebenen Lebensbewältigungsfunktion. ${ }^{425}$ Groos' Behauptung, das Spiel diene der Lebensbewältigung, denn in ihm finde ein „spielendes Durchkosten von Lebensmöglichkeiten“426 statt, entspricht der auf das Theater bezogenen These von Fedor Steptun, „daß die jeweilige Kultur (...) Lebensmöglichkeiten in dramatischer Form vorstellt““. ${ }^{427}$ Groos betont dabei die ergänzende und kathartische Funktion des Spiels, Steptun spricht von der "theatralischen Ergänzung“. ${ }^{428}$ In beiden Fällen können die unterschiedlichen Lebensmöglichkeiten symbolisch - also nicht real, sondern imaginativ - erlebt werden. In diesem Zusammenhang ist der Begriff der Simulation ${ }^{429}$ zu erwähnen, den Rapp als erste Eigenschaft des Spiels nennt ${ }^{430}$ und auf dessen Bedeutungswandel er aufmerksam macht: „Ursprünglich Fälschung und Unwahrheit, also Entstellung und Irreführung, bedeutet Simulation heute das experimentelle Durchspielen von möglichen Systemen (...). Diese simulative Handlungsweise ist aber in der menschlichen Intelligenz als solcher angelegt (...) und strukturiert alles Denken als Erprobungsspiel, in der Form von imaginativer Nachahmung vorgestellter Möglichkeiten. “431

425 Vgl. dazu Theorien über das Spiel aus psychologischer Sicht (v. a. Freud), aber auch funktionsorientierte Spieltheorien, beispielsweise von Groos, Sutton-Smith, Stepina.

426 Groos: Das Spiel. Zit. nach Scheuerl: Theorien des Spiels. S. 72.

427 Rapp: Handeln und Zuschauen. S. 236.

428 Fedor Steptun: Theater und Film. München 1953. Zit. nach Rapp: Handeln und Zuschauen. S. 236.

429 Zur engen Beziehung zwischen den Begriffen „Simulation“ und „Repräsentation“ siehe unter anderem Alfonso M. Iacono: Lillusione e il sostituto. Mailand 2010. Zur zwischen „Simulation“ und „Repräsentation“ schwankenden Bedeutung des aristotelischen Begriffs der „Mimesis“ siehe Diego Lanza: Introduzione a Aristotele. In: Aristotele: Poetica. Hg. und übers. von Diego Lanza. Mailand 1987.

430 Vgl. Rapp: Rolle, Interaktion, Spiel. S. 98.

431 Rapp: Handeln und Zuschauen. S. 128. 
Das „Durchkosten von Lebensmöglichkeiten“ erfolgt in Spiel und Theater in der Vorstellung der Menschen, also in Form einer bewussten Illusion. Der Bezug zur Realität geht dabei allerdings nicht verloren, auch wenn das „mimetische Spiel“ sich in einer „Sphäre des Scheins“ abspielt.

Dieser Erprobungsfunktion von Spiel und Theater wird generell eine gewisse Nützlichkeit für das reale Leben zugeschrieben. Seit Platon ${ }^{432}$ wird dem Spiel aufgrund seiner Übungsfunktion ein erzieherischer Wert beigemessen. Analog dazu wird auch dem Theater und der Oper eine erzieherische Funktion zugeschrieben. Bezeichnend dafür ist beispielsweise eine Wendung in Goldonis Vorwort zu seiner ersten veröffentlichten Komödiensammlung. Er nennt die Komödie nämlich „uno spettacolo destinato all'istruzion sua per mezzo del suo divertimento e diletto “, ${ }^{433}$ wodurch das Ziel dieser Gattung zum Ausdruck kommt: Sie soll nämlich mittels Vergnügung das Volk bilden, eine Definition, die genauso gut für das Spiel zutreffen könnte. Der erzieherische Wert des Theaters und der Oper kommt allerdings vor allem in zeitgenössischen Abhandlungen zum Vorschein: Planelli macht es regelrecht zum Ziel seines Operntraktats, die Abhängigkeit zwischen den spettacoli und den Sitten der Nationen aufzuzeigen: „Lo scopo di questo Trattato è (...) il dimostrare quanta dipendenza abbiano dagli Spettacoli, e massimamente da quello dell'Opera in Musica, il gusto delle Arti, e 'l costume delle Nazioni; e quanto agevolmente l'inosservanza delle leggi di questa pomposa scenica Rappresentazione possa corrompere il gusto, e favorire la scostumatezza, ch’è la più deplorabile sventra, che possa avvenire a uno Stato. " 434 Diese Ansicht teilt unter anderen grundsätzlich auch Zulatti, der sich auf Platon berufend ein erzieherisches Potenzial vor allem in der Musik vermutet: „La Musica moderna ha molta influenza sull'anima, e sarebbe utilissima per dirigere i costumi al giusto ed all'onesto. “435

Hier wird ein wesentlicher Bestandteil der Oper angesprochen, der bisher außer Acht gelassen wurde, nämlich die Musik. Nachdem nun auf viele Berührungspunkte zwischen Spiel und Theater hingewiesen wurde, die selbstverständlich auch für die Oper (als besondere Art des Theaters) gelten und nicht besonders verwundern, wenn man bedenkt, dass Theater im Allgemeinen als Spiel angesehen werden kann, sollen im nächsten Kapitel die verschiedenen Verbindungsmöglichkeiten zwischen Musik und Spiel erörtert werden.

432 „Wie wir also zu Anfang gesagt haben, müssen sich die Kinder in den ersten Jahren durch Spiele und ehrbare Scherze gewöhnen, denn wenn sie unter nicht ehrbaren Scherzen aufwachsen, so können sie später niemals gute Männer werden." Platon: Gesetze. Zit. nach Colozza, S. 104.

433 Goldoni: Memorie. Con un'appendice di scritti goldoniani. S. 630.

434 Antonio Planelli: Dell'opera in musica. Neapel 1772, S. 9.

435 Zulatti, S. 31. 
io. Musik und Spiel

Huizinga bezeichnet die Musik als die „reinste und höchste Manifestation der menschlichen Facultas ludendi“ ${ }^{436}$ und beschreibt den Zusammenhang zwischen Musik und Spiel folgendermaßen: „Musizieren trägt von vornherein beinahe alle formalen Merkmale des Spiels an sich: die Tätigkeit verläuft auf einem begrenzten Gebiet, ist wiederholbar, besteht in Ordnung, Rhythmus und geregeltem Wechsel und entrückt Zuhörer und Ausführende aus der ,gewöhnlichen' Sphäre in ein Gefühl der Heiterkeit, das auch bei schwermütiger Musik noch Genuß und Erhebung bringt. An sich wäre es vollkommen begreiflich, wenn man alle Musik unter Spiel einbezöge. “437 Allerdings bemerkt er selbst die Schwierigkeit des Versuchs, diese anscheinend so einleuchtende Verbindung rational zu erklären: „Wie sehr nun auch dieser Zusammenhang von Musik und Spiel uns als eine natürliche Gegebenheit vorkommen mag, es dürfte nicht leicht sein, sich von der Ratio dieses Zusammenhanges eine deutlich umrissene Vorstellung zu machen." ${ }^{438}$

Was zunächst in Bezug auf die Gemeinsamkeiten zwischen Musik und Spiel auffällt, ist die Bedeutung von „spielen“ als „musizieren“, ein Instrument spielen. Aus dieser sprachlichen Gegebenheit stammt wohl Huizingas Behauptung, „die wesentliche Art aller musikalischen Aktivität“ sei „ein Spielen“. ${ }^{439}$ Huizinga selbst fügt allerdings Folgendes hinzu: „Zieht man jedoch in Betracht, daß Spielen als Musizieren niemals auf Singen angewendet wird und lediglich in einigen Sprachen gebräuchlich zu sein scheint, dann wird es wahrscheinlicher sein, daß hier das verbindende Moment zwischen Spiel und instrumentaler Technik in dem Begriff der raschen, behenden und geordnet verlaufenden Bewegung zu suchen ist. " 440 In dieser Hinsicht spielt also die ursprüngliche etymologische Bedeutung des Wortes Spiel als „tänzerischer Bewegung " 441 eine Rolle, wobei Huizinga sie lediglich auf die physische Bewegung des Musikers bzw. Spielers bezieht. Das Spielen eines Instruments könnte so als eine Art Geschicklichkeitsspiel gesehen werden, die Virtuosität würde in diesem Fall seine höchste Ausformung darstellen. Aus psychologischer Perspektive bemerkt Rolf Oerter eine Entsprechung zwischen Musizieren und sensomotorischem Spiel: Die Gemeinsamkeit liegt dabei in der Interaktion von Wahrnehmung und Motorik, also in der Abstimmung zwischen dem auditiven und dem motori-

436 Huizinga, S. 179.

437 Ebd. S. 48.

438 Ebd. S. 153.

439 Ebd. S. 157.

440 Ebd. S. 48.

441 Vgl. Duden Etymologie. S. 659. Siehe Kapitel „Begriffsbestimmung“. 
schen System, die sowohl für das sensomotorische Spiel als auch für das Musizieren typisch ist. ${ }^{442}$

Eine weitere Verbindungsmöglichkeit zwischen Spiel und Musik besteht darin, die „tänzerische Bewegung “ auf die Töne zu beziehen und analog zum Farbenspiel, Lichtspiel oder Wellenspiel von einem „Spiel der Töne“ zu sprechen. Eine ähnliche Ansicht äußert Eduard Hanslick in seiner Schrift Vom Musikalisch Schönen, beispielsweise in der berühmten Behauptung: „Tönend bewegte Formen sind einzig und allein Inhalt und Gegenstand der Musik. " 443 Diese Aussage erklärt Hanslick anhand eines Vergleichs zwischen der Musik und einem faszinierenden Spielzeug: „Jeder von uns hat als Kind sich wohl an dem wechselnden Farben- und Formenspiel eines Kaleidoscops ergötzt. Ein solches Kaleidoscop auf incommensurabel höherer Erscheinungsstufe ist Musik. Sie bringt in stets sich entwickelnder Abwechslung schöne Formen und Farben, sanft übergehend, scharf contrastirend, immer symmetrisch und in sich erfüllt. “444 Diese allgemeine Beschreibung der Musik weist eine gewisse Ähnlichkeit mit der Definition von Spiel als „Bewegungsform von besonderer Ablaufsgestalt“, als „spezielle Dynamik“ und als „ein entspanntes und doch in sich variables, immer wieder neues, nie genau vorhersehbares, in Grenzen hin- und herspielendes Geschehen " 445 auf. Hanslick selbst fasst - natürlich ohne seinen Spielbegriff näher zu definieren - gegen Ende der eben erwähnten Schrift seine Gedanken in folgender These zusammen: „Die Musik ist ein Spiel, aber keine Spielerei. “446 Der hier äußerst positiv konnotierte Begriff des Spiels kann in diesem Zusammenhang als gestaltende Bewegung der Töne verstanden werden, die auf einleuchtende Weise durch die lebendig bewegte und abwechslungsreiche Bilderfolge eines Kaleidoskops veranschaulicht wird.

Dieses „Spiel der Töne“ verläuft aber nicht, wie es die Metapher des Kaleidoskops suggerieren könnte, rein zufällig, sondern es folgt bestimmten Regeln. Das Vorhandensein von unbedingt bindenden und Ordnung schaffenden Spielregeln ist wiederum ein typisches Wesensmerkmal des Spiels. ${ }^{447}$ Huizinga bemerkt Folgendes zu diesem Berührungspunkt zwischen Spiel und Musik: „Die musikalischen Formen an sich sind Spielformen. Musik beruht auf freiwilliger Unterwerfung und strenger Anwendung eines Systems von konventionellen Regeln, die Ton, Zeitmaß, Melodie und

442 Vgl. Oerter: Psychologie des Spiels. S. 294.

443 Eduard Hanslick: Vom Musikalisch Schönen. Leipzig 1854, S. 32.

444 Hanslick, S. 33.

445 Scheuerl: Theorien des Spiels. S. $201 \mathrm{f}$.

446 Hanslick, S. 102.

447 Vgl. Kapitel „Spiel und Theorien des Spiels“. 
Harmonie bestimmen. " ${ }^{488}$ Selbstverständlich gelten für jede Art und Stilrichtung der Musik unterschiedliche und kaum zu verallgemeinernde Regeln, ${ }^{449}$ ein Grundprinzip, auf dem allerdings jede Musik basiert, ist die Abwechslung von Spannung und Entspannung. Es verwundert nicht, dass dieses so allgemeine „Grundmuster des Lebens" auch in Bezug auf das Spiel thematisiert worden ist: Schon Groos bemerkt das beim Spiel auftretende "Gefühl der Spannung" ${ }^{450}$ Huizinga nimmt diesen Punkt wieder auf und baut ihn in seine Definition des Spiels ein. Buytendijk bezeichnet "die Abwechslung von Spannung und Lösung" als „eine Eigenschaft der Dynamik des Spielens". ${ }^{451}$ Charakteristisch für das Spiel ist der Aufbau einer Spannung, die erst „bei Sieg oder Niederlage, bei Erreichen des Ziels oder Erfüllung der Aufgabe“, 452 also bei der Beendigung des Spiels einer Lösung entgegengeht. Denselben Spannungsbogen kann man bei jeder Art von Aufführung wiederfinden, denn ihr Beginn und ihr Schluss gehen immer mit einem Auf- und Abbau der Spannung einher. Abgesehen von diesem allgemeinen, makrostrukturellen Spannungsbogen, können in der Musik untergeordnete Spannungskurven wahrgenommen werden, die auf Phrasierung, Melodieführung, Abfolge von harmonischen Funktionen etc. beruhen, so dass Musik im Allgemeinen auch als Spannungszusammenhang erlebt werden kann. ${ }^{453}$

Ein weiteres Prinzip, das jeder Art von Musik (und auch von Kunst, die sich in der Zeit abspielt) eigen ist, besteht in der Wiederholung als Zusammenhänge schaffendes Gestaltungsmittel. Auch in Bezug auf das Spiel ist Ähnliches festgestellt worden: Scheuerl spricht in Anlehnung an ältere Theorien ${ }^{454}$ von der „Wiederholungstendenz" des Spiels, die er zum Merkmal der „inneren Unendlichkeit“ erweitert, Huizinga (allerdings in einer etwas anderen Variante) von der "Wiederholbarkeit“ des Spiels: „Diese Wiederholbarkeit ist eine der wesentlichsten Eigenschaften des Spiels. Sie gilt nicht allein vom Spiel als ganzem, sondern auch von seinem inneren Aufbau. In beinahe allen höher entwickelten Spielformen bilden die Elemente der Wieder-

448 Huizinga, S. 180.

449 Der Spielbegriff im Sinne eines Form- oder Kombinationsspiels eignet sich besonders für eine Musik, in der das strukturelle Moment im Vordergrund steht, was in der Musik der Opera buffa nicht der Fall ist. Analysen zu einzelnen Stücken, z. B. von Bachs Inventionen, mit dem in diesem Sinne angewandten Spielbegriff als Leitfaden sind zu finden in: Christoph Richter: Musik als Spiel. Orientierung des Musikunterrichts an einem fachübergreifenden Begriff. Ein didaktisches Modell. Wolfenbüttel und Zürich, 1975. Als „Regelspiel“ hingegen könnte jede Art von Musik bezeichnet werden.

450 Vgl. Groos: Das Spiel. Zit. nach Scheuerl: Theorien des Spiels. S. 72.

451 Buytendijk, S. 122.

452 Richter, S. 188.

453 Vgl. ebd. S. 66.

454 Schon Buytendijk hatte im Zusammenhang mit dem Spiel der Menschen und Tieren vom „Wiederholungsdrang" gesprochen. (Buytendijk, S. 161). 
holung, des Refrains, der Abwechslung in der Reihenfolge so etwas wie Kette und Einschlag. “ 455

Im eingangs wiedergegebenen Zitat hatte Huizinga die Ähnlichkeit zwischen Musik und Spiel nicht nur im Prinzip der Wiederholbarkeit gesehen, sondern auch in „Ordnung, Rhythmus und geregeltem Wechsel“. Zum Zusammenhang zwischen Wiederkehr und Rhythmus als Merkmalen des Spiels schreibt Friedrich Georg Jünger: „Da die Regeln eines Spiels Wiederkehr und Wiederholungen sind, läßt sich an ihnen zugleich absehen, welchen Rhythmus und welche Symmetrie ein Spiel hat. Rhythmus ist Wiederkehr in der Zeit, Symmetrie Wiederholung im Raum. Rhythmisierung und Symmetrisierung kennzeichnen die Spiele. “456 Sowohl Rhythmus als auch Spannung sind in der Musik so wie im Spiel eng mit der schon angedeuteten Dimension der Bewegung verbunden. In der Musik kann Bewegung nicht nur durch Rhythmus, Metrum und Tempo zum Ausdruck kommen, sondern auch durch Melodie, Harmonie, Klangfarbe und Dynamik, denn durch jede Veränderung eines musikalischen Parameters entsteht der Eindruck einer Bewegung. Sigrun Witt schreibt dazu: „Musik verändert sich fortlaufend, indem sie eine Folge von Zuständen durchschreitet, jeder durch eine Vielzahl von Veränderungen in den musikalischen Variablen gekennzeichnet. “ 457 Der Schluss, den sie daraus zieht, lautet folgendermaßen: „Musikalische Zustandsveränderung bzw. -entwicklung ist gleichbedeutend mit Bewegung. “458 Bewegung wäre also in dieser Hinsicht ein grundlegender gemeinsamer Nenner, der Musik und Spiel verbindet.

Witt bezeichnet die „musikalische Zustandsveränderung als Grundlage des musikalischen Ausdrucks: (...) Die Musik vermag ,sich psychischen Ereignissen anzuschmiegen' (de la Motte-Haber, I980, I4I), indem sie den dynamischen Aspekt emotioneller Qualitäten nachzeichnet. Entlang der Zeitachse ist Musik imstande zu stauen, zu entladen, impulsive Ausbrüche, statisches Verharren oder ruhiges Fließen zu implizieren. Musik trägt damit zwangsweise die Dimension der Bewegung in sich. “459 In diesem Zusammenhang ist die Etymologie des Wortes „Emotion“ interessant, dessen Grundwort motion „Bewegung“ bedeutet: Aus dem Lateinischen emovere, wörtlich „herausbewegen“, ist über das französische émouvoir das Substantiv émotion mit der Bedeutung von „Gemütsbewegung“ oder „seelische Erregung“ entstanden. ${ }^{460}$

455 Huizinga, S. 17.

456 Jünger, S. 104.

457 Sigrun Witt: Kreierte Emotionen in der Musik. Die elementaren Dimensionen von Gefüblen und Emotionen. Hamburg 2004, S. 153.

458 Ebd. S. 152.

459 Ebd.

460 Art. Emotion. In: Duden - Das große Fremdwörterbuch. 4. Aufl. Mannheim 2007 [CD-ROM]. 
Hier haben wir es also mit einer weiteren Möglichkeit der „Bewegung“ in der Musik zu tun.

In Verbindung mit der angesprochenen Fähigkeit der Musik, „sich psychischen Ereignissen anzuschmiegen ", ist die Theorie von Friedrich Georg Jünger erwähnenswert, neben Huizinga einer der wenigen Spieltheoretiker, der sich zum Verhältnis zwischen Musik und Spiel äußert. Er zählt die Musik zu der Kategorie der „auf Ahmung abgestellten vorahmend-nachahmenden Spiele“. ${ }^{461}$ Was er mit dem Begriff der Ahmung meint, erklärt er folgendermaßen : „Ahmung ist der weiteste Begriff, den wir mit Spiel verbinden können, weiter als Zufall und Geschicklichkeit. Um ihn unzweideutig zu bestimmen, sei an den Vorgang erinnert, durch den das kleine Kind sich die Sprache zu eigen macht. (...) Lauschend folgt das Kind den Tönen, die von Erwachsenen kommen. Aus den Lauten bildet es Silben, aus den Silben Wörter, aus den Wörtern Sätze. Das geschieht spielend, ohne daß ein bestimmtes Spiel vorläge. Die Aneignung der Sprache beruht auf der Ahmung, die das Kind vollzieht. Es ahmt das nach, was es hört (Nachahmung). Zugleich aber ahmt es das vor, was es hört und in Zukunft sprechen wird (Vorahmung). “462

Der Begriff der Ahmung scheint also eng mit dem der Einfühlung und der Empathie verbunden zu sein, auch wenn in der philosophischen Theorie von Theodor Lessing, ${ }^{463}$ der den Begriff in dieser abstrakten Bedeutung geprägt zu haben scheint, dieser Zusammenhang verneint wird. ${ }^{464}$

Marylka Bender versucht den Begriff der Ahmung von dem der Nachahmung abzugrenzen: „Es besteht ein Unterschied zwischen Ahmen und Imitieren, also Nachmachen. Ahmung im eigentlichen Sinn ist ein völlig unbewusster, physisch-psychischer Vorgang. Das heißt, an jeder Wahrnehmung sind Körper, Nerven und Gefühl

461 Jünger, S. 47. Jünger teilt die Spiele in drei Kategorien ein: Glücksspiele, Geschicklichkeitsspiele und vorahmend-nachahmende Spiele, die wiederum in darstellend oder nicht-darstellend unterteilt sind.

462 Ebd. S. 47f.

463 Vgl. Theodor Lessing: Geschichte als Sinngebung des Sinnlosen. (1919).

464 „Mit ,Leben“ bezeichnet Lessing die ,alle Subjekt-Objekt-Relation unterströmende, allverbindende Mitlebendigkeit.' Sie erfaßt sich gleichsam selbst - und das nennt er ,Ahmen' oder ,Ahmung', sozusagen den semantischen Kern des Wortes ,nach-ahmen' herausschälend. Ausdrücklich handelt es sich hier nicht um eine Einfühlung; denn es ist ein Zustand, aus dem ja allererst Unterscheidungen wie die zwischen Subjekt und Objekt oder Ich und Du hervorgehen. Beim Menschen unterscheidet nun Lessing im Gegensatz zu allen übrigen Lebendigen ,sozusagen zwei Stockwerke' der Ahmung, die ,natürliche‘ oder die ,geistige'. Während die natürliche Ahmung eine Art ,Mitahmen' ist (eben die bloße Mitlebendigkeit), wird die geistige Ahmung zur ,Aufahmung ' (...)“(Ernst Wolfgang Orth: Bemerkungen über Theodor Lessings Topos von der, Geschichte als Sinngebung des Sinnlosen؛ In: KarlHeinz Lembeck (Hg.): Geschichte und Geschichten. Studien zur Geschichtsphänomenologie Wilhelm Schapps. Würzburg 2004, S. 77f.). 
beteiligt, noch ehe sie bis zum Bewusstsein vordringt - was übrigens keineswegs immer der Fall ist, denn der weitaus größere Teil unserer Wahrnehmungen bleibt unbewusst. Die Imitation dagegen ist ein bewusster, gewollter Entschluss. Manchmal gelingt auch eine Verschmelzung von beidem, so zum Beispiel, wenn ein Schauspieler in die Rolle einer Person schlüpft, deren Charakteristik er zwar bewusst ,nachmacht', sie aber zusätzlich so stark in sich aufnimmt, sich so sehr in sie einfühlt, dass er sie schließlich auch unbewusst ahmt." 465

In diesem Sinne wäre Ahmung ein unbewusstes Nachahmen, das auf einer natürlichen und unwillkürlichen Einfühlung beruht. An einer anderen Stelle spricht sie bezüglich der Ahmung der Tiere von einer Art „Anpassung an die Umwelt" ${ }^{466}$ und nennt als bemerkenswertestes Beispiel das des Chamäleons. In der Biologie wird dieser Anpassungsvorgang „Mimikry“ genannt, derselbe Begriff, den Caillois für eine seiner vier Spielkategorien wählt, die jede Art von Nachahmungs- und Rollenspiel und somit auch das Theater umfasst. Im Prinzip handelt es sich also um dieselbe Kategorie, für die Jünger die Bezeichnung „vorahmend-nachahmende Spiele“ verwendet. Jünger ordnet dieser Kategorie explizit auch die Musik zu und äußert sich entschieden gegen die These, Musizieren gehöre zur Kategorie der Geschicklichkeitsspiele. Geschicklichkeit sei eine notwendige aber keine hinreichende Bedingung, denn „Musik beruht auf Ahmung, und alle bei ihr verwendeten Instrumente sind nicht Spielzeuge, mit denen gespielt wird, sondern Klangkörper, die der Ahmung dienen. “ ${ }^{467}$ Geschicklichkeit ist demnach also nur ein Nebenaspekt des Musikspiels, der je nach Art der Musik mehr oder weniger in den Vordergrund treten kann.

Die Ahmung bzw. Mimikry kann also als eine weitere Gemeinsamkeit zwischen Musik und Spiel aufgefasst werden. In diesem Zusammenhang ist auch die Theorie von Marco de Natale zu erwähnen, der der Musik „capacità illusorie“ 468 zuschreibt, also die Fähigkeit, Zuhörer und Ausführende in eine Imaginationssphäre zu versetzen, die sie selbst herstellt. Auch Oerter bestätigt aus psychologischer Perspektive diese These, denn die Musik schaffe genauso wie das Spiel „eine zweite Realitätsebene, die von der Alltagsrealität abgegrenzt ist“. ${ }^{469}$ In dieser Hinsicht besteht eine deutliche Analogie zu Huizingas Kriterien der Abgegrenztheit der Spielsphäre und des „Anderssein als das gewöhnliche Leben“, aber auch zur Idee der "Zwischenwelten“, zur „Scheinhaftigkeit“ der Spielwelt und zur „Enthebung aus der reellen Weltwirklichkeit,

465 Marylka Bender: Das Geheimnis des ansteckenden Lachens. Über das Phänomen der „Ahmung“. Hg. von Hans Christian Meiser. München 2009, S. $14 f$.

466 Ebd. S. 16.

467 Jünger, S. 67.

468 Marco de Natale: La Musica come Gioco. Il dentro e il fuori della Teoria. Bern 2004, S. 177.

469 Oerter: Psychologie des Spiels. S. 293. 
die bis zur Entrückung, bis zur Verzauberung gehen kann““.470 Diese Entrückung aus der Realität geschieht durch dasselbe „mimetische Spiel“471 und dasselbe „innere Miterleben ", ${ }^{472}$ die Rapp und Groos in Bezug auf das Spiel festgestellt haben. Es kann sowohl bei Zuhörern als auch bei den Ausführenden durchaus auch zu einer Ambivalenz oder einem Wechselspiel zwischen Empathie und Distanz kommen, wobei der Schwerpunkt im Fall der Musik vielleicht eher auf der Seite der Einfühlung verlagert ist, da die Musik die Fähigkeit besitzt, auf einem ganz unmittelbaren Wege die Gefühlsebene des Menschen anzusprechen. Der Psychoanalytiker Helmuth Figdor behauptet diesbezüglich: „Kein Medium (...) reicht wie die Musik so selbstverständlich auch in jenen Teil des Unbewussten hinein, der als nicht (...) bewusstseinsfähig gilt. “473

Bei der Einfühlung kommt es je nach Musikart oder -stück zum Miterleben unterschiedlicher Emotionen. Durch Musik können also Gefühle „wie im Spiel“ durchlebt werden, für die im „gewöhnlichen Leben“ ein realer Anlass fehlt. So wie schon für das Spiel und das Theater festgestellt, können auch in der Musik gewissermaßen "Lebensmöglichkeiten spielend durchkostet" werden. Figdor schreibt der Musik die Fähigkeit zu, ein „affektives Geschehen“ symbolisch ausdrücken zu können, ${ }^{474}$ und stellt diesbezüglich Folgendes fest: „Die Musik bildet einen Übergangsraum (im winnicottschen Sinn), der (...) dem begrifflich nicht Fassbaren die Möglichkeit bietet, sich symbolisch zu gestalten und somit den beteiligten affektiven Regungen sowohl einen Zugang zum Bewusstsein als auch eine Form der Abfuhr zu eröffnen. “475 Es sei kurz daran erinnert, dass mit „winnicottschem Übergangsraum“ ein Bereich gemeint ist, der die „intrapsychische Realität" mit der äußeren Welt verbindet. ${ }^{476}$ Spiel und Musik finden nach Winnicott also - so wie jedes „kulturelle Erleben“ - an demselben „Ort" statt, nämlich im „Spielraum“ zwischen innerer und äußerer Realität.

Die „Abfuhr“, von der Figdor spricht, sowie die damit verbundene Erleichterung werden nicht nur durch Musik bewirkt, sondern verschiedene Theoretiker haben dieselbe Funktion auch in Bezug auf das Spiel festgestellt. Huizinga spricht beispielsweise von der im Spiel stattfindenden „Aufhebung aller Schwere des Lebens, Denkens,

470 Fink: Oase des Glücks. S. 39.

471 Vgl. Rapp: Rolle, Interaktion, Spiel. S. 103.

472 Groos: Das Spiel. Zit. nach Scheuerl: Theorien des Spiels. S. 72.

473 Helmuth Figdor: Die Gefühle und das Musizieren: Musik als überlebendes Symbolsystem sensomotorischen Erlebens. In: Ders. und Peter Röbke: Das Musizieren und die Gefühle. Instrumentalpädagogik und Psychoanalyse im Dialog. Mainz 2008, S. 143.

474 Vgl. ebd. S. 119 und 131.

475 Ebd. S. $132 f$.

476 Vgl. Winnicott, S. 63. 
Handelns“477, Fink bezeichnet die Wirkung des Spiels als „des ,Lebens Leichtwerden““ und als „Lösung von den Gewichten der Daseinslast“ ${ }^{478}$ und Groos führt die kathartische Funktion des Spiels auf die „Befreiung von dem Druck und Zwang des Ernstlebens“ 479 zurück. Plessner erklärt dies etwas genauer: „Spielen macht Freude, weil es uns erleichtert, den alläglichen Druck von uns nimmt und den aufgestauten Bewegungsdrang, dem (in der Jugend besonders starken) Drang nach Betätigung der Einbildungskraft freie Bahn schafft. “480

Figdor stellt eine vergleichbare Wirkung auch im Musik-Erleben fest und begründet dies aus psychoanalytischer Sicht folgendermaßen: „Was ich in einem bestimmten Augenblick bewusst fühle bzw. die bewusste Stimmung, in der ich mich gerade befinde, macht nur einen kleinen Teil meiner affektiven Regungen aus, die vor- oder unbewusst dennoch zu jeder Zeit auf mich einwirken. Die Musik bietet sich an, diese latenten, vom Bewusstsein ferngehaltenen Regungen aufzunehmen (...) und mir in Form bewegenden Kunstgenusses zurückgeben, womit sie im bewussten Erleben einen Platz bekommen, der Erregungsanteil abgeführt werden kann und meine positive Stimmung nicht nur nicht beeinträchtigt, sondern sich durch den Wegfall des (unbewussten) Affektdrucks unter Umständen beträchtlich heben kann. Was das Vorbewusste und Verdrängte betrifft, kann eine solche kathartische Wirkung auch von anderen kulturellen Aktivitäten ausgehen. Kein Medium aber reicht wie die Musik so selbstverständlich auch in jenen Teil des Unbewussten hinein, der als nicht (...) bewusstseinsfähig gilt. “ 481

Huizingas Aussage, Musik entrücke „Zuhörer und Ausführende aus der ,gewöhnlichen' Sphäre in ein Gefühl der Heiterkeit, das auch bei schwermütiger Musik noch Genuß und Erhebung bringt", wird hier also psychoanalytisch untermauert: Musik bereitet in der Regel aufgrund ihrer kathartischen Wirkung Vergnügen, denn durch sie werden latent vorhandene Affekte bewusst erlebt und so unerfüllte affektive Wünsche auf einer „ungefährlichen“ symbolischen Ebene, also wie im Spiel in einem ambivalenten Zustand zwischen Sein und Schein, ausgelebt und entladen.

In der Fähigkeit, auf die eben beschriebene Art Entlastung und Vergnügen zu bereiten, besteht also eine weitere Gemeinsamkeit zwischen Musik und Spiel. Huizinga bemerkt im I 8. Jahrhundert bzw. im Zeitalter des Rokoko, deren „wesenhaftes Kennzeichen“ er gerade in der speziellen „Spielqualität“ sieht, eine besondere Betonung der vergnüglichen und spielerischen Qualität der Musik und der Kunst im Allge-

477 Huizinga, S. 78.

478 Fink: Oase des Glücks. S. 38.

479 Vgl. Groos: Das Spiel. Zit. nach Scheuerl: Theorien des Spiels. S. 72.

480 Plessner, S. 289.

481 Figdor, S. $142 f$. 
meinen. Zur Musik schreibt er: „Auf den Abbildungen von Musikaufführungen aus dem achtzehnten Jahrhundert sieht man die Zuhörer immer in elegantem Gespräch. (...) Die Musik war und blieb in der Hauptsache Divertissement, und die Bewunderung (...) galt vor allem der Virtuosität. " 482 An einer anderen Stelle beschreibt er die Stellung, die die Kunst bis ins I 8. Jahrhundert innehatte: „Kunst war eine vornehme Ausschmückung des Lebens der Bevorzugten. Der ästhetische Genuß wurde ebensogut wie jetzt erlebt, man interpretierte ihn aber in der Regel entweder als religiöse Erhebung oder als eine höhere Art von Kuriosität, die ihr Ziel in Vergnügung und Zerstreuung hatte. " 483

Letzteres gilt erst recht für die Opera buffa im Venedig des I 8. Jahrhunderts, die, wie schon hervorgehoben wurde, nicht nur als Gattung, sondern auch als Veranstaltung Unterhaltung bot. Das Opernhaus als Spielraum, als ideales „Biotop“ für den homo ludens, der - durch das spielfreudige, maskierte venezianische Publikum verkörpert - dort das maximale Vergnügen suchte, wurde schon eingehend geschildert.

Die Oper, die zentrale Attraktion im „Erlebnisraum Opernhaus“, ist gleichzeitig sowohl Theater als auch Musik und vereinigt alle gemeinsamen Merkmale, die schon zwischen Theater und Spiel sowie zwischen Musik und Spiel hervorgehoben worden sind. Alle schon besprochenen Gemeinsamkeiten zwischen Aufführung und Spiel treffen selbstverständlich auch für die Aufführung einer Oper zu: Als Phänomen ,in der Zeit' ist sie genauso wie das Spiel eine „Bewegungsform von besonderer Ablaufsgestalt", ${ }^{484}$ der die Spannung, die Wiederholbarkeit bzw. Wiederholungstendenz, die Flüchtigkeit sowie das „Merkmal der Gegenwärtigkeit“ ${ }^{485}$ eigen sind. Die Ästhetizität bzw. der „ästhetische Faktor “, ${ }^{486}$ den Huizinga im Spiel feststellt, herrscht in der Oper genauso wie in jeder anderen Kunstform vor. Die "Scheinhaftigkeit“ des Spiels bzw. der Spielwelt äußert sich in der Aufführung einer Oper nicht nur in einem „ästhetischen Schein“, sondern auch in einem regelrechten „illusorischen“ Schein, der jedem Theaterspiel aufgrund der Fiktivität der dargestellten Rollen und Handlung eigen ist.

Was das Thema „Identifikation versus Distanz" betrifft, herrscht in der Opera buffa (wie auch in der Komödie) eher eine "theatralische Perspektive“ vor. Allein schon die Unnatürlichkeit des Sprechens im Rezitativ macht eine gewisse Distanz aus, außerdem werden (wie wir später genauer untersuchen werden) in der Opera buffa viele der „distanzierenden Mittel“ verwendet, die das Spiel als solches bewusst werden lassen

482 Huizinga, S. 158.

483 Ebd. S. 191.

484 Scheuerl: Theorien des Spiels. S. $201 \mathrm{f}$.

485 Scheuerl: Das Spiel. S. 95.

486 Huizinga, S. 18. 
und die Zuschauer in eine Distanz zur dargestellten Handlung rücken lassen. Einfühlung und Betroffensein werden zwar nicht so sehr durch eine beinahe vollständige Illusion herbeigeführt, wie es im „dramatischen Theater“ der Fall ist, aber durch die „capacità illusorie“487 und die empathische Wirkung von Musik wird diese Distanz gewissermaßen ausgeglichen. In der Oper können ebenso wie im Spiel Lebensmöglichkeiten symbolisch durchkostet werden, und zwar sowohl wie im Theater über die dargestellten Situationen als auch wie in der Musik über die ausgedrückten Emotionen. Diese beiden Wege sind in der Oper untrennbar miteinander verbunden, genauso wie Text und Musik in einem engen funktionalen Verhältnis zueinander stehen. So wie im Theater und in der Musik kann in der Oper dieses symbolische Erleben von Lebensmöglichkeiten eine kathartische Wirkung haben, die im Fall der Opera buffa zum heiteren Inhalt ein zusätzliches Vergnügungsmoment darstellt.

Die vielfältigen Momente des Spiels der Opera buffa als Veranstaltung sind nun ausführlich besprochen worden. Wenden wir uns nun der Opera buffa selbst als Gattung zu: Auf inhaltlicher Ebene sind ebenfalls eine Fülle von Momenten zu finden, die als Spiel bezeichnet werden können und unter anderem für den unterhaltsamen Charakter der Gattung ausschlaggebend sind. Bevor im Einzelnen auf diese spielhaften gattungsimmanenten Elemente eingegangen wird, soll das System von Konventionen erläutert werden, in denen sie eingebettet sind.

487 de Natale, S. 177. 


\section{Die Gattungskonventionen der Opera buffa ALS „SPIELREGELN“}

Wie eng die Opera buffa als Werk an das Moment der Aufführung gebunden ist, auf die der Schaffensprozess ausgerichtet ist, wurde dargelegt. Mit der Flexibilität des Werks, das im Namen einer höchst pragmatischen Wirkungsästhetik für eine bestimmte Aufführung unter bestimmten Aufführungsbedingungen konzipiert ist und für jede neue Aufführung bearbeitet und verändert werden darf, geht eine strenge und hoch konventionalisierte Regelpoetik einher, die sowohl die Form als auch den Inhalt betrifft. Huizingas für viele Spiele gültige Feststellung eines „genau umschriebenen Kodex von Spielregeln in striktem System mit zwingender Gültigkeit aber endloser Variationsmöglichkeit" ${ }^{488}$ könnte also genauso auf die Opera buffa bzw. ganz allgemein auf die Oper des I 8. Jahrhunderts übertragen werden: Innerhalb eines strengen Systems von ungeschriebenen, aber bindenden Gattungskonventionen öffnet sich ein "Spielraum“, in dem unendliches Variieren möglich ist, wodurch jedes Mal eine neue Aufführung, also aufgrund der großen Bearbeitungsfreiheit auch ein „neues Werk“ entstehen kann, genauso wie sich bei ein und demselben Spiel mit strengen Spielregeln jeder Spielverlauf von den übrigen unterscheidet. Demnach würden also gerade die vorgegebenen Konventionen diesen Spielraum abstecken, innerhalb dessen ein unendliches Variations- bzw. Kombinationsspiel stattfinden kann.

„Non sapete dunque che il dramma in musica è un'opera imperfetta, sottoposta a regole e usanze che sono prive, è vero, di senso comune, ma che devono essere applicate alla lettera. (...) vi sono regole per ogni cosa, e sarebbe un delitto di lesa drammaturgia se si osasse infrangerle, se non si volesse osservarle. " ${ }^{889}$

Dieses Zitat aus den Memoiren Goldonis, der bedeutendsten Persönlichkeit der Buffa-Libretto-Literatur und Bezugspunkt für viele Buffa-Librettisten der späteren Jahrzehnte, ist nicht das einzige Zeugnis dafür, dass in der zweiten Hälfte des I 8 . Jahrhunderts die Erstellung einer Oper ungeschriebenen, aber bindenden Regeln und Bräuchen unterlag, die unter keinen Umständen missachtet werden durften. Verschiedene Quellen lassen die Strenge dieses Regelsystems erahnen: In erster Linie sind es die Werke selbst, die (wenigstens aus heutiger Sicht) den Eindruck einer starken

488 Huizinga, S. 132. Ähnliches stellt auch Buytendijk fest: „Innerhalb der Grenzen der Spielregeln hat man Freiheit des Handelns und das Spiel kann also die unberechenbare Abwechslung zeigen, welche seiner Dynamik entspricht. Das ist gerade ein Merkmal des Spiels, dass es innerhalb gewisser Grenzen unbestimmt ist, undeterminiert, im Gegensatz zu bestimmten Handlungen, (...) deren Ablauf bis ins Einzelne vorgeschrieben ist." (Buytendijk, S. 119).

489 Goldoni: Memorie. Con un appendice di scritti goldoniani. S. 128. 
Stereotypie erwecken, da sie nach immer gleich bleibenden Mustern aufgebaut zu sein scheinen. Abgesehen von der Konventionalität der Werke wird in zeitgenössischen Quellen immer wieder die Anwesenheit von streng zu befolgenden Regeln erwähnt. Wie wenig in der Opernpraxis ein Abweichen davon geduldet wurde, geht beispielsweise aus einer Anekdote in Goldonis Memoiren hervor. Im Vorwort des I I. Bandes der venezianischen Edition seiner Werke erzählt Goldoni von einem seiner ersten Versuche, ein Opernlibretto zu verfassen und von der naserümpfenden Reaktion einiger Sänger in Mailand und der Zurechtweisung eines gewissen „Conte Prata Cavalier Milanese, gran conoscitore del Teatro, e dilettante di musica e di poesia teatrale“, von dem auch die oben zitierte Feststellung stammt:

„La vostra Opera, se fosse scritta diversamente, potrebbe essere una buona Tragedia; ma il Dramma per musica, ch'è per se stesso un Componimento imperfetto, è stato suggettato dall'uso a delle regole, contrarie, egli è vero, a quelle di Aristotile, di Orazio e di tutti quelli che hanno scritto della Poetica, ma necessarie per servire alla Musica, agli Attori e ai Compositori. Il profondo Apostolo Zeno, il melifluo, elegante e dottissimo Metastasio si sono a queste regole conformati, e quel che parrebbe difetto in una regolata Tragedia, diviene bellezza in un Dramma per musica. Leggete con attenzione i due Autori suddetti, comprenderete a poco presso che cosa è il Dramma di cui parliamo, e ne rimarcherete le regole. Io ve ne additerò alcune delle più materiali, la mancanza delle quali ha disgustato i Musici che vi ascoltavano. Il primo Soprano, la prima Donna e il tenore, che sono i tre principali Attori del Dramma, devono cantare cinque arie per ciascheduno, una patetica, una di bravura, una parlante, una di mezzo carattere ed una brillante. Il secondo Uomo e la seconda Donna devono averne quattro per uno, e l'ultima parte tre, ed altrettante il settimo personaggio, se l'Opera lo richiede; poiché (per parentesi) i personaggi non devono essere mai più di sei o sette, e voi ne avete nove nel vostro Dramma. Le seconde parti pretendono anch'esse le arie patetiche, ma le prime non lo permettono, e se la Scena è patetica, l'aria non può essere che al più al più di mezzo carattere. Le quindici arie dei primi Attori devono essere distribuite in maniera, che due non si succedano dello stesso colore, e le arie degli altri Attori servono per formare il chiaro scuro. Voi fate cantare un personaggio che resta in Scena, e questo è contro le regole. Voi all'incontro fate partire un Attor principale senz'aria, dopo una Scena di forza, e questo ancora è contro le regole. Voi non avete nel vostro Dramma che tre cambiamenti di Scena, e ve ne vogliono sei o sette. Il terzo Atto del vostro Dramma è il migliore dell'Opera, ma questo ancora è contro le regole ..." 490

490 Carlo Goldoni: Prefazione al tomo XI all'edizione veneziana G.B. Pasquali. In: Ders.: Il teatro comico. Memorie italiane. S. $162 \mathrm{f}$. 
Goldoni berichtet ferner von seiner entsetzten Reaktion auf diese Auflistung einengender und aus seiner Sicht merkwürdiger regole, die zwar für das dramma per musica, also die Opera seria, etabliert waren, aber zum Großteil auch auf die Buffa angewandt und mit einigen Abänderungen an den komischen Inhalt angepasst wurden.

Der Conte Prata erklärt zunächst, dass für die Oper spezifische Regeln gelten, die denen des Sprechtheaters (Horaz, Aristoteles) widersprechen, aber der Musik, den Sängern und den Komponisten zugutekommen. Das Libretto steht also im multimedialen Phänomen Oper in einem funktionalen Zusammenhang zu den restlichen Elementen, in erster Linie zur Musik und zur Gesamtperformance. Den Konflikt der Libretto-Autoren zwischen dem Regelwerk, dem rein literarische Texte unterliegen, und den Vorgaben der Sänger und Komponisten, die einen absoluten Vorrang beanspruchen, erwähnt mit einem satirischen Unterton auch Arteaga in den Anweisungen eines fiktiven Impresario an seinen Librettisten: „Voi altri poeti avete certe regole di stile che vi fanno lambiccar il cervello per tornire acconciamente un periodo. Si dice, che v'abbia con i suoi precetti comunicata cotal malattia contagiosa un maestro dell'arte, chiamato Orazio, e che i greci, e i francesi v'abbiano fornito l'esempio. Quanto a me vi dispenso volentieri dalla eleganza, e se vi piace, anco della grammatica, insegnandomi l'esperienza che si può senza l'una e senza l'altra riscuoter sul teatro un durevole applauso." ${ }^{991}$

Arteagas pragmatischer Impresario empfiehlt seinem Librettisten außerdem, sich auf keinen Fall an die „leggi di Aristotele“ zu halten, „le quali nulla han che fare coll'opera“, denn „il teatro non ha altra poetica che quella delle usanze.“492

Diese „usanze“ 493 bilden also die ungeschriebenen Regeln des dramma per musica, die der Conte Prata dem in der Opernpraxis noch unerfahrenen Goldoni aufzählt: Die Anzahl der Personen ist geregelt und auf sechs bis sieben beschränkt. Diese Regel gilt nicht nur für die Opera seria, sondern auch für die Buffa, denn eine compagnia bestand in der Regel aus sieben Personen, meistens vier Männer und drei Frauen. Traten seltenerweise acht Figuren auf, wurden oft zwei von einem einzigen Sänger interpretiert. Im venezianischen Repertoire sind auch einige Opern mit lediglich vier oder fünf Rollen zu finden. Dabei handelt es sich entweder um farse oder um aus Rom importierte zweiteilige Intermezzi, die dort als Zwischenspiele in den Pausen von dreiaktigen Schauspielen aufgeführt wurden, während dieselben Opern in Venedig (manchmal mit einer zusätzlich hinzugefügten Figur ohne dramaturgisch rele-

491 Arteaga, Bd. 3, S. 144.

492 Ebd. S. $144 f$.

493 Wie stark der Opernbereich vom Usus und von der Praxis geprägt ist, zeigt auch folgende kategorische Aussage aus Galeazzis Musiktraktat Elementi teorico-pratici di musica: „L'Arte di Teatro non si può insegnare, e solo si acquista colla pratica." (Galeazzi, Bd. 2, S. 297). 
vante Funktion) häufig als abendfüllendes spettacolo verwendet wurden, dessen Pause zwischen dem ersten und dem zweiten Teil wie die meisten Zwischenaktpausen im venezianischen Opernbetrieb mit einem Ballett „ausgefüllt“ wurde.

Aus der Belehrung des Conte Prata geht auch hervor, dass die Dramaturgie im starken Maße von den „Regeln der Produktion“ abhängig ist: Haupt- und Nebenrollen haben Anspruch auf eine durch Regeln festgelegte Anzahl von Arien, wobei in der Buffa unter diesem Aspekt etwas mehr Flexibilität zu herrschen scheint als in der Seria; bestimmte Rollen sind mit spezifischen Stimmfächern zu besetzen und sind mit konventionellen Arientypen verbunden. In diesem Zusammenhang erwähnt Conte Prata ein bemerkenswertes Detail, nämlich dass die prime parti (um ihre Stellung in der Hierarchie zu bewahren) den secondi nicht erlauben, arie patetiche zu singen. In der Buffa wird es vermutlich ähnlich zugegangen sein, auch wenn es wahrscheinlich nicht um pathetische Arien ging, sondern um andere Arten von effektvollen Arien, woran erneut die Allmacht der Star-Sänger und ihr Einfluss auf die Komposition und folglich auf die Dramaturgie eines Werkes ersichtlich wird. ${ }^{494}$

Die Aufeinanderfolge der Arien ist nach dem chiaroscuro-Prinzip geregelt: Kontrast und Abwechslung im colore heben die vielen Arien voneinander ab und verleihen ihnen eine stärkere Wirkung.

Nicht nur die Anzahl der Personen und ihrer Arien ist vorgeschrieben, sondern selbst die Zahl der cambiamenti di scena unterliegt einer impliziten Regel.

Die Regel, die Goldoni die Geduld verlieren lässt, ist die, dass der dritte Akt nicht besser sein darf als die beiden anderen. Diese merkwürdige Konvention wird auch von Arteagas fiktivem Impresario bestätigt: „L'ultimo atto; basta che sia curto, che non vi si frammezzino arie d'impegno, nè decorazioni importanti, e che i personaggi alla perfine si rappattumino insieme così che ogni cosa fornisca amichevolmente. Mi direte, che ciò non si conviene, e che anzi l'ultimo atto dovrebbe essere il più vivo e in-

494 Die absolute Priorität der Hierarchie der Sänger bestätigen die Worte von Arteagas fiktivem Impresario: „Sapete qual carattere devono avere le prime due parti. Al terz'uomo, ovvero sia al tenore darete carattere sostenuto di padre, di vecchio, di geloso, di mercante Olandese, o di qual più v'aggradi. Se colui che fa la parte del padre ha quindici o vent'anni meno del figliuolo poco mi cale. Il viso acconciamente forbito, il rossetto in buona dose, e la lontananza aggiusta ogni cosa. (...) v'avvisarete di fare, che il primo uomo sia innamorato della prima donna, e il secondo della seconda; senza codesta legge non ci sarebbe verso di contentare le mie virtuose, le quali vogliono ad ogni modo smaniare un tantino in presenza del pubblico." (Arteaga, S. 147) Selbst der Inhalt muss sich also an diese Regeln der Hierarchie anpassen, denn primo nomo und prima donna müssen ein Paar bilden sowie seconda donna mit secondo uomo. Es kommt nicht in Frage, dass eine secondo-Rolle sich in eine prima verliebt. Um die Hierarchie der Sänger zu befolgen, werden sogar in Bezug auf das physique du rôle absurde Situationen geduldet. Arteagas Impresario nennt das Beispiel einer Vaterrolle, die von einem Sänger besetzt wird, der 15 bis 20 Jahre jünger ist, als der Sänger, der seinen Sohn interpretiert. 
calzante. Ma coteste sono sottigliezze dell'arte, nelle quali non me ne intrico. Quello, ch'io so è, che fornito il secondo ballo, l'uditorio va via, e che i suonatori e virtuosi non vogliono più faticare. “495

Der dritte Akt soll nicht anspruchsvoll sein, denn nach dem zweiten ballo in der Pause zwischen dem zweiten und dem dritten Akt verlässt das Publikum üblicherweise den Saal. Vielleicht erklärt das die Tendenz, den dritten Akt immer mehr zu verkürzen, bis man ab der Mitte der I770er Jahre anfing, ihn vollkommen zu streichen. Ab I 777 begannen in Venedig zweiaktig konzipierte Opern zu überwiegen und ab I780 wurden fast ausschließlich zweiaktige Buffe zur Aufführung gebracht. Ausnahmen bildeten die Wiederaufnahmen von früher entstandenen Werken, wobei selbst dann der dritte Akt in einigen Fällen - ohne Bearbeitung des zweiten Finales! - einfach weggelassen wurde. Die Zweiaktigkeit wurde offenbar so konventionell, dass sogar eine ungelöste Handlung im Namen der strafferen zweiaktigen Form in Kauf genommen wurde. Dies geschah nicht nur bei wiederaufgenommenen Opern, wie beispielsweise „Il geloso in cimento“, sondern auch bei venezianischen Erstaufführungen von „importierten“ Opere buffe namhafter Komponisten, wie Anfossis „La finta giardiniera“ oder Sartis „Fra i due litiganti il terzo gode“. Auf der letzten Seite des Librettos zur Wiederaufnahme der Oper „Il geloso in cimento“ am Teatro San Moisè im Jahr I784 befindet sich folgende unsignierte Bemerkung zur Streichung des dritten Aktes: "L'uso invalso da qualche tempo di ristringere le Rappresentazioni di questo genere a due soli Atti, trovandosi anche di maggior comodo al Pubblico, fa che si ometta l'Atto Terzo di questo Dramma; resterebbe perciò l'Azione indecisa, e dovrebbe terminare col matrimonio fra D. Flavia, e D. Fabio, come si trova nel Dramma stampato nel I774, la qual cosa non potevasi far seguire nell'Atto Secondo senza cambiar il Finale, la Musica del quale ha fatto molto piacere al Pubblico, ed è uno de' più bei parti del rinomato Sig. Maestro Anfossi."

Der Geschmack des Publikums wird hier sowohl als Grund für die Verkürzung der Oper auf zwei Akte als auch für das Ausbleiben einer Adaptierung des besonders beliebten zweiten Finales genannt. Nur im Falle der zehn Jahre früher in Venedig uraufgeführten Oper „Il geloso in cimento“ wurde offensichtlich die Notwendigkeit einer (wenn auch sehr indirekten) Rechtfertigung für die unschlüssige Handlung verspürt, während die anderen beiden genannten Opern kommentarlos - wenigstens ohne schriftlichen Kommentar - ohne den dritten Akt aufgeführt wurden.

Die aus der Opera seria übernommene und zunächst als unumstößlich geltende Regel der Dreiaktigkeit ${ }^{496}$ wurde also weitgehend durch die publikumswirksamere

495 Arteaga, S. 150.

496 Vgl. unten Barettis Zitat. 
zweiaktige Form verdrängt, wodurch sich selbstverständlich Verschiebungen in der Gesamtdramaturgie ergaben.

Dass die Dreiaktigkeit zu den festen Regeln der Oper zählte, wird im nun folgenden Zitat von Baretti aus der Zeitschrift „La frusta letteraria“ bestätigt. Etwa zur selben Zeit wie Goldoni beklagt sich Baretti über die strikten Regeln des dramma per musica, die den Autoren keinerlei künstlerische Freiheit gestatten. Diesen Konventionszwang bringt Baretti mit der nachdrücklich wiederholten Wendung „è forza“ zum Ausdruck.

„(È) forza che il poeta (...) abbia riguardo alla musica e alle ristrette facoltà di quella (...). ( (̇) forza che ogni dramma non oltrepassi un certo numero di versi, e che sia diviso in tre soli atti, e non in cinque, come le aristoteliche regole richiederebbono. È forza che ogni scena sia terminata con un'aria. È forza che un'aria non esca dietro un'altra dalla bocca dello stesso personaggio. È forza che tutti i recitativi sieno brevi, e rotti assai dall'alterno parlare di chi appare in iscena. $\grave{E}$ forza che due arie dello stesso carattere non si sieguano immediatamente, ancorchè cantate da due diverse voci, e che l'allegra, verbigrazia, non dia ne' calcagni all'allegra, o la patetica alla patetica. $\grave{E}$ forza che il primo e second'atto finiscano con un'aria di maggior impegno che non l'altre sparse qua e là per quegli atti. È forza che nel secondo atto si trovino due belle nicchie, una per collocarvi un recitativo romoroso seguito da un'aria di trambusto, e l'altra per collocarvi un duetto o un terzetto, senza scordarsi che il duetto dev'essere sempre cantato dai due principali eroi, uno maschio e l'altro femmina. Queste ed alcune altre leggi de' drammi appaiono ridicole alla ragion comune d'ogni poeta; ma chi vuole conformarsi alla privata ragione de' drammi destinati al canto è d'uopo si pieghi a tutte queste leggi non meno dure che strane, e che badi ad esse più che non alle stesse intrinseche bellezze della poesia. “ 497

Barettis Regeln beziehen sich wie die des Conte Prata Cavalier Milanese auf das dramma per musica, können aber zum Großteil auch auf das dramma giocoso übertragen werden. Abgesehen von den schon besprochenen regole, kommen hier weitere hinzu, beispielsweise die Höchstgrenze in der Gesamtanzahl der Verse, die übliche Position der Arien am Ende einer Szene (Abgangsarie ${ }^{498}$ ) und die erwünschte Kürze

497 La frusta letteraria. Venedig 1763. In: Giuseppe Baretti: Opere. S. 311f. Zit. nach Feldman, S. 10.

498 Dass die Arien, in der Seria wie in der Buffa, in der Regel Abgangsarien sind, erwähnt auch Arteagas fiktiver Impresario : „Avrete cura di fare, che tutti gli attori abbandonino il teatro dopo aver cantato le loro ariette, e che verso la fine dell'atto vadino sfilando a poco a poco. Cotal costume mi piace assai ed è caratteristico dell'opera.“ (Arteaga, S. 150) In der metatheatralischen Oper „L'opera seria“ von Calzabigi und Gassmann nennt der Poeta ebenfalls diese Regel und bezeichnet sie sogar als legge, als Gesetz: „Stupisco che non sa / La legge impreteribile dettata / Da più antichi Licurghi / Del musico Teatro: un Personaggio / Per quanto va di fretta / Di Scena non può uscir senza l'arietta." (Calzabigi/ 
und dialogische Form der Rezitative. Baretti bestätigt, dass das Aufeinanderfolgen zweier Arien desselben Charakters verboten ist, und fügt hinzu, dass auch zwei Arien derselben Person nicht aneinandergereiht werden dürfen, selbst wenn ihre Stimmung unterschiedlich ist.

Die Regel, nach der die Arie am Schluss des ersten und zweiten Aktes anspruchsvoller sein soll als die übrigen Arien, gilt zwar nur für die Seria, aber auch in der Buffa ist die Tendenz feststellbar, vor den Finali eine besonders wirksame Arie zu positionieren.

Dass die Duette ausschließlich von der prima donna und dem primo nomo gesungen werden dürfen, ${ }^{499}$ gilt ebenfalls eher für die Opera seria; dasselbe trifft auch für das in der Buffa obligatorische Liebesduett vor dem Schlusschor des dritten Aktes zu. An anderen Stellen werden gelegentlich andere Arten von Duetten eingefügt, die aber tendenziell auch von in der Rollenhierarchie höherstehenden Personen interpretiert werden.

Barettis Schlussbemerkung, die Goldonis bzw. Conte Pratas Feststellung entspricht, bekräftigt das Gebot der strengen Einhaltung der genauso wie von Arteaga leggi, also „Gesetze“, genannten Regeln, obwohl sie den Dichtern „hart“ und merkwürdig („,non meno dure che strane“) sowie lächerlich („ridicole“) erscheinen.

Viele weitere ungeschriebene Regeln lassen sich - obwohl sie nicht explizit in zeitgenössischen Quellen formuliert werden - aus den Libretti und Partituren ableiten, die immer denselben Mustern zu folgen scheinen.

\begin{tabular}{|c|c|}
\hline Sinfonia & 3 Sätze (später 1 Satz) \\
\hline I. Akt & $\begin{array}{l}\text { Introduzione } \\
\text { Abfolge Rezitativ + Arie } \\
\text { evt. cavatine, Accompagnato-Rezitative, Ensembles } \\
\text { I. Finale }\end{array}$ \\
\hline 2. Akt & $\begin{array}{l}\text { Abfolge Rezitativ + Arie } \\
\text { evt. cavatine, Accompagnato-Rezitative, Ensembles } \\
\text { 2. Finale }\end{array}$ \\
\hline $\begin{array}{l}\text { 3. Akt (fällt ab den späten } \\
\text { I77oer Jahren häufig weg) }\end{array}$ & $\begin{array}{l}\text { Abfolge Rezitativ + Arie } \\
\text { Liebesduett } \\
\text { Schlusschor }\end{array}$ \\
\hline
\end{tabular}

Gassmann: L'opera seria. Wien 1769. II,6).

499 Die Strenge dieser Regel bestätigt auch Arteagas fiktiver Impresario: „(...) duetto, il quale, come sapete, appartiene esclusivamente al primo uomo e alla prima donna. Guai se venisse cantato da altri che da loro! Nascerebbe un dissidio poco minore di quello che accese in altri tempi i Geminiani contro ai Petroniani per la Secchia rapita." (Arteaga, S. 149). 
Goldoni, Baretti und Arteaga nennen an den zitierten Stellen Regeln, die vor allem die Form einer Oper betreffen, auf die der Dichter Rücksicht nehmen muss. Der Inhalt eines Dramas muss sich also an ein konventionelles Schema halten (s. Tabelle S. I I 5).

Der Dichter muss den Text im Hinblick auf die Vertonung verfassen und außer der Unterteilung in Rezitative, Arien und Ensembles und der Beachtung der Konventionen der Metrik ${ }^{500}$ die Handlung an dieses von der Opera seria abgeleitete Formschema anpassen, das jeglicher sich natürlich ergebender Dramaturgie übergeordnet ist.

Die Verknüpfung von Inhalt (Motiven), Text (Metrik, Form), Dramaturgie und Musik folgt bestimmten gattungsspezifischen Konventionen, so dass sich daraus typische „Bausteine“ oder Topoi ergeben. Der Zeitdruck, unter dem im I 8. Jahrhundert Opern komponiert wurden - Manfredini spricht von einer durchschnittlichen Zeit von I 8 bis 20 Tagen $^{501}$ und führt die schlechte Qualität der Stücke unter anderem auf diesen Umstand zurück -, hängt mit der Praxis zusammen, standardisierte „Versatzstücke“ zusammenzustellen.

Die Konventionalität betrifft zunächst die Stoffe der Opera buffa, die vorwiegend aus der Komödie bzw. Commedia dell'arte stammen. Die vor allem aus der Alltagssphäre entnommenen Handlungen drehen sich um die Themen Liebe, Heirat, Rivalitäten, zwischenmenschliche Konflikte, Standesunterschiede und entsprechende Verhaltensweisen, wobei das häufigste Grundmuster das der Brautwerbung mit Hochzeit oder Eheversprechen am Schluss abgibt. Ebenso beliebt ist das Muster der Verlachkomödie, in der lasterhafte Eigenschaften wie Eifersucht, Geiz, Habgier, Neugier, Dummheit, Hochmut, Eitelkeit, Leichtgläubigkeit, oder Gegebenheiten wie cicisbeismo und „moderne Sitten“ nach französischem Vorbild, Drang zum gesellschaftlichen Aufstieg, (falsche) Gelehrtheit, Frauenhass etc. lächerlich gemacht

500 Rezitative sind in der Regel in Siebensilblern und Elfsilblern verfasst, während das häufigste Versmaß für geschlossene Musiknummern der Achtsilbler ist. Auch Fünf- und Siebensilbler finden immer wieder Verwendung, Sechs-, Zehn- und Elfsilbler sind dagegen etwas seltener. Bei zwei- oder mehrteiligen Arien und Ensembles beruht der Takt- und Tempowechsel fast immer auf einem Wechsel des Versmaßes, wodurch eine Aneinanderreihung blockhafter Abschnitte entsteht. Zur Metrik der Opera buffa siehe Giovanni Polin: Introduzione. In: Carlo Goldoni: Drammi comici per musica (1748-1751). Hg. von Silvia Urbani. Venedig 2007, S. 41f. Zu den seltenen Arien im Elfsilbler und ihren Wurzeln in der Volksdichtung siehe Wolfgang Osthoff: Gli endecasillabi villottistici in „Don Giovanni" $e$ "Nozze di Figaro". In: Maria Teresa Muraro (Hg.): Venezia e il melodramma nel settecento. Florenz 1981, S. 293-311.

501 „(...) quelle Opere, siano buffe, o serie, scritte in diciotto, o venti giorni, da certi maestri ..." (Manfredini, S. 134). 
werden. ${ }^{502}$ Besonders häufig ist auch die Verknüpfung beider Motive, wobei meist „hindernde Personen“ (Väter, Vormünder oder Rivalen) die besagten Eigenschaften besitzen und zum Schluss von den schlaueren jungen innamorati hereingelegt und ausgelacht werden. Betrifft die Handlung schon verheiratete Paare, dann wird die Ehe durch Liebhaber (cicisbei) oder unbegründete Eifersucht gestört; der Konflikt endet in solchen Fällen meistens mit einem Friedensschluss und gelegentlich mit der Hochzeit von Nebenfiguren. Stets kommt es nach der größtmöglichen Verwirrung (imbroglio) zur Wiederherstellung der Ordnung und der Ruhe in einem lieto fine.

Einen Sonderfall, der durch seine Beliebtheit auch konventionell wurde, bildet der larmoyante Strang der Opera buffa, vornehmlich der „Cecchina-Stoff“. Dieser erntete durch Piccinnis Vertonung von „La buona figliuola“ ( 760 ), dessen Libretto Goldoni schon 1757 für Egidio Romualdo Duni in Anlehnung an Samuel Richardsons Roman „Pamela, or Virtued rewarded“ (I740) verfasst hatte, einen riesigen Erfolg und wurde daraufhin nicht nur mehrfach vertont, sondern auch als Vorlage für unzählige neue Libretti verwendet. ${ }^{503}$ Es handelt sich dabei um die Geschichte eines gemein geglaubten Mädchens, das trotz seiner Güte und seines Edelmuts von allen zu Unrecht beschuldigt und schlecht behandelt wird, bis zum Schluss seine Unschuld und seine adelige Herkunft bewiesen werden, wodurch die Hochzeit mit dem Geliebten von hohem Stande ermöglicht wird. Der Standesunterschied, der im Gegensatz zur englischen Vorlage ein Hochzeitshindernis darstellt, wird dabei in der Buffa durch das typische dramaturgische Mittel der Anagnorisis getilgt. ${ }^{504}$

Die Standeszugehörigkeit (cavaliere, contessa, servo, contadina) zählt neben den spezifischen Eigenschaften zu den wichtigsten Charakterisierungen der Personen, denen

502 In den theoretischen Schriften der Zeit wird ausführlich erläutert, welche Arten von menschlichen Schwächen thematisiert werden dürfen. Planelli unterscheidet beispielsweise zwischen großen/tragischen und leichten/komischen Schwächen. Nur Letztere eignen sich für die Komödie bzw. die Opera buffa und können durch Lachen bzw. Auslachen verbessert werden: „Il bersaglio adunque, che l'Opera Comica musicale prenderà di mira, sono que' leggieri difetti, che si oppongono, come sogliam dire, al Galateo: una donna vana, un saccentino, una salamistra, un tagliacantoni, un affettato, ed altri caratteri equivalenti. Questi sono i vizi, contro i quali il riso è l'antidoto più possente, $\mathrm{e}$ più efficace, i vizi comici, e che non possono essere esposti che in Commedia." (Planelli, S. 269).

503 Im venezianischen Repertoire der 1770er und 1780er Jahre findet man dieses Handlungsmuster beispielsweise in Gazzaniga: La vendemmia. Venedig 1778; Petrosellini/Anfossi : L'Incognita perseguitata. Venedig 1778; Anfossi: La Pescatrice fedele o La Vera costanza. Venedig 1783.

504 Goldoni erklärt in seinen Memoiren die Motivation dieser Änderung: „,...) le but moral de l'auteur anglais ne conveneait pas aux mœurs et aux lois de mon pays. A Londres, un Lord ne déroge pas à la noblesse en épousant une paysanne; à Venise, un patricien qui épouse une plébéienne, prive ses enfans de la noblesse patricienne." (Zit. nach Ruth Müller-Lindenberg: Weinen und Lachen. Dramaturgie und musikalisches Idiom der Opéra-comique im Vergleich zur Opera buffa (1750-1790). Berlin 2006, S. 56). 
im Personenverzeichnis auch einige Grundzüge der Handlung, z. B. Betrüger- und Betrogenen-Rolle zugeordnet sind, woraus man den Handlungsverlauf im Vorhinein erahnen kann.

Eine gängige „Regel“ zur Typisierung von Figuren und Situationen legt Arteaga seinem fiktiven Impresario in den Mund: „Ho sentito dire altresì, che il ridicolo comico dev'essere cavato dalla esperienza non tratto dalla fantasia, che si devono studiare profondamente gli uomini prima d'esporli sul teatro, che le debolezze di temperamento non i vizj di riflessione, i difetti nati da una stranezza di pensare innocenti non i delitti odiosi e nocivi sono la materia propria della scena comica, che questa materia dee rappresentarsi abbellita da un colore alquanto caricato e forte ma non esagerato (...). “505

Dass es sich um aus dem Alltag gegriffene und überspitzt charakterisierte, aber nicht übertrieben dargestellte Figuren und Situationen handelt, bestätigt auch Giovanni Gherardo De Rossi in seinem Trattato sull'arte drammatica (1790), in dem er unter anderem die Regel erklärt, nach der ein „,ingrandimento dei caratteri“ erfolgen soll: „In luogo di caricare, e d'ingrandire un carattere vizioso, o difettoso alterando le azioni viziose, o difettose oltre i comuni limiti di ciò che vediamo frequentemente accadere; pare a me, che l'ingrandimento dei caratteri possa ottenersi moltiplicando con avvedutezza i tratti più verosimili del vizio, o del difetto, e riunendoli in un soggetto solo, che resta ingrandito del tutto; ma non eccede poi i limiti della natura nelle parti separate. Le diverse, ma sempre verisimili sordidezze di molti avari si radunino con buon giudizio, e con naturalezza in un solo avaro (...) “506

An dieser Stelle sei kurz an Arteagas Kritik an dem Gefälle zwischen Theorie und Praxis erinnert. Tatsächlich scheinen sich die Autoren, nach den Werken zu urteilen, meist sehr eng an konventionelle standardisierte Muster gehalten zu haben und nicht so sehr, wie es Giovanni Gherardo De Rossi fordert, an die Regel der Zusammenfassung von natürlichen Zügen und Eigenschaften. Einige Beispiele von Arteagas fiktivem Impresario verdeutlichen die starke Typisierung der Figuren der Opera buffa:

„Il teatro non ha altra poetica che quella delle usanze, e poichè queste vogliono, che deva ognor comparir sulle scene un martuffo con un visaccio da luna piena, con una boccaccia non differente da quella de' leoni che si mettono davanti alla porta d'un gran palazzo con parruccone convenzionale, e con un abbigliamento, che non ha presso alla civile società nè originale nè modello; poichè è deciso, che cotal personaggio ridicolo abbia ad essere ognora un padre balocco, od un marito sempre geloso e

505 Arteaga, S. 145.

506 Giovanni Gherardo De Rossi: Commedie I. Bassano 1790, S. III. Zit. nach Guido Nicastro: Goldoni e il teatro del secondo Settecento. 3. Aufl. Bari 1986, S. 117. 
sempre beffato, od un vecchio avaro, che si lascia abbindolare dal primo che gli sa destramente piantar le carote, poichè il costume comanda, che per tariffa scenica devano mostrarsi in teatro ora un Olandese col cappello alla quakera, che sembri muoversi colle fila di ferro a guisa di burattino, ora un francese incipriato e donnajuolo, che abbia nelle vene una buona dose d'argento vivo, ora un goffo tedesco, che non parli d'altro che della sciabla e della fiasca, ora un Don Quisciotte spagnuolo, che cammini a compasso come figura geometrica, pieno di falsi puntigli, ed abbigliato alla foggia di due secoli addietro; poichè insomma tutto ha da essere stravagante, esagerato, eccessivo e fuori di natura, voi mi farete la grazia d'accomodarvi mandando al diavolo quanti precettori v'ammonissero in contrario."507

Arteagas Impresario beschreibt einige typische „Exemplare“ von buffi caricati, die prädestinierten Opfer einer Burla (dumme Väter, übertrieben eifersüchtige Ehemänner oder alte Geizhälse) und karikierte Vertreter verschiedener Nationalitäten (den steifen holländischen Kaufmann, den galanten französischen Libertin, den gewalttätigen betrunkenen Deutschen und den altmodischen Spanier), wie sie in unzähligen Opere buffe vorkommen.

Die aus der Commedia dell'arte stammende Behandlung der Figuren nach einfach und klar umrissenen Typen wird beispielsweise auch in einer Passage aus „Le finte gemelle“ von Piccinni und Petrosellini deutlich, in der wenige Worte zur Skizzierung vier verschiedener Rollen genügen: zwei buff caricati („due sciocchi, sbarcati adesso di provincia") und zwei Frauenrollen, die die schlaue Isabella zu spielen plant, um den beiden „sciocchi“ einen Streich zu spielen:

$\begin{array}{ll}\text { Isabella: } & \text { Il loro debole, } \\ & \text { Il carattere qual'è? } \\ \text { Olivetta: } & \text { Guerriero è l'uno } \\ & \text { L'altro fa l'uom di corte. }(\ldots) \\ \text { Isabella: } & \text { Voglio con uno fingermi } \\ & \text { Zitelluccia innocentina } \\ & \text { Che si vergogni di parlar. (...) } \\ & \text { Con quell'altro } \\ & \text { Fingerò d'esser vedova } \\ & \text { Che sospiri, che pianga } \\ & \text { Il perduto consorte. }{ }^{508}\end{array}$

507 Arteaga, S. $145 f$.

508 Petrosellini/Piccinni: Le finte gemelle. Venedig $1783(\mathrm{I}, 4)$. 
Diese bündige Rollenbeschreibung erinnert an die Angaben in den canovacci der Commedia dell'arte. Schauspieler und Zuschauer verstehen, auf welche Typen Isabella und Olivetta anspielen: Der "guerriero“ ist vermutlich ein aufschneiderischer, eingebildeter capitano, eine typische Figur aus der Commedia dell'arte, der andere, der den „uom di corte“ spielt, ein affektierter, Französisch sprechender Galan, der sich nach französischer Art benimmt. Diesen Rollentypen entsprechen nicht nur gewisse Verhaltensmuster und sprachliche Ausdrucksweisen, sondern auch bestimmte musikalische Topoi, beispielsweise einzelne Arientypen: Der capitano wird mit großer Wahrscheinlichkeit eine „militärische Arie“ singen, deren Inhalt vorwiegend aus Kriegsmetaphern besteht, wobei der stolze und triumphierende Ton und Gestus durch den sonst unüblichen Trompetenklang unterstrichen wird, deren Musik voraussichtlich in C- oder D-Dur (u. a. wegen der Stimmung der Trompeten) und im 4/4-Takt (oder jedenfalls in einer geraden Taktart) steht, womöglich mit „Maestoso“ als Tempobezeichnung. Selbstverständlich singt ein capitano nicht ausschließlich solche Arien, aber sie sind häufig genug, um von einem Topos und bei den genannten Eigenschaften einer solchen Arie von Regeln bzw. Konventionen sprechen zu können.

Dieses Beispiel soll nur einen kleinen Einblick in die Regelpoetik der Gattung Opera buffa vermitteln, die durch ein regelrechtes Netz von Topoi gekennzeichnet ist, in denen sich Motive, Rollentypen, Arientypen, sprachliches und musikalisches Idiom vielfach verknüpfen. Auf einige dieser Topoi, insbesondere die, die eine Verbindung mit dem Spiel aufweisen, wird später in einzelnen Kapiteln und anhand von konkreten Beispielen näher eingegangen. Eine vollständige Erfassung des der Opera buffa zugrundeliegenden Regelsystems ist aufgrund der Vielfalt an Konventionen beinahe unmöglich, deshalb soll lediglich ein kurzer Überblick über die konventionellsten Figuren und ihre Verbindung zu einigen musikalischen „Grundregeln“ folgen.

Die typischsten Personenkonstellationen der Opera buffa entstammen der Commedia dell'arte, in der fixe Rollen, einige davon einer charakteristischen Maske zugeordnet, in folgende Kategorien unterteilt waren: innamorati, vecchi, zanni, ${ }^{509}$ servette sowie der oben beschriebene capitano. Folgende Gegensatzpaare spielen dabei eine grundlegende Rolle: männlich-weiblich, herrschaftlich-bedienstet, jung-alt, ernstkomisch. Dieselben Grundmuster dienen der Opera buffa zwar als Basis, unterliegen aber auch Erweiterungen oder Variationen.

Innamorati-Typen der Commedia kommen in der Opera buffa beispielsweise vor als edle oder listige junge Liebende, karikierte dumme, eingebildete pretendenti, kari-

509 Einige Figuren der Commedia dell'arte wie etwa Pantalone, Dottore, typische Vertreter der Vecchi, oder Arlecchino, einer der beliebtesten Zanni, trugen Masken. Dieser Usus wurde in der Opera buffa nicht übernommen. 
kierte Fremdländer - die beiden Letzteren können sich mit dem capitano-Typ überschneiden -, junge naive oder schlaue Mädchen, welterfahrene locandiere (Wirtinnen). Der Vecchio-Typ erscheint als Vater, Vormund oder Obrigkeit, der in der Regel Hochzeitspläne junger Frauen verhindert und sich zuweilen in sie verliebt. Bedienstete treten oft als Helfer ein. Gesellschaftliche Hierarchien der Zeit spiegeln sich in Rollentypen wider: Den höheren Ständen entsprechen in der Regel parti serie, den niedrigen parti buffe, allerdings mit zahlreichen differenzierten Facetten und einer großen Typenvielfalt. Die Palette reicht von den wirklich ernsten adeligen personaggi seri bis hin zu den parodistisch gezeichneten, nicht ernst zu nehmenden Adeligen, die genauso wie Charaktere aus anderen Ständen mit ausgesprochen lasterhaften Eigenschaften die Rolle des buffo caricato spielen können. Zwischen diesen beiden Extremen liegen die Rollen der „normalen“ oder „einfachen“, also nicht-karikierten buffi und die parti di mezzo carattere, zu denen unter anderem die larmoyanten Partien gehören. Diesen verschiedenen Rollenfächern sind "gesetzmäßig" nicht nur bestimmte Stimmlagen - komische Alte sind in der Regel Bässe, junge innamorati Tenöre und Soprane - und ein spezifischer Verhaltenskodex ${ }^{510}$ zugeordnet, sondern auch unterschiedliche Stilebenen in Sprache und Musik. ${ }^{511}$

Der sprachliche wie auch der musikalische Stil der parti serie sind direkt aus der Opera seria übernommen. Gewählte Ausdrücke, blumige Metaphern und Gleichnisse sind charakteristisch für ihre gehobene Sprache. Musikalisch geht es vorwiegend um die Darstellung von Affekten. Die musikalisch meist anspruchsvolleren und differenzierteren arie serie sind gekennzeichnet durch Virtuosität und Pathos, die sich unter anderem in elegischen kantablen langatmigen Melodien, konzertierenden SoloInstrumenten, Koloraturen und großen „heroischen“ Sprüngen ausdrücken. Die bekannteste zeitgenössische Arientypologie stammt von John Brown, der die arie serie systematisch in folgende Kategorien unterteilt: aria cantabile, aria di portamento, aria di mezzo carattere, aria parlante, aria di bravura o di agilità, rondò, cavatina. ${ }^{512}$

510 In Matteo Borsas Traktat ist folgende Gegenüberstellung zwischen parti serie und parti buffe zu finden: „Si cangain [sic] dall'opera seria alla buffa passando i personaggi talmente, che restano in opposizion diametrale. I primi sono gravi, monotoni, misurati, e nei discorsi loro niente modulati e cantanti, se non quando per forte commozione di spirito si scordano formalità, e ogni circospezione (...). Sarà poi inoltre una chiarissima verità, che questi semi di musica nei personaggi buffi sono a dismisura più feraci, e copiosi (...). E infatti costoro ad ogni poco riscaldansi, e prendon fuoco, e son più aperti e spiegati, e mille cose riuniscono insieme, le quali rendono i trattenimenti loro sì vivaci, e sì varj, che vizio induce la copia soverchia anzi che la penuria." (Borsa, S. 218f.).

511 Zur Rollentypologie der Opera buffa siehe Gianni Cicali: Attori e ruoli nell'opera buffa italiana del settecento. Florenz 2005, sowie Christine Villinger: Bedeutung und Grenzen der zeitgenössischen Rollentypologie anhand der Ariengestaltung. In: Dies.: Mi vuoi tu corbellar. S. 170-219.

512 Zur genauen Beschreibung der einzelnen Arientypen siehe John Brown: Letters upon the Poetry and 
Die parti buffe dagegen sprechen eine einfache Umgangsprache. Natürlichkeit charakterisiert ihren sprachlichen und musikalischen Ausdruck im Gegensatz zur eher artifiziell wirkenden Sprache der parti serie. Matteo Borsa hebt die Syllabik in der Musik der buff hervor, die ihm zur Nachahmung des natürlichen Sprechens besonders geeignet erscheint: „La più importante scoperta, che fatta abbiano i buffi nell'osservar la natura, è stata quella, che li conduce a prefiggere quasi ad ogni sillaba anche una nota, con che s'accostan di molto al naturale discorso. "513 Dieselbe Funktion erfüllen die typischen kurzen und kleingliedrigen musikalischen Gedanken. Würde man von der Tonhöhe und den Instrumenten absehen, dann würde nach Borsas Meinung ein vollkommen natürliches Sprechen übrigbleiben: „(...) ciò poi, che è interessante ancor più del resto, hanno i buffi imparato da questa Maestra d'ogni vero, a tener sempre i sentimenti musicali assai corti, e più corti ancora i periodi, ossia i membri di tal sentimenti: e son da lodarsi, giacché esaminando a dovere le conversazioni degli uomini non si può non sentire, che in parlando si formano certe breve inflessioni di voci, le quali appartengono al total dei periodi sempre brevi ancor essi nel famigliare, e che queste inflessioni, ch'io direi quasi totali, di nuovo si spezzano in altre anche più corte proprie dei membri del periodo medesimo, comodissime e all'individuare preciso d'ogni minima differenza, e al comodo del respirare. (...) Leggete la musica buffa prescindendo dagli strumenti, e abolendo a poco a poco la intonazione più fina, col tempo più risentito e marcato, e vi troverete ridotti al parlar semplice e piano, senza avvedervene. Quale prova più chiara volete mai d'un espressione, e imitazione verissima della natura?" 514

Nicht von ungefähr wird die Technik des schnellen, syllabischen, den Text hervorhebenden Buffo-Gesangs als Parlando bezeichnet. Gemeinsam mit kleingliedrigen, oft prägnanten gestischen Motiven, die sich an den Text gut „anschmiegen“, bildet das wie ein Plappern wirkende, witzige Parlando ein typisches Element für die Arien der buffi caricati, während „einfache“ buffi vorwiegend schlichte, liedhafte Arietten mit volkstümlich anmutender Melodik singen. Charakteristisch für die - ebenfalls kantablen - Arien der parti di mezzo carattere sind dagegen die Chromatik in Melodie und Harmonie, die in der Opera buffa sonst äußerst sparsam eingesetzten Molltonarten sowie die Häufigkeit von Vorhaltsbildungen (Seufzermotiven), die den larmoyanten rührenden Charakter des Gesangs prägen. Größere musikalische Unterschiede

Music of the Italian Opera adressed to a Friend. Edinburgh 1789. Zur Rondo-Arie siehe Helga Lühning: Die Rondo-Arie im späten 18. Jahrhundert. Dramatischer Gehalt und musikalischer Bau. In: Hamburger Jahrbuch für Musikwissenschaft 5 (1981), S. 219-246.

513 Borsa, S. 123.

514 Ebd. S. 123f. 
zwischen parti serie und parti buffe sind vor allem in den Arien und Duetten ${ }^{515} \mathrm{zu}$ bemerken, während in den Secco-Rezitativen und in den groß besetzten Ensembles tendenziell eine Vereinheitlichung der musikalischen Sprache stattfindet.

Eine zeitgenössische Arientypologie für Buffa-Arien ist nicht überliefert. Um einen Einblick in die Vielfalt der Buffa-Arientypen zu gewinnen, seien hier die von zwei heutigen Musikwissenschaftlern, Ruth Müller-Lindenberg und Christian Kipper, ${ }^{516}$ erstellten Systematiken angeführt: Müller-Lindenberg nennt zwei „entgegengesetzte“ Arientypen: „Expressive Arien“, in denen der Gefühlsausdruck vorherrscht und die Kippers „Emotionsarien“ entsprechen, und „handlungstragende Arien“, in Kippers Systematik „Aktionsarien“ genannt. Zwischen diesen beiden Extremen befinden sich nach Müller-Lindenberg die „deskriptiven Arien“ (Kipper: „Deskriptionsarien“), die „räsonierenden Arien“ (Kipper: „Reflexionsarien“) und die „drameninhärenten“ Arien (Kipper: „Situationsarien“). Kipper nennt zusätzlich dazu die „Argumentationsarien“ und verwendet dieselben Kategorien auch für die Ensembles.

Schon aus diesen Kategorisierungsversuchen werden die buffo-spezifische Situationsgebundenheit sowie das Vorwiegen von Aktion und Dialog im Vergleich zu den abstrakteren Seria-Arien deutlich. Kipper behauptet sogar, Buffa-Arien seien so sehr auf die konkrete Situation bezogen, dass sie kaum noch austauschbar seien. ${ }^{517}$ Diese Aussage kann meines Erachtens nur bis zu einem gewissen Punkt bestätigt werden, denn auch in der Buffa sind immer wieder dieselben oder ähnliche Situationen (Topoi) anzutreffen, so dass darin auch immer wieder dieselben Arientypen eingesetzt werden konnten. (Außerdem waren Abänderungen im vorangehenden Rezitativ zur Rechtfertigung einer Einlagearie immer möglich.)

Zur Stellung der Buffa-Arien sei noch erwähnt, dass sie genauso wie in der Opera seria in der Regel am Szenenende oder aber als cavatina ${ }^{518}$ am Anfang oder in der

515 Zum Duett siehe Reinhard Wiesend: Zwischen Aria a due und Ensemble. Zum Duett in der Opera buffa der zweiten Hälfte des 18. Jahrhunderts. In: Markus Engelhardt und Wolfgang Witzenmann (Hg.): Convegno italo-tedesco „Mozart, Paisiello e l'Opera buffa“ (Rom 1993). (Analecta musicologica Bd. 31), Laaber 1998, S. 259-287.

516 Müller-Lindenberg, S. 108ff. und Kipper, S. 137ff.

517 Vgl. Kipper, S. 11.

518 Zur cavatina siehe Helga Lühning: Die Cavatina in der italienischen Oper um 1800. In: Friedrich Lippmann (Hg.): Colloquium „Die stilistische Entwicklung in der italienischen Musik zwischen 1770 und 1830 und ihre Beziehung zum Norden" (Rom 1978). Laaber 1982 (Analecta musicologica 21), S. 333-368. Gerhard Allroggen: Die Cavatine in der italienischen Oper des 18. Jahrhunderts. In: Gerhard Allroggen und Detlef Altenburg (Hg.): Festschrift Arno Forchert zum 60. Geburtstag am 29. Dezember 1985. Kassel 1986, S. 142-49. Wolfgang Osthoff: Mozarts Cavatinen und ihre Tradition. In: Wilhelm Stauder, Ursula Aarburg und Peter Cahn (Hg.): Frankfurter musikhistorische Studien: Helmuth Osthoff zu seinem siebzigsten Geburtstag. Tutzing 1969, S. 139-77. 
Mitte einer Szene stehen. Im letzteren Fall handelt es sich um eine einsätzige Komposition, während das mit Abstand häufigste und konventionellste Schema der Abgangsarie in der Buffa eine zweiteilige Anlage nach dem Muster langsam-schnell aufweist. Gelegentlich finden sich auch einteilige oder mehrteilige Buffa-Arien. ${ }^{519}$

Eine der weiteren auffälligsten buffa-spezifischen formalen Konventionen ist die Verwendung von groß besetzten und umfangreichen Ensembles sowie ihre Stellung an den Eckpunkten des Werks. Der Beginn einer Oper ist in der Regel durch eine Introduzione gekennzeichnet, die nach der rein instrumentalen Sinfonia ${ }^{520}$ in die Stimmung und die Handlung der Oper einführt. Dabei handelt es sich entweder um ein als Präsentation der Personen und des Ambiente dienendes statisches Tableau oder um ein aktionsreicheres Ensemble, in dem die Teilnehmer miteinander interagieren. ${ }^{521}$

Eine strukturell wichtige Funktion erhalten auch die für die Buffa-Gattung charakteristischen großangelegten Finali, in denen jeweils am Schluss des ersten und zweiten Aktes die Handlung durch Zuspitzung der Intrige, Missverständnisse, Burle und maximale Verwirrung ihren dramatischen Höhepunkt erreicht bzw. durch Anagnorisis oder anderen Überraschungsmomenten eine Auflösung erfährt. Besonders an diesen Finali ist - wie auch bei mehrteiligen Arien und Ensembles ${ }^{522}$ - eines

519 Zur Arienform siehe Hunter, S. 304ff. Christine Villinger: Zu den Arienformen. In: Dies.: Mi vuoi tu corbellar. S. 137. Sieghart Döhring: Formgeschichte der Opernarien vom Ausgang des 18. bis zur Mitte des 19. Jahrhunderts. Marburg-Lahn 1975.

520 Die dreisätzige Form der Sinfonia (meist in den Sätzen Allegro 4/4-Takt - langsamer Satz - schneller, tänzerischer Satz, oft Presto, oft 3/8-Takt) verlor ab den späten 1770er Jahren zugunsten der einsätzigen Sinfonia an Bedeutung, und zwar etwa gleichzeitig zum tendenziellen Übergang von der Drei- zur Zweiaktigkeit der Oper. Zur Sinfonia siehe u. a. Christine Villinger: Form und Funktion der Ouvertüren. In: Dies.: Mi vuoi tu corbellar. S. 111-122.

521 Vgl. Stefan Kunze: Per una descrizione tipologica della introduzione nell'opera buffa del settecento e particolarmente nei drammi giocosi di Carlo Goldoni e Baldassarre Galuppi. In: Maria Teresa Muraro (Hg.): Galuppiana 1985: Studi e ricerche. Florenz 1986, S. 165-78.

$522 \mathrm{Zu}$ Finali und Ensembles siehe Friedrich Lippmann: Das „Große“ Finale in Opera buffa und Opera seria. Paisiello und Rossini. In: Klaus Hortschansky (Hg.): Traditionen - Neuansätze. Für Amalie Abert (1906-1996). Tutzing 1997, S. 377-398; John Platoff: Music and Drama in the Opera Buffa Finale: Mozart and his Contemporaries in Vienna. Ph. D. Dissertation, University of Pennsylvania 1984; John Platoff: Musical and Dramatic Structure in the Opera Buffa Finale. JM 7 (1989), S. 191230; Marianne Fuchs: Die Entwicklung des Finales in der italienischen Opera Buffa vor Mozart. Diss. Wien 1932; Edward J. Dent: Ensembles and Finales in 18th Century Italian Opera. (part I) SIMG 11 (1909-10), S. 543-69, (part II) 12 (1910-11), S. 112-38; Daniel Heartz: The Creation of the Buffo Finale in Italian Opera. In: Proceedings of the Royal Musical Association 104 (1977-78), S. 67-78; Sabine Henze-Döhring: La tecnica del concertato in Paisiello e Rossini. NRMI 22 (1988), S. 1-23; Francesco Blanchetti: Tipologia musicale dei concertati nell'opera buffa di Giovanni Paisiello. RIM 19 1984, S. 234-60. 
der grundlegenden Kompositionsprinzipien der Opera buffa zu erkennen, nämlich die blockhafte Aneinanderreihung von kontrastreichen Abschnitten meist ohne motivisch-thematische Beziehung. Jeder Szenen- bzw. Situationswechsel wird durch eine durch Tempo- und Taktwechsel hervorgerufene musikalische Zäsur hervorgehoben, ${ }^{523}$ woraus sich der gewünschte chiaroscuro-Effekt ergibt. ${ }^{524}$ Der bei dreiaktigen Opere buffe aus der Seria übernommene typische, aus einem Liebesduett zwischen prima donna und primo nomo und einem kurzen, meist homophonen Chor bestehende Schluss entfällt bei zweiaktigen Opern. Ein abschließender Tutti-Gesang bildet ohnehin den konventionellen Schluss aller Finali. Anders positionierte Chöre sind in der Buffa eher selten, besonders im venezianischen Repertoire, in dem aufgrund des kommerziellen Produktionssystems möglichst kostengünstige Lösungen angestrebt wurden.

Das soeben grob skizzierte System von Gattungskonventionen der Opera buffa bietet auf inhaltlicher Ebene - gerade weil es sich um eine komische Gattung handelt Raum für vielfälttige Momente des Spiels. Diese Phänomene, seien es weit verbreitete Topoi oder einzelne konkrete Szenenbeispiele, sollen in der Folge im Hinblick auf ihren Spielcharakter untersucht werden, auch wenn die Fülle an teilweise sehr unterschiedlichen Spielelementen eine umfassende Kategorisierung erschwert.

Für die Einteilung der verschiedenen Momente des Spiels eignet sich Caillois' Systematik nach anthropologischen Kriterien besser als andere, häufig aus psychologischer und pädagogischer Sicht entworfene Gliederungsversuche, die aufgrund ihrer ausgesprochenen Spezifität und ihrer Organisation nach bestimmten (insbesondere entwicklungspsychologischen und soziologischen) Kriterien bei der Betrachtung einer musiktheatralischen Gattung wenig sinnvoll wären. Caillois' vier Grundkategorien des Spiels, nämlich Agon, Mimicry, Alea und Ilinx, werden also - obwohl sie in der Opera buffa sehr unterschiedlich stark vertreten sind - das Grundraster für die nun folgende Darstellung der spielhaften Momente der Opera buffa bilden, die selbstverständlich auch Kategorien und Begriffe anderer Theorien aus verschiedenen Disziplinen, darunter auch Psychologie und Pädagogik, integriert. Wie bei jeder Kategorisierung der Realität erweist sich auch bei der Zuordnung der Momente des Spiels in der Opera buffa der Vorgang als artifiziell und unzulänglich. Deshalb sollen

$523 \mathrm{Vgl}$. Manfredini: „L'uso di mutar varie volte la battuta in un solo pezzo di musica, fu introdotto nello stil buffo, e segnatamente nei finali“" (Manfredini, S. 121).

524 Vgl. Goldoni: Prefazione al tomo XI all'edizione veneziana G.B. Pasquali. In: Ders.: Il teatro comico. Memorie italiane. S. $162 \mathrm{f}$. 
die hier angewandten, von Caillois definierten Grundkategorien des Spiels eher als Anhaltspunkte für die Untersuchung verstanden werden, wobei kein Anspruch auf absolute Gültigkeit erhoben wird. 


\section{Elemente des Spiels in Werkbeispielen}

Die Herkunft der einzelnen Momente des Spiels bzw. des Spielerischen im Inneren der Gattung wird im Folgenden nicht berücksichtigt. Ihre Wurzeln reichen teilweise bis in die griechische Antike. „Direkt“ übernommen wurden sie vermutlich zum Großteil aus einer allgemeinen Theatertradition, vor allem aus der Commedia dell'arte, deren Grundbestandteile gerade die vor allem von Dienerfiguren (Arlecchino, Brighella, Pulcinella etc.) gespielten Späße und Possen waren. Die Tatsache, dass frühe komische Opern der ersten Hälfte des I8. Jahrhunderts nicht selten von Commedia-dell'arte-Truppen gespielt wurden, ${ }^{525}$ ist ein zusätzlicher Beweis für die enge Verbindung zwischen den Inhalten und Darstellungsmodi der Opera buffa, aber auch für die ausschlaggebende Rolle der Schauspielkunst der Buffa-Sänger. Silke Leopold erinnert aber auch an die „enorme Bedeutung des Pastoraldramas der Renaissance für die Entstehung des Buffa-Librettos",526 wobei vor allem „die heitere Grundstimmung" und „die verspielte pastorale Gemeinschaft“ mit den für die Gattung typischen Ensembleszenen zusammenhängen. ${ }^{527}$

\section{Agon}

\section{I.I Allgemeines}

Huizinga unterteilt in seinem Homo ludens das Spiel in zwei Hauptgruppen, Kampf und Darstellung, und unterstellt dabei auch die Möglichkeit von Mischformen. ${ }^{528}$ Die Opera buffa als Gattung gehört in dieser allgemeinen Unterteilung selbstverständlich, wie das Theater überhaupt, zu den Darstellungsspielen, weist aber inhaltlich - von den mit dem sozialen Kontext verbundenen Konkurrenzkämpfen zwischen rivalisierenden Sängern und Sängerinnen soll in diesem Zusammenhang abgesehen werden - durchaus auch Aspekte des Kampfspiels auf. McColloms hebt selbst in einer

525 Vgl. Silke Leopold: Einige Gedanken zum Thema Komische Oper in Venedig vor Goldoni. In: Christoph-Hellmut Mahling und Sigrid Wiesmann (Hg.): Bericht über den internationalen musikwissenschaftlichen Kongress Bayreuth 1981. Kassel 1984, S. 90.

526 Leopold, S. 87.

527 Vgl. ebd. S. 88.

528 „Das Spiel ist ein Kampf um etwas oder eine Darstellung von etwas. Diese beiden Funktionen können sich auch vereinigen, in der Weise, daß das Spiel einen Kampf um etwas darstellt oder aber ein Wettstreit darum, wer etwas am besten wiedergeben kann." (Huizinga, S. 20). 
kurzgefassten Definition der Komödie vor allem Erfolg und Niederlage in sozialen Beziehungen sowie das Moment des Sieges am Schluss der Komödie als Charakteristika hervor: „Comedy is an amusing, relatively discontinuous action concerning succes and failure in social relations and culminating in a judgement whereby the divine average" triumphs over the exceptional or peculiar."529 Diese Gegenüberstellung von Gewinnern und Verlierern am Ende einer Handlung ist ein deutliches Zeichen dafür, dass davor ein Kampf (oder Ähnliches) stattgefunden haben muss. Beinahe jede Handlung der Opera buffa beruht auf einem Konflikt, der in der Regel mit einer Rivalitätssituation verbunden ist. Ohne diese Elemente würde eine Handlung gar nicht in Gang kommen; sie besteht zum Großteil aus den Auswirkungen des Rivalitätskampfs zwischen den unterschiedlichen Kontrahenten. Wie McCollom hinsichtlich der Komödie feststellt, siegen zum Schluss immer die „Normalen“ und „Durchschnittlichen“ über die „Außergewöhnlichen“ und „Eigenartigen“.530 Wer gegen die Regeln der Natur oder der Gesellschaft verstößt, wird in der Welt der Opera buffa von den anderen Personen hereingelegt und gnadenlos ausgelacht. Das ist beim Vorliegen schlechter Eigenschaften wie übertriebene Eifersucht, Neugier, Geiz, Habgier etc. der Fall, oder wenn alte Männer junge Frauen heiraten, autoritäre Väter ihre Töchter oder auch ihre Söhne mit (reichen, aber) nicht geliebten Partnern verheiraten wollen. Im Allgemeinen gewinnt nicht nur die „Norm“ gegen die „Ausnahme“, sondern auch immer die Schlauheit gegen die Dummheit und die Jugend gegen das Alter.

Diese dualistische Struktur ist auch ein typischer Aspekt des agonalen Spiels, wie Huizinga feststellt: „Gemeinsames Spielen hat in seinen wesentlichen Zügen antithetischen Charakter. Meistens spielt es sich ,zwischen“ zwei Parteien ab. "531 Caillois konkretisiert diese These folgendermaßen: „Es gehört zur Regel der sportlichen Wettkämpfe und zur Begründung ihrer vielfachen Unterteilungen, daß sich zwei Einzelkämpfer oder zwei Mannschaften gegenüberstehen (...) oder aber, daß eine nicht festgelegte Anzahl an Konkurrenten gegeneinander antritt." 532 Vergleichbare Situationen kann man in der Opera buffa vorfinden: Die Antagonisten können zwei konkurrierende Gruppen sein - Normale gegen Eigenartige, Schlaue gegen Dumme, Junge gegen Alte, Frauen gegen Männer - oder zwei Einzelpersonen, wie z. B. zwei Frauen, die denselben Mann heiraten möchten, oder umgekehrt zwei Männer, manchmal sogar

529 McCollom: The Divine Average. A View of Comedy. S. 7. Zit. nach Grimm u. Berghahn (Hg.): Wesen und Formen des Komischen im Drama. S. XII.

530 Die doppelte Bedeutung des Wortes „komisch“ als „eigenartig“ und „erheiternd“ spiegelt sich in der Opera buffa in der Tatsache, dass häufig der „Eigenartige“, nämlich der Träger einer lasterhaften Eigenschaft, tatsächlich auch den buffo caricato, also die Rolle des Lächerlichen spielt.

531 Huizinga, S. 52.

532 Caillois, S. 21. 
Vater und Sohn, die um dieselbe Frau werben. Die Konkurrenten können aber auch mehr als zwei sein: Eine häufige Buffa-Konstellation besteht beispielsweise darin, dass alle oder fast alle Männer der Dramatis personae dieselbe Frau im Visier haben. Gewinnen bedeutet nach Huizinga „im Ausgang eines Spiels sich als der Überlegene erweisen",533 in der Opera buffa heißt es konkret, den gewünschten Partner heiraten. Gleichzeitig bedeutet die Eroberung einer besonders begehrten Zielperson einen Erfolg bei der Überwindung von Hindernissen und vor allem eine Überlegenheit, einen Triumph über die Rivalen. Der Verlierer ist meistens eine einzige Person, der lächerliche Alte, Dumme, Geizige etc., der zwar wütend wird, aber seine Niederlage hinnehmen muss und in der Regel auch relativ leicht hinnimmt, so wie es beim Spiel sein sollte. Die übrigen Konkurrenten, die den gewünschten Partner nicht „gewinnen“ können, geben sich leicht mit einem anderen Partner zufrieden, denn es ist alles „nur ein Spiel“ und die Hauptsache ist Heiraten. Ruth Müller-Lindenberg führt diese „prinzipielle Austauschbarkeit von Beziehungen“534 auf die moralische Gleichgültigkeit des Buffa-Personals zurück; meines Erachtens beruht sie allerdings vorwiegend auf dem spielerischen Charakter der gesamten Gattung. Müller-Lindenberg bezeichnet die Funktionsweise der von ihr negativ konnotierten „Welt der falschen Gefühle“535 als „,Bäumchen wechsle dich'-Muster“536 und wählt dafür selbst - bezeichnenderweise - den Namen eines Spiels.

„Wie jedes andere Spiel muß man den Wettkampf als bis zu einem gewissen Grade zwecklos bezeichnen. (...) Als objektive Tatsache ist das Spielergebnis an und für sich unwesentlich und gleichgültig. "537 Diese Aussage Huizingas ist nicht oder höchstens teilweise auf die Opera buffa übertragbar, obwohl sie meine These in Bezug auf die von Müller-Lindenberg genannte moralische Indifferenz der Buffa-Figuren untermauern würde. Der wenngleich spielerisch wirkende Kampf zwischen den Liebesrivalen in der Opera buffa ist nämlich nicht selbstzwecklich, denn er bezweckt die ersehnte Hochzeit am Schluss. Das Spielergebnis kann also aus handlungsimmanenter Perspektive nicht als „unwesentlich“ bezeichnet werden, während für den Zuschauer der Ausgang des Spiels an sich eher gleichgültig ist.

Als Antriebe für das agonale Spiel nennt Caillois „die Lust an der Herausforderung (...) oder einfach an der überwundenen Schwierigkeit“, „das Bedürfnis, sich zu behaupten“, und den „Ehrgeiz, sich als Bester zu beweisen“. ${ }^{538}$ Das Element des

533 Huizinga, S. 55.

534 Müller-Lindenberg, S. 51.

535 Ebd. S. 52.

536 Ebd. S. 51.

537 Huizinga, S. 54.

538 Vgl. Caillois, S. 75. 
Wetteiferns spielt dabei eine wesentliche Rolle, wie auch Huizinga in Bezug auf das Spiel erklärt: „Man kämpft, um der Erste an Kraft oder Gewandtheit, an Wissen oder an Reichtum (...) zu sein. Man kämpft mit der Kraft seines Körpers, mit den Waffen, mit dem Verstande oder mit der Faust, mit Zurschaustellung von Aufwand, mit großen Worten, prahlend, renommierend, schimpfend, mit dem Würfelbecher oder endlich mit List und Betrug. Für unser Gefühl wird allerdings durch Anwendung von List und Betrug das Spielhafte des Wettstreits offensichtlich gesprengt und aufgehoben." 539 In der Opera buffa ist dieses Element des Wetteiferns ebenfalls präsent: Jeder kämpft um seine eigenen Interessen und in erster Linie, um eine gute Partie zu ergattern. Die Hochzeit am Schluss scheint das Ziel des Spiels zu sein. Die Mittel, mit denen gekämpft und meistens gesiegt wird, sind dabei Burle, Verkleidungen, Doppelspiel, Verstellungen, z. B. vorgetäuschte Ohnmachten, falsche Liebeserklärungen, die Huizinga insgesamt als „List und Betrug“ und als nicht-spielhaft bezeichnen würde. Allerdings berücksichtigt Huizingas Theorie auch gewisse Fälle, in denen „das Übertölpeln selbst wieder ein Thema des Wettstreits und eine Spielfigur geworden“ ist. „Der Falschspieler ist (...) nicht Spielverderber. Er stellt sich so, als hielte er die Spielregeln, und spielt mit, bis er ertappt wird. "540 Die für die Opera buffa typischen „Manöver“ können zwar auch als Falschspiel bezeichnet werden, von den übrigen Personen werden sie aber meistens geduldet, vermutlich aus Achtung vor der besonderen überlegenen Schlauheit der „Falschspieler“ bzw. weil der Zweck - in der Regel eine Hochzeit aus Liebe - alle Mittel heiligt, oder aber weil zum Zeitpunkt der Ertappung oder Demaskierung die Hochzeit meistens schon stattgefunden hat. Mathias Fuchs macht auf die generelle Abgrenzungsschwierigkeit zwischen Falschspiel und gerade noch zugelassenen Tricks aufmerksam und bezeichnet Letztere als eine eigene Art des Spiels: „Es scheint (...), dass das Spiel mit den Grenzen des gerade noch Zugelassenen selbst ein spielerischer Akt ist. "541

Gerade weil die Tricks der Buffa-Figuren oft nicht ganz sauber sind, müssen die besagten "Manöver“ - spieltheoretisch könnte man von einem „hoax“ sprechen geheim gehalten werden, wobei Caillois’ Spielantrieb des „Vergnügens an [der] Heimlichkeit“542 zum Tragen kommt, der für die Spannung sorgt, die Huizinga als eines der allgemeinen Wesensmerkmale des Spiels bezeichnet. Die Spannung beruht nicht nur auf dem Geheimhalten und auf Informationsgefällen zwischen den

539 Huizinga, S. 56.

540 Ebd. S. 57.

541 Mathias Fuchs: Fair enough! Über Spielverderber und Falschspieler. In: Mathias Fuchs und Ernst Strouhal (Hg.): Das Spiel und seine Grenzen. Wien 2010, S. 181.

542 Caillois, S. 75. 
Figuren, ${ }^{543}$ sondern auch auf der Ungewissheit des Ausgangs, die Huizinga wie Caillois und Sutton-Smith als typischen Aspekt des Spiels hinstellen. Huizinga betont dabei die Verbindung zwischen dieser Spannung und dem agonalen Aspekt des Spiels : „Im antithetischen Spiel agonaler Art (...) erreicht dies Element der Spannung, der ungewissen Aussicht auf Gelingen, der Unsicherheit, den höchsten Grad. (...) Je ,schwieriger' das Spiel ist, desto größer wird die Spannung bei den Zuschauern. “544

\section{I.2 Agonale Topoi in der Opera buffa}

I.2. I Agon als Geschlechterkampf

Da Liebeswerbung und Heirat in der Opera buffa allgegenwärtige Themen sind, verwundert es nicht, dass in vielen Arien die Gegenüberstellung von Männern und Frauen thematisiert wird. Einer der häufigsten Arientypen überhaupt ist die meist ad spectatores gerichtete Geschlechterarie, die auf allgemeinen, meist klischeehaften Bemerkungen über ein ganzes Geschlecht basiert. Von einigen Ausnahmen abgesehen, fallen diese Kommentare ausgesprochen negativ aus, denn den Frauen wird in der Regel Falschheit, Wankelmut und Launenhaftigkeit vorgeworfen, ${ }^{545}$ den Männern im Gegenzug Untreue, Unbeständigkeit und Grausamkeit, ${ }^{546}$ wodurch jeweils

543 Manfred Pfister spricht von der „diskrepanten Informiertheit“ im Drama und meint damit einerseits „die Relation zwischen dem Grad der Informiertheit der Figuren“ untereinander und andererseits das Verhältnis zwischen dem Grad der Informiertheit der Dramenfiguren und dem der Zuschauer. In diesem Zusammenhang zitiert er Friedrich Dürrenmatt, der gerade in dem „Unterschied zwischen Figureninformiertheit und Zuschauerinformiertheit die entscheidende Qualität des Dramatischen“ gesehen hat. (Vgl. Manfred Pfister: Das Drama. Theorie und Analyse. 11. Aufl. München 2001, S. 79f.).

544 Huizinga, S. $52 \mathrm{f}$.

545 Beispielsweise: Petrosellini/Anfossi: Lincognita perseguitata. Venedig 1778 (II,3):

Aria Asdrubale:

Come son Donne, son tutte simili,

Pensano, ed oprano tutte così.

Son tutte istabili, tutte variabili,

Tutte fanatiche, tutte lunatiche

Superbe indomite, incorregibili,

Amiche false, nemiche orribili,

E senza trappole, e senza inganni

Appena appena, come un fenomeno,

Ogni cent'anni una n'uscì.

Ah Donne amabili sono sincero.

Deh perdonate, s'io dico il vero.

Siete dannose, pericolose,

$\mathrm{E}$ voi medesime dite di sì.

546 Beispielsweise: Livigni/Cherubini: Lo sposo di tre e marito di nessuna. Venedig 1783 (I,5): 
eine höchst antagonistische Haltung beider Geschlechter zueinander zum Vorschein kommt. Unzählige Beispiele könnten hier angeführt werden, denn beinahe jede Opera buffa enthält eine oder mehrere solcher Arien. Typisch ist dabei die direkte Anrede an das Publikum, in der das jeweils angesprochene Geschlecht oft vor dem anderen Geschlecht gewarnt wird. Auch die Klage über die gesamte Kategorie der Ehefrauen bzw. Ehemänner liefert ein beliebtes Motiv. Nach der Häufigkeit solcher Arien zu urteilen, fand dieser Topos großen Anklang, wahrscheinlich weil er eine starke Identifikationsmöglichkeit für das Publikum bot, die durch die Wendung ad spectatores zusätzlich verstärkt wurde.

Die Gegenüberstellung der beiden Geschlechter erscheint im venezianischen Repertoire in vereinzelten Opern auch als Hauptthema der Handlung, wie es beispielsweise in Giacomo Rusts „L'isola capricciosa“ der Fall ist, für die Goldonis „Il mondo alla roversa" als Vorlage diente. Diese Oper spielt auf einer Insel, in der die Frauen nicht nur die herrschende Rolle innehaben, sondern sich auch wie Männer benehmen, während die Männer weibliche Verhaltensweisen annehmen. Dabei erscheinen alle geschlechtsbezogenen Klischees mit umgekehrten Vorzeichen, wodurch der Eindruck einer „verkehrten Welt“ entsteht. Nach einer Reihe von Episoden treten zum Schluss männliche europäische Soldaten auf, die der Herrschaft der Frauen ein gewaltsames Ende bereiten („Alle Donne è tolto il Regno“).

Eine Oper, in der die Gegenüberstellung von Frauen und Männern einen ausgesprochen kämpferischen Charakter erhält und der agonale Aspekt einen Höhepunkt erreicht, ist „La forza delle donne“ von Giovanni Bertati und Pasquale Anfossi. Die Anfangssituation wird durch die Erzählung der Vorgeschichte geschildert: Die italienischen Frauen waren ihrer Unterwerfung durch die untreuen und autoritären Männer überdrüssig, wanderten aus und gründeten eine eigene, Ginopoli genannte, Kolonie. Die Handlung setzt bei der ıoo-jährigen Jubiläumsfeier der Stadtgründung

\footnotetext{
Aria Baronessa:

Chi crede a voi altri uomini

Bugiardi, ed ingannevoli

Fra pene, affanni e spasimi

Meschina sempre sta.

Avete un cor durissimo

Con noi non siete stabili,

Il vostro amor è perfido

E pien di falsità.

Così con questi barbari

Parlar bisogna o Femmine

L'avere un cor di zucchero

Del danno assai ci fa.
} 
ein, die allerdings von der Ankunft der Männer gestört wird. Die Männer werden von einem Frauenfeind angeführt, der kriegerische Absichten gegen die Frauen hegt. Auf die Kriegserklärung der Männer hin bitten die Frauen um einen dreitägigen Waffenstillstand, den sie strategisch zur Eroberung des frauenfeindlichen Anführers nützen wollen. Nach mehreren misslungenen Versuchen von höhergestellten Frauen schafft es schließlich ein einfaches, aber schlaues Mädchen niedrigen Standes, den Frauenfeind zu verführen. In dieser Situation herrscht auch unter den Frauen Rivalität und Konkurrenz. Schmeicheleien, Zärtlichkeiten und spielerisches Kokettieren bilden gemeinsam mit dem Argument, dass in der Tierwelt die jeweiligen Männchen und Weibchen auch liebevoll zueinander sind, die Strategie der Gewinnerin.

Die Bekehrung eines Frauenfeinds ist in der Opera buffa ein relativ verbreiteter Topos. Der Misogyn wird dabei als gesellschaftlich unangepasst und anormal angesehen und dementsprechend ausgelacht und zurechtgewiesen. Seine feindliche Haltung fordert die umstehenden Frauen in der Regel zum Kampf und zur Eroberung heraus. Sie erteilen ihm eine wirksame Lektion, indem sie ihn dazu bringen, sich in sie zu verlieben. Die „Lust an der Herausforderung“ ist ein typischer Aspekt des agonalen Spiels, das in diesem Fall zwischen Frauen und Männern stattfindet. Nur in „La forza delle donne" kommt es allerdings zu einer geradezu kriegerischen Auseinandersetzung zwischen den beiden Geschlechtern, die wie zwei Mannschaften geschlossen gegeneinander antreten und dabei unterschiedliche Strategien anwenden: Die Taktik der Männer leitet sich direkt aus der Kriegsstrategie ab und besteht in Belagerung, Waffenkampf, Eroberung, Unterwerfung. Die Frauen gehen dagegen raffinierter vor: Sie erobern ihren Feind, indem sie ihn verführen, verliebt machen und durch Schlauheit für sich gewinnen. Der entscheidende Moment ist der, in dem der Misogyn vor Liebe schmachtend seine Niederlage zugibt, was von allen Beteiligten als Zeichen für den Sieg der Frauen anerkannt wird.

Ogus: Smanio, delirio, e fremo,

Tutto di foco avvampo:

Cerco, ma invan lo scampo:

Vinto da te son già. ${ }^{547}$

Typische Aspekte des Spiels sind in diesem Kampf zwischen den Geschlechtern die Unterteilung in zwei „Mannschaften“, die bewusste Anwendung von Spielstrategien, der Drang nach Überlegenheit und Sieg sowie der Ausgang des Spiels mit einem klaren Ergebnis: Eine Mannschaft gewinnt, die andere verliert. Gewiss könnten diese

547 Bertati/Anfossi: La forza delle donne. Venedig 1778 (II,16). 
Kriterien auch für einen ernsthaften und blutigen Krieg gelten; wie Huizinga zeigt, sind die Grenzen zwischen Spiel und Ernst oft fließend, und der Krieg weist Züge des agonalen Spiels auf. Hier ist der Geschlechterkampf jedoch eindeutig der Spielsphäre zuzuordnen, nicht nur wegen der heiteren Stimmung und des guten und friedlichen Ausgangs, sondern auch aufgrund der Strategie der Frauen, die spielerisch mit der drohenden Gefahr umgehen und mit Leichtigkeit, ja sogar Leichtsinn, alles aufs Spiel setzen und gerade wegen ihrer Bereitschaft zum Spiel und zum Risiko am Ende gewinnen.

\section{I.2.2 Rivalität und Eifersucht als Auslöser für agonale Momente}

Agonale Situationen, wie der eben geschilderte Kampf zwischen den Geschlechtern, beruhen im Prinzip auf Feindschaft und Rivalität zwischen zwei oder mehreren Antagonisten. Rivalität ist in der Opera buffa nicht nur allgemein ein „dramatischer Motor“, sondern häufig auch Grund für Streit und Kampf. Das Gefühl der Eifersucht spielt dabei eine wesentliche Rolle, wie schon der etymologische Zusammenhang mit dem Wetteifer nahelegt.

Diese „Krankheit des Eiferns“ ist ein allgegenwärtiges Thema der Opera buffa und wird häufig explizit thematisiert, wie aus vielen Operntiteln ${ }^{548}$ ersichtlich ist. Ein regelrechter Topos ist jener der tugendhaften Frau, die zu Unrecht von ihrem Ehemann oder Liebhaber der Untreue verdächtigt wird und somit - ähnlich wie die Figur der buona figliuola - zum unglücklichen Opfer der Eifersucht des Mannes wird, wie es beispielsweise in "Il geloso in cimento“, „Il marito geloso“ und „Giannina e Bernardone" der Fall ist. Die Eifersucht wird in der Opera buffa nicht nur als Anomalie betrachtet, sondern das irrationale und impulsive Handeln der Eifersüchtigen wird als regelrechte Verrücktheit angesehen. In Salieris „La scola de’ gelosi“ spielt die Handlung teilweise in einem Irrenhaus mit einer eigens für die Eifersüchtigen vorgesehenen Abteilung. Die Ehepartner der Eifersüchtigen werden ebenfalls im Irrenhaus aufgenommen, weil die ständigen Verdächtigungen und Beschuldigungen der Eifersüchtigen auch sie verrückt werden lassen. Eifersucht muss geheilt werden, denn bloßes Einreden bzw. Versprechen nützt wenig, wie der Topos des selten eingehaltenen Schwurs des Eifersüchtigen, nie wieder eifersüchtig zu sein, lehrt. Cecchino aus Sartis „Le gelosie villane“ weiß ein hervorragendes Mittel zur Heilung der Eifersucht, nämlich eine Waldwurzel, deren Anwendung er in einer sentenziösen Buffa-Arie ${ }^{549}$

548 Z. B. „Le gelosie villane“, „Il geloso in cimento“, „Il marito geloso“, „La scola de’ gelosi“, „I puntigli gelosi“, „Il villano geloso“, „Le gelosie fortunate“, „L'amor bizzarro o La gelosa di se stessa“.

549 Aria Cecchino (Grandi/Sarti: Le gelosie villane. Venedig 1776, I,10) 
erklärt. Meistens wird den Eifersüchtigen aber eine härtere Lehre erteilt: Sie werden auf die Probe gestellt und oft auch ausgelacht.

Als eine Art „pädagogisches“ Werk zur Heilung von der Eifersucht kann die schon erwähnte Oper „La scola de’ gelosi“ von Antonio Salieri und Caterino Mazzolà gelten, die - ähnlich wie die spätere Oper „Così fan tutte ossia La scuola degli amanti“, deren Libretto Lorenzo Da Ponte nach der Vorlage von Mazzolàs erfolgreichem Text schrieb - wie ein mechanistisches Verhaltensexperiment in Sachen der Eifersucht anmutet. Protagonisten der Handlung sind zwei Ehepaare, ein adeliges (Conte und Contessa) und ein bürgerliches (Blasio und Ernestina). Der Symmetrie halber ist bei beiden Paaren ein Partner eifersüchtig: bei einem die Frau (Contessa), beim anderen der Mann (Blasio). Blasio ist der für die Opera buffa typische altmodische eifersüchtige Ehemann, der seine Frau Ernestina zu Unrecht verdächtigt, der Conte di Bandiera $^{550}$ dagegen ein „marito moderno“, eine Art Don Giovanni, der auf Ehefrauen von eifersüchtigen Männern „spezialisiert“ ist, während er seine eifersüchtige Contessa vernachlässigt und unglücklich macht.

Die Beziehung zwischen Blasio und Ernestina nimmt durchaus agonale Züge an, als die von der übertriebenen und unberechtigten Eifersucht ihres Ehemannes gereizte Ernestina seinem Ärger zum Trotz ankündigt, dass sie ausgehen und sich amüsieren will.

Ernestina: In buona compagnia

Oggi a vostro dispetto

Mi voglio divertir.

\footnotetext{
Questa radica produce

Un effetto naturale,

Che a chi indosso tien quel male

Lo guarisce in pochi dì.

Tutto sta nell'applicarla,

Nel saper apparecchiarla

La mattina innanzi dì.

Se la prima applicazione

Il suo effetto non produce

Replicate la lezione,

Che la Moglie si riduce

In perfetta sanità.

Io qual'ora mi ricordo

Di quel giorno fortunato,

Ch'il rimedio ho adoperato

Sempre ridere mi fa.
}

550 Bandiera bedeutet Fahne, Flagge. Vermutlich handelt es sich um einen sprechenden Namen, der die Flatterhaftigkeit des Conte zum Ausdruck bringt. 
Blasio: Chi ve l'ha detto?

Vi sfido, lo vedremo. ${ }^{551}$

Blasio nimmt die Herausforderung an („Vi sfido“), und der Kampf beginnt. Er sperrt Ernestina in der Wohnung ein und hängt ein Schild mit der provokatorischen Inschrift „Qui alcun non entrerà “ an die Tür. Ernestina lässt das Schloss austauschen, schreibt auf der Rückseite des Schildes als spöttische Gegeninschrift „La donna ve la fa“ und geht trotzig aus. So muss der eifersüchtige Blasio seine erste Belehrung und gleichzeitig eine Niederlage hinnehmen. Die nächste Lehre erfolgt im Irrenhaus, als die beiden Paare sehen, wie (und wo) die Eifersüchtigen enden, die der Wächter wie eine Jahrmarktattraktion anpreist. Die eigentliche „Schule der Eifersüchtigen“ findet aber in der Gemäldegalerie des Conte statt, die den titelgebenden Namen „La scola de’ gelosi“ trägt. Anhand von vier exemplarischen Bildern erteilt der Conte dem eifersüchtigen Blasio eine Lektion in Sachen der Lebensphilosophie: Das erste Bild stellt ein gähnendes Bauernpärchen in Begleitung der personifizierten Langeweile dar. Der Conte erklärt, dass die absolute Sicherheit über die Treue des Partners Langeweile verursacht. Das zweite Bild stellt die personifizierte Eifersucht dar, die vom (ebenfalls personifizierten) Hass gefolgt wird, denn der Eifersüchtige ist - wie der Conte erklärt - eine Qual, so dass er als natürliche Reaktion den Hass auf sich zieht. Die nächsten zwei Gemälde stellen Dreieckskonstellationen unter antiken Gottheiten dar: In einem Fall steht der misstrauische Vulkan mit einem Schlüssel in der Hand da, während seine Gattin Venus, die er eingesperrt zu haben glaubt, sich mit ihrem Liebhaber Mars unterhält. Im anderen Bild ist Jupiter dargestellt, der Junos Bewachung zum Trotz in Stiergestalt Europa entführt.

Die Contessa, die die ganze Lektion mitgehört hat, die der Conte insgeheim auch an sie gerichtet hatte, wendet das Gelernte sofort an, zeigt sich nicht mehr verliebt und eifersüchtig, sondern kühl und distanziert. Das weckt automatisch das Interesse des Conte, der seine Ehefrau plötzlich wieder begehrenswert findet. Später fasst die Contessa den Mechanismus folgendermaßen zusammen: „Perché m’ami, a me conviene / Fargli creder, che non l'amo. “552 Die „scola“ lehrt die Eifersüchtigen also spielerischer vorzugehen, Gleichgültigkeit vorzutäuschen, um Liebe zu erhalten, Leichtigkeit vorzuspielen, um zu gefallen. Die so belehrten Eifersüchtigen schaffen es nun, durch falsche Liebesbriefe und unechte Portraits die Eifersucht des jeweiligen Ehepartners zu wecken - denn die Opfer der Eifersucht können die (vermeintliche) Untreue ihres Partners genauso wenig ertragen wie die ursprünglich Eifersüchtigen -, so dass schließlich alle genügend belehrt sind. Die Moral zum Schluss lautet:

551 Mazzolà/Salieri: La scola de’ gelosi. Venedig 1779 (I,15).

552 Ebd. (II,10). 
Stia ciascun colla sua sposa

Ch'è follia cangiar pietanza.

(...)

Chi disturba il sacro nodo

La sua pace perderà.

(...)

Non v'è cosa più gioconda

D'un felice matrimonio. ${ }^{553}$

Für die Zuschauer erhält dieses „nur als Spiel“, d. h. auf der Theaterbühne, durchgeführte „Laborexperiment“ den häufig für das Spiel festgestellten Probecharakter (im Sinne von Rapps „Erprobungsspiel“), ermöglicht also ein simuliertes „Durchkosten von Lebensmöglichkeiten" ${ }^{554}$ und besitzt einen eindeutig erzieherischen Zweck. Gerade wegen des symbolischen Erlebens ist für das Publikum die aus dem Experiment gezogene Lehre besonders wirksam.

\section{I.2.3 Agonale Szenen}

Die allegorische Darstellung im zweiten Bild der „scola de’ gelosi“, in dem die Eifersucht vom Hass gefolgt wird, könnte als Emblem für viele Opere buffe verwendet werden, denn die in den Libretti allgegenwärtige Eifersucht dient häufig als Auslöser von Hass und Wut. Müller-Lindenberg sieht Wut und Angst als „zentrale Affekte der Buffa" 555 und zählt für die Wut drei typische Gründe auf, nämlich „den Widerstand gegen ein aufgezwungenes Heiratsprojekt“, „die ohnmächtige Erkenntnis, Opfer einer Intrige geworden zu sein“ und „die Eifersucht“, die mit Abstand den häufigsten Grund für Wutausbrüche abgibt. Der Zusammenhang zwischen Rivalität, Eifersucht und Wut scheint also eines der typischsten Grundmechanismen der Buffa zu bilden, aus dem wiederum „agonale“ Szenen hervorgehen, deren Spielcharakter häufig durch den heiteren komödiantischen Kontext zusätzlich betont wird.

Huizinga zählt unterschiedliche Möglichkeiten des Agons auf, die teilweise auch in der Opera buffa eine Rolle spielen: „Man kämpft mit der Kraft seines Körpers, mit den Waffen, mit dem Verstande oder mit der Faust, mit Zurschaustellung von Aufwand, mit großen Worten, prahlend, renommierend, schimpfend (...)." ${ }^{\text {"556 Als }}$

553 Ebd. (II,22).

554 Groos: Das Spiel. Zit. nach Scheuerl: Theorien des Spiels. S. 72.

555 Vgl. Müller-Lindenberg, S. 57.

556 Huizinga, S. 56. 
„Kampf mit dem Verstand“ kann das schon erwähnte strategische Spiel der Intrige und Burla gelten, mit dem in der Regel die Schlauen die Dummen hereinlegen. Gelegentlich kommt es in der Buffa zu Schlägereien, die man als „Kampf mit der Faust“ bezeichnen kann. Besonders verbreitet sind „Prahlerei-Arien“, die Huizingas „Kampf mit großen Worten“ entsprechen. Das Duell als „Kampf mit Waffen und Körperkraft“ und der Streit als „Kampf mit Worten, schimpfend“ dagegen werden in der Folge näher untersucht.

\section{I.2.3. I Duell- und Kampfszenen}

Schon Matzat hat bemerkt, dass „der Einfluß des Kampfspiels in vielen Formen des Theaters deutlich erkennbar“ ist, und nennt dafür „Fechtszenen, Schaukämpfe, aber auch Rededuelle und Streitszenen" 557 als typische Beispiele. Aufgrund seiner besonderen Bühnenwirksamkeit und seines dramatischen Potenzials wird das Duell, das als gesellschaftliches Ritual zum damaligen Alltagsleben gehörte, in der Opera buffa immer wieder verwendet. Huizingas Bemerkung über den antithetischen Charakter des Spiels, das sich in der Regel zwischen zwei Parteien abspielt, trifft auf das Duell in besonderem Maße zu, denn es handelt sich um einen damals in der Regel mit Schwertern ausgetragenen Zweikampf. Als Topos der comedia de capa y espada kommt das Duell besonders in Opere buffe vor, die auf Stoffen spanischer Herkunft basieren. Der Auslöser des als Zweikampf ausgetragenen Konflikts ist meistens eine Ehrenverletzung. Als Beispiel dafür kann „Bellezza ed onestà“, besser bekannt unter dem Titel „Una cosa rara“, des spanischen Komponisten Vincente Martín y Soler und des Librettisten Lorenzo Da Ponte als Beispiel dienen. Hier macht der Infante di Spagna dem schon verlobten Bergmädchen (serrana) Lilla den Hof und singt ihr ein Ständchen. Unwissend, um welch fürstlichen Verehrer es sich handelt, tritt Lillas in seiner Ehre verletzter und vor Wut rasender Bräutigam Lubino mit seinem Freund Tita gegen den Nebenbuhler an, um seine eigene Ehre und die seiner Braut zu retten.

In einer finaleartigen Ensemblenummer findet in dunkelster Nacht der Kampf des Prinzen, unterstützt von seinem Oberstallmeister Corrado und dem podestà Lisargo, gegen Lubino und Tita statt. Die beiden Mädchen, Lilla und Ghita, folgen ihren Verlobten in Mäntel gehüllt und mit Schwertern in der Hand („con cappa, e spada“), um ihnen im Kampf heroisch beizustehen.

Tita/Lubino D'ammazzarci han l'intenzione;

a due: $\quad$ Fuori fuori lo spadone,

557 Matzat, S. 49. 
E meniam senza pietà.

Ih $\ldots$ eh $\ldots$ ih $\ldots$

Lisargo/Corrado

a due: $\quad$ Villani indietro,

Tita/Lubino

a due: $\quad$ Ih $\ldots$ eh $\ldots$ ih $\ldots$

Lilla e Ghita con spada sguainata si mettono davanti ai loro sposi.

Lilla/Ghita: $\quad$ Siam qui anche noi.

E vogliam morir con voi,

Per mostrarvi fedeltà. ${ }^{558}$

Der Kampf endet abrupt, als beim Auftreten der beiden Frauen der Infant allzu große Gefahr wittert und sich zu erkennen gibt, worauf die vier Bergbewohner demütig in die Knie sinken.

Das Spannungspotential dieser Kampfszene beruht nicht nur auf dem „Missverständnis“ - der erhebliche Standesunterschied gestattet kein Austragen eines Duells -, sondern auch auf der Gefahr eines tödlichen Ausgangs, dem sogar die beiden Frauen ausgesetzt sind. Aktionsreiche Kampf- und Duellszenen erfreuten sich besonderer Beliebtheit, nicht nur wegen ihrer hohen Bühnenwirksamkeit, sondern auch aufgrund des spielhaften Charakters dieser Wettkämpfe.

Ein weiteres Beispiel für eine besonders wirksame Duellszene bietet der in Venedig sowohl von Giuseppe Calegari ${ }^{559}$ als auch von Giuseppe Gazzaniga ${ }^{560}$ vertonte, ebenfalls aus Spanien stammende Don-Giovanni-Stoff. Die Verführung der Donna Isabella bzw. Donna Anna durch den Titelhelden bewirkt die Herausforderung des Familienoberhauptes zum Duell. Die höchst dramatisch wirkende Tötung des Komturs stellt aber eine absolute Ausnahmesituation in der Buffa-Gattung dar, denn der Tod auf offener Bühne fällt aus dem spielerisch-leichten und komödiantischen Rahmen der Opera buffa heraus. Diesbezüglich meint Huizinga, bei agonalen Spielen brauche „die Grenze dessen, was im Spiel erlaubt ist, nicht beim Blutvergießen, ja nicht einmal beim Totschlag gezogen zu sein",561 allerdings herrscht bei einer solch extremen Aussage die Gefahr, dass der Spielbegriff grenzenlos ausufert. Im Schlussteil seines Homo ludens greift Huizinga dieses Thema wieder auf und meint, die Grenze

558 Da Ponte/Martín y Soler: Bellezza ed onestà. Venedig 1788 (II,16).

559 Pariati/Calegari: Il convitato di pietra. Venedig 1777.

560 Bertati/Gazzaniga: Don Giovanni o sia Il convitato di pietra. Venedig 1787. Eine dritte, diesmal parodistische Vertonung des Don-Giovanni-Stoffs stammt von Francesco Gardi. Hier findet das Duell zwischen Don Giovanni und dem Komtur aber in der Vorgeschichte statt und wird folglich nicht auf der Bühne gezeigt.

561 Huizinga, S. 90. 
zwischen Spiel und Ernst liege im Ethischen. ${ }^{562}$ Bei einer Tötung oder einer schweren Verletzung ist meines Erachtens diese „ethische“ Grenze bald erreicht und das „Spiel“ endet schlagartig, wobei Heiterkeit und Freude in ihr Gegenteil kippen.

Die Duellszene weist durchaus Züge des agonalen Spiels auf: Von einer Rivalitätssituation ausgehend, beinhaltet der Zweikampf das Moment der Herausforderung, den Spannung erzeugenden ungewissen Ausgang und die für das Spiel typische Dynamik der „Hin- und Herbewegung“, die sich aus den abwechselnden Degenstößen ergibt. Sie ist nämlich nicht nur szenisch sichtbar, sondern zusätzlich auch durch die Vertonung verdeutlicht. In Calegaris erstem Finale wird das Duell textlich (genauso wie im vorigen Beispiel von Martín y Soler) vor allem durch die Ausrufe (eh, eh, ah, ah) der beiden Kämpfenden zum Ausdruck gebracht, denn während des Duells werden nur wenige Worte gewechselt. Die eigentliche Gestaltung dieser Szene liegt zunächst in den Händen des Komponisten, der hier - so wie in den meisten Duellvertonung der Buffa - auf sehr einfache Weise die Ausrufe der Kämpfenden in die Musik einflicht. Wie es häufig bei Duellszenen der Fall ist, „singen“ hier die Kämpfenden ihre Ausrufe sogar immer auf demselben Ton, es besteht allerdings auch die Möglichkeit, dass es sich um eine Schreibweise handelt, die eine möglichst realitätsnahe Ausführung der Ausrufe auf unbestimmter bzw. ungenau bestimmter Tonhöhe anweisen soll. Der Schwerpunkt solcher Szenen liegt nämlich nicht so sehr in der Vertonung, sondern vor allem in der szenisch-gestischen Ausführung des Duells. Die Ausrufe dienen dabei als Anhaltspunkt bzw. als „Regieanweisung“ für das szenische Spiel, denn es liegt nahe, dass Degenstöße und Ausrufe simultan erfolgen.

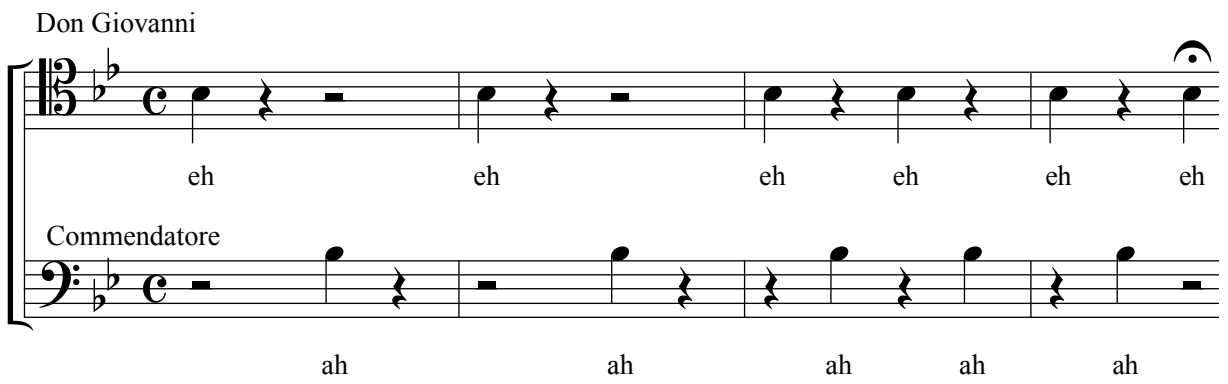

1 Calegari/Pariati: Il convitato di pietra. Venezia 1777 (F-Pn D 1793) ${ }^{563}$

562 „Wer in der ewigen Umwälzung des Spiel-Ernst-Begriffs fühlt, wie seinen Geist ein Schwindel ergreift, der findet den Stützpunkt, der ihm im Logischen entsank, im Ethischen wieder." (Huizinga, S. 203).

563 Als Abkürzung für die Bibliotheken, aus denen die Partituren stammen, werden in dieser Arbeit die im Sartori-Katalog gebrauchten Bibliothekssigel verwendet. 
Don Giovannis Überlegenheit gegenüber dem alten Komtur wird hier durch die Position seiner Ausrufe und Schwerthiebe zum Ausdruck gebracht, die sich auf den betonten und deswegen musikalisch „stärkeren“ Zählzeiten befinden, während die Ausrufe des commendatore gewissermaßen „nachhumpeln“. Die Verdichtung der Repliken ist als implizite Regieanweisung für eine Beschleunigung des Duellgeschehens zu verstehen, die zum tödlichen Stich auf dem letzten, mit Fermate versehenen Ausruf Don Giovannis hinführt.

Die Vertonung einer Duellszene als einfache rhythmische Hin- und Herbewegung der Ausrufe der Kontrahenten ist für die Opera buffa sehr typisch. Eine weitere durchaus übliche Vertonungsmöglichkeit ist die der bildlichen, tonmalerischen Darstellung der Schwertstreiche durch die Figur der tirata, wie es in Gazzanigas Introduzione der Fall ist.

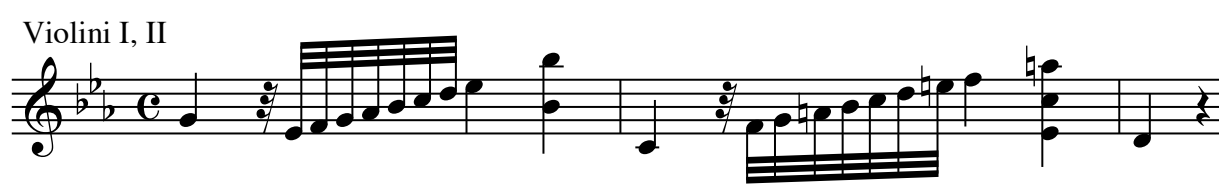

2 Gazzaniga/Bertati: Don Giovanni o sia Il convitato di pietra. Hg. von Stefan Kunze. Kassel u.a. 1974

Selbst die Bezeichnung für diese Figur entstammt der Fechtterminologie. Typisch ist auch, dass die Musik in solchen Szenen eine vorwiegend unterstützende Funktion erhält und dass die Verständlichkeit und Wirksamkeit des Geschehens beinahe gänzlich der Pantomime überlassen bleibt.

Das Duell zwischen Don Giovanni und Komtur ist in engem Zusammenhang mit dem „virtuellen“ Duell der beiden gegen Ende der Oper zu sehen, als der tote commendatore als Statue und Repräsentant einer überirdischen Macht erscheint. Hier ist wie auch bei „konkreten“ Duellen das Moment der Herausforderung besonders relevant; in Calegaris Oper wird es, wie damals üblich, gestisch durch den Wurf eines Handschuhs signalisiert. Der Zweikampf zwischen Don Giovanni und der Statue wird auf einer transzendenten Ebene durchgeführt, in der selbstverständlich die überirdische Macht gegen den Menschen gewinnt.

Alle bisher beschriebenen Duellszenen und Kampfsituationen sind eigentlich ernst gemeinte Tapferkeitsbeweise. In Calegaris „Convitato di pietra“ ist eine zusätzliche Duellszene eingebaut, die aufgrund des Kontextes komisch konnotiert ist, denn der Diener Passarino spielt hier in der Dunkelheit seinem Herren Don Giovanni einen Streich : Er gibt sich als Don Slosa Baccalà (baccalà = Stockfisch) aus, verspottet und provoziert also seinen draufgängerischen Herren, der sofort zur Waffe greift. So kommt es zu einer Buffo-Duellszene im Dunkeln, die 
zwar genauso wie der spätere Zweikampf zwischen Don Giovanni und dem Komtur vertont ist, nämlich durch abwechselnde, auf derselben Tonhöhe notierte Ausrufe der beiden Gegner, deren Rhythmus zum Ende des Duells hin beschleunigt wird,

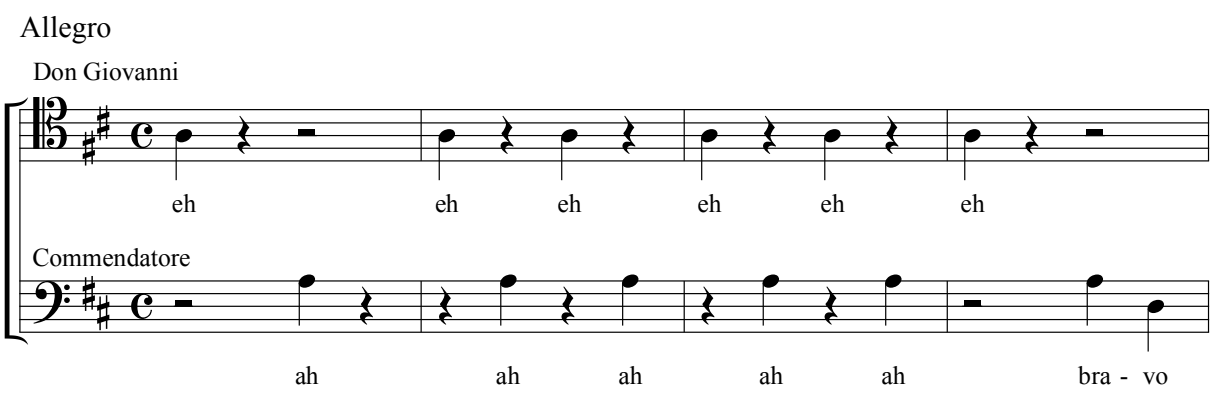

3 Calegari/Pariati: Il convitato di pietra. Venezia 1777 (F-Pn D 1793)

aber durch den burlesken Kontext kippt die gleiche Duellsituation ins Komische. In der neutral gehaltenen Vertonung deutet nichts auf Komik hin, ja sie ist sogar mit der des ernst gemeinten Duells beinahe identisch. Der Ausdruck der Komik wird allein den schauspielerischen Fähigkeiten der Sänger, vor allem Passarinos, überlassen, der vermutlich die von Bateson theoretisierte metakommunikative Botschaft „Dies ist ein Spiel“ implizit, also möglicherweise pantomimisch, mitgeteilt haben wird. Das auch unabhängig vom Kontext spielhafte Züge aufweisende Duell erhält in diesem von Passarino nur zum Spaß provozierten duello buffo eine zusätzliche spielerische und heitere Facette und erfüllt die sowohl für das Komische als auch für das Spiel typische Bedingung der Harmlosigkeit.

Ein ähnliches „Ins-Komische-Kippen“ einer ernsten Duellszene ist auch in Anfossis Oper „Isabella e Rodrigo“ zu finden, deren erster Akt Züge des Don-GiovanniStoffs enthält. Im ersten Finale kommt es hier ebenfalls zu einem Duell zwischen dem commendatore, Isabellas Vater, und ihrem Liebhaber Rodrigo. In dem Glauben, Isabella habe aus Verzweiflung darüber, dass ihr Vater sie mit dem verhassten Don Sancio verheiraten will, Selbstmord begangen, fordern sich Rodrigo und der Komtur zum Duell heraus. Der zunächst ernst gemeinte Zweikampf endet hier allerdings in einer komischen, ja parodistischen Szene, in der die beiden vor Schmerz über den Verlust der Tochter bzw. Geliebten wahnsinnig gewordenen Männer aufhören zu kämpfen (die Regieanweisung lautet: „vanno per ferirsi, e nell'avventarsi il colpo sorpresi da 
furore, restano taciti traballando alcun poco“564) und sich den verschiedensten Wahnvorstellungen hingeben.

D. Rodrigo e Commendatore a 2: Veggo oscurarsi il cielo ...

L'ombra ... la voce ascolto ...

Quel d'Isabella è il volto ...

Ride ... no, no: minaccia ...

Chiama: no, no: mi scaccia ..

(...)

D. Rodrigo :

Chi mi stringe? Quest'è il caro bene ...

Commendatore:

Chi mi tocca? la mia cara figlia ...

$(\ldots)^{565}$

Der Wahnsinn der beiden Männer verursacht ein vollkommenes Durcheinander, mit dem das Finale endet.

Dieses „Kippen“ zwischen Ernst und Komik - hier werden unter anderem Elemente des Ombra-Topos aus der Opera seria parodistisch eingesetzt - ist anscheinend ein derart wesentliches Charakteristikum, dass Wolfgang Iser das Komische allgemein als „Kipp-Phänomen“ definiert. ${ }^{566}$ Diese Eigenschaft wurde auf eine sehr ähnliche Weise auch für das Spiel theoretisiert, vor allem von Scheuerl, der die vorwiegend auf das Verhältnis zwischen Spiel und Ernst bezogene „labile Ambivalenz“ als eines der Wesenskriterien des Spiels bezeichnet.

An gewissen Stellen, vor allem in manchen Arien und Duetten, überlagern sich agonales Spiel und Als-ob-Spiel. In der Arie „Avrò cuor di cimentarmi“ aus Sartis „Le gelosie villane“ trägt beispielsweise Cecchino ein imaginäres Duell gegen den Marchese aus, der gegen seinen Willen seine schon (mit Tognino) verlobte Tochter heiraten will. Um den an seiner Tapferkeit im Kampf zweifelnden Tognino eines Besseren zu belehren, prahlt Cecchino mit seiner Fechtkunst, indem er die verschiedenen Hiebe vorführt. Der Interpret führt laut Regieanweisung die genannten Bewegungen aus, wodurch das Duell tatsächlich „gespielt“ wird.

Avrò cuor di cimentarmi

Col Marchese in Campo armato;

564 Bertati/Alessandri: Isabella e Rodrigo o sia La costanza in amore. Venedig 1776 (I,16).

565 Ebd.

566 Siehe Iser: Das Komische: ein Kipp-Phänomen. In: Preisendanz u. Warning (Hg.): Das Komische. S. 398. 
Venga pur, son pronto all'armi

Lo vedrai che disarmato

$\mathrm{Al}$ mio piede caderà.

Già lo vedo il poverino

Steso in terra tutto sangue

Fa pietade il suo destino.

(...)

Della scherma io sono inteso

E son stato ad imparar.

Osserva ignorante

Questa è una stoccata, (eseguisce)

Questa è una parata,

Di fianco, di testa,

Che sembra tempesta

Per farlo tremar. ${ }^{567}$

In musikalischen Nummern, die den Kampf thematisieren, kommt es öfter zu einer solchen Mischung zwischen Agon und Als-ob-Spiel, wie in einem Duett aus Paisiellos Oper „L'innocente fortunata“. Hier fordern sich die Liebesrivalen Brettone und Don Gusmano gegenseitig zum Kampf heraus, d.h. zu einem regelrechten militärischen Krieg, der ihren Rollen entspricht (Brettone ist ein englischer Kriegsschiffskapitän, Don Gusmano ein spanischer Oberleutnant). Den Kampf, der auf der Bühne ausgetragen werden soll, simulieren die beiden im Duett gewissermaßen im Voraus:

Brettone: Alto là mie sentinelle,

Che il nemico a noi si avanza;

Moschettate in ordinanza

Via tirate presto sù.

D. Gusman: Fuego fuego, all'armi all'armi

Marcia aglià l'Infanteria;

Venga a qui l'Artiglieria.

Cannonate via bù bù ...

Brett: $\quad$ Si ritira quella fila ...

D. Gus: Granaderos avanzate ...

Brett: Questa parte riparate...

D. Gus: Respingete...

567 Grandi/Sarti: Le gelosie villane. Venedig 1776 (II,11). 
Brett: $\quad$ State forti ...

D. Gus: Via levate quelli morti ...

Brett: $\quad$ Custodite i Prigionieri ...

D. Gus: Quei feriti all'Ospitale ...

Brett: $\quad$ Retro guardia al Generale ...

D. Gus: Mas chittemos tantas burlas

Brett: Via facciamo un po' davvero.

a 2: $\quad$ E così poi Cavaliero

Noi vedrem chi vincerà.

$(\ldots)^{568}$

Der imaginäre Kampf wurde wahrscheinlich von einer Pantomime begleitet, wie es Kinder bei einem Kriegsspiel tun würden. Den Eindruck des Kinderspiels vermittelt nicht nur die Fiktivität des Ganzen, sondern auch die Nachahmung der Schüsse durch entsprechende Laute (bù, bù).

\section{Allegro spiritoso}

Bretton

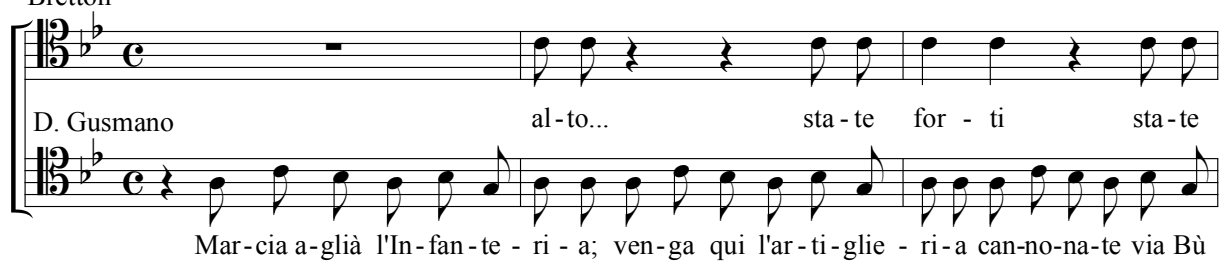

Bret.

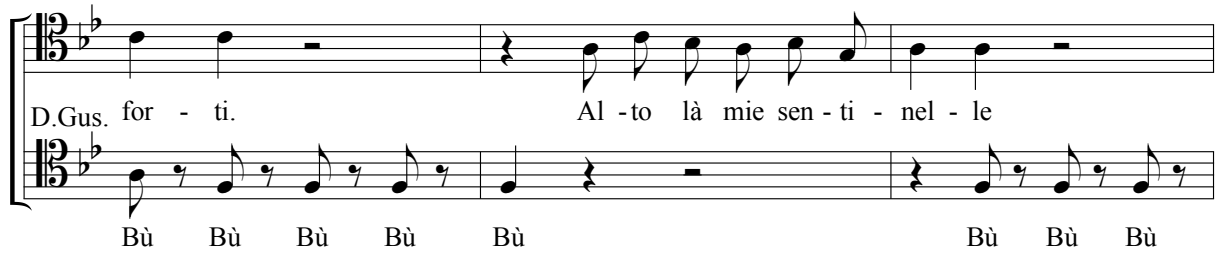

4 Paisiello/Livigni: L’innocente fortunata. Venezia 1773 (I-Fc D. I. 464-465-466)

Außerdem bekräftigt den Spielcharakter die Tatsache, dass ab einem gewissen Moment das „Spiel“ explizit mit dem gemeinsamen Entschluss, die Spielebene zu ver-

568 Livigni/Paisiello: L'innocente fortunata. Venedig 1773 (II,9). 
lassen, beendet wird („Mas chittemos tantas burlas / Via facciamo un po’ davvero“" = Lassen wir doch diese Scherze / Machen wir mal Ernst).

Die Möglichkeiten und Formen des Als-ob-Spiels in der Opera buffa werden im Kapitel „Mimicry“ genauer erläutert, in den letzten beiden Beispielen wurde aufgrund ihres Bezugs zum agonalen Spiel dieses Thema nur kurz vorweggenommen.

\section{I.2.3.2 Streitszenen}

Weitaus häufiger als Duell- und Kampfszenen sind in der Opera buffa Streitszenen. Sie bieten einen Anlass für ein lebendiges und aktionsreiches szenisches Spiel, das von heftigen Gemütsbewegungen, wie Wut und Ärger, beherrscht ist, und setzen wie die meisten agonalen Szenen die Anwesenheit von mindestens zwei Personen voraus, weswegen sie sich zur Vertonung als Ensemblenummern eignen. Gründe für Streit und Zank sind in der Buffa fast immer Unzufriedenheit, Rivalität oder Eifersucht. Ein Streit zwischen zwei Gatten zieht sich wie ein roter Faden durch die gesamte Oper von Sarti „I pretendenti delusi“, besser bekannt unter dem Namen „Fra i due litiganti il terzo gode“ ${ }^{569}$ Der Streit dreht sich um die Verheiratung von Dorina, der Dienerin der Contessa di Belfiore, die sie mit dem Gärtner Mingone vermählen will, während ihr Gatte, der Conte di Belfiore, auf seinen Diener Titta als Bräutigam besteht. Hinter diesen Wünschen verbirgt sich jeweils ein persönliches Interesse: Der Conte hat eine geheime Zuneigung zu Dorina und will sie durch die Hochzeit mit seinem eigenen Diener in seiner Nähe behalten; die eifersüchtige Contessa möchte diesen Plan durch die Wahl eines anderen Bräutigams scheitern lassen. Diese Rivalität überträgt sich auch auf die beiden pretendenti, die sich ihrerseits in einen Streit verwickeln. Der Ausgang der Handlung ist vom Titel her zu erahnen, trotzdem bewirkt der anhaltende Streit eine große Spannung über zwei Akte. Der dritte Akt ist bei der venezianischen Aufführung, nach dem Libretto zu urteilen, ersatzlos gestrichen worden, so dass die Oper mit einer ungelösten Handlung endet. Die großen Streitszenen sind aus dramaturgischen Gründen an den Eckpunkten der Oper positioniert: In allen größeren Ensembles, nämlich in der Introduzione, im ersten und zweiten Finale, veranlassen sie eine extreme spektakuläre Erregung und ein aktionsreiches Spiel. Bei Aufgehen des Vorhangs ist der Streit zwischen Conte und Contessa schon im Gange, dessen Grund - zum Aufbau einer beträchtlichen Spannung - erst am Ende der Introduktion geklärt wird. Am Schluss des ersten Finales kann eine Schlägerei zwischen den beiden pretendenti nur durch den Eingriff der fünf übrigen Personen verhindert werden. Hier wird durch die Streitsituation ein Höhepunkt an Spannung und Aufre-

569 Als Vorlage diente Carlo Goldonis Libretto „Le nozze“. 
gung erreicht, wie es am Schluss eines Binnenfinales üblich und von der Konvention vorgegeben war. Im zweiten Finale kommt es zu einem erneuten Streit zwischen den vorher vom klugen und gutmütigen Masotto (dem „terzo“, der schließlich Dorina heiraten wird) beruhigten Eheleute. Zornige Ausrufe, Beschimpfungen oder sogar Drohungen sind die Hauptingredienzien solcher Streitszenen. In größeren Ensembles mischen sich häufig die Umstehenden zur Streitschlichtung ein, so dass auch die formalen Konventionen des großen Ensembles erfüllt werden.

Die kompakteste und üblichste Form, in der in einer Opera buffa Streitszenen „verpackt“ werden, ist das Zank- oder Streitduett. Immer wieder kommt es in der Buffa zu Auseinandersetzungen, ja zu regelrechten Rededuellen zwischen zwei Personen, wobei der für das agonale Spiel typische antithetische Charakter besonders zur Geltung kommt. In der Regel beginnt der Streit schon im Rezitativ vor dem eigentlichen Zankduett. In Paisiellos „I filosofi immaginari“ kommt es beispielsweise zu einer Diskussion zwischen dem Philosophen Petronio und seiner Tochter, die sich gegen den Heiratsplan des Vaters auflehnt. Zwei entgegengesetzte Meinungen prallen aufeinander und münden in folgendes Streitduett.

Clarice: Non lo voglio non lo prendo;

No Signore, Signor no.

Petronio: Che lo sposi io pretendo;

Sì Signora, io così vò.

Clarice: La vedremo.

Petronio: Certamente.

Di tuo padre uom prudente

Devi far la volontà.

Clarice: Saria bella in verità!

Petronio: Bella, o brutta, la vedremo.

Clarice: No l'faremo.

Petronio: Lo faremo.

Clarice: No.

Petronio: Sì.

Clarice:

No.

Petronio:

Clarice:

Sì.

Petronio:

No.

a due: La vedrem s'ella è così. ${ }^{570}$

570 Bertati/Paisiello: I filosofi immaginari. Venedig 1782 (II,2). Diesen Text entnimmt Bertati aus einem 
Trotz der Häufigkeit von Vater-Tochter-Zwisten in Bezug auf Heiratsabsichten in der Opera buffa kommt es jedoch selten zu einer derart offenen Konfrontation. ${ }^{571}$

Die erregte Situation des Zanks wird hier musikalisch durch ein lebhaftes Tempo (Allegro spiritoso) und ein aufgeregtes, typisch buffoartiges Singstimmen-Parlando zum Ausdruck gebracht. Das rasche Hin und Her der Repliken in Text und Musik vermittelt einen realistischen Eindruck des Streitens und des Wettkampfs, aber auch des Spiels: Dieses könnte von der Bewegungsart her beispielsweise mit einem Tennisspiel verglichen werden, deckt sich aber auch auf einer abstrakteren Ebene mit Buytendijks allgemeiner Definition der Grunddynamik des Spielens als „Hin- und Herbewegung“. ${ }^{572}$ Den häufigen Sprecherwechsel bzw. die hohe Unterbrechungsfrequenz im Drama bezeichnet Pfister als Kennzeichen für den „engen Bezug zwischen den Dialogpartnern“, eine „stark ausgeprägte Dialoghaftigkeit“ und ein „aktionales Sprechen“. ${ }^{573}$ Bei diesem Duett wird die Stichomythie, die Pfister unter anderem als charakteristische „Struktur konflikthaften Sprechens“574 definiert, so sehr radikalisiert, dass sie zur Antilabe wird, d. h., die Länge der Repliken beträgt hier oft weniger als einen Vers, manchmal sogar nur eine einzige Silbe: „no - sì - no - sì“. Dieses Beharren der beiden Zankenden auf „ja“ bzw. „nein“ bringt auf einfache und anschauliche Art die entgegengesetzten Positionen der Streitenden auf den Punkt. Der Kontrast wird zusätzlich durch die weit (zwei Oktaven) auseinanderliegenden Stimmlagen (hoch - tief, Sopran - Bass, d2 - d) verstärkt.

\section{Clarice}

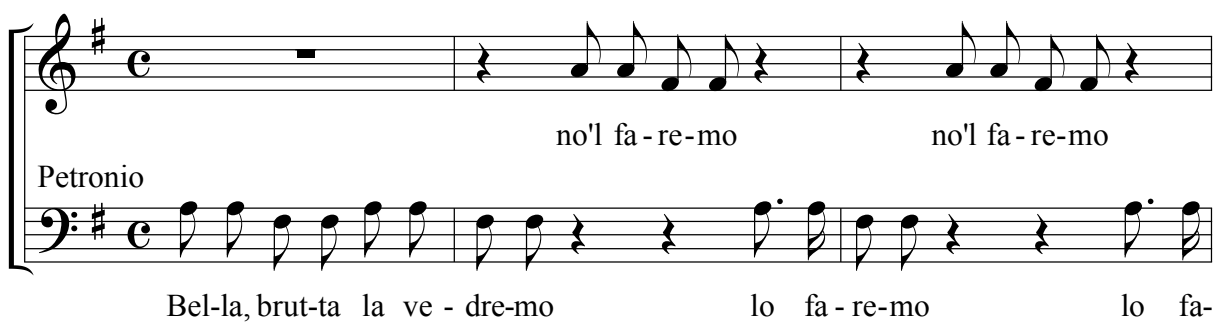

schon früher von ihm für Anfossi verfassten Libretto, nämlich „L'avaro“ (Venedig 1775). Der Kontext des Streitduetts ist ein ähnlicher: Rosalinda weigert sich den alten, tauben, aber reichen Mann zu heiraten, den ihr geiziger Vater nur für sie ausgesucht hat, weil er auf die Mitgift verzichten würde.

571 Meistens versucht das Mädchen bzw. das Liebespaar die Autorität des Vaters zu umgehen, statt offen dagegen zu kämpfen. Auch in diesem Libretto wird letztendlich die Hochzeit der innamorati durch List und Betrug erreicht, denn im offenen Kampf zwischen Vater und Tochter würde das Familienoberhaupt durch seine Autorität seinen eigenen Willen durchsetzen.

572 Vgl. Buytendijk, S. 118.

573 Pfister, S. 198.

574 Ebd. 
Cla.

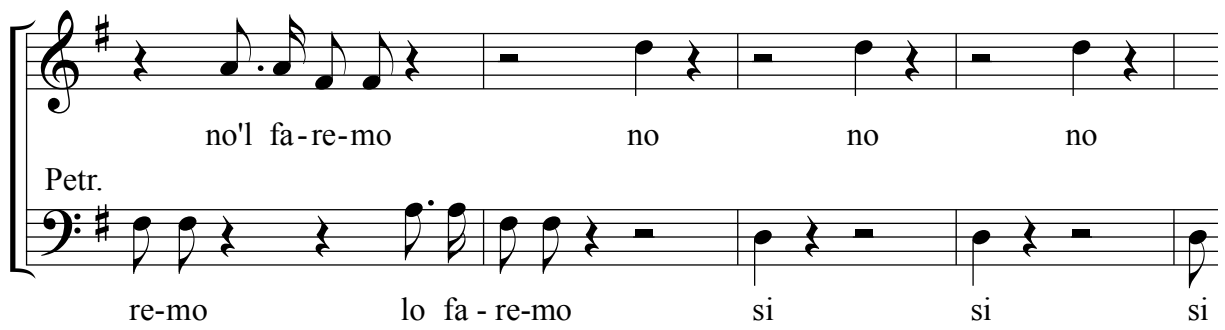

5 Paisiello/Bertati: I flosofi immaginari. (I-Pi ATVa 60/I-II)

Auch wenn der Gewinner schon im Vorhinein erahnt werden kann, geht aus diesen Zankduetten nie ein klarer Sieg hervor; die Funktion des Streits ist eher eine performative. Selten findet im konventionellen a due zum Schluss eine Versöhnung statt, in der Regel dient es dem Ausdruck des „geteilten“ Ärgers und der gemeinsamen Wut. Das eben untersuchte Streitduett endet sogar mit einer von beiden ausgesprochenen Herausforderung („La vedrem s'ella è così.“), die beinahe wie eine Wette klingt und auf eine Fortsetzung des „Kampfes“ hindeutet.

Eine klassische Situation, die in der Opera buffa als Streitduett vertont wird, besteht in der Rivalität zweier Frauen, die häufig die auch von Huizinga erwähnte Form des „Wetteifers in Höflichkeit“ annimmt. Charakteristisch für dieses „Spiel“ ist nach Huizinga folgendes Verhalten: „Man übertrumpft den Gegner, indem man ihm Platz räumt oder den Vortritt lässt. " 575 In der Buffa verbirgt sich häufig hinter einer vorgeheuchelten Höflichkeit eine extreme Gehässigkeit und Verachtung. In Bertatis und Gazzanigas Oper „Il serraglio di Osmano“, deren Stoff der „Entführung-aus-dem-Serail“-Thematik angehört, kommt es zu einem Zankduett zwischen Rosana, einer schon liierten Italienerin, in die sich der morgenländische Herrscher Osmano verliebt hat, und Zaida, einer Zirkassierin aus seinem Harem, die große Eifersucht und Wut gegen Rosana hegt. Vor dem eigentlichen Streitduett begegnen sich in einem langen Rezitativ die beiden Rivalinnen, von denen keine eine Begrüßung wagt und jede da parte die Situation und die Gesten der anderen kommentiert, die wie Züge einer Spielstrategie wirken. Schließlich beginnt ein Dialog mit vorgetäuschter Herzlichkeit („Oh cara“ / „Oh bella“).

Das Streitduett folgt dem klassischen, aus der Opera seria übernommenen DuettFormschema: Zunächst singen beide hintereinander jeweils eine vierzeilige Strophe, wobei jede für sich ihre Bemerkungen über die Rivalin so laut ausspricht, dass es die andere hören kann. Die hochmütige Rosana lacht über die Wut der Zirkassierin, diese

575 Huizinga, S. 70. 
hingegen bezeichnet das Geschrei und Geschwätz der Italienerin als Verrücktheit. Zur zusätzlichen Unterstreichung des Gegensatzes zwischen den beiden Fronten werden die unterschiedlichen Nationalitäten der beiden erwähnt. In einem kurzen a due lachen sie sich da parte gegenseitig aus. Der zweite Abschnitt, der aufgrund des rascheren Replikenwechsels im Seria-Liebesduett in der Regel eine Art Annäherung der beiden Liebenden darstellt, dient hier dem eigentlichen „Wetteifer in Höflichkeit“. So wie in anderen Streitduetten in diesem dialogischen Teil mit Worten, Beschimpfungen und Beleidigungen "gekämpft“ wird, findet hier ein Wettstreit mit Höflichkeiten statt. Jede will der anderen einen Gefallen erweisen, den die andere nicht annehmen will. Diese Höflichkeiten haben beide etwas mit dem Geruchssinn zu tun: Rosana bietet der Zirkassierin Schnupftabak an, Zaida der Italienerin ein Parfüm. Bezeichnenderweise finden beide den Geruch des ihnen angebotenen Geschenks widerwärtig, was besonders anschaulich zum Ausdruck bringt, dass sich die beiden „nicht riechen können“. Schließlich nehmen beide mit dem eigenen Riechstoff vorlieb - Rosana schnupft ihren Tabak, Zaida riecht an ihrem Duftfläschchen - und überschütten sich gegenseitig mit Komplimenten. Im obligatorischen a due zum Schluss, das im Liebesduett ursprünglich die Vereinigung der Liebenden symbolisiert, nehmen die beiden mit geheuchelter Herzlichkeit Abschied voneinander, während im (abwechselnden) da parte die kaum unterdrückte Wut wiederholt zum Vorschein kommt. Schließlich geht jede von einer anderen Seite ab.

Rosana: Passeggi, passeggi,

La bella Circassa

Infin che le passa

La rabbia dal sen.

Zaida: Che cianci, che strilli

La bella Italiana;

Che quand'una è insana

Soffrirla convien.

a due: Ah ah ah! nel guardarla

Da rider mi vien.

Rosana: Se prende Tabacco

Servita la rendo. (Cava la Tabacchiera, e gliela presenta)

Zaida: Tabacco non prendo.

Rosana: Perdoni l'ardir.

Zaida: $\quad$ Se a me fa il favore,

Io d'Acqua l'odore

La posso servir. (presentandole una boccetta d'odore)

Rosana: L'odor non mi piace. 
Zaida: $\quad$ Mi fa ben stupir.

Rosana: Osservi.

Zaida: Lei veda.

a due: Mi servirò io.

Lo prenderò io.

Che grazia; che brio!

Che ha lei nel nasar!

Rosana: Oh cara!

Zaida: Oh gentile

a due: Vorrei dalla bile

Che avesse a crepar,

L'interna mia bile

Mi fa oror crepar,

La prego a scusarmi

Ch'io prendo congedo.

La sua protezione

Divota le chiedo.

Ch'io l'ho già nel ... core

Si può assicurar.

Vorrei dalla bile

Che avesse a crepar,

L'interna mia bile

Mi fa oror crepar.

(Partono Rosana da una parte e Zaida dall'altra) ${ }^{576}$

Der von Huizinga theoretisierte antithetische Charakter des agonalen Spiels wird hier nicht nur durch die Opposition zweier Kontrahentinnen, sondern unter anderem auch durch die aus dem Text resultierende szenische Symmetrie zum Ausdruck gebracht. Das höfliche „Vortritt lassen“ im Rezitativ, das gegenseitige Beäugen, das da-parte-Kommentieren, das gegenseitige Auslachen, die Szene des gegenseitigen Beschnupperns und des Riechens am eigenen Requisit, die formellen Höflichkeitsgesten, das überschwängliche Loben, das überhöfliche Verabschieden, der verborgene Ärger und das wütende Abgehen in entgegengesetzte Richtungen bergen ein großes Potenzial an gestisch-mimischem Spiel und spielen sich in einer nahezu perfekten szenischen Spiegelsymmetrie ab, die auch optisch den Eindruck eines Spiels zwischen zwei einander gegenüberstehenden „Parteien“ erweckt. 
Solche Streitduette können in der Opera buffa als ausgesprochener Topos gelten. Der Zank findet in der Regel wie im letzten Beispiel zwischen zwei rivalisierenden Frauen statt, deren Gemeinheiten ins Komische ausarten, wodurch das Ganze einen spielerischen Charakter erhält: In der Oper „Castrini padre e figlio“ beispielsweise, in der sich der Streit $(I, 8)$ um das heikle Thema der Suche nach einem Bräutigam dreht, behauptet jede Rivalin, die andere werde keinen Bräutigam finden und müsse sich einen aus Stuck bzw. Holz basteln. In Gazzanigas „Il convitato di pietra“ streiten Donna Elvira und Maturina, beide von Don Giovanni erobert, darum, wer den Verführer heiraten wird, nachdem er, um sich aus einer heiklen Lage zu retten, beiden heimlich erzählt hatte, die andere sei verrückt. Der typische Buffo-Streit artet hier wie so oft in grobe und zugleich witzige Beschimpfungen wie sardella (Sardine) oder polpetta (Fleischklößchen) aus.

Spielcharakter haben häufig auch Streitszenen zwischen zwei Liebenden, der Streit erfüllt dabei gleichzeitig die Funktion eines Liebesspiels, ${ }^{577}$ denn er erhöht durch den unvermeidlich folgenden Friedensschluss die Freude an der Wiedervereinigung. Außerdem bietet aus dramaturgischer Perspektive der Streit auch bei Liebespaaren einen Anlass für spektakuläre Wutausbrüche, wie es beispielsweise in Bertatis und Anfossis „Il geloso in cimento“ der Fall ist. Hier bricht zwischen Donna Flavia und ihrem Geliebten Fabio ein heftiger Streit aufgrund der übertriebenen, unerträglichen und vor allem unbegründeten Eifersucht des „Titelhelden“ aus. Donna Flavia verliert die Geduld und verlässt ihn. Wütend werfen beide nach und nach alle Geschenke des Geliebten auf den Boden und zerreißen alle Liebesbriefe. Sie streiten noch eine Weile weiter, beruhigen sich schließlich, geben sich die weggeworfenen Geschenke (Ringe, Portraits etc.) wieder zurück und schließen Frieden unter der Bedingung, dass der Eifersüchtige sich bessern muss. Der Topos des hier in Fabios Arie integrierten Schwurs des Eifersüchtigen, nie wieder eifersüchtig zu sein, beendet die Streitszene.

Fabio: Voi siete un infedel

D. Flavia: Voi siete un pazzo.

(...)

Quando è così, finiamola.

(...)

Finiamola per sempre.

577 Im Liebesduett der Opera buffa können unterschiedliche Formen des Liebesspiels vorkommen, die allerdings im Kapitel „Liebesspiel“ besprochen werden, denn der agonale Aspekt ist in ihnen nicht immer vertreten. 
D. Flavia: Tenete. Ecco l'anello,

Che mi avete donato.

Fabio: Sì? Questo è il vostro astuccio

Con tutti i steccadenti.

D. Flavia: Questo nastro da petto

Pur è vostro. Ecco, a terra.

Fabio: Questo è il vostro ritratto.

Ecco, al Diavolo.

D. Flavia: Io deggio

Aver anche un viglietto. Eccolo appunto,

Cara. Più che me stesso (leggendo)

V'amo, e v'amerò ogn'ora...

Bugie, bugie. Sen vada alla malora. (lo strappa)

Fabio: Viglietti io qui non ho; ma giunto a casa

Tutti li incenerisco.

Vado. Padrona mia. (per partire poi si ferma in qualche distanza.)

D. Flavia: La riverisco. (fa lo stesso)

(...)

Ma bisogna emendarsi.

Fabio: Lo farò ... Ripigliate il vostro anello ...

E il vostro nastro. (ripigliandolo da terra)

D. Flavia: A voi,

Riprendete l'astuccio ... Ecco il ritratto ... (ripigliandolo da terra)

Fabio: Torniamo in pace?

D. Flavia: Sì ; ma con un patto.

Voi dovete giurarmi

Che geloso con me più non sarete.

Fabio: Sì, cara. Giurerò quel che volete.

ARIA: $\quad$ Non sarò mai più geloso $(\ldots)^{578}$

578 Bertati/Anfossi: Il geloso in cimento. Venedig 1774 (I,14). Diese Oper wurde nebenbei bemerkt in Venedig in der Herbstsaison des Jahres 1774 am Teatro San Samuele uraufgeführt und nicht in Wien im Mai 1774 wie in MGG und New Grove - vermutlich aufgrund einer Aussage in Gustav Zechmeister: Die Wiener Theater nächst der Burg und nächst dem Kärntnerthor von 1747 bis 1776. Wien 1971, S. 353 - fälschlicherweise behauptet wird. In Wien wurde „Il geloso in cimento“ erst im Jahr 1775 aufgeführt, wie sowohl das Wiener Libretto als auch folgende Quellen bestätigen: Johann Heinrich Friedrich Müller (Hg.): Genaue Nachrichten von beiden kaiserlich=königlichen Schaubühnen und anderen öffentlichen Ergötzlichkeiten in Wien. Wien 1772. Tagebuch des Fürsten Johann Josef Khevenhüller-Metsch, Kaiserlichen Obersthofmeisters, 1742-1776. Bd. 7. 1770-1773. Hg. von Rudolf Graf Khevenhüller-Metsch und Dr. Hanns Schlitter. Wien 1925. 
Auch in diesem Fall fällt der Streit höchst performativ aus: Das Wegwerfen der Geschenke, das Vorlesen und anschließende Zerreißen eines Liebesbriefs sowie das Auseinandergehen und die Versöhnung der Streitenden bieten die Möglichkeit eines aktionsreichen Schauspiels.

\section{I.3 Gesellschaftsspiele mit agonalem Charakter}

Nicht nur Streit- oder Kampfszenen bieten in der Opera buffa Gelegenheit zu Momenten des spielerischen Agons, sondern es werden gelegentlich auch Spiele im Sinne von games agonalen Charakters auf die Bühne gebracht. In der eben beschriebenen Oper „Il geloso in cimento“ von Anfossi werden beide Möglichkeiten miteinander kombiniert: Der eifersüchtige Fabio versucht seinen Schwur einzuhalten, nie wieder eifersüchtig zu sein, verfällt jedoch bei einem zum Zeitvertreib begonnenen Kartenspiel gegen Ende des ersten Finale (I,I7) erneut in einen Ausbruch von Wut und Eifersucht. Das Kartenspiel selbst besitzt einen vorwiegend agonalen Charakter, der aber auch wie bei den meisten Gesellschaftsspielen mit einer Alea-Komponente verbunden ist. Aus dramaturgischer Sicht dient dieses Kartenspiel vor allem als Anlass, um alle Personen zusammenzubringen, wie es die Konvention für jedes Finale vorschreibt, und einen Konflikt entstehen zu lassen, dessen Eskalation der konventionellen Steigerung am Ende des ersten Finales dient. Aus inhaltlicher Sicht ist das Kartenspiel eine Gelegenheit, um eine typische Beschäftigung der damaligen mondänen Gesellschaft auf die Bühne zu bringen, wobei Spiel und Zeitvertreib sowie die damit einhergehende Leichtigkeit und Sorglosigkeit explizit thematisiert wird.

Um Fabios Standhaftigkeit gegen die Eifersucht auf die Probe zu stellen, gewährt Donna Flavia ihren beiden Verehrern, Don Perichetto und dem Engländer Rosbif, Einlass in ihr Haus. Rosbifs Vorschlag „A qualche gioco giocar si può “ wird sofort von Donna Flavia akzeptiert, wobei als gioco automatisch ein Kartenspiel verstanden wird.

Die gesamte Aktion vom Vorschlag bis zur Beendigung des Spiels macht den Großteil des Finales aus und ist musikalisch in vier Abschnitte unterteilt:

\begin{tabular}{l|l}
\hline Allegro comodo, D-Dur, 3/8 & $\begin{array}{l}\text { Vorschläge und Entscheidung zum Spiel; Vorbereitung des Spiel- } \\
\text { tisches. }\end{array}$ \\
\hline Allegro con spirito, A-Dur, C & $\begin{array}{l}\text { Modesta lädt zum Spiel ein und kommentiert da parte die Situation. } \\
\text { Flavia entscheidet, welches Kartenspiel gespielt wird, und lässt die } \\
\text { Karten bzw. das Los über die Zusammensetzung der Mannschaften } \\
\text { entscheiden. }\end{array}$ \\
\hline Andantino, F-Dur, 3/8 & $\begin{array}{l}\text { Eigentliches Kartenspiel. Heimlicher Dialog zwischen Flavia und Pe- } \\
\text { richetto, von den beiden anderen Rivalen bemerkt und kritisiert. }\end{array}$ \\
\hline
\end{tabular}




\begin{tabular}{l|l}
\hline Presto, A-Dur, C & $\begin{array}{l}\text { Fabios Wutausbruch: Er schmeißt dem Rivalen die Karten ins Ge- } \\
\text { sicht. Alle stehen auf. Das Finale endet im Durcheinander. }\end{array}$ \\
\hline Allegro con spirito, I2/8 & Schluss-Tutti \\
\hline
\end{tabular}

Der gesamte Verlauf ist reich an Aktion, die Bertati durch häufige Regieanweisungen detailliert vorgibt. Nach der Entscheidung, ein Kartenspiel zu spielen - die vorgeschlagenen Alternativen sind „far all'amor" (Flirten) und „un passeggio“ (ein Spaziergang) -, bringt die Dienerin Modesta Karten und Stühle herbei und bereitet den Spieltisch vor. Auf ihre Einladung hin, mit der der lebhafte Allegro-con-spirito-Abschnitt beginnt, nähern sich die Spieler dem Spieltisch. Die schlaue Dienerin durchschaut dabei sofort die Rivalitätssituation:

(Questi Galli, poveretti,

Tendon tutti a una Gallina.

Che si spennano fra loro

Ci scommetto per mia fé.) $)^{579}$

In Staccato-Tönen fasst Modesta die Lage mit der witzigen Metapher der Hähne zusammen, die es alle auf dieselbe Henne absehen und sich gegenseitig die Federn ausrupfen.

Donna Flavia, die Herrin des Hauses, entscheidet sich für das tresette, ein heute noch gebräuchliches Spiel mit neapolitanischen Karten, zu viert in zwei Paaren gespielt. Im I 8. Jahrhundert war dieses Kartenspiel so verbreitet, dass seine Regeln sogar in einem lateinischen Traktat (De regulis ludendi ac solvendi in mediatore et tresseptem, 1750) von Chitarrella ${ }^{580}$ festgehalten wurden. Kartenspiele waren auch in Theatern bzw. Opernhäusern üblich, weshalb hier die Beschäftigung der Figuren auf der Bühne die des Publikums gewissermaßen widerspiegelte.

In einer Art „Vor-Spiel“ teilt Donna Flavia die Karten aus, um das Los über die Zusammensetzung der Spielerpaare entscheiden zu lassen, wobei der Schwerpunkt auf dem Moment des Zufalls, der Alea im Sinne Caillois', liegt. Zwischen Flavias Ankündigung „Or decidono le carte“ und dem Ergebnis „Ecco usciti i primi Re“ baut Anfossi einige rein instrumentale Takte ein, was in diesem Finale bis zu diesem Zeitpunkt so gut wie nie geschehen war. Dadurch lässt er der szenischen Ausführung der in der Regieanweisung nachdrücklich vorgeschriebenen Gesten des Karten-Austeilens

579 Ebd. (I,17).

580 Pseudonym eines unbekannten Autors aus dem 18. Jahrhundert. 
Raum bzw. Zeit, so dass der beinahe rituelle Charakter der Zufallsentscheidung betont wird. Die wiederholt auftretende, aus einer Sechzehntel und einer Achtel bestehende Figur in den ersten Geigen könnte sogar die vorgegebene Geste des sfogliare le carte tonmalerisch darstellen.

Rosbif und Donna Flavia ziehen als Erste einen König, bilden also ein Spielerpaar. Das erweckt den Verdacht der Rivalen, Don Perichetto und Fabio, es handle sich dabei nicht um einen Zufall, sondern um einen Trick. Da das zweite Paar aus Vittorina und Fabio besteht, wird der vom Spiel ausgeschlossene Don Perichetto wütend, und Flavia holt ihn zum Trost als Berater zu sich. So ist sie zugleich auf unterschiedliche Weise mit beiden Verehrern verbündet und spielt gegen ihren eifersüchtigen Liebhaber.

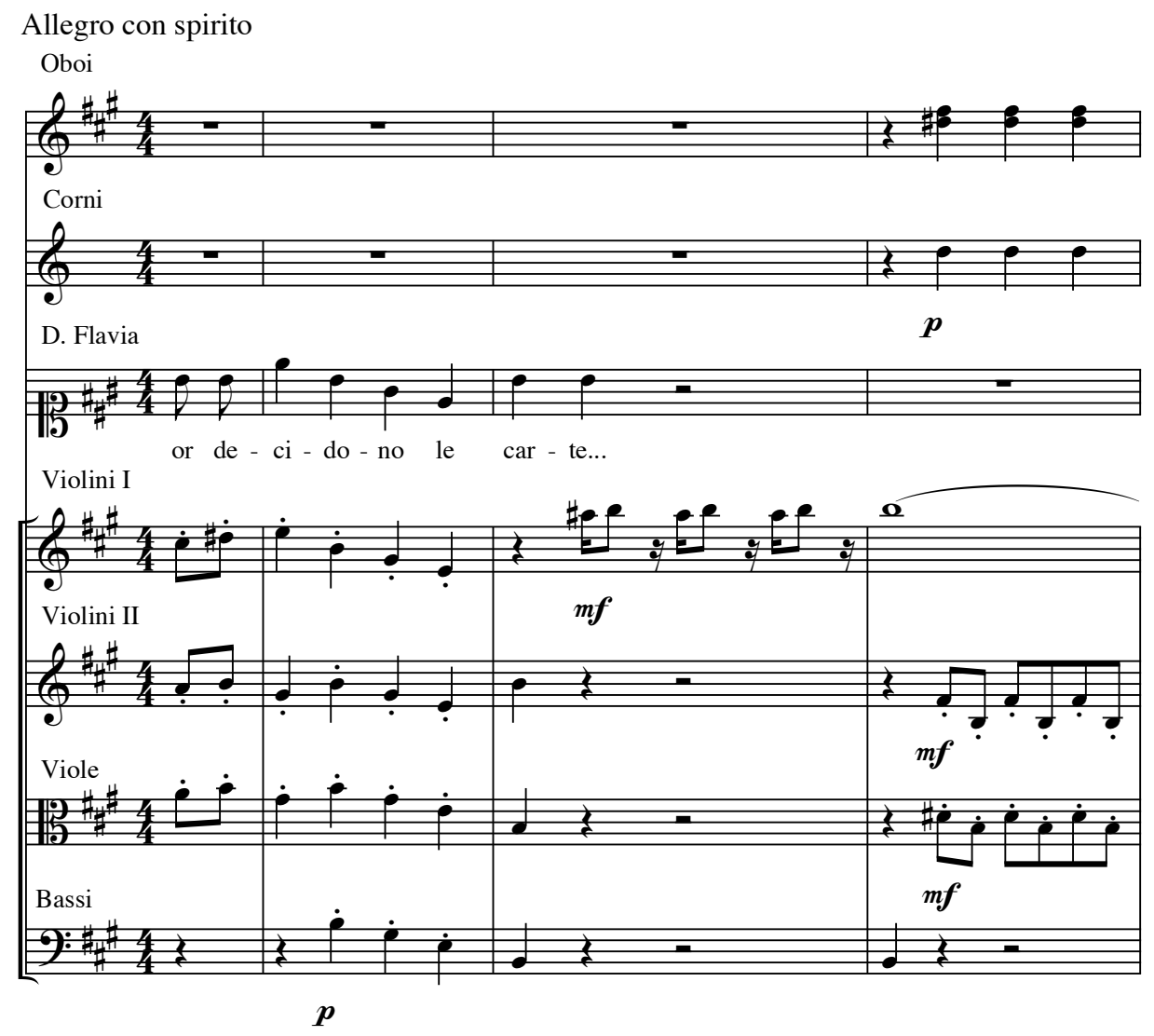




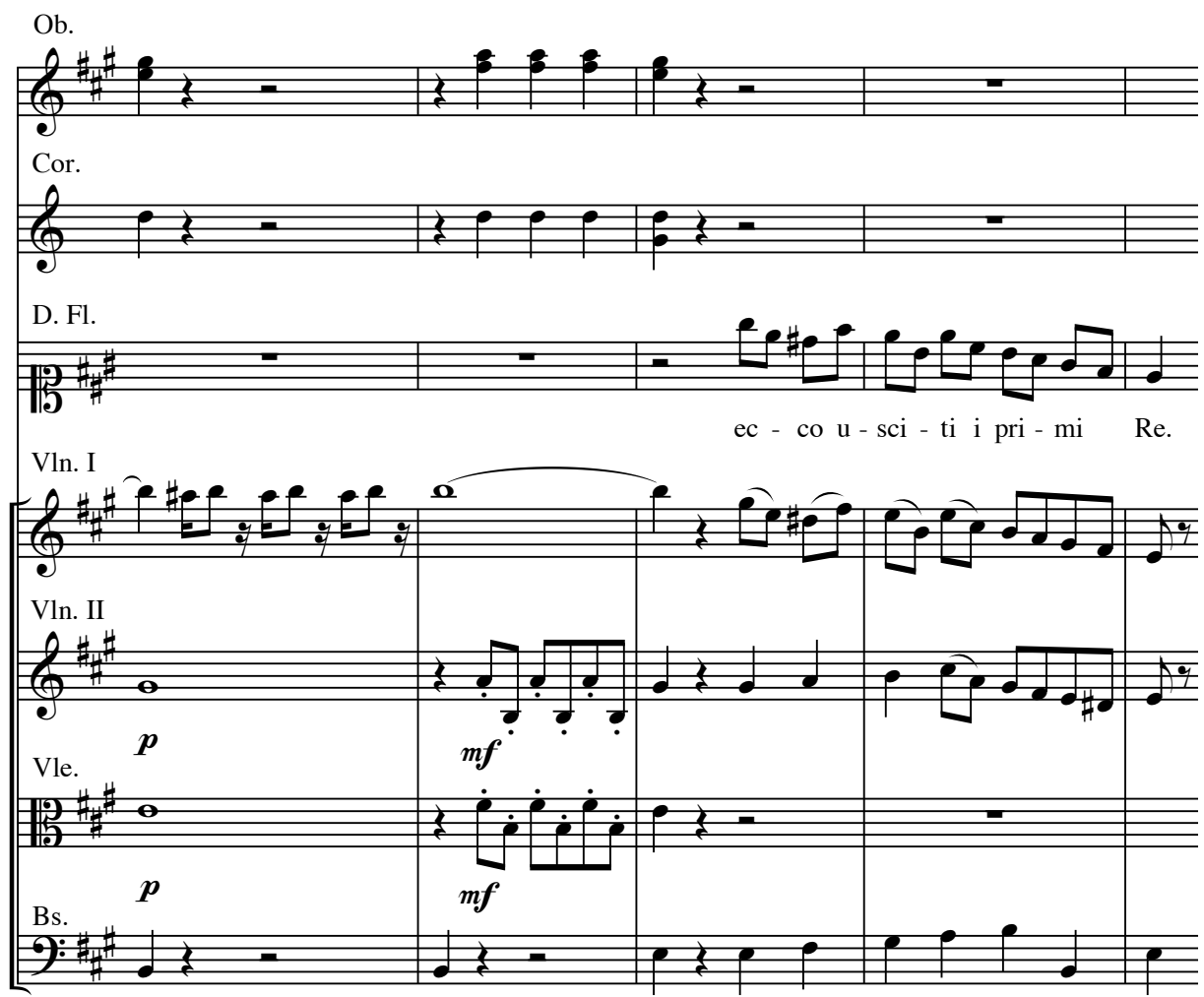

6 Anfossi/Bertati: Il geloso in cimento. Venezia 1774 (I-Gi B.7.7/8)

Der eigentliche Spielbeginn wird musikalisch durch einen Takt-, Tonart- und Tempowechsel (Andantino, 3/8, F-Dur) markiert. Das mediantische Verhältnis der Tonart F-Dur zum A-Dur des vorhergehenden sowie des nachfolgenden Abschnitts verleiht den Eindruck einer „anderen Welt“. Auch die Änderung der Besetzung - die Oboen werden durch Traversflöten ersetzt - trägt klanglich zu einem Atmosphärenwechsel bei. Die Tempoverlangsamung ins Andantino und der langsam tanzende 3/8-Takt erzeugen im Verhältnis zum vorigen Allegro con spirito im $4 / 4$-Takt ein schwebendes Gefühl, das stark an die von Huizinga festgestellte, beim Spiel auftretende „zeitweilige Aufhebung der ,gewöhnlichen Welt“" und die „Aufhebung aller Schwere des Lebens, Denkens, Handelns“"581 erinnert. Die schwebende Leichtigkeit, von der viele Spieltheoretiker sprechen, wird in diesem Abschnitt unter anderem durch die häufige Verwendung des Staccato hergestellt (s. Notenbeispiel 7a \& 7b, S. I 58f.).

581 Huizinga, S. 78. 


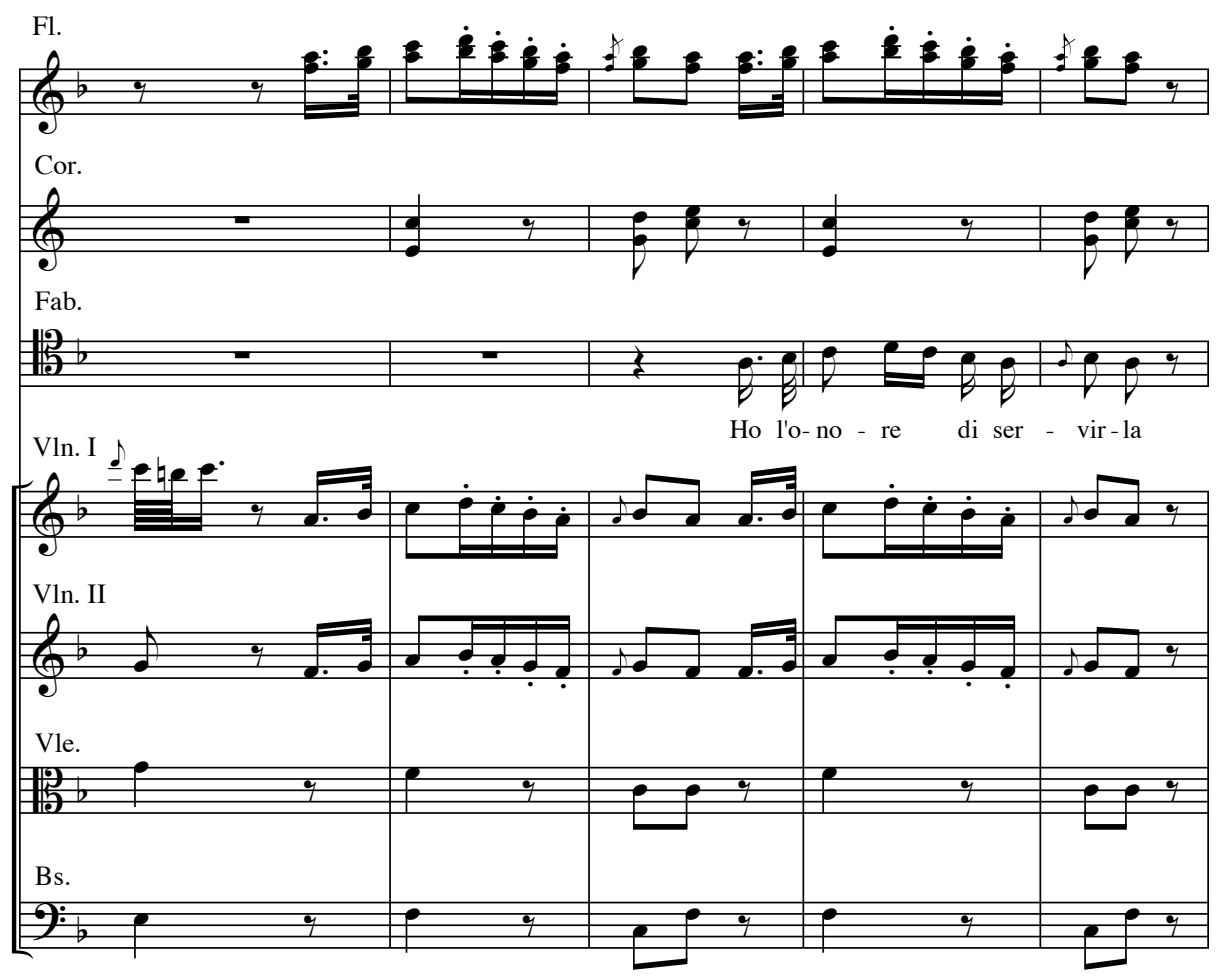

7a Anfossi/Bertati: Il geloso in cimento. Venezia 1774 (I-Gi B.7.7/8)

Das Gesellschaftsspiel wird als frivoler Zeitvertreib mit einer galanten Sphäre assoziiert: Die Höflichkeit und das galante Benehmen der Spieler werden durch eine graziöse, zierliche Musik im leichten und tänzerischen 3/8-Andantino - der 3/8-Takt gilt generell als frivol, leicht und galant ${ }^{582}$ - zum Ausdruck gebracht, in der ausgeschriebene Verzierungen und kleingliedrige Figuren und Motive den galanten Gestus auszieren. Kleingliedrig wirkt auch die bewegliche Dynamik. Gelegentlich fehlende Bässe verstärken zusätzlich den Eindruck von Leichtigkeit und Zierlichkeit (s. Notenbeispiel 8, S. I60).

582 Vgl. Wye J. Allanbrook: Rhythmic Gesture in Mozart's „Le nozze di Figaro“ \& „Don Giovanni“. Chicago 1983, S. 22 und 67. Allanbrook bezieht sich dabei wiederum auf Johann Phillipp Kirnberger: Die Kunst des reinen Satzes in der Musik. Berlin 1774-79, Bd. 2, S. 133. 


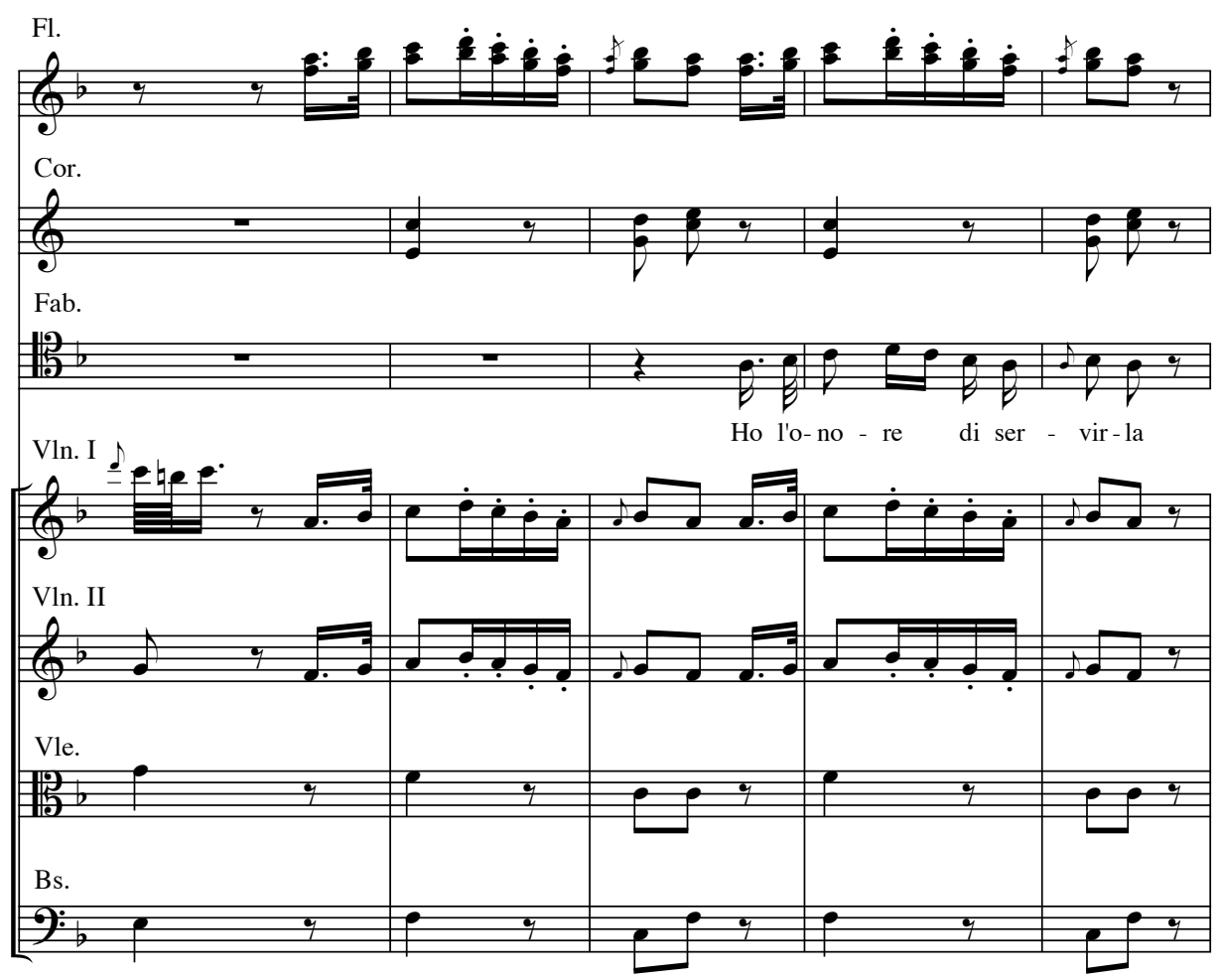

7b Anfossi/Bertati: Il geloso in cimento. Venezia 1774 (I-Gi B.7.7/8)

Immer wieder geben längere, rein instrumentale Momente einerseits Raum für Aktion und szenisches Spiel, andererseits verlangsamen sie den allgemeinen Rhythmus der Repliken, wodurch das schon erwähnte Schweben ebenfalls unterstrichen wird.

Die galante Konversation, die zwischen Donna Flavia und ihrem Berater Don Perichetto heimlich stattfindet, verärgert die beiden anderen Rivalen. Rosbif tadelt die Nähe und Intimität zwischen dem flüsternden Paar. Flavia ist nicht bei der Sache und wird von Fabio immer wieder darauf hingewiesen, dass sie an der Reihe ist („A lei tocca"). Entgegen der Regel des Schweigens beim tresette-Spiel wird hier hin und wieder beim Ausspielen einer Karte eine Bemerkung abgegeben. Donna Flavia sagt beispielsweise "Gioco Spade; ed ho tre Fanti“, wobei die letzte Aussage metaphorisch durchaus auf die aktuelle Situation bezogen werden kann: Donna Flavia spielt „Schwerter“ - eine der vier „Farben“ der neapolitanischen Karten - und hat drei „Buben" in der Hand, denn sie hat in der Realität tatsächlich drei Verehrer. Auf ihre Aussage "Gioco sette di bastoni“" baut Fabio sofort ein Wortspiel auf: „Sulla testa 


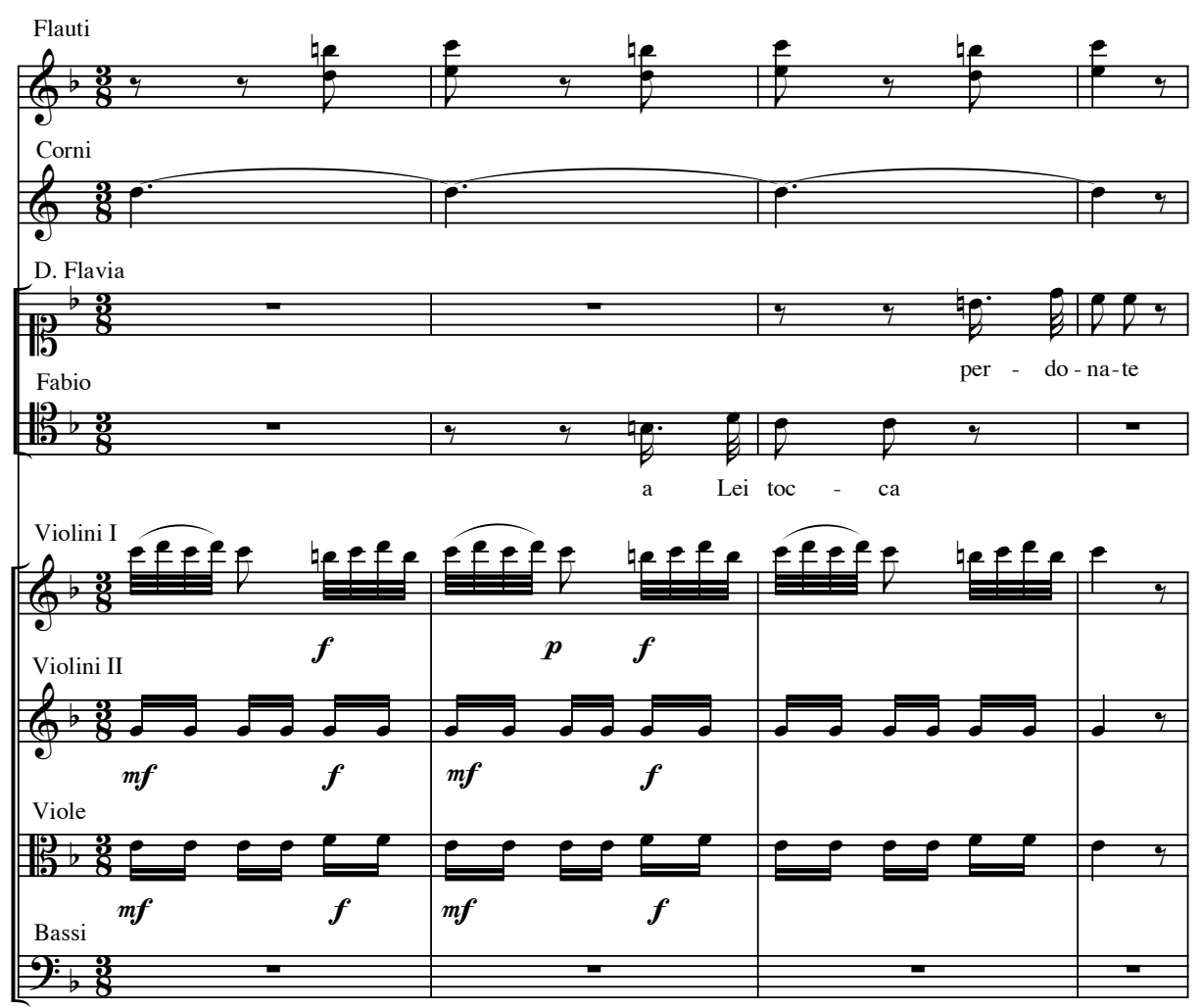

8 Anfossi/Bertati: Il geloso in cimento. Venezia 1774 (I-Gi B.7.7/8)

a quel, ch'io dico.“ „Bastoni“ bedeutet „Knüppel“ und ist eine weitere „Farbe“ der neapolitanischen Karten; Fabio will damit in seiner Wut „jemandem“, nämlich dem flirtenden Rivalen Don Perichetto, auf den Kopf schlagen. Kurz darauf kann sich Fabio nicht mehr beherrschen und springt wütend (Regieanweisung: „con impeto") auf, wobei wiederum ein Umschlag ins vorherige A-Dur und in einen 4/4-Takt, diesmal im raschen Presto, stattfindet. Die zauberhafte, schwebende Atmosphäre ist zerbrochen, das Spiel wird unterbrochen, außer sich vor Wut und Eifersucht wirft Fabio seinem Nebenbuhler die Karten ins Gesicht. Don Perichetto empfindet diese Geste als höchste Beleidigung und fordert Fabio zum Duell heraus. Damit wird wiederum auf einer anderen Ebene eine agonale Situation erreicht, allerdings kippt gleichzeitig das Spiel in Ernst, das Vergnügen in einen Konflikt. Alle beteiligten Personen stehen auf und versuchen gemeinsam mit den herbeieilenden Dienern die beiden zu beruhigen und vom Kampf abzuhalten. In einem großen Durcheinander endet schließlich das Finale. 
Das Einsetzen des Kartenspiels als unterhaltsame Beschäftigung bei angespannten Situationen in größeren Ensembles kommt zwar nicht häufig vor, ist aber auch kein Einzelfall. ${ }^{583}$ Im untersuchten Repertoire findet sich eine Schachspiel-Szene dagegen ausschließlich in „Il burbero di buon cuore“ von Martín y Soler und Da Ponte. Als strategisches Brettspiel gehört das Schachspiel zur Kategorie „Agon“. Es ist in folgenden Kontext eingebettet: Ferramondo, der „burbero di buon cuore“, erwartet seinen Freund Dorval zum Schachspielen. Dorval lässt aber auf sich warten, und Ferramondo wird immer ungeduldiger, weil er sich unbedingt für seine Niederlage bei der Partie des Vortrags revanchieren will. Er legt schon die Spielsteine, um anknüpfend an die Spielsituation des Vortags eine optimale Strategie herauszufinden.

\section{(...) ma perchè mai}

Non arriva Dorval? Muojo di voglia

Di riveder quel maledetto colpo,

Che la partita jer perder m'ha fatto:

Vincer doveasi, s'io non era un matto.

Pian pianin veggiamo un poco: (comincia a metter i pezzi)

Questo è il mio, quell'è il suo gioco:

A me tocca: il Re si arrocca;

E la torre va di quà.

Quì Dorval metter l'alfiere ... (s'infiamma a poco a poco per gradi)

Bravo ... scacco ... siam in ballo:

Ei la torre ... sta a vedere ...

Doppio scacco col cavallo ...

La Regina perderà.

Via col Re ... ma s'io la piglio ...

Il cavallo egli mi prende;

Tanto meglio ... è il Re in periglio ...

La Regina or qui discende ...

Scacco ... scacco ... è matto, è matto,

Cosa chiara, il colpo è fatto;

E finita la partita,

Non ci è scampo in verità.

Ho già vinto; gli sta bene,

583 Vgl. Mazzolà/Salieri: La scola de’ gelosi. Venedig 1779 (II,10) und Tassi/Felici: L'amore soldato. Venedig 1769 (2. Finale). 
Ehi Castagna ... Castagna ... ho vinto, ho vinto: $\quad$ (verso le quinte) $)^{584}$

Der gesamte Verlauf des Schachspiels, das zwar gegen einen imaginären Gegner, den abwesenden Dorval, trotzdem konkret stattfindet, wird als dramaturgischer Höhepunkt der Situation musikalisch als Aktionsarie umgesetzt. Der im Spiel versunkene Ferramondo kann nicht davon ablassen, bis er einen Weg zum Sieg gefunden hat. Dabei kommentiert er seine Züge und stellt strategische Überlegungen an, die durch kurze Phrasen in Musik umgesetzt werden, so dass Szene, Text und Musik eine natürlich wirkende Einheit bilden. Jeder Vershälfte folgt eine Fermate in der Musik, wodurch die langsame, konzentrierte in einzelnen Gesten unterteilte Aktion der Vorbereitung des Spiels zum Ausdruck kommt. Das Tempo (Andante maestoso) und die äußerst leise Dynamik unterstreichen ebenfalls die feierliche und zugleich spannende Atmosphäre, ohne jedoch den Buffo-Stil und den Rahmen der Spielsituation zu sprengen.

Andante maestoso

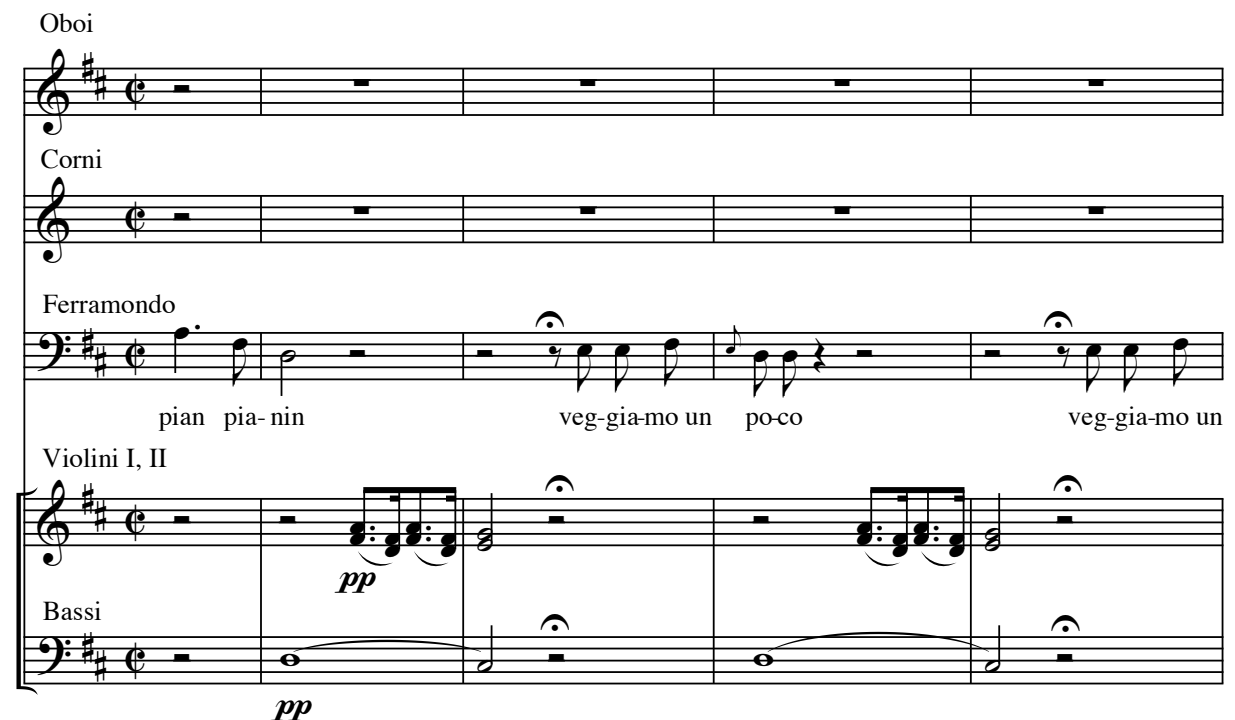

584 Da Ponte/Martín y Soler: Il burbero di buon cuore. Venedig 1789 (I,8). 


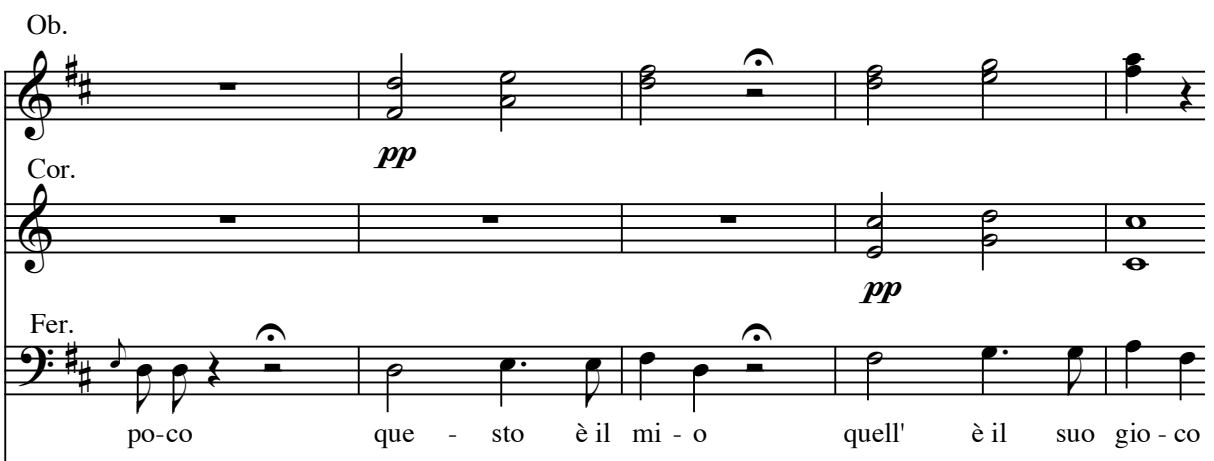

Vln. I, II

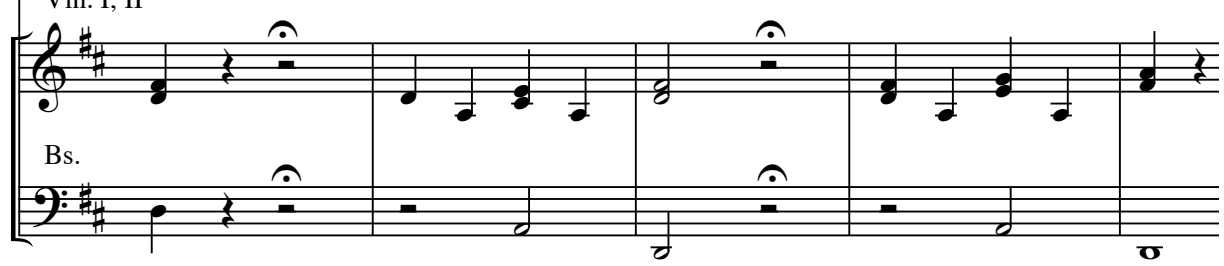

pp

9 Martín y Soler/Da Ponte: Il burbero di buon cuore. Hg. von Leonardo J. Waisman. Madrid 2003

Durch eine erstmalig erscheinende durchgängige Achtelbewegung in der Orchesterbegleitung kommt die Musik ins Fließen, wodurch gemeinsam mit Ferramondos Feststellung „a me tocca“ (,ich bin dran“) der Beginn des Spiels signalisiert wird. Noch während der besagten Achtelbewegung der Geigen und Oboen wird der erste Zug angekündigt, eine Rochade, ein komplizierter Doppelzug, bei dem König und Turm nacheinander aber in ein und demselben Zug bewegt werden. Auf die Ankündigung „il Re s'arrocca“ („der König rochiert“) folgen zwei rein instrumentale Takte, die der Aktion, nämlich den zwei Schritten des Königs, Raum geben. Nicht nur durch Instrumentierung und Motivik, sondern vor allem durch die Dynamik wird ein starker Kontrast zum vorangehenden Abschnitt erzeugt. Das plötzliche Forte bzw. Sforzato nach 16 Takten Piano bis Pianissimo könnte dabei die Größe und Wichtigkeit der Königsfigur bzw. das Verb arroccarsi bzw. die Bedeutsamkeit dieses wirkungsvollen Zugs, das nur einmal in einem Schachspiel erlaubt ist, symbolisieren. Der zweite Teil der Rochade, die Bewegung des Turms, wird musikalisch kontrastreich durch eine Staccato-Bewegung im Piano umgesetzt, die die „Fortbewegungsart" des Turms darstellen könnte, der bei der Rochade über den König springen muss. 
Andante maestoso

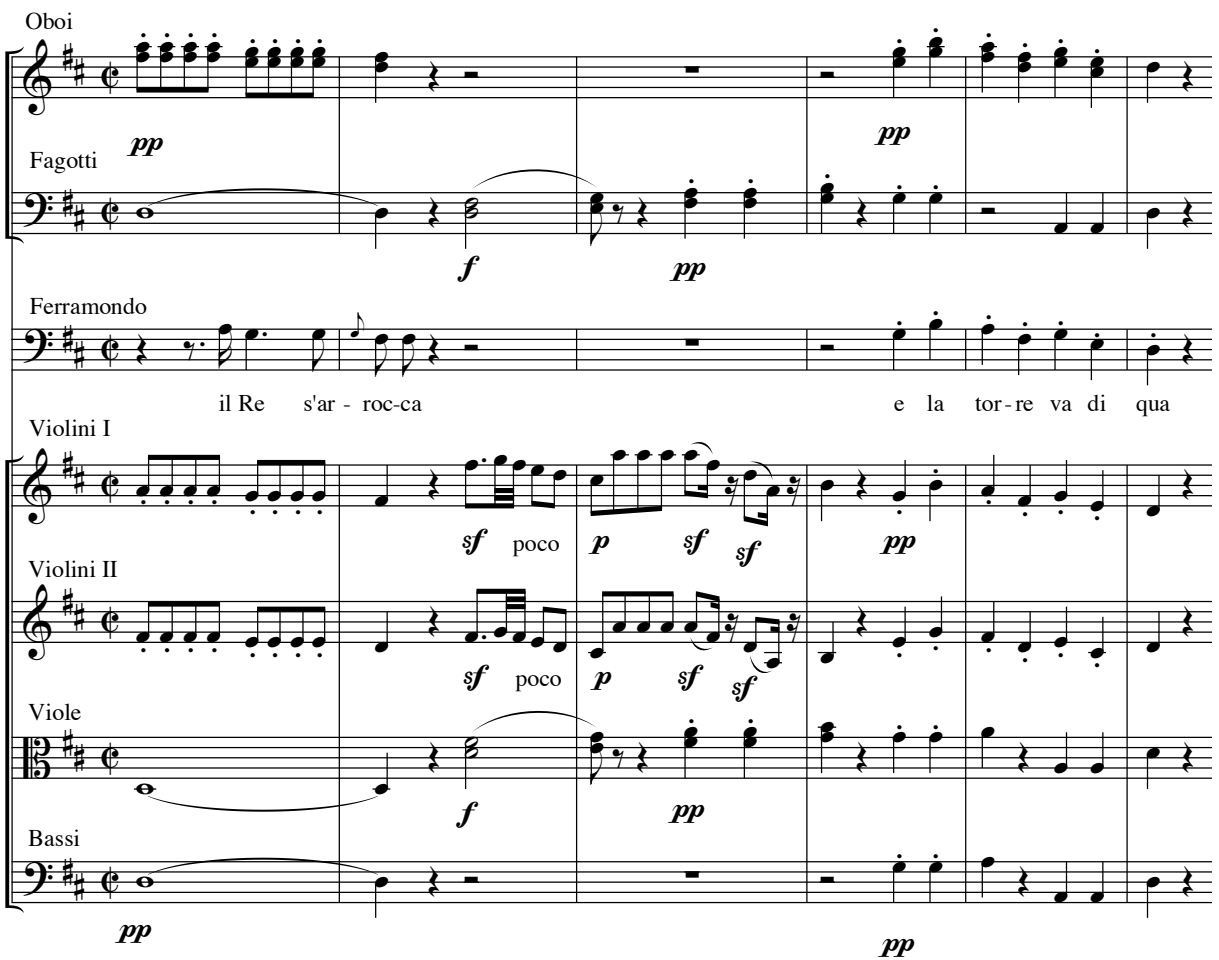

10 Martín y Soler/Da Ponte: Il burbero di buon cuore. Hg. von Leonardo J. Waisman. Madrid 2003

Der imaginierte Dorval ist nun am Zug. Ferramondo spielt an seiner Stelle, schlüpft aber gleich wieder in seine eigene Rolle, indem er ihn lobt. Das Spiel geht weiter, es fallen weiterhin viele Begriffe aus dem Schachspiel, in erster Linie die Namen der Spielfiguren (alfiere $=$ Läufer torre $=$ Turm ; cavallo $=$ Springer ; regina $=$ Dame). Musikalisch ist der Satz weiterhin durch kurzatmige Phrasen in der Singstimme gekennzeichnet, die durch rein instrumentale „Pausen“ getrennt sind, in denen Ferramondo strategisch überlegt, die Situation auf dem Schachbrett analysiert und die Züge des imaginären Partners voraussieht. Ferramondos zunehmender Eifer - die Regieanweisung lautet: „sinfiamma a poco a poco per gradi“ - wird im Text durch allmählich kürzere Sätze wiedergegeben, die durch den Einsatz von Fortführungspunkten offen bleiben. Musikalisch werden die Einsätze der Singstimme nach und nach dichter bis durch eine verhältnismäßig längere Phrase im Crescendo der Übergang zum Allegro, also zum B-Teil dieser zweiteiligen Arie geschaffen wird. Waisman, der die Arie im Vorwort der Edition von „Il burbero di buon cuore“ analysiert, bemerkt zu diesem 
Agon

I 65

Übergang: „The orchestral fanfare inflames him, and leads directly to a change in tempo (Allegro). "Tatsächlich ist mit dem besagten Crescendo ein fanfarenartiges Motiv im Orchester gekoppelt, das von allen Streichern und Holzbläsern im Unisono gespielt wird, wodurch die Crescendo-Passage besonders mächtig wirkt. Die Fanfare wird im allerersten Moment des Triumphs eingesetzt, nachdem Ferramondo bemerkt hat, dass sein Gegner die regina, die stärkste Figur im Schachspiel, verlieren wird.

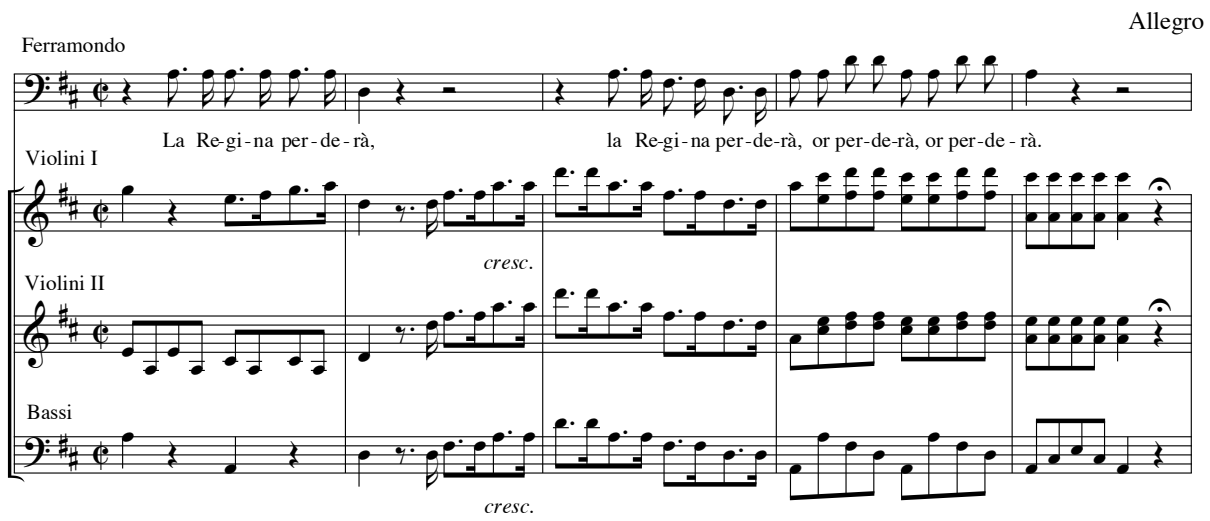

11 Martín y Soler/Da Ponte: Il burbero di buon cuore. Hg. von Leonardo J. Waisman. Madrid 2003

Der Übergang zum Allegro hängt also genau mit dem Moment zusammen, in dem Ferramondo einen möglichen Weg zum Sieg entdeckt.

Allegro

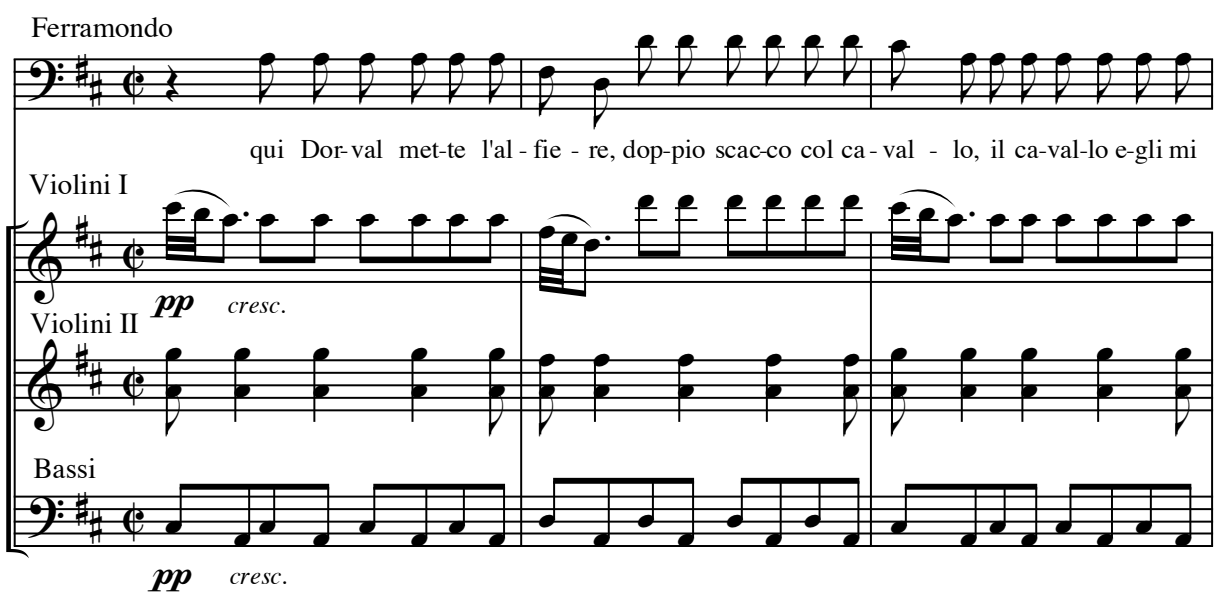




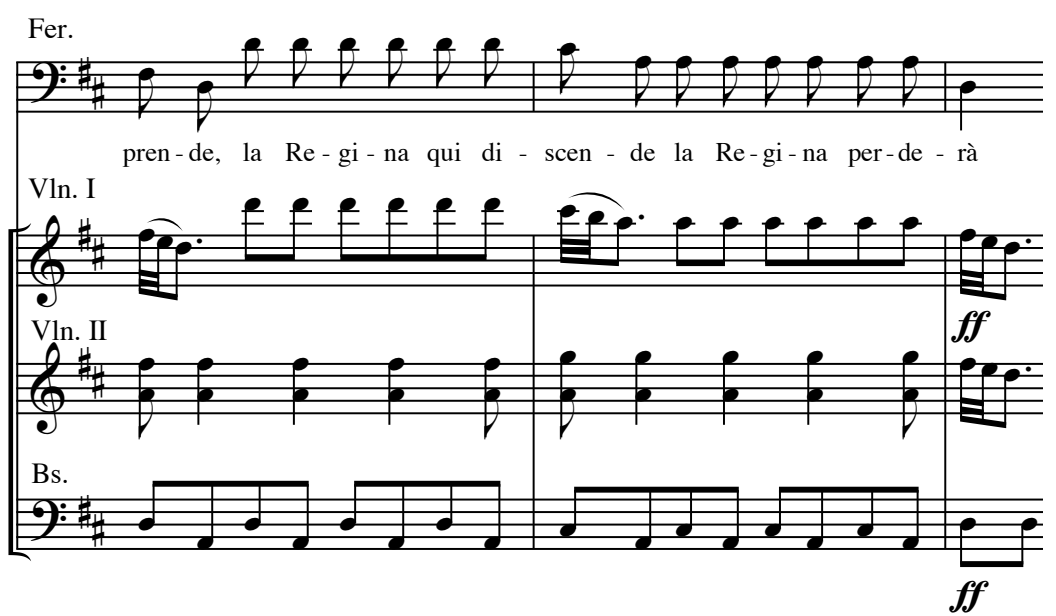

12 Martín y Soler/Da Ponte: Il burbero di buon cuore. Hg. von Leonardo J. Waisman. Madrid 2003

Im Allegro-Teil äußert sich Ferramondos freudige Erregtheit nicht nur durch die höhere Geschwindigkeit und die dichteren Einsätze der Singstimme, sondern vor allem auch durch längere Phrasen in raschem Parlando sowie durch wiederholte Oktavsprünge, wenn es um den gewinnenden Zug und das Schachmatt geht.
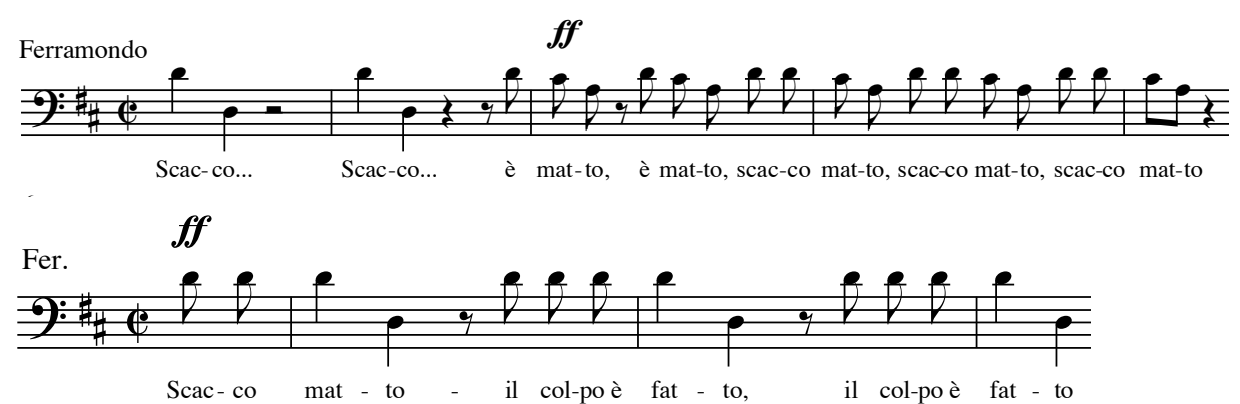

13, 14 Martín y Soler/Da Ponte: Il burbero di buon cuore. Hg. von Leonardo J. Waisman. Madrid 2003

Die Dynamik spielt auch eine wichtige Rolle: In Momenten des höchsten Triumphs schreibt Martín y Soler regelmäßig Fortissimo vor, um den Freudenschrei möglichst realistisch darzustellen. Dieses Maximum an Lautstärke aber auch an Freude, Erregung und Genuss am Sieg erreicht er mehrmals durch ein Crescendo, das immer wieder vom Pianissimo neu angesetzt wird, so dass das gesamte dynamische Spektrum durchschritten wird. 
An den letzten Siegesjubel knüpft sich direkt Ferramondos Ruf nach seinem Diener Castagna an, mit dem die Arie endet.
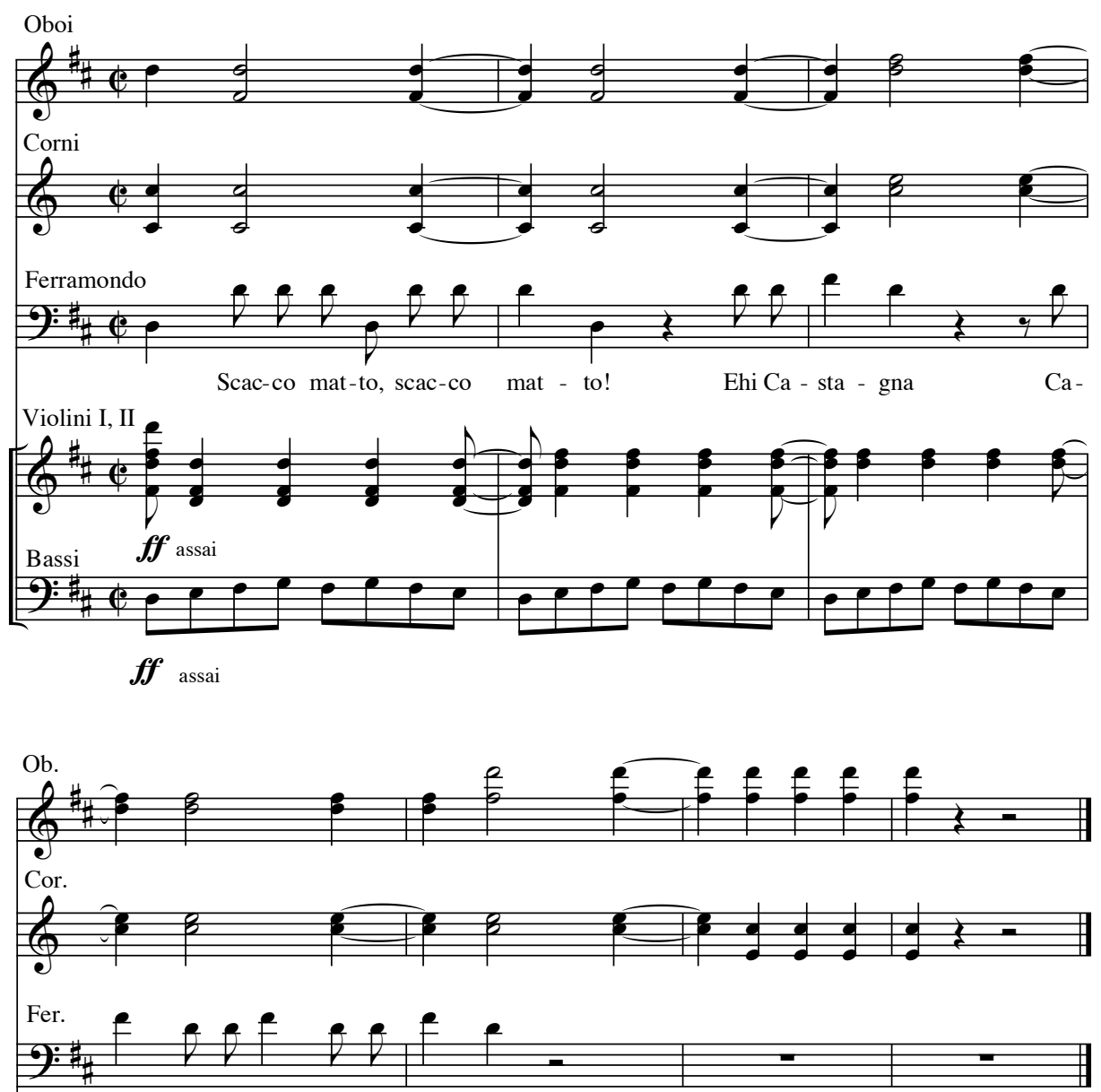

sta - gna, Ca-sta - gna, $\mathrm{Ca}$ - sta - gna...

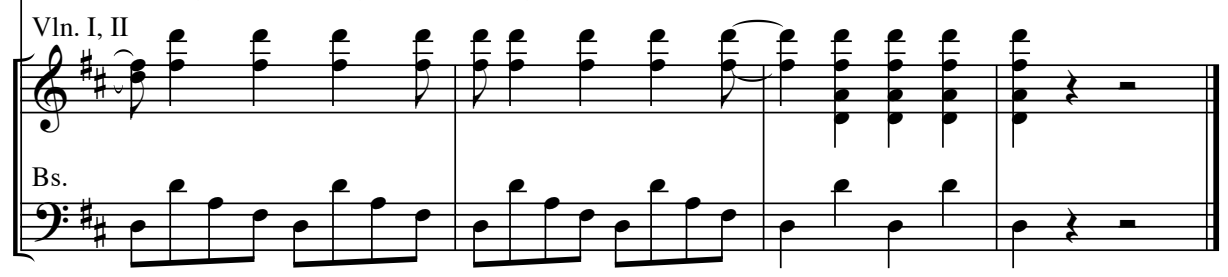

15 Martín y Soler/Da Ponte: Il burbero di buon cuore. Hg. von Leonardo J. Waisman. Madrid 2003 
Der letzte Satz dieser Szene („Ehi Castagna ... Castagna ... ho vinto, ho vinto“) steht schon außerhalb des Spiels und ist im Textbuch als Secco-Rezitativ gedruckt, wird aber von Martín y Soler teilweise in die Arie integriert. Dorothea Link, die in ihrer Dissertation diese Arie auf rein musikalisch-formaler Ebene analysiert, ohne Text und Inhalt zu berücksichtigen, weist darauf hin, dass Martín y Soler dabei das Ziel verfolgte, „to give an open-ended effect to the aria“. ${ }^{585}$ Dazu kann allerdings auch hinzugefügt werden, dass durch die unkonventionelle Einfügung von Ferramondos Ruf nach seinem Diener Castagna in die Arie auch die Ungeduld des erregten Spielers hervorgehoben wird, der es gar nicht erwarten kann, jemandem seine übermäßige Siegesfreude mitzuteilen, und deshalb noch im Orchesternachspiel der Arie zu rufen beginnt. Ungeduld ist durchaus eine Eigenschaft, die zur Figur des übermäßig cholerischen, sehr leicht erregbaren burbero passt. Die beschriebenen Crescendi können ebenfalls als übertriebenes Sich-Hineinsteigern in das Spiel und als „Flammen“ der Spielleidenschaft gedeutet werden und sind möglicherweise karikaturistisch gemeint.

Insgesamt findet in dieser Arie, die den Verlauf des Schachspiels nachzeichnet, eine große Steigerung statt, die vom ruhigen Beginn des Spiels über das aufgeregte Allegro bis hin zur triumphierenden Freude am Sieg reicht. Daraus resultiert meines Erachtens eine plastische und natürliche Darstellung des schon im Text vorgegebenen Sicham-Spiel-Ereiferns. Dabei werden typische Begleitphänomene des Spiels, wie sie von vielen Theoretikern festgestellt werden, dargestellt und musikalisch umgesetzt: Die Konzentration und der heilige Ernst am Beginn des Spiels, die Spannung, der Spaß am strategischen Denken, der lustvolle Sog des Wetteiferns, die Mitgerissenheit, der Ehrgeiz, die Revanchelust, die Vorfreude auf den Sieg, der Triumph und das Gefühl der Überlegenheit am Schluss.

Diese Szene enthält zweierlei „Spiele“: Einerseits ein agonales, weil eine Schachpartie eine Art Wettkampf ist, der mit einem Sieg oder einem Verlust endet, und Ferramondo geht es eindeutig darum, einen Sieg davonzutragen. Andererseits handelt es sich aber auch um ein Als-ob-Spiel, bei dem der Gegner imaginär und der antithetische Charakter des Spiels virtueller Natur ist. Nichtsdestotrotz findet das Schachspiel als Aktion konkret statt, und die dabei auftretenden Gefühle sind bei aller Virtualität durchaus echt.

585 Dorothea Link: The Da Ponte Operas of Martin y Soler. Ph. D. Dissertation, University of Toronto 1991, S. 126. 


\section{I.4 Musikalischer Agon}

Alle bisher beschriebenen „agonalen Momente“ der Opera buffa beruhen auf einer im Libretto vorgegebenen Kampfsituation. Das zuletzt beschriebene Schachspiel sowie andere agonale Szenen werden zwar von der Musik untermalt, sind aber immer primär inhaltlicher Natur. Nun soll aber vom ,agonalen Spiel“ in der Musik die Rede sein. Interessant dabei ist, dass schon im I 8. Jahrhundert in Italien die Metapher des Spiels im Zusammenhang mit der Musik der Opera buffa verwendet wurde. In einer in der Gazzetta urbana veneta des Jahres 1789 abgedruckten Streitkorrespondenz ist beispielsweise folgende auf Paisiellos Oper „Le gare generose“ bezogene Behauptung zu finden: „Infatti quel sentire le parti di un tutto, che si dice armonico, che fanno ai calci tra di loro, i violini che giuocano di scherma con gl'istrumenti da fiato, i corni, e le violette, che si corrono dietro continuamente senza potersi mai raggiungere, mi pare che sia un'affettazione, ed una ciarlataneria veramente ridicole. "586 Der zeitgenössische Kritiker verwendet, um den musikalischen Stil Paisiellos zu beschreiben, verschiedene Metaphern, die allesamt dem Bereich des Spiels mit agonalem Charakter entstammen: fare a calci kann als eine Form des Kampfspiels (mit Fußtritten) gelten, giocare di scherma bedeutet Fechten und corrersi dietro kann als Fangspiel gedeutet werden. Der Kritiker verwendet hier den Spielbegriff in seiner häufig gebrauchten negativen Bedeutung als überflüssige und müßige Tätigkeit, die er wegen ihrer Unernsthaftigkeit nicht nur abfällig als lächerlich und affektiert bezeichnet, sondern sogar als Scharlatanerie verurteilt. Die Antwort auf diese Verurteilung des Spiels in der Musik lautet folgendermaßen: „Il giuoco degli istrumenti si rende necessario particolarmente nelle Opere buffe, e forma una parte essenziale del loro bello. Provate un poco a fare che gli istrumenti accompagnino sempre secchi secchi la parte cantante, e poi vedrete all'aria prima sbavigliar l'uditorio, alla seconda terribilmente contorcersi per sonnolenza, ed alla terza ronfare altamente. Da questo giuoco ben usato dai giudiziosi moderni maestri ne nacque il maraviglioso effetto. "587

In dieser Antwort wird dagegen das "giuoco degli istrumenti“ mit dem Argument verteidigt, es sei in der Musik der Opera buffa besonders notwendig und als „ein wesentlicher Teil ihrer Schönheit“ bringe er letztendlich ihre „wunderbare Wirkung“ hervor. Der Autor schlägt ein Gedankenexperiment vor: Man stelle sich den Gesang mit einer Secco-Begleitung vor („,che gli istrumenti accompagnino sempre secchi secchi la parte cantante“). Daraus würden sich bei den Zuschauern sicher Ermüdung und Langeweile einstellen. Hinter dieser Aussage verbirgt sich also die Auffassung

586 Gazzetta urbana veneta Nr. 67, Sabbato 22 Agosto 1789, S. 553f. Zit. nach Villinger, S. 313. 587 Gazzetta urbana veneta, Nr. 69, Sabbato 29 Agosto 1789, S. 546. Zit nach Villinger, S. 314. 
vom Spiel als Abwechslung, Spannung, Schönheit, Genuss und Unterhaltung erzeugendes Phänomen, wie sie auch von mehreren Spieltheoretikern vertreten wird.

In dieser Diskussion, die selbst als „agonales Spiel“ definiert werden könnte, sind also die beiden typischen entgegengesetzten Positionen vertreten, die immer wieder auftauchen, wenn es um das Thema „Spiel“ geht: Einerseits wird vom Paisiello-Kritiker die typische abwertende Auffassung vom Spiel als unernstes, unvernünftiges Tun vertreten, das mit Unwürde und hier sogar mit Betrug („ciarlataneria“) assoziiert wird. Diese Ansicht ist in diesem Kontext auch verbunden mit der herkömmlichen Meinung, die Musik solle gegenüber dem Text eine lediglich begleitende und unterstützende Funktion haben. Im Gegensatz dazu vertritt der anonyme Verfasser des Antwortbriefes eine positive, fortschrittlichere Meinung, die das Spiel aufwertet: Das „giuoco degli istrumenti“ sei eine unerlässliche ästhetische Notwendigkeit, ohne die die Opera buffa ihren Reiz verlieren würde. Was darunter verstanden wird, scheint für die Autoren selbstverständlich zu sein. Als Teilnehmer an diesem „giuoco“ nennt der Paisiello-Kritiker zunächst die „parti di un tutto“, womit gleichermaßen alle Stimmen gemeint sein könnten. Dann zählt er aber lediglich Orchesterinstrumente auf, was wiederum die Vermutung nahelegen würde, dass lediglich von der Instrumentationspraxis die Rede ist. Welchen hohen Stellenwert die Instrumentation generell in der Opernkomposition der Zeit hatte, erklärt Francesco Galeazzi in seinem Traktat Elementi teorico-pratici di musica. Unter den sechs Fähigkeiten, die beim Komponieren im „stile teatrale“ notwendig sind, betont er mit Nachdruck, dass der „buon gusto nell'istromentare“ zu den zwei „essenzialissime“ Eigenschaften gehört. ${ }^{588}$

Mit dem „Fechten zwischen Geigen und Blasinstrumenten“ könnte der PaisielloKritiker also möglicherweise eine Art „Abwechslungs- und Ergänzungsspiel“ meinen, das sich aus dem zunehmenden solistischen Einsatz bzw. aus der unabhängigeren Behandlung der Bläser ergibt, eine Neuerung, die der traditionalistische Kritiker vermutlich nicht zulässt. Mit der Bewegung des „Nachlaufens“ (oder Fangen-Spielens) könnte man am ehesten die Technik der Imitation assoziieren. Passagen mit imitatorischen Einsätzen sind in der Opera buffa durchaus üblich, sie erfolgen aber eher zwischen den Singstimmen als zwischen Bratschen und Hörnern, wie es der PaisielloKritiker beschreibt. Möglicherweise verwendet er den Spielbegriff nur als allgemeine Metapher und meint mit den erwähnten Instrumenten und Spielen keine bestimmten Techniken, wie auch aus den Aussagen des zweiten Schreibers herauszulesen ist: Wenn

588 „A 6 ridur si possono i capi principali, e le principali cognizioni che dee avere un Compositore, che si vuol accingere a comporre per il Teatro. (...) 5. Genio inventore. 6. Buon gusto nell'istromentare. (...) Ma essenzialissime poi sono le ultime due cose, cioè il genio creatore ed inventore, e l'arte d'istromentare." (Galeazzi, Bd. 2, S. 297f.). 
dieser nämlich eine „trockene Begleitung“ als Gegensatz zum „giuoco degli istrumenti“ nennt, dann muss das „Spiel der Instrumente“ einfach generell einen dichteren, lebendigeren und farbigeren Orchestersatz bezeichnen, den sein Gegenpart als überflüssige, müßige Verzierung („ozioso ornamento“) empfindet. (Dazu wäre zu bemerken, dass in dieser Auseinandersetzung das Begriffspaar Müßigkeit und Muße in ähnlicher Weise behandelt wird wie im Bereich der Diskussion um das Spiel.) Diese Auffassung von einem lebendig bewegten und abwechslungsreichen Orchestersatz als Spiel steht in einem engen Zusammenhang mit dem im Kapitel „Opera buffa im Licht der Spieltheorien“ erläuterten Musikbegriff als „Spiel der Töne“, der ähnlich wie das Farben- oder Lichtspiel auf der Grundbedeutung des Spiels als tänzerischer Bewegung basiert.

Wenn man in der Opera buffa aber nach einer konkreten Umsetzung des „giuoco degli istrumenti“ sucht, können unter anderem Arien mit obligatem Solo-Instrument als ergiebiges Beispiel herangezogen werden. In diesen in der Regel im Seria-Stil komponierten Arien findet nicht nur das in der Gazzetta veneta erwähnte „Fechten zwischen Geigen und Blasinstrumenten“, sondern vor allem ein regelrechtes „agonales Spiel“" zwischen dem Solo-Instrument, meistens ein Blasinstrument, und dem Sänger statt. Dass solche Arien schon von den Zeitgenossen als musikalischer Wettstreit, also als eine Art Kampfspiel verstanden wurden, bezeugen die Worte, die Arteaga seinem fiktiven Impresario in den Mund legt: „Sarà poi mio pensiero far che il maestro vi adatti sopra una musica sfoggiata e pomposa, e affinchè spicchi di vantaggio la di lui abilità, faremo nascere una tenzone musicale fra la voce del cantante e un qualche strumento con botte, e risposte da una parte e dall'altra, che sarà proprio una delizia."589 Der musikalische Wettstreit scheint also dem Komponisten, dem Sänger und dem Solo-Instrumentalisten eine Möglichkeit, ihre virtuosen Fähigkeiten zur Schau zu stellen, sowie dem Publikum einen besonderen musikalischen Höhepunkt geboten zu haben. Dafür liefert eine Arie der Barberina aus Giovanni Carusos I780 in Venedig uraufgeführter Oper „L'albergatrice vivace“ ein treffendes Beispiel. Schon die Positionierung dieser Sopranarie als letzte musikalische Nummer vor dem zweiten Finale ist ein Zeichen für ihre Bedeutung im Werk. Dieser Bravourarie der Protagonistin geht ein Rezitativ voran, in dem sie ihre Wut auf Michieluccio durch das (möglicherweise parodistisch gemeinte) Gleichnis der ein wildes Tier bezwingenden „Amazzone guerriera" freien Lauf lässt. Auch thematisch eignet sich diese Arie zu einem musikalischen Kampfspiel, denn die Jagd kann ebenfalls als eine Form des agonalen Spiels angesehen werden. ${ }^{590}$ Hier könnte der rein musikalische „Wettstreit“ der

589 Arteaga, S. $148 \mathrm{f}$.

590 „Auch die Beschäftigungen, die geradewegs auf die Befriedigung von Lebensbedürfnissen abzielen, z. B. die Jagd, nehmen in den archaischen Gesellschaften gern Spielform an." (Huizinga, S. 51). 
musikalischen Ausdeutung der Jagd- bzw. Kampf-Metapher dienen. Eine zusätzliche Verbindung zwischen dem Arientext und seiner Vertonung wird durch das im Text erwähnte Horn hergestellt, das der Komponist als obligates Solo-Instrument einsetzt. Die konventionelle Orchestereinleitung ist durch ein zweimal eingefügtes punktiertes Unisono-Quarten-Motiv im Tutti geprägt, das zur klangmalerischen Darstellung eines Jagdhorn-Signals dient. Unerwarteterweise beginnt nach der Einleitung nicht die Sängerin mit dem anfangs schon erklungenen Motiv, sondern das Solo-Horn, wodurch die Wichtigkeit seiner Rolle und seine Ebenbürtigkeit mit der Singstimme zum Ausdruck kommen. Dem Solo-Horn ist ein langer Abschnitt gewidmet, der durch höchst virtuose Figuren und Läufe charakterisiert ist und nur einmal durch das TuttiJagd-Signal unterbrochen wird. Das Solo-Instrument wird in diesem Abschnitt genauso wie eine Singstimme behandelt, dementsprechend schließt eine freie Kadenz, wie es sonst bei Sängern üblich ist, diesen virtuosen Auftritt ab. Nach einem kurzen Tutti-Zwischenspiel setzt endlich - nach 7 I rein instrumentalen Takten - die Singstimme ein, allerdings mischt sich schon im dritten Takt das Solo-Horn ein, womit das eigentliche „agonale Spiel“ beginnt. Die Singstimme verschafft sich durch eine Kadenz etwas Freiraum von ihrem Kontrahenten; das dabei tonmalerisch vertonte Wort ist (bezeichnenderweise) „suono“, d.h. Klang. Durch die sicherlich virtuos ausgeführte Kadenz hat die Singstimme wenigstens kurzfristig die Oberhand gewonnen und darf ungestört eine Phrase singen. Der Text verrät dabei, um wessen Klang es sich handelt: „del bellicoso corno“, des kriegerischen Horns. Der Text dient dem Komponisten in diesem Fall also als Programm. Auf dem Wort „corno“ ertönt zum letzten Mal das besagte Jagd-Signal, das nun endgültig den musikalischen Wettstreit eröffnet. Von diesem Moment an beginnen die beiden Solisten wirklich miteinander zu „fechten“ („giuocano di scherma“), „sich gegenseitig mit Füßen zu treten“ („fanno ai calci tra di loro“) und „einander nachzulaufen“ („si corrono dietro“) (s. Notenbeispiel I6, S. I72f.), denn sie singen bzw. spielen Koloraturen um die Wette, versuchen sich gegenseitig zu übertreffen, eifern einander mit großem Ehrgeiz nach, um im Virtuositätswettbewerb als Sieger hervorzugehen.

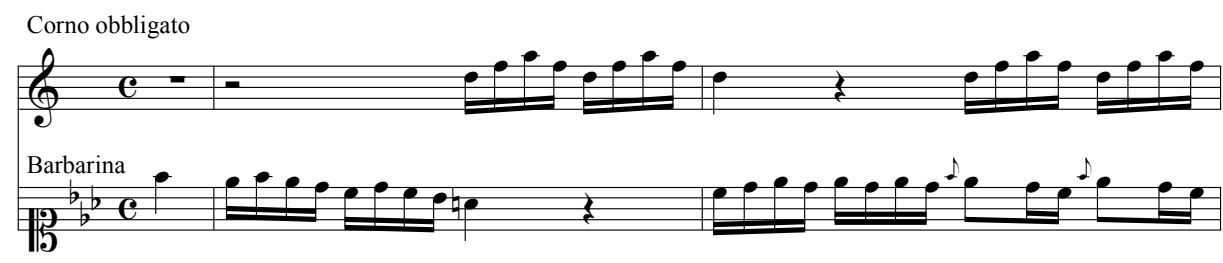




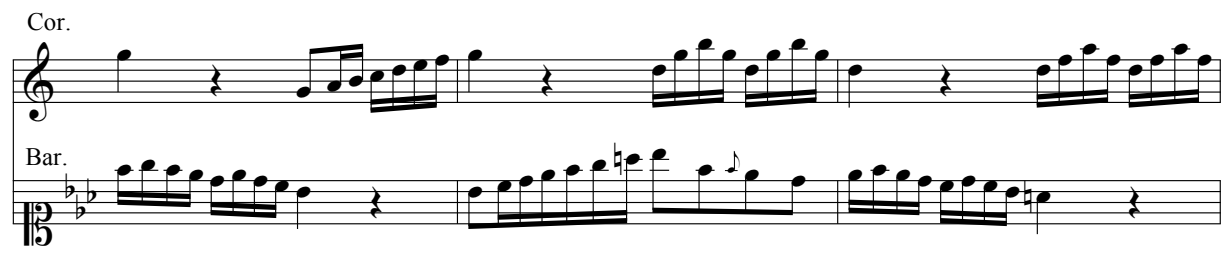

16 Caruso/Palomba: L'albergatrice vivace. (F-Pn D 1859-1860)

Corno obbligato
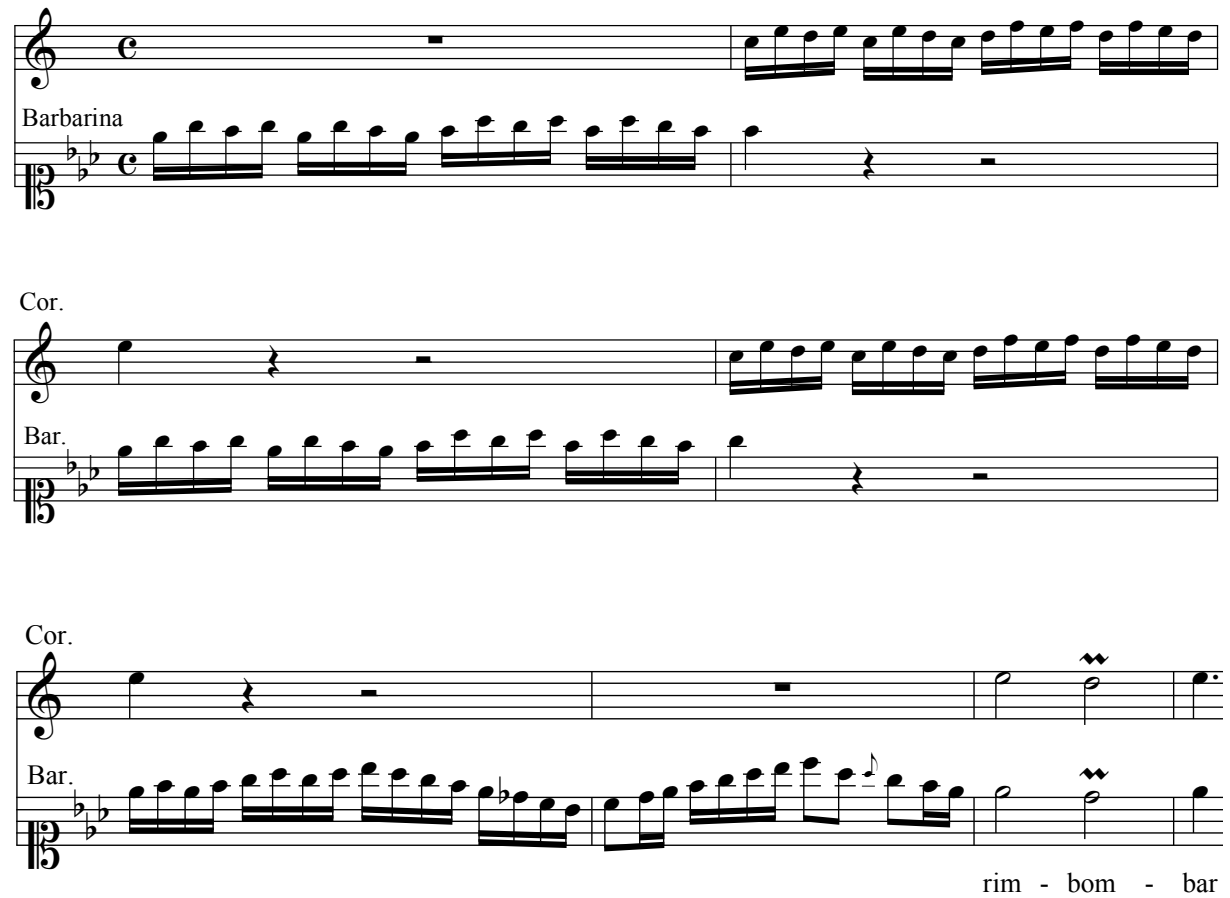

17 Caruso/Palomba: L'albergatrice vivace. (F-Pn D 1859-1860)

Der Kampf wird mit imitatorischen Einsätzen, abwechselnden Einwürfen und Zurschaustellung von bravourösen Koloraturen fortgesetzt, bis die Arie schließlich wie ein Duett im simultanen $a$ due endet.

Die Zuhörer können aus ihrer distanzierten Position den musikalischen Wettkampf als spettacolo genießen, können mitfiebern und bei besonders virtuosen und riskanten Passagen den Atem anhalten; sie können das sich immer wieder ändernde Wechselspiel zwischen der Sängerin und dem Solo-Hornisten mitverfolgen und sich 
von der Spannung fesseln lassen, die die beiden durch ihre akrobatische Höchstleistung erzeugen. Huizingas Definition des Spiels als Kampf und/oder Darstellung ist in dieser Art von Seria-Arien mit obligatem Solo-Instrument - auch in solchen, deren Text keine Thematisierung des Kampfes enthält - in hohem Maße verwirklicht. Die Wettstreitsituation bietet Momente höchst intensiver Performativität und entfaltet bei dieser Bewunderung bewirkenden „Zurschaustellung von Aufwand“591 und „Vorführen von etwas Ungewöhnlichem, höchst Besonderem“592 ein maximales Darstellungs- und Spannungspotential.

Hinter den unterschiedlich facettierten agonalen Momenten der Opera buffa verbirgt sich meist die Intention einer Erhöhung der dramatischen Spannung und der Performativität. Ob in allen Fällen von agonalem Spiel gesprochen werden kann, sei dahingestellt. Über die Spielhaftigkeit der ins Komische kippenden Streit- oder Kampfszenen, der Brett- und Kartenspiele sowie des eben untersuchten musikalischen Wettstreits bestehen meines Erachtens keine Zweifel. Die Frage stellt sich in erster Linie bei ernst gemeinten agonalen Situationen. Dazu muss bemerkt werden, dass die meisten Spieltheoretiker sich darüber einig sind, dass Spiel zwar als Gegensatz von Ernst verstanden werden, aber gleichzeitig auch Ernst einschließen und somit eine gewisse Ambivalenz enthalten kann. ${ }^{593}$ Buland unterscheidet in diesem Zusammenhang zwischen „zwei verschiedenen Formen des Ernstes“, nämlich zwischen einem „Ernst der Zwecke oder Arbeitsernst“ und einem „heiligen Ernst“.594 Bei den höchst ernst gemeinten Duellen kann beispielsweise die Ernsthaftigkeit kaum auf einen Zweck oder eine Arbeit bezogen werden. Als in der Gesellschaft des I 8. Jahrhunderts übliche ritualisierte Zweikämpfe entsprechen sie aber sehr wohl dem „heiligen Ernst“, den Buland (aber auch schon Huizinga und andere) als eine im Spiel durchaus enthaltene, wenn nicht sogar für das Spiel typische Art von Ernst sieht. Ob Huizingas Kriterien für die Spielhaftigkeit agonaler Situationen, nämlich der „anti-

591 Huizinga, S. 56.

592 Ebd. S. 21.

593 Huizinga spricht von der „verwirrenden Unauflösbarkeit des Problems Spiel oder Ernst“ (Huizinga, S. 200) und schreibt dazu: „Der Gegensatz Spiel-Ernst bleibt stets schwebend. (...) Das Spiel schlägt in Ernst um, der Ernst in Spiel." (Ebd. S. 16).

594 Über den Ernst des Fehlens von Festen. Hans-Georg Gadamer im Gespräch mit Rainer Buland. In: Günther G. Bauer (Hg.): Homo ludens. Fest und Spiel. Bd. 8. Internationale Beiträge des Institutes für Spielforschung und Spielpädagogik an der Hochschule „Mozarteum“ Salzburg. München, Salzburg 1998, S. 25. 
thetische Charakter", 595 der ungewisse Ausgang und das Spannungselement ${ }^{596}$ sowie der besagte „heilige Ernst“ ausreichen, um solche Handlungsmomente als „Spiele“ zu bezeichnen, bleibt subjektiven Bewertungen überlassen. Wenn man allerdings Gadamers Spielbegriff folgt, der explizit nicht auf die Aktivität des Spielers, sondern auf die sich daraus ergebende Hin- und Herbewegung gerichtet ist, ${ }^{597}$ dann kann jeder Wettkampf als Spiel definiert werden.

\section{LiEBESSPIEL}

Innerhalb der Opera buffa ist prinzipiell überall und stets die Möglichkeit vorhanden, spielhafte Momente einzubringen. Allerdings öffnet sich an bestimmten Stellen besonders häufig ein Raum für Spiel und Phantasie, wie bei der klassischen Burla, die meistens in einem Finale stattfindet und sich besonders gut für spielerische Einfälle eignet. Entgegen jeder Erwartung sind besonders im Liebesduett zwischen prima buffa und primo buffo unterschiedliche Arten von Spiel eingeflochten. Das in der Regel mehrgliedrige, verhältnismäßig lange Liebesduett stammte aus der Opera seria ${ }^{598}$ und konnte entweder - wie ursprünglich - im ernsten und pathetischen Seria-Stil gehalten oder aber an den leichteren, spielerischeren Charakter der Opera buffa angepasst werden. Dies wurde häufig gerade durch Einfügung von Spielen, Liebesspielen und Neckereien bewirkt, die dem Buffa-Liebesduett und der Opera buffa im Allgemeinen ihre typische Anmut verliehen.

In der Regel reicht das Spektrum dieser unterschiedlichen spielhaften Momente von der harmlosen Neckerei bis hin zum Aufführen ganzer Szenen. Die Schwierigkeit diese unterschiedlichen Erscheinungsformen einer einzigen Kategorie zuzuordnen, rechtfertigt die Stellung dieses Kapitels zwischen „Agon“ und „Mimicry“.

Dramaturgisch gesehen dienen diese „Spiele“ zur Verzögerung des Moments der Vereinigung, der Hochzeit, der höchsten Freude und Wonne, des Jubels, die am Schluss jedes Liebesduetts im a due der beiden Singstimmen vertont sind. Aufgrund

595 Huizinga, S. 52.

596 Ebd.

597 „Gewiß gilt für den Wettkämpfer seinem eigenen Bewußtsein nach nicht, daß er spielt. Wohl aber entsteht durch den Wettbewerb die spannungsvolle Bewegung des Hin und Her, die den Sieger hervorgehen und so das Ganze ein Spiel sein läßt." (Gadamer: Wahrheit und Methode. S. 101).

598 Aus der Opera seria wurde - gemeinsam mit der dreiaktigen Form - der gesamte konventionelle Opernschluss als Abfolge von finalem Liebesduett, Rezitativ mit Handlungsaufösung und kurzem Coro finale übernommen. Dieses Finalkomplex hielt sich in der Opera buffa mindestens bis zum Ende der 1770er Jahre, als zweiaktige Opere buffe zu überwiegen begannen, in denen die Liebesduette an anderen Stellen der Oper positioniert wurden. 
des Kontextes, in dem diese "Spiele“ eingebettet sind, sind sie hier unter dem Titel „Liebesspiele“ zusammengefasst, auch wenn dieser Begriff eine erotische Bedeutung suggeriert, die in den Liebesduetten in der Regel nicht explizit geäußert wird.

Nicht alle Spieltheoretiker ziehen den der Alltagssprache entnommenen Begriff des „Liebesspiels“ in Betracht: In Caillois' Theorie, dessen Spielkategorien in dieser Arbeit als allgemeines Einteilungsraster dienen, werden Liebesspiele nicht berücksichtigt. Ebensowenig ist in Gliederungen aus pädagogischer Sicht eine solche Spielkategorie zu finden. Huizinga unterscheidet streng zwischen dem nicht-spielhaften Paarungsakt und dem ihm vorangehenden Liebesspiel: „Es ist allen Anschein nach eigentlich nicht der biologische Paarungsakt an sich, der vom sprachschöpferischen Geist als Spiel aufgefasst wird. Auf diesen kann man weder die formalen noch die funktionellen Kennzeichen des Spiels anwenden. Dagegen ist die Vorbereitung oder die Einleitung dazu, der Weg zu ihm, öfters mit allerlei Spielmomenten durchsetzt."599

Der vorsichtigen Formulierung Huizingas steht Buytendijks emphatische Definition gegenüber: Letzterer betrachtet nämlich das Liebesspiel als „das reinste Beispiel aller Spiele“, das allen Merkmalen des Spiels, vor allem dem des „Spielens mit etwas, das auch mit dem Spieler spielt“, entspricht. Er hebt besonders die Momente der Hinund Herbewegung, des Bewegungsdrangs, der Lustbetontheit, des Spontanen, der Schüchternheit und vor allem der Überraschung hervor, um deretwillen die Spieler „Hindernisse, Regeln, Gewohnheiten, Situationen“ erfinden. ${ }^{600}$

Es verwundert ein wenig, dass Huizinga sich gegenüber dieser Feststellung skeptisch äußert, obwohl er selbst von den Spielmomenten gesprochen hatte, die den Paarungsakt vorbereiten: „Die dynamischen Elemente des Spiels, von denen Buytendijk spricht: das Aufrichten von Hindernissen, das Überraschen, das Sich-zieren, das Spannungselement, all das gehört zum Flirt und zur Liebeswerbung. Auch diese Funktionen jedoch kann man noch nicht im strikten Sinn als ein richtiges Spiel auffassen. "601

599 Huizinga, S. 49.

600 „Das Liebesspiel ist das reinste Beispiel aller Spiele; (...) Hier ist wirklich das Spielen bedingt durch ein Spielen mit etwas, das auch mit dem Spieler spielt, hier ist die Überraschung, das Abenteuer, das dunkle Unbekannte, Flackernde, Unberechenbare, Spontane. (...) In der Dynamik des Liebesspieles kommt nicht nur das Zusammenspielen am ausgesprochensten zur Geltung, das Hin und Her der Bewegung und Intentionalität (...). Die Spielsphäre, das Spielklima ist mit diesen lustbetonten Handlungen geladen. (...) Die Spieler erfinden Hindernisse, Regeln, Gewohnheiten, Situationen, um den Überraschungen ihre volle Wirkung zu verbürgen, um damit Spielentwicklung, Differenzierung, Organisierung, Wachstum und Dauer zu ermöglichen. Das Liebesspiel ist auch Spiel im vollsten Sinne, weil es bekanntlich die jugendliche Dynamik fordert, die Schüchternheit, den ungerichteten Bewegungsdrang, das zielfreie Verhalten." (Buytendijk, S. 121).

601 Huizinga, S. 49. 
Groos hingegen betrachtet gerade diese „natürlichen Bewerbungsspiele“602 als Spiel und zählt „die allgemeine Tendenz zur Annäherung und Berührung, zur Selbstdarstellung und Coquetterie“ ${ }^{603}$ zur Kategorie der Liebesspiele. In vielen Buffa-Liebesduetten sind meines Erachtens eben solche für Flirt und Liebeswerbung typische Spielmomente enthalten, die der symbolischen Vereinigung am Schluss des Liebesduetts vorangehen und nun anhand folgender Beispiele untersucht werden.

„Il geloso in cimento“ (III, 5$)$

Wie schon erwähnt, dreht sich die Handlung dieser Oper um Fabios für seine Geliebte Flavia unerträgliche Eifersucht. Als „moderne“ Frau möchte Donna Flavia ihn nur unter der Bedingung der Freiheit, sich mit jedem unterhalten zu dürfen, heiraten. Fabio antwortet mit einer Gegenbedingung: Gäste - gemeint sind wohl cicisbei müssen mindestens 70 Jahre alt sein. Daraufhin beginnt das Duett in einem für SeriaLiebesduette typischen elegischen Duktus (Larghetto, 3/4-Takt). Dabei alternieren liebevolle Gefühlsausdrücke mit weiteren Bedingungen: Fabio soll „star soggetto e farsi regolar“ - es geht um die Mäßigung seiner Eifersucht -, Flavia darf den Leuten keine Gelegenheit geben, über sie zu „flüstern“. Darauf folgt ein Zank, der im Gegensatz zum vorherigen Cantabile im typischen Buffa-Parlando vertont ist.

D. Flavia

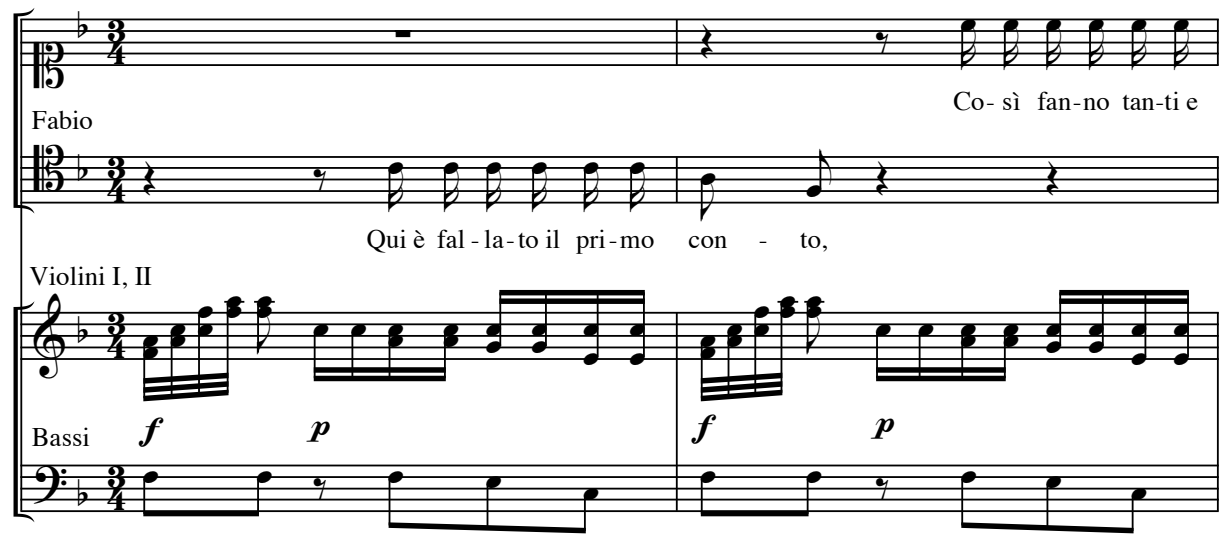

602 Groos: Die Spiele der Menschen. S. 325.

603 Ebd. 
D. Fl.

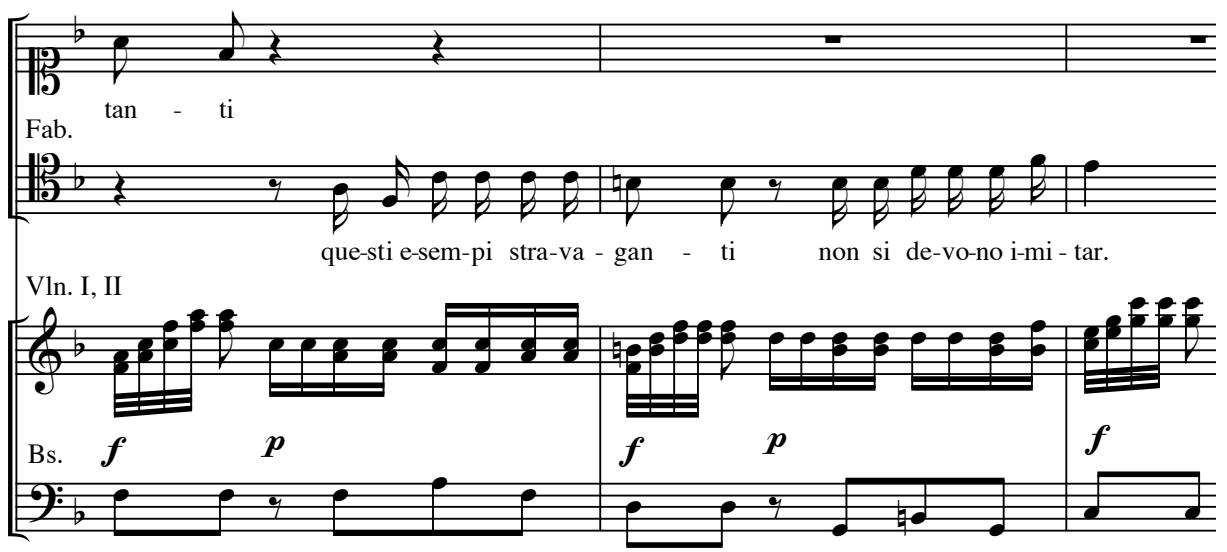

18 Anfossi/Bertati: Il geloso in cimento. Venezia 1774 (I-Gi B.7.7/8)

Beide bezweifeln den Sinn einer solchen Hochzeit, verabschieden sich in einem neuen musikalischen Abschnitt (Andante grazioso) und gehen auseinander (Regieanweisung: „si separano“). Der fröhliche Ton der Musik und der Zusatz grazioso in der Tempobezeichnung verraten allerdings, dass es sich bei dieser Trennung nur um ein Spiel handelt: Während die ersten Geigen „neckische“ 32 stel-Figuren spielen, bleiben beide stehen (Regieanweisung: „poi si fermano") und brechen schließlich in ein herzhaftes Lachen aus, in das das gesamte Orchester einstimmt. Hörner und Traversflöten verdoppeln dabei die Töne der Singstimmen bzw. der Streicher und heben diese Passage klanglich von der vorherigen und nachfolgenden reinen Streicherbegleitung ab.

Mit dem (augenzwinkernden) Vorwand, dass dem Partner eine Trennung schwer fallen würde, nähern sie sich wieder einander. Typische neckische Kosenamen („Furbetta“ / „Tristarello“) führen schließlich zur Ringübergabe und zum Hochzeits- und Treueversprechen im Schluss-a-due (Allegro, 6/8-Takt).

Spielhaft wirkt dabei zunächst der nicht allzu ernst zu nehmende Streit der Liebenden sowie ihre Zweifel und Unentschlossenheit, die eine für das Spiel typische Ambivalenz und Hin- und Herbewegung ausdrücken. Dieselbe Dynamik wohnt auch der darauffolgenden Trennung inne, die die Wiedervereinigung nur hinauszögert und für Spannung sorgt. Es handelt sich dabei um die „künstliche Herstellung einer Distanz und damit Spannung“, ${ }^{604}$ die Buytendijk als typisches Merkmal des Liebesspiels definiert. Der neckische Ton und das schon von James Sully als Signal von Spielorientie- 
rung bezeichnete Lachen ${ }^{605}$ unmittelbar nach der Trennung sind ebenfalls deutliche Hinweise für den leichten und spielerischen Charakter der ganzen Auseinandersetzung.

Andante graziosino

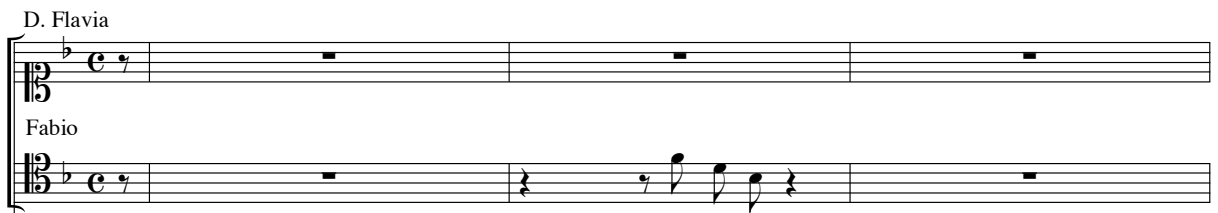

Oh bel-la!
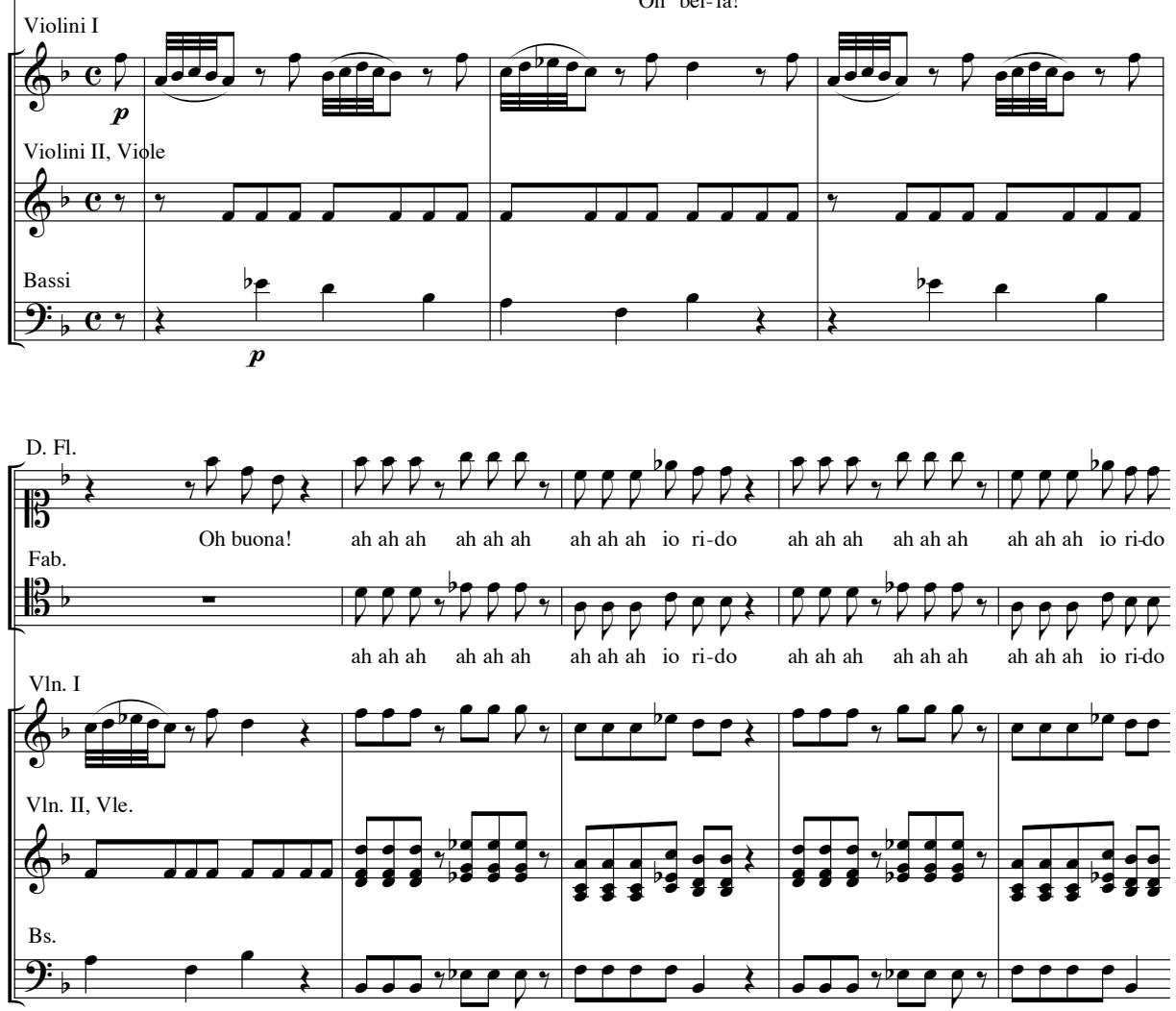

19 Anfossi/Bertati: Il geloso in cimento. Venezia 1774 (I-Gi B.7.7/8)

605 „It is a matter of common observation that joyous laughter is a frequent concomitant of the playattitude." (James Sully: An Essay of Laughter. London 1902, S. 76). 
„L'inimico delle donne“ (III,8)

Dieses Spiel zwischen Nähe und Distanz tritt in Liebesduetten sehr häufig auf, beispielsweise auch in „L'inimico delle donne“ (III,8) von Galuppi und Bertati. Hier treffen sich zwei Missachter der Liebe, der chinesische Prinz Zon-zon und die italienische Schiffbrüchige Agnesina, und verlieben sich ineinander zum ersten Mal in ihrem Leben. Erst gegen Ende des dritten Akts gestehen sie sich ihre Liebe ein. Bei der Thematisierung dieses für beide noch unbekannten Affekts handelt es sich - genauso wie bei der Figur des Misogynen - um einen Topos. Im Liebesduett fühlen die beiden zum ersten Mal die Macht der Liebe („Non intendo“, Allegro, C) und spielen das in Liebesduetten häufige Spiel des Sichentfernens, das hier wie eine Art Experiment mit der zum ersten Mal gefühlten Bindungskraft der Liebe anmutet.

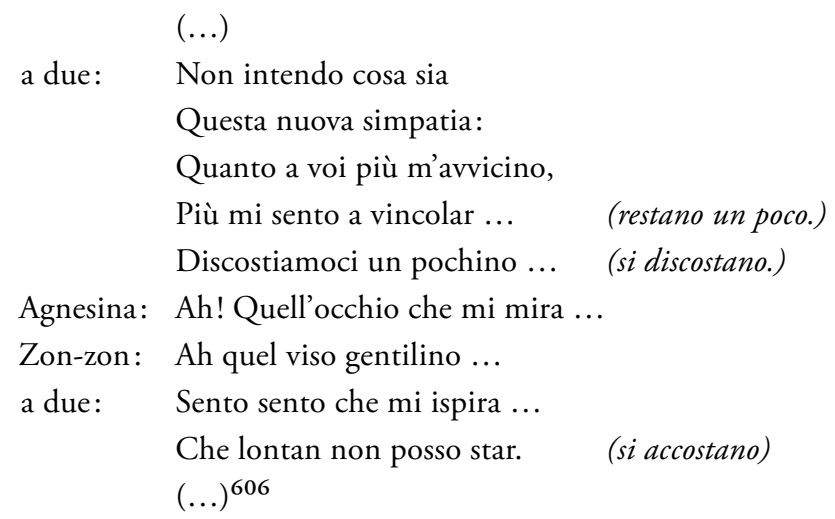

Galuppi komponiert dieses „Spiel mit der natürlichen Anziehungskraft“ in enger Anlehnung an den Text und an die szenische Situation: Der Vorsatz „Discostiamoci un pochino" wird in einem eigenen, sehr kurzen musikalischen Abschnitt (Andantino, $3 / 4$ ) vertont, das im Verhältnis zum vorhergehenden Allegro (C) auf ein Innehalten deutet. Für das szenische Spiel des Sich-Entfernens wird erneut Takt und Tempo gewechselt: Die ersten Takte des Andante sostenuto (C) werden zur Ausführung des szenischen Spiels zunächst rein instrumental vertont, wobei der fanfarenartige Beginn im plötzlichen Forte einen starken Kontrast zum vorhergehenden Abschnitt bewirkt. Durch die Staccato-Bewegung und die lustig „herunterpurzelnde“ melodische Linie kippt die feierliche Fanfare sofort ins Parodistische und Spielerische.

606 Bertati/Galuppi: L'inimico delle donne. Venedig 1771 (III,8). 

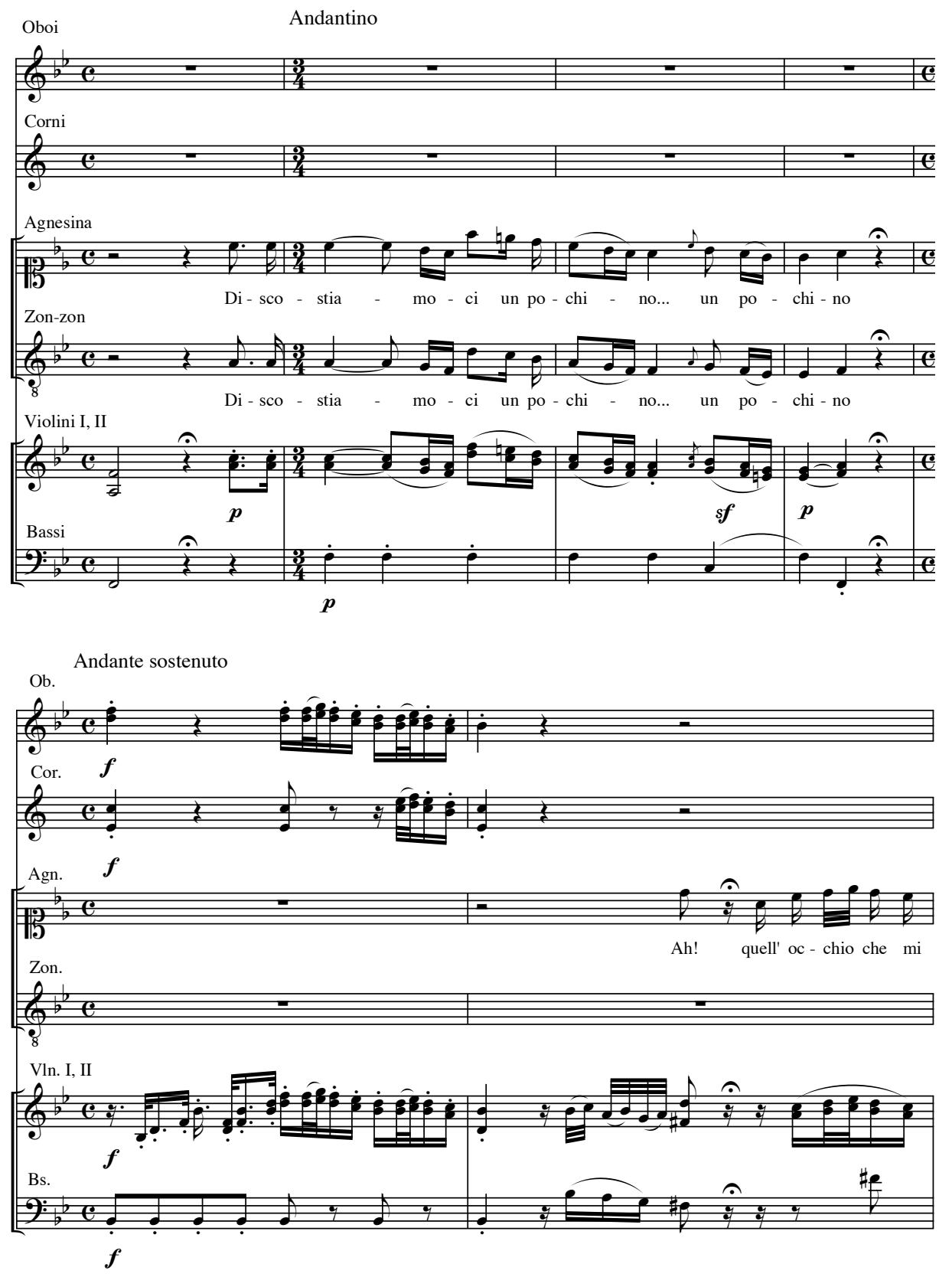

20 Galuppi/Bertati: Linimico delle donne. Hg. von Helen Geyer-Kiefl. Mailand 1986 
Die Folge der Entfernung ist ein beidseitiges „Schmachten“ („Ah! Quell'occhio che mi mira“ / „Ah! Quel viso gentilino“), das möglicherweise ebenfalls parodistisch gemeint ist. Bald ertragen die beiden Liebenden die Entfernung nicht mehr und nähern sich wieder einander im aufgeregten Allegro (2/4). Die beiden disprezzatori haben ihre Lektion erhalten: Am Schluss des Duetts verkünden sie a due, dass man nicht als „nemico d'amor“ leben kann. Hier erfüllt das klassische Entfernungsspiel zwischen zwei Liebhabern also nicht nur die Funktion des Spannungsaufbaus und des die Bindung festigenden Liebesspiels, sondern auch die eines Experiments, das zu einer bestimmten Erkenntnis führt, zur „Moral der Geschichte“, dass man nicht ohne Liebe leben kann. Hinter dem Spiel steckt also ein erzieherischer Zweck: Durch spielerische Erfahrung soll etwas erlernt werden. Die Figuren auf der Bühne lernen aus ihrer eigenen Erfahrung, das Publikum lernt durch symbolisches Miterleben und Teilnahme an der Erfahrung der Figuren mit; beides geschieht auf eine spielerische Art und Weise.

Le due finte gemelle (II, I3)

Die nach Buytendijk für das Liebesspiel typischen Merkmale des Sich-Zierens, der Scham und der Schüchternheit äußern sich besonders im Liebesduett aus Petrosellinis und Piccinnis „Le due finte gemelle“ zwischen Isabella und Belfiore. Beide beginnen mehrmals eine Liebeserklärung und unterbrechen sich dann aus Scham. Die Autoren gehen dabei spielerisch mit der konventionellen Form des Duetts um: Die formal und inhaltlich einem Seria-Duett entsprechende Liebeserklärung - beide Personen singen in elegischem Seria-Ton (Larghetto cantabile) nacheinander einen Vierzeiler, der jeweils mit einer messa di voce beginnt - wird durch ein schamhaftes „SichZieren“ unterbrochen, das jeweils beim vierten Vers durch ein (in einem Seria-Duett undenkbaren) Kippen in eine lebhafte, tänzerische, neckische Buffa-Musik unterstrichen wird. Die Liebenden fallen im buffoartigen Allegro vivace (3/8) in ihre eigene Rolle zurück und erscheinen dabei spontan und authentisch, während die vorangehende seriaartige Liebeserklärung im Vergleich damit „aufgesetzt“, also gewissermaßen „gespielt“ wirkt (s. Notenbeispiel 2 I, S. I 83).

Dieses „Spiel“ des Sich-Zierens macht offensichtlich Spaß und wird wiederholt, so dass es zu insgesamt vier abwechselnd von Belfiore und Isabella vorgetragenen Vierzeilern kommt, die immer aus drei Versen im Seria-Stil und dem Kippen in die BuffaSphäre im letzten Vers bestehen. Die Wiederholungstendenz definieren verschiedene Theoretiker als typisches Spielkriterium. ${ }^{607}$ Hier wird, was anfangs wahrscheinlich

607 „In beinahe allen höher entwickelten Spielformen bilden die Elemente der Wiederholung, des Refrains, der Abwechselung in der Reihenfolge so etwas wie Kette und Einschlag." (Huizinga, S. 17). 
Larghetto cantabile
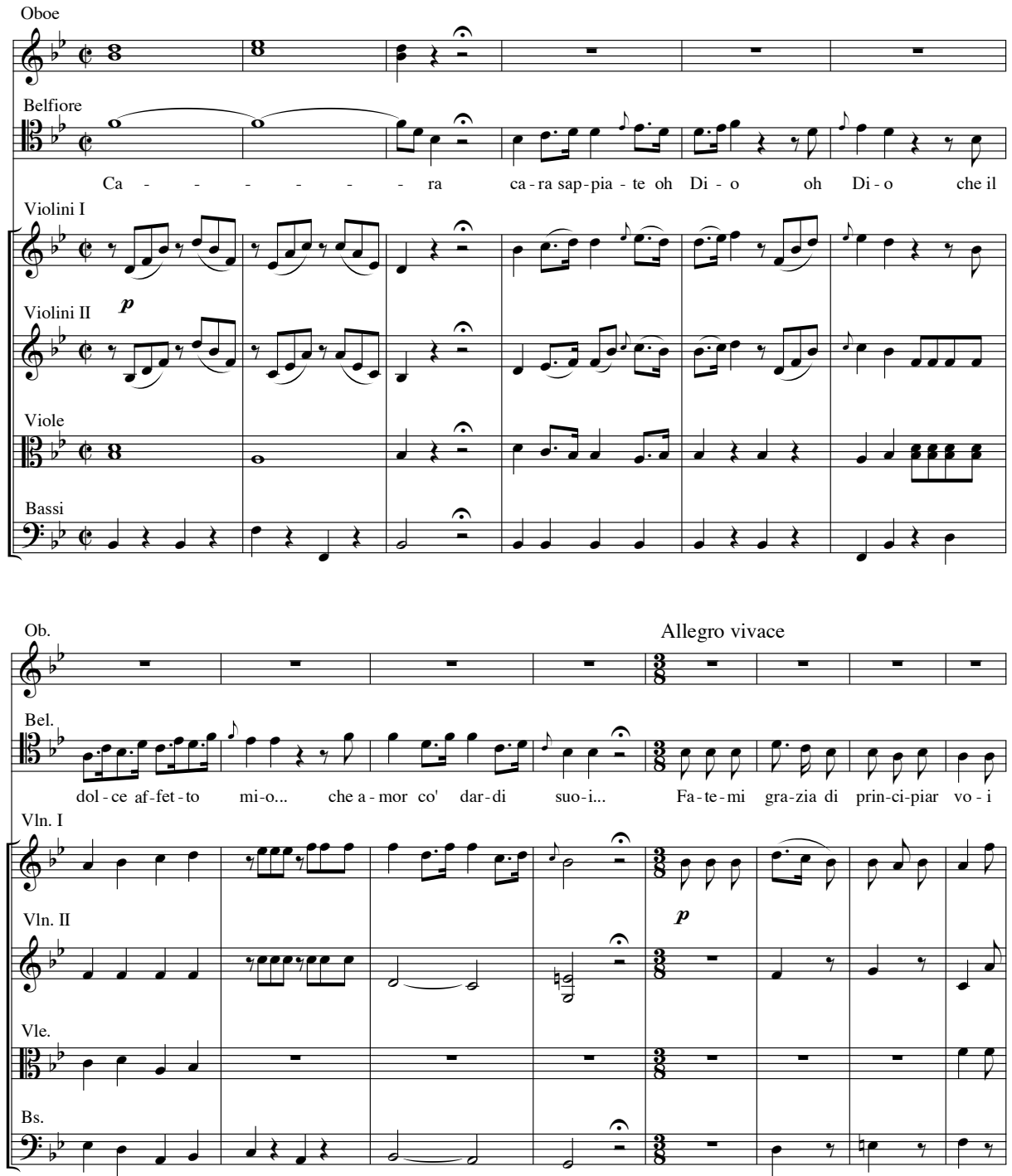

21 Piccinni/Petrosellini: Le finte gemelle. (A-Wn Mus. Hs. 17828) 
spontan und zufällig passiert, als Muster bzw. Regel für ein spielerisches Weiterführen verwendet.

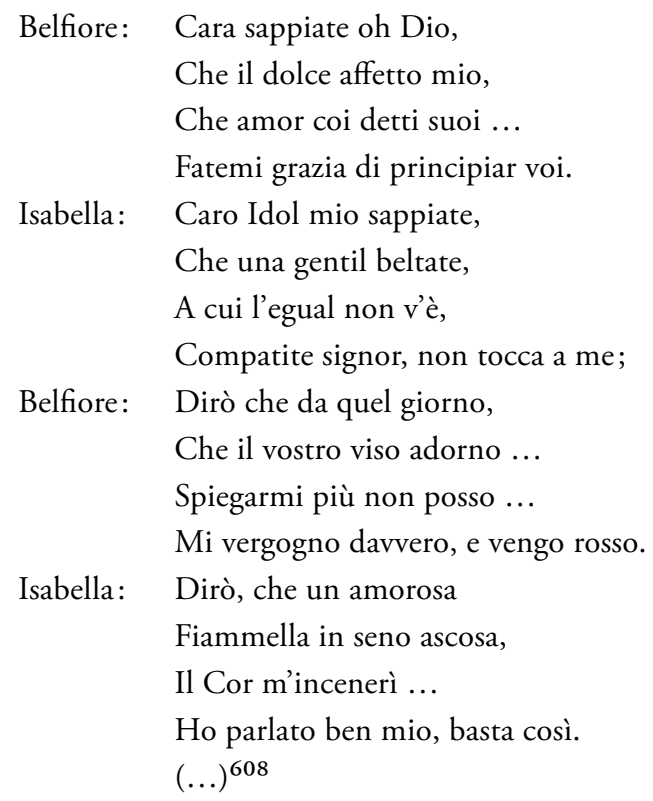

Beim zweiten „Durchlauf“, also beim dritten und vierten Vierzeiler, trauen sich die beiden schamhaften innamorati schon mehr und lassen sich in ausdrucksvolleren und rührenderen Harmonien ( $\mathrm{f}-\mathrm{Moll}$ ) und melodischen Wendungen ergehen, wodurch der chiaroscuro-Kontrast zum vorangehenden und zum nachfolgenden Allegro vivace in fröhlichem Dur und hüpfend-tänzerischem 3/8-Takt zusätzlich verstärkt wird (s. Notenbeispiel 22, S. I 85 ).

Der Mut verlässt die beiden vollkommen im nächsten Abschnitt, in dem die Einsätze der Singstimmen dichter werden („Si ferma la parola. / S'arresta nella gola. / Ne posso seguitar"). Die beiden Liebenden trauen sich zwar nicht, eine Liebeserklärung auszusprechen, erkennen jedoch in den Augen bzw. an den Lippen des Partners die Liebesbotschaft, kommen sich langsam näher und geben sich schließlich im konventionellen Schluss-a-due die Hand. Dieser Moment der Vereinigung wird durch die

„Da die Regeln eines Spiels Wiederkehr und Wiederholungen sind, läßt sich an ihnen zugleich absehen, welchen Rhythmus und welche Symmetrie ein Spiel hat. Rhythmus ist Wiederkehr in der Zeit, Symmetrie Wiederholung im Raum. Rhythmisierung und Symmetrisierung kennzeichnen die Spiele." (Jünger, S. 104).

608 Petrosellini/Piccinni: Le due finte gemelle. Venedig 1783 (II,13). 
Primo Tempo
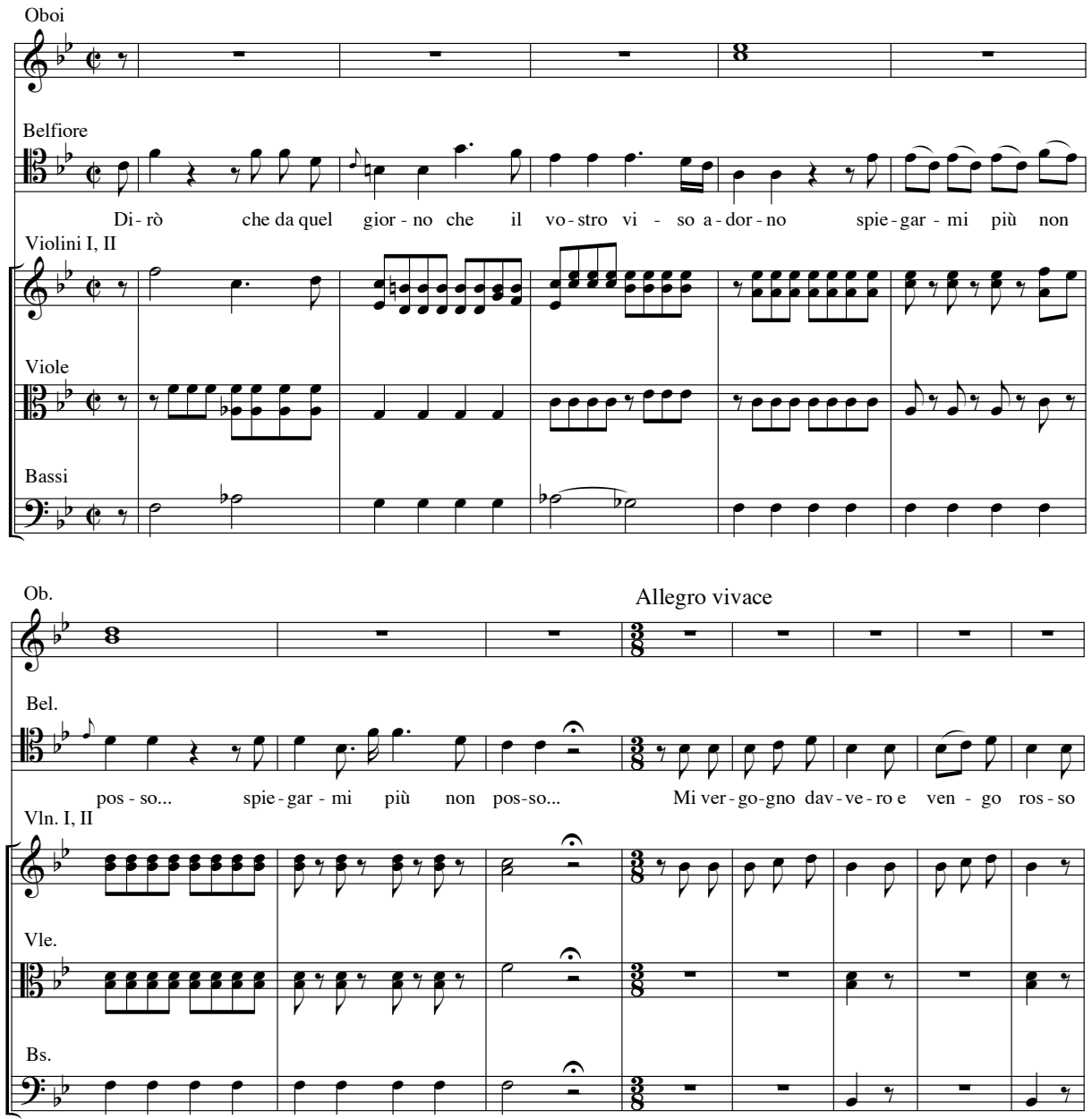

22 Piccinni/Petrosellini: Le finte gemelle. (A-Wn Mus. Hs. 17828)

typischen Liebesspiel-Elemente des leichten Neckens, des Spiels der Blicke („Mi dice quell'occhietto ..."), aber vor allem der Schüchternheit, des Errötens und des SichZierens hinausgezögert.

Darüber hinaus „spielt“ der Komponist gewissermaßen mit der „klassischen“ Form des Seria-Liebesduetts: Statt der reinen Erfüllung der Konvention findet ein Variieren innerhalb einer vorgegebenen konventionellen Struktur statt, wobei durch das „Aus-derRolle-Fallen“ und die Stilbrüche - in einem Seria-Duett undenkbare Distanzierungsmit- 
tel - nicht nur Überraschungsmomente bewirkt werden, sondern auch die für BuffoFiguren typische und mit dem Spiel assoziierbare Spontaneität auskomponiert wird.

Castrini padre e figlio (I, I I)

Ein regelrechter Topos ist das der amanti ritrosi, der zurückhaltenden und schüchternen Liebenden, die oftmals nur auf spielerische Art aus der Reserve gelockt werden können. In „Castrini padre e figlio“ von Ferdinando Robuschi und Florimondo Ermioneo (Pseudonym von Giovanni Greppi) traut sich Giacinto nicht, um die Hand seiner geliebten Liberata anzuhalten, denn er fürchtet die Wut seines Vaters, der sie ebenfalls heiraten möchte. Nur dank einem vom schlauen Diener Mortadella angeleiteten „Spiel“ wird er dazu gebracht, Liberata eine Liebeserklärung zu machen, jedoch nicht im Rahmen eines Liebesduetts, sondern als Rezitativ:

Mortadella rät dem befangenen Giacinto, sich an den Tisch neben Liberata zu setzen, als diese so tut, als schreibe sie einen Brief. Liberata geht daraufhin zwar zu einem anderen Tisch, hinterlässt aber ein Schreiben. Nun beginnt eine dichte Korrespondenz zwischen den an zwei verschiedenen Tischen sitzenden Liebenden. Der als Bote dienende Mortadella bewegt sich zwischen den beiden unentwegt hin und her, und die Nachrichten werden vom jeweiligen Empfänger immer laut vorgelesen, so dass der Zuschauer den ganzen Inhalt und Verlauf der Korrespondenz mitverfolgen kann. Bei den Liebeserklärungen angelangt, kürzt Mortadella durch seinen Kommentar „ È un po' lungo, mi sembra, questo gioco“ das Spiel ab, um schnell ein Heiratsversprechen herbeizuführen. Die ganze Szene wirkt wie ein Spiel, Mortadella selbst bezeichnet sie als „gioco“. Einerseits verleiht das szenische Element, nämlich die ständige Hin- und Herbewegung des Boten, der Szene eine gewisse Mechanik und einen spielerischen Charakter, andererseits baut die Verlangsamung der Kommunikation eine Spannung auf, denn das Publikum muss, um den Inhalt des Briefes zu erfahren, jeweils warten, bis der Empfänger ihn vorliest.

Dieses „Spiel“ ist in den übrigen untersuchten Opere buffe kaum anzutreffen, stammt aber offenbar aus einem typischen lazzo der Commedia dell'arte, dem „dialogo in terzo“, der folgendermaßen beschrieben wird: „gioco scenico che per riuscire sfrutta lo spazio teatrale del palcoscenico: due personaggi situati ai lati estremi del palco dialogano attarverso un terzo personaggio - un ruolo spesso affidato allo Zanni nella commedia dell'arte - che si sposta incessantemente fra l'uno e l'altro."609

609 Melania Bucciarelli : „Parto o bella, ma con qual cuore... “. Riflessioni sulla drammaturgia del dramma per musica e il suo rapporto con l'arte comica. In: Paologiovanni Maione und Alessandro Lattanzi (Hg.): Commedia dell'Arte e spettacolo in musica tra Sei e Settecento. Neapel 2003, S. 244. 
Aus psychologischer bzw. pädagogischer Sicht könnte man dieses „Spiel“ unter die „Spiele mit willkürlicher Regel“610 einordnen. In dieser Art von Spielen, geht es darum, „daß die Willkürregel ein Hindernis liefern soll, mit dem man fertig werden muß“. ${ }^{611}$ Die Regel würde hier darin bestehen, dass man etwas nicht direkt mündlich mitteilen darf, sondern über den Umweg des vom Diener übermittelten Briefs. In diesem Fall ist keine Regel vorher ausgemacht, und das Spiel ergibt sich spontan mithilfe des Intriganten Mortadella. Es handelt sich dabei insofern um ein Liebesspiel, als es die spielerische Annäherung zwischen zwei schüchternen Liebenden bewirkt und zu einer Liebeserklärung führt.

L'astratto (III,6)

Eine andere Möglichkeit des Spiels, das in Liebesduetten gelegentlich vorkommt, ist das Spielen einer regelrechten Schauspielszene, also ein „Als-ob-Spiel“. In Piccinnis Oper „L'astratto“ macht sich der bürgerliche Leandro einen Spaß daraus, seiner aus dem Volk stammenden Braut, der Gärtnerin Laurina, die Manieren der höheren Stände beizubringen, indem er eine kleine galante Szene spielt. Im Rezitativ skizziert er die von ihm dabei gespielte Rolle und kündigt somit das „Spiel“ an:

Leandro: (Che spirito! Che grazia!

Voglio prendermi spasso.) Figuratevi,

Che un Cavaliere io sia

Che venga a visitarvi!

Ma di quelli alla moda,

Che alle spose d'intorno

Van facendo i galanti, ed i Zerbini:

Prima con mille inchini,

Con mille cerimonie io mi presento.

Poi con vezzo così sciolgo l'accento. ${ }^{612}$

Der Beginn der Als-ob-Szene fällt - wie es bei solchen „Ebenenwechseln“ in der Opera buffa häufig der Fall ist - mit dem Beginn der musikalischen Nummer zusammen. Leandro spielt die Rolle eines galanten, modischen, verführerischen cicisbeo, Laurina geht auf das Spiel ein, ohne jedoch ihre Identität aufzugeben. Im galanten,

610 Vgl. Jean Château: Spiele des Kindes. Stuttgart 1974, S. $51 \mathrm{ff}$. (französische Originalausgabe unter dem Titel Jeux de l'enfant. In: Jeux et Sports. Paris 1968).

611 Ebd. S. 52.

612 Petrosellini/Piccinni: L'astratto o Il giocator fortunato. Venedig 1772 (III,6). 
schmeichlerischen Larghetto (3/4) versucht er zunächst ihre Hand zu küssen. Auf Laurinas abwehrende Reaktion hin tut er so, als würde er in Ohnmacht fallen, um das Herz seiner „Beute“ zu erweichen. Als sich dieses Mittel als erfolglos erweist, beginnt nach Leandros rezitativischem Kommentar („Non giovano le buone“) ein neuer rascherer musikalischer Abschnitt (Allegro, 2/4), in dem er versucht, sich mit Gewalt seinem „Opfer“ zu nähern („Per forza m’avvicino“), das sich aber entschlossen wehrt („Io prenderò un bastone“). Auch der letzte Versuch mit dem üblichen Entfernungsspiel scheitert an Laurinas Unerschütterlichkeit. An dieser Stelle fällt Leandro aus dem Rollenspiel in die Wirklichkeit zurück, enthüllt seine echte Identität und bittet Laurina um ihre Hand.

$\begin{array}{ll}\text { Leandro: } & \text { Ah Sposa fedele } \\ & \text { Leandro son io. } \\ & \text { Vi chiedo ben mio } \\ & \text { La destra, e l'amor. } \\ \text { Laurina: } & \text { Leandro voi siete? } \\ & \text { Che gioja ch'io provo: } \\ & \text { Tenete, tenete } \\ & \text { La mano, ed il cor. }\end{array}$

Der Rollenwechsel wird musikalisch durch einen abrupten Tempo- und Taktwechsel untermalt - vom raschen, entschlossenen Allegro im 2/4-Takt des gewalttätigen Cavaliere hin zum weichen und wiegenden Andantino im 6/8-Takt, der dem zärtlich liebenden Leandro entspricht (s. Notenbeispiel 23, S. I 89).

Von hier an mischt sich das Spiel mit der Wirklichkeit: Leandros explizite Ankündigung über seinen Rollenwechsel („Leandro son io“) sollte eigentlich ein klares Signal für das Ende des Als-ob-Spiels sein, aber Laurina gibt sich überrascht, spielt also das Rollenspiel gewissermaßen weiter. Sie fragt sicherheitshalber nach, ob er wirklich Leandro ist, und reicht ihm schließlich die Hand, wodurch die Hochzeit symbolisch besiegelt wird. Laurinas Überraschung über die wahre Identität ihres Gegenübers und ihre Nachfrage („Leandro voi siete?“) kann nur gespielt sein, aber die Freude ist echt, wie der darauffolgende typische Schluss-Jubel im a due („Evviva gli sposi / Evviva l'amor“) beweist, dem sich unüblicherweise alle übrigen Personen im Tutti anschließen. ${ }^{614}$ Die Grenze zwischen Spiel und Ernst ist wie so häufig nicht genau

613 Ebd.

614 Der konventionelle Schluss würde zwischen Liebesduett und Schluss-Tutti eigentlich ein Rezitativ vorsehen. 

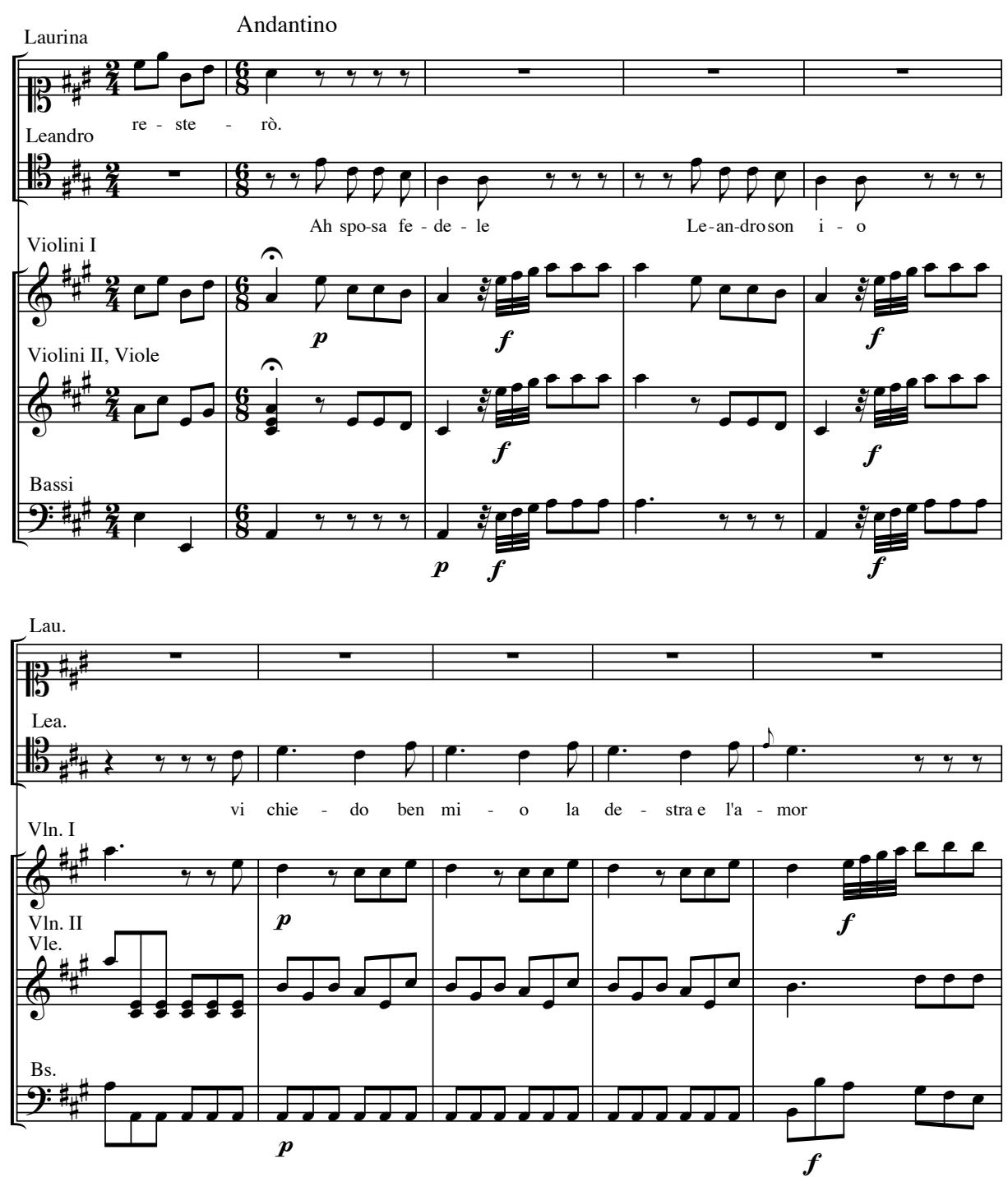

23 Piccinni/Petrosellini: L'astratto o Il giocatore fortunato. (F-Pn MS. 2372)

festzustellen. Die Ambivalenz äußert sich außerdem auch darin, dass im leichten und sorglosen Spiel zwei ernste "Proben“ stattfinden: Laurina besteht in dieser spielerischen Szene nämlich nicht nur die Liebesprobe, sondern beweist auch, dass ihr die Verhaltensweisen der höheren Stände nicht fremd sind. 
L'americano (II, I 3)

Ein weiteres Liebesduett, in dem ein Als-ob-Spiel gespielt wird, ist in Piccinnis „L'americano“ zu finden. Hier verliebt sich Villotto, ein „wilder“ Jüngling, den ein Cavaliere aus Amerika mitgebracht hat und der Rousseaus Mythos des „edlen Wilden“ verkörpert, in das Schäfermädchen Silvia. Die beiden beschließen zu heiraten, aber Villotto ist über den europäischen Hochzeitsbrauch entsetzt. Er findet ihn umständlich und unnatürlich und erzählt, wie in seinem Land üblicherweise eine Hochzeit gefeiert wird: Ein Jüngling trifft ein Mädchen auf einer Wiese und gibt ihr zu verstehen, dass er sie mag. Das Mädchen errötet und läuft schüchtern davon, bleibt aber bald darauf stehen, wirft ihm einen Blick zu, lacht, seufzt und erwidert die naive Liebeserklärung des Jünglings. Dieser freut sich, lacht, singt und macht Freudensprünge. Schließlich geben sich beide die Hand und die Hochzeit ist vollzogen. ${ }^{615}$

Silvia schlägt vor, diesen Brauch „im Spiel“ nachzuvollziehen. Villottos Worte dienen dabei als Regieanweisung für das darauffolgende Liebesduett, dessen Beginn mit dem Anfang des eigentlichen „Spiels“ zusammenfällt.

(Zur Tabelle: Um zur ursprünglichen Reihenfolge des Textes zu kommen, muss man die drei Spalten hintereinander lesen. Durch das „Nebeneinander“ soll dargestellt werden, wie die Umsetzung von Villottos Schilderung zur im Duett stattfindenden Als-ob-Szene erfolgt. Zwischen diesen beiden Teilen werden die Entscheidung zum Als-ob-Spiel und kurze vorbereitende Abmachungen getroffen, die in einer eigenen (mittleren) Spalte eingetragen sind. Die fettgedruckten Textstellen machen auf die beinahe wörtliche Umsetzung von Villottos als Regieanweisung dienender Beschreibung aufmerksam.)

615 Dieser amerikanische Hochzeitsbrauch ist keineswegs erfunden; er entspricht dem - in den USA in etlichen Staaten bis heute noch anerkannten - sogenannten common-law marriage, aufgrund dessen eine lediglich auf einem gegenseitigen Zugeständnis beruhende Ehe als abgeschlossen und rechtskräftig gilt und zur Aufösung einer gerichtlichen Entscheidung bedarf. (Vgl. Francesco De Franchis: Dizionario giuridico - Law dictionary. Mailand 1987, S. 998). 

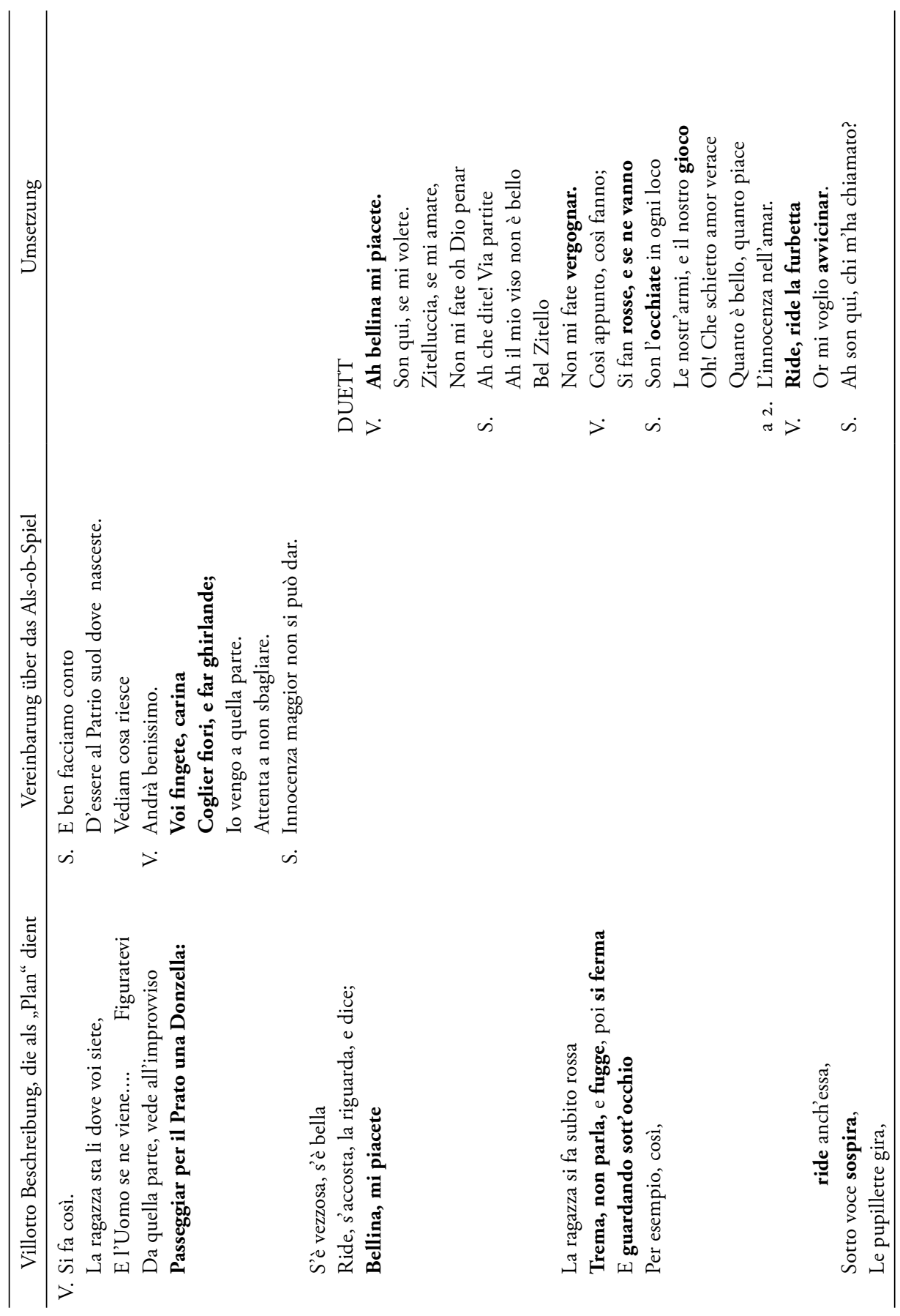


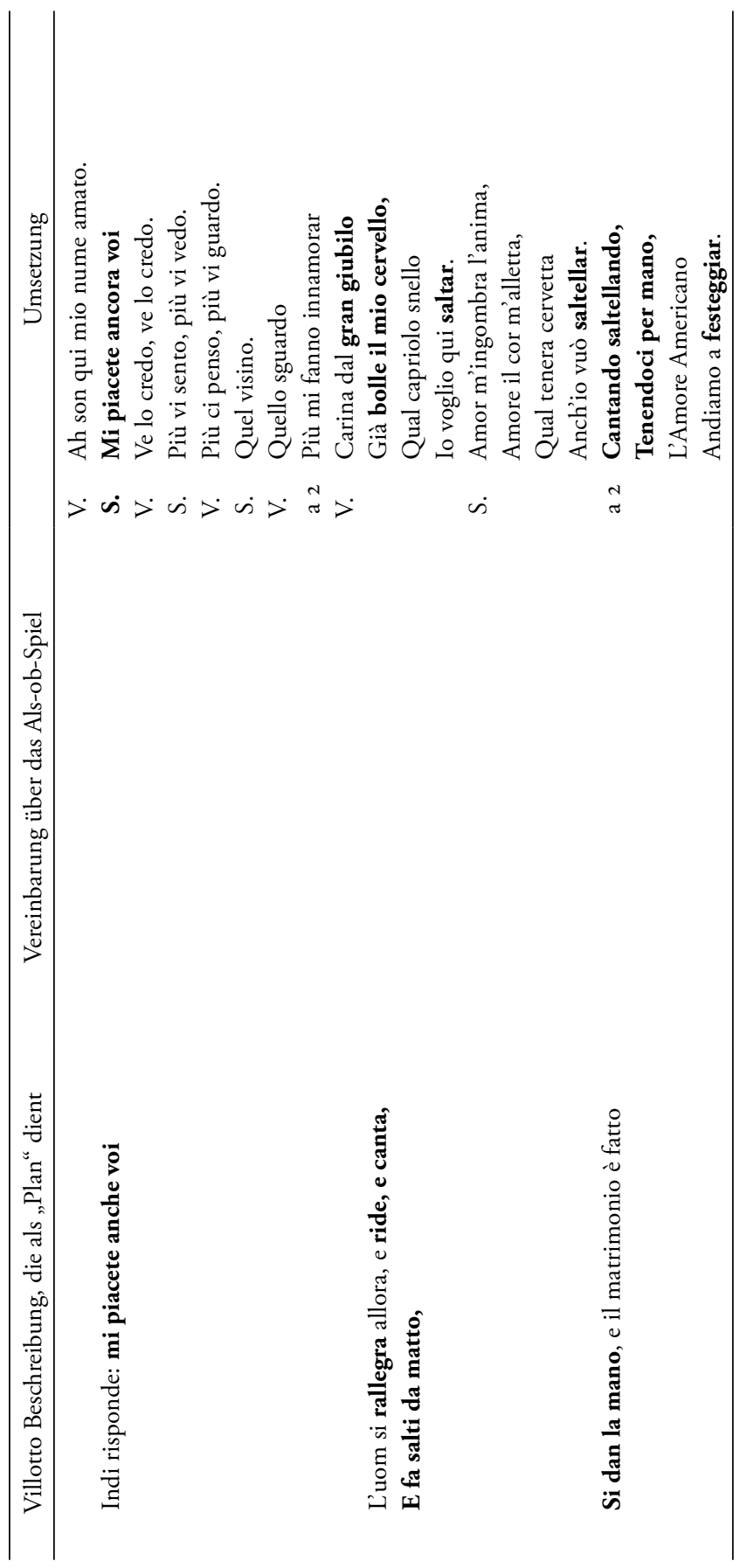


In diesem Liebesduett überlagern sich Als-ob-Spiel und Liebesspiel. Die von Villotto beschriebenen „Etappen“ des „amerikanischen“ Hochzeitsbrauchs entsprechen den typischen Elementen der Liebeswerbung: Blicke, Komplimente, Scham und Erröten, Lachen, Rufen, Annäherung, Hände-Reichen und Schluss-Jubel (Singen und Springen als spontaner Ausdruck der Freude).

In diesem Liebesduett wird ein fremdes „Ritual“ gespielt, das aber zugleich auch der vollkommensten Natürlichkeit entspricht, wobei der im I 8. Jahrhundert beliebte Mythos des „guten Wilden“ durchscheint. Bei dieser als natürlich gespielten Hochzeitsszene handelt es sich jedoch um eine höchst artifiziell erzeugte Natürlichkeit. Die Ambivalenz des Ganzen liegt aber nicht nur im Verhältnis zwischen Natürlichkeit und Künstlichkeit, sondern vor allem auch darin, dass innerhalb eines scheinbar nur zum Spaß stattfindenden Spiels eine ernst gemeinte und gültige Hochzeit stattfindet.

Nun stellt sich die Frage, wie und ob „Spiel“ überhaupt in Musik umgesetzt wird bzw. werden kann. Betrachten wir also das Liebesduett aus „L'americano“, das folgendermaßen beginnt:

Andante sostenuto

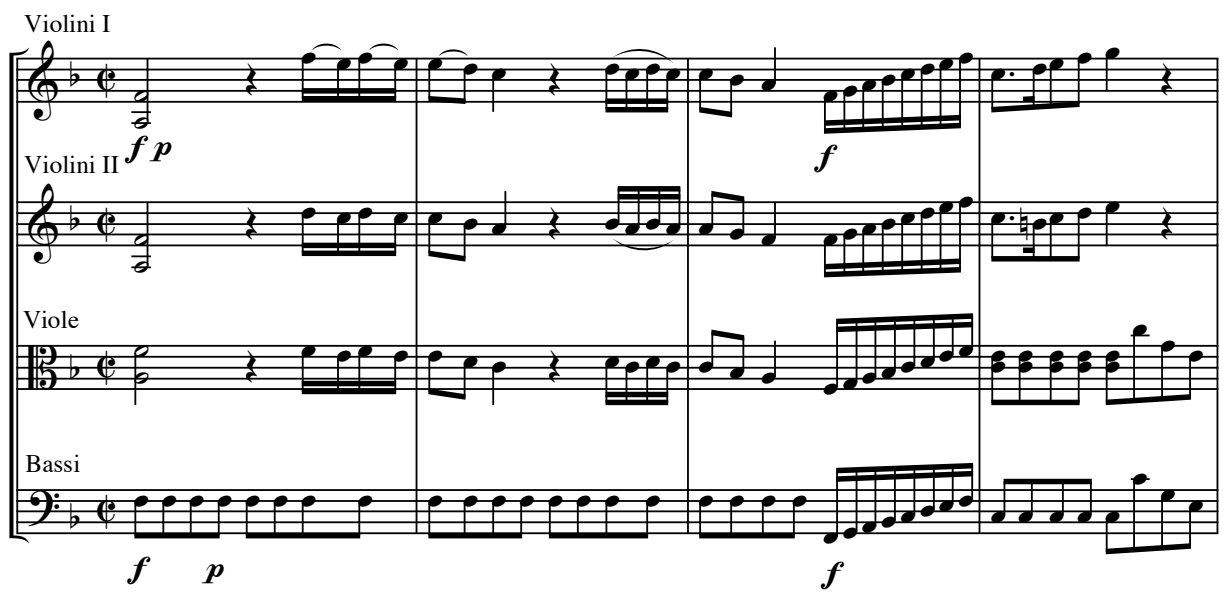




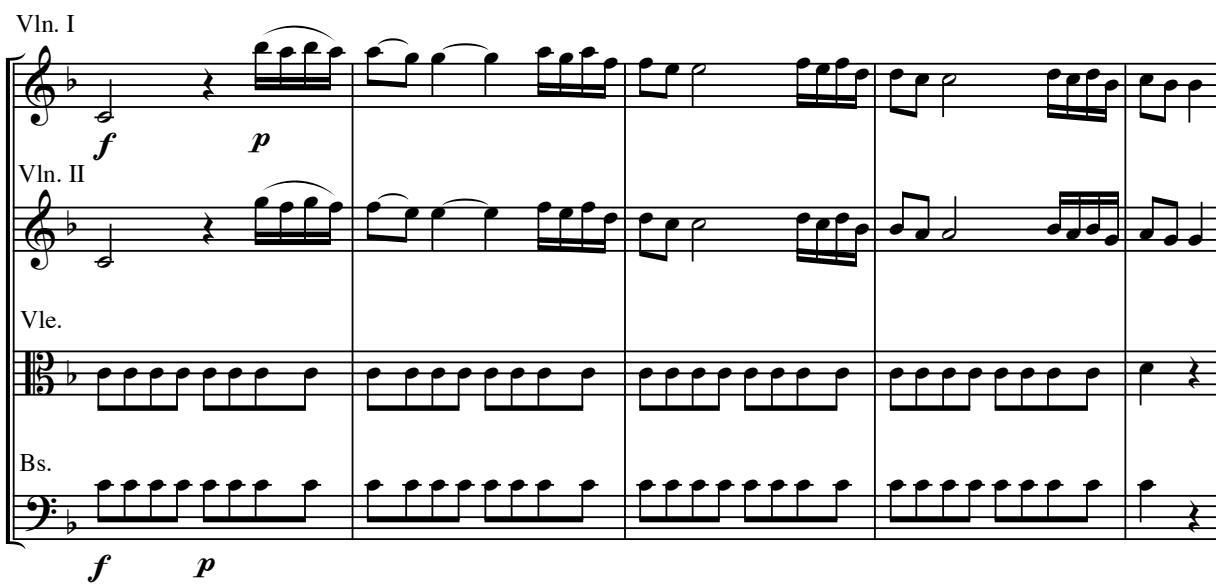

24 Piccinni: L'americano. (A-Wn Mus. Hs. 17825)

In der verhältnismäßig langen Einleitung (24 Takte) fällt immer wieder eine Pendelbewegung in I6teln auf, die sich wie ein roter Faden durch den gesamten umfangreichen ersten Abschnitt dieses Liebesduetts zieht und das Hauptthema des Duetts charakterisiert. Sie ist nicht nur im ersten Einsatz des Tenors zu finden, der konventionsgemäß die Anfangsmelodie der instrumentalen Einleitung wiederholt,

Villotto

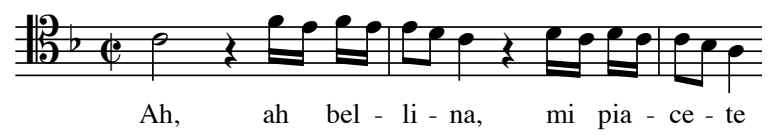

sondern ist in verschiedenen Varianten, z. B.

Villotto

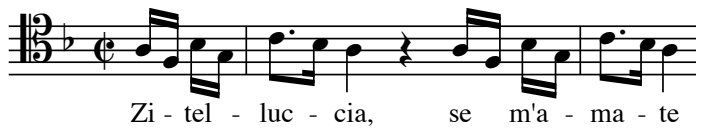

mehrmals in Villottos (von den Geigen verdoppelter) Melodie zu hören, die dann von Silvia genau wiederholt wird. Die Pendelbewegung wird auch ausgeweitet, so dass folgendes Motiv daraus entsteht, das zunächst von Geigen und Bratschen vorgespielt wird, dann von der jeweiligen Singstimme imitiert wird. 


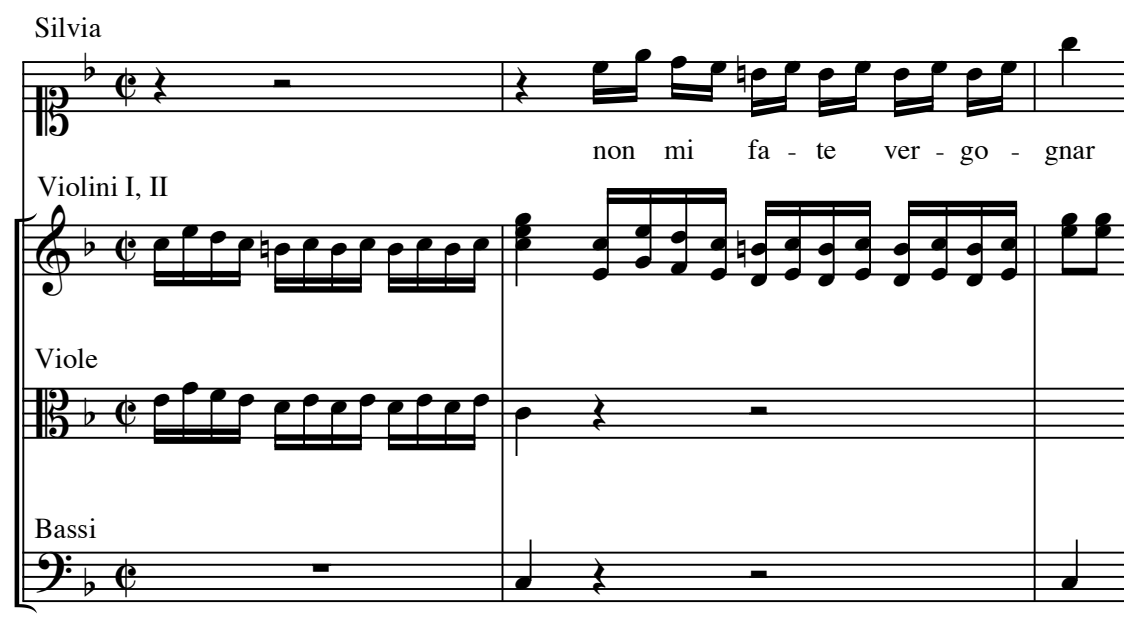

27 Piccinni: L’americano (A-Wn Mus. Hs. 17825)

Nicht nur der „spielerische“ Umgang des Komponisten Piccinni mit dem PendelMotiv, aus dem die unterschiedlichen Varianten resultieren, sondern vor allem die Gestalt dieser immer wieder eingesetzten Pendelbewegung selbst könnte als „spielerisch“ gedeutet werden. Als rasche „Hin- und Herbewegung“ verkörpert sie die Grunddynamik des Spiels, wie sie von vielen Spieltheoretikern beschrieben wird. Bezeichnenderweise wird sie, gerade als Silvia von den Blicken als „armi“ und „gioco“ des Flirts und der Liebe spricht, vermehrt eingesetzt. (Die ersten Geigen verdoppeln dabei die Singstimme, während die zweiten Geigen in parallelen Terzen dazuspielen):

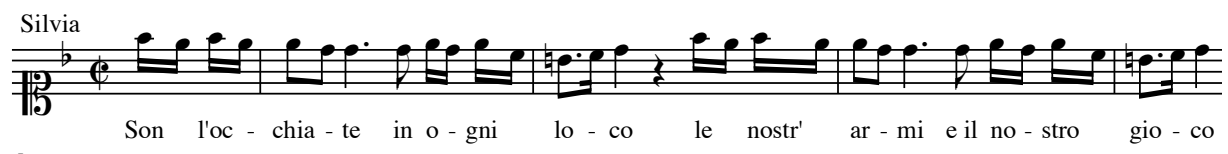

Die Gleichsetzung von Blicken und Waffen könnte auf einen agonalen Zug des „Liebesspiels“ hindeuten. Dass Silvia so selbstbewusst über die Blicke als „Spiel“ spricht, erweckt den nachträglichen Eindruck, ihre vorherige Scham („Non mi fate vergognar") und ihr Erröten seien ein bewusstes Spiel im Sinne von Koketterie und Flirt gewesen. Allerdings ist auch dieser Eindruck durch eine gewisse Ambivalenz geprägt. 
Im jubelnden Abschluss dieses ersten Arienabschnitts erscheint die Pendelbewegung erneut sowohl in den beiden parallelen Singstimmen als auch (in anderer Form) in den Begleitfiguren der Geigen und Bratschen.

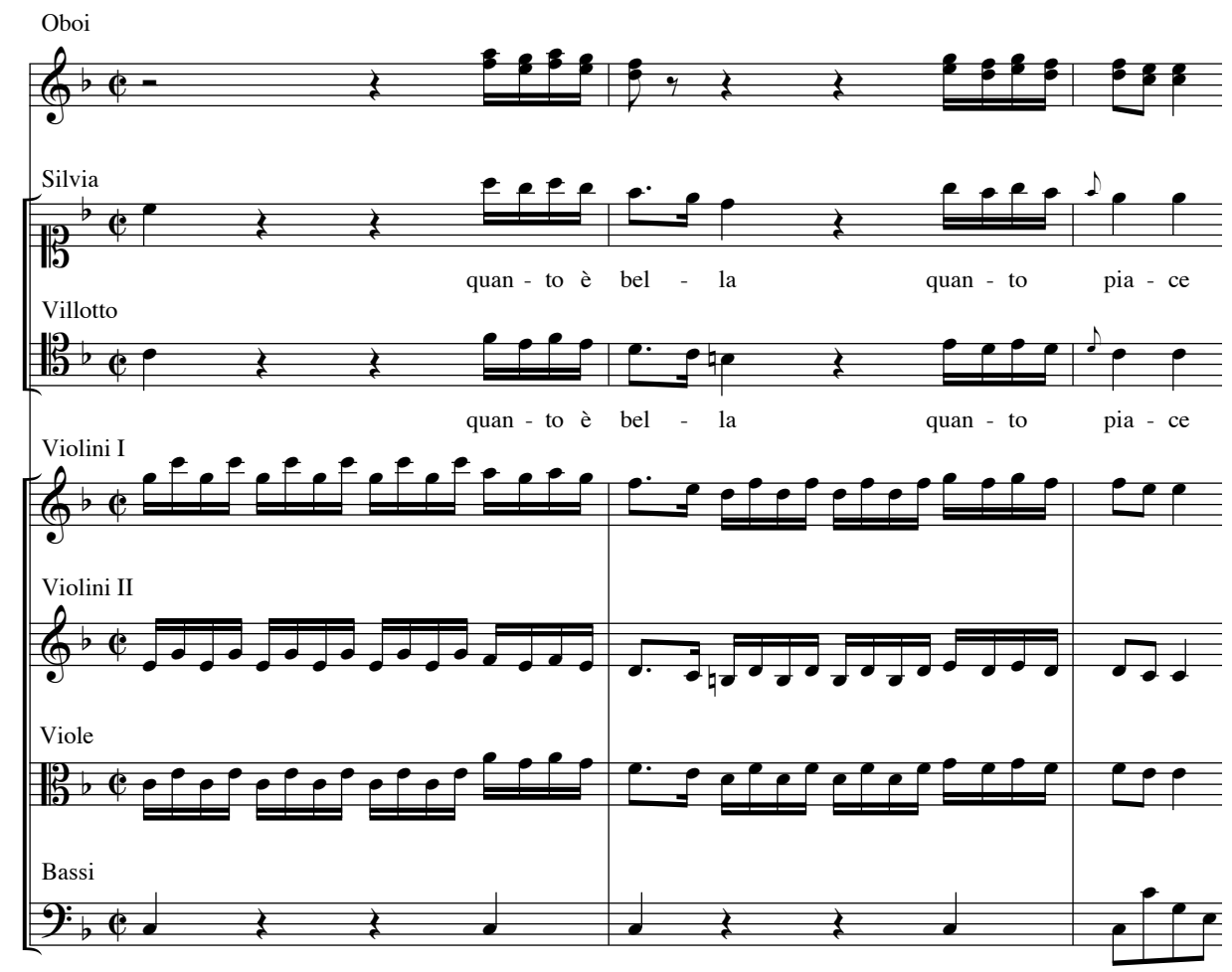

29 Piccinni: Ĺamericano. (A-Wn Mus. Hs. 17825)

Es stellt sich die Frage, ob die beschriebenen Pendelbewegungen allein aufgrund der Pendel-Dynamik „spielerisch“ wirken oder ob der lustig-spielerische Eindruck nicht auch im Allgemeinen bei raschen, beinahe verzierungsartigen Tongruppen entsteht, denen diese Pendelbewegungen unter anderem angehören.

Im darauffolgenden musikalischen Abschnitt (Andante con moto, 3/8), das mit Villottos Kommentar über Silvias neckisches Lachen („Ride ride la furbetta“) beginnt, sind beispielsweise in der Geigenmelodie folgende Schleiferfiguren integriert, die gemeinsam mit dem schwungvollen 3/8-Takt eine leichte und fröhliche Stimmung suggerieren. 
Andante con moto

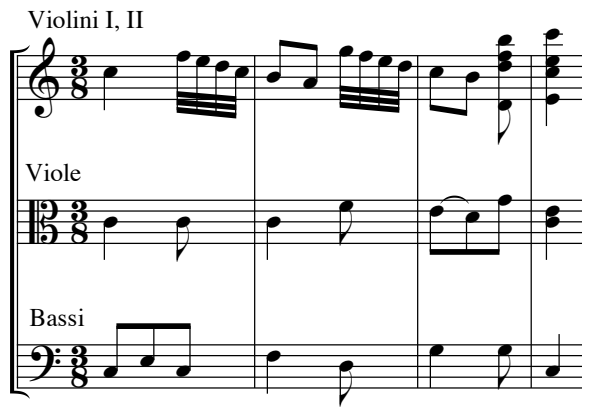

30 Piccinni: L'americano. (A-Wn Mus. Hs. 17825)

Vermutlich kann die Hypothese, dass rasche verzierungsartige Tongruppen eine heitere Stimmung erzeugen, nicht zu einer Gesetzmäßigkeit erhoben und verallgemeinert werden, weil die Wirkung solcher Figuren immer kontextgebunden und tempoabhängig ist. Dennoch ist eine - wenn auch etwas vage - Assoziation zwischen Beweglichkeit, Lebendigkeit, Heiterkeit und spielerischem Charakter möglich. Es ist kein Zufall, dass rasche Tempi tendenziell mit Heiterkeit assoziiert werden und dass die üblichste Tempobezeichnung für schnelle Tempi allegro (fröhlich) heißt. Von der Verbindung zwischen dem Begriff des Spielerischen und dem Gemütszustand der Heiterkeit sowie der etymologisch verwurzelten Idee einer tänzerischen (eher raschen) Bewegung war schon die Rede. ${ }^{616}$

Die Musik mit ihren spielerisch-beweglichen Figuren trägt in starkem Maße zur fröhlichen, manchmal sogar übermütigen Stimmung der Buffa-Liebesduette bei und untermalt die Liebesspielchen und Neckereien der Liebespaare. Besonders charakteristisch für die Liebesduette sowie für die Opera buffa allgemein ist die spielerische Leichtigkeit und Spontaneität, mit der Ehen geschlossen werden. Diese ambivalente Gleichzeitigkeit von Spiel und Ernst, die verschiedene Spieltheoretiker in Bezug auf das Spiel im Allgemeinen feststellen, ist in der Opera buffa immer wieder anzutreffen. Gerade die Hochzeit am Schluss, die bindend und ernst gemeint ist, wird in der Regel auf eine leichte und spielerische Weise herbeigeführt, so dass der Eindruck entsteht, als sei die Botschaft dieser Gattung insgesamt: „Das Leben ist ein Spiel“.

616 Siehe Kapitel „Die Opera buffa im Licht der Spieltheorien“. 


\section{Mimicry}

\section{I Allgemeines}

Die beiden letzten der untersuchten Liebesduette beinhalten - genauso wie schon einige der behandelten „agonalen Spiele“ - eine Form von Spiel, die man als „Als-ob-Spiel“ bezeichnen kann, in der Opera buffa die mit Abstand häufigste Art von Spiel, weswegen dieses Kapitel unverhältnismäßig länger ausfällt als die übrigen. In Caillois’ Klassifikation sind diese Als-ob-Spiele der Kategorie „Mimicry“ bzw. „Maske“ zugeordnet.

Auf den engen Zusammenhang zwischen den auf Mimesis beruhenden „games of make-believe“ der Kinder und den „representational works of art“ (Werken der darstellenden Kunst) baut der Philosoph Kendall L. Walton seine Theorie der „Mimesis as make-believe“ auf. Walton weist auf die Zentralität und Universalität der Als-ob-Spiele hin, die von allen Kindern der Welt unabhängig vom jeweiligen kulturellen Kontext gespielt werden. Ähnlich wie Jean Château, der aus einer pädagogischpsychologischen Perspektive das „Fiktionsspiel“ als einen „Spieltyp, der bis in das Erwachsenenalter hineinreicht" ${ }^{17}$, bezeichnet, stellt Walton fest, dass das Bedürfnis nach solchen Spielen im Erwachsenenalter weiterbesteht. Demselben Bedürfnis nach „games of make-believe“ entspringen nach Waltons Meinung im Allgemeinen die Werke der darstellenden Kunst: „Children devote enormous quantities of time and effort to make-believe activities. And this preoccupation seems to be nearly universal, not peculiar to any particular cultures or social groups. The urge to engage in makebelieve and the needs such activities address would seem to be very fundamental ones. If they are, one would not expect children simply to outgrow them when they grow up; it would be surprising if make-believe disappeared without a trace at the onset of adulthood. It doesn't. It continues, I claim, in our interaction with representational works of art." 618

Dementsprechend können auch Theater und Oper gewissermaßen als „games of make-believe" gelten. Obwohl es sich von den meisten Als-ob-Spielen der Kinder darin unterscheidet, dass es für ein Publikum gespielt wird, wird Theater im Allgemeinen aus unterschiedlichen Disziplinen und Perspektiven heraus als eine besondere Form von Spiel betrachtet. Huizinga sieht das Drama als das einzige Gebiet der Dichtung an, das durch „seine Eigenschaft, Handlung zu sein“, einen „festen Zusammenhang mit dem Spiel“ hat, denn „das Drama heißt ein Spiel, es wird

617 Château, S. 35.

618 Kendall L. Walton: Mimesis as Make-Believe. On the Foundation of the representational Arts. Cambridge, London 1993, S. 11 f. 
gespielt."619 Scheuerl nennt das Theater eine besondere Form des Darstellungsspiels, in der Darsteller und Zuschauer auseinandertreten;620 Uri Rapp schreibt: „Theater als Ganzes ist Spiel“. ${ }^{621}$ Max Herrmann behauptet, der „Ursinn des Theaters“ bestehe darin, „daß das Theater ein soziales Spiel war, - ein Spiel für Alle. Ein Spiel, in dem Alle Teilnehmer sind, - Teilnehmer und Zuschauer. (...) Das Publikum ist als mitspielender Faktor beteiligt." ${ }^{22}$ Augenzwinkernd bemerkt Jorge Luis Borges, dass der Schauspieler auf der Bühne spielt, als ob er jemand anders wäre, vor $\mathrm{Zu}$ schauern, die spielen, als ob sie ihn wirklich für diese Person halten würden. ${ }^{623}$ Es ist die „gemeinsame Verabredung des ,als-ob““, 624 die dem „Spiel“ in Theater und Oper - genauso wie jedem der Kategorie „Mimicry“ zugehörigen Spiel - zugrunde liegt und die bewirkt, dass die Theatersituation während einer Aufführung im Großen und Ganzen verleugnet bzw. verdrängt wird. Allerdings werden besonders in den komischen Gattungen immer wieder bestimmte Mittel eingesetzt, die auf den Spielcharakter der Theatersituation hinweisen und somit die theatralische Perspektive aktualisieren. Es sind dabei einerseits dramatische Mittel bzw. Techniken der Illusionsdurchbrechung und Verfremdung, wie beispielsweise die direkte Publikumsanrede oder das Aus-der-Rolle-Fallen, die eine Distanzierung und somit das Bewusstsein über die Theatersituation hervorrufen, „denn immer, wenn der Schauspieler freiwillig aus der Rolle tritt oder unfreiwillig aus der Rolle fällt, wird diese als nur gespielte erkennbar." ${ }^{25}$ Andererseits sind es die Thematisierung des Theaterspiels auf handlungsimmanenter Ebene bzw., allgemeiner formuliert, jegliche Form der Selbstbezüglichkeit sowie regelrechte Als-ob-Spiele innerhalb der fiktiven Wirklichkeit auf der Bühne - um die es in diesem Kapitel hauptsächlich geht -, die das Rollenspiel als solches zeigen und somit die theatralische Perspektive aktualisieren. Die dabei erfolgende "Thematisierung des Spielcharakters" führt zu einer „Stärkung des Spielbewusstseins"626 und erhöht die Komplexität des Wechselspiels

619 Vgl. Huizinga, S. 140.

620 Vgl. Scheuerl: Das Spiel. S. 148.

621 Rapp: Rolle, Interaktion, Spiel. S. 103.

622 Vgl. Erika Fischer-Lichte und Jens Roselt: Attraktion des Augenblicks - Aufführung, Performance, performativ und Performativität als theaterwissenschaftliche Begriffe. In: Erika Fischer-Lichte und Christoph Wulf (Hg.): Theorien des Performativen. (Paragrana. Internationale Zeitschrift für Historische Anthropologie. Bd. 10, 2004, Heft 1) Berlin 2001, S. 238.

623 "(The actor) on a stage plays at being another before a gathering of people who play at taking him for that other person." (Jorge Luis Borges: Everything and Nothing. Zit. nach Walton, S. 209).

624 Vgl. Arno Paul: Theaterwissenschaft als Lehre vom theatralischen Handeln. In: Kölner Zeitschrift für Soziologie und Sozialpsychologie 23, 1 (1971), S. 186. Zit nach Matzat, S. $39 f$.

625 Matzat, S. 47.

626 Vgl. Matzat, S. 50. 
zwischen Identifikation und Distanzierung, worin ein großes Reiz- und Spannungspotential liegt. Über die Wirkung des handlungsimmanenten Als-ob-Spiels schreibt Fritz Martini: „Die Illusion, die sich in der (...) vorgespielten fiktiven Wirklichkeit herstellt, wird potenziert durch die zweite Illusion, die das fingierte Spiel in diese fiktive Wirklichkeit einlagert. Die Dialektik von Schein und Sein, von Illusion und Desillusion, die zum Wesen des Theaters gehört, kehrt also im komischen Spiel vermannigfaltigt wieder."627 Durch die Einbettung eines zweiten Als-ob innerhalb der primären Fiktionsebene wird also der Spielcharakter der Theatersituation nicht nur bewusst gemacht, sondern weiterhin verstärkt. Gerade diese durch Spiel im Spiel bewirkte Potenzierung des Spielcharakters macht nach Martini „den spezifischen Charakter des Lustspiels aus, ist also das eigentlich Lustspielhafte",628 woraus sich der zur Häufigkeit dieser Art von Spielen in der Opera buffa proportionale Umfang dieses Kapitels erklärt.

Nun sind solche Momente des Als-ob-Spiels auf handlungsimmanenter Ebene in der Komödie wie in der Opera buffa allgegenwärtige und unerlässliche dramaturgische Mittel, worauf die Tatsache zurückzuführen ist, dass in den komischen Gattungen die theatralische Perspektive überwiegt. Die Harmlosigkeit der immer wieder eingesetzten Täuschungen, Verstellungen, Verkleidungen, die im Lustspiel für die Entwicklung der Handlung hauptsächlich verantwortlich sind, ${ }^{629}$ unterscheidet diese dramaturgischen Formen von den böswilligen Intrigen und Täuschungen der Tragödie und verleiht ihnen unter anderem den Charakter des Spiels. Nicht immer sind die von den Bühnenfiguren gespielten Als-ob-Spiele für die Gesamtdramaturgie relevant, aber immer handelt es sich um Mittel, die vielleicht gerade wegen ihrer Fähigkeit, auf lustvolle Weise den Spielcharakter der Theatersituation zu vergegenwärtigen, für Unterhaltung sorgen.

Obwohl alle diese Spiele auf einem „Als-ob“ beruhen, können sie in der konkreten Umsetzung sehr unterschiedlich ausfallen und vielfältige Facetten aufweisen. Caillois' übergeordneter Begriff „Mimicry“ erscheint nicht ungeeignet, um alle diese Spiele zusammenzufassen, denn er umfasst genauso wie der Begriff der Mimesis, auf den er

627 Martini, S. 351.

628 „Das Lustspiel gelangt ästhetisch zu sich selbst durch die Potenzierung seines Spielcharakters; mit anderen Worten: es erfüllt um so mehr die Eigengesetzlichkeit der ästhetischen Form, je mehr es im fiktiven Spiel durch ein zusätzliches fingiertes Spiel diesen Spielcharakter unterstreicht. Das Spiel im Spiele macht den spezifischen Charakter des Lustspiels aus, ist also das eigentlich Lustspielhafte (...).“ (Martini, S. 321).

629 Michele Metzeltin stellt im Zusammenhang mit Goldonis drammi giocosi fest: „Lo sviluppo della sostanza narrativa si fa sempre per mezzo di finzioni e d'imposture." (Michele Metzeltin: Appunti sulla poetica dei drammi giocosi di Carlo Goldoni. In: Albert Gier (Hg.): Oper als Text. Romanistische Beiträge zur Libretto-Forschung. Heidelberg 1986, S. 55-64). 
zurückgeht, sowohl die Bedeutung der Nachahmung und der Simulation als auch die der Darstellung oder der Verstellung, die alle beim Als-ob-Spiel zum Tragen kommen und oft untrennbar miteinander verbunden sind. In pädagogischen Spielklassifikationen ist besonders häufig die Bezeichnung „Fiktionsspiel“630 anzutreffen. Piaget verwendet den Begriff des „Symbolspiels“, aber auch andere Termini wie „Als-ob-Spiele“, „dramatische Spiele“ oder „Darstellungsspiele“ sind durchaus gebräuchlich und werden in der Literatur größtenteils synonym verwendet. Die Vielfalt an Begriffen für diese universelle Art von Spiel, die Oerter und Montada aus entwicklungspsychologischer Perspektive als "die eigentliche kindliche Spielform "631 bezeichnen, entspricht der großen Vielfalt an Erscheinungsformen des Als-ob-Spiels, nicht nur im Leben, sondern auch in den Handlungen der Opere buffe. Letztere werden nun anhand ausgewählter Beispiele gezeigt, wobei die Gruppierung unter den Begriffen der Nachahmung, der Imagination, der Fingiertheit bzw. Fiktion nur einen Anhaltspunkt bietet und eine allgemeine Tendenz aufzeigt, jedoch keine absolute Kategorisierung darstellt, der sich die meisten konkreten Beispiele eher entziehen würden.

\subsection{Mimicry als Nachahmungsspiel}

Als erste Stufe des (kindlichen) Als-ob-Spiels kann die spielerische Imitation gelten. Als Nachahmung einer Handlung oder einer Rolle kann diese Art von Spiel häufig auch als Fiktionsspiel interpretiert werden, von dem sie oft nicht zu trennen ist. Wenn, wie es in den Handlungen der Opere buffe eher selten geschieht, das „Original“ und die „Kopie“ aufeinanderfolgen, dann steht der Imitationsprozess meines Erachtens so deutlich im Vordergrund, dass schwerpunktmäßig von einem Nachahmungsspiel gesprochen werden kann. Eine solche Situation ist beispielsweise im zweiten Akt von Niccolò Piccinnis „L'americano“ zu finden, ein 1772 in Rom uraufgeführtes zweiaktiges Intermezzo, das mit wenigen Änderungen im Vergleich zur Uraufführung in Venedig im Herbst des Jahres 1779 aufgeführt wurde. Die Handlung dieses Vier-Personen-Stücks beginnt mit der Rückkehr des Cavaliere, der den Typus des Reisenden verkörpert ${ }^{632}$ und als Mitbringsel aus Kalifornien einen wilden americano namens Villotto nach Europa mitgebracht hat. Der größte Spaß des Cavaliere sowie der Zuschauer der Oper besteht darin, zu sehen, wie der „gute Wilde“ - die Verkörperung des Mythos des Naturmenschen - auf die in Europa herrschenden Bräuche re-

630 Beispielsweise bei Ch. Bühler, J. Château, C. Garvey und K. Kreuzer.

631 Rolf Oerter und Leo Montada (Hg.): Entwicklungspsychologie. 4. Aufl. Weinheim 1998, S. 253.

632 „Ne L'Americano di Piccini il Cavaliere Lisandro incarna il tipo del viaggiatore, la sua visione apertamente liberale e illuminista del vivere." (Stefano Capone: Piccinni e l'opera buffa. Modelli e varianti di un genere alla moda. Foggia 2002, S. 219). 
agiert. Alle sind entzückt über seine Natürlichkeit und Naivität, aber auch über seine Schönheit, vor allem die Frauen, die sich beide in ihn verlieben: die Hirtin Silvia, die Villotto zum Schluss heiraten wird, und Donna Aurora, die jähzornige Verlobte des Cavaliere, die, um die Liebe zwischen Silvia und Villotto zu verhindern, dem hübschen Fremden einflüstert, dass Silvia ihn hässlich findet. Im untersuchten Szenenkomplex (II,6 - II,8) erlaubt sich der Cavaliere gegenüber Villotto eine kleine Burla, indem er eine Art Nachahmungsspiel veranlasst: Dem nun von seiner Hässlichkeit überzeugten americano zeigt er einen Toilettentisch, an dem er sich verschönern kann, was er der sich an der toletta schminkenden Donna Aurora abschauen soll.

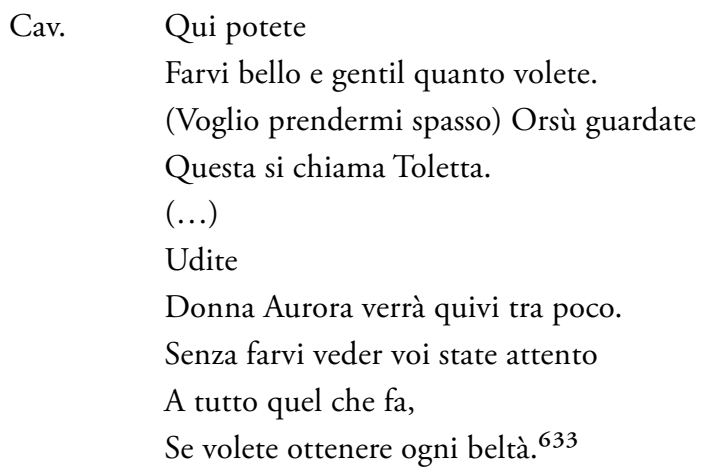

Der Cavaliere erteilt also Villotto die Aufgabe, Donna Aurora nachzuahmen, nachdem er da parte dem Publikum verraten hat, dass es sich um einen Spaß handelt. Vor seinem Abgang singt er noch eine Arie über den Toilettentisch, das Reich der Frauen, wo man an Schönheit gewinnen kann und die Alten sich verjüngen können.

Questo è il regno delle femmine,

Qui si acquista la beltà,

Qui la vecchia si fa giovine

A dispetto dell'età. $(. . .)^{634}$

In der darauffolgenden Szene (II,7) führt Donna Aurora, von Villotto dabei beobachtet, am Frisiertisch ein an den stummen Diener Tibet gewandtes Selbstgespräch. Ihrem impulsiven Charakter entsprechend gehen ihre Gedanken sprunghaft durcheinander: Sie beschreibt ihr eigenes Spiegelbild, ihre Frisur, ist entsetzt über ihre gelbe

633 Piccini: L'americano. Venedig 1779 (II,6).

634 Ebd. 


\begin{tabular}{ll}
\hline \multicolumn{1}{c}{ II,7 Donna Aurora } & \multicolumn{1}{c}{ II,8 Villotto } \\
\hline Ci va un moschin più grande ... & Quanti moschini! Quante mosche \\
& Oh cospetto! Vi sono anche i mosconi; \\
Ti ricordi dell'aria del moschino? & Ve ne son d'ogni razza. \\
Oh quanto è bella! & Tibet la sai tutta \\
Quanto fu dalle Donne applaudita. & La canzoncina? Oh senti non è brutta. \\
L'unica cosa buona, ch'ho sentita. & \\
& \\
Quanto piace quel moschino & Quanto piace quel moscone \\
Sopra un viso, che sia bello; & Sopra un verde praticello, \\
Quel moschin appunto è quello, & Quel moscone ladroncello \\
Che fa i cuori innamorar. & Qualche fior vorria rubar. \\
& \\
Oh mi pare di star meglio. & Oh mi par di star bene. Venga Silvia \\
Si questa mia bellezza & A dirmi che son brutto \\
Farà gran colpo, ma ci vuol destrezza. & Queste bellezze non vi son per tutto. \\
\hline
\end{tabular}

Aus dem Gedächtnis versucht Villotto also Auroras Verhalten am Toilettentisch nachzuspielen, vergisst dabei einige Passagen, wie die Bemerkung über den aufgelösten buccolo (Locke) und das Buch, bemüht sich jedoch - angefangen von der Feststellung der gelblichen Farbe „seiner“ Haut - um eine treue Nachahmung jeder Geste und Äußerung der Donna Aurora. Spannender als die Gemeinsamkeiten sind in diesem auf der Bühne durchgeführten Imitationsspiel die Unterschiede bei der „Wiederholung“. Auffällig ist aus musikalischer bzw. musikdramaturgischer Sicht, dass Donna Auroras Szene, abgesehen von der kurzen Arie, im Secco-Rezitativ gehalten ist, während Villottos Nachahmung im recitativo accompagnato vertont ist. AccompagnatoRezitative werden in der Opera buffa äußerst selten, in der Regel maximal ein- bis zweimal Mal pro Oper, und nur in besonders dramatischen Szenen eingesetzt. Villottos „Spiel“ muss also als ein Höhepunkt der Handlung betrachtet worden sein, was wiederum die Hauptthese dieser Arbeit bestätigen würde, dass insbesondere spielerische Momente den Unterhaltungscharakter der Gattung ausgemacht haben könnten. Das Accompagnato-Rezitativ könnte in dieser Szene also zur Hervorhebung des „Spiels“ eingesetzt worden sein. Für die Wahl des Accompagnato-Rezitativs könnte aber auch eine andere Hypothese ins Auge gefasst werden: Villotto erzeugt durch sein Nachahmungsspiel unwillkürlich eine Karikatur der ohnehin überzeichnet dargestellten Donna Aurora, und das Accompagnato bietet die Möglichkeit einer viel größeren Ausdrucksamplitude als das einfache Secco-Rezitativ, wodurch ihre ohnehin schon übertriebenen Gesten weiter übertrieben nachgeahmt bzw. unwillkürlich nachgeäfft wirken können. 

Allegro
Andantino

Villotto

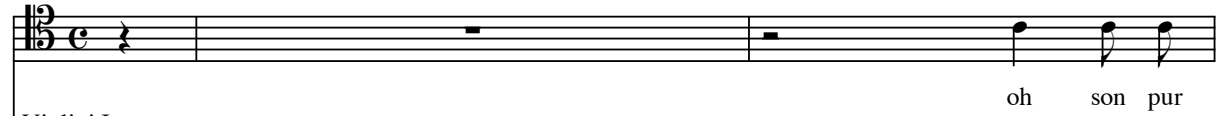

Violini I

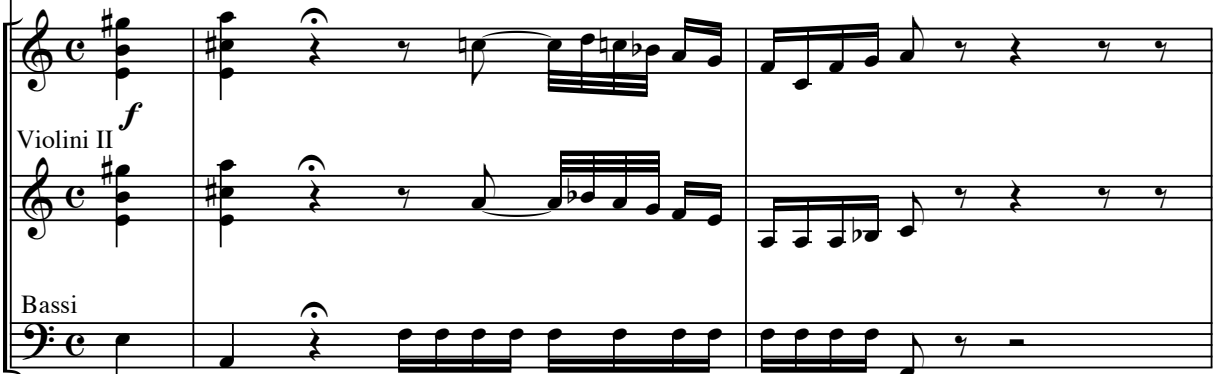

Vil.

Allegro
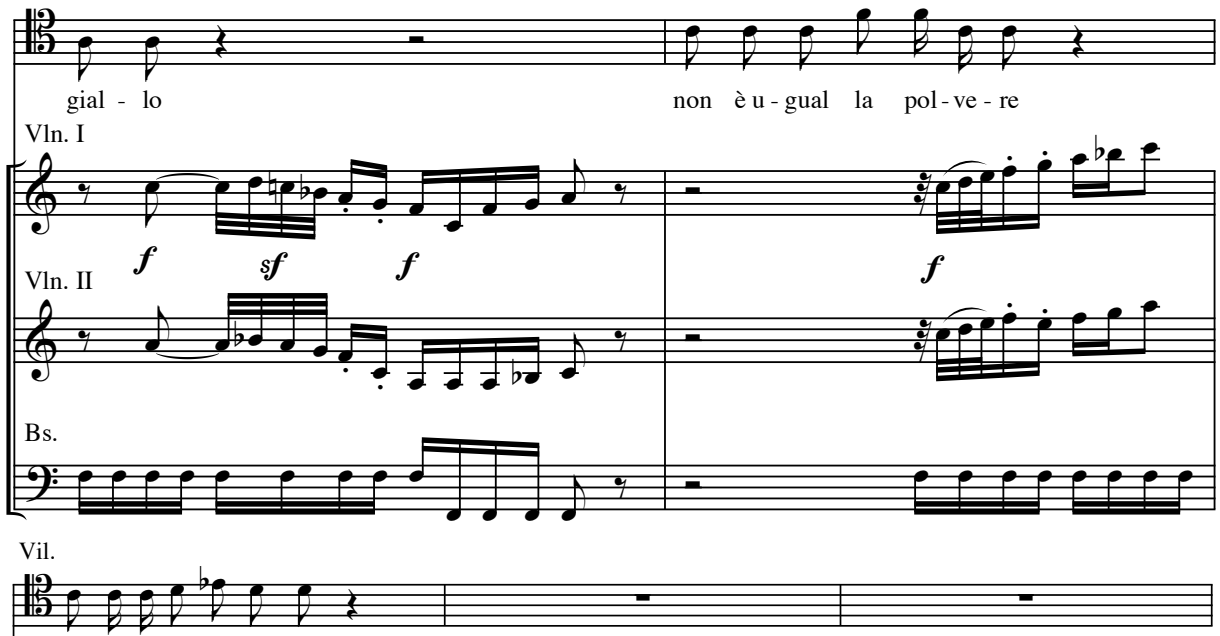

so-no u-na ve-ra fu - ria

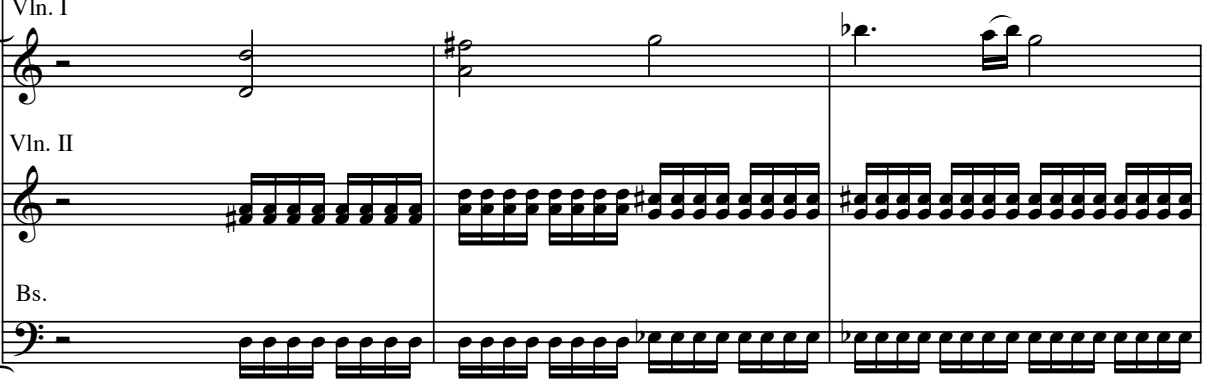

31 Piccinni: L'americano. (A-Wn Mus. Hs. 17825) 
Es lohnt sich ein Blick auf dieses Accompagnato-Rezitativ (II,8), das mit Villottos Austreten aus seinem Versteck in A-Dur beginnt. Villotto setzt sich an den Toilettentisch und als musikalisches Signal für den Beginn des Spiels dient nach einer klaren Schluss-Kadenz mit Fermate die Rückung von A-Dur nach F-Dur. Im Vergleich zu den sonst gebräuchlicheren dominantischen Verbindungen bei Tonartenwechseln in angrenzenden Abschnitten vermitteln mediantische Beziehungen in der Opera buffa oft den Eindruck einer „neuen Welt“; hier handelt es sich um den Eintritt in die Welt des Spiels. Villottos Nachahmung beginnt genauso wie Donna Auroras Szene mit dem Erschrecken über die gelbe Hautfarbe und den ungleich verteilten Puder. Beide Bemerkungen sind durch Einwürfe des Orchesters umspielt, die durch rasche, wendige, „spielerische“ Figuren in den Violinen charakterisiert sind. Auroras eher beiläufige Feststellung „Sono una furia“ wird von Villotto nicht nur übernommen, sondern dramatisiert: Auf seine Aussage „Sono una vera furia“ folgt eine radikale Tempobeschleunigung (von Andantino zu Allegro), die gemeinsam mit einer aufsteigenden Melodie in den ersten Geigen sowie mit dem typischen Tremolo-Effekt der Sechzehntel-Begleitung der übrigen Streichinstrumente die „furia“ musikalisch ausdeutet (s. Notenbeispiel 3 I, S. 205).

Tonmalerisch ist auch die Darstellung des Südwinds (scirocco), über den sich Donna Aurora nebenbei beklagt. Seine wirbelnde Bewegung wird in Villottos Nachahmung durch rasche aufsteigende Läufe in den Violinen dargestellt.

Andante vivace

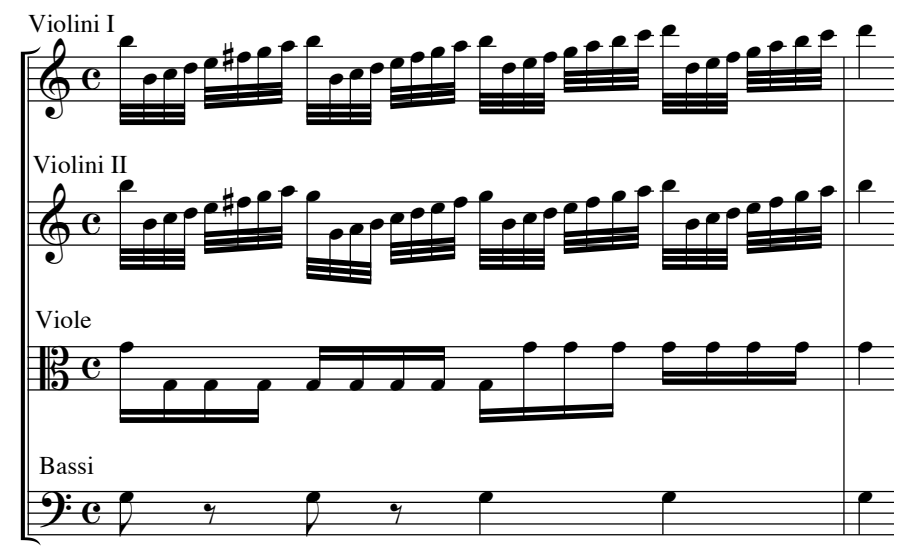

32 Piccinni: Ĺamericano. (A-Wn Mus. Hs. 17825) 
Besonders lustig wirkt Villottos Imitation, als er auf das Schönheitspflästerchen zu sprechen kommt, weil er offensichtlich Auroras Worte missverstanden hat: Moschino (kleine Mouche) versteht er wörtlich als kleine Fliege, moscone (größere Mouche) als große Fliege. Den Arientext passt er dementsprechend an seinen Interpretationshorizont an, wodurch der Sinn vollkommen verdreht wird: Donna Auroras frivole Arie über das im I 8. Jahrhundert so beliebte Schönheitspflästerchen wird von Villotto in eine „canzoncina“ über eine große Fliege umgewandelt, die über eine grüne Wiese fliegt und Blumen stehlen will. Villottos naives Missverständnis ist vollkommen nachvollziehbar: Ein wilder americano kann das von Mode, Frivolität und Flirt dominierte städtische Leben nicht verstehen und singt die Arie so, wie er sie versteht, nämlich als ein der pastoralen Sphäre entstammtes Lied über die Natur. Auroras einsätzige Cavatina oder Arietta „Quanto piace quel moschino“ im langsamen 3/4-Takt (Andante, A-Dur), die Einlagecharakter besitzt und als diegetische Musik bezeichnet werden kann, wird von Villotto - abgesehen von der wenigstens in der Partitur A-Wn Mus. Hs. 17825 weggelassenen Orchestereinleitung und von einer einzigen Abweichung in der Melodie - eins zu eins wiederholt. Der komische Kontrast des missverstandenen Textes wirkt also umso stärker, weil er sich auf der „Folie“ einer musikalisch exakten Kopie abspielt.

Nicht nur in Villottos Ariette, sondern im gesamten Nachahmungsspiel ist es generell die Diskrepanz, die Komik bewirkt. Ein gutmütiger Naturmensch, der unschuldig und eifrig eine jähzornige Dame des i 8. Jahrhunderts am Schminktisch nachahmt, die personifizierte Natürlichkeit, die in die Rolle der personifizierten Künstlichkeit schlüpft - die denkbar größten Gegensätze spielen in diesem Nachahmungsspiel eine Rolle. Das Ergebnis des Schminkens ist dementsprechend keine „Verschönerung“, sondern eine groteske „Verhässlichung“. Interessant ist dabei, dass Villotto nicht nur die ihm am entferntesten gelegene Rolle - gerade eine Schminkszene - spielen muss, sondern dass der Vorgang des Schminkens schon an sich einer Maskierung, einer Transformation gleichkommt, wobei die Maske ein typisches Signal für ein Als-ob-Spiel darstellt. Villottos Imitation erinnert sehr an die Nachahmungsspiele der Kinder: Der Naturmensch könnte durchaus mit einem Kind verglichen werden, das sich im Spiel durch Nachahmung die Verhaltensmuster der Erwachsenen aneignet, wobei üblicherweise die Bedeutung des Spiels als Übung und Vorbereitung für das Erwachsenendasein zum Tragen kommen würde. In diesem Fall ist das Nachahmungsspiel eher als Anpassung an die gesellschaftlichen Normen zu verstehen, wobei deutlich wird, wie sehr sich die damalige Gesellschaft durch Schminke und „Maskierung“ in Szene setzte. Ganz allgemein scheint diese Oper unter anderem auf eine satirische Wirkung abzuzielen: Man macht sich über die Sitten und die Mode der eigenen Zeit lustig, indem man sie distanziert aus der 
naiven Sichtweise eines Naturmenschen betrachtet, der zunächst wie ein Kind experimentierfreudig und staunend mit einer für ihn unverständlichen und unnatürlichen Welt umgeht. Das Nachahmungsspiel dient in der Schminkszene einerseits der komisch-niedlichen Wirkung, wie es häufig bei Momenten des Spiels der Fall ist - man lacht zwar über den naiven americano, fühlt aber gleichzeitig Sympathie für ihn -, andererseits dient es einer distanzierten und entfremdenden Betrachtung der eigenen Kultur und Gesellschaft.

Nachahmung und Spiel sind häufig mit einem pädagogischen Aspekt verbunden. Das Lernen beruht in starkem Maße auf Nachahmung, Kinder eignen sich beispielsweise die Sprache bzw. das Sprechen in erster Linie durch spielerische Nachahmung an. Ein solcher Vorgang wird in einem Abschnitt des ersten Finales von Cherubinis Opera buffa „Lo sposo di tre e marito di nessuna“ auf die Bühne gebracht, in einer dramaturgisch irrelevanten, aber sehr anmutigen Szene zwischen einem Gauklerpaar, wie es in der Opera buffa sonst kaum anzutreffen ist. Folletto bringt hier Bettina ein neues Lied bei; es handelt sich also um einen spontanen Musikunterricht, bei dem durch Vor- und Nachsingen ein Lied gelernt wird.

Fol. Oh che vago giardinetto!

Mi consola, o mia Bettina;

Qui la nuova canzoncina

Insegnar ti vuò a cantar.

Bet. Questo sito, sì mi piace

Accordate gl'istrumenti;

Ma compagni state attenti

Che son solita a stonar.

(...)

Fol. $\quad$ Prima solo cantar voglio.

Bet. Dici ben, se no m'imbroglio.

a 2 Starò/Stammi attenta ad ascoltar. ${ }^{636}$

Abgesehen von der verbalen Ankündigung des darauffolgenden Musikunterrichts und der Herangehensweise durch Vor- und Nachsingen wird hier die Musikeinlage durch das Stimmen der Instrumente signalisiert, ein in der Opera buffa beliebter Topos, der an sich schon diegetische Funktion besitzt. Während die zwei begleitenden Musiker ihre Instrumente stimmen, warnt Bettina sie vor der eigenen schlechten Intonation. Mit dem von Folletto vorgesungenen Lied beginnt im Finale ein neuer musikalischer

636 Livigni/Cherubini: Lo sposo di tre e marito di nessuna. Venedig 1783 (I,15). 
Abschnitt, der entsprechend der ländlichen Sphäre des Liedes in der typischen Tonart F-Dur und im ebenfalls typischen $6 / 8$-Takt steht.

Fol. $\quad$ Nella Campagna

I pinti Augelli

Canori e belli

Cantan così.

Chiò, chiò, chiò, chiò.

Nfri, nfri, nfri, nfri. ${ }^{637}$
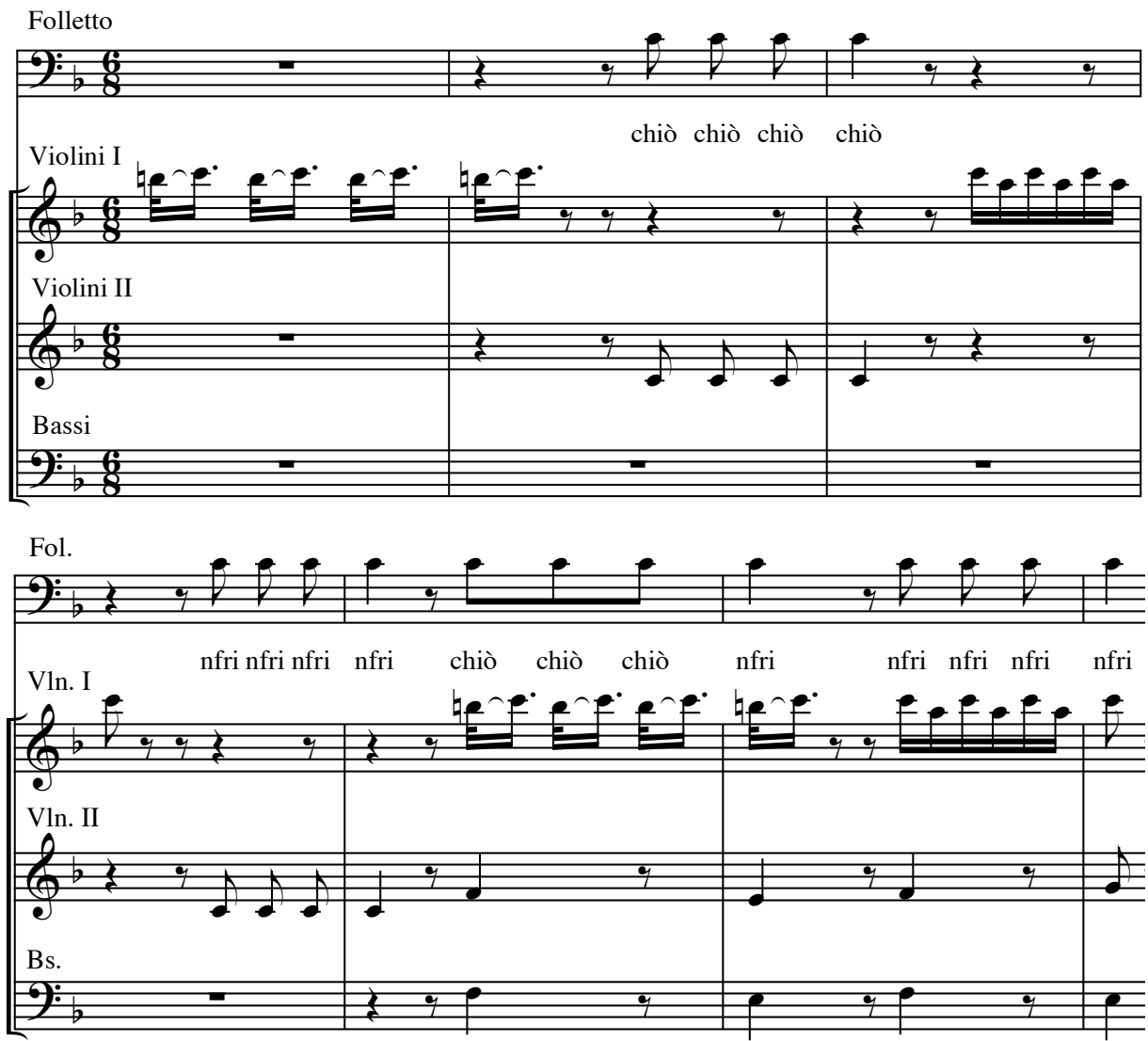

33 Cherubini/Livigni: Lo sposo di tre e marito di nessuna. Venezia 1783 (F-Pn D 2022-2023)

637 Ebd. 
Das Thema des Liedes ist der Vogelgesang, der sich besonders gut für eine Umsetzung in Musik eignet. Die Vogellaute werden nicht nur sprachlich (durch „chiò, chiò “ und „nfri, nfri“") nachgeahmt, sondern auch musikalisch, und zwar von den ersten Violinen und von der Singstimme. Das Schweigen der Bässe dient dabei der besseren Hörbarkeit der nachgeahmten Vogellaute und einer realistischen Darstellung der hohen Töne des Vogelgezwitschers (s. Notenbeispiel 33, S. 209).

Es findet also zunächst innerhalb des vorgesungenen Liedes ein Nachahmungsspiel im Sinne einer klangmalerischen Umsetzung statt. Bettina wiederholt das Lied, begeht bei „nfri, nfri, nfri, nfri“ allerdings einen Fehler: Im vorhergehenden Abschnitt hatte sie die Musiker vor ihrer Neigung zum Falschsingen gewarnt, an dieser Stelle singt sie irrtümlich auf d statt auf c, als handle es sich um eine Rückung von F-Dur nach G-Dur. Folletto fällt ihr ins Wort und macht sie auf den Fehler aufmerksam. Seine spontane Unterbrechung wird musikalisch von einem plötzlichen Forte und einer raschen Abwärtsbewegung der Geigen untermalt, wobei durch eine Umdeutung des (imaginären) G-Dur-Akkords als fünfte Stufe nach C-Dur moduliert wird (s. Notenbeispiel 34, S. 2 I of.).

In der zweiten Strophe des Liedes, in der es um die Grillen und ihr Zirpen („tri, tri, tri, tri“) geht, findet dasselbe Vor- und Nachsingen statt. Folletto muss Bettina erneut korrigieren, diesmal nicht nur weil sie in der Tonhöhe einen Fehler macht, sondern auch weil sie „nfri“ und „chiò“ (die Vogellaute aus der ersten Strophe) statt des Zirplauts „tri“ singt. Folletto fällt ihr zur Verbesserung mit der richtigen Melodie ins Wort. Bettina verharrt aber hartnäckig auf ihrer Tonhöhe.

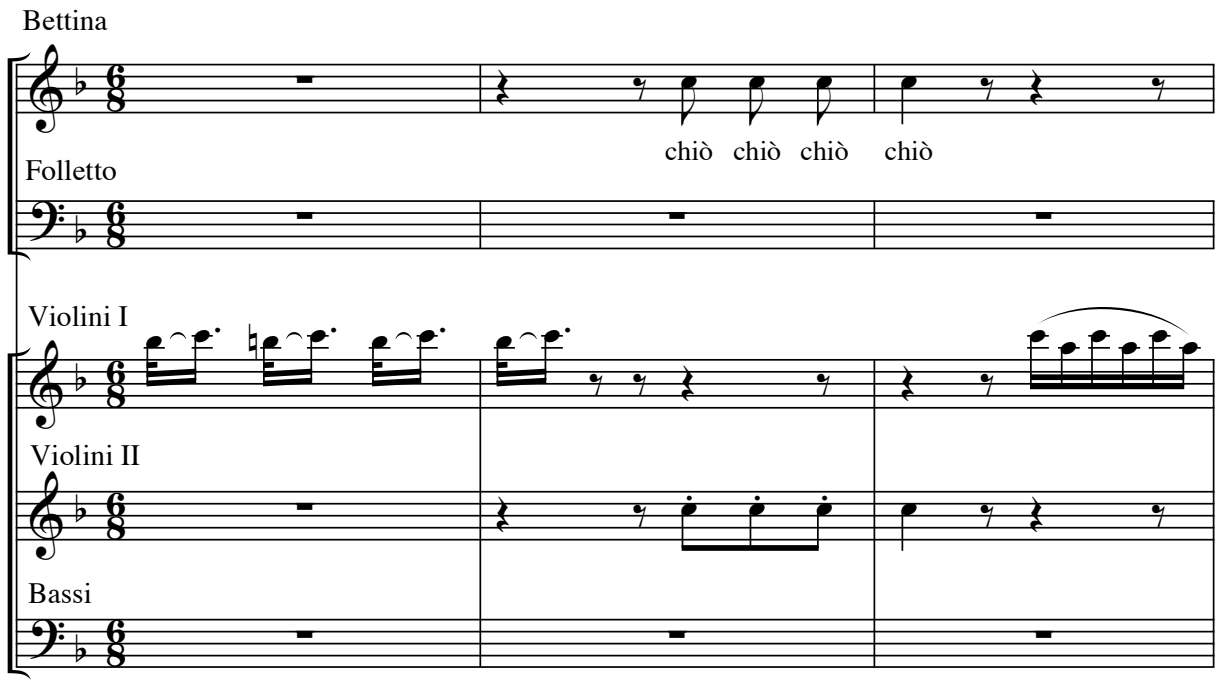




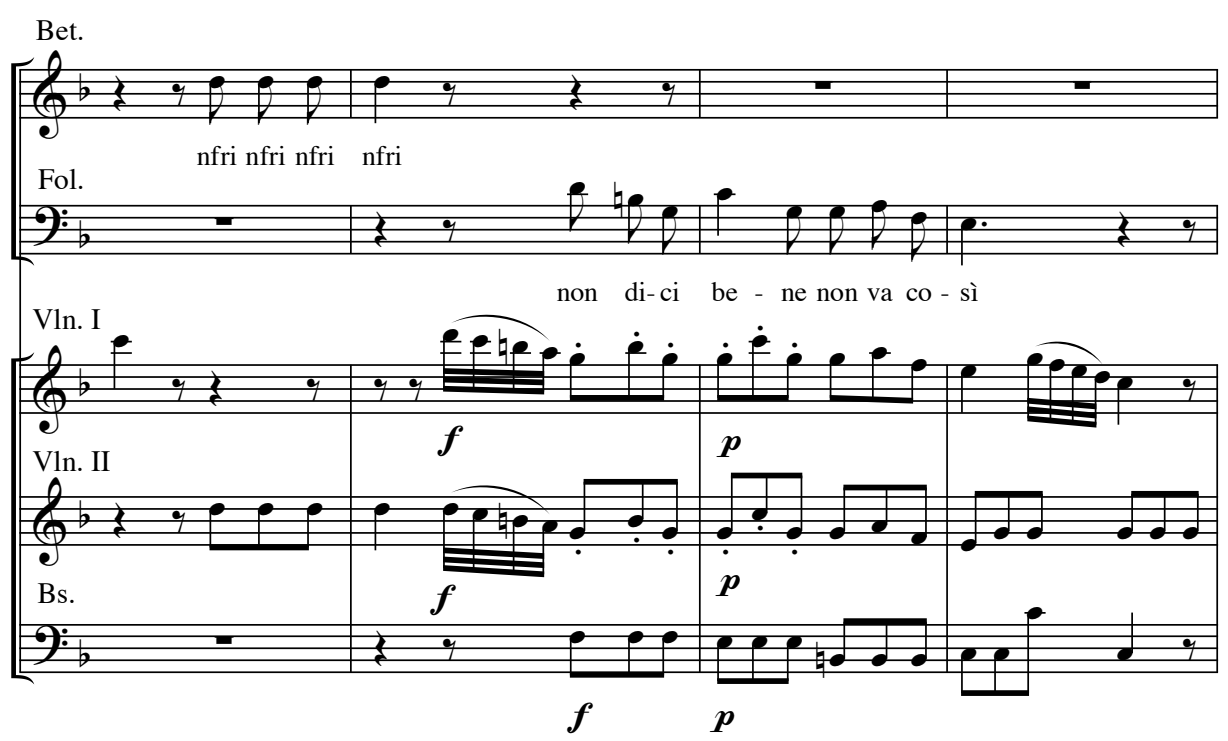

34 Cherubini/Livigni: Lo sposo di tre e marito di nessuna. Venezia 1783 (F-Pn D 2022-2023)

Das Hin und Her der Einsätze, die Pendelbewegung in den ersten Violinen und die tonmalerischen Silben verleihen dieser Stelle einen spielerischen Charakter. Die Szene endet damit, dass die beiden beim Herannahen von Leuten beschließen, ihre Übungen anderswo fortzusetzen. Diese Unterbrechung sowie Bettinas Fehler und Follettos Korrekturen bezeugen die große Spontaneität dieser Szene und bringen Lebendigkeit und Wirklichkeitsnähe in den Nachahmungsvorgang. Genauso wie es im oben besprochenen Imitationsspiel trotz der Bemühungen des americano zu keiner reinen „Kopie“ kommt, schafft es Bettina nicht, auf Anhieb das Lied fehlerfrei zu wiederholen, bei jeder Strophe unterläuft ihr ein Fehler, was aber der Szene einen Eindruck von Spontaneität und Menschlichkeit verleiht, der ihre Anmut und ihren Reiz ausmacht. Das Vor- und Nachsingen eines Liedes, das schon in sich die bei Kinderspielen besonders beliebte Nachahmung von Tierlauten enthält, bildet den Rahmen dieser kleinen Szene. Ob es sich bei dieser Lernmethode um ein regelrechtes Nachahmungsspiel handelt, sei dahingestellt, jedenfalls wirkt der mimetische Lernprozess spontan und spielerisch. Die Nachahmung ist hier allerdings nicht mit einem Als-ob-Spiel verbunden wie im vorherigen Beispiel, in dem eine Rolle und ihre Handlung imitiert wurden. Hier bezieht sich die Nachahmung auf das Singen eines Liedes, und die Spontaneität der Szene ist eher ein Zeichen von Wahrhaftigkeit als von einem Als-ob. 


\subsection{Zwischen Nachahmung und Fiktion}

Als letztes Beispiel für ein Nachahmungsspiel soll ein Quartett aus Domenico Cimarosas und Filippo Livignis erfolgreicher Oper „Giannina e Bernardone“ dienen, die I78 I in Venedig uraufgeführt wurde. In dieses Quartett (I,I2) ist eine französische Einlage eingefügt, die der Capitan Francone für Giannina vorträgt, um ihr eine Freude zu bereiten und ihren Mann Bernardone eifersüchtig zu machen. An diesem Beispiel, in dem im Gegensatz zu den beiden zuletzt untersuchten Szenen kein nachgeahmtes „Original“ vorhanden ist, soll die Untrennbarkeit zwischen Imitations- und Fiktionsspiel gezeigt werden. Die Besonderheit dieser Szene liegt nämlich nicht darin, dass in einem Ensemble der Vortrag eines Liedes eingeflochten ist, wobei wie schon in den eben besprochenen Beispielen durch Ebenenwechsel die theatralische Perspektive aktualisiert wird, sondern darin, dass der Capitano im Secco-Rezitativ vor dem Vortrag ankündigt, dass er seine Traversflöte nicht bei sich hat und deswegen auf seinem Stock spielen wird.

Mas. Sentiam la Canzonetta

Cap. $\quad$ Mi dispiace di non aver indosso

Il mio Flauto traverso; ma non serve,

Supplirà al Traversiero il mio bastone. ${ }^{638}$

Daraufhin beginnt das Quartett und nach einigen Aufforderungen zu Ruhe und Aufmerksamkeit beginnt die Einlage des Capitano mit einem Flötenvorspiel, wobei er sich laut Regieanweisung seines Stockes als Flöte bedient und dabei mit dem Mund den Flötenklang nachahmt.

Cap. $\quad$ Fate silenzio.

Gia. Zitti!

Cap. Attenzione.

(Si serve del bastone per Flauto traverso, e con la bocca fa la voce del Traversiero, e si accompagna, e canta.)

Liran lillera,

Liron lillara,

Lirin lillera,

Liron lillù,

Vù set, ma scere,

638 Livigni/Cimarosa: Giannina e Bernardone. Venedig 1781 (I,12). 
Giannina emable,

La belle Mere

Del Diù d'amur.

Lirin lillera,

Liron lillù.

$(\ldots)^{639}$

Der Capitano tut im Vorspiel so, als würde er Flöte spielen, führt die Spielbewegungen mithilfe eines Stockes aus und singt die Melodie der Flöte auf Trällersilben, während ihn im Orchester eine echte Solo-Flöte dabei unterstützt. Die Strophe des französischen Liedes singt er „wirklich“, während er sich beim Nachspiel wieder mit seiner imaginären Flöte begleitet (s. Notenbeispiel 35, S. 2 I 4).

Dabei findet einerseits ein Nachahmungsspiel statt, denn der Capitano ahmt mit seiner Stimme den Flötenklang nach, mit seinem Körper imitiert er die mit dem Flötenspielen verbundenen Bewegungen, aber gleichzeitig ergibt sich bei diesem Nachahmungsvorgang ein fiktives Flötenspielen, ein regelrechtes Fiktionsspiel: Der Capitano tut nämlich so, als würde er Flöte spielen, und verwendet dabei den Stock als Flötenersatz. Wie beim Als-ob-Spiel der Kinder findet die Umdeutung eines Gegenstands statt, der Stock dient als „prop“640 für die Vorstellung einer Flöte. Zu der typischen Objekttransformation schreibt Garvey: „Ein begeisterter und phantasievoller ,Als-ob'-Spieler benutzt meist das, was zur Hand ist. "641 Das fiktive Flötenspiel hätte auch ohne Stock vollzogen werden können, eine Flöte hätte auch ohne einen Substituten imaginiert werden können, aber das Objekt "gives substance“, wie Walton schreibt; als etwas Reales und Anfassbares erzeugt es einen lebendigeren Eindruck. ${ }^{642}$ Der Spielgegenstand ist aber nur ein Teil des Als-ob-Spiels, die Pantomime der dazugehörigen Spielbewegung und die Nachahmung des Flötenklanges vervollständigen das Spiel.

639 Ebd.

$640 \mathrm{Vgl}$. Walton, S. $37 f$.

641 Garvey, S. 119.

642 Vgl. Walton, S. 26. 

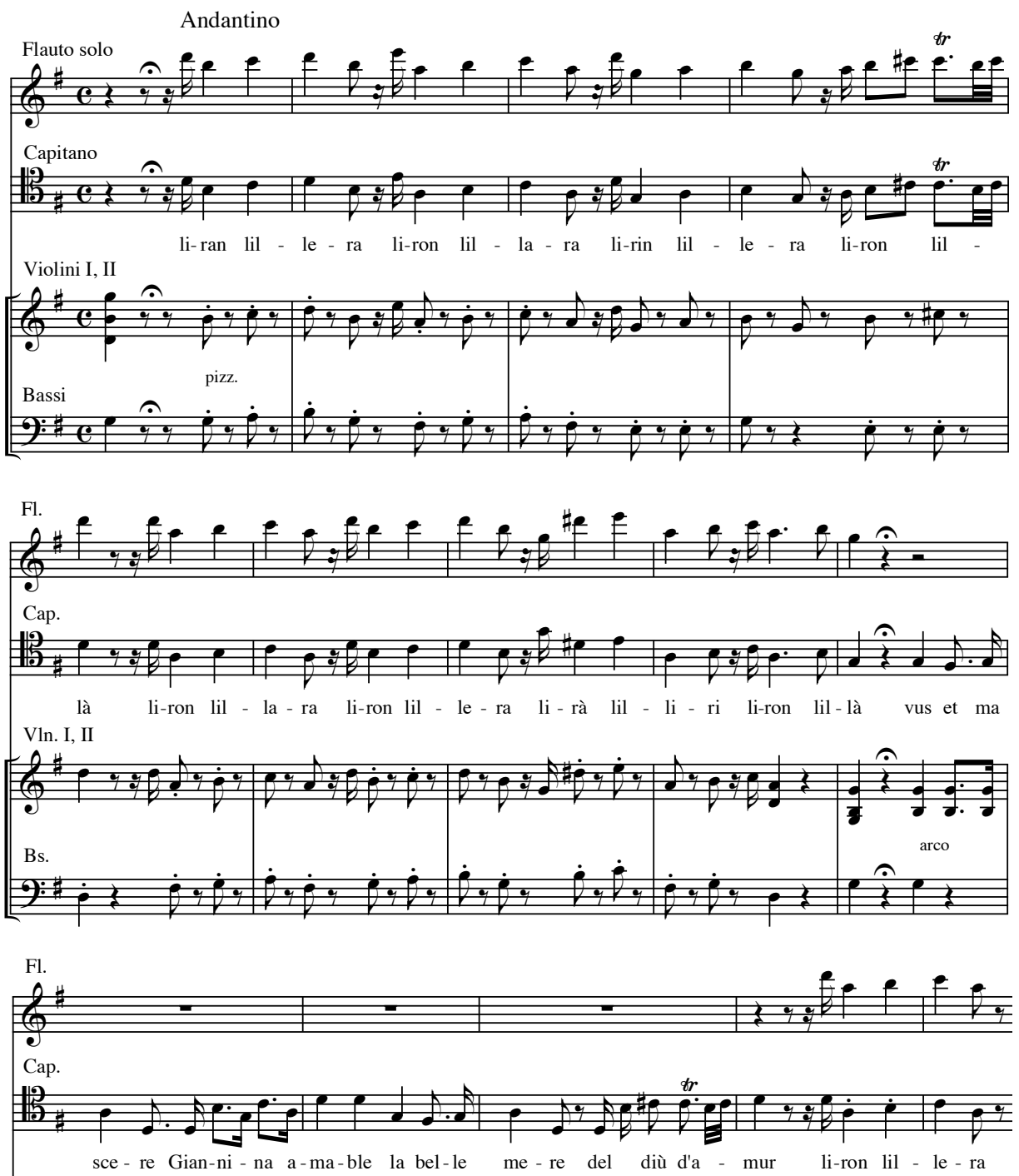
Vln. I, II

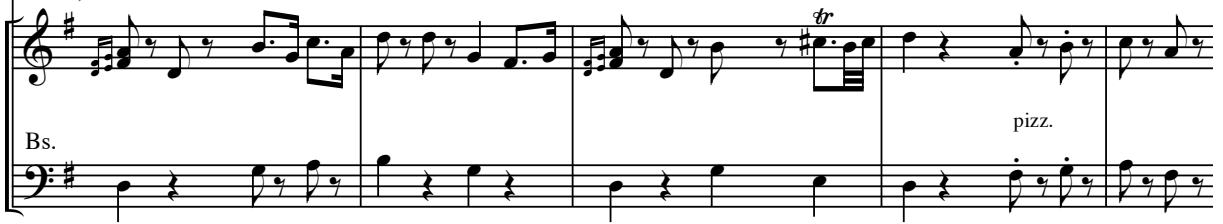

35 Cimarosa/Livigni: Giannina e Bernardone. (I-Mc Noseda E.1/I-II) 
Es ist erstaunlich, mit welcher Selbstverständlichkeit die auf der Bühne dargestellte Realität in dieser Szene mit einem Als-ob-Spiel vermischt wird. Die Substitution der Flöte mit dem Stock wird zwar unmittelbar vor dem Quartett angekündigt, überrascht aber trotzdem, weil das im Kontext einer Liedeinlage in der Opera buffa unüblich ist. Im Vergleich zu einer mit einer echten Flöte gespielten und an sich schon unterhaltsamen Einlage kommt für den Zuschauer die Freude am Erkennen und Imaginieren des symbolisierten Objekts bzw. am In-Beziehung-Setzen des realen Stocks mit der imaginären Flöte hinzu. Das spontane Als-ob-Spiel des Capitano ist nicht nur ein wirksames theatralisches Mittel, das den Spielcharakter der Bühnenhandlung unmittelbar vergegenwärtigt, sondern vermittelt dem Publikum gewissermaßen auch die Botschaft „alles ist Spiel“. Nur in einer Welt des Spiels oder in einer spielerischen Realität kann eine fehlende Flöte mit einem Stock ersetzt werden. Für den Zuschauer erweist sich diese Umdeutungsfreiheit, die Bereitschaft zum Spiel sowohl vonseiten des Capitano als auch der Bühnenzuschauer und die Einführung eines der primären Fiktionsebene untergeordneten Als-ob als besonders lustig und lustvoll.

\subsection{Mimicry als Imagination}

In den letzten Ausführungen über die Nähe zwischen Nachahmungs- und Fiktionsspielen ist nebenbei mehrmals ein Begriff gefallen, der nun, um die in der Opera buffa vorhandenen Als-ob-Spiele genauer zu erfassen, näher unter die Lupe genommen werden soll: Imagination. Der Stock des Capitano dient gemeinsam mit den Spielbewegungen und dem nachgeahmten Flötenklang als Hilfsmittel, um die Vorstellungskraft der Zuschauer (sowohl auf der Bühne als auch im Theaterraum) anzuregen und sie die Vorstellung einer Flöte erzeugen zu lassen. Ein ähnlicher Vorgang findet statt, wenn Buffa-Figuren immer wieder von kleinen Szenen erzählen, die sich in ihrer Vorstellung abspielen. Solche imaginierten Szenen haben mit „doppelt-fiktiven“ - also auf einer zweiten, untergeordneten Fiktionsebene gespielten - Szenen das Moment des Irrealen, des Illusionären gemeinsam, müssen aber von den ersteren unterschieden werden. Das „Musizieren auf dem Stock“ des Capitan Francone kann als fiktives Flötenspiel bezeichnet werden, das konkret auf der Bühne stattfindet. Bei imaginierten Szenen werden der primären Spielebene Handlungssequenzen untergeordnet, die in der Vorstellung der Bühnenfiguren stattfinden. ${ }^{643}$ Diese sind in der Regel ebenfalls fiktiv, also erfunden, und finden auch in einem der primären Fiktionsebene untergeordneten Als-ob statt. Der Unterschied zwischen dem fiktiven Flötenspiel und der Erzählung

643 Pfister spricht in Bezug auf Traumeinlagen, die mit den imaginierten Szenen der Opera buffa vergleichbar sind, von der „Merkmalkomplexion von Fiktionalität und Imaginiertheit“. (Vgl. Pfister, S. 297). 
einer fiktiven imaginierten Szene scheint demnach in der sinnlichen Vergegenwärtigung und in der Wahrnehmbarkeit der untergeordneten Handlungssequenz zu liegen. Problematisch wird die Unterscheidung dann, wenn, wie es meistens in der Opera buffa der Fall ist, die imaginierte Szene nicht nur narrativ vermittelt, sondern auch dargestellt, also sinnlich vergegenwärtigt wird. Als imaginierte Szenen bezeichne ich, um Missverständnisse zu vermeiden, hier Szenen, die der Vorstellung einer fiktiven Figur entspringen und deren Vermittlung in erster Linie narrativ (also verbal) vollzogen wird, unabhängig davon, ob dabei die Narration mit darstellerischen Mitteln ausgeschmückt und mit in direkter Rede wiedergegebenen Dialogen durchsetzt wird.

In den untersuchten Opere buffe sind immer wieder solche kleinen imaginierten Szenen zu finden; sie können realitätsnah sein oder phantastisch, wie es im folgenden Beispiel aus der schon erwähnten Oper „Il geloso in cimento“ von Pasquale Anfossi der Fall ist. Die Grundsituation ist hier die Rivalität zwischen drei Verehrern, dem eifersüchtigen Fabio, dem Engländer Rosbif und Don Perichetto. Letzterer sagt in einem Moment, in dem er allein zu sein glaubt, dass er einen seiner beiden Rivalen, entweder den Engländer oder Fabio, umbringen will, wenn er einen von ihnen mit Donna Flavia ertappt. Als Don Perichetto bemerkt, dass Fabio diese Drohung mitgehört hat, erfindet er in seiner Not eine feige Ausrede, die aufgrund seines panischen Zustands besonders phantasievoll und zugleich absurd ausfällt. Um die Begriffe Inglese und Fabio logisch miteinander und mit der Morddrohung zu verknüpfen, behauptet er, seinen englischen Kater Fabio umbringen zu wollen, der ihm keine Ruhe lässt.

D.P. Un equivoco è questo. Ho un gatto Inglese,

Che ha nome Fabio: nome,

Che per altro gli han posto in Inghilterra,

Ma non io già, credetelo. E siccome

Fa mille impertinenze

Ho detto di ammazzarlo. E innamorato

Col suo gnao mai non tace,

Né mi lascia dormir la notte in pace. ${ }^{644}$

Nach dieser Erklärung im Secco-Rezitativ beginnt Don Perichettos Erzählung einer imaginierten Szene, deren Beginn und Ende, wie in der Opera buffa in solchen Fällen üblich, mit dem Anfang und Ende der Arie zusammenfällt.

Vi dirò di questo gatto

Una cosa singolar.

644 Bertati/Anfossi: Il geloso in cimento. Venedig 1774 (II,8). 
Par che impari a solfeggiar

Tre, quattr'ore avanti dì.

Quando vede la sua gatta

Incomincia a far così .....

Cosa nasce! Lei s'appresta;

Ed in Musica ancor essa

Incomincia a modular .....

Ecco qua che dopo un tratto

Giunge ancor qualche altro gatto,

Che cantando il minuetto,

Maledetto così fa .....

Poi facendosi più avanti,

Fan baruffa tutti quanti:

Chi qua scappa, e chi di là. ${ }^{645}$

Allegro

Oboi

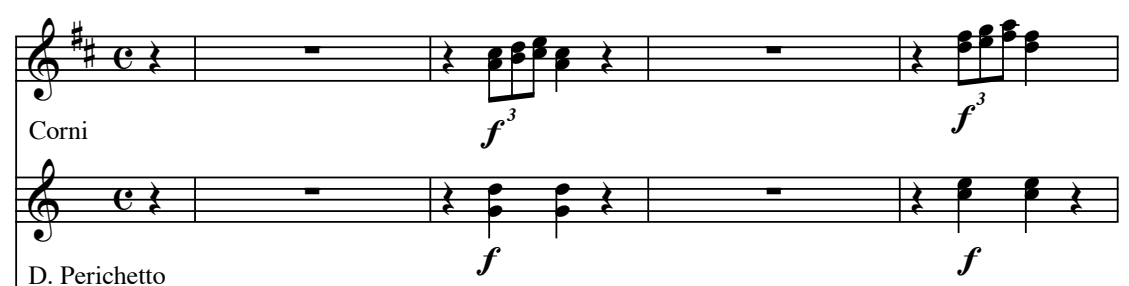

Q: "

Violini I

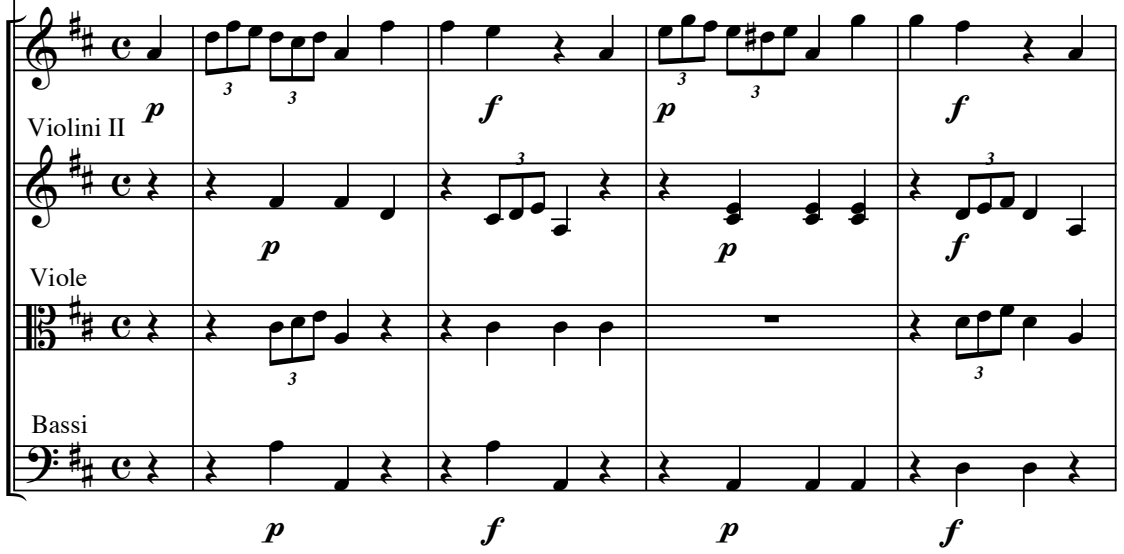

645 Ebd. 


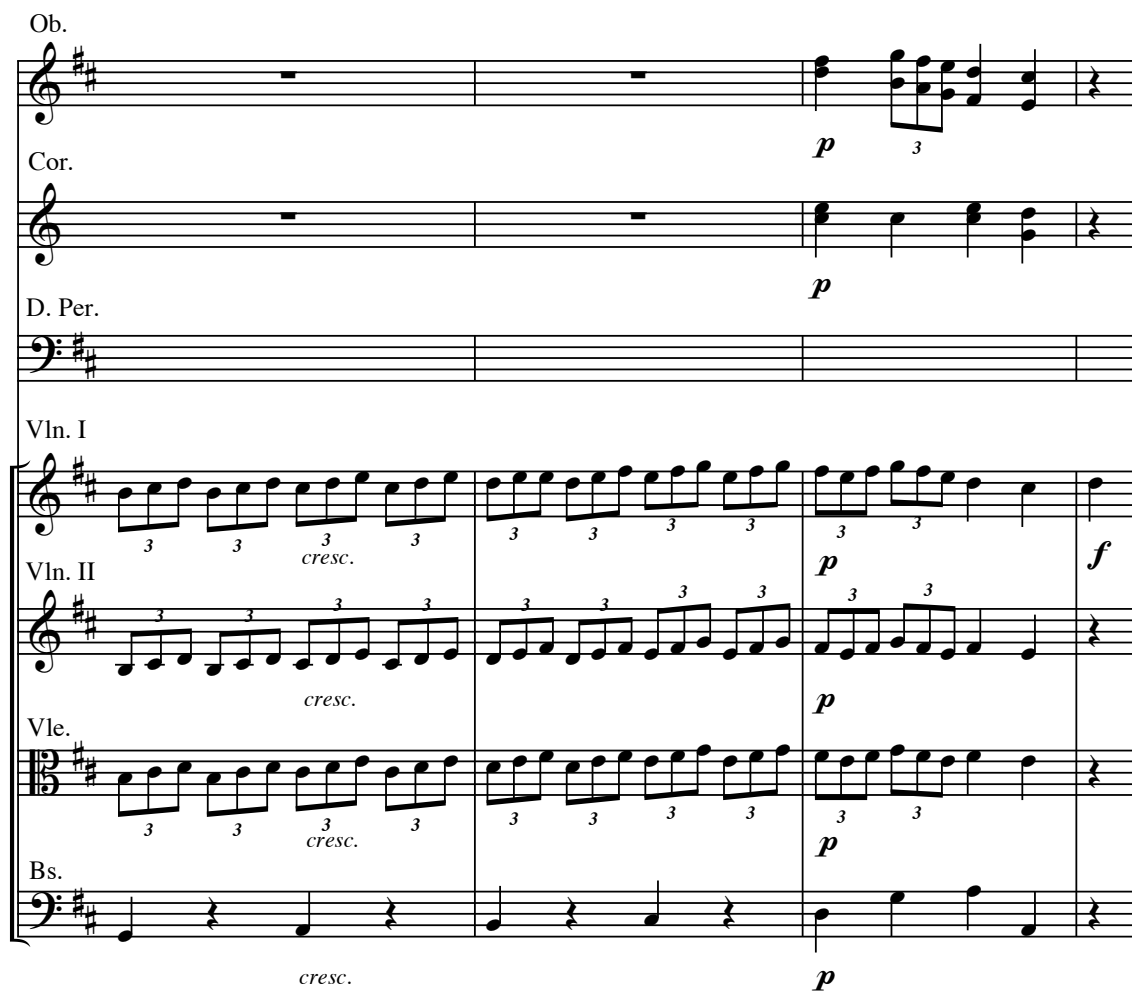

36 Anfossi/Bertati: Il geloso in cimento. Venezia 1774 (I-Gi B.7.7/8)

Akustische Phänomene werden in der Opera buffa oft musikalisch umgesetzt, so wird hier das Katzengejammer zunächst mit einem Solfeggio verglichen. Die imaginierte Szene beginnt damit, dass mitten in der Nacht der Kater seine Katzenfreundin trifft und Laute von sich gibt, die sich wie ein Solfeggio anhören. Um seiner Notlüge größere Glaubwürdigkeit zu verleihen, ahmt Don Perichetto die Stimme des von ihm erfundenen Katers nach, die also nicht nur narrativ vermittelt, sondern „sinnlich vergegenwärtigt“ wird, denn nach „fa così“ und einem imaginären Doppelpunkt folgt in einer Art direkter Rede das Solfeggio des Katers (s. Notenbeispiel 36, S. 2 1 7 f.).

Die Regieanweisung lautet dabei : „solfeggiando con la voce del gatto“, wobei die Art und Weise, in der der Gesang des Katers erfolgt, dem Sänger überlassen bleibt. Eine naheliegende Möglichkeit wäre, dass er mit verstellter Stimme die Melodie der ersten Geige auf Solfeggio-Silben mitsingt. Die raschen Triolen würden dem Kater bzw. dem Sänger erlauben, seine Virtuosität im Solfeggio zur Schau zu stellen. Durch das schnelle Tempo (Allegro) würden die Solfeggio-Silben zusätzlich einen Zungen- 
brecher-Effekt bewirken, der gemeinsam mit einer witzig wirkenden Verstellung der Stimme und dem wahrscheinlich dabei stattfindenden Schauspiel eine ungewohnte und höchst komische Szene abgeben würde. Denkbar wäre auch der Einsatz von falscher Intonation als lustige Darstellung des Katzengejammers. Die Erzählung der imaginierten Szene ist aber noch nicht zu Ende: Die ebenfalls „musikalische“ Freundin des Katers tritt auf und beginnt zu modulieren („Ed in Musica ancor essa / Incomincia a modular ..."). Anfossis Musik, die eng am Text entlang komponiert ist, moduliert tatsächlich, nämlich nach a-Moll und bleibt eine Zeit lang in dieser Tonart. Dabei ist zu bemerken, dass Moll-Tonarten in den in Italien produzierten Opere buffe eher selten eingesetzt werden. ${ }^{646}$ Ihre Verwendung wird für besondere Momente aufgespart; in diesem Fall dient das a-Moll vermutlich dazu, die Modulation so deutlich hörbar zu machen, dass die Aufmerksamkeit des Publikums auf das im Text erwähnte Modulieren der Katze und auf die Thematisierung der Musik gelenkt wird.

Wie Don Perichetto die modulierende Stimme der Katze („modulando la voce del gatto “) interpretiert, bleibt wiederum dem Sänger überlassen, der hier über eine längere Zeit verfügt, um sich im pantomimischen komischen Spiel zu produzieren. Es würde sich anbieten, für die Rolle der modulierenden Katze eine andere Stimmqualität zu wählen, um sie von der Stimme des solfeggio-singenden Katers zu differenzieren.

D. Perichetto

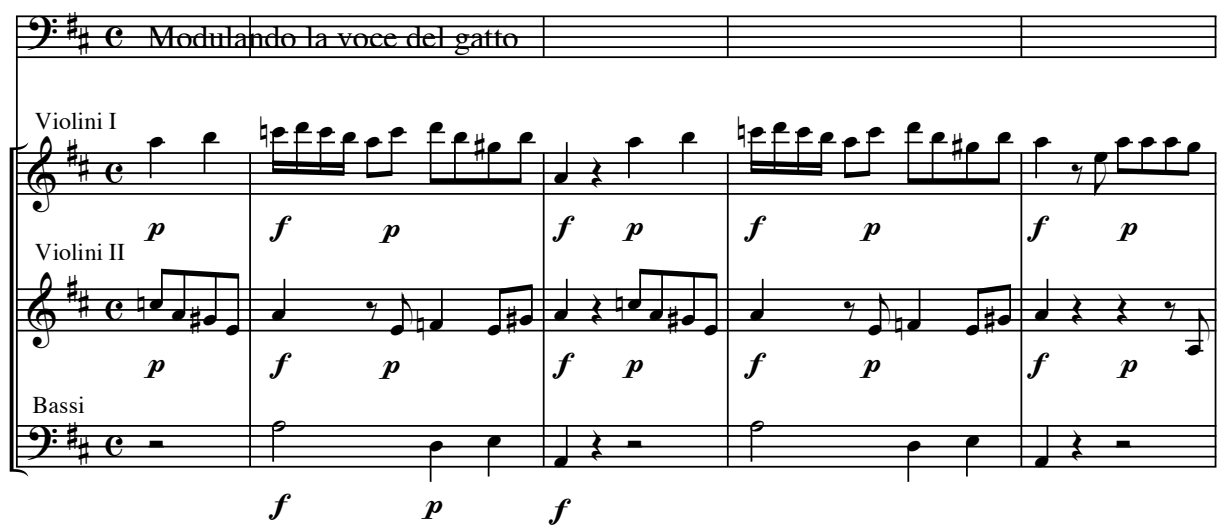

646 In der Gazzetta urbana veneta wurde Paisiello sogar vorgeworfen, dass er nach seiner Rückkehr aus Russland und Wien zu viele Moll-Tonarten verwendete, was auf das kalte Klima der nordischen Länder zurückgeführt wurde: „(...) lo stesso Sig. Paisiello. Durante il suo lungo soggiorno nei peasi settentrionali dell'Europa, ove l'orror del clima non può far nascere nella fantasia di un maestro immagini molto allegre sfortunatamente ei contrasse un inclinazione fortissima per i minori (...)“. (Gazzetta urbana veneta Nr. 67, Sabbato 22 Agosto 1789, S. 533f. Zit. nach Villinger, S. 312). 
D. Per.

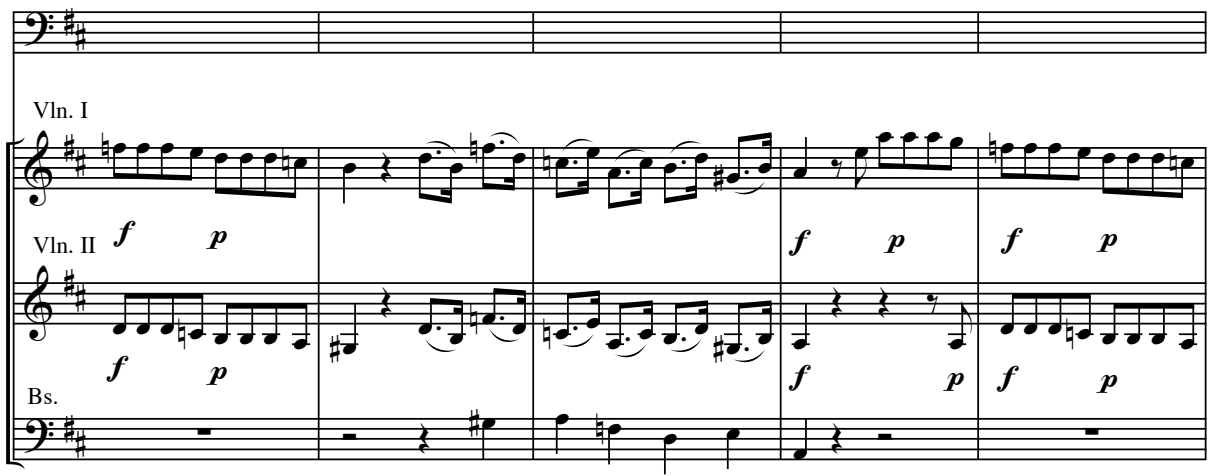

D. Per.

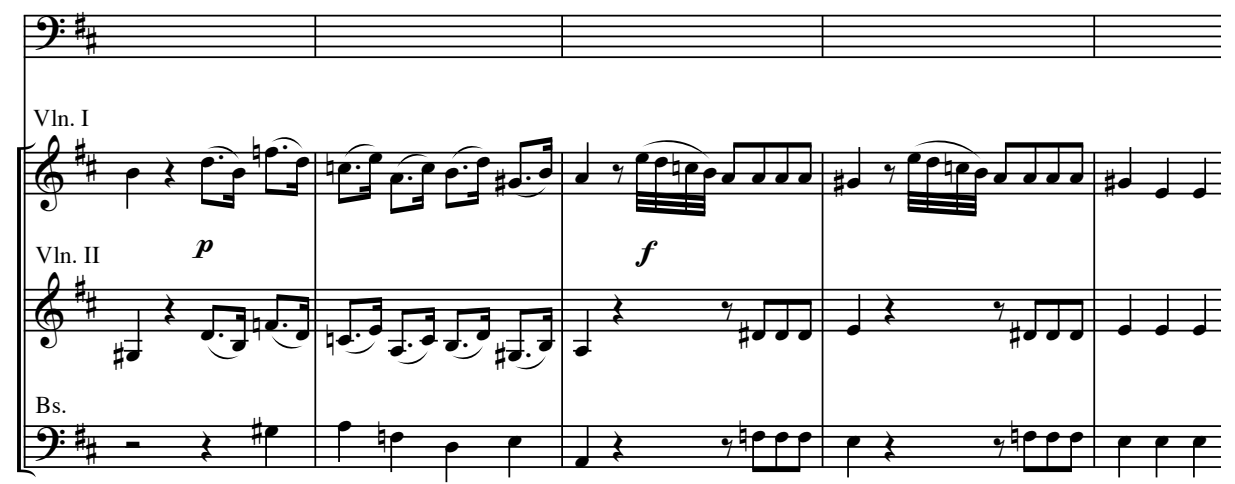

37 Anfossi/Bertati: Il geloso in cimento. Venezia 1774 (I-Gi B.7.7/8)

Um sein Gegenüber zu überzeugen bzw. um ihm keine Zeit zum Nachdenken und zum Misstrauen zu lassen, spinnt Don Perichetto die Phantasieszene noch weiter: Mehrere Kater und Katzen kommen hinzu, eines der Tiere singt sogar ein ganzes Menuett. Musikalisch folgt hier ein neuer Abschnitt, denn Anfossi setzt den Librettotext wörtlich um und komponiert an dieser Stelle ein echtes Menuett, das Don Perichetto mit einer Katzenstimme singt („,cantando il minuetto con la voce del gatto"), wobei der Sänger wiederum Raum genug hat, um seiner Kreativität freien Lauf zu lassen und seine Komiker-Fähigkeiten szenisch und musikalisch zur Schau zu stellen (s. Notenbeispiel 38, S. 22I).

Schließlich kommt es zwischen den vielen Katzen zu einer Balgerei, die durch ein lärmendes Motiv im Orchester zum Ausdruck gebracht wird, zu der Don Perichetto verschiedene Katzenstimmen nachahmen soll (s. Notenbeispiel 39, S. 222). 

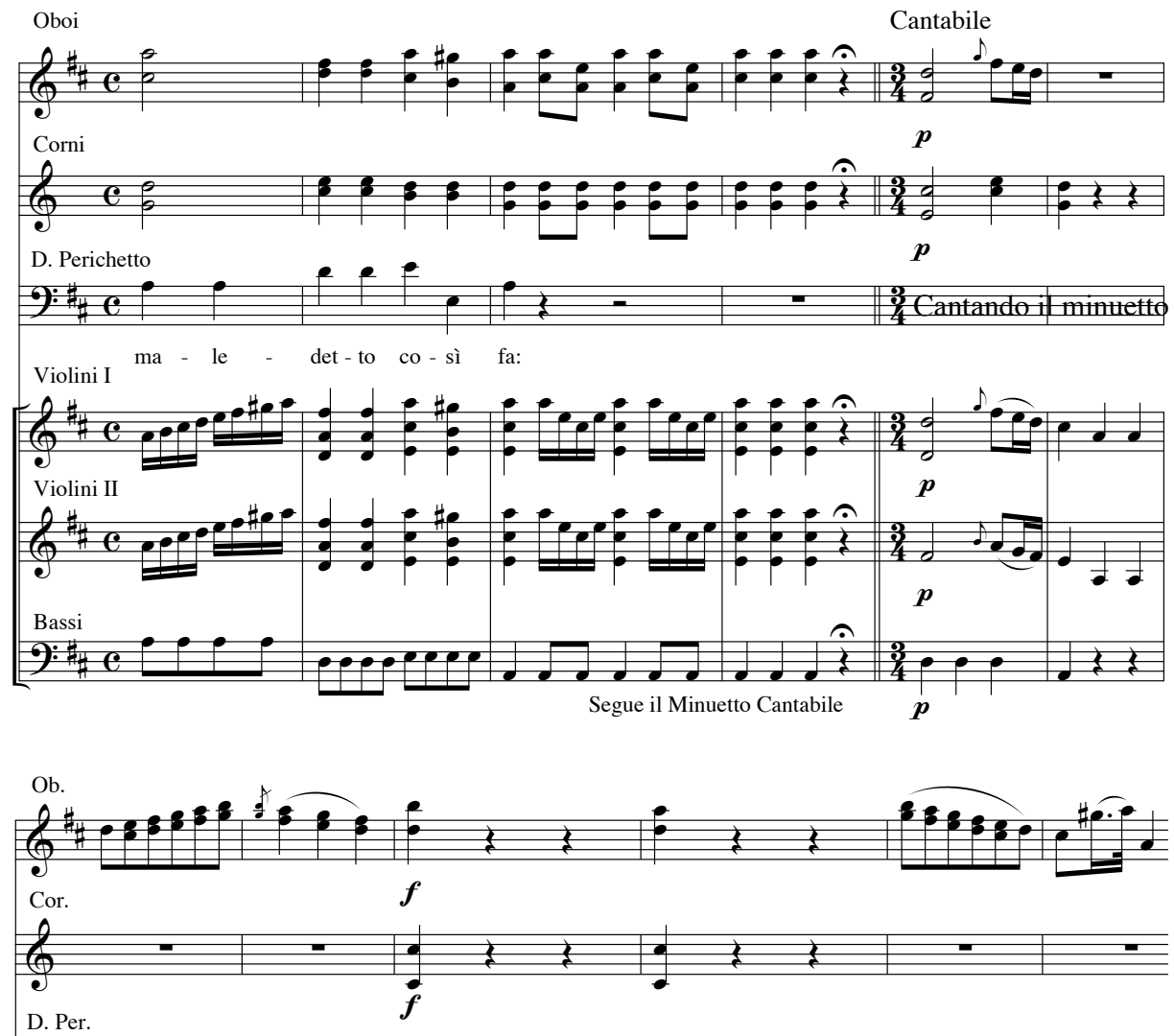

9: "\# con la voce del gatto

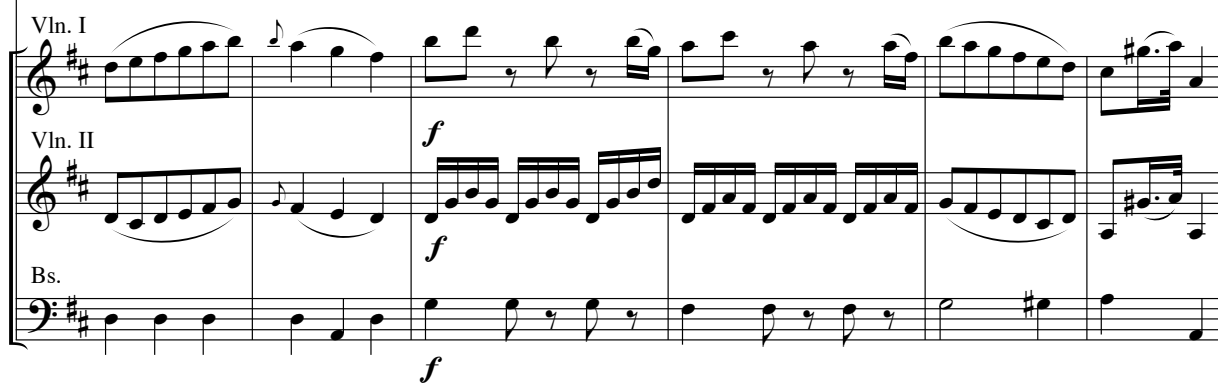

38 Anfossi/Bertati: Il geloso in cimento. Venezia 1774 (I-Gi B.7.7/8) 
Allegro assai

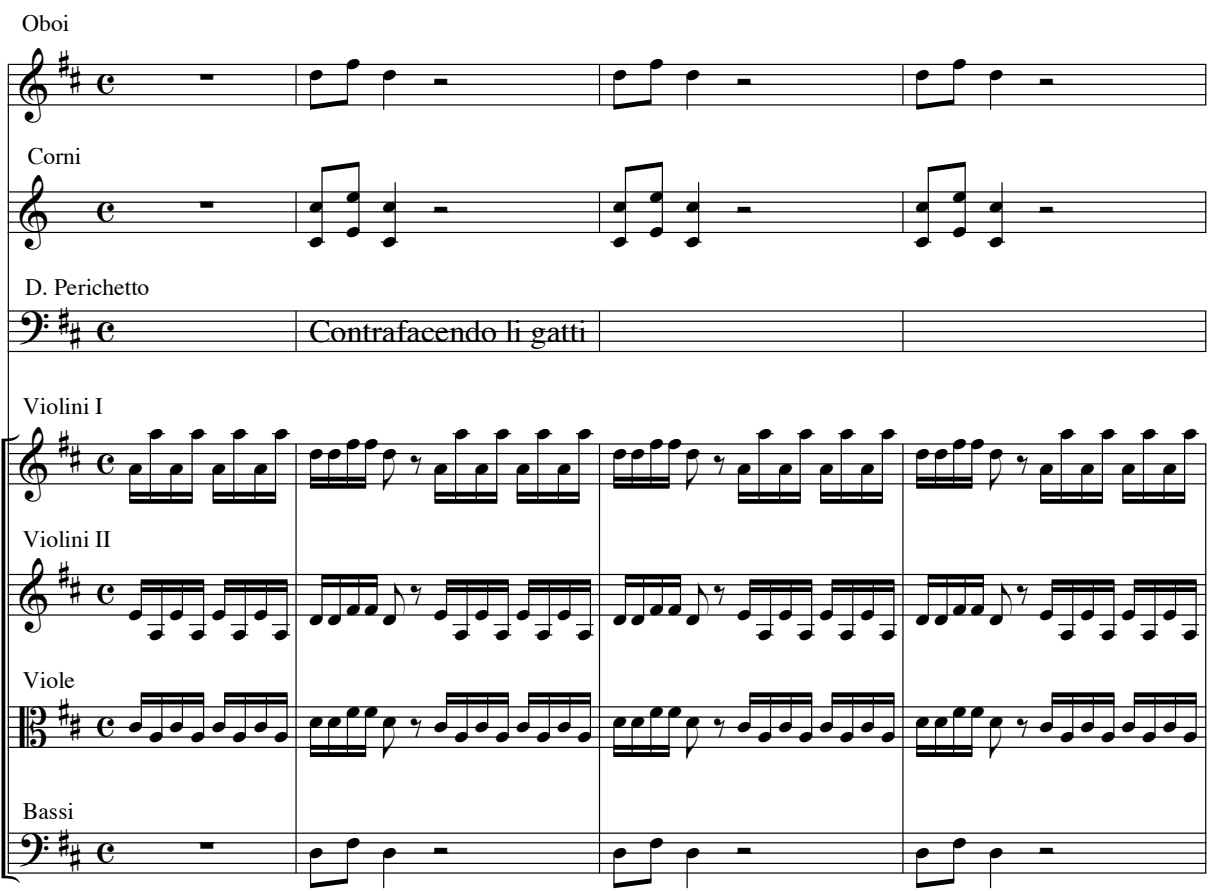

39 Anfossi/Bertati: Il geloso in cimento. Venezia 1774 (I-Gi B.7.7/8)

Am Ende der Erzählung dieser imaginierten Szene laufen alle Katzen in unterschiedliche Richtungen davon. Bevor die Arie mit den konventionellen lärmenden Schlussformeln endet, wird das Auseinanderlaufen der Katzen (nach dem Satz „Chi qua scappa, e chi di là.") musikalisch dargestellt (s. Notenbeispiel 40, S. 223).

Nicht nur die Katzen laufen bei diesem raschen Unisono-Streicher-Motiv davon, sondern auch ihr „Interpret“ Don Perichetto nützt die Gelegenheit, um sich fortzuschleichen.

Don Perichettos „Spiel“ besteht darin, eine Phantasiefigur zu erfinden, nämlich die des englischen Katers Fabio, dessen unrealistische Fähigkeit, Solfeggio zu singen, zunächst als Metapher für einen lästigen Lärm dient. Nach und nach imaginiert Perichetto eine Szene um dieses Phantasietier herum und „spielt“ die Rolle des Katers, indem er seine Stimme durch ein musikalisches Solfeggio „nachahmt“ und somit sinnlich vergegenwärtigt. Weitere mit musikalischen und sängerischen Fähigkeiten ausgestattete Katzen treten auf und bringen immer virtuosere Beweise ihrer Musikalität, die Don Perichetto „in die Tat umsetzt“, wobei prinzipiell zwei Interpretationsmöglichkeiten bestehen: Die Darstellung 


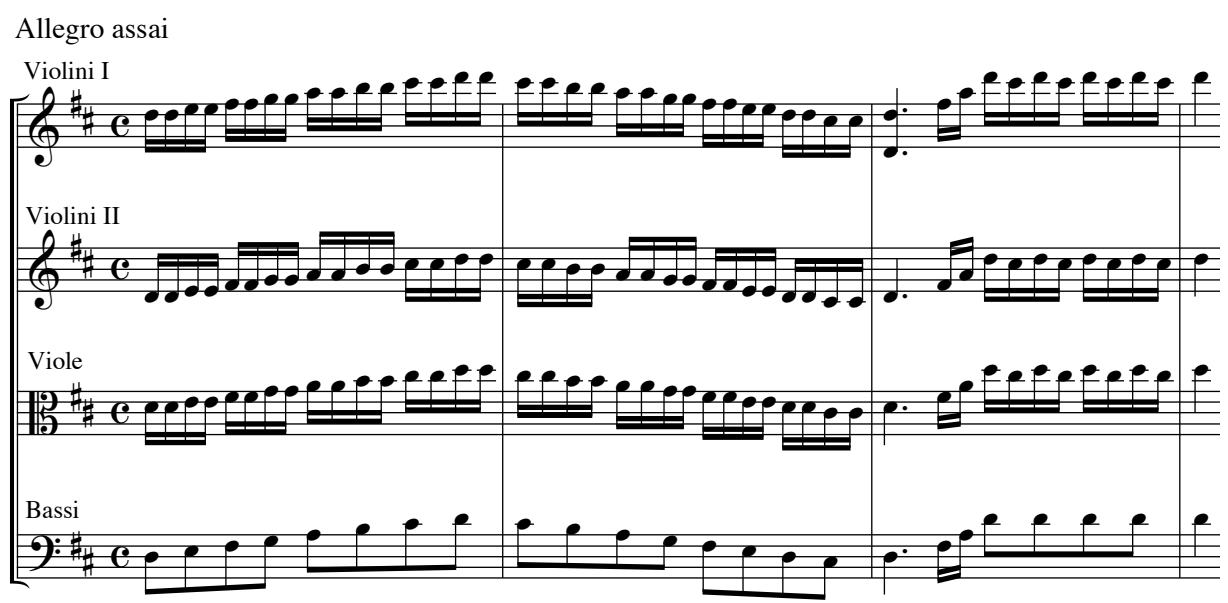

40 Anfossi/Bertati: Il geloso in cimento. Venezia 1774 (I-Gi B.7.7/8)

des reinen Metapherninhalts, also des Solfeggio, der Modulation und des Menuetts, oder die Darstellung der gemeinten Bedeutung, nämlich eines furchtbar klingenden Katzengejammers. Denkbar und vielleicht naheliegender wäre auch eine Kombination dieser Möglichkeiten. In beiden Fällen beruht Perichettos Als-ob-Spiel in erster Linie auf der Verstellung der Stimme, also auf einer Art „stimmlicher Verkleidung“ und auf einer Zurschaustellung der besonderen Gesangsfähigkeiten der imaginierten Katzen.

Die Thematisierung von Musik auf der Bühne bewirkt eine lustvolle Vergegenwärtigung der Theatersituation. Unkonventioneller, aber ebenso lustvoll ist die Erfindung der singenden Katzen. Der kreative Akt besteht dabei darin, ein Tier mit einer ihm fremden, weil menschlichen Fähigkeit auszustatten. Kreativität, wie sie in einem ganz allgemeinen Sinn heute aufgefasst wird, besteht im Grunde genommen in einer Neukombination von Informationen, inbesondere durch einen Verknüpfungsprozess von weit entfernt liegenden Elementen, der in diesem Fall auch die komisch wirkende Diskrepanz herbeiführt. „Kennzeichnend für Kreativität ist“ gerade die "Spielorientierung", ${ }^{647}$ also eine lockere, spielerische Haltung.

Die innere dramaturgische Motivation für die phantasievolle und spielerische Imagination und Darstellung der Katzenszene ist Don Perichettos Bemühung, den erzürnten und sich herausgefordert fühlenden Fabio davon zu überzeugen, dass er etwas ganz anderes meinte, als er gesagt hat, und ihn vor allem durch das Spektakel des Katzengesangs abzulenken. Der grundlegende Unterschied im Vergleich zu den Phantasiespielen der Kinder besteht darin, dass hier hinter dem Spiel ein konkreter Zweck steckt:

647 Vgl. Garvey, S. 65. 
Don Perichetto will, um sich aus einer heiklen Lage zu retten, sein Gegenüber etwas glauben lassen; er will ihm eine Phantasieszene als wahr „verkaufen“ und ihn in ein make-believe-Spiel verwickeln, was ihm aber nicht gelingt, weil Fabio „nicht mitspielt“ bzw. ihn nicht ernst nimmt. Er bleibt unbeeindruckt und empfindet Don Perichettos feiges Benehmen sogar als lächerlich, wie er, bevor er anderen Beschäftigungen nachgeht, in einem kurzen und trockenen Kommentar zum Ausdruck bringt („La sua viltà mi move a riso"). Die äußere dramaturgische Motivation dieser Szene ist natürlich vor allem die Erzeugung einer unterhaltsamen Show. Sowohl das einfallsreiche Phantasiespiel als auch die szenisch-musikalische Vergegenwärtigung der imaginären Katzen bieten dabei ein großes Potenzial an Komik und sorgen für eine heitere Stimmung.

In den untersuchten Opere buffe sind die meisten imaginierten kleinen Szenen wesentlich realistischer als die eben analysierte Katzenszene. In Anfossis schon in Bezug auf die agonale Auseinandersetzung zwischen Frauen und Männern erwähnter Oper "La forza delle donne“ imaginiert beispielsweise Barbarina eine Szene, in der sie verschiedene Soldaten und Offiziere unterschiedlichen Ranges verführt. Der Bezug zur primären Handlung ist sehr eng, denn die Männer, mit denen sie in ihrer Vorstellung interagiert, gehören allesamt dem Militär an, genauso wie die Männer, die den Frauen aus Ginopoli den Krieg erklärt haben. Außerdem ist die Verführung gerade die Strategie, mit der die Frauen die ihnen an Kraft und im Waffenkampf überlegenen Männer erobern und besiegen wollen. Die in Barbarinas Imagination stattfindende Verführung ist zwar eine Wunschvorstellung, dennoch ist sie nicht unrealistisch, denn nach mehreren fehlgeschlagenen Verführungsversuchen von hierarchisch höherstehenden Frauen wird am Schluss der Oper gerade sie, die zuerst belächelte Bäuerin, es schaffen, den frauenfeindlichen Anführer der Männer zu verführen und dadurch die Männer auf eine friedliche und ausgesprochen weibliche Art zu besiegen.

Nach Barbarinas ehrgeiziger Ankündigung ihres Vorhabens im Rezitativ folgt die Erzählung einer imaginierten Szene, die sich wie immer im Rahmen einer Arie abspielt.

Infatti io voglio venir al campo. Adesso la paura ch'io avea m’è già passata.

Son donna puntigliata: Basta così. Vedrete se anch'io so le maniere

d'allettar e di piacere;

E se per far con tutti la civetta

Donna son'io d'abilità perfetta.

Aria: $\quad$ Ecco qua, quest'è un soldato.

Camerata, addio, addio.

Alla guerra vengo anch'io,

E con te mi fo arrolar. 
Prendo il gotto, e si tracanna,

Ballo un poco un'Alemanna.

Quando il caldo poi l'assale,

L'uffiziale vo a trovar.

Per Bacco, mio signore,

Che senza far l'amore

Fra noi non si può star.

Son qua, ragazza mia,

Incominciamolo a far.

Due parolette tenere,

Due languide occhiatine,

E qualcos'altro infine,

Vedetelo a cascar.

Ma osservate: ecco qua il Generale:

Tutto spira fortezza e valore.

Eccellenza mi faccia l'onore

Di poterle la mano baciar.

Tu chi sei? Son fanciulla, rispondo.

Cosa brami? Ah, che dirlo non oso!

Ho perduta la pace, il riposo;

E sospiro senz'altro parlar.

E Tizian se vede, e sente,

Zitto, zitto se ne resti;

Che in tai casi chi è prudente

Serra gli occhi, e lascia andar. ${ }^{648}$

Eigentlich handelt es sich um die Aneinanderreihung von drei verschiedenen imaginierten kleinen Szenen mit Dialogen, während Barbarina im vierten und letzten Abschnitt der Arie die Reaktion beschreibt, die sie sich von ihrem Verlobten wünscht, falls er von ihren Verführungen Wind bekommen sollte. Jede der drei imaginierten Mikro-Szenen beinhaltet die Verführung des Vertreters eines bestimmten militärischen Ranges. Die verschiedenen kleinen Szenen sind nicht nur im Librettodruck durch unterschiedlich starkes Einrücken gekennzeichnet, sondern jeder Szene entspricht formal auch ein musikalischer Abschnitt. Barbarinas Verführungskunst besteht in der Differenzierung der Eroberungsstrategie je nach dem hierarchischen Rang des jeweiligen Mannes. In der ersten Mikro-Szene stellt sie sich einen einfachen Sol- 
daten vor, mit dem sie kameradschaftlich umgeht, den sie duzt, mit dem sie reichlich trinkt und eine „Alemanna“ (Allemande) tanzt, während es musikalisch im schwungvollen Allegro moderato (C) lustig zugeht.

In der zweiten kleinen Szene besucht Barbarina in ihrer Vorstellung einen Offizier, den sie im etwas gemächlicheren Andantino (2/4) mit „mio signore“ anspricht und mit zärtlichen Worten und schmachtenden Blicken im Handumdrehen erobert. Im imaginären Dialog, den sie mit dem Offizier führt, sind die beiden Rollen stilistisch differenziert: Wenn Barbarina in der von ihr imaginierten Szene sich selbst spielt, singt sie in einfachem Buffa-Ton, während sie in der (natürlich ebenfalls von ihr gesungenen) Antwort des Offiziers eine affektiert wirkende, durch kleinere Notenwerte charakterisierte punktierte Melodie verwendet, wodurch der Standesunterschied zwischen den beiden Dialogpartnern verdeutlicht wird.
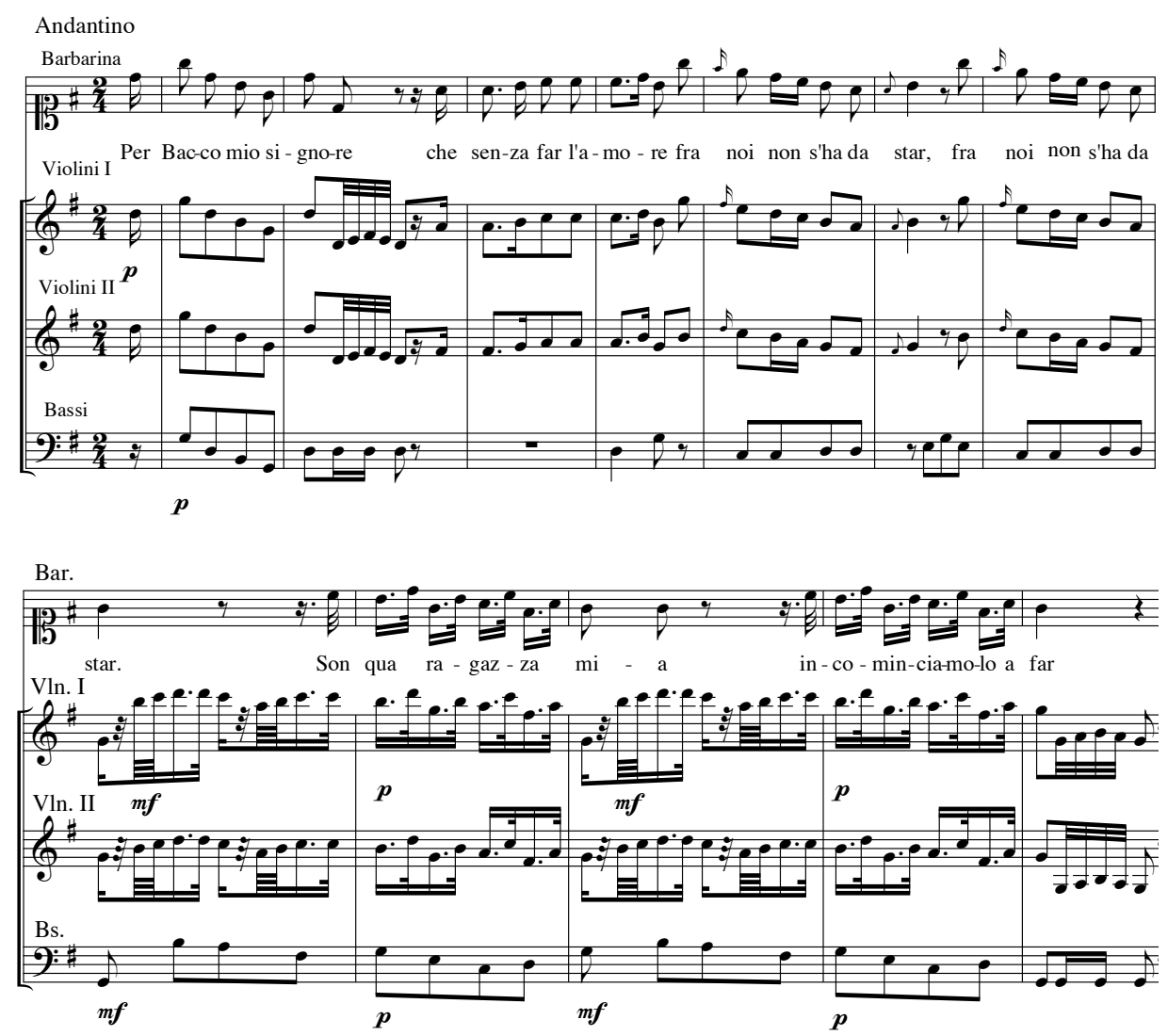

41 Anfossi/Bertati: La forza delle donne. 1778 (I-BGc C.2.23/1-2) 
Je höher der militärische Grad desto langsamer die Musik: Die dritte Mikro-Szene, in der Barbarina den General verführt, steht im Larghetto und im seltenen 12/8-Takt. Der feierliche Duktus spiegelt dabei die von Barbarina bewunderte „fortezza“ (Stärke) und den „valore“ (Tapferkeit) des Generals. Barbarina spricht ihn ehrfürchtig mit „Eccellenza“ an und bittet darum, ihm die Hand küssen zu dürfen. Der Dialog mit dem General, in dem sie erneut beide Rollen spielt, dauert am längsten und endet mit respektvollen Seufzern, an deren Wirkung Barbarina aber nicht zu zweifeln scheint.

Über die Imagination von Kindern und Erwachsenen schreibt Kendall Walton: „It is my impression that virtually all of our imaginings are partly about ourselves. (...) I am inclined to think that imagining is essentially self-referential." ${ }^{649}$ Im Fall von Barbarinas imaginierter Szenenfolge trifft, im Gegensatz zu Don Perichettos Katzenszene, diese Feststellung zu, denn die Bäuerin stellt sich selbst als mit besonderen Fähigkeiten ausgestattet vor. In den imaginierten Dialogen spielt sie sich selbst in Interaktionen mit drei verschiedenen Männern, die in ihrer Vorstellung so reagieren, wie sie es sich wünscht. Wie in vielen anderen, von Buffa-Figuren imaginierten Szenen findet hier das für das Spiel typische „spielende Durchkosten von Lebensmöglichkeiten“650 statt, das auch als "Simulation“ oder „Erprobungsspiel“ definiert werden kann. ${ }^{651}$

Wie es häufig in der Opera buffa der Fall ist, wird die imaginierte Szene abwechselnd narrativ, in Form von Beschreibungen und Kommentaren, vermittelt und durch Rollenspiele, also durch in direkter Rede wiedergegebene Dialoge, vergegenwärtigt. Genau genommen spielt in dieser Arie Barbarina fünf verschiedene Rollen: die der außenstehenden Erzählerin, die der drei verschiedenen Männer und ihre eigene Rolle in den imaginären Dialogen, wobei sie ihre Verhaltensweise der jeweiligen Situation und dem jeweiligen Gegenüber anpasst. Die Sängerin muss nicht nur die verschiedenen Rollen spielen, sondern auch sehr schnell zwischen den Rollen wechseln können. Besonders eng beieinander liegen diese Sprünge im Vers „Tu chi sei? Son fanciulla, rispondo", in dem wenige Worte auf drei verschiedene Rollen aufgeteilt sind, die des Generals, die der Barbarina und die der Erzählerin. Die Wendigkeit, mit der Barbarina in dieser imaginierten Szene zwischen verschiedenen Rollen hin und her wechselt, ist ein in der Opera buffa charakteristisches Zeichen für Schlauheit und Geschicktheit. Tatsächlich wird sie auch in der auf der Bühne dargestellten Realität am Ende der Handlung die gebildeteren Frauen aus höheren Ständen übertreffen und aufgrund ihrer Verführungskünste alleine für den Sieg der Frauen gegen die Männer verantwortlich sein. Die in der imaginierten - man könnte auch sagen simulierten - Verführungs-

649 Walton, S. 28.

650 Groos: Das Spiel. Zit. nach Scheuerl: Theorien des Spiels. S. 72.

651 Vgl. Rapp: Handeln und Zuschauen. S. 128. 
szene geäußerte Wunschvorstellung bewahrheitet sich also am Ende der Oper, woraus ersichtlich wird, wie eng imaginierte, von der primären Fiktionsebene abgehobene Szenen mit der eigentlichen Handlung der Oper verknüpft sein können. Das ist in der Opera buffa natürlich vor allem bei realitätsnahen Imaginationen der Fall, während die wesentlich selteneren phantasievollen Vorstellungen, wie die der imaginierten Katzenszene des Don Perichetto, von der Opernhandlung eher losgelöst erscheinen.

Die Gemeinsamkeit der beiden untersuchten imaginierten Szenen liegt dagegen in ihrer theatralischen Funktion und Wirkung im Sinne einer lustvollen Distanzierung. Durch die Sichtbarmachung des Rollenspiels als solches und im ersten Fall zusätzlich durch die Thematisierung von Musik wird der Spielcharakter der Theatersituation bewusst gemacht. In beiden Fällen ist es die Darstellung des Eintritts in die Welt des Spiels und der „Enthebung aus der reellen Weltwirklichkeit“, ${ }^{652}$ die den Zuschauer von der primären Handlung distanziert und ihn an die Theatersituation erinnert, denn es handelt sich um das Spiel und die dazugehörige Enthebung der Buffa-Figuren aus ihrer Realität, also aus der auf der Bühne dargestellten Wirklichkeit. Einerseits bewirkt diese Verschachtelung von „Welten“ bzw. von „Spielen“ im Zuschauer eine Distanzierung gegenüber dem gesamten Geschehen auf der Bühne, andererseits empfindet der Zuschauer die Lust der fiktiven Figuren am Phantasieren und ihre Freude am Imaginieren einer „anderen Welt“ nach, identifiziert sich also mit ihrem Phantasiespiel und ,imaginiert mit“, indem er die von der jeweiligen Bühnenfigur nur erzählte bzw. in Ansätzen dargestellte imaginierte Szene in seiner eigenen Vorstellung ergänzt. Die Verwicklung des Zuschauers in ein zusätzliches Imaginationsspiel macht also unter anderem den besonderen Reiz solcher imaginierter Szenen gegenüber anderen Formen von „Spiel im Spiel“ aus.

\subsection{Mimicry als Fingiertheit: Verstellungsspiele in "La Frascatana“}

Imaginierte Szenen haben einlageartigen Charakter, es sind abgeschlossene, meistens auf eine Arie bzw. eine musikalische Nummer beschränkte Sequenzen, die in der Vorstellung der fiktiven Figuren stattfinden. Als-ob-Spiele, die dagegen laufend innerhalb der primären Fiktionsebene vorkommen, sind die nicht nur für komische Gattungen typischen Verstellungsspiele. Genau genommen basieren die meisten in der Opera buffa enthaltenen Als-ob-Spiele sowie jedes Rollenspiel auf Verstellung: Villotto verstellt sich, um Donna Aurora am Toilettentisch nachzuahmen, genauso verstellt Don Perichetto seine Stimme, um „con la voce del gatto“ den Gesang der imaginären Katzen darzustellen. $\mathrm{Zu}$ den Verstellungsspielen schreibt Pfister: „Auch hier spielen die Figuren 
des Spiels zusätzliche Rollen vor anderen Figuren, doch sind diese Rollen nicht fiktional, sondern fingiert. "653 Der Unterschied besteht nach Pfister darin, dass Fiktionalität im Gegensatz zur Fingiertheit „nicht Täuschung intendiert, sondern gerade auf einer Übereinkunft zwischen Spielern und Zuschauern über den besonderen ontologischen Status des Spiels, seine Scheinhaftigkeit, beruht. "654 Diese Aussage erscheint mir etwas problematisch: Wären also beispielsweise die in Verkleidungsszenen zur Täuschung und Burla einer ahnungslosen Figur gespielten Rollen nicht fiktiv bzw. fiktional?

Die Verstellungsspiele, um die es hier geht, haben meistens die dramaturgisch unerlässlichen Funktion, andere Figuren auf der Bühne bewusst zu täuschen und so die für jede Opera buffa oder Komödie nötigen Missverständnisse und Informationsunterschiede zwischen den verschiedenen Figuren herbeizuführen. Das von Huizinga theoretisierte Spielkriterium des „Ziels in sich selbst“, also der "Selbstzwecklichkeit“ des Spiels, ist bei Verstellungen nicht gegeben. Trotzdem können Verstellungen höchst spielerisch sein - Pfister selbst spricht von Verstellungsspielen ${ }^{655}$ - und als Alsob-Spiele definiert werden; auch in ihnen findet eine Potenzierung des Spielcharakters durch fingiertes Spiel im fiktiven Spiel ${ }^{656}$ statt. Verstellungen bewirken außerdem die für das Spiel als charakteristisch festgestellte Ambivalenz, ${ }^{657}$ denn es entsteht eine „Hin- und Herbewegung“ zwischen zwei Rollen, zwischen einer „echten“ und einer "gespielten“. In der Regel ist bei Opere buffe das Publikum über die Verstellungen informiert: Oft werden sie schon im Titel angekündigt ${ }^{658}$ oder im Personenverzeichnis angegeben. Der Zuschauer kann so den Überblick über die stattfindenden Täuschungen behalten und sich seiner überlegenen Position erfreuen. In vielen Fällen wird die Ambivalenz jedoch erst im Nachhinein mit der Mitteilung über eine stattgefundene Verstellung oder manchmal sogar überhaupt nicht aufgelöst, so dass das Publikum oft bis zum Schluss in der Ungewissheit bleibt.

Letztere Möglichkeiten können am Beispiel von „La Frascatana“, einer besonders erfolgreichen $^{659}$ Oper von Giovanni Paisiello und Filippo Livigni, erläutert werden, die im Herbst des Jahres 1774 im Teatro San Samuele in Venedig uraufgeführt und I782 im San Moisè wiederaufgenommen wurde. Die Handlung von „La Frascatana“ dreht sich, wie der Titel besagt, um ein Mädchen aus Frascati (bei Rom), Violante, in

653 Pfister, S. 306.

654 Ebd.

$655 \mathrm{Vgl}$. ebd.

656 Vgl. Martini, S. 321.

657 Scheuerl: Theorien des Spiels. S. 204.

658 „La finta giardiniera“, „La finta cingara per amore“, „Le due finte gemelle“ etc.

659 „La Frascatana“ wurde nach ihrer Uraufführung in Venedig bis zum Ende des 18. Jahrhunderts in über 50 italienischen und europäischen Städten aufgeführt. 
das sich abgesehen von einem Diener alle Männer der Dramatis personae verlieben. Ihr tutore Don Fabrizio, der - wie die Konvention der Opera buffa es jedem Vormund „vorschreibt“ - in sie verliebt ist, beschreibt sie noch vor ihrem Auftritt als „d'amore nemica“ und „semplicetta un poco“. Diese Charakterisierung entspricht dem Typus des unschuldigen, einfältigen und unerfahrenen jungen Mädchens, und Violantes erster Auftritt bestätigt dieses Bild: Sie betritt nämlich Blumen pflückend und eine fröhliche Cavatina singend („Giovinette semplicette“) die Bühne. Schon diese Auftritts-Cavatina birgt eine gewisse Ambivalenz in sich: Das Thema ist eine Warnung an die einfachen Mädchen vor Amor, der Liebe, die denen, die sich ihr hingeben, die Freiheit entzieht. Es stellt sich dabei die Frage, ob Violantes fröhlicher Ton und ihre Überlegenheit gegenüber Amor auf ihre Naivität oder auf Welterfahrenheit zurückzuführen sind. Ihre Worte im Anschluss an die Cavatina erklären dies nur teilweise:

Mi son finta semplice

Per burlarmi del mio sciocco Tutore,

Che pretende con me fare all'amore. ${ }^{660}$

Hier gesteht Violante, sie habe sich nur „semplice“ (naiv, einfältig) gestellt („finta“), um ihren dummen tutore, der sie zur Liebe zwingen will, an der Nase herumzuführen (burlare). Diese Mitteilung über ihre Verstellung lässt sie als pfiffiges und ganz und gar nicht naives Mädchen erscheinen.

Unmittelbar darauf tritt der Schäfer Nardone auf. Er singt ebenfalls eine Cavatina, die sich um dasselbe (in der Opera buffa allgegenwärtige) Thema dreht: „Amor non so che sia / Ma so ch'è un traditor". Nardone ist vor Amor schon gewarnt worden, kennt aber die Liebe noch gar nicht und würde sich gerne verlieben. Violante findet ihn anziehend, spielt aber, wie sie da parte dem Publikum verrät, weiterhin das unschuldige Mädchen. Dasselbe Verstellungsspiel geschieht hier aus einem anderen strategischen Grund, durch die fingierte semplicità stellt sich Violante nämlich auf dieselbe Ebene wie der hübsche und unerfahrene Jüngling, den sie durch diese Taktik erobert:

(Grazioso veramente

Ma d'esser fingiam sempre innocente. $)^{661}$

660 Livigni/Paisiello: La Frascatana. Venedig 1774 (I,3).

661 Ebd. 
Die Begegnung der beiden, die zum Schluss heiraten werden, findet in einem von der schlauen Violante eingeleiteten Spiel statt: Sie spielt das schamhafte Mädchen, das sich nicht traut einen fremden Jüngling anzuschauen, und in dieser Rolle spielt sie wiederum ein Spiel, das sich als eine Art „Kennenlernspiel“ erweist und in einem Gespräch ohne Augenkontakt mit einander zugewandtem Rücken besteht. Dieses spontane und unkonventionelle Spiel kann einerseits den „asketischen Spielen“ zugeordnet werden, einer Art von Selbstbeherrschungsspielen, „,bei denen man sich nicht bewegen, nicht lachen, nicht schreien, nicht atmen darf" ${ }^{\prime 66}$ andererseits handelt es sich um den damit verwandten und schon erwähnten Typus der „Spiele mit willkürlicher Regel“, bei denen das Spiel darin besteht, eine bestimmte, willkürlich gewählte Regel zu befolgen. Hier ist die Regel eine spontane Erfindung der schlauen Frascatana - die besagt, dass kein Augenkontakt zwischen ihr und dem Jüngling bestehen darf - und ist ein Mittel, um die fingierte Kindlichkeit und Schamhaftigkeit glaubwürdig erscheinen zu lassen.

Violante macht sich einen Spaß daraus, den ahnungslosen Nardone in dieses Spiel zu verwickeln - da parte bemerkt sie „Io crepo dalle risa“ -, aber auch Nardone macht das Kennenlernspiel Spaß („Oh questo sì ch’egl'è vero spassetto.“), vor allem weil er glaubt, Violante spiele es wirklich aus reiner Scham. Er merkt nicht, dass dieses „Spiel mit willkürlicher Regel“ Teil eines Verstellungsspiels ist. Die ganze Szene könnte auch als eine Art Liebesspiel interpretiert werden, Violantes falsche Einfalt als Flirt und Koketterie, die der Liebeswerbung und Eroberung dient. Der Dialog mit einander zugekehrtem Rücken würde dann die für das Liebesspiel typische Funktion der Verzögerung annehmen, denn er würde das sich aus der natürlichen Anziehungskraft ergebende Sichanschauen-Wollen aufschieben.

Violante führt ihr Verstellungsspiel weiter, auch nachdem das Spiel des Dialogs mit einander zugekehrtem Rücken beendet ist und die beiden sich einander zugewendet haben, bis zu ihrer Arie "Son fanciulla e tanto basta“. In dieser Arie verkörpert Violante den Topos des unschuldigen Mädchens, das die ersten Anzeichen einer Verliebung fühlt und beschreibt, aber nicht deuten kann.

Son fanciulla e tanto basta;

Non sò far la fraschettona;

Sono stata sempre buona,

Né malizia non v'è in me.

Ma per voi a dirla schietta,

Sento un certo pizzicore ...

662 Château, S. 19. 
Una specie di calore ...

Per esempio ... No che sbaglio ...

Voglio dir ... Né pur va bene ...

Come fosse ... l'ho trovata:

Priggioniera, sventurata

Divenuta son per te. ${ }^{663}$

Die Arie wirkt im ersten Moment wie die Weiterführung und der Höhepunkt von Violantes Verstellungsspiel: Sie beschreibt sich als einfältiges, gutmütiges, zur Lüge und zur Arglist unfähiges junges Mädchen ${ }^{664}$ und zeigt sich dann verwirrt über ein neues unbekanntes Gefühl, das sie als „pizzicore“ (Jucken), Hitze und Sich-gefangenFühlen beschreibt.

Die Eigenschaften der semplicità, der Gutmütigkeit bzw. Güte und Arglosigkeit, mit denen sie angibt, erscheinen zunächst nicht glaubwürdig und lassen auch an der Aufrichtigkeit der daraufhin geäußerten Gefühlen zweifeln. Ein Mädchen, das sich so geschickt einen Jüngling um den kleinen Finger wickeln kann, wird sich nicht unmittelbar darauf so naiv und hilflos verlieben. Im Nachhinein wird man sich aber der Ambivalenz der Arie bzw. der Figur der Frascatana bewusst, als diese für sich selbst einige Szenen später von ihrer Liebe zu Nardone spricht:

Quando Nardon non vedo

Non sò trovar più pace. Oh quanto è caro!

Quanto mi dà piacer! ${ }^{665}$

Es stellt sich zwar die Frage, ob diese Worte ehrlich gemeint sind oder nur ehrlich erscheinen, aber nachdem Violante sie ausspricht, als sie allein zu sein meint, würde man an die Echtheit ihrer Liebe zu Nardone glauben. Findet in der Arie „Son fanciulla e tanto basta" demnach nur scheinbar eine Verstellung statt? Mit Sicherheit kann man behaupten, dass Violantes Benehmen eine vollkommene Ambivalenz an den Tag legt.

Bevor am Ende Violante und Nardone tatsächlich aus Liebe heiraten, treibt die Frascatana allerlei Verstellungsspiele mit allen Männern, die sie begehren. Gerade dieses Spielen, das Violante sehr genießt, macht sie so undurchschaubar und anzie-

663 Livigni/Paisiello: La Frascatana. Venedig 1774 (I,3).

664 Die Verwendung des Wortes fraschettona, leichtes flatterhaftes Mädchen, lässt an ein Wortspiel mit dem Titel Frascatana, Bewohnerin von Frascati, denken.

665 Livigni/Paisiello: La Frascatana. Venedig 1774 (I,9). 
hend. Von ihrer spielerischen und lustvoll erlebten Ambivalenz zwischen Ehrlichkeit der Gefühle und Verstellung geht eine außerordentliche Faszination aus, die unter anderem für den großen Erfolg dieses Werks in ganz Europa ausschlaggebend gewesen sein könnte, denn die gesamte Oper steht im Zeichen dieser spielerischen Mehrdeutigkeit.

Die Handlung wird zwar hauptsächlich von den Spielen der Frascatana getragen, aber alle übrigen Figuren spielen und verstellen sich ebenfalls, wenn auch auf eine weniger virtuose, das heißt auf eine (wenigstens für das Publikum) explizitere und weniger ambivalente Art und Weise. Ein Beispiel dafür bietet Lisetta, die den Typus der schlauen Dienerin verkörpert. Sie ist am Cavaliere interessiert, der aber in Violante verliebt ist und die Dienerin gar nicht beachtet. Als Letztere zufällig seinen Diener Pagnotta trifft, der Violantes Portrait in der Hand hält, erkennt sie sofort die Möglichkeit einer Intrige und überredet Pagnotta, ihr das Portrait anzuvertrauen. Um Pagnottas Vertrauen zu gewinnen, singt sie eine Arie über ihre Verlässlichkeit. Dass sie dabei nicht die Wahrheit ausspricht, sondern nur so tut als ob, erfährt man unmittelbar darauf, als sie in derselben Arie da parte Pagnottas Dummheit und Leichtgläubigkeit verspottet.

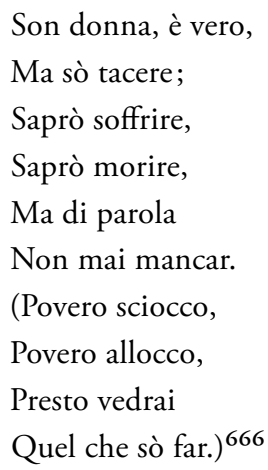

Nach Kippers allgemeiner Systematik würde diese Arie zu den „Argumentationsarien“ zählen, in denen eine „Figur ein konkretes Gegenüber anspricht und zu beeinflussen versucht“ ${ }^{667}$ In diesem Fall handelt es sich allerdings um einen speziellen, sehr weit verbreiteten Arientypus, in dem nicht nur ein Gegenüber angesprochen und überredet wird, sondern dann da parte erklärt wird, dass gerade eine Verstellung stattgefunden hat. Man könnte diesen Typus, in dem Täuschung und Wahrheit innerhalb

666 Ebd. (I,5).

667 Kipper, S. 193. 
einer einzigen Arie direkt gegenübergestellt werden, als ,janusköpfige Arie“ und als Inbegriff der für die Opera buffa typischen offengelegten Verstellung bezeichnen.

Die Verstellung ist in dieser Gattung nicht nur eine Strategie der „Schlauen“, denn nahezu alle Figuren versuchen durch diese List ihre Ziele zu verwirklichen. Nicht bei jeder Verstellung ist es notwendig, eine neue Persönlichkeit anzunehmen oder seinen Charakter zu verstellen. Die Verhüllung der eigenen Identität kann schon als Verstellung gelten, denn die Person tut so, als wäre sie nicht sie selbst. Diese Täuschungsstrategie wendet der „sciocco tutore“ bei allen zufälligen Begegnungen mit den Anbetern seines Schützlings an: Dabei hält er stets seine Identität geheim und spricht von Violantes tutore in dritter Person, wodurch selbstverständlich Missverständnisse entstehen.

Ähnlich benimmt sich Pagnotta, als er die Verlobte seines Herrn trifft, die von der Untreue ihres Bräutigams erfahren hat und sich dafür rächen will. Pagnotta hüllt sich - wie es in der Regel ängstliche Diener tun - in Unschuld, gibt seine Identität nicht preis und behauptet, der Cavaliere sei schon abgereist. Später rät der vorsichtige, aber weitblickende Diener seinem Herrn, er solle sicherheitshalber Donna Stella nicht abweisen, sondern Liebe vortäuschen.

Ma per poter salvar la Capra, e i Cavoli,

Fingete almeno amor con Donna Stella. ${ }^{668}$

Der Cavaliere befolgt diesen Ratschlag, was einige Szenen später erneut zu einer an Donna Stella gerichteten ,janusköpfigen Arie“ führt.

Belle luci vezzosette

Quanto oh Dio, che m'accendete:

Siete voi, e voi sarete,

La mia calma il mio piacer.

(Sei matta se mi credi

Sei sciocca se ti fidi;

Dispetto tu mi fai,

Non ti poss'io veder. $)^{669}$

Dieser Typus eignet sich hervorragend für die in der Opera buffa so häufige zweiteilige Arienform: Im ersten Teil findet die Verstellung statt, in einem neuen musikalischen

668 Livigni/Paisiello: La Frascatana. Venedig $1774(\mathrm{II}, 2)$.

669 Ebd. (II,9). 
Abschnitt wird da parte die Wahrheit mitgeteilt. Die Zweiteiligkeit des Textes kann direkt in musikalische Zweiteiligkeit übertragen werden, so wie es in der Arie „Belle luci vezzosette“ der Fall ist. Der erste Vierzeiler enthält eine Liebeserklärung des Cavaliere an Donna Stella und wird von Paisiello als elegisches Larghetto im 3/4-Takt vertont.

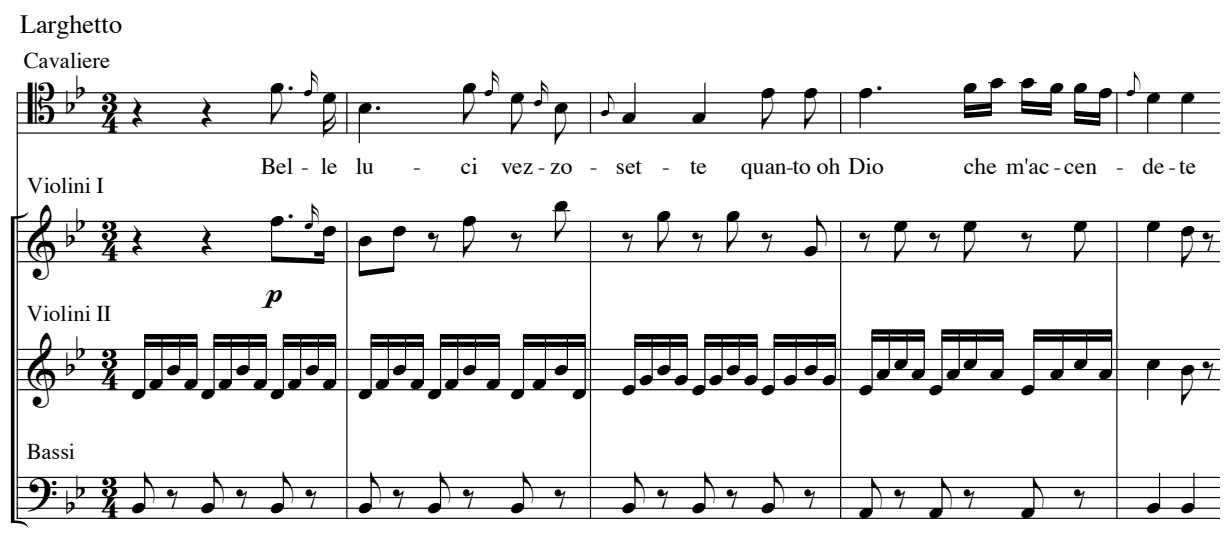

42 Paisiello/Livigni: La Frascatana. (I-Mc Part. Tr. Ms. 308)

Im zweiten Vierzeiler singt der Cavaliere, was er wirklich denkt: Er kann Donna Stella nicht ausstehen; ihre Leichtgläubigkeit ist seiner Meinung nach ein Zeichen von Dummheit und zugleich Verrücktheit. Die Da-parte-Aussprache der wahren Gedanken geschieht im Allegro und im 2/4-Takt.

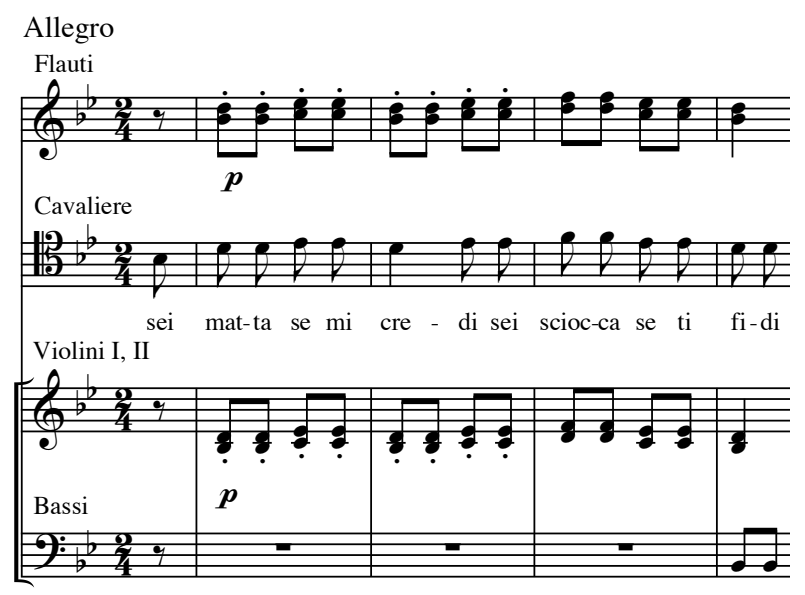

43 Paisiello/Livigni: La Frascatana. (I-Mc Part. Tr. Ms. 308) 
Hier wird der Gegensatz zusätzlich durch einen Stilbruch verdeutlicht: Der erste Abschnitt ist sowohl im Text als auch in der Musik eher im Seria-Stil gehalten. Die ernst klingende Liebeserklärung wird unmittelbar darauf durch den raschen und buffohaften zweiten Abschnitt relativiert, in dem die Falschheit der Liebeserklärung enthüllt wird. Der Seria-Ton in Text und Musik erweist sich als geheuchelt, als Maske, denn der Cavaliere ist keine wirklich ernste Figur. Die verschiedenen Stile stehen hier für verschiedene Rollen, die der Cavaliere spielt, eine „falsche“ Seria-Rolle und eine „authentische" Buffa-Rolle.

Es stellt sich im Allgemeinen die Frage, inwieweit eine Verstellung als Spiel definiert werden kann, denn die Grenzen zwischen Als-ob-Spiel und Täuschung bzw. Betrug sind manchmal verschwommen. Kann beispielsweise das Benehmen des Cavaliere gegenüber Donna Stella noch als Spiel gelten? Selbst wenn man die Flatterhaftigkeit und Unernsthaftigkeit des Cavaliere als „spielhaft“ ansehen möchte, schwingt immer ein Gefühl von „Betrug“ mit. Andererseits besitzt der Spielbegriff durchaus auch eine negative Konnotation und man könnte ohne weiteres behaupten, der Cavaliere spiele ein Doppelspiel, indem er gegenüber Donna Stella die Rolle des Verliebten spielt.

Bei den Täuschungen des tutore ist es noch schwieriger, von einem Spiel zu sprechen. Der bösartige Intrigant beabsichtigt mit seinen Verstellungen die Verhinderung der Liebesbeziehung zwischen Nardone und Violante zu seinem eigenen "schlechten“ Zweck: Er als alter Mann will ein junges naives Mädchen zur Hochzeit zwingen, wenn notwendig auch mit Gewalt. Bei der Entlarvung einer seiner Intrigen ruft Nardone aus: „Ah viso a due faccie, ah mentitore!"670 Die „Janusköpfigkeit" wird hier eindeutig als negativ empfunden, und Don Fabrizio wird offen als Lügner beschimpft. Dadurch fühlen sich die anderen Figuren dazu berechtigt, mit dem bösen und wenig intelligenten Don Fabrizio Spiele zu treiben, die größtenteils auf lustigen und harmlosen Verstellungen beruhen.

Wer den tutore am meisten durch Verstellungsspiele aufs Korn nimmt, ist die pfiffige Violante. Um im zweiten Finale beispielsweise bei der unerwünschten Begegnung im Dunkeln dem tutore unerkannt zu bleiben und ihn auf die falsche Fährte zu locken, hat sie den Einfall, in vier unterschiedlichen Sprachen zu sprechen, um die Anwesenheit mehrerer Menschen vorzutäuschen. Das verwirrt Don Fabrizio, der sich ängstlich entfernt.

Viol. (Or vedrai quel che farò.)

(...)

Viol. Chi vaglià?

670 Ebd. (II,7). 
D.F. Un Spagnol! ...

Viol. Zerrucche tu!

D.F. Un Tedesco! ...

Viol. Où allez vous?

D.F. Un Francese! ...

Viol. Alakalà.

D.F. Anche un Turco! ... e come mai

Tanta gente adesso qua. ${ }^{671}$

Violante treibt ihr virtuoses Verstellungsspiel hier auf die Spitze: durch „sprachliche Verkleidung" und Verstellung der Stimme spielt sie innerhalb kürzester Zeit vier verschiedene Rollen. Musikalisch ist dieses Spiel in eine Sequenz umgesetzt, wobei bei jedem „Rollenwechsel“ das sequenzierte Motiv auf einer neuen Tonstufe und in einer neuen Tonart erscheint: So ergibt es sich, dass Violante sich auf Spanisch in Es-Dur ausdrückt, auf Deutsch in c-Moll, als Franzose in As-Dur und als Türke in f-Moll singt. Die verschiedenen Tonarten aber vor allem die unterschiedlichen Tonhöhen in Violantes Melodie unterstützen die Differenzierung der Ausrufe, so dass der Eindruck verstärkt wird, es handle sich tatsächlich um Stimmen von vier unterschiedlichen Personen.

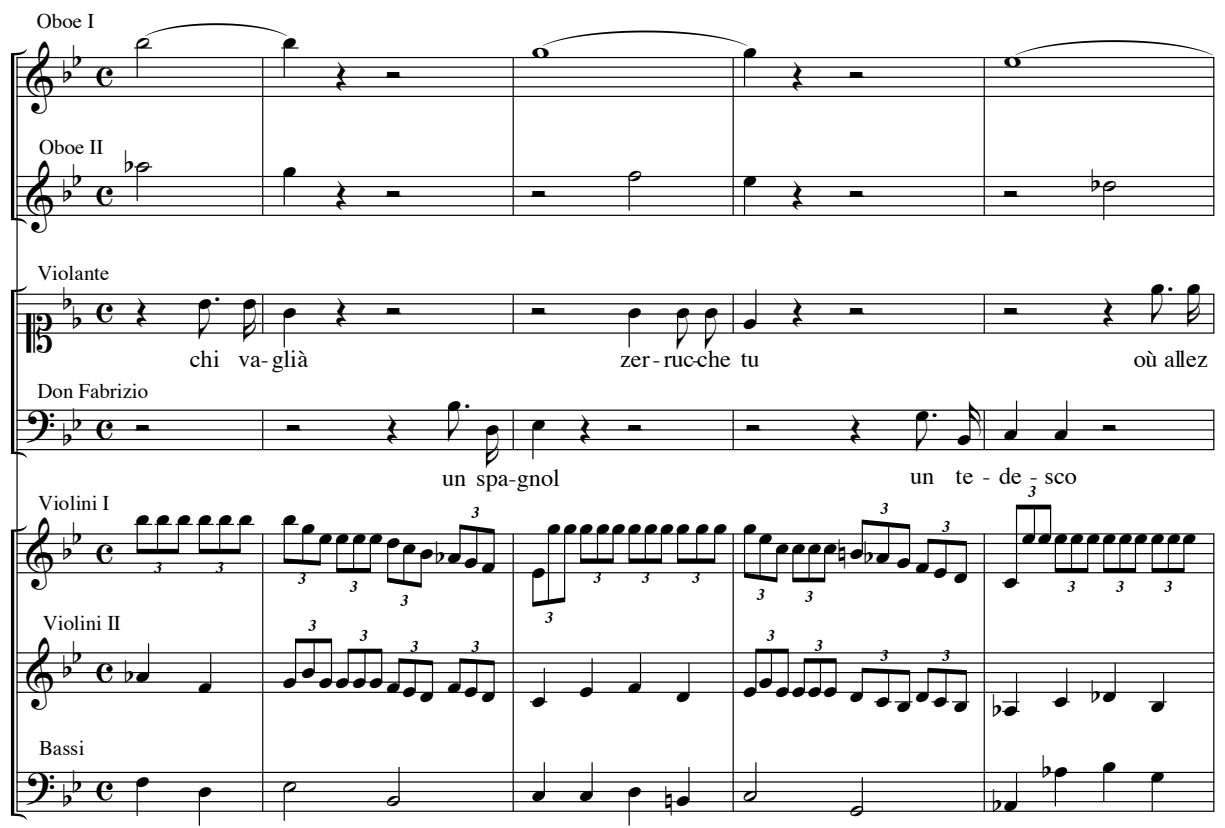

671 Ebd. (II,21). 


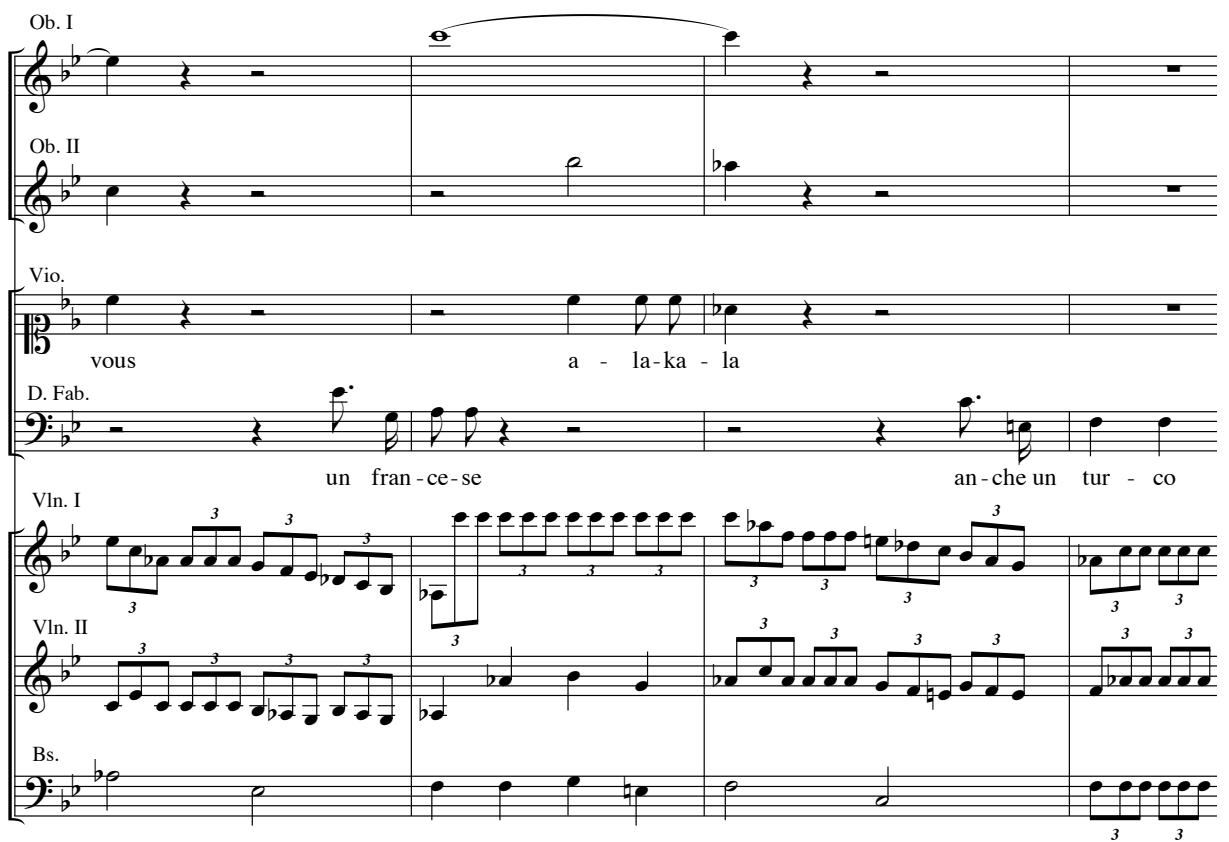

44 Paisiello/Livigni: La Frascatana. (I-Mc Part. Tr. Ms. 308)

Nicht nur an dieser Stelle, sondern während der gesamten Handlung beweist Violante, mit welch spielerischer Souveränität und Geschicktheit sie das Verstellungsspiel beherrscht. Mit allen Männern, die sie begehren, treibt sie ein Spiel, vor allem aber hält sie ihren tutore zum Besten, der sie bis zum Schluss für ein vollkommen unschuldiges naives Mädchen hält, bis sie ihn endlich über ihre Verstellung aufklärt:

D.F. Capisco; ma siccome Tu sei sì semplicetta ...

Viol. Eh, v'ingannate:

Se semplice mi finsi,

Fu sol che il genio mio,

Col vostro non poteva andar d'accordo. ${ }^{672}$

Trotz dieses Geständnisses kann ihre Unschuld nicht immer nur als gespielt und ihre Überlegenheit und Listigkeit als wahr angesehen werden. Die Frascatana ist eine echte

672 Ebd. (III,5). 
„Spielerin“ und verkörpert auf eine sehr ambivalente Weise zwei gegensätzliche und in der Opera buffa außerordentlich beliebte Frauentypen: einerseits - ähnlich wie die schlaue Bäuerin Barbarina aus der schon erwähnten Oper „La forza delle donne“ den Typus des gewieften, souveränen Mädchens, das alle hereinzulegen vermag; andererseits den Cecchina-Typus, die personifizierte Unschuld und Ehrlichkeit. Letzterer ist teilweise, wie sie selbst zugibt, nur gespielt, was zum etwas verwirrenden Paradox der gespielten Ehrlichkeit führt. Oft herrscht allerdings Unklarheit darüber, ob die Unschuld wirklich nur gespielt ist. Beispielsweise in der Szene, in der Don Fabrizio sie zu Unrecht, ja mit Gewalt in einen Turm einsperrt, scheint Violante wirklich erschrocken und ängstlich zu sein. An dieser Stelle singt sie eine Arie („Dove son ... che cosa è questa ..."), in der sie über ihre Angst und ihr Zittern spricht, die vollkommen dem Topos der zu Unrecht schlecht behandelten, im Wald verlaufenen incognita perseguitata entspricht. ${ }^{673}$ Auch Violantes Verlieben in Nardone scheint ehrlich zu sein, obwohl sie bis zum Schluss mit ihm „spielt“ und ihn zappeln lässt. Oder beherrscht sie selbst in den „ehrlichen“ Szenen die Rolle des naiven Mädchens so hervorragend, dass ihre Gefühle glaubwürdig erscheinen, aber nicht echt sind? Allein, dass man sich überhaupt diese Frage stellen kann, zeugt von der als typisch für das Spiel festgestellten labilen Ambivalenz. ${ }^{674}$ Es ist die Gleichzeitigkeit bzw. das unberechenbare Kippen von einem Frauentypus zum anderen, das den Reiz dieser Figur ausmacht und ein undurchschaubares Spiel zwischen Sein und Schein auf die Bühne bringt. Obwohl die Fähigkeit, sich unterschiedliche Rollen zu eigen zu machen, zum Grundwesen des Menschseins ${ }^{675}$ gehört und somit nicht weiter verwundern sollte, dürfte für das an die eher typenhaften Figuren der Opera buffa gewöhnte venezianische Publikum dieses „Kippen“ besonders reizvoll gewesen sein, denn die beiden Frauentypen, die Violante verkörpert, sind derart gegensätzlich, dass sie eigentlich im Sinne der Konvention einander ausschließen würden. Es handelt sich um die zwei beliebtesten Frauentypen, die das Publikum aus unzähligen Opere buffe sowie Komödien der Zeit kennen musste. Wenn, wie es häufig in der Buffa vorkommt, alle männlichen Figuren in dieselbe Frau verliebt sind, entspricht diese in der Regel einem der beiden genannten Typen. In „La Frascatana“ sind sie in einer einzigen Figur miteinander verquickt, wodurch aus

673 In Anfossis Oper „L'incognita perseguitata“ beginnt das erste Finale mit einer solchen Szene und die ersten Worte der incognita („Dove vado ... tremo tutta“) sowie die daraufhin geäußerten Gefühle sind denen in Violantes Arie „Dove son ... che cosa è questa ..." erstaunlich ähnlich. Vermutlich entsprechen sie einem aus der Commedia dell'arte überlieferten Topos, und die Anfangsformel einem standardisierten Einstieg in eine solche Szene. Ab den 1760er Jahren brach eine regelrechte Cecchina-Modewelle aus, die von Piccinnis Oper „La buona figliuola“ (Rom 1760) ausgelöst wurde.

674 Vgl. Scheuerl.

675 Vgl. Rapp: Handeln und Zuschauen. S. $54 f$. 
wirkungsästhetischer Sicht ein doppelter Reiz entsteht: Das von Mary Hunter festgestellte „pleasure of the familiar“, nämlich die Lust am Wiedererkennen von familiären Mustern, vermischt sich hier mit dem für das Spiel charakteristischen Reiz des Ambivalenten, des Uneindeutigen, wodurch ein besonders lustvolles "Schweben“ hergestellt wird, das hier auf die Spitze getrieben wird: Violante ist in ihrer Fähigkeit zur Mimicry extrem „virtuos“ und führt die höchste Stufe des Verstellungsspiels vor, nämlich die der perfekten Verkörperung von zwei gegensätzlichen Rollen. Man könnte auch behaupten, ihre Verstellungskunst sei gerade deswegen so perfekt, weil sie in Wirklichkeit die zu ihrer Persönlichkeit gehörenden Rollen spielt, also im Grunde genommen stets „sie selbst“ ist. In diesem Fall würde ihr Rollenspiel, abgesehen von dem Spiel der vier Fremden im zweiten Finale, gar keine Verstellung voraussetzen, was wiederum ihre eigenen Aussagen „mi son finta semplice“ und „semplice mi finsi“ widersprechen würde. Eine eindeutige Lösung dazu kann es offensichtich nicht geben, allenfalls bleibt es bei der Feststellung einer starken Ambivalenz.

\subsection{Mimicry als Verkleidung}

Ebenfalls auf Verstellung beruhen die in der Opera buffa sehr beliebten Verkleidungsszenen. Während bei anderen Formen der Verstellung häufig nur Charaktereigenschaften oder Gefühle vorgetäuscht werden - die Frascatana beispielsweise täuscht semplicità vor, Lisetta täuscht Pagnotta Ehrlichkeit und Vertrauenswürdigkeit vor, der Cavaliere täuscht Donna Stella Liebe vor - werden bei Verkleidungen ganze Rollen gespielt. Das Als-ob betrifft die ganze Person, es findet eine Identitätstransformation statt, die häufig durch Kostümierung sichtbar gemacht wird; aufgrund der Fiktivität der gespielten Rolle entsteht eine der primären Spielebene untergeordnete, zweite Fiktionsebene. Häufig im Rahmen einer Burla eingesetzt haben Verkleidungsszenen in der Dramaturgie der Opera buffa meist eine handlungsvorantreibende Funktion und bewirken generell eine heitere, spielerische Atmosphäre auf der Bühne; ihre Wirkung reicht aber noch viel weiter, denn sie bieten vielfältige Möglichkeiten für die Herstellung von Außenbezügen. Als karnevaleskes Element ruft die Maskierung den außerhalb von der Bühne stattfindenden Karneval in Erinnerung, wobei der nicht unrealistische Eindruck vermittelt wird, dass nicht nur auf der Bühne und im Theater, sondern überall in der Außenwelt eine spielerische Stimmung herrscht. Während dies bei den meisten Verkleidungsszenen auf eine sehr diffuse Art geschieht, steht der Bezug zum Karneval bei den Verkleidungen, in denen das Tragen einer Maske explizit gemacht wird und den anderen Figuren auf der Bühne bewusst ist, sehr stark im Vordergrund. Dies ist beispielsweise im zweiten Finale von Anfossis Oper „Il geloso in cimento" der Fall, in dem alle Figuren zum Spaß maskiert auf die Straße gehen. 
Donna Flavia kündigt die Maskierung als Zeitvertreib und Spiel an („Oggi pertanto / in Maschera vò andarmi a divertirmi, / Osservando per gioco gli andamenti / De' miei amanti, o siano poi Serventi. “676) und verkleidet sich als „ortolana“ (Gemüsegärtnerin). Das zweite Finale, das aus einem galanten, durch die ungewissen Identitäten der maskierten Figuren und die dadurch erweckte Neugier bewegten Erkennungsspiel besteht, beginnt folgendermaßen:

D. Fl. Donne è qua l'Ortolanella,

Ho lattuga, e ravanelli,

Dei Carcioffoli novelli,

Endivietta, cicorietta;

Chi mi chiama? Sono qua.

Robba fresca, erba novella

A buon prezzo qui si dà.

D. Per. (O che bella Mascheretta!)

Ros. (Il suo canto m'innamora.)

Pat. Ah ch'io sono innamorato,

Mascheretta in verità! ${ }^{677}$

Die anderen Figuren sind ebenfalls maskiert und erkennen die „ortolana“, vermutlich aufgrund einer Gesichtsmaske, als maskierte Person, wissen aber nicht, wer sich hinter dieser Maske verbirgt. Während bei anderen, üblicheren Arten von Verkleidungen, wie sie häufig in der Burla eingesetzt werden, beabsichtigt wird, die übrigen Figuren von der Echtheit der dargestellten Rolle zu überzeugen und sie somit zu täuschen, geht hier ein bewusstes, mit einem Trompe-l'œil vergleichbares Spiel mit falschen Identitäten vor sich. Die anderen Figuren und Interaktionspartner genießen das Spiel der bewussten Täuschung und der Ungewissheit über die wahre Identität der Person hinter der Maske.

Besonders reizvoll ist dieses für den karnevalesken Alltag übliche Selbstinszenierungsspiel des expliziten Tragens einer Maske gerade weil es auch tatsächlich in eine echte und folglich nicht bewusste Täuschung kippen kann, wie es in „Il geloso in cimento “ bei der Maskierung der Dienerin Modesta geschieht: Sie ist nämlich als Mann im Petit-maître-Stil, ${ }^{678}$ also modisch und elegant, gekleidet und wird tatsäch-

676 Bertati/Anfossi: Il geloso in cimento. Venedig 1774 (II,4).

677 Ebd. (II,15).

678 Der Petit Maître gilt als Vorfahre des Dandys und wird definiert als „eitler, junger Mann mit auffallend modischer Kleidung und auffälligem Benehmen“. (Duden - Das große Fremdwörterbuch. S. 790). 
lich für einen Mann gehalten, weil ihre Maske nicht als solche erkennbar ist und eine echte Täuschung bewirkt, was Modesta sehr genießt.

\section{Modesta mascherata da Uomo a la Petit-Maitre}

Per la piazza, così vestita,

Mi corre dietro la gente unita,

Ciascun mi dice: Monsiù, Monsiù.

Così da uomo pur me la godo!

Ah, se potessi trovar il modo!

Ritornar femmina non vorrei più $!^{679}$

Ihre Verkleidung ist so trügerisch, dass Fabio auf sie eifersüchtig wird, weil er glaubt, sie sei Donna Flavias Freund. Als Fabio ihr mit dem Messer droht, nehmen Modesta, Donna Flavia und Vittorina ihre Masken ab, um ein Blutvergießen zu verhindern. Wie es häufig bei Verkleidungsszenen in der Opera buffa der Fall ist, endet das Alsob-Spiel mit einer Demaskierung, die einen starken Überraschungseffekt bewirkt und die Figuren aus der karnevalesken Spielsphäre zurück in ihre Realität führt. Es ist kein Zufall, dass die Handlung von "Il geloso in cimento“ gerade in Venedig stattfindet, wo die Maskierung als galantes Gesellschaftsspiel an der Tagesordnung war.

In Szenen, in der die Maske explizit thematisiert wird, besteht immer wieder ein klarer Bezug zu Venedig, oder sogar zum Bereich des Theaters und der Oper. Anfossis Oper „Lo sposo disperato“ beispielsweise spielt zwar in Rom, aber die Figuren maskieren sich, um ins Theater zu gehen, wo das gesamte zweite Finale stattfindet. Der Bezug zu Venedig wird besonders deutlich, als Don Eustochio erzählt, er habe zu diesem Anlass eine Maske venezianischer Art bestellt:

D.E. Il vestito da maschera

L'avete ancor veduto?

Canz. Io? La maschera?

D.E. Sì, per questa sera

Per andare al Teatro. Io l'ho ordinata

All'uso Veneziano,

Ch'è assai comodo, nobile, e bizzarro;

S'intende la Bauta, ed il Tabarro. ${ }^{680}$

679 Bertati/Anfossi: Il geloso in cimento. Venedig 1774 (II,16).

680 Bertati/Anfossi: Lo sposo disperato. Venedig 1777 (II,6). 
Hier wird die bauta (oder bautta), die typische venezianische Maske, angesprochen, die die Adeligen in der Öffentlichkeit, also auch im Theater tragen mussten. Don Eustochios Worte („il vestito da maschera“) klingen so, als ob er sich „als Maske“ verkleiden würde. Aus römischer Sicht beurteilt er diese Art von Maske als bequem, nobel und bizarr, also nachahmenswert.

Der im Bühnengeschehen auf Fremde wirkende Eindruck eines Identitätsmerkmals der Stadt Venedig und der Venezianer sprach indirekt das venezianische Publikum an, zumal es bei der Aufführung zum Großteil wahrscheinlich genau die besagte Maske trug. Das positive Urteil kann als indirektes Kompliment und eine Ehrenerweisung an die Stadt und an die Sitten ihrer Bewohner verstanden werden. An das venezianische Publikum wird die schmeichelnde Botschaft gerichtet, dass der venezianische Karneval in Rom, also in der Fremde, nicht nur berühmt ist, sondern so sehr bewundert wird, dass er zur Nachahmung und zur Modebildung verlockt, wobei dem einzelnen Zuschauer die Einzigartigkeit seiner Stadt bewusst gemacht wird.

Der Bezug zu Venedig als Stadt des Karnevals herrscht auch in einer Verkleidungsszene im zweiten Finale von Carusos Oper „L'albergatrice vivace“ vor, als Barberina sich als venezianische „barcariuola“ maskiert:

\section{Barberina in maschera da barcariuola Veneziana}

Momoletta semplizetta

Fà el sò ziro in mascheretta,

Per trovar un buon partio,

Che Novizza se vol far.

Lo vojo belo,

Ch'el sia putelo,

E frà sti cocoli [sic]

L'ho da trovar. ${ }^{681}$

Hier stellt sich Barberina als Momoletta ${ }^{682}$ vor, die auf der Suche nach einem Bräutigam maskiert umhergeht. Sie spielt also eine Rolle, die durch typische Attribute ihrer venezianità gekennzeichnet ist: venezianischer Dialekt, typischer venezianischer Name, der auch auf ihre semplicità hinweist, und Maske als „Markenzeichen“ für Venedig und seinen Karneval.

681 Palomba/Caruso: L'albergatrice vivace. Venedig 1780 (II,18).

682 Der typisch venetische Name entspricht einer Verweiblichung des männlichen Kosenamens Momoletto für Gerolamo bzw. Girolamo oder Geronimo. Momoletto bedeutet in der Triester Mundart auch Dummkopf, Einfaltspinsel, weshalb die weibliche Form gut zu „semplizetta“ passen könnte. 
Es ist kein Zufall, dass die drei letzten Beispiele allesamt gerade im zweiten Finale der jeweiligen Oper eingebettet sind: In den Finali, insbesondere im zweiten Finale, kommt es immer zu einer Verdichtung der Spannung und Dramatik, die dramaturgisch gesehen vorwiegend auf spielerischen, burlesken Elementen und verschiedenen Arten von Als-ob-Spielen (insbesondere in der Form des Spiels mit Identitäten) beruht. Vor allem aber stammen nicht von ungefähr dieselben Beispiele aus Opern, die für das venezianische Publikum geschrieben und in Venedig uraufgeführt wurden.

Dies ist auch in der Oper „Il carnovale“ (I770) von Chiari und Boroni der Fall, deren gesamte Handlung in Venedig in der Karnevalszeit eingebettet ist. Es werden dieselben Spiele gespielt wie in den beschriebenen Beispielen: Ähnlich wie Momoletta suchen hier drei maskierte Frauen einen Ehemann, verdecken dabei ihre Identitäten nicht nur durch Masken, sondern tauschen auch untereinander Rollen und sozialen Status, um sich nicht zu kompromittieren. Dass es gerade die Maske ist, die solche Flirt- und Identitätsspiele erlaubt, bemerkt Florina:

Eh bene.

Faremo che Cattina

Faccia da padroncina. In Carnovale

La maschera permette

Un po' di tutto alfin. ${ }^{683}$

Auch in dieser Oper sind die Anspielungen auf den realen Kontext der Aufführung sicherlich bewusst eingesetzt, um den besonderen Reiz herzustellen, den solche Außenbezüge ausüben können und der unter anderem in der Verdichtung und Komplizierung des Wechselspiels zwischen Identifikation und Distanz besteht: Der Zuschauer wird durch den innerhalb einer fiktiven Handlung stattfindenden Bezug zu seiner Realität verstärkt zur Identifikation hingeführt, gleichzeitig distanziert er sich einerseits von der dargestellten Handlung, andererseits von sich selbst durch den Blick „von außen“ auf „seine Welt“, die auf der Bühne fiktiv dargestellt wird. Im Prinzip handelt es sich um denselben Mechanismus, der sich bei jeder Art von „Spiel im Spiel“ in Gang setzt: Durch das Hinzufügen einer Fiktionsebene und durch die mehrfachen Spiegelungen, die sich zwischen den verschiedenen Ebenen ergeben, kehrt „die Dialektik von Schein und Sein, von Illusion und Desillusion, die zum Wesen des Theaters gehört, (...) vermannigfaltigt wieder “. ${ }^{684}$ Zwischen den drei Ebenen - der Realität, der ersten und der zweiten Fiktionsebene - entsteht ein Spiel

683 Chiari/Boroni: Il carnovale. Venedig 1770 (I,5).

684 Martini, S. 351. 
von Reflexionen und Bezügen, das den Spielcharakter der Theatersituation nicht nur ins Bewusstsein bringt, sondern auch potenziert. ${ }^{685} \mathrm{Im}$ Vergleich zu anderen, üblicheren Verkleidungsszenen sind in den zuletzt beschriebenen Beispielen die Bezüge zur Außenwelt allerdings wesentlich stärker, weil sie standortspezifisch und gezielt auf das venezianische Publikum abgestimmt sind. So wirken sie auf die Zuschauer besonderes stark ein, weil sie eine direkte Verbindung zu ihrer Realität herstellen und somit die erwähnten Identifikations- und Distanzierungsprozesse verstärkt anregen. Für das Publikum besonders schmeichelhaft wirkt der in diesen Szenen meist mitschwingende Hinweis auf die Einzigartigkeit der Lagunenstadt hinsichtlich ihrer geographischen Lage und ihrer karnevalesken Vergnügungsdichte. Hervorzuheben ist dabei, dass als Symbol klischeehaft für die Stadt Venedig gerade die Maske gewählt wird, die nicht nur ein typisches Spielelement darstellt, sondern geradezu als Emblem für das Als-ob-Spiel gilt.

Die Thematisierung der Maske ist allerdings eher als Sonderfall der Maskierung zu betrachten, weitaus häufiger sind in der Opera buffa Verkleidungen zu finden, bei denen meistens eine, selten mehrere Figuren durch Maskierung anderen gegenüber eine falsche Identität vortäuschen.

Einen weiteren Bezug, den alle Arten von Verkleidungen genauso wie jedes andere Element der Opernhandlung herstellen können, ist der intertextuelle Bezug zu anderen Opern bzw. Theaterstücken. So wie Kinder den Stoff für ihre Fiktionsspiele aus ihrem realen Leben schöpfen, ${ }^{686}$ spielen Buffa-Figuren meist Rollen, die ihrer „Welt“ entstammen, nämlich der Welt der Oper und des Theaters. So trifft man bei Verkleidungsszenen häufig altbekannte Typen an, wie den des gewalttätigen deutschen Soldaten ${ }^{687}$ oder des jähzornigen spanischen Offiziers, ${ }^{688}$ die im italienischen Theater des I 8. Jahrhunderts, in der Commedia dell'arte, aus der sie ursprünglich stammen, und in der Komödie oder in der Opera buffa auch als „normale“, also unverkleidete Figuren auftreten, wodurch sich Bezüge als „Resonanzverhältnisse“ zu anderen Komödien und Opere buffe ergeben können.

Selbstverständlich können solche Anknüpfungen an andere Werke bzw. an eine gewisse Tradition auch die darin enthaltenen Verkleidungsszenen betreffen. Typen, die lediglich in Verbindung mit Verkleidungen vorkommen und aufgrund ihrer besonderen Beliebtheit oder Wirksamkeit immer wieder eingesetzt werden, wodurch sie zu regelrechten Topoi werden, sind beispielsweise die hellseherische

685 Vgl. Martini, S. 321.

686 Vgl. Garvey: Spielen. S. 98.

687 Livigni/Gazzaniga: La moglie capricciosa. Venedig 1785; Bertati/Valentini: La statua matematica. Venedig 1781.

688 Cimarosa: Le donne rivali. Venedig 1780. 
Zigeunerin, die Statue oder aber Phantasiegestalten wie Geister, Teufel, Idole und Orakel. Bei Verkleidungen können prinzipiell alle möglichen Rollen gespielt werden, und zwar nicht nur konventionelle Rollentypen, wie der des Arztes oder der ombra (Schatten) einer (vermeintlich) verstorbenen Person, sondern auch unüblichere Rollen wie die des „chincagliere“ (Kurzwarenhändlers) ${ }^{689}$ oder des „baccelliere“ (Bakkalaureus). ${ }^{690}$

Welche Rolle auch immer bei Verkleidungsszenen gespielt wird, muss unmittelbar verständlich sein und wird durch wenige, äußerst klischeehafte Elemente vermittelt, durch die sie gewissermaßen den Fiktionsspielen der Kinder nahekommt. Empirische Beobachtungen von kindlichen Darstellungsspielen haben nämlich Garvey zu dem Schluss geführt, dass viele der dabei verwendeten Darstellungselemente „hochgradig stereotyp“ sind. ${ }^{691}$ In Bezug auf die gespielten Rollentypen bemerkt sie unter anderem Folgendes: „Diese Typen wurden hinsichtlich ihrer Persönlichkeit meist recht flach gezeichnet, ihre Handlungen und Attribute waren höchst vorhersehbar, und ihr Aktionsspektrum erwies sich als allgemein äußerst beschränkt. "692 Ähnliches kann für die in der Buffa bei Verkleidungen vorkommenden Rollentypen gelten: Für die Identitätstransformation reichen meistens wenige Attribute und klischeehafte Eigenschaften aus. Häufig werden typische Kostüme und/oder Requisiten eingesetzt, die zwar karnevalesk und komisch wirken, aber für das Rollenspiel nicht so unentbehrlich sind wie Sprache bzw. Sprachstil und Handlungsweise. Den klischeehaften, konventionellen Charakter der Verhaltensmuster, der Gestik und der Eigenschaften der verkleideten Figuren in der Opera buffa beschreibt an einer schon zitierten Stelle der von Arteaga erfundene Impresario: „poichè il costume comanda, che per tariffa scenica devano mostrarsi in teatro ora un Olandese col cappello alla quakera, che sembri muoversi colle fila di ferro a guisa di burattino, ora un francese incipriato e donnajuolo, che abbia nelle vene una buona dose d'argento vivo, ora un goffo tedesco, che non parli d'altro che della sciabla e della fiasca, ora un Don Quisciotte spagnuolo, che cammini a compasso come figura geometrica, pieno di falsi puntigli, ed abbigliato alla foggia di due secoli addietro;"693 Arteagas Impresario bezieht sich zwar auf unverkleidete Figuren, aber dieselben klischeehaften Verhaltensweisen würden die in Verkleidungsszenen auftretenden Typen aufweisen. Dabei wird klar, dass es sich in beiden Fällen um reine, beliebig einsetzbare Spielfiguren - Arteaga selbst vergleicht sie mit Mari-

689 Bertati/Anfossi : Il matrimonio per inganno. Venedig 1781.

690 Petrosellini/Paisiello: Linutile precauzione. Venedig 1787.

691 Vgl. Garvey, S. 109.

692 Ebd. S. 110.

693 Arteaga, S. 146. 
onetten („burattini“) - handelt, bei denen prägnant typisierte Verhaltensweisen beim Zuschauer sowie bei den übrigen Figuren auf der Bühne die Vorstellung einer bestimmten Rolle hervorrufen, die schon aus anderen Theaterstücken oder Opern bzw. aus der Tradition bekannt sind.

Es ist nicht von ungefähr, dass Arteaga gerade einen Holländer, einen Franzosen, einen Deutschen und einen Spanier als Beispiele nimmt. Karikierte Fremdländer, wie sie in Ansätzen im schon beschriebenen Beispiel der Frascatana beim Spiel der vier fremdländischen Männer vorkamen, sind bei „doppelt fiktiven“ Rollen in Verkleidungen wie auch bei „einfach fiktiven“ Rollen besonders beliebte Typen. In diesen Fällen fungieren in erster Linie die Sprache, aber auch die mit dem jeweiligen Land assoziierten Klischees als Verkleidungsmittel.

Als Beispiel für die Beliebtheit und das häufige Auftreten solcher nationalen Stereotypen kann Carusos Oper „L'albergatrice vivace“ dienen: Hier wird die schlaue und welterfahrene Gastwirtin Barberina von drei Verehrern, einem Franzosen, einem Deutschen und einem Spanier umschwärmt, ${ }^{694}$ heiratet am Schluss aber einen Landsmann, einen Kalabresen. Im ersten Finale dieser Oper verkleidet sich der Franzose als Furcht einflößender, gewalttätiger Türke, im zweiten Finale verkleidet sich Barberina als im venezianischen Dialekt sprechende „barcariola veneziana“. Im Hinblick auf die Charakterisierung der einzelnen Rollen nimmt die jeweilige Landessprache eine vorrangige Bedeutung an. In der schon erwähnten Passage aus dem zweiten Finale der „Frascatana“ konnte Violante in vier kurzen Ausrufen im Dunkeln die Anwesenheit von vier Personen aus verschiedenen Ländern vortäuschen. Allein die Sprache konnte hier als einziges angewandtes Verkleidungsmittel, durch die Dunkelheit unterstützt, in kürzester Zeit vier verschiedene Rollen vermitteln.

\subsection{Exkurs: Sprachspiele}

Fremdländische Figuren sprechen in der Opera buffa nicht immer ihre Muttersprache in reiner Form, vielmehr herrscht ein spielerischer Umgang mit Sprachen vor, woraus sich oft lustige Sprachmischungen ergeben. Wie schon Folena festgestellt hat, dienen die in Buffa-Libretti immer wieder eingesetzten Fremdsprachen nicht einer realistischen Darstellung, sondern erfüllen als Verkleidungsmittel eine rein spielerische und komische Funktion: „Il plurilinguismo (...) non riveste d'altra parte generalmente funzione realistica, caratterizzante, ma soltanto ludica e si inserisce nella tradizione

694 Eine solche Konstellation ist übrigens typisch für Witze, in denen mehrere Vertreter unterschiedlicher Nationalitäten einander gegenübergestellt und in wenigen Sätzen klischeehaft und karikiert dargestellt werden. 
delle metamorfosi e dei travestimenti, ingrediente comico puramente giocoso, vero e proprio lazzo mimico-verbale-musicale. “695

Fremdsprachen werden meistens in karikierter, verballhornter Form so wiedergegeben, wie sie von Italienern wahrgenommen werden. Dabei ergeben sich aufgrund der damals in Italien üblichen Fremdsprachenkenntnisse folgende konventionalisierte Abstufungen.

Französisch, die in Italien mit Abstand am meisten gesprochene bzw. beherrschte und in der Opera buffa am häufigsten vorkommende Fremdsprache, wird als gängige Sprache der Galanterie und der Konversation verhältnismäßig korrekt gesprochen, wenn auch mit Italienisch vermischt und teilweise in italienischer Lautschrift wiedergegeben. ${ }^{696}$

In Anfossis Oper „I viaggiatori felici“ spielen beispielsweise Giannetto und Bettina die Franzosen: Giannetto gibt sich als ein Tanzmeister namens „Monsiù Ballonè “ aus und Bettina, die eigentlich seine Ehefrau ist, als seine Schülerin „Mamsella Tortiglie““, zwei Namen, die offensichtlich aus dem Tanzvokabular stammen, wie Don Gastone bemerkt („Ma questi nomi son due passi da Ballo“). Beide behaupten, sie kämen aus Paris, und ihr als „Sprachmaske“ dienendes Französisch lautet folgendermaßen:

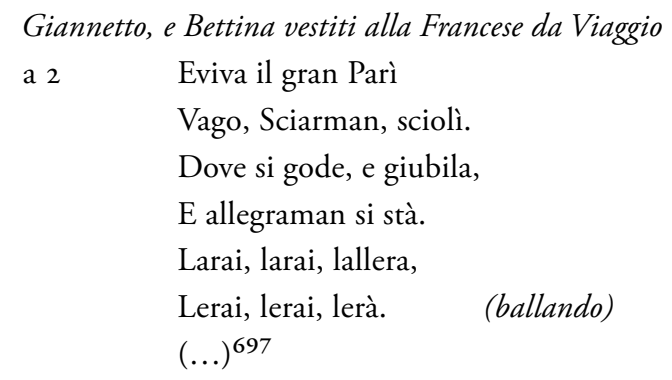

Wie so oft beim in der Opera buffa auftretenden Sprachengemisch werden auch hier die französischen Wörter nach den italienischen Rechtschreibregeln geschrieben. Ein Klischee, das in dieser Auftritts-Cavatina auf Frankreich hinweist, ist der nach französischer Art auf Trällersilben gesungene Refrain, genauso wie in der französischen Einlage im Quartett aus „Giannina e Bernardone“. Diese wenigen Klischees reichen offenbar aus, um die beiden unmittelbar für Pariser zu halten, wie Laurettas Ausruf „che

695 Gianfranco Folena: Litaliano in Europa. Esperienze linguistiche del Settecento. Turin 1983, S. $314 \mathrm{f}$.

696 Zur Verwendung der französischen Sprache im Italien des 18. Jahrhunderts siehe Gianfranco Folena, S. $371 \mathrm{ff}$.

697 Livigni/Anfossi : I viaggiatori felici. Venedig 1780 (I,2) (,Sciarman“ = charmant; „scioli“ $=$ joli). 
vago Parigino“ beweist. Etwas später spielen Bettina und Giannetto, um Don Gastone von ihrer falschen Identität zu überzeugen, eine typische Tanzunterricht-Szene. ${ }^{698}$

$$
\text { (...) }
$$

Gia. L'espression, morblù, comsà.

Bett. Oui, Monsiù, ne criè pà.

Gia. Attenzion: Demicuppè ...

Fliccheflacche ... Tordescian ....

Bett. Se Ballè quant'è Sciarman.

$$
(\ldots)^{699}
$$

Die Rollen des Tanzmeisters und der Tänzerin werden unmittelbar mit Frankreich bzw. Paris assoziiert, aber auch ihre Bemühungen, reineres Französisch zu sprechen, und das Nennen der französischen Namen von Tanzschritten führen dazu, dass die gespielten Rollen echt und professionell wirken und dass die „Verkleidung“ nicht durchschaut wird.

Nach dem Französischen erscheinen in der Opera buffa Spanisch und Deutsch als häufigste Fremdsprachen. Während Spanisch mit italienischer Färbung wiedergegeben wird, wobei spanische und italienische Wörter alternieren, und italienische Wörter durch Anhängen des Buchstaben „s“ „hispanisiert“ sind, werden deutschen Figuren deutsche Wörter nach italienischer Schreibweise und ein kauderwelschartiges Italienisch in den Mund gelegt, als wolle ein Italiener einen Italienisch sprechenden Deutschen nachahmen.

So spricht beispielsweise der als deutscher Offizier mit Schnurrbart verkleidete Cavaliere in Carusos „La statua matematica“:

\section{Il Cavaliere da Ufficiale Tedesco co' baffi}

Taifel? State voi due, che sposare

Belle junfre con muse si brutte?

698 Das Motiv des von einem französischen Tanzmeister gehaltenen Tanzunterrichts war schon in der Commedia dell'arte ein bewährter Topos und wurde von der Opera buffa übernommen. (Vgl. Daniel Brandenburg: Zu Tanz- und Bewegungsphänomenen in der Opera buffa des 18. Jahrhunderts. In: Sibylle Dahms und Stephanie Schroedter (Hg.): Tanz und Bewegung in der barocken Oper. Kongressbericht Salzburg 1994. Innsbruck, Wien 1996 (Derra de Moroda Dance Archives 3), S. 161f.).

699 Ebd. (I,5). Die genannten Tanzschritte entsprechen folgenden im Traktat von Gennaro Magri Trattato teorico-prattico di ballo (Neapel 1779) bzw. im Trattato del ballo nobile von Giambattista Dufort (Neapel 1728) erscheinenden Schritten: tortiglié, balonné, demi coupé, flinc flanc, tordichamb. (Vgl. Carmela Lombardi: Danza e buone maniere nell'antico regime. Trattati e altri testi italiani tra 1580 e 1780. Arezzo 1991, S. 147f.). 
( ...)

Oggi fatti voi questi sponsali,

Poi domani voi far sepelir.

Vostre pancie voi grandi canaglie

Je di paglie voler far empir. ${ }^{700}$

Die beiden einzigen deutschen, in italienischer Lautschrift aufgeschriebenen Wörter sind "Taifel“ (= Teufel) und ,junfre“ (= Jungfrau), der Rest ist Italienisch mit starkem deutschen Akzent; typische „Grammatikfehler" sind dabei die Endungen auf -e (unter Nichtbefolgung der Kongruenzregeln) und die unkonjugierten Verben im Infinitiv. Im Gegensatz zur französischen Sprache wirkt in der Opera buffa Deutsch immer karikaturhaft.

Als Beispiel für das in einer Verkleidungsszene gesprochene Spanisch kann der Arienbeginn des als spanischer Offizier verkleideten Don Annibale aus „Le donne rivali“ von Cimarosa dienen:

\section{Don Annibale finto Uffiziale Spagnuolo}

Ah Cavron con quella faccia

Con quell'occhios del demonio

Vuoi far vezzi alla mucciaccia

Vuoi parlar de matrimonio?

Su soldados preparatevi

Chiero farlo moschettar.

$(\ldots)^{701}$

In diesem Textausschnitt sind spanische Wörter größtenteils in italienischer Lautschrift zu finden (,cavron“ = cabrón, "mucciaccia“ = muchacha, "chiero" = quiero, „soldados"), aber auch im Italienischen und Spanischen gleich lautende Wörter („demonio“, „matrimonio“) sowie ein hispanisiertes italienisches Wort („occhios“ als „hispanisierte" Pluralform von occhio statt occhi bzw. Spanisch ojos). Die Grundlage ist hier die italienische Sprache, die durch das Ersetzen einiger Wörter mit spanischen oder spanisch klingenden Ausdrücken als Spanisch „verkleidet" wird und trotzdem für den italienischen Zuschauer verständlich bleibt.

Deutsch und Spanisch sind oft jähzornigen Rollentypen zugeordnet, Schimpfwörter bzw. Ausrufe wie „cabrón“ oder "Teufel“ sowie die in beiden Beispielen vorkommenden, witzigen Morddrohungen sind dabei durchaus typisch.

700 Bertati/Valentini: La statua matematica. Venedig 1781 (I,17).

701 Cimarosa: Le donne rivali. Venedig 1780 (II,8). 
Latein ist die einzige Fremdsprache der Opera buffa, die nicht mit der Herkunft einer Figur, sondern mit bestimmten Berufsgruppen verbunden ist. Eine klassische Verkleidung ist beispielsweise die des Latein sprechenden Notars, aber auch Ärzte und Philosophen bzw. Gelehrte im Allgemeinen sprechen Latein. In der Regel wird ein witziges Sprachengemisch, das latino maccheronico, verwendet, in dem nicht nur rein italienische und rein lateinische Ausdrücke vorkommen, sondern lateinisierte italienische sowie fehlerhaft wiedergegebene lateinische Wörter, wodurch echte oder simulierte Gelehrtheit oder Bildung in ein komisches Licht gerückt wird. Als kurzes Beispiel dafür kann der Auftritt von drei falschen Ärzten im zweiten Finale von Paisiellos berühmter Oper „Lamor contrastato“ (besser bekannt unter dem Titel „La Molinara") dienen. Hier nützt der Gouverneur Rospolone die Information über die baldige Ankunft dreier echter Ärzte aus, die zur Heilung des verrückt gewordenen Don Calloandro herbeigerufen worden sind, um sich an seinem Liebesrivalen, dem Notar Pistofolo, zu rächen und ihn, als Arzt verkleidet, von seiner vermeintlichen Verrücktheit zu „heilen“.

Rospolone da Medico seguito da altri due finti Medici

Med. 3 Siste insanus, vel freneticum

In consulto Medicorum

Notomia de cervellorum

Nel tuo capo si ha da far. ${ }^{702}$

Das „Sprachenspiel“ besteht auch hier im Vermischen von Latein und Italienisch, wobei das Italienische teilweise durch das Anhängen von lateinischen Endungen als Latein „verkleidet“ wird, wie beispielsweise bei „freneticum“ oder „cervellorum“.

Weitere typische Fremdländerfiguren sind Engländer und Holländer; diese kommen allerdings kaum als Verkleidungen vor und werden in der Regel nicht durch ihre Sprache, sondern durch andere Eigenschaften, wie Ernsthaftigkeit oder Schweigsamkeit, charakterisiert.

Noch viel spielerischer als die genannten Sprachmischungen ist der Umgang mit exotischen Fremdsprachen wie Türkisch, Chinesisch, Griechisch oder Ägyptisch. Diese Sprachen werden nämlich größtenteils mit phantasievoll erfundenen Lauten wiedergegeben, die ihre Unverständlichkeit und ihren lustigen Klang in den Ohren und in der Vorstellung eines Italieners vermitteln sollen.

Türkisch nimmt eine Mittelstellung zwischen den echten und den erfundenen Sprachen ein und ist nur teilweise durch erfundene Wörter wiedergegeben. Als der

702 Palomba/Paisiello: L'amor contrastato. Venedig 1789 (II,17). 
Franzose Monsieur Floran sich im ersten Finale von Carusos Oper „L'albergatrice vivace“ als Türke verkleidet, beginnt sein Auftritt folgendermaßen:

Al, Bilà, Salamelech,

Scarabac, Smiluch, Lamech,

Riverentia via fascira (facendo far riverenza ai Turchi a tempo di musica)

A surel di Mustafa.

(...)

Ah Surella, salutara,

Quanta Gente cun tì stara!

Nun bulira Mustafa. ${ }^{703}$

Neben einigen erfundenen Wörtern wie „scarabac“ oder „smiluch“ tauchen vereinzelte Anklänge ans Arabische auf („Salamelech“ = Salam aleikum, „Lamech“ = La Mecca, „Al“ als arabischer Artikel sowie der Name „Mustafa“). Der Rest ist ein nach bestimmten Regeln „verkleidetes“ Italienisch. Als Kennzeichen für Türkisch dienen neben der typischen Begrüßung "Salamelech“ in Buffa-Verkleidungen vor allem die Verben, die nicht nur alle im Infinitiv stehen, sondern witzigerweise immer auf -a statt auf -e enden und gelegentlich zusätzlich entstellt sind („fascira“ statt fare, „salutara“ statt salutare, „stara“ statt stare, „bulira“ statt volere). Außerdem spricht der „Türke“ jedes „o“ als „u“ aus („surel“ bzw. „surella“ statt sorella, „nun“ statt non) und redet von sich selbst in dritter Person („Nun bulira Mustafa“). Bei diesen „türkischen“ Klischees handelt es sich nicht um Erfindungen des Librettisten, sondern um Topoi, die schon Goldoni in den $1750 e r$ Jahren in seinen Libretti verwendet hatte. ${ }^{704}$

703 Palomba?/Caruso: L'albergatrice vivace. Venedig 1780 (I,18).

704 Lucrezia verkleidet sich in Goldonis „La conversazione“ aus dem Jahr 1758 beispielsweise als Türkin (III,3) und spricht folgendermaßen:

Salamelecch

Stara sultana

Con ottomana

Nozze mi far.

Auch in Goldonis „Lo speziale“ (1754) verkleiden sich mehrere Figuren als Türken (III,6) und singen:

Salamelicca

Semprugna cara,

Costantinupola

sempre cantara,

sempre ballara

la, la, la, la. 
Wesentlich exotischer als die Türkei ist das Ursprungsland des Astrologen Houbabalà, als den sich Felicino in Anfossis Oper „L'avaro“ verkleidet, um den geizigen Herrn Orgasmo dazu zu bringen, den Hochzeiten seiner Kinder zuzustimmen. Houbabalà kommt nämlich aus den Molukken, einer Inselgruppe in Indonesien, und dementsprechend exotisch und unverständlich klingt seine Sprache:

Felicino vestito all'indiana, ed Orgasmo

Salama mi lecca;

Macacca rebecca,

Urgasma ti Kà,

Houlà babalà. ${ }^{705}$

und später :

Per Kaniska, Kanuska, Kakis,

Per Kin, Kin, Skaqueras, Skaquiris. ${ }^{706}$

Durch erfundene Wörter wird hier eine fremd klingende und unverständliche Sprache dargestellt. Im Vordergrund stehen vor allem der klangliche Aspekt der Nonsense-Sprache und ihr humoristischer Effekt. Manchmal ergeben sich aus Anklängen an italienische Wörter Wortspiele, Zweideutigkeiten und Sinnverdrehungen. In Felicinos Cavatina wird beispielsweise die arabische Begrüßung „salam aleikum“ - ein Topos der türkischen Verkleidungsszenen - in ein Lachen erregendes „salama mi lecca“ (salame = Salami; „lecca“, von leccare = lecken) umgeschrieben. Auch bei anderen, scheinbar sinnlosen Wörtern bestehen Bezüge zu Bedeutungen im Italienischen: „macacca“ $(\operatorname{macac}(c)$ o = Affe, übertragen auch Trottel), „rebecca“ ist ein weiblicher Name und ein Musikinstrument; „Urgasma“ und „Houlà babalà“ sind Verdrehungen der an sich schon witzigen Namen der beiden Personen, Orgasmo und Houbabalà.

In den beiden letzten zitierten Zeilen steht vor allem der klangliche Aspekt der erfundenen Wörter im Vordergrund, das Spiel besteht hier vor allem in der „Manipulation“ bzw. Variation von lustig wirkenden Klängen („Kaniska, Kanuska“, „Kin kin“, „Skaqueras, Skaquiris“). Dabei fällt die Häufigkeit des Buchstaben „k“ auf, der in italienischen Wörtern nicht vorkommt, wobei der dazugehörige Klang sehr wohl existiert und auf die fäkale Sphäre anspielt, was auch bei der Wortbildung „Skaqueras“ der Fall ist, denn squacquera oder squacchera bedeutet Durchfall.

705 Bertati/Anfossi : L'avaro. Venedig 1775 (II,9).

706 Ebd. (II,12). 
Das Sprachspiel besteht in dieser Verkleidungsszene also sowohl in der Erfindung einer Phantasiesprache, die den Klang einer fremden Sprache nachbildet, als auch in einer Art „Manipulationsspiel“ mit witzigen Klängen sowie in An-spielungen auf echte Wörter, deren Bedeutung und Kombination zum Lachen bringt.

Bachtin behauptet im Zusammenhang mit als Sprachmasken fungierenden Dialekten: „Die Vielsprachigkeit entdogmatisiert und setzt ,unerlaubte‘ Bedeutungen frei. " ${ }^{707}$ Ähnliches geschieht in der Opera buffa bei erfundenen Sprachen, in denen erotische oder fäkale Anspielungen sowie Schimpfwörter „versteckt“ werden, die in einem Opernlibretto ohne die „sprachliche Verkleidung“ nicht erlaubt gewesen wären. Es ist nach Bachtin unter anderem der typisch karnevaleske „obszöne Bezug zum Materiell-Leiblichen “, 708 der bei den als Fremdsprache verkleideten Anspielungen das Lachen erregt.

Ähnliche Klänge und Anspielungen verwendet Bertati im Libretto der Oper „L'inimico delle donne“, die auf einer chinesischen Insel spielt. Schon die Namen der Personen und Orte sind um des „chinesischen“ Flairs willen erfunden: Die imaginäre chinesische Stadt, in der die Oper spielt, heißt Kibin-Kin-Ka, der dort herrschende Prinz nennt sich Zon-zon, seine Minister sind Sy-lam und Si-sin, die drei Frauen, die ihn heiraten wollen, heißen Xunchia, Zyda und Kam-si. Das Idol, das in der Introduzione angebetet wird, um dem Prinzen die schlechte Laune vergehen zu lassen, heisst Ka-na-gà, und der Text des dabei gesungenen cantico lautet:

Kacomira Ka-na-gà

Ti Kakira squaquerà. ${ }^{709}$

Hier handelt es sich zwar nicht um eine Verkleidungsszene, sondern um die Darstellung der chinesischen, fremd klingenden Sprache, aber die eingesetzten Mittel ähneln denen des verkleideten Felicino. Auch hier kommen der Buchstabe „k“, die fäkalen Anspielungen und sogar das Wort „squaquerà “ vor. ${ }^{710}$ Das Wort „Kacomira“ weist wie viele der erfundenen Wörter (z. B. „macacca“, „kakis“, „kakira“) auf cacca hin, zugleich aber auch auf den derben venetischen Ausdruck cacomiro. ${ }^{711}$

707 Bachtin, S. 32.

708 Ebd. S. 165.

709 Bertati/Galuppi: L'inimico delle donne. Venedig 1771 (I,1).

710 Beinahe ausschließlich auf dem offensichtlich beliebten Wort squaquera basiert auch das an Amor gerichtete griechische Gebet in „Il convito“ von Livigni und Cimarosa: „Squacqua quaglia squacquara / Mà mà mà marméo / Squaraquacchia squicquera / Squacqua squà quarà."

711 Nach Patriarchis Vocabolario veneto e padovano aus dem Jahr 1821 bedeutete „cacomiro“ zu der Zeit "gufaccio, babbuino, povero in canna, malestante“, also Dummkopf und armer Schlucker. (Gasparo Patriarchi: Vocabolario veneto e padovano co' termini e modi corrispondenti toscani. Padova, 1821, S. 32). 
Ein in einer erfundenen Sprache gesungener cantico ist in der Opera buffa ein regelrechter Topos: In der Regel an ein Idol oder Orakel gerichtet, wird es als diegetische Musik öfters angestimmt, um in einem Ritual den Kontakt zu einer überirdischen Macht herzustellen, von der man sich Hilfe und Rat erbittet. Vertont werden solche feierlichen Gesänge als einfache homophone Chöre, wie im beschriebenen cantico aus "L'inimico delle donne“. Das gleichmäßige, fast mechanisch wirkende Metrum der erfundenen Verse wird bei der Vertonung häufig in eine rhythmische Schablone eingebettet, die mehrmals wiederholt wird, wodurch eine gewisse zum Gebet passende Monotonie entsteht. In diesem Beispiel deuten das schnelle Tempo (Allegro) und die lustig wirkenden Sechzehntel-Einwürfe der Geigen gemeinsam mit der absurd-witzigen Sprache darauf hin, dass das Gebet nicht allzu ernst genommen werden soll; man könnte die Summe dieser Elemente auch als die von Bateson in Bezug auf das Spiel festgestellte metakommunikative Botschaft „This is play“ interpretieren.

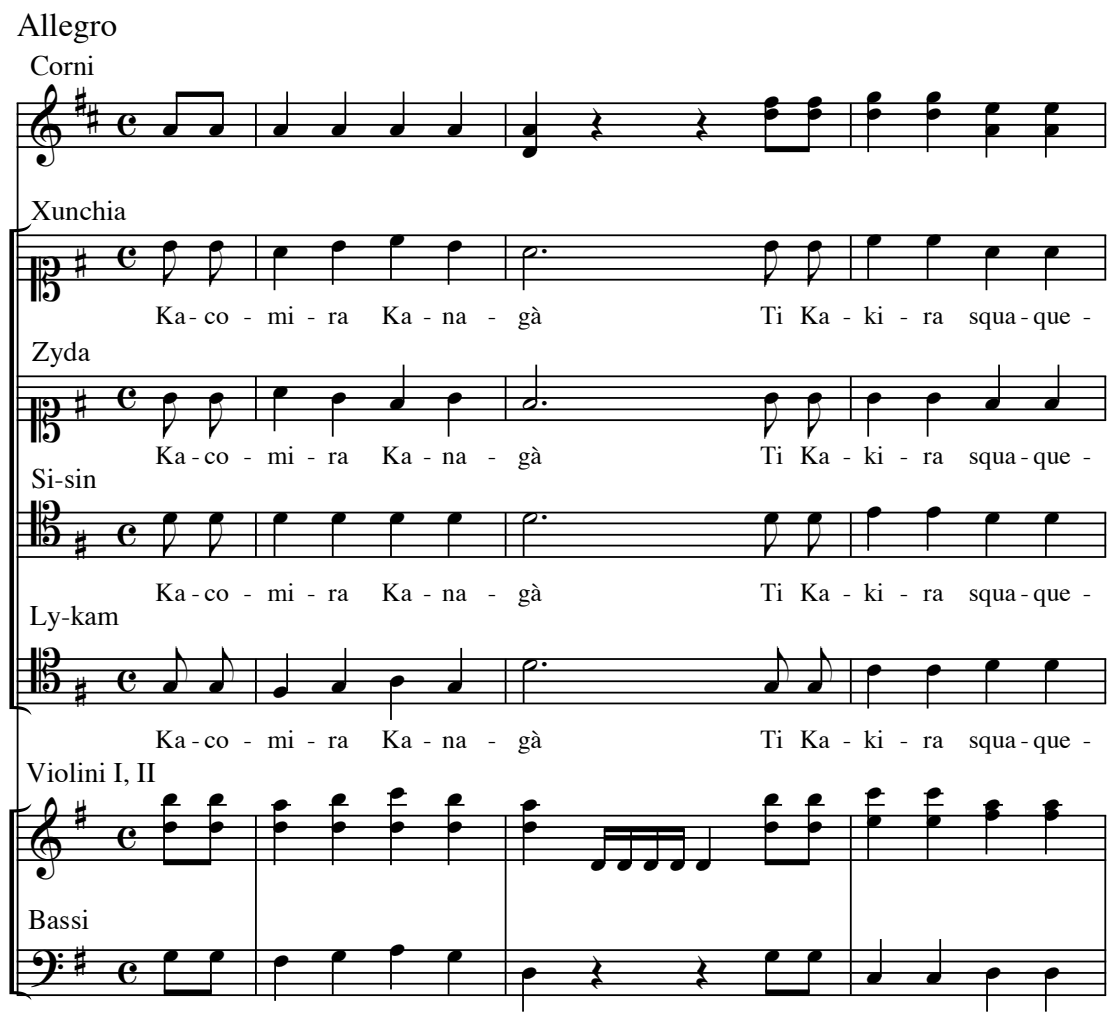




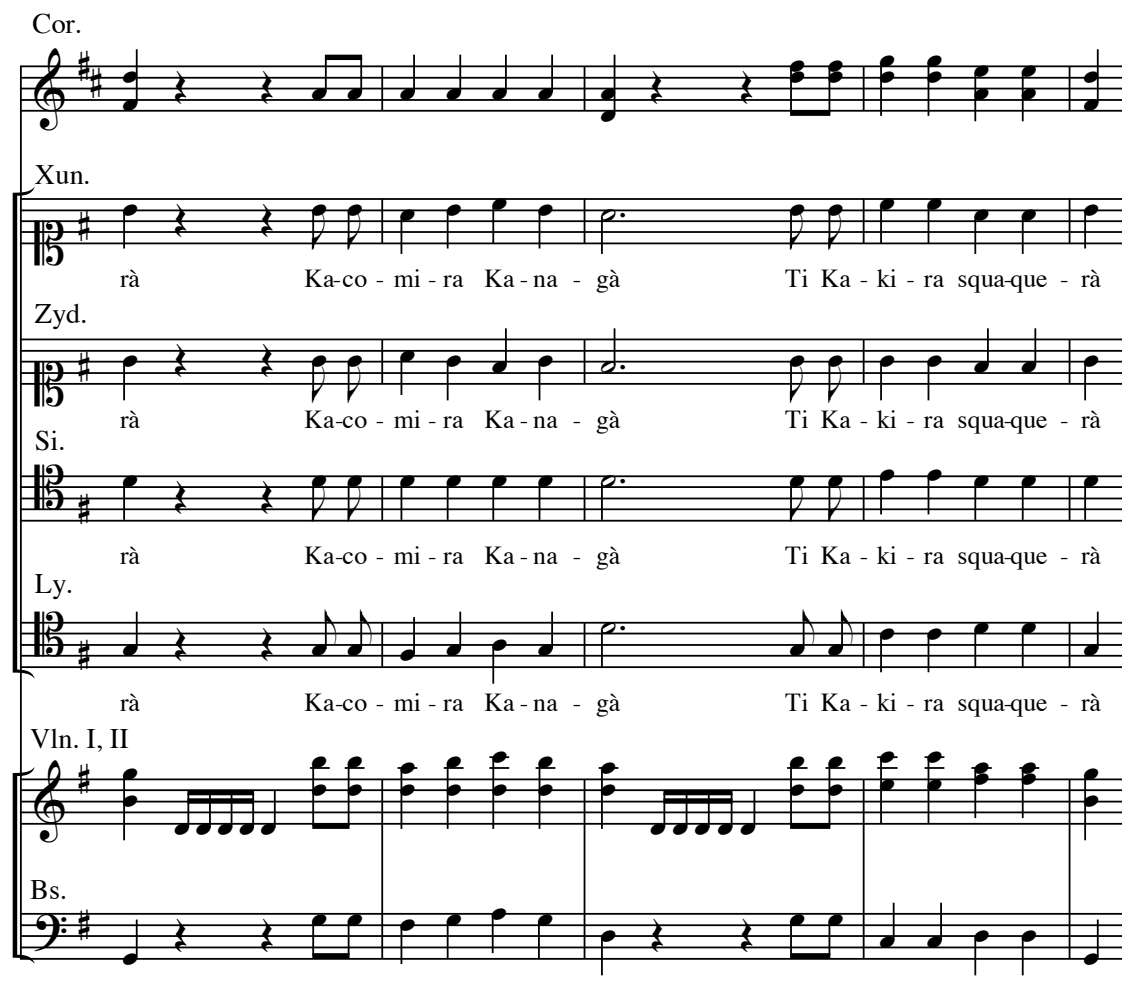

45 Galuppi/Bertati: L'inimico delle donne. Hg. von Helen Geyer-Kiefl. Mailand 1986

Die Buffa-Figuren bedienen sich bei solchen Gebetsgesängen einer fremden, gelegentlich als archaisch hingestellten Sprache, um sich bei ihren Idolen und Orakeln verständlich zu machen und um - ähnlich wie es mit Zaubersprüchen geschieht eine magische Atmosphäre hervorzurufen oder das Numinöse heraufzubeschwören. So singen sechs Figuren in "Le gelosie fortunate" der Statue des „Moro dell'oblio“ folgendes ,ägyptische“ Gebet:

Bas basacca bas Kulà

Nas obecca bus lukù

Boccarà bus Kuli Kì

Kà mi Kà Ko Kà mi Kà. ${ }^{712}$

712 Livigni/Anfossi: Le gelosie fortunate. Venedig 1786 (II,19). 
Diese an den „Moro dell'oblio“ gerichtete „preghiera egiziana“ soll angeblich unangenehme Geschehnisse vergessen lassen. Allerdings ist die Statue niemand anderer als der verkleidete Diener Giacomino.

Ähnlich soll folgender "cantico greco" in „Lo sposo di tre e marito di nessuna“ der Sibilla Cumana - an deren Stelle sich aber der Gaukler Folletto befindet - einen Orakelspruch entlocken:

Askara ki kila,

Kiriki ko kola,

Ka kara ka kala

Kula kulà. ${ }^{713}$

Zwischen Chinesisch, Ägyptisch und Griechisch scheint für Opera-buffa-Figuren klanglich kein großer Unterschied zu bestehen: Das Spiel mit den Lauten verläuft nach denselben Regeln, das „, $\mathrm{k}$ “ ist mit Abstand der häufigste Konsonant und wird spielerisch mit unterschiedlichen Vokalen und mit anderen Silben kombiniert. Dieser Vorgang erinnert an die kindlichen Spiele mit Geräuschen und Lauten, die Garvey in ihren unterschiedlichen Formen und Entwicklungsstadien von der experimentell-spielerischen Lautbildung vor der Sprachaneignung bis zu „Folgen von Nonsense-Silben“ und "Singsang-Produktionen auf der Grundlage erkennbarer Wortformen" beschreibt und diesbezüglich Folgendes feststellt: „In allen diesen Formen des spielerischen Vokalisierens ist der Sinn der Worte zweitrangig oder nichtexistent: allein Klang und Rhythmus sind diejenigen Elemente, die das Kind erbauen." den erfundenen Sprachen in der Opera buffa behauptet werden, denn das Spiel besteht dabei vor allem im Kombinieren und Variieren von Silben bzw. im Experimentieren mit Klängen innerhalb eines metrischen Schemas und im kreativen Prozess der Erfindung von etwas Neuem bzw. einer neuen „Sprache“, wobei sich aus der Absurdität der Nonsense-Wörter und aus ihrem lustigen Klang ein komischer Effekt ergibt.

Die erfundene Sprache bzw. das „Spiel, als ob man eine fremde Sprache sprechen würde", ist natürlich nur ein Teilaspekt der insgesamt spielerischen Szenen, in denen sie eingesetzt werden: Die Absurdität der erfundenen Sprache trägt einerseits zur karikaturistischen Zeichnung eines fremden Typen bei, dessen „Anderssein“ in Benehmen, Sitten und Ausdrucksweise im Allgemeinen verspottet wird; andererseits dient die Nonsense-Sprache der Veralberung der Leichtgläubigkeit des Gegenübers.

Bei cantico-Gesängen ist die erfundene Sprache Teil eines Rituals. Rituale entsprechen nach Huizinga formal dem Spiel, mit dem sie vor allem die „Heraushebung der

713 Livigni/Cherubini: Lo sposo di tre e marito di nessuna. Venedig 1783 (II,9).

714 Garvey, S. 80. 
Handlung aus dem gewöhnlichen Leben "715 und die Fähigkeit, die Teilnehmer in eine andere Welt zu versetzen, ${ }^{716}$ gemein haben. Ausgehend von einer ganz anderen Perspektive kommt Garvey bei der pädagogischen Analyse des „ritualisierten Spiels“ der Kinder zu demselben Schluss. ${ }^{717}$

In der Opera buffa trägt bei rituellen cantico-Gesängen die Darstellung einer exotischen Fremdsprache dazu bei, die magische bzw. sakrale Stimmung eines feierlichen Rituals zu schaffen, gleichzeitig aber dienen ihre Absurdität, ihr komischer Klang und ihre teilweise obszönen Anspielungen gemeinsam mit dem häufig burlesken Kontext (falsches Idol, Verkleidung, Burla) als Hinweis dafür, dass das Ganze nicht ernst zu nehmen ist. So kippt das schon an und für sich an ein Spiel erinnernde Ritual zusätzlich ins Komische und läuft auf eine Parodie des Rituals hinaus, wobei ähnlich wie in den Verkleidungsszenen die Leichgläubigkeit oder Ehrfurcht gegenüber den magischen Zeremonien der im Buffo-Ritual involvierten Personen verspottet wird. Gerade dieses Kippen ist ein typisches Merkmal von Komik, aber auch von Spiel. Die Voraussetzung für die Ermöglichung dieser Kipp-Bewegung ist die von Scheuerl als Wesenskriterium des Spiels festgestellte „labile Ambivalenz“, die sowohl in den Ritual- als auch in den Verkleidungsszenen unter anderem durch die erfundene Sprache gegeben ist, die die meisten Figuren auf der Bühne für echt halten, aber die sich bei genauem Hinhören als gespielt erweist.

\subsection{Onomatopoesie als Spielfunktion}

Spielerisches Umgehen mit der Sprache wie mit Geräuschen und Lauten kommt in der Opera buffa nicht nur in Zusammenhang mit Verkleidungsszenen und mit kauderwelschartigen Sprachen vor. Häufig findet man eine für kindliche Als-ob-Spiele typische spielerische Nachahmung von Geräuschen oder Klängen vor, die „ein beinahe unerläßlicher Bestandteil des Ereignisses oder der Handlung zu sein"718 scheinen, die gerade gespielt wird. Es handelt sich dabei um konventionalisierte Geräusche, die die verbal und szenisch vermittelte Handlung zusätzlich verdeutlichen und aufgrund ihrer Konventionalität unmittelbar verständlich sind. Im schon erwähnten Duett aus „L'innocente fortunata“ (II,9), in dem der englische Kriegsschiffkapitän

715 Huizinga, S. 26.

716 Vgl. ebd. S. 25.

717 „Ein Ritual ist unmißverständlich ein Spiel. Es zeigt alle deskriptiven Eigenschaften, an denen richtiges Spielen zu erkennen ist. Es ist augenscheinlich genußreich und wird um seiner selbst willen praktiziert (...). Die Botschaft „Dies ist Spiel“ steht gewissermaßen als Devise über dem Ritual.“ (Garvey, S. 144).

718 Garvey, S. 80. 
Brettone und der spanische Oberleutnant Don Gusmano wie zwei kleine Jungen Krieg spielen, wird das gestisch gespielte Schießen mit verbal artikulierten Schussgeräuschen (bù, bù, bù) untermalt. ${ }^{719}$ Dabei handelt es sich nicht um einen Einzelfall: In Anfossis „L'avaro“ $(\mathrm{I}, 3)$ spielt Stefanello auf den Wunsch seines Vaters hin, er solle Berufssoldat werden, eine Kriegsszene vor, um schließlich seine Verweigerung kundzugeben. Nach dem Befehl „Via tirate“ beginnt er in der imaginierten Szene zu schießen, wobei er Schussgeräusche nachahmt:

Allegro

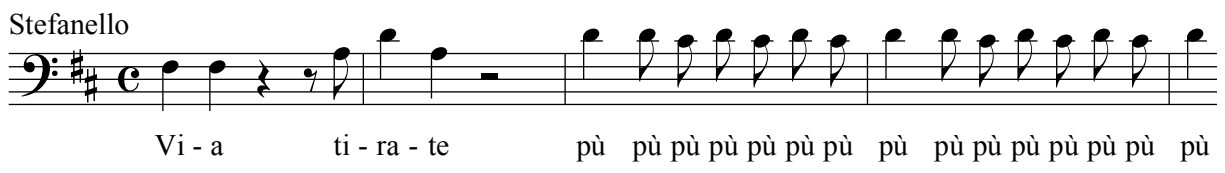

46 Anfossi/Bertati: L'avaro. Venezia 1775 (F-Pn D 105-106)

Auf der Bühne wird ein regelrechtes kindliches Als-ob-Spiel gezeigt, mit dem die Lautmalerei untrennbar verbunden ist, wobei das Verhalten eines erwachsenen Menschen ausgesprochen regressiv wirkt. Die ausgiebige Wiederholung einer einzelnen Silbe scheint bei solchen Kinderspielen typisch zu sein, wie Garvey beobachtet: „Die Wiederholung einer Silbe ist das charakteristische Bauprinzip der meisten dieser Formeln. Sie werden benutzt, um den gespielten Kontext anzureichern oder auszuschmücken, und begleiten stets die passende physische Aktivität."720 Das Prinzip der Wiederholung herrscht auch in der Vertonung solcher Klang- und Geräuschnachahmungen vor, denn die onomatopoetischen Silben werden in den meisten Fällen musikalisch durch Wiederholung desselben Tons oder, wie im eben genannten Beispiel, durch ein wiederholtes Hin- und Herpendeln zwischen zwei Tönen umgesetzt.

Nicht nur in imaginierten Kriegsszenen wird in der Opera buffa das onomatopoetische Spiel betrieben. Wo von Geräuschen und Klängen die Rede ist, wird häufig die Gelegenheit genutzt, diese verbal nachzuahmen und musikalisch umzusetzen, wobei die spielerische Haltung der Buffa-Figuren besonders stark zum Vorschein kommt.

Die lustige Figur des Dieners Raggiro in Paisiellos „La discordia fortunata“ klagt beispielsweise in einer Arie über den Hunger, den er als Diener des geizigen Dottore leiden muss. Die witzige Klage einer Dienerfigur über Hunger und Müdigkeit ist zwar ein beliebter Topos, seine Umsetzung ist in diesem Fall aber originell, denn nach dem lustigen Vergleich seines Bauches mit einer zu vermietenden (also leerstehenden)

719 Siehe Kapitel „Agon“.

720 Garvey, S. 81. 
Wohnung, beschreibt er das Geräusch, das seine Eingeweide in seinem leeren hungrigen Bauch bei jedem Schritt machen.

Par meschina la mia pancia

Una Casa d'affittar.

Slicche slacche le budella,

Che di qua di la sen vanno

Slicche slacche dentro fanno

Se mi metto a camminar. ${ }^{721}$

Das mit dem onomatopoetischen „Slicche slacche“ ausgedrückte Geräusch des hinund herschlotternden Gedärmes ist dabei zudem auch musikalisch wiedergegeben:

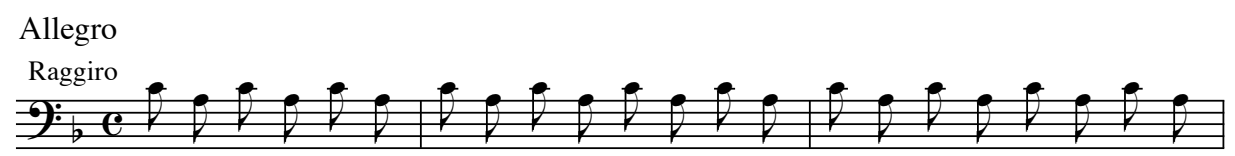

slic-che slac-che le bu - del-la slic-che slac-che den-tro fan-no slic-che slac-che, slic-che

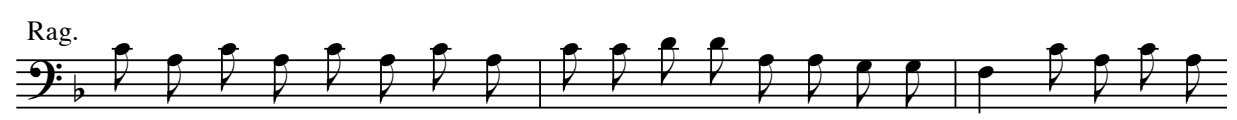
slac-che, slic-che slac-che, slic-che slac-che, se mi met-to a cam-mi - nar, slic-che slac-che,

47 Paisiello: La discordia fortunata. (I-Mc Part. Tr. Ms. 2)

Das Hin und Her der Eingeweide äußert sich musikalisch in einer Is Mal wiederholten Pendelbewegung zwischen den Tönen c und a, die durch das rasche Tempo unterstützt einen für das musikalische Buffa-Idiom charakteristischen mechanischen, zungenbrecherartigen Effekt erzeugt, das Parlando-Plappern, das das Komische und Spielerische des Ausdrucks treffend wiedergibt.

Für solche für die Buffo-Sprache typischen onomatopoetischen Laute könnten noch unzählige Beispiele genannt werden : Der taube Macobrio aus der Oper „L'avaro“ ahmt zum Beispiel das Geschwätz der Frauen nach (brù, brù, brù, brù, brù, brù) und erzählt in der darauffolgenden Arie, wie es sich anhört, wenn Pulcinella auf der Straße spielt $(\mathrm{I}, \mathrm{I} 3)$ :

721 Paisiello: La discordia fortunata. Venedig 1775 (I,9). 
Allegro con spirito

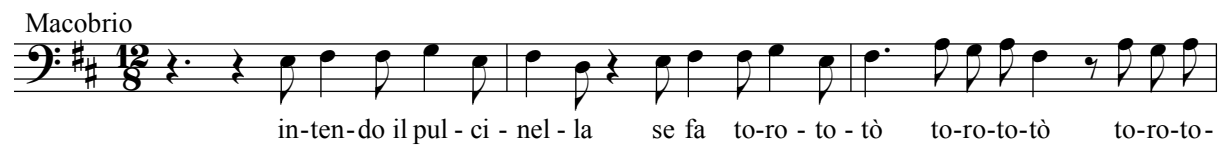

Mac.

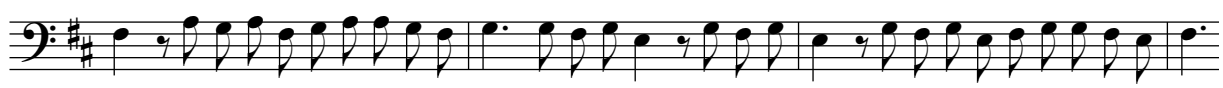

tò to-ro-to to-ro-to to-ro-to - tò to-ro-to-tò to-ro-to - tò to-ro-to to-ro-to to-ro-to - tò

48 Anfossi/Bertati: L'avaro. Venezia 1775 (F-Pn D 105-106)

Tierlaute, vor allem der Vogelgesang, werden gelegentlich imitiert, wie es in der schon untersuchten Einlage im ersten Finale von Cherubinis Oper „Lo sposo di tre“ der Fall war. Hier sangen die Vögel auf „nfri, nfri“ und „chiò, chiò “ genauso wie in der im Quartett (II,IO) aus „Le gelosie fortunate“ eingelegten „canzonetta“ über einen „ruscignuolo“ (Nachtigall), deren Refrain folgendermaßen lautet: „Nfri, Nfrinfrinfri / Chiò, chiocchiorocchiò.“

Häufig werden auch Instrumentenklänge nachgeahmt, vor allem innerhalb von sogenannten Instrumentenarien. In einem vermutlich von Guglielmi stammenden Terzett, das im venezianischen Libretto von Cimarosas „Il falegname“ erscheint, vergleichen beispielsweise drei Figuren in einem Augenblick der Überraschung ihren Herzschlag mit Geklingel, Glocken- und Trommelschlägen, deren Klänge sie auch unmittelbar onomatopoetisch untermalen:

\section{(...)}

Elena: Come suona il mio Campanello!

Va facendo din din, din din din.

Fabio: Come batte il mio Tamburetto!

Ei fa tuppete tuppete ta.

Cecco: Come suona la mia gran Campana!

Don don, don don don, don don don. ${ }^{722}$

Das spielerische Imitieren von Geräuschen und Lauten weist unter den „Spielen der Opera buffa“ meines Erachtens eine sehr große Ähnlichkeit bzw. Übereinstimmung mit den Spielen der Kinder auf und verdeutlicht in besonderem Maße die spielerische Einstellung der Buffa-Figuren. Die verbale Nachahmung von Klängen und Geräuschen beim

722 Palomba/Cimarosa: Il Falegname. Venedig 1784 (II,8). 
Erzählen oder beim Spiel der entsprechenden Handlung ist ein typisches Merkmal der Kindersprache bzw. der „Spielsprache“ der Kinder. Dieses Verhalten könnte auf psychologischen Begründungen fußend als regressiv gedeutet und die sich daraus für die Zuschauer möglicherweise ergebenden Folgen könnten dementsprechend analysiert werden. Das kindliche Benehmen erwachsener Figuren könnte andererseits auch als rokokoartige Verniedlichung oder komische - weil unpassende - Verhaltensweise angesehen werden. Was mit Sicherheit bei diesen Spielen mit Geräuschen und Lauten sowie im Grunde genommen bei allen Momenten des Spiels in der Opera buffa gezeigt wird, ist die Bereitschaft der Buffa-Figuren in beinahe jeder Lebenssituation zu spielen, wodurch eine „von Spiel durchtränkte“ Sichtweise auf die Welt bzw. die Botschaft „alles ist Spiel“ vermittelt wird.

\subsection{Die Burla}

Der absolute Höhepunkt des Spielerischen in einer Opera buffa ist meines Erachtens die für diese Gattung charakteristische Burla. Dieser „Scherz“ oder „Spaß“ - burlare bedeutet „einen Streich spielen“ - findet vorwiegend in den Finali, also in den dramaturgischen und musikalischen Höhepunkten der Opera buffa statt. Es handelt sich um ein typisches Phänomen des Karnevals, währenddessen jeder Scherz erlaubt ist ( $a$ carnevale ogni scherzo vale) und jede Verspottung und jeder Schelmenstreich ungestraft bleibt. Die schon beschriebenen Formen der Verstellung und der Verkleidung sind meistens Bestandteile einer Burla, die immer aufTäuschung beruht, aber im Gegensatz zur Intrige der ernsten oder tragischen Gattungen immer die für die komische Sphäre unerlässliche Harmlosigkeit besitzt und meistens einem guten Zweck dient, beispielsweise der Überwindung von Hochzeitshindernissen. Burle werden gelegentlich einfach aus reinem Spaß zum Zeitvertreib gespielt, sind aber häufig mit intrigenartigen Strategien verbunden, um scheinbar unüberwindbare Probleme auf eine spielerische Art zu lösen und sich aus heiklen Situationen zu retten. Ein solcher Vorgang wird häufig von den Bühnenfiguren selbst mit dem Begriff des Spiels assoziiert, wie beispielsweise aus folgendem Dialog aus Borghis „La schiava amorosa“ ersichtlich ist:

Lelio: Albina, il tuo coraggio

Parmi quasi avvilito.

Albina: $\quad$ Eh non è ver, non son da tanto poco.

Sto ruminando un gioco.

Basta, per or partite

Lasciatemi pensar. ${ }^{723}$

723 Capua/Borghi: La schiava amorosa. Rom 1770 (II,8). 
Lelio fragt Albina, ob sie angesichts der Lage ihren Mut verloren habe, worauf sie zuversichtlich antwortet, sie schmiede gerade einen Plan: ruminare, wörtlich „wiederkäuen“, bedeutet hier im übertragenen Sinne „nachgrübeln“, und als Synonym für Burla, Plan oder Intrige verwendet Albina den Ausdruck gioco. Die Synonymie zwischen Spiel und Burla - ein Synonym des Verbs burlare ist beispielsweise auch prendersi gioco - ist hier kein Zufall, denn eine Burla ist ein spielerisches, kreatives, einfallsreiches, raffiniertes Manöver, um ein bestimmtes Ziel zu erreichen. Die enge Verbindung zwischen Spielorientierung, Problemlösung und Kreativität ist schon häufig festgestellt und durch Experimente bestätigt worden. ${ }^{724}$ Auch in der Opera buffa sind es meist kreative, für die übrigen Figuren auf der Bühne nicht vorhersehbare Einfälle, die einerseits handlungsimmanent die geschickteste Strategie zur Lösung eines Problems darstellen, andererseits dramaturgisch einen Höhepunkt an Heiterkeit und Spannung bewirken. Die Verwendung des Wortes gioco erklärt sich in diesem $\mathrm{Zu}$ sammenhang außerdem auch dadurch, dass Burle immer auf Als-ob-Spielen beruhen und meistens in Heiterkeit mit einem Lachen enden. Was Bachtin über das kollektive Karnevalslachen meint, trifft auch für die Burle der Opera buffa zu: Das „Lachen [ist] ambivalent: es ist heiter, jubelnd und zugleich spöttisch." 725 Das Lachen am Schluss entsteht nämlich immer einerseits aus Freude über das erreichte Ziel, aber auch aus Schadenfreude über das Gelingen eines Täuschungsmanövers und über die Bloßstellung einer dummen oder lasterhaften Person. Die Aufgabe der Komödie, menschliche Schwächen ins Lächerliche zu ziehen, findet also vor allem in der Burla ihre Erfüllung. Wie bei den agonalen Spielen sind die Figuren auf der Bühne auch bei einer Burla gewissermaßen in zwei „Parteien“ unterteilt: die Autoren der Burla bzw. die Eingeweihten, die als Mitwirkende oder als Zuschauer am „Spiel“ beteiligt sind, und die Opfer der Burla, die Ahnungslosen, die hereingelegt und ausgelacht werden. Der Autor einer Burla, also der Erfinder der Strategie, der Drahtzieher des Streichs, ist meistens eine einzelne Person, die nicht unbedingt an der Ausführung der Burla beteiligt sein muss. Nicht selten handelt es sich um eine Dienerfigur, die die Rolle des „Regisseurs“ spielt, denn Schlauheit und Geschicktheit sind Charakteristika, die in der Opera buffa eher den niedrigen Ständen zugeschrieben werden. Die Ausführenden sind meistens die am Resultat der Burla interessierten Figuren, die oft (besonders bei komplexeren Burle) durch weitere Mitwirkende unterstützt werden. Das Opfer einer Burla ist in der Regel eine lasterhafte, gesellschaftlich unangepasste Figur, häufig ein Mann im Rollentypus des lächerlichen buffo caricato, ein geiziger oder tyrannischer Vater, ein alter Mann, der ein junges Mädchen heiraten will, ein übertrieben und zu Unrecht eifersüchti-

724 Vgl. Garvey, S. 65ff.

725 Bachtin, S. 60f. 
ger Ehemann, ein dummer und eitler Geliebter, aber auch eingebildete Gelehrte, die bloßgestellt und lächerlich gemacht werden. Informierte oder nicht informierte Außenstehende, aber auch die an der Burla beteiligten Personen genießen häufig den Streich als Spektakel und kommentieren die Situation von außen wie die Zuschauer eines Theaterstücks. Die Anzahl der Beteiligten kann von zwei Personen (Vollführer und Opfer der Burla) bis zur Teilnahme aller Mitwirkenden auf der Bühne (sieben bis acht Personen) bei großangelegten Burle variieren. Meistens sind sie in einer Gruppe von schlauen Gewinnern gegen einen einzelnen dummen Verlierer unterteilt, wobei die Schlauheit der Buffa-Figuren sich gerade in ihrer spielerischen Haltung, ihrem Einfallsreichtum und ihrer Geschicktheit und Geistesgegenwart äußert, die ihnen erlauben, sich - eben häufig durch Burle - aus schwierigen, ungünstigen Situationen mit Leichtigkeit herauszuwinden. Burle können spontan, also ungeplant durchgeführt werden, wenn sich gerade die Gelegenheit dazu ergibt, wobei nicht nur die Pfiffigkeit der ausführenden Figur, sondern vor allem auch ihre ständige Bereitschaft zum Spiel zum Ausdruck kommt. In diesen Fällen übt die Burla auf das Publikum wie auch auf die übrigen Bühnenfiguren einen Überraschungseffekt aus. Den Burle kann aber auch ein genauer Plan zugrunde liegen, der häufig schon vorher erklärt oder angedeutet wird. In diesen Fällen spielt eher der strategische Aspekt des Spiels, die ausgeklügelte, kreative Problemlösung eine Rolle. Eine oder mehrere Personen werden in den geheimen Plan eingeweiht, gleichzeitig zeichnet sich für das Publikum die Entwicklung der Handlung in Umrissen ab. Durch das dramatische Mittel der Vorausdeutung wird so die Neugier des Publikums geweckt, das sich schon im Vorhinein auf eine lustige Burla freuen kann. Die Burla selbst wird in der Regel äußerst flexibel an die jeweilige Situation angepasst und beruht auf dem Einfall einer Person für Als-ob-Spiele, Tricks, Fallen, Verkleidungen, Verwechslungen und Täuschungen, die unterschiedlich ausfallen können und das Ziel haben, jemanden auf eine mehr oder weniger gutmütige Art hereinzulegen. Die Burla, die immer auf der Verschleierung von wahren Umständen und generell auf Täuschungen beruht, endet fast immer mit einer überraschenden Enthüllung oder Demaskierung. Die Auflösung ist für das oder die Opfer der Burla meistens demütigend, denn sie müssen den erlittenen Betrug eingestehen und sich mit dessen Ergebnis abfinden, wie jeder Verlierer beim Spiel eine Niederlage hinnehmen muss, auch wenn die „Gewinner" ihn auslachen und über ihren Sieg jubeln. ${ }^{726}$

Dieser in groben Zügen geschilderte Mechanismus der Burla erscheint in unzähligen Variationen und Ausformungen in beinahe jeder Opera buffa und verleiht ihr un-

726 Das Opfer der Burla erfährt eine delusione, eine Ent-täuschung, und zwar auch im etymologischen Sinn des italienischen Wortes deludere, aus dem Spiel heraustreten (lassen), wobei der Zusammenhang mit dem Spiel (ludus) wiederum sprachlich zum Vorschein kommt. 
ter anderem den spielerischen, eben „burlesken“ Charakter. Burle können sehr unterschiedliche Ausmaße haben, sie können sich als Bestandteil der Haupthandlung über ganze Finali oder sogar über die gesamte Oper erstrecken, können aber auch auf dramaturgisch vollkommen irrelevante Nebenszenen beschränkt sein und sozusagen als spielerisch-komische Ausschmückung dienen. Letzteres ist beispielsweise bei einem Streich aus der schon untersuchten Oper „La Frascatana“von Giovanni Paisiello der Fall. Der Diener Pagnotta und der Hirt Nardone verstecken sich an unterschiedlichen Stellen und hören dem Gespräch des tutore Don Fabrizio mit Violante zu, während er sie zu einem Turm führt, in den er sie einsperren will. Aus ihren Verstecken heraus mischen sie sich abwechselnd mit frechen Bemerkungen in das Gespräch ein, um den gemeinen Don Fabrizio zu verspotten. Dieser glaubt zunächst, die gegen ihn gerichteten Beschimpfungen kämen von Violante, aber als diese immer dreister werden, bemerkt er, dass die Stimmen aus unterschiedlichen Richtungen kommen, und meint, er werde von einer wilden Bestie angegriffen, die er in einer typischen Echo-Arie zum Kampf herausfordert. Das Witzige an dieser Arie besteht darin, dass Nardone und Pagnotta nach jedem Zweizeiler das letzte Wort wie ein Echo wiederholen, wobei wiederum Beschimpfungen gegen Don Fabrizio entstehen.

Non parlar più da lontano,

Vieni avanti orrenda bestia.

(Na. e Pa. Bestia)

Non credea che qui ci fosse

Un parlar sì brutto, e sporco.

(Pa. e Na. Porco)

Se non freni i detti audaci,

Io, per bacco, qui ti scorno ...

(Na. e Pa. Corno)

Questo tenero compagno,

Venga sempre appresso a te ...

(Pa. e Na. A te.)

Oh cospetto questo è l'Eco

Che ripete i detti a me.

$(\ldots)^{727}$

Nach der vierten Wiederholung dieses Nachäffungsspiels kommt Don Fabrizio schließlich auf die Idee, es könne sich um ein Echo handeln, welches das letzte Wort seiner

727 Livigni/Paisiello: La Frascatana. Venedig 1774 (II,12). 
Sätze nachhallen lässt. Über diese Erkenntnis erfreut, beginnt er fröhlich zu trällern. Pagnotta und Nardone äffen auch sein Trällern spöttisch nach und machen sich darüber lustig, dass der dumme Don Fabrizio sich dadurch in seiner Annahme bestätigt fühlt.

In dieser Echo-Szene, ein bewährter burlesker Topos, dessen Ursprung auf die antike Komödie zurückgeht und in der Opera buffa immer wieder Verwendung findet, ${ }^{728}$ spielen Nardone und Pagnotta ein regelrechtes "game of make-believe“: Aus Spaß lassen sie den tutore glauben, ihre Stimmen seien das natürliche Echo seiner Worte. Ihr Versteckspiel dient dabei gewissermaßen als „Verkleidungsmittel“, denn die Glaubwürdigkeit eines Echos ist an seine Unsichtbarkeit gebunden. Als akustisches Phänomen eignet es sich, in Musik umgesetzt zu werden, so wiederholen Nardone und Pagnotta immer Don Fabrizios letztes Wort und die dazugehörenden Töne.

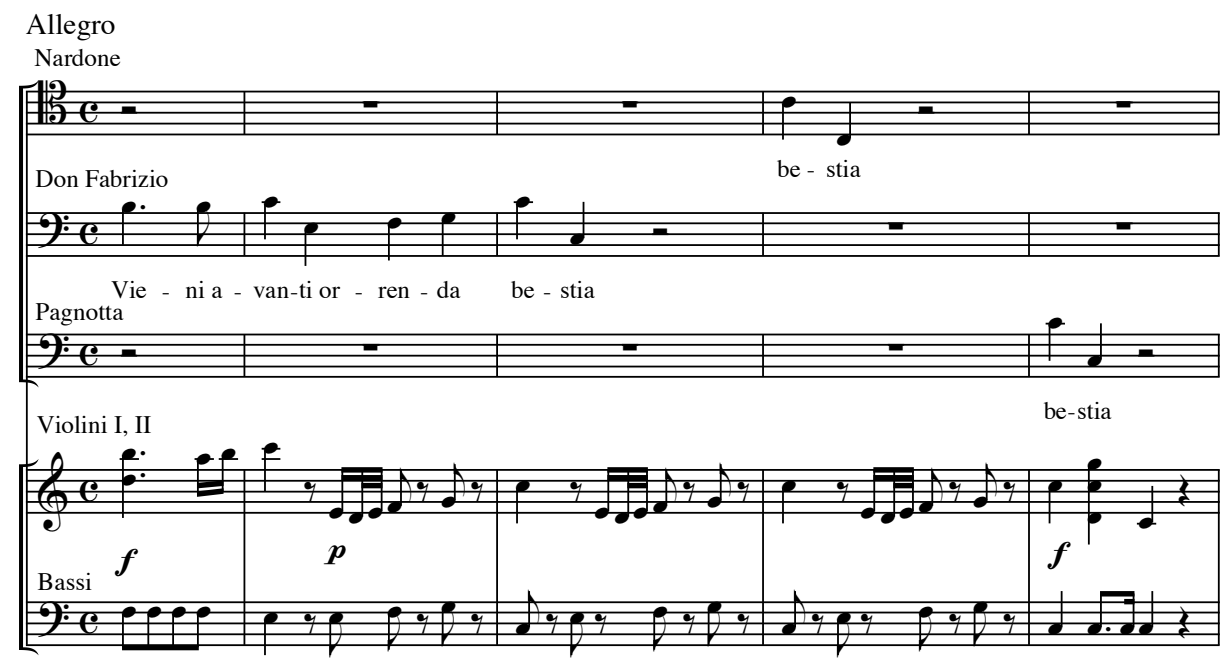

49 Paisiello/Livigni: La Frascatana. (I-Mc Part. Tr. Ms. 308)

Die Musik dieser Arie trägt generell durch das Allegro-Tempo, den Buffo-Stil und das Echo-Spiel zur fröhlichen und spielerischen Atmosphäre der gesamten Szene bei. In der instrumentalen Einleitung fällt erneut ein Motiv auf, das von der schon angesprochenen verzierungsartigen Pendelbewegung geprägt ist, die meines Erachtens den burlesken Charakter besonders zur Geltung bringt.

728 Beispielsweise in „La discordia fortunata“ (I,16), „I pretendenti delusi“ (II,7), „Larbore di Diana“ (II,6). 

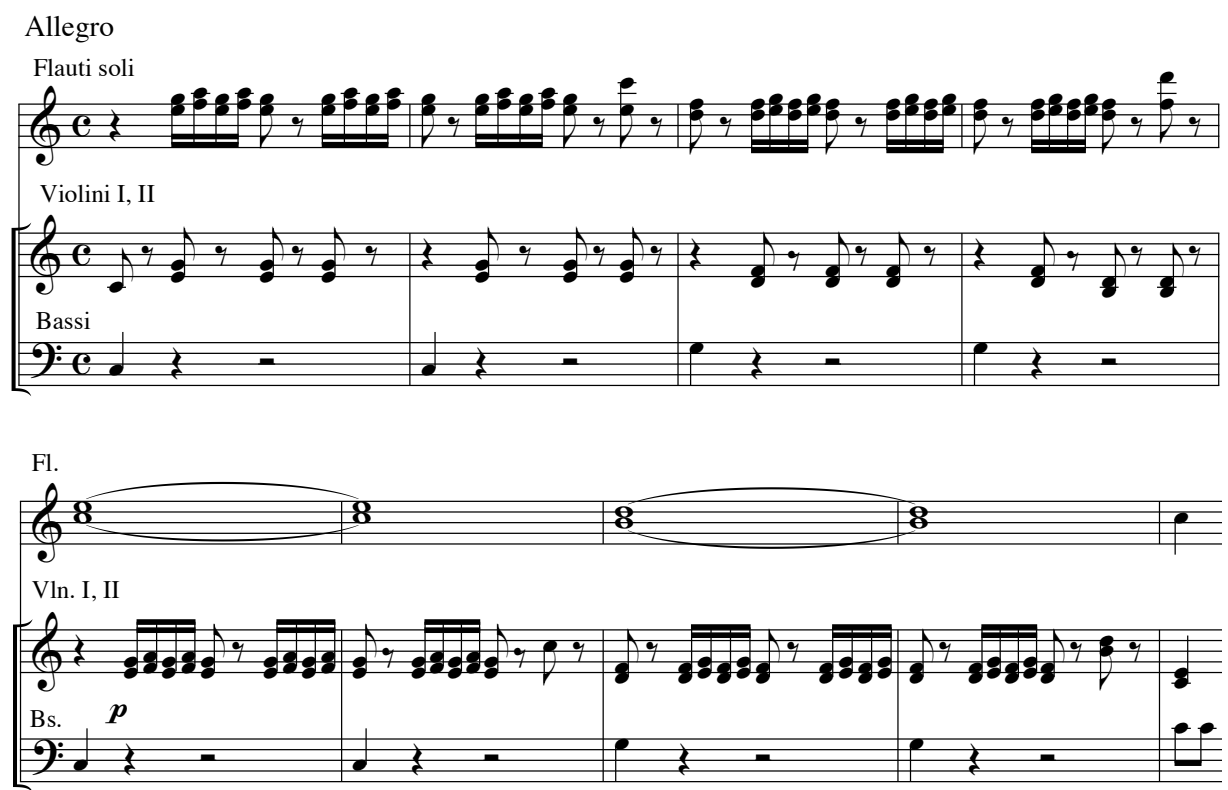

50 Paisiello/Livigni: La Frascatana. (I-Mc Part. Tr. Ms. 308)

Bei diesem im Hinblich auf die Gesamtdramaturgie folgenlosen Scherz findet am Ende keine Demaskierung oder Enthüllung statt, die Bloßstellung des bösen tutore wird für den Schluss der Oper aufgehoben. Die kleine Burla wird aus reinem Spaß gespielt und erfüllt die an Spiel und Komik gebundene Bedingung der Harmlosigkeit. Das Gelingen dieser ungeplanten und spontanen Burla ergibt sich aus dem komplizenhaften Zusammenspiel der im Laufe der Handlung angefreundeten und verbündeten Pagnotta und Nardone.

Das Gegenteil ist im folgenden Beispiel der Fall, in dem die Burla bis ins letzte Detail vorbereitet ist, aber trotzdem nicht ganz aufgeht. Im ersten Finale von Cimarosas "Le donne rivali" nimmt sich Fernando vor, den alten und dummen Sempronio zu verspotten, der eine viel jüngere Frau, Don Annibales Geliebte Emilia, zu heiraten beabsichtigt. Fernando heckt, wie er seinem Freund Don Annibale schon im Vorhinein ankündigt, einen Plan für einen Streich aus:

Fer. Amico ho già l'affare accomodato.

A Sempronio una burla

Noi farem così bella,

Che non sposerà più questa né quella. 


\section{(...)}

Già il tutto preparato; ci pens'io. ${ }^{729}$

Fernando spielt hier den Drahtzieher, reibt sich darüber vor lauter Vorfreude schon die Hände und macht durch mehrere Vorausdeutungen das Publikum auf den Fortgang des Geschehens gespannt. In der darauffolgenden Szene signalisiert er da parte den Beginn der Burla: „incominciam la trama“. Dabei stellt er sich verzweifelt und verrät erst nach und nach den (vermeintlichen) Grund seines Zustands, nämlich seine Vermutung über Emilias Selbstmord, worauf die Anwesenden, Sempronio, das Opfer der Burla, und die in den Plan nicht eingeweihte Laurina sich große Sorgen machen. Die Angabe des Zimmers, in dem Emilia Selbstmord begangen haben soll, ist für das Gelingen der Burla strategisch wichtig, denn Sempronio soll in den eigens für die Burla vorbereiteten Raum gelockt werden.

Fer. In quella stanza oscura,

Ch'è vicina al Parterre, sola sola

A pianger se ne andò. ${ }^{730}$

In einer Zwischenszene (I, I 2) findet eine Absprache zwischen Fernando und Don Annibale „außerhalb des Spiels“ statt. Fernando weiht Don Annibale und vor allem auch das Publikum über die Details und den Fortgang der Burla ein, erteilt Anweisungen für die nächsten Schritte und gibt Emilias Einverständnis und ihre Mitspielbereitschaft bekannt.

Fer. $\quad$ È fatto

Già il colpo. Ritrovatevi

Giù nel Giardin, che riderete. Ho finto

Ch'ella estinta sia già.

$(\ldots)$

Con Emilia istessa

Già il tutto è concertato,

Ella stessa è d'accordo. ${ }^{731}$

729 Cimarosa: Le donne rivali. Venedig $1780(\mathrm{I}, 10)$.

730 Ebd. (I,11).

731 Ebd. (I,12). 
In der nächsten Szene (I, I 3) sucht Sempronio in dem besagten Zimmer nach Emilia, während Fernando sich schon auf die „bella scena“ freut und seine Absicht verrät:

Fer. Or or vedrete, amico,

La bella scena. Fuori che Laurina

Sono tutti d'accordo. Oh che spavento

Avrà Sempronio! Io voglio che rinunzi

Alle nozze d'Emilia,

Dal Tutor ingannata. ${ }^{732}$

Die Burla läuft darauf hinaus, Sempronio Angst einzujagen und ihn zum Verzicht auf die Heirat mit Emilia zu bewegen.

Nach diesen ausgiebigen Vorbereitungen beginnt die eigentliche Burla: Der in die Falle gelockte Sempronio sucht in der besagten „camera oscura“ nach Emilia bzw. nach ihrer Leiche. Don Annibale und Fernando löschen Sempronios Licht aus und nützen seine Angst und die Dunkelheit aus, um ihm als Geister zu erscheinen. Mit ihrer im Accompagnato-Rezitativ vertonten Frage „Olà chi sei?“ beginnt das erste Finale. Sempronio ist von den furchterregenden Stimmen und der unheimlichen Anwesenheit der beiden unbekannten Wesen im Dunkeln derart beängstigt, dass er beinahe meint, sich schon im Reich der Toten zu befinden. In seiner Einbildung sieht er sogar Charon. Um ihm noch größere Furcht einzujagen, machen Annibale und Fernando ihm weis, sie seien „ombre erranti“, worauf Sempronio sich endgültig tot und in der Unterwelt wähnt. Als er nach Emilia fragt, antworten sie, dass sie gerade im Elysium heirate, so dass er sich keine Hochzeit mehr mit ihr erhoffen könne. Der Bezug auf den damals allgemein bekannten Orpheus-Stoff tritt besonders stark in der Abmachung zwischen den „ombre“ und Sempronio auf dessen Wunsch hin hervor, Emilia noch einmal sehen zu dürfen:

D. An. Fer. a 2. La vedrai con patto espresso

Di doverla rinunziar. ${ }^{733}$

Der zu Tode erschrockene Sempronio verzichtet auf die Heirat und darf nun den Geist der verstorbenen Emilia erblicken, was in einer regelrechten Inszenierung erfolgt, die den Höhepunkt der Burla ausmacht: Während sich Fernando und Annibale zurückziehen, um die Szene zu genießen, öffnet sich der Vorhang, ein Garten wird

732 Ebd.

733 Ebd. (I,13). 
sichtbar und Emilia tritt auf, während ein neuer musikalischer Abschnitt beginnt (Allegro maestoso). Die Szenenanweisung ist hier besonders ausführlich und präzise:

Fer., e D. Ann. si ritirano, ed intanto si alza la tela, e si vede un delizioso Parterre guarnito di vaghi Mirtetti, e di Statuette coronate di fiori; dal fondo del quale comparisce Emilia in altro abito; $(\ldots)^{734}$

An dieser Stelle wird klar, warum Fernando ausgerechnet diesen Raum für seine Burla ausgesucht hat: Er ist dunkel und unheimlich und geht auf Sempronios Garten. Um den Auftritt der toten Emilia als Geist glaubwürdig erscheinen zu lassen, musste in Anlehnung an den Orpheus-Stoff das Ambiente der Elysischen Gefilde dargestellt werden. Dafür wurde der Garten eigens für diese regelrechte Inszenierung mit Myrthen und Statuetten geschmückt („artificiosamente adornato"), also gewissermaßen ,verkleidet“. Emilia tritt ebenfalls verkleidet auf und die dazu erklingenden Flöteneinwürfe untermalen die idyllische, pastorale Stimmung der campi elisi. Emilia spielt die Rolle ihres Geistes sehr gut, aber durch das hereinfallende Licht erkennt Sempronio seinen eigenen Garten und beginnt Verdacht zu schöpfen. Während Emilia nach Pluto und Cerbero ruft, tut Sempronio, als würde er weggehen, um dann seine vermeintlich verstorbene Braut mit ihrem Geliebten Don Annibale genau dann zu ertappen, als diese sich über die gelungene Burla freuen. Die Szene endet, wie für ein erstes Finale üblich, mit einem großen Durcheinander: Sempronio hat die Burla aufgedeckt, fühlt sich von Emilia betrogen und will sie auf der Stelle heiraten, Fernando versucht, ihn zu beruhigen und die Burla als harmlosen Scherz hinzustellen. Obwohl die Burla unterbrochen und vom Opfer frühzeitig als solche erkannt wird, kann sie als typisches Beispiel für einen großangelegten Streich dienen: Eine nicht direkt betroffene Person spielt die Rolle des Intriganten, plant und organisiert die einzelnen strategischen Schritte und bereitet die übrigen Spieler vor. Durch die Ankündigung eines Selbstmordes und die im Dunkeln gespielten „ombre“ wird eine Unterweltstimmung geschaffen, um dem Opfer der Burla schreckliche Angst einzuflößen und ihm ein gegen seine Interessen gerichtetes Versprechen abzugewinnen. Nach Erreichung des Zwecks der Burla wird die Darstellung der Unterwelt jedoch durch die Inszenierung der elysischen Gefilde ins Positive gewendet. Der Hebelpunkt des Ganzen ist der Bezug zum damals überaus bekannten Stoff des Orpheus-Mythos: Sempronio muss wie Orpheus einen im Vergleich zum mythologischen Stoff umgekehrten Pakt schließen: Orpheus wird Eurydike wieder ins Leben zurückführen können, wenn er sich nicht nach ihr umschaut, Sempronio dagegen darf seine Braut nur 
unter der Bedingung wiedersehen, dass er auf die Heirat mit ihr verzichtet. Eurydike beklagt sich darüber, dass Orpheus sie keines Blickes würdigt, Emilia tut so, als wäre sie enttäuscht darüber, dass Sempronio auf sie verzichtet hat („Infedel, mi hai rinunziata, / E se Pluto or ora io chiamo ..."). Für das Opfer der Burla soll die Bekanntheit des Stoffs Glaubwürdigkeit erzeugen, während die Außenstehenden bzw. Bühnenzuschauer gerade darüber lachen, dass er eine aus der Mythologie bzw. aus dem Theater als fiktiv bekannte Situation für wahr hält. Wie häufig bei größeren Burle findet hier ein regelrechtes Spiel im Spiel statt, eine kleine fiktive Szene innerhalb der Opernhandlung, die dem Opfer der Burla glaubwürdig, also nicht fiktiv erscheint, während die übrigen Personen diese als Theatereinlage genießen, wie aus ihren Kommentaren am Anfang und Ende der Szene zu schließen ist. Das Spiel besteht hier wie in den meisten Burle also einerseits im durch Verkleidung und Inszenierung erzeugten Theaterspiel, dessen Als-ob-Charakter nur dem Opfer nicht bewusst ist und wofür er am Schluss ausgelacht wird, andererseits in diesem speziellen Fall im „intertextuellen Spiel“ mit einem allgemein bekannten Stoff, der teilweise parodistisch verdreht wird. Das „Spiel“, in das die Zuschauer verwickelt werden, ist durchaus komplex, denn zu den mehrfachen Identifikations- und Distanzierungsvorgängen, die jede „Fiktion in der Fiktion“ in Gang setzt, kommt hier die Identifikation mit den Bühnenzuschauern hinzu, die die Burla als Theaterszene betrachten und genauso wie das „echte“ Publikum „von außen“, also von einem distanzierten Standpunkt aus, über die Bloßstellung des dummen Sempronio lachen. Die Tatsache, dass die Bühnenfiguren die Burla als Theaterszene genießen, verstärkt die Illusion, dass es sich bei der primären Opernhandlung um Realität handelt, und bewirkt so den theatergleichnishaft begründeten Eindruck, dass die Realität voller theatralischen Szenen ist, dass Schauspiel und Verstellung an der Tagesordnung stehen und zur Erreichung von bestimmten Zielen von schlauen Personen eingesetzt werden dürfen.

Zusätzlich tritt hier beim Erkennen der Anspielung auf den bekannten OrpheusStoff „the pleasure of the familiar" ins Spiel, das zunächst Identifikationsvorgänge auslösen kann, aber spätestens beim Bewusstwerden der im Vergleich zur Vorlage komischen Diskrepanzen ein distanzierendes Lachen erregt.

Die Burle und die durch sie erzeugte Heiterkeit tragen nicht nur wesentlich zum giocoso-Charakter der Buffa-Stoffe bei, sondern sind in starkem Maße für den Handlungsfortgang verantwortlich. Als Beispiel dafür, wie sehr eine Opernhandlung von der Aneinanderreihung vieler Burle „lebt“, kann die 1772 in Venedig uraufgeführte Oper von Galuppi „Gl’intrighi amorosi“ dienen. Dieses vor dem ab ca. I776 in Europa erfolgten Boom an Don-Giovanni-Opern entstandene Werk kennzeichnet sich insofern durch einige Don-Giovanni-artige Züge, als im Mittelpunkt der Handlung die Eroberungen des Conte Fioribello stehen, der im Personenverzeichnis als ,amante 
volubile" charakterisiert wird und gewisse Ähnlichkeiten mit dem berühmten burlador aufweist. Sein Diener Pasquino steht ihm nicht nur immer treu zur Seite, sondern zettelt häufig selbst Burle an, die er höchst geschickt an die jeweilige Situation anpasst. Im ersten Akt wünscht sich Fiorbello ein Treffen mit der vom Hörensagen bekannten, wunderbaren Sängerin Donna Aurora, die allerdings von ihrem Gesangslehrer Cromatico unter Verschluss gehalten wird. Von der Dienerin Serpilla erfährt Pasquino, dass Aurora und Cromatico auf eine Gelegenheit für ihr Theaterdebüt warten. Der schlaue Pasquino nutzt sofort die Chance und verschafft sich als polnischer „Principe Impresario“ verkleidet, der für eine neue Oper auf der Suche nach einer Primadonna ist, und seinem sich als Sänger ausgebenden Herrn Zutritt in Donna Auroras Haus. Die große Verkleidungsszene, die Fioribello die Gelegenheit zu einem Flirt mit Donna Aurora bietet, schließt verschiedene kleine Burle ein: Der Diener stellt beispielsweise zwischendurch seinen eigenen Herrn bloß, indem er ihn, der überhaupt nicht singen kann, darum bittet, eine Arie zu singen. Der als Sänger verkleidete Fioribello ist, wie er da parte mitteilt, entsetzt, aber es bleibt ihm nichts anderes übrig, als eine Ariette zu singen. Dabei kommt es zu einer vielfachen Überlagerung von Ebenen, denn ein Sänger interpretiert die Rolle eines Nicht-Sängers, der so tut, als wäre er ein Sänger, aber nicht singen kann. Die mehrere Szenen umfassende Burla wird schließlich vom Auftritt der „ortolana“ Lena gestört, der Fioribello die Ehe versprochen hatte.

Im zweiten Akt sind etliche Burla-Szenen in rascher Folge aneinandergereiht. Ähnlich wie schon im ersten Akt helfen wenige Informationen der Dienerin Serpilla dem Herr-Diener-Paar (Fioribello und Pasquino) eine raffinierte List auszuklügeln, um ins Haus der hübschen Rosina zugelassen zu werden. Serpillas Mitteilung, dass ihr Onkel, der Alchemist Fulgenzio, seine Nichte erst heiraten lässt, wenn es ihm gelingt, Gold herzustellen, ist für die darauffolgende Burla ausschlaggebend. Auch das Detail, dass im Haus keine Männer zugelassen werden, ist für die Wahl der Verkleidung entscheidend. Hier ist es wieder Pasquino, der die Burla ausführt: Als eine gewisse Madama Cornelia verkleidet, ${ }^{735}$ die mit ihrer adeligen Herkunft, mit ihrem hohen Alter ( 998 Jahre) und anderen Spitzenleistungen ( 82 Ehemänner, Iooo Kinder) prahlt, spielt er erneut eine große Karikaturszene. Seine Aussagen sind natürlich vollkommen absurd, aber der von seiner Goldgier geblendete Fulgenzio glaubt ihm alles, sobald er ihm verspricht, ihm bei der Herstellung von Gold zu helfen. Fulgenzio notiert fleißig das abenteuerlich und absurd klingende Rezept, während Pasquino da parte verrät,

735 Die Szenenanweisung lautet: Pasquino vestito da donna il quale fa chiamarsi Madama Cornelia, con gran Cuffia, guardinfante, e coda lunghissima sostenutagli da un Paggio. (...) Diversi Paggi, uno de quali tiene la Cagnola di Madama Cornelia, uno l'ombrello chiuso, e l'altro una Sedia portatile, che si apre, $e$ si serra. (II,7). 
er wolle Goldstaub in Fulgenzios Tiegel legen. Der als Donna Cornelia verkleidete Pasquino verabschiedet sich und verspricht zurückzukehren, sobald Fulgenzio das Gold erzeugt hat. Bevor diese Burla weitergeführt wird, gerät Fioribello in eine andere heikle Lage, aus der er sich nur durch weitere Burle retten kann, nämlich in die an Don-Giovanni erinnernde Situation, dass er gleichzeitig von Lena und Donna Aurora, denen er beiden die Ehe versprochen hatte, überrascht wird. Sekundenschnell entscheidet er sich für das für einen Don Giovanni typische „doppelte Spiel“, beiden Frauen zu schmeicheln, beiden erneut eine baldige Hochzeit zu versprechen und dabei jede glauben zu lassen, die andere sei verrückt.

Fior. Una parola. (piano a Lena)

(...)

È pazza. (accennando D. Aur.)

Colei, non vi fidate. Si figura

D'esser qualche gran cosa,

D'esser una Sovrana.

(...)

Tacete (piano ad Aur. accennando Lena)

La poverina è pazza,

Ed io mi ci diverto: mena schiaffi

Da disperata. ${ }^{736}$

Fioribello betont immer wieder, dass er zum Spaß mit der vermeintlichen Verrückten spiele:

Fior. Lasciate,

Ch'io ci rida un pochetto:

I Pazzi mi divertono.

(...)

Riderete ancor voi, ma ben di core.

(...)

È uno spasso, è un gusto,

(...)

Riderete da vero;

Non v'è simil piacer nel mondo intiero. ${ }^{737}$

736 Petrosellini/Galuppi: Gl'intrighi amorosi. Venedig 1772 (II,9).

737 Ebd. 
Nach und nach schafft er es, sein jeweiliges Gegenüber in sein scheinbar unschuldiges Verlach-Spiel mit einzubeziehen, in dem er sich abwechselnd an Lena und Aurora wendet und jede an die eine Frau gerichtete Schmeichelei der anderen als Burla erklärt.

Fior. Se lo crede la pazza: Deh ridete (piano a D. Aur.)

Scherzo con lei, mio ben, non v'offendete. (piano a Lena)

Son quegli occhi da Sovrana (a D. Aur. e Lena ride credendo che Fioribello la burli)

No non v'è da dubitar:

Deh non siate così strana; $\quad$ (a Lena e D. Aur. ride)

$(\ldots)^{738}$

Fioribellos „doppeltes Spiel“ besteht darin, seine Worte je nach der Gesprächspartnerin abwechselnd als jeweils wahr und falsch vorzuführen, wobei er die Falschheit als harmlosen Scherz hinstellt. Die Wirkung dieser ambivalenten, mehrschichtigen Burla hält allerdings nicht lange an, denn, nachdem sich Fioribello davongeschlichen hat, bemerken die beiden Frauen, dass er sie beide getäuscht hat, und beschließen, sich gemeinsam dafür zu rächen.

Wenige Szenen später wird die von Pasquino begonnene Burla fortgesetzt in der Absicht, Fulgenzio zu überreden, seine Nichte mit Fioribello zu verheiraten. Eigentlich müsste Fulgenzio jetzt, da er dank Pasquinos Goldstaub endlich Gold hergestellt hat, ohnehin bereit sein, in Rosinas Hochzeit einzuwilligen; also dient diese weitere Burla vorwiegend der Bloßstellung des leichtgläubigen Fulgenzio. Unter einem Tisch versteckt, hört Pasquino dem Selbstgespräch des Alchemisten zu, das ihm die Idee für eine passende Burla eingibt.

Ful. Ecco qui: l'oro è fatto.

Non può esser più lucido ...

E pur mi batte il cor ... Sia maledetto

Quel libraccio, ch'ho letto.

Mi par di veder sempre

Astarot, Belzebù, con tutti i Diavoli,

Che ho nominati ... e poi quella Cornelia ...

Quella Matrona ... ho del sospetto grande

Che non fosse un Demonio ...

738 Ebd. 
Pas. $\quad$ Ha letto un Libro, $\quad$ (alzando il tappeto ed uscendo pian piano)

Teme di Belzebù? Zitto; t'ho inteso. ${ }^{739}$

Der schlaue Diener Pasquino erkennt an Fulgenzios Angst, das Gelingen der Goldherstellung könne einem Teufelspakt zu verdanken sein, sofort die Gelegenheit zu einer Burla und setzt sie auch blitzschnell in die Tat um, indem er Fulgenzios eigene Idee aufgreift. Dieser glaubt nämlich, Cornelia (d.h. der vorher als Cornelia verkleidete Pasquino) sei ein Teufel und nehme ihn als Gegenleistung für das geheime Goldrezept mit. Der Beginn der Burla ist durch den Übergang vom Secco- zum AccompagnatoRezitativ gekennzeichnet, das die unheimliche Stimmung unterstreicht. Um als Teufel glaubwürdig zu wirken, stellt Pasquino die angebliche Verwandlungsfähigkeit des Teufels unter Beweis, indem er so tut, als würde er sich in Fioribellos Gestalt verwandeln. Der Trick besteht darin, in einer Cavatina einen Zauberspruch zu singen und sich zu verstecken, während der echte Fioribello eintritt. Als vermeintlicher Teufel will Fioribello nun Rosina statt ihres Onkels mitnehmen und heiraten, die Burla wird aber durch die beiden inzwischen verbündeten Rivalinnen Lena und Donna Aurora gestört. Pasquino wird schließlich (gegen Ende des zweiten Finales) hinsichtlich der drei Streiche und der jeweiligen Verkleidungen zum Geständnis gezwungen.

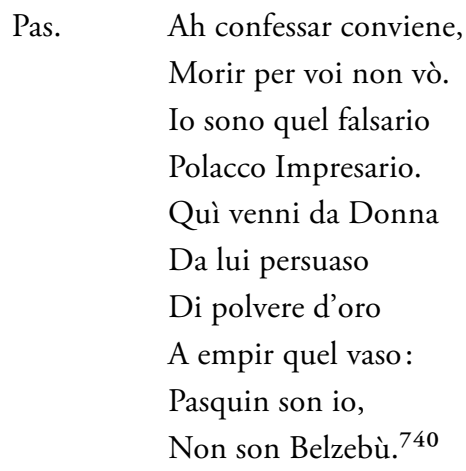

Im dritten Akt hegen alle Rachepläne gegen den Conte Fioribello, wofür der klügste Vorschlag von der schlauen Lena kommt:

Il mio consiglio poi

Per punirlo sul vivo

739 Ebd. (II,13).

740 Ebd. (II,13). 
Sarebbe quel di maritarsi tutte,

E trovarsi all'istante

Uno Sposo, un Amante. ${ }^{741}$

Cromatico soll Rosina und Fulgenzio Donna Aurora heiraten. Niemand durchschaut jedoch, dass Lena damit beabsichtigt, ihre Rivalinnen aus dem Feld zu schlagen und Fioribello selbst zu heiraten.

Len. (Le rivali

Ci son cascate.) Mie Signore addio

${\text { (Son sola adesso, Fioribello è mio. })^{742}}^{72}$

Als der von allen Frauen abgewiesene Fioribello Selbstmord begehen will, verlangt Pasquino von seinem Herrn für alle geleisteten Dienste eine Entlohnung und erinnert dabei an den geldgierigen Diener Sganarelle in Molières Dom Juan, der beim Untergang seines Herrn „Mes gages! Mes gages!“ ruft. Die Rechnung für alle Burle, die Pasquino für seinen Diener ausgeheckt hat, ist in einer typischen Katalogarie vertont:

Per le lettere portate

Alle vostre innamorate

Cento scudi almen vorrei,

E la tassa è poca ancor.

Perchè feci da Impressario

Mi contento d'altri cento.

Mille scudi come Femmina,

Mille scudi come Diavolo,

Altri mille per gl'incomodi,

Per il rischio, e la paura.

Fate presto la scrittura,

Poi scannatevi, uccidetevi,

Che Pasquin secondo il solito

Vi sarà buon servitor. ${ }^{743}$

741 Ebd. (III,1).

742 Ebd.

743 Ebd. (III,4). 
Trotz der vielen Anspielung auf den aus dem Sprechtheater bekannten Don-GiovanniStoff, ist diese Oper an die Konventionen der Buffa-Tradition angepasst und endet mit einer dreifachen Hochzeit. Die Gestalt des Libertins, der eigentlich als burlador und Spieler schlechthin gilt, erscheint hier als eine eher passive Figur, während die Vertreter der niederen Stände mit ihrer Schlauheit und ihrem spielerischen Einfallsreichtum die Aktion lenken. Der Erfinder und Protagonist der vielen Burle, ohne die beinahe keine Handlung bestehen würde, ist meistens der Diener Pasquino, und es ist gerade die listige Gemüsegärtnerin Lena, die nach einem geschickt geführten Konkurrenzkampf gegen ihre weiblichen Rivalinnen schließlich den Schürzenjäger Fioribello heiratet.

In "Gl'intrighi amorosi“ wird der Handlungsverlauf hauptsächlich durch eine Folge von Burle katalysiert; häufig besteht das Gerüst einer Buffa-Handlung auch aus einer einzigen, sich wie ein roter Faden durch das gesamte Stück ziehenden Burla. Als Beispiel dafür kann Paisiellos „I filosofi immaginari“ dienen, das 1779 in St. Petersburg uraufgeführt und 1782 in Venedig erstaufgeführt wurde. Die Konstellation ist typisch: Ein schrulliger Vater, der visionäre Philosoph Petronio, möchte seine Tochter Clarice verheiraten, akzeptiert aber ihren Geliebten nicht, weil dieser seine wissenschaftlichen Untersuchungen über die Vogelsprache und den unsichtbar machenden Stein Heliotrop nicht ernst nimmt. Daraufhin heckt der Bewerber, der den sprechenden Namen Giuliano Tiburla trägt, eine raffinierte Burla aus, um trotzdem zur Heirat zu gelangen. Als Latein sprechender Philosophiestudent verkleidet, kündigt er die Ankunft seines (natürlich imaginären) Lehrers, des berühmten Philosophen Argatiphontidas an. Der eitle Petronio fühlt sich durch diesen Besuch geschmeichelt und hegt keinerlei Verdacht. Eine große Burla durchzieht beinahe den gesamten zweiten Akt, in dem Giuliano als uralter, vom Husten geplagter Argatiphontidas auftritt, der behauptet, seinem hundertsten Geburtstag nahe zu sein, an dem er seine Haut wechseln wird. Giuliano macht sich Petronios Interesse für die Sprache der Vögel zunutze und behauptet, er habe vom Phönix in Arabien das Hautwechseln gelernt. Petronio ist natürlich begeistert („Che sento! Oh che gran cose voi capite il parlar degli uccelli?"“), will von Argatiphontidas die Vogelsprache lernen und fragt ihn nach der Bedeutung bestimmter Stellen in Argatiphontidas' Wörterbuch. Giuliano nützt die Gelegenheit, um Clarice wichtige Mitteilungen zu machen, die Petronio als Übersetzung bestimmter Vogellaute versteht. Als „Angelpunkt“ für diese „doppelte Kommunikation“ dient Giulianos Ankündigung „Io vi darò la Scuola“, die angeblich an Petronio gerichtet ist und sich auf den Unterricht in der Vogelsprache bezieht, in Wirklichkeit aber an Clarice gerichtet ist, der er daraufhin erklärt, sie sollten nach der Burla lieber fliehen, um zu heiraten, während Petronio diesen Satz als Übersetzung des Vogellautes „cioch, cioch“ versteht. Der Höhepunkt der Burla findet aber im zweiten Finale statt, als Giuliano ein nächtliches Erneuerungsritual inszeniert. Zunächst lässt er alle 
Anwesenden ein Schriftstück unterschreiben, wie es zu Beginn des Rituals angeblich vorgeschrieben ist. Während alle damit beschäftigt sind, einen an Pluto, den Gott der Unterwelt, gerichteten feierlichen cantico anzustimmen, der konventionsgemäß spielerisch erfundene Lautbildungen enthält,

Coro: $\quad$ Sia propizio ser Pluton

Col flin, flin, e col flon, flon,

E rinnovi in lui l'età

Per virtù del Tapatà. ${ }^{744}$

legt Giuliano seine Philosophenverkleidung ab. Alle Anwesenden bewundern seine Verjüngungsfähigkeit, aber der eigentliche Überraschungsmoment kommt erst, als Petronio den verjüngten Argatiphontidas als Giuliano erkennt und sich herausstellt, dass er zu Beginn des Rituals seine Zustimmung zur Hochzeit von Clarice und Giuliano unterschrieben hat. Petronio reagiert auf den Reinfall mit einem Wutanfall.

Petr. Il Signor Giulian Tiburla (ironicamente e con rabbia)

Mi ha burlato già. ${ }^{745}$

Schließlich bleibt ihm aber nichts anderes übrig, als seine Niederlage hinzunehmen und der Hochzeit zuzustimmen. Trotzdem bleibt hier im Gegensatz zu allen anderen untersuchten Opere buffe, in denen zum Schluss immer Freude und Fröhlichkeit siegen, die Stimmung etwas gedrückter: Die gemischten Gefühle der Anwesenden sind das Thema des Schluss-Chores.

Tutti: Oh che funesta scena,

Mista di gioja, e pena!

Oh che fatal momento

Di smania e di contento

Amor provar ci fa. ${ }^{746}$

Die Besonderheit dieser beinahe die gesamte Handlung durchlaufenden Burla liegt vor allem in der Inszenierung der Demaskierung und in der ambivalenten Stimmung am Ende. Ansonsten entspricht sie den typischen Kriterien der Burla: Diese wird

744 Bertati/Paisiello: I filosofi immaginari. Venedig 1782 (II,10).

745 Ebd.

746 Ebd. 
erst dann in Gang gesetzt, wenn über „normale“ oder erlaubte Wege - Giuliano hält im ersten Akt umsonst bei Petronio um Clarices Hand an - das Ziel nicht erreicht werden kann. Die Schwäche einer Person wird wie üblich nicht nur bloßgestellt und ausgelacht, sondern dient als Angelpunkt für die Burla: Während bei vielen Burle die Dummheit oder Angst des „Opfers“ genutzt wird, ermöglicht hier (genauso wie im vorigen Beispiel) die Leichtgläubigkeit der in der Opera buffa immer als etwas verrückt, aber vor allem eitel und wichtigtuerisch dargestellten Wissenschaftler oder Gelehrten das Gelingen der Burla. Ihre fixen Ideen, wie die Vogelsprache oder die Golderzeugung, werden als Schwachstelle immer für die Erfindung einer Burla genutzt. Durch absurde und komisch wirkende „Experimente“, wie den Hautwechsel in Argatiphontidas' Erneuerungsritual oder das absurde Rezept für Fulgenzios Golderzeugung, nehmen die realistisch und praktisch denkenden Buffa-Figuren die schrulligen, in den Wolken schwebenden Wissenschaftler aufs Korn. Einfallsreichtum und Strategie sind typische Merkmale, die den Burle einen spielhaften Charakter verleihen. Dasselbe gilt für die dabei angewandten Mittel, die als phantasievolle Alsob-Spiele bezeichnet werden können; Verkleidungen, manchmal regelrechte Inszenierungen, wie der Auftritt des Geistes der Emilia in dem als Elysium „verkleideten“ Garten oder das Erneuerungsritual als Beweis für die scienza des Argatiphontidas, dienen der Erschaffung einer „anderen Welt“. Häufig ist es gerade die mysteriöse, magische, suggestive Stimmung, die das Gelingen einer Burla ermöglicht: Die Darstellung der Unterwelt mit den unheimlichen ombre in „Le donne rivali“, der Auftritt eines Teufels in "Gl'intrighi amorosi“ oder das vom mythischen Phönix in Arabien in einer geheimnisvollen Vogelsprache erlernte magische, in der Nacht bei Mondschein vollzogene Ritual schaffen zusammen mit magischen Formeln, Zaubersprüchen und cantico-Gesängen immer eine suggestive Atmosphäre, die die Opfer der jeweiligen Burla in die Falle lockt und es ermöglicht, ihnen Verträge zuzuschieben und Unterschriften, Versprechen, Schwüre, Pakte u. ä. abzunötigen.

Während aufgrund dieser Zweckmäßigkeiten bei solchen burlesken Intrigen Huizingas Spielmerkmal des „Ziels in sich selbst“ nicht erfüllt wird, könnten die dabei erschaffenen „magischen Welten“ durchaus mit der für das Spiel typischen „zeitweiligen Aufhebung der ,gewöhnlichen Welt “" in Verbindung gebracht werden. Nicht in jeder Burla werden solche überirdischen Bezüge simuliert, aber meistens wird doch durch Verkleidung und Schauspiel innerhalb der Bühnenwirklichkeit eine zweite Fiktionsebene geschaffen, wobei von einem regelrechten „Spiel im Spiel“ gesprochen werden kann. Die Überlagerung oder Verschachtelung von Fiktionsebenen vergegenwärtigt und potenziert dabei einerseits den Spielcharakter der Theatersituation, ${ }^{747} \mathrm{schafft}$

747 Vgl. Martini, S. 351. 
aber andererseits auch durch die besondere performative Dichte und die der Burla innewohnende Komik ein höchst unterhaltsames Spektakel, das als dramatischer Höhepunkt der Oper meist in einem umfangreichen Finale placiert ist. Bei aller Heiterkeit schwingt in vielen Burle auch ein gewisser Ernst mit, denn aus der Perspektive des Opfers des Streichs wird die Burla meist nicht so sehr als Spiel, sondern eher als eine gemeine Bloßstellung und ein Betrug verstanden. Wie auch das Spiel im Allgemeinen weisen also auch manche Burle einen ambivalenten Charakter auf.

\subsection{Selbstbezüglichkeit als Spielfunktion: Die Oper in der Oper}

Mit „Spiel im Spiel“ sind in dieser Arbeit im Gegensatz zu Pfisters engerer Definition $^{748}$ im Allgemeinen alle Momente der Opernhandlung gemeint, in denen durch das schauspielerhafte Verhalten einer Figur eine zweite Fiktionsebene, also ein zweites Als-ob innerhalb der primären Spielebene entsteht. Einen speziellen Fall bildet dabei das „Theater im Theater“, also die Theatereinlage, die im Rahmen der primären Spielebene eines Theaterstücks stattfindende Theateraufführung, von der Pfister spricht. Auf den Bereich der Oper übertragen, würde man von einer in einer Opernhandlung eingebetteten Opernaufführung sprechen. Unter dem Begriff „Oper in der Oper“ wird allerdings im Allgemeinen nicht nur eine Operneinlage verstanden, sondern jeder in einer Opernhandlung eingebaute direkte Bezug zur Welt der Oper und des Opernbetriebs, und zwar zu Recht, denn es findet dabei ein sehr ähnliches „Spiel“ zwischen Theater bzw. Oper und Realität statt, das das Funktionieren des Mediums Oper zur Schau stellt. Dabei kann es sich um einzelne Elemente, wie einzelne Personen, einzelne Arien oder Szenen handeln, oder um ganze Opern, die sogenannten metamelodrammi, die der Realität des Opernbetriebs entnommen sind und auf der primären Spielebene verbleiben. In beiden Fällen handelt es sich um einen besonders beliebten Topos der Opera buffa.

Zunächst werden nun im Anschluss an das Kapitel über die Burla Fälle untersucht, in denen „Opern in der Oper“ im Rahmen von Burle und Verkleidungen, also auf einer sekundären Spielebene stattfinden. Anhand eines Beispiels aus der Oper „Il pittore parigino" von Domenico Cimarosa, die I78 I in Rom uraufgeführt und 1783 in Venedig wiederaufgenommen wurde, kann zusätzlich gezeigt werden, wie die bisher der Übersichtlichkeit halber eher getrennt behandelten Arten von Als-ob-Spiel, die selten in reiner Form vorkommen, miteinander vermischt und verknüpft sind. Die-

748 „Ein Teil des Personals der übergeordneten Sequenzen führt vor einem andern Teil ein Theaterstück auf. Durch diese Einbettung einer zweiten Fiktionsebene wird im inneren Kommunikationssystem die Aufführungssituation des äußeren Kommunikationssystems wiederholt." (Pfister, S. 299). 
selbe Szene kann nämlich als Beispiel für eine Verkleidung, für eine Burla, für eine metatheatralische und eine imaginierte Szene dienen. Es handelt sich um die Burla der schlauen Cintia zur Rückgewinnung ihres geliebten Baron Cricca, der aufgrund einer Testamentklausel die Dichterin Eurilla heiraten soll, die wiederum in einen französischen Maler verliebt ist. Mit dieser Heirat ist auch eine beträchtliche Geldsumme verbunden, die im Fall von Eurillas Verzicht auf die Heirat mit dem Baron an ihre Kusine Cintia gehen würde. Cintia versucht also, den Baron in ein schlechtes Licht zu bringen, damit Eurilla ihn zurückweist. Als die Sängerin Farfallina verkleidet sucht sie Eurilla auf mit dem Vorwand, in ihrem dramma die Primadonna spielen zu wollen. Den anwesenden Baron Cricca stellt sie als einen protettore hin, der nur die Sängerinnen protegiert, die mit ihm Affären haben, während er die anderen mit seiner Claque niedermacht. Um Eurilla davon zu überzeugen, schildert sie einen offensichtlich erfundenen, also imaginierten Vorfall, ihren eigenen vom Baron verdorbenen Auftritt. Die Erzählung wird nicht nur mit zitierter Figurenrede und darstellerischen Mitteln ausgeschmückt, sondern musikalisch durch die Vertonung in einem Accompagnato-Rezitativ und einer Arie hervorgehoben, deren Beginn mit dem Anfang der in der imaginierten Szene von ihr gesungenen Arie zusammenfällt. In diesem Beispiel sind also besonders viele Spielebenen übereinandergeschichtet: In eine primäre Fiktionsebene, in der die Sängerin Giulia Moroni Raffanelli die Rolle der Cintia spielt, wird durch Cintias Verkleidung als Sängerin Farfallina eine zweite Fiktionsebene eingebettet. Diese imaginiert eine Opernszene, in der Farfallina eine zusätzliche Rolle in einer imaginären Oper spielt und eine Arie singt, die die Sängerin tatsächlich vorträgt, wobei es sich um eine Operneinlage, eine Arie in der Arie handelt. Das „Spiel“ und somit der Reiz der Szene besteht hier also nicht nur wie bei jeder Verkleidungsszene im schauspielerhaften Verhalten der verkleideten Person, die hier zusätzlich eine imaginierte Szene „nachspielt“, sondern auch in ihrem höchst performativen, ja beinahe akrobatischen Hin und Her zwischen den komplex ineinander verschachtelten Spielebenen und Rollen. „Spielerisch“ sind auch die vielfältigen Bezüge zwischen den verschiedenen Ebenen: Typisch ist das selbstbezügliche Element bei Cintias Verkleidung als Sängerin Farfallina: Die Interpretin spielt trotz der mehrfachen Rollenverschachtelung gewissermaßen sich selbst in ihrer eigenen Rolle als Sängerin, die aber natürlich durch karikaturistische Überzeichnung wiederum verfremdet wirkt. Abgesehen von diesem Realitätsbezug herrschen zwischen den verschiedenen Fiktionsebenen diverse Analogien. Die von Cintia imaginierte Opernhandlung spiegelt nämlich exakt die Konstellation der primären Spielebene wider: Cintia spielt in der imaginären Oper die Rolle einer „amante tradita“, die ihrer Rolle der verlassenen Liebhaberin in der „Haupthandlung“ entspricht. Während auf der imaginären Bühne ihr „amante disleale“ und ihre Rivalin anwesend 
sind - auf der echten Bühne hören ihr der Baron, also ihr untreuer Liebhaber, und Eurilla, ihre Rivalin zu -, singt sie eine Arie vor, deren Beginn dem Typus der aria di amante abbandonata entspricht. Die Einlage enthält also indirekte Mitteilungen an die anwesenden Bühnenzuschauer: Bei der typischerweise mit einer Frage („Perché togliermi lo sposo ... ?") beginnenden Klage der betrogenen Liebhaberin wendet sich Cintia/Farfallina an Eurilla; die darauffolgende Morddrohung an den untreuen Mann richtet sie an den Baron. Schließlich wendet sie sich (mit dem typischen Versbeginn „Donne mie ...") an die Frauen im Publikum, um ihr Schicksal zu beklagen. Auch die charakteristische illusionsbrechende Wendung ad spectatores ist also in der Einlage eingeflochten und trägt dazu bei, das Publikum in das komplexe Beziehungsspiel zwischen den verschiedenen Fiktionsebenen und der Realität der Theatersituation einzubeziehen. So wie in den meisten metatheatralischen Momenten der Opera buffa geben selbstbezügliche Elemente einen Einblick in die Funktionsweise des Mediums Oper: Farfallina schildert während ihrer Erzählung nicht nur die Ereignisse, die sich im imaginären Zuschauerraum abspielen, das Gelächter und die Ausrufe des Barons und seiner Claque samt ihrer wörtlichen Wiedergabe, sondern kommentiert auch ihre eigenen Aktionen und Gesten auf der Bühne, beispielsweise ihre bei der klagenden Wendung ad spectatores durchgeführte flehende Armbewegung („come fan le brave attrici“ = wie es die guten Schauspielerinnen machen), wodurch der Zuschauer einen Einblick in das „Spiel“ erhält. Die Anspielung auf bestimmte Topoi der Opera buffa, die der erfahrene Zuschauer leicht wiedererkennen kann, sowie die Spiegelungen zwischen den verschiedenen Ebenen machen den Spielcharakter der Opernhandlung bewusst und setzen eine Art Illusionsspiel in Gang, das aufgrund seines starken Realitätsbezugs insbesondere an Finks Feststellung hinsichtlich der Seinsverfassung des Menschenspiels als „ein seltsames Ineinander von ,Sein“ und Schein'“749 erinnert.

An einem zweiten Beispiel für die „Oper in der Oper“ wird ersichtlich, wie eine solche metatheatralische Verschachtelung von Schein und Sein als Trick für eine Burla dienen und den roten Faden einer ganzen Buffa-Handlung ausmachen kann. In der I773 in Venedig aufgeführten Oper „Don Anchise Campanone“ von Lorenzi und Paisiello, die 1772 in Neapel unter dem Titel „Gli amanti comici“ uraufgeführt worden war, geht es um den Streit zwischen der frivolen Sofonisba und ihrem altmodischen Ehemann Ruttilio darüber, wen Candida, Ruttilios Tochter aus erster Ehe, heiraten soll. Sofonisba möchte sie mit ihrem eigenen Cicisbeo, dem Conte Piroletto verheiraten, während Ruttilio seine Tochter einem unbekannten Baron (Don Anchise Campanone) versprochen hat. All diesen Plänen zum Trotz ist Candida heimlich in

749 Fink: Spiel als Weltsymbol. S. 32. 
den schüchternen Ottavio verliebt, der ihre Liebe ebenso heimlich erwidert, aber nicht wagt, es ihrem Vater mitzuteilen. Gerade in dem Moment, in dem der zurückhaltende Ottavio endlich Candida seine Liebe erklärt ( $\mathrm{I}, \mathrm{IO})$, werden sie vom Vater ertappt. Ruttilio ist aufgebracht, seine Tochter hat aber einen guten Einfall, um sich aus dieser heiklen Situation herauszuwinden: Sie dreht den Spieß um, spielt die Rolle des Opfers, das wegen Sofonisbas schlechter Laune betrübt ist und zur Aufheiterung eine Komödienszene spielt, und beklagt sich weinend darüber, dass ihr selbst dieses unschuldige „divertimento“ verboten wird.

Candida: Ma proprio Carità voi non avete.

Dal mal umor di vostra Moglie oppressa

Cerco di sollevarmi recitando:

E mentre una Scenetta di Commedia

Concerto appena ... Voi barbaramente ... (piang. $)^{750}$

Der Trick besteht also darin, so zu tun, als ob die gerade erlebte Szene nur eine Fiktion, eine Operneinlage wäre. Glaubwürdig ist die Ausrede deswegen, weil das Komödien-Spielen offensichtlich eine übliche Beschäftigung der gehobenen Gesellschaft der Zeit war. ${ }^{751}$ Dem gutgläubigen Ruttilio tut es aufrichtig leid, Candida unterbrochen und ungerecht behandelt zu haben, und er ermuntert sie sogar dazu, die Szene mit Ottavio weiterzuspielen, ahnungslos darüber, was er sich gerade einbrockt. Zunächst möchte er nur zuschauen, ist aber, nachdem Candida eine an Ottavio gerichtete Liebesarie - diesmal eine bewusst vorgetragene Einlage, wobei der "falsche“ Name Flaminio als eindeutiges Zeichen der Fiktivität dient - gesungen hat, derartig begeistert, dass er selbst mitspielen möchte und spontan in der Rolle des Regisseurs in das Spiel eintritt, während der Diener Tiberio in die Rolle des Souffleurs schlüpft. Aus Candidas Notlüge entwickelt sich also ein regelrechtes Gruppenspiel, ein Alsob- bzw. Theaterspiel, in dem die Probe einer Opernszene fingiert wird, wobei es zu einer Differenzierung zwischen Personen kommt, die die Opernszene spielen, und solchen, die diese von außen beobachten und kommentieren. Wie es häufig in solchen Situationen der Fall ist, verweist die zweite Fiktionsebene auf die Handlung der primären Spielebene: Hier ist der Kern des Spiels im Spiel, die Liebesszene zwischen Candida und Ottavio, derart mit der „Haupthandlung“ identisch, dass Ottavio sogar dieselben Worte, die er vorher im Ernst gesprochen hatte („La mia pace sol da te di-

750 Lorenzi/Paisiello: Don Anchise Campanone. Venedig 1773 (I,11).

751 Ein berühmtes Beispiel dafür findet sich auch in Goldonis berühmtem dramma giocoso „L'Arcadia in Brenta"; hier spielt eine Gesellschaft in der Sommerfrische zum Zeitvertreib eine Komödie. 
pende“), in der absichtlich gespielten Szene wieder aufgreift („Cara, la pace mia, da te dipende“). ${ }^{752}$ Der Einzige, dem die Übereinstimmung zwischen der gespielten Szene der Realität entgeht, ist Ruttilio. Besonders komisch wirkt seine Ahnungslosigkeit, als er nach Anweisungen zu der von ihm zu spielenden Vaterrolle fragt und auf die Erklärung hin, er solle eine lächerliche Figur darstellen, begeistert behauptet, diese Rolle würde gut zu ihm passen.

Rut. Ehi, dì, Tiberio, il Padre è di Carattere Grottesco, o Serio?

Tib. Oibò: lui è ridicolo

Rut. Or vedi, questa parte

Io la farei con genio. ${ }^{753}$

Vorerst begnügt er sich allerdings mit seiner Regisseur-Rolle und singt eine Abgangsarie, in der er Ottavio und Candida in ihrer Liebesszene im Schauspiel unterweist. Ruttilios Abgang ist für alle Anwesenden das Zeichen für das Ende des Spiels, das sich ohne ihn erübrigt, weil die anderen anwesenden Personen eingeweiht sind. Im ersten Vers der darauffolgenden Szene bemerkt die Dienerin Carmosina bezeichnenderweise „Che Commedia!“, während das Pärchen seine Liebesszene weiterspielt, diesmal jedoch nicht zum Schein.

Das verzwickte und typisch spielerische „Ineinander von Schein und Sein“ äußert sich hier darin, dass das „Spiel im Spiel“ der Verheimlichung der Realität dient. Die für das Spiel charakteristische „labile Ambivalenz“ besteht hier darin, dass dieselbe Szene abwechselnd wirklich erlebt und gespielt wird, wobei Ruttilio als Einziger glaubt, es handle sich immer um ein Spiel.

Dasselbe „Spiel“ wird im Laufe der Handlung wiederholt aufgegriffen, und zwar jedes Mal wenn dem Vater verheimlicht werden soll, dass Candida und Ottavio tatsächlich ein Liebespaar sind. Im zweiten Akt kommt es beispielsweise erneut zu einem Umschlagen von einer höchst ernsthaften Situation - Ottavio ist verzweifelt und will Selbstmord begehen - zurück in das frühere Spiel. Diesmal wird das Kippen von Ernst in Spiel von Ruttilio selbst veranlasst, der Ottavios Verzweiflung und Candidas Schrecken nicht ernst nimmt, die Szene als Fortsetzung der Commedia missversteht und auch seine Frau Sofonisba davon überzeugt:

752 Diese Worte ähneln übrigens sehr dem Anfangsvers der Arie „Dalla sua pace la mia dipende“ aus Da Pontes und Mozarts „Don Giovanni“, die ebenfalls von einem „Ottavio“ gesungen wird.

753 Lorenzi/Paisiello: Don Anchise Campanone. Venedig 1773 (I,11). 
Rut. $\quad$ Eh lasciali pur far, che non è nulla.

Sof. Ma s'ella quasi more...

Rut. $\quad$ È tutta Comica:

Questa è una Scena di disperazione. ${ }^{754}$

Zusätzlich von den zwei soufflierenden intriganten Dienern dazu ermutigt, wechseln die beiden verdutzten Liebhaber also abrupt die Ebene und setzen die gerade nicht zum Schein erlebte dramatische Situation als Schauspiel fort. Ihr unmittelbares „InsSpiel-Kippen“ ist derart geschickt und unauffällig, dass Sofonisba - ähnlich wie schon vorher ihr Ehemann - begeistert mitspielt und mit einer großartigen, wenn auch vollkommen aus dem Rahmen fallenden Kleopatra-Szene ihre besonderen darstellerischen Fähigkeiten zur Schau stellt, um den anderen, besonders ihrem Ehemann, zu imponieren, mit dem nach wie vor Streit herrscht. Wie bei einem echten kindlichen Als-ob-Spiel wählt Sofonisba einige Requisiten aus, erklärt, bevor sie zu spielen beginnt, die Funktion dieser Gegenstände in ihrem Spiel sowie ihre eigene Rolle.

Sof. $\quad(.$.$) presto: olà una Sedia$

Sarà questo il soffa: questo ventaglio

Il serpe, Io la Regina

Tratta dal duolo e dal veleno a morte. ${ }^{755}$

Mit einem als Sofa dienenden Stuhl und einem Fächer als Schlange spielt sie die am Schlangengift sterbende Königin. Die unmittelbare Bereitschaft zum „Spiel“, die typische spontane „Objekttransformation“ und die einleitende Erklärung der gespielten Situation sind sämtlich Elemente, die diese Szene den Fiktionsspielen der Kinder annähern. Sofonisba singt daraufhin eine große Kleopatra-Szene, eine tragische Operaseria-Szene, also eine regelrechte Aufführung in der Aufführung, in der die Primadonna gewissermaßen sich selbst spielt. Genauso wie Ruttilio ist Sofonisba vom „Spielen“ einer Opernaufführung so begeistert, dass ihr nicht auffällt, dass Ottavios und Candidas „Spiel“ eigentlich kein „Spiel“, sondern Ernst ist. Ermöglicht wird dieses unbemerkte Kippen in die zweite Fiktionsebene gerade dadurch, dass die metatheatralische Burla stets im Medium Oper verbleibt und sich auf beiden Ebenen klischeehafte Situationen ergeben: Der Operntopos „Liebesszene“ kann leicht als „Schaltstelle“ dienen, denn er wird unmittelbar mit dem Kontext „Oper“ assoziiert, was einen bruchlosen Übergang zwischen primärer und sekundärer (metatheatralischer) Ebene gestattet. Als in

754 Ebd. (II,9).

755 Ebd. 
der letzten Szene der Oper Candida und Ottavio sich die Hand geben, nimmt Ruttilio immer noch an, es handle sich um das Spielen der fiktiven Liebesszene. Erst am Ende der Handlung wird die Burla und somit das Als-ob-Spiel aufgelöst.

Cand. Son tua. (si dà la mano con Ott.)

Rut. È sempre la Commedia?

Ott. $\quad$ È già finita. ${ }^{756}$

Für das Publikum kann dieses während der gesamten Handlung mehrmals und in unterschiedlichen Kontexten wiederholte Kippen vom Ernst ins Spiel (und umgekehrt) besonders reizvoll sein. Faszinierend ist dabei besonders das labile Gleichgewicht zwischen Spiel und Ernst, das Erkennen der metakommmunikativen Botschaft „Dies ist Spiel“, in den Szenen, in denen die Schauspieler das Schauspielern spielen. Dass sie dabei teilweise exakt dieselbe Szene spielen, die sie unmittelbar davor als wirklich erlebtes Geschehnis dargeboten haben, deckt nicht nur die Mechanismen des Opernspiels als solches auf, sondern stiftet zudem eine durchaus genüssliche Verwirrung und Ambivalenz.

Das faszinierende Spiel zwischen Realität und Fiktion ist unter anderem der Grund für die besondere Beliebtheit der sogenannten metamelodrammi, den „Opern über die Oper“, von denen im venezianischen Buffa-Repertoire der I770er und I780er Jahre mehrere Beispiele zu finden sind. In diesem schon auf das frühe i 8. Jahrhundert zurückgehenden Genre ${ }^{757}$ wird die Realität des Opernbetriebs auf die Bühne gebracht, wobei die Selbstbezüglichkeit in der Opera buffa ihren Höhepunkt erreicht. Durch satirische Verzerrung wird Kritik an den bestehenden Zuständen der zeitgenössischen Opernpraxis geübt und so die Aufgabe der Komödie erfüllt, soziale Unsitten und menschliche Schwächen durch Verspottung humoristisch anzuprangern. Das eigentliche Ziel dieser Werke besteht jedoch in der Unterhaltung und Belustigung des Publikums, deshalb stehen bei solchen Opern die karikaturistische Darstellung von launischen und eitlen Primedonne, ihren streitsüchtigen Müttern, ignoranten Sängern, wichtigtuerischen, geizigen protettori, stotternden Souffleuren, unter Zeitdruck stehenden Komponisten und Librettisten sowie die von all ihren Eifersüchteleien und Streitereien um die sogenannten convenienze teatrali, Affären und Rivalitäten überforderten und überdies meist nahe am Bankrott stehenden Im-

756 Ebd. Scena ultima.

757 Frühe Beispiele sind Intermezzi wie „La Dirindina“ von Girolamo Gigli und Domenico Scarlatti (1712) oder Metastasios „L'impresario delle Canarie“ (1724). Mit diesem Genre inhaltlich verwandt ist auch das berühmte satirische Pamphlet „Il teatro alla moda“ (1720) von Benedetto Marcello. 
presari im Vordergrund. ${ }^{758}$ Ihren Reiz macht in erster Linie das komplexe Verhältnis zwischen Wirklichkeit und Fiktion aus, denn es wird die - wenn auch parodistisch verzerrte - Realität der Opernwelt auf die Opernbühne gebracht. Ob in dieser inszenierten Wirklichkeit auch Anspielungen auf Zeitgenossen oder damals aktuelle Gegebenheiten enthalten waren, ist für den heutigen Rezipienten kaum mehr nachvollziehbar, aber der normalerweise unerlaubte voyeuristische Blick hinter die Kulissen gestattet Einsicht in die Mechanismen der (damaligen) Opernproduktion, von denen der Zuschauer üblicherweise nur das fertige Endprodukt zu Gesicht bekommt, wobei sich unter anderem das sonst nicht sichtbare Verhältnis zwischen der Persönlichkeit des Sängers und der von ihm gespielten Rolle in der fiktiven Handlung abzeichnet. Das ist beispielsweise in „L'opera nuova“ von Giovanni Bertati und Matteo Rauzzini der Fall, in der weite Teile der aufzuführenden Oper geprobt werden. Noch stärker kommt das Verhältnis zwischen Realität und Fiktion in Giovanni Bertatis und Felice Alessandris 1775 in Venedig uraufgeführter Oper „La novità“ zum Vorschein, die als metatheatralischer Rahmen für den als zweiten Akt aufgeführten Einakter „L'Italiano a Parigi“ dient. Im ersten Akt diskutieren der Impresario, die Sänger und der protettore über die Notwendigkeit, „Neuheiten“ auf die Bühne zu bringen, um das vergnügungs- und sensationssüchtige Publikum zu befriedigen. Als aufgrund von Uneinigkeiten zwischen den Beteiligten die schon angekündigte Oper beinahe nicht zur Aufführung kommt und der seines Bankrotts sichere Impresario mit der Kassa flieht, einigt sich schließlich das streitsüchtige und zugleich geldgierige Ensemble und führt im zweiten Akt „L'italiano a Parigi“ auf. Dieser Einakter erfüllt in diesem Kontext die Funktion einer Operneinlage, einer Aufführung in der Aufführung, die von denselben Sängern interpretiert wird, die im ersten Akt in ihren zwar ebenfalls fiktiven, aber „realistischen“ Rollen als Sänger aufgetreten waren und die überdies den Beginn des Finales von „L'italiano a Parigi“ auf der Bühne geprobt hatten. Nicht nur die Anwesenheit einer umfangreichen und vollständigen, in sich geschlossenen Opernaufführung auf einer zweiten Fiktionsebene, sondern auch die Diskussionen um dieses Werk und die Probe desselben verstärken hier die Illusion, dass es sich bei der primären Spielebene, dem metatheatralischen Rahmen, um Realität gehandelt hat. Das reizvolle Spiel besteht also in der sowohl durch Bezüge zwischen fingierter Realität und Spiel im Spiel als auch durch Selbstbezüglichkeit geschaffenen Illusion einer Realität. Schöpflin bringt die im Theater im Theater herge-

758 Mehr dazu u. a. in Giulio Ferroni: L'opera in commedia. Una immagine del melodramma nella cultura veneziana del settecento. In: Maria Teresa Muraro (Hg.): Venezia e il melodramma nel settecento. Bd. 1. Florenz 1978 (Studi di musica veneta 6), S. 63-78; Manuela Hager: Die Opernprobe als Theateraufführung: Eine Studie zum Libretto in Wien des 18. Jahrhunderts. In: Albert Gier (Hg.): Oper als Text: Romanische Beiträge zur Libretto-Forschung. Heidelberg 1986, S. 101-24. 
stellte reizvolle Ambivalenz auf den Punkt: „In dieser Verwechselbarkeit des Theaters mit der Realität liegt der besondere Reiz."759

\section{Io „Zerrspiegel“ als Spielfunktion}

3. Io. I Die Zeitsatire

Der in den metamelodrammi durch Selbstbezüglichkeit erreichte Realitätsbezug kann als Teil einer allgemeineren Zeitsatire betrachtet werden, die in den Opere buffe immer wieder anzutreffen ist. Durch die verzerrte Spiegelung der Realität werden auf humoristische Weise Unsitten und Schwächen nicht nur der Institution Oper und ihrer Vertreter, sondern der damaligen Gesellschaft im Allgemeinen aufgezeigt, um diese durch spottende Kritik zu tadeln, wobei die Unterhaltung und Belustigung des Publikums immer im Vordergrund steht. Die für die Komödie typische Lebensnähe zeigt sich in den Buffa-Libretti also nicht nur in den der Alltagssphäre entnommenen Figuren und Themen, sondern auch im Bezug zur zeitgenössischen Aktualität, vor allem zur damals vorherrschenden französischen Mode in Kleidung, Verhaltensweise und gesellschaftlichen Bräuchen, wie die galante Lebensweise, die Verwendung der französischen Sprache oder die Gewohnheit der Ehefrauen, einen cavalier servente, den sogenannten cicisbeo, zu haben bzw. ganz allgemein die Freiheit der Ehegatten. Das Zusammenprallen der „altmodischen“ italienischen bzw. venezianischen mit der „modernen“ französischen Denkweise, wenn Personen aus dem bürgerlichen Milieu versuchen, den Adel in seiner freizügigeren Einstellung nachzuahmen, oder die Diskrepanz zwischen städtischen und ländlichen Bräuchen sind in unzähligen BuffaLibretti thematisiert und liefern manchmal den Stoff für ganze Handlungen. Diese Realitätsspiegelung fällt häufig ambivalent aus, denn die galanten französischen Manieren werden einerseits bewundert, andererseits aber auch karikaturistisch verzerrt und lächerlich gemacht.

Letzteres ist beispielsweise in Paisiellos I775 in Venedig uraufgeführter Oper „La discordia fortunata“ der Fall, in der der „Dottor Cristeriale“ als Zielscheibe des allgemeinen Spotts dient. Dieser buffo caricato wird schon im Personenverzeichnis als „Medico, Avaro, fanatico per la lingua francese“ charakterisiert und nicht nur wegen seines Geizes, sondern auch seiner besessenen Leidenschaft für die französische Mode aufs Korn genommen. Schon zu Beginn wird er von anderen Figuren als überheblich und eingebildet hingestellt:

759 Karin Schöpflin: Theater im Theater. Formen und Funktionen eines dramatischen Phänomens im Wandel. Frankfurt am Main 1993, S. 688. 
Ros. $\quad \grave{E}$ stato in Francia:

Esser crede gran cosa.

Rag. Mirate che figura!

Da far il petit maitre,

Da parlar in Francese $!^{760}$

Um Corilla zu erobern, zieht der Dottore alle Register der französischen Galanterie. Corilla empfindet seine Affektiertheit aber als lästig und sucht nach einer Ausrede.

Il Dott. Andiamo da Corilla: Allons: il faut

Prendre l'air conquerant:

Ah! Prenez mes pensées: le tour galant.

(...)

Cor. Qui sen viene il Dottor. Ah come i suoi

Importuni discorsi,

Come evitar di questo

Sguajato Petit maitre.

Il Dott. Me folatre mignonne,

Me voici tou-à-vous.

Cor. Serva ...

Il Dott. Al mio complimento,

Rispondete in francese.

L'on dit; votre servente,

Et se pliant en Cadance,

L'on fait la reverence. ${ }^{761}$

Der karikiert dargestellte Dottore besteht darauf, Corilla französische Manieren beizubringen, und spricht dabei typische Elemente des galanten Benehmens an, nämlich die französische Sprache, die Reverenz und die Kunst der Komplimente. Später singt er eine Arie, deren zweiter Teil nicht nur in französischer Sprache, sondern auch musikalisch im französisierenden Stil gehalten und durch notierte Mordente und Molltonarten gekennzeichnet ist.

Gegen Ende der Oper ist in einem Quintett ein französisches Duett (Dottore Corilla) eingefügt, das ebenfalls durch Mordente, durch die Tempobezeichnung Alle-

760 Paisiello: La discordia fortunata. Venedig 1775 (I,2).

761 Ebd. (I,10-11). 
gretto alla francese und den auf Trällersilben gesungenen Refrain als typisch französisch charakterisiert ist. Dass in diesen Fällen die Häufung von Verzierungen eine parodistische Funktion erfüllt, ist aufgrund des Kontexts, nämlich der als lächerlich dargestellten Frankreich-Versessenheit des Dottore, sehr wahrscheinlich.

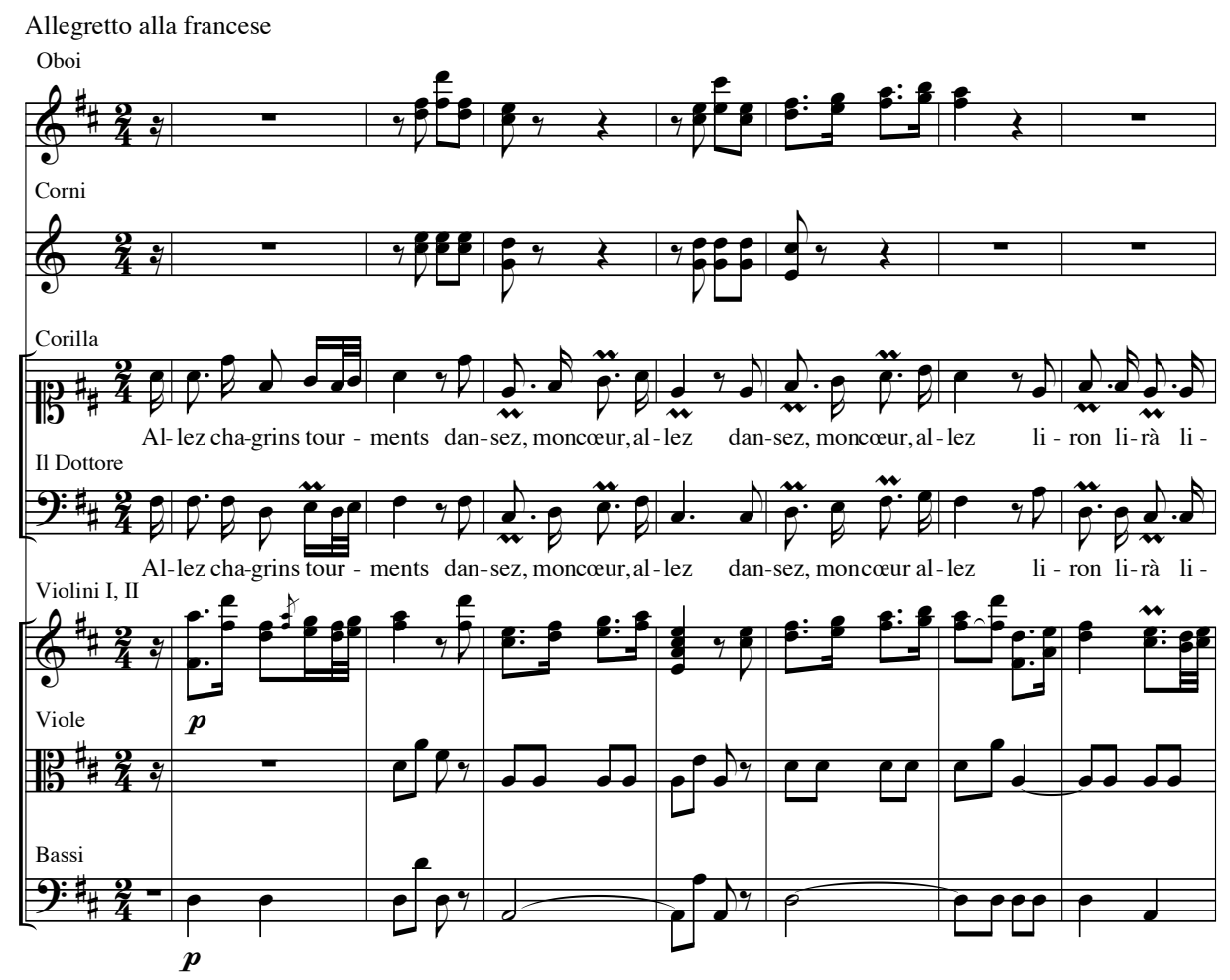

51 Paisiello: La discordia fortunata. (I-Mc Part. Tr. Ms. 2)

Etwas ambivalenter erscheint die Darstellung der französischen Mode in Livignis und Gazzanigas 1785 in Venedig uraufgeführter Oper „La moglie capricciosa“. Wie schon aus dem Titel ersichtlich ist, dreht sich hier die Handlung um eine „moderne“ kapriziöse Ehefrau, die der neuesten Mode folgt und das gesamte Vermögen ihres bürgerlichen Ehemannes für Kleidung, Schuhe, Friseure und jede Art von Vergnügungen ausgibt. Mit ihrem galanten, französisch sprechenden cicisbeo führt sie beispielsweise folgenden bezeichnenden Dialog: 
Cav. Madama, sanfason: la vostra grazia,

La gentile maniera, ed obbligante,

Schiavo mi rese, e Cicisbeo costante.

Mad. Monsieù, san compliman: il vostro brio,

Il cor sincero, e nobile contegno,

Dell'amicizia mia vi fé ben degno.

Cav. Al Teatro, al Passeggio,

A Festini, a Ridotti,

Ombra amorosa, ed immancabilmente,

Vi seguirò da Cavalier Servente.

Mad. Bene obbligata. Orsù, mio Cavaliere,

Vogliamo divertirci a qualche cosa?

Cav. Io dipendo da voi Dama vezzosa.

Mad. Giochiamo un pò a Picchetto.

Cav. Ehi là, chi è fuori? Sedie, Tavolino,

Carte da giuoco, Marche qui portate,

Presto Servi, Lacchè, sollecitate. ${ }^{762}$

Nach etlichen mit französischen Floskeln ausgeschmückten gegenseitigen Komplimenten und Höflichkeiten und der Aufzählung der typischen Vergnügungsmöglichkeiten, nämlich Theater, Spaziergängen, Feste und Redouten, wenden sich die beiden dem damals sehr beliebten Kartenspiel picchetto zu; später nehmen sie bei einem mâेtre de danse Unterricht, um die neuesten Tänze zu lernen. Madamas Ehemann Simone lässt sich alles gefallen, denn „Madama Moglie / Non fa che secondar l'uso presente; / La moda vuole il Cavalier servente. "763 Die Modesucht der Madama und ihres affektierten cicisbeo wird zwar als übertrieben hingestellt, aber schließlich ist es Simone, der wegen seines Versuchs, seiner Ehefrau Grenzen zu setzen, von dieser gemeisam mit dem cicisbeo in einer großen Verkleidungs-Burla aufs Korn genommen wird. Die Oper endet mit Simones Bitte um Vergebung und mit einer fröhlichen „cena all'osteria“, bei der „all'usanza Parigina“ auf Französisch gesungen und mit Weingläsern angestoßen wird. Es stellt sich die Frage, ob diese Oper, in der die „Modernen“ bzw. „Modischen“ am Schluss als „Gewinner“ dastehen, als Loblied auf die französische Galanterie verstanden werden soll oder als eine Art „,verkehrte Welt“, die von den absurden Regeln der Mode beherrscht wird, die dadurch der Lächerlichkeit preisgegeben werden. Möglicherweise trifft Letzteres eher zu, wobei gerade die Ambivalenz das für das Spiel

762 Livigni/Gazzaniga: La moglie capricciosa. Venedig 1785 (I,3).

763 Ebd. (I,10). 
typische Schweben herstellt und den Reiz dieser feinen Satire ausmacht. Das venezianische Publikum, für das die Oper geschrieben ist, gehörte nämlich wenigstens teilweise selbst zur „Kategorie“ der unterhaltungssüchtigen, von einer Vergnügung zur anderen schweifenden und der französischen Mode folgenden gehobenen städtischen Gesellschaft und befand sich beim Zuschauen der Oper selbst in einer der typischsten Vergnügungsstätten, dem Opernhaus. Das Publikum spiegelte und identifizierte sich also gewissermaßen in der auf der Bühne dargestellten Handlung, lachte aufgrund der satirischen Überspitzung aber gleichzeitig über sich selbst, wobei wiederum eine distanzierte Haltung überwiegen musste. Vermutlich bestand gerade in dieser Ambivalenz, in diesem labilen Gleichgewicht im Verhältnis zwischen dem Publikum und der dargestellten „Wirklichkeit“ der Reiz eines solchen „Spiels“.

Zwiespältiger und durch eine größere Distanz charakterisiert ist dagegen die Darstellung der Bauern in der Opera buffa, denn sie werden einerseits idealisiert, die ländliche, pastorale Sphäre wird als idyllisch und ursprünglich dargestellt und entspricht dem damaligen Ideal der Natürlichkeit, der wahren Gefühle, der Treue und Gutherzigkeit. Andererseits sind die Landleute insofern einer scharfen und groben Satire unterworfen, als sie, vor allem wenn sie sich in einem städtischen Milieu befinden oder gesellschaftlich aufsteigen und das Benehmen der Adeligen nachzuahmen versuchen, als stumpf, ungeschickt und ungebildet dargestellt und dementsprechend verspottet werden. Beide Fälle sind für ein städtisches Publikum konzipiert, denn sowohl die Idealisierung des Landlebens als auch die Satire der Bauern setzen eine erhebliche Distanz gegenüber der realen ländlichen Sphäre voraus.

Als Beispiel für eine scharfe Bauernsatire kann Bertatis und Anfossis Oper „Lo sposo disperato“ dienen, die I777 in Venedig uraufgeführt wurde. Die Handlung beginnt hier nach der nur aus finanziellen Gründen erfolgten Hochzeit zwischen der adeligen, aber armen Donna Aurora und dem reichen Bauern Canziano. Donna Auroras Vater möchte aus dem plumpen und ungebildeten Bräutigam einen zivilisierten und manierlichen Mann machen und lässt ihn modische Kleider anziehen, die dem Bauern eng und unbequem erscheinen, engagiert einen Tanzmeister, der Canziano das Menuett beibringen soll und ihn dabei nicht nur restlos überfordert, sondern auch - ähnlich wie beim späteren Fechtunterricht - körperlich strapaziert. Ständig wird Canziano von allen als „scimmiotto“, „buffalo“, „asino“, „gran babuino“, „gran bestia“, „grand'animale“, „somaro“ und „can barbone“ und mit anderen abwertenden Tiermetaphern beschimpft. Als er gegen seinen Willen gezwungen wird, auf die Freiheitsansprüche seiner mondänen und frivolen städtischen Ehefrau einzugehen, kann er seine Wut kaum unterdrücken und verjagt einen Cavaliere, wofür er eine Morddrohung erhält. Wie schon unter dem Thema der Maskierung erwähnt wurde die Bühnenfiguren tragen beim Opernbesuch nämlich venezianische Masken -, endet 
die Handlung im Opernhaus, wo sich Canziano mehrmals aufgrund seines unangebrachten, tölpelhaften Benehmens blamiert und Aufsehen erregt. Auch hier kommt es also zu einer direkten Spiegelung des Zuschauerraums auf der Bühne, die unter das Kapitel „Oper in der Oper" fallen könnte. Das satirische Element besteht dabei aber in der Anwesenheit des unmanierlichen Bauern, der noch nie in der Oper gewesen ist und die dort herrschenden gesellschaftlichen Regeln nicht kennt, wobei eine möglicherweise in der Realität gelegentlich vorkommende Situation nachgezeichnet wird. Die komische Diskrepanz ergibt sich aus der Unangebrachtheit seines bäuerlichen Benehmens im typisch städtischen Kontext eines Opernhauses, und die satirische Verzerrung besteht in der karikaturistischen Übertreibung dieser inconvenienza. Dieser typische Mechanismus der Satire kann mit dem auf Jahrmärkten üblichen Spiel der Vexierspiegel verglichen werden: In beiden Fällen wird die Wirklichkeit verzerrt wiedergegeben und bringt wegen der Inkongruenz mit dem erwarteten oder bekannten Bild zum Lachen.

\subsubsection{Die Parodie}

Eine ähnliche Zerrspiegel-Funktion liegt dem in der Opera buffa immer wieder vorkommenden Element der Parodie zugrunde, wobei die spielerische Verzerrung nicht wie in der Satire die soziale Wirklichkeit selbst, sondern eine Kunstgattung oder deren Formen und Inhalte bzw. Stoffe betrifft, die durch eine karnevaleske Verkehrung ins Komische gekippt werden. Die Bekanntheit der Vorlage ist dabei eine unerlässliche Voraussetzung, denn ohne die Kenntnis ihres Bezugspunkts kann keine Parodie verstanden werden. Die auf verzerrender bzw. verspottender Imitation beruhende Parodie führt zum ersten Beispiel dieses Kapitels zurück: Beim dort besprochenen Nachahmungsspiel des americano ergaben sich nämlich aufgrund der Unwissenheit und der naiven Missverständnisse des Protagonisten ausgesprochen parodistische Züge. Daraus wird erneut die Schwierigkeit ersichtlich, einzelne spielhafte Momente eindeutig einer einzigen Kategorie zuzuordnen. In jeder Parodie ist gleichzeitig eine Art "Nachahmungsspiel“ enthalten sowie das erwähnte „Zerrspiegel-Spiel“, nämlich die durch eine deformierende Spiegelung bzw. Imitation bewirkte Transposition einer an sich neutralen oder ernsten Vorlage auf die Ebene des Komischen.

Für die Opera buffa bildet die Seria einen ständigen Bezugspunkt, der gelegentlich parodistisch angehaucht ist: Aus der Opera seria übernimmt die Buffa viele ihrer Grundelemente wie ihre Makrostruktur, bestimmte Figuren, nämlich die Vertreter der parti serie, gemeinsam mit ihrem sowohl musikalischen als auch sprachlichen Idiom; gleichzeitig aber kann sie es sich als komisches Genre erlauben, ihre nicht 
nur „Mutter-“, sondern auch Konkurrenzgattung zu persiflieren. Dafür eignen sich besonders die heroischen und pathetischen Züge der Opera seria. So wird in der Buffa beispielsweise bei Verzweiflungs- und Angstszenen immer wieder das Muster des großen dramatischen Seria-Monologs, der als Accompagnato-Rezitativ beginnt und in eine Arie mündet, übernommen und durch Übertreibung und Verzerrung ins Lächerliche gezogen. Generell entsteht in solchen Fällen die komische Wirkung gerade aus der Diskrepanz zwischen dem pathetischen Charakter des Monologs und der buffohaften Situation, also aus der Übertragung eines Seria-Musters in einen fremden, unangemessenen Kontext, wodurch ein verfremdender Effekt und eine ironische Distanzierung erzeugt werden. Als Beispiel dafür soll die falsche SelbstmordSzene des Baron Cricca aus der schon erwähnten Oper „Il pittore parigino“ von Cimarosa dienen. Die Szene findet nach Eurillas Entscheidung statt, die Heirat mit dem Baron auszuschlagen. Dieser ist verzweifelt und kündigt - ohne es ernsthaft zu meinen, sondern nur um Eurilla umzustimmen - seinen Selbstmordplan an. Seine ehemalige Geliebte Cintia, die ihn aus Rache bloßstellen will, bringt ihm ein Messer, so dass der Baron gezwungen ist, den angekündigten Selbstmord wirklich durchzuführen, wenn er seine Ehre retten will. So spielt er eine große seriaartige Solo-Szene (Accompagnato-Rezitativ und Arie), die die schlaue Cintia aber unbeeindruckt lässt und sogar zum Lachen bringt, weil sie genau weiß, dass Cricca zu feige ist, um Hand an sich zu legen. Die Anrufung der Götter weist schon zu Beginn auf die SeriaSphäre hin, genauso wie die Erwähnung der Unterwelt und ihres Herrschers Pluto, der Düsterkeit und der Geister, die charakteristische Elemente für die Vision des nahenden Todes einer Seria-Figur sind. Dabei erklingt eine „schreckliche“ Musik („orribil sinfonia“), die das Numinose durch Streicher-Tremoli und fallende chromatische Linien kompositorisch ausdeutet. Die für die Ombra-Szenen der Opera seria charakterstische Tonart Es-Dur, in der das Accompagnato-Rezitativ beginnt, der pathetische Abschied von der Geliebten und die Bitte, ein Mausoleum mit einer glorreichen Inschrift zu errichten, deuten ebenfalls auf eine tragische Todesszene aus der Opera seria hin, allerdings werden sie vom Baron Cricca kontinuierlich mit Buffo-Elementen vermengt, die im folgenden Textzitat unterstrichen sind, während der Fettdruck für die Seria-Sphäre steht:

\section{Numi, Numi bestiali}

Del non affumicato Erebo ombroso

A ricever venite un mezzo sposo.

Ecco già il vedo ... Oimè che tetra

Orribil Sinfonia!

Non avete paura figlia mia? (ride Cintia e dice di no) 
Un bel coraggio! Zitto ... udir mi pare Anche i corni da caccia in lontananza.

Oh bellissima usanza!

Plutone, che va a caccia. Ah non è vero

Vengono a pigliar me con faccia tetra

I spiriti folletti

$\mathrm{Al}$ suon di dolci flauti e clarinetti.

Addio, Cintia mia cara. (Turca indegna

Si fosse impallidita!) Sol vi prego

Alla patria tornando

Far eseguire questo mio comando.

$\underline{\text { S’innalzi un Mausoleo }}$

Sotto del qual sia scritto:

Il Baron Cricca invitto

Odiato da una femmina

$\underline{\text { S'uccise, e giace qui. }}$

Ma ancor non ho finito

L'Oboè m'ha seccato

I corni m'han stordito

Le trombe m'han stonato ...

(E non si muove ancora,

E intrepida sta lì.)

$\underline{\text { Si mora si mora }}$

Con alma orgogliosa

Almeno un altro mese

Lasciatemi campar.

Amanti sospirate

Piangete, strepitate,

Datevi i pugni in testa;

Ma l'ammazzarsi poi

Per quella, né per questa

Oibò, non s'ha da far. ${ }^{764}$

Schon in der anfänglichen Anrufung der Götter fallen die ständigen Stilbrüche zwischen Seria- und Buffa-Sprache auf. Durch die für einen Seria-Monolog unangebrachte Ansprache eines anwesenden Gegenübers sowie den während des Abschieds

764 Petrosellini/Cimarosa: Il pittore parigino. Venedig 1783 (II,12). 
da parte gesprochenen und eine grobe Beschimpfung („turca indegna“) enthaltenden Buffo-Kommentar fällt der Baron mit einer an Cintia gerichteten Frage aus der Rolle und verrät durch den Ebenenwechel, dass die Seria-Szene nur gespielt ist. Einen ebenso theatralischen und distanzierenden Effekt hat die sowohl im Rezitativ als auch in der Arie stattfindende Erwähnung von einzelnen Instrumenten und das illusionsdurchbrechende „dialogische Spiel“ mit den Orchesterinstrumenten, das als Topos der Opera buffa gilt. Alle diese Mittel, nämlich die sich aus der Mischung von Seria- und Buffa-Sprache ergebenden Stilbrüche, die Thematisierung der Musikinstrumente und die Ebenenwechsel, lassen die an sich seria-mäßige Selbstmord-Szene ins Parodistische kippen und als „nur gespielt“ erscheinen. Der Schlussteil der Arie, in der Cricca die „amanti“ in einer ad-spectatores-ähnlichen Wendung direkt anspricht, um ihnen von einem Selbstmord aus Liebe abzuraten, rundet die buffoneske Szene ab. Die parodistische „Verkleidung“ einer tragisch-heroischen Szene dient hier unter anderem dazu, die komische Diskrepanz zwischen den - dem zeitgenössischen Publikum als Seria-Muster vertrauten - Gefühlen von Ehre und Tapferkeit und der Feigheit, Ängstlichkeit und Unernsthaftigkeit des Baron Cricca zu überzeichnen und so den Baron zu verspotten und lächerlich zu machen.

Abgesehen von solchen parodistischen Bezügen zur Gattung der Opera seria sind im venezianischen Repertoire des untersuchten Zeitraums auch ganze Opern zu finden, die als Parodie eines bekannten Opernstoffes bezeichnet werden können. Als Beispiel für eine solche komische Verzerrung eines ernsten Sujets kann die in Venedig im Jahr I785 uraufgeführte Opera buffa „Le spose ricuperate“ von Giovanni Bertati und Luigi Caruso dienen, die auf den schon seit der Entstehung der Gattung Oper weit verbreiteten Orpheus-Stoff Bezug nimmt und mit diesem „spielt“. Das Motiv der Reise in die Unterwelt, die hier von zwei miteinander befreundeten Männern unternommen wird, um ihre verstorbenen Ehefrauen wiederzuerlangen, wird hier in eine irdische und buffoartige Rahmenhandlung eingebettet, in der zwei Bauernpaare sowie der ehemalige cicisbeo einer der beiden verstorbenen Frauen eine Rolle spielen. ${ }^{765}$ Die Parodie des Orpheus-Sujets besteht darin, dass die Handlung im Vergleich zur Vorlage weitergeführt wird, wobei nach der geglückten Wiedererlangung der Frauen die Eheleute nur noch miteinander streiten und die Männer - wie sie der Geist des hochzeits- und frauenfeindlichen Diogenes gewarnt hatte - es bereuen, sie aus der Unterwelt heraufgeholt zu haben. Die für die Opera buffa typischerweise auf den irdischen Alltag bezogene Moral dieser Geschichte ist, dass man lieber nicht gegen die

765 Überhaupt ist die Menge der Personen auffällig, denn an der Handlung sind außer den acht „regulären“ Figuren in den Unterwelt-Szenen auch vier „ombre“ von bekannten Persönlichkeiten aus der Antike (Cleopatra, Lucrezia, Virgilio, Diogene) beteiligt. 
Natur und das Schicksal handeln sollte. Eine detaillierte Untersuchung dieser Oper und ihr Vergleich mit dem ernsten Orpheus-Stoff wäre zwar lohnenswert, würde aber den Rahmen dieser Arbeit sprengen, dennoch soll wenigstens eine Szene betrachtet werden, die mit einem deutlichen intertextuellen Bezug verbunden ist. Während nämlich das restliche Werk trotz seines parodistischen Gewands den gängigen formalen und stilistischen Konventionen der Buffa-Gattung entspricht und inhaltlich auf den bekannten Stoff, aber nicht auf eine spezifische Orfeo-Oper bezogen zu sein scheint, fällt die Elysiumsszene, die den bekanntesten Topos des Orpheus-Stoffes verkörpert, wegen einer klaren Anspielung auf Bertonis bzw. Glucks Orfeo-Vertonung auf. Vorauszuschicken ist, dass in Venedig in den Jahren vor "Le spose ricuperate“ anscheinend in keinem öffentlichen Theater eine Orfeo-Oper aufgeführt wurde, mit Ausnahme von Ferdinando Bertonis „Orfeo ed Euridice“ im Jahr 1776 im Teatro San Benedetto, das 1783 an demselben Theater wiederaufgenommen wurde. In diesem Werk wird nicht nur Ranieri de' Calzabigis Libretto haargenau, wie es für Gluck in Wien (I762) geschrieben worden war, (samt Tänzen und Chören) vertont, sondern auch die Musik Glucks, die in Venedig im I8. Jahrhundert anscheinend nie erklungen ist, diente offensichtlich als Vorlage. ${ }^{766}$ In Carusos parodistischen „Le spose ricuperate" ist allein die Ankunft der beiden "Orfei“ in den campi elisi als umfangreiche durchkomponierte Szene vertont, die aus einer Abfolge von Chören, Sologesängen und (rein instrumentalen) Tänzen besteht und somit auf Bertonis Oper „Orfeo ed Euridice" anspielt, die das Publikum von ihrer Wiederaufnahme im Jahr 1783, also zwei Jahre vor „Le spose ricuperate“, gekannt haben könnte.

$\mathrm{Zu}$ Beginn der Szene sind zunächst keine parodistischen Elemente zu erkennen. Dem homophonen blockhaften Chor über die überirdischen Freuden des Elysiums geht eine Orchestereinleitung voran, bei der die Melodie der ersten Violinen durch gebrochene Akkorde in den zweiten Violinen begleitet wird, die möglicherweise auf Orfeos bei Bertoni in Anlehnung an Gluck von einer Harfe ausgeführte Lyra-Begleitung anspielen. ${ }^{767}$ Die Musik selbst wirkt nicht parodistisch, allein die Verdoppelung der Geigenmelodie durch die Fagotte erscheint etwas merkwürdig. Möglicherweise ist hier der häufig als lustig empfundene Fagottklang als Hinweis auf die Unernsthaftigkeit der idyllischen Elysiumsszene zu verstehen.

766 Der Altkastrat Gaetano Guadagni, der sowohl in Wien bei der Uraufführung von Glucks Werk (1762) als auch in Venedig bei der Uraufführung von Bertonis Oper (1776) die Rolle des Orfeo interpretierte, dürfte für die Verbindung verantwortlich gewesen sein.

767 Allerdings spielen die beiden „Orfei“ in dieser Oper keine Instrumente und müssen auch keine Furien besänftigen. 
Andante Scena 8. Campi Elisi

Flauti
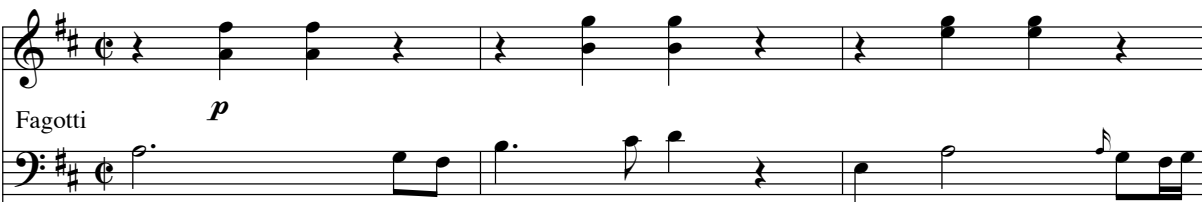

Corni
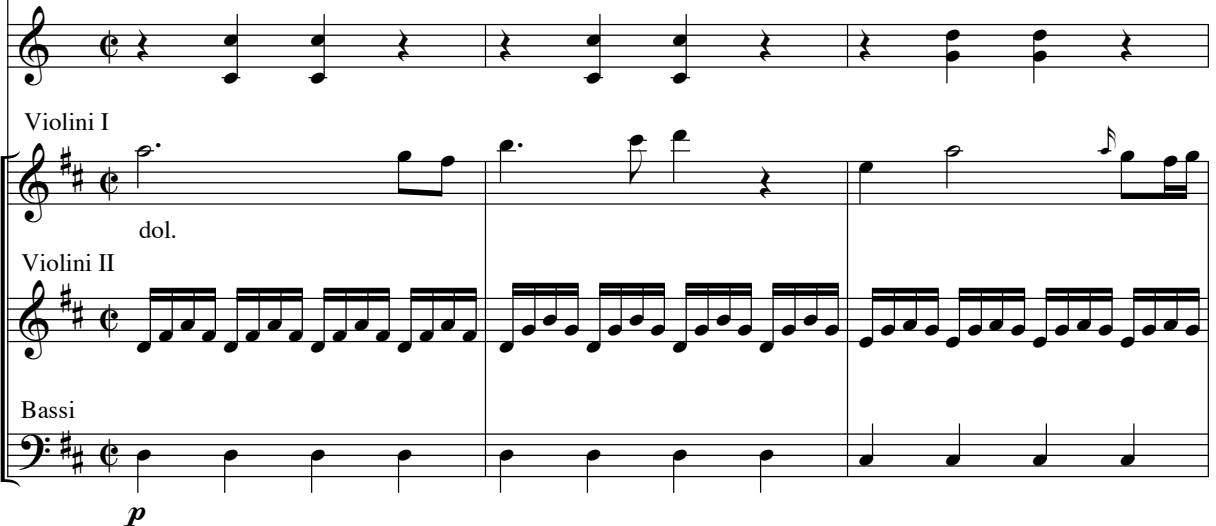

Fl.

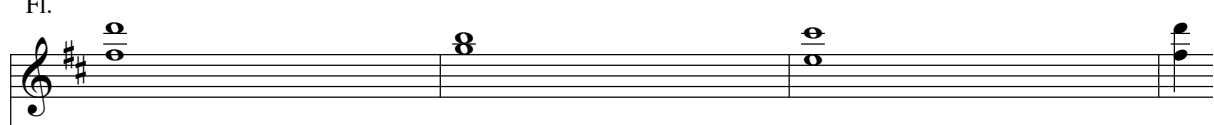

Fag.

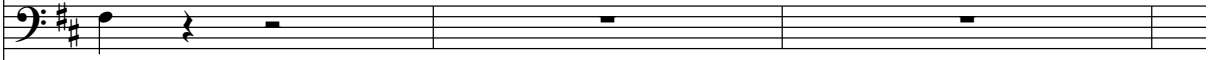

Cor.
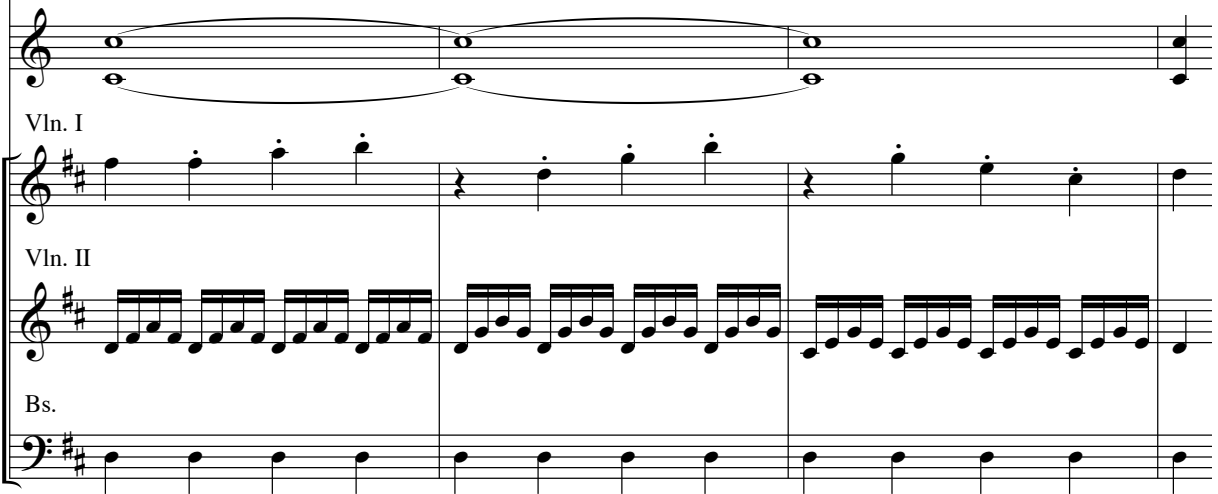

52 Caruso/Bertati: Le spose ricuperate. (F-Pn D 1871-1872) 
Nach einem von Virgilio veranlassten „ballo espressivo amoroso“768 folgen triviale Bemerkungen der beiden „Euridici“ über die irdische Liebe, wobei vor allem die aus Felicinas Geständnis, im Leben viele Liebhaber gehabt zu haben, ersichtliche Flatterhaftigkeit eindeutig parodistisch gemeint zu sein scheint. Ähnliches gilt für den darauffolgenden, von Diogene veranlassten grotesken „ballo dei deliri amorosi“, denn hier kippt - wie es bei der Parodie üblich ist - die Hauptbotschaft des Orpheus-Stoffes in ihr Gegenteil: Anstelle der Bewunderung für die tiefe Liebe des Orfeo für seine Euridice tritt Diogenes' Zynismus zutage, zumal er die in der Opera buffa immer wieder auftretende Meinung vertritt, dass man sich von Liebe, Heirat und Frauen lieber fernhalten sollte, und die Liebe für eine Art Verrücktheit hält. Nach dem Gesang der beiden Frauen über die schönen Seiten der irdischen Liebe und nach einem sanften „ballo della pace“, in dem erneut die Melodien durch Akkordbrechungen (in verschiedenen Besetzungen) begleitet werden, kommt es bei der Ankunft der beiden „Orfei“ zu einem „tabló di sorpresa“, einem Moment des Stillstands, das im stockenden homophonen Tutti ein Überraschungs- und Schreckenstableau bietet. Die Anspielungen auf Bertoni bzw. Gluck enden mit einem „ballo di furie“ mit gleichzeitigem Chor, währenddessen alle fliehen; anschließend wird die Handlung konventionell im Secco-Rezitativ fortgesetzt. Durch Imitation eines damals in Venedig ausschließlich mit dem Orpheus-Sujet assoziierten musikdramaturgischen Konzepts, der für die italienische Oper der Zeit unüblichen starken Einbindung von Chören und expressiven Tänzen bei gleichzeitiger Eliminierung der Secco-Rezitative wird hier die Elysiumsszene illustriert und die Ankunft der beiden „Orfei“ im Elysium dramatisiert. Gleichzeitig wird durch den intertextuellen Bezug die dramaturgisch zentrale Szene zusätzlich hervorgehoben und die Spannung zwischen Vorlage und Anlehnung sowie die Freude am Wiedererkennen von Bekanntem („the pleasure of the familiar“) durch die „Konkretheit“ der Anspielung erhöht. Der parodistische Charakter ergibt sich hier einerseits aus der verfremdenden Einbettung eines mit einer ernsten Sphäre verbundenen Musters in einen andersartigen, komischen Kontext, andererseits durch die Vermischung der stilistischen Imitation von Bertonis „Orfeo“ mit konventionellen Buffa-Elementen, wodurch es insgesamt zu einer Verlächerlichung des OrpheusStoffs kommt, die in erster Linie der Belustigung des Publikums dient.

Derselbe Vorgang liegt auch der zwei Jahre später in demselben Theater (San Samuele, I787) uraufgeführten Oper „Il nuovo convitato di pietra“ von Francesco Gardi

768 Dass von den „balli“ im Libretto keine Rede ist und dass in der Partitur die unmittelbar vor den Tänzen stehenden Texte zu Tanzaufforderungen verändert wurden, deutet darauf hin, dass es sich bei der Bertoni-Anspielung um eine späte bzw. nach dem Librettodruck entstandene, vermutlich vom Komponisten stammende Idee gehandelt haben muss. 
zugrunde, einer Parodie des Don-Giovanni-Stoffs. In diesem als dramma tragicomico bezeichneten Stück mischen sich tatsächlich Ernst und possenhafte Komik, denn die für die Handlung wesentlichen (ernsten) Szenen wie die Kirchhofsszene, die beiden Gastmähler mit der Erscheinung der Statue und dem spektakulären Untergang Don Giovannis am Ende bleiben als Gerüst vorhanden, aber alle Verführungsspiele des Protagonisten sowie die Ermordung des Komturs sind in die Vorgeschichte verlegt, und die Handlung ist vom Konkurrenzkampf zwischen den vier (in der Vergangenheit) verführten, besonders karikiert als heiratswütig hingestellten Frauen geprägt. Diese streiten ständig miteinander darüber, wer von ihnen Don Giovanni heiraten wird, beschimpfen sich gegenseitig und verfolgen ihn, als er heimlich abreist, um sie loszuwerden. Don Giovanni verliert schließlich die Geduld und lässt zwei von den Frauen an einen Baum anbinden. Zwischendurch kommt es zu weiteren absurden, vom traditionellen Don-Giovanni-Stoff vollkommen abweichenden Situationen: Die als genauso wie Don Giovanni unseriös charakterisierte Donna Anna verspricht seinen beiden Dienern die Ehe, will sie aber in Wirklichkeit nur ausnützen und spielt ihnen im ersten Finale eine Überfallszene vor, um ihnen beizubringen, wie man zu Geld kommt. In der ersten Gastmahlszene, bei der im Gegensatz zum traditionellen Stoff alle Frauen anwesend sind, wird Donna Anna von ihrem Vater bei Don Giovanni „erwischt“; sie bittet den als Statue erscheinenden Komtur um Vergebung, wird aber von ihm verstoßen („No, padre tuo non sono / Va', scostati da me“). Auch in dieser Opernparodie wird jedes Detail genutzt, um durch karnevaleske Verkehrungen bzw. verspottende Verzerrungen, bei denen immer Batesons metakommunikative Botschaft „Dies ist ein Spiel“ mitschwingt, einen komischen Effekt zu erzielen. Der Aktualitätsbezug tritt hier besonders stark zum Vorschein, weil die Parodie sich nicht nur generell auf den aus dem Sprechtheater her schon lange bekannten DonGiovanni-Stoff bezog, der in Venedig schon im Jahr I 777 von Giuseppe Calegaris „Il convitato di pietra" als Opernsujet verwendet worden war, sondern weil in derselben Karnevalsaison der Uraufführung von Gardis Oper Gazzanigas nicht-parodistischer "Convitato di pietra“ im Teatro San Moisè uraufgeführt wurde. Die miteinander in Konkurrenz stehenden Theater und die jeweiligen Autoren versuchten einander offensichtlich durch unterschiedliche Strategien zu übertreffen: Bertati und Gazzaniga betteten ihren einaktigen „Convitato“ durch Voranstellung des Einakters „Il capriccio drammatico“,769 einer „Oper in der Oper“, in einen metatheatralen Kontext ein, um das Werk attraktiver zu gestalten, während Gardi zum Mittel der Parodie griff und

769 Es handelt sich dabei um Bertatis mit einem neuen Titel versehenes Libretto „La novità“, das 1775 gemeinsam mit „Litaliano a Parigi“ in der Vertonung von Felice Alessandri am Teatro San Moisè uraufgeführt wurde. 
durch den Hinweis auf die Neuigkeit seines „Convitato“ im Titel („Il nuovo convitato di pietra“) mehr Publikum anzulocken versuchte. In beiden Fällen handelt es sich um eine Art „Manipulationsspiel“ mit dem Don-Giovanni-Stoff. Während dabei in Gazzanigas Stück der traditionelle, neu eingerahmte Stoff unangetastet bleibt, unterliegt er im Falle der Parodie einer Transformierung, einer Verzerrung bzw. einer Art „Travestie“ im Sinne der „Mimicry“. Der Reiz dieser Werke besteht für die Zuschauer hauptsächlich im lustvollen "game of cross-identification“,770 im „Hin- und Herspielen“ zwischen der Vorlage und ihrer parodistischen Verzerrung und im Erkennen ihrer komisch wirkenden Inkongruenz. Im Fall der Don-Giovanni-Oper erhöhen die Möglichkeit des direkten Vergleichs zwischen einer ernsten und einer parodistischen Version der Oper und die Aktualität des Konkurrenzkampfes den Reiz und die Lebhaftigkeit der Rezeption - Max See behauptet: „Solange die Oper sich selbst parodiert, wird sie eine lebendige Kunstform bleiben." ${ }^{771}$

In den untersuchten Opere buffe wurden besonders viele Beispiele von Spielen vorgefunden, die der Kategorie Mimicry zuzuordnen sind. Dies erklärt sich einerseits dadurch, dass Theater und Oper selbst als Darstellungs- oder Als-ob-Spiele bezeichnet werden können, so dass die für die komischen Gattungen wesentlichen ${ }^{772}$ und deswegen sehr häufig vorkommenden selbstbezüglichen Elemente, also im weitesten Sinne jede Form von Spiel im Spiel bzw. Theater im Theater, ebenfalls derselben Spielkategorie zugeordnet werden können. Andererseits spiegelt die Menge an Als-ob-Spielen in der Opera buffa auch generell ihre Häufigkeit im Leben wider, denn sie gelten als eine besonders universelle und weit verbreitete Art von Spiel. Nicht umsonst bezeichnen sie Oerter und Montada aus einer entwicklungspsychologischen Perspektive als „die eigentliche kindliche Spielform“. ${ }^{773}$ Dieser Häufigkeit entspricht auch die Vielfalt an Erscheinungsformen und Facetten der unter Mimicry zusammengefassten Spiele: Durch unterschiedliche Formen von Rollenspiel, Nachahmung, Verkleidung, Verstellung und Verzerrung kann eine Als-ob-Wirklichkeit hergestellt werden, eine

770 Vgl. Hunter, S. 30.

771 Max See: Opernparodie und Parodieoper. In: Neue Zeitschrift für Musik. Jg. 127, 10/1966. Mainz 1966, S. 387.

772 „Das Lustspiel gelangt ästhetisch zu sich selbst durch die Potenzierung seines Spielcharakters; mit anderen Worten: es erfüllt um so mehr die Eigengesetzlichkeit der ästhetischen Form, je mehr es im fiktiven Spiel durch ein zusätzliches fingiertes Spiel diesen Spielcharakter unterstreicht. Das Spiel im Spiele macht den spezifischen Charakter des Lustspiels aus, ist also das eigentlich Lustspielhafte (...).“ (Martini, S. 321).

773 Rolf Oerter und Leo Montada (Hg.): Entwicklungspsychologie. 4. Aufl. Weinheim 1998, S. 253. 
Transformation der Realität, die die von Huizinga festgestellte „zeitweilige Aufhebung der ,gewöhnlichen Welt “"774 und den Eintritt in die Welt des Spiels herbeiführt.

\section{Sonderfälle : Gestaltungsspiele}

In Caillois' Typologie der Spiele vermisst Buland zu Recht die Anwesenheit von „Gestaltungsspielen“. ${ }^{775}$ Sein Verständnis dieser Spielkategorie geht über die von anderen Autoren „Konstruktionsspiele“776 bzw. „Spiele mit Schaffenscharakter"777 genannten Spiele hinaus, denn er fasst sie in seiner eigenen Einteilung mit den Mimicry- bzw. Als-ob-Spielen zusammen und bezeichnet die übergeordnete Kategorie insgesamt als „Gestaltungsspiele“. ${ }^{778}$ Aus diesem Grund ist die Einfügung dieser Ergänzung unmittelbar im Anschluss an das Kapitel „Mimicry“ angebracht, denn hier werden drei unterschiedliche Beispiele untersucht, die gewissermaßen zwischen den Gestaltungsspielen und den Mimicry-Spielen angesiedelt werden können und somit im Großen und Ganzen unter Bulands sehr weitgefasste Kategorie der Gestaltungsspiele fallen können. Bei den drei Beispielen handelt es sich im Gegensatz zu den meisten bisher beschriebenen Fällen nicht um wiederkehrende Motive oder gar um regelrechte Topoi der Opera buffa, sondern um Einzelfälle, was auch eine gesonderte Behandlung rechtfertigt.

\section{I Spielendes Schaffen in "L'inutile precauzione“}

Der Aspekt der Kreativität der Buffa-Figuren wurde schon im Kapitel „Mimicry“ erörtert. Vor allem im Rahmen von einfallsreichen Burle, sei es bei „strategisch“ geplanten oder spontan improvisierten Burle, wurde ein kreatives Gestalten beobachtet; die Buffa-Figuren zeigten sich dabei erfinderisch und spielerisch. In Paisiellos Oper „L'inutile precauzione“, besser bekannt unter dem Titel „Il barbiere di Siviglia“, wird dagegen ein regelrechter Schaffensprozess auf die Bühne gebracht. Hier komponiert

774 Huizinga, S. 78.

775 „In der Einteilung von Roger Caillois fehlt mir eine große Gruppe von Spielen, und zwar all jene, die sich um Bauen und Gestalten drehen." (Buland: Die Einteilung der Spiele nach ihren Freiheitsaspekten. S. 265).

776 Oerter u. Montada, S. 253; Château, S. 27.

777 Hans Scheuerl: Das Spiel. Bd. 1. Untersuchungen über sein Wesen, seine pädagogischen Möglichkeiten und Grenzen. 9. Auflage Weinheim, Basel 1979, S. 142ff.

778 „Ob soziale Interaktionen gestaltet werden, Theaterimprovisationen, Schauspiele, Musik, Kartenhäuser oder Türme aus Anker-Steinbaukästen bleibt sekundär gegenüber der Frage: wie groß ist der Gestaltungsfreiraum des Spielers?" (Buland: Die Einteilung der Spiele nach ihren Freiheitsaspekten. S. 270). 
Figaro bei seinem ersten Auftritt eine Arie und singt sie gleichzeitig. Die Regieanweisung lautet dabei: „Figaro con una chitarra dietro alle spalle, cantando allegramente, con una carta, e penna di lapis in mano."779 Besonders realistisch wirkt der Kompositionsprozess aufgrund der ständigen Unterbrechungen des Gesangs durch rezitativische Abschnitte - im Librettodruck durch unterschiedlich starkes Einrücken markiert -, in denen Figaro im Selbstgespräch Überlegungen anstellt, seine eigene Komposition beurteilt und Fragen an sich selbst richtet.

Diamo alla noja il bando,

Che sempre ci consuma.

Del vino andiam cantando,

Che il foco in seno alluma.

Ogn'uomo senza vino

Morrebbe il poverino,

Come giusto un Babbuino.

Sino a qua non va male.

Il vino e la pigrizia

Disputano il mio cor ... (componendo e cantando)

Oibò, non se'l disputano;

Ma vi regnano insieme...

Spartiscono il mio cor ...

Ma si può dir spartiscono? sì bene:

E perché no? Quel che va male in versi,

In musica si mette,

E così si compongon le Burlette.

Il vino e la pigrizia

Spartiscono il mio cor. (Mette un ginocchio a terra scrivendo)

Finir vorrei con un qual cosa di bello ...

Con una opposizione, un'antitesi ...

Cospetto! l'ho trovata.

S'una è la mia delizia,

E l'altro il servitor. (scrive, cantando)

Oh! quando ci saranno gl' istromenti,

Con quest'aria farò certo portenti. ${ }^{780}$

779 Petrosellini/Paisiello: L'inutile precauzione. Venedig 1787 (I,2).

780 Ebd. 
Allegretto

Oboi

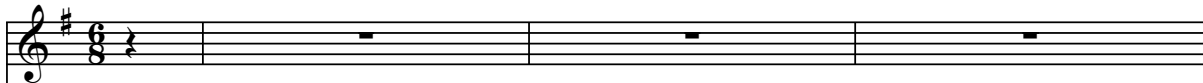

Figaro
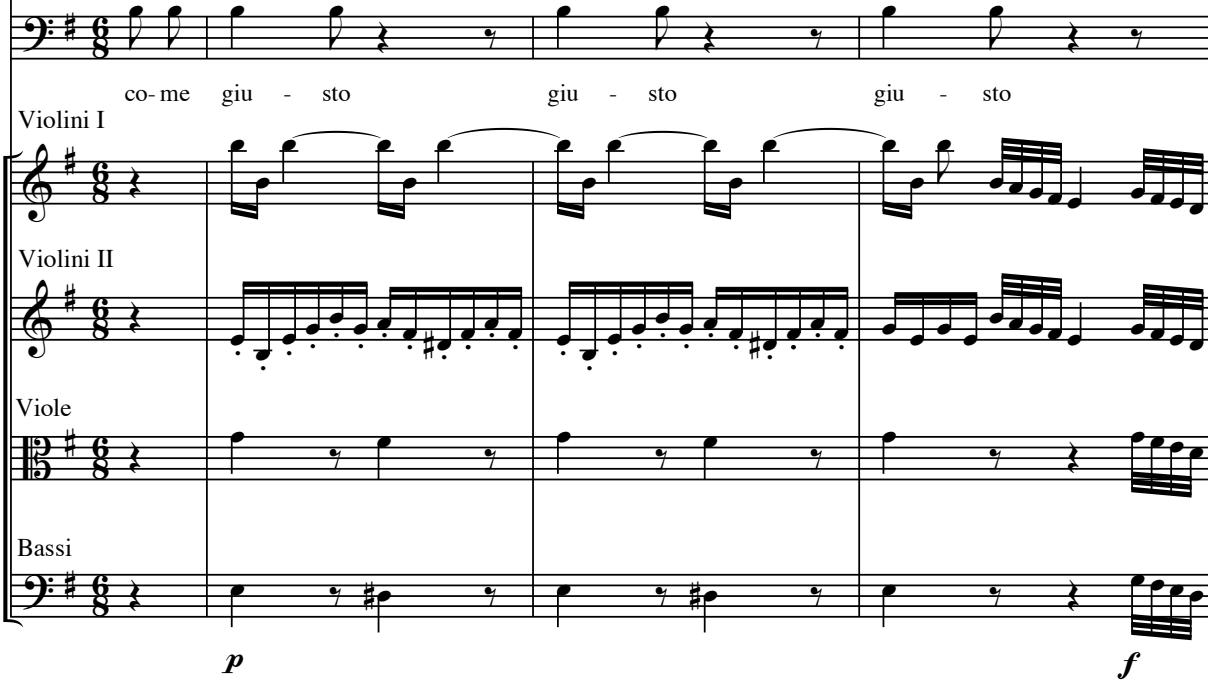

Ob.

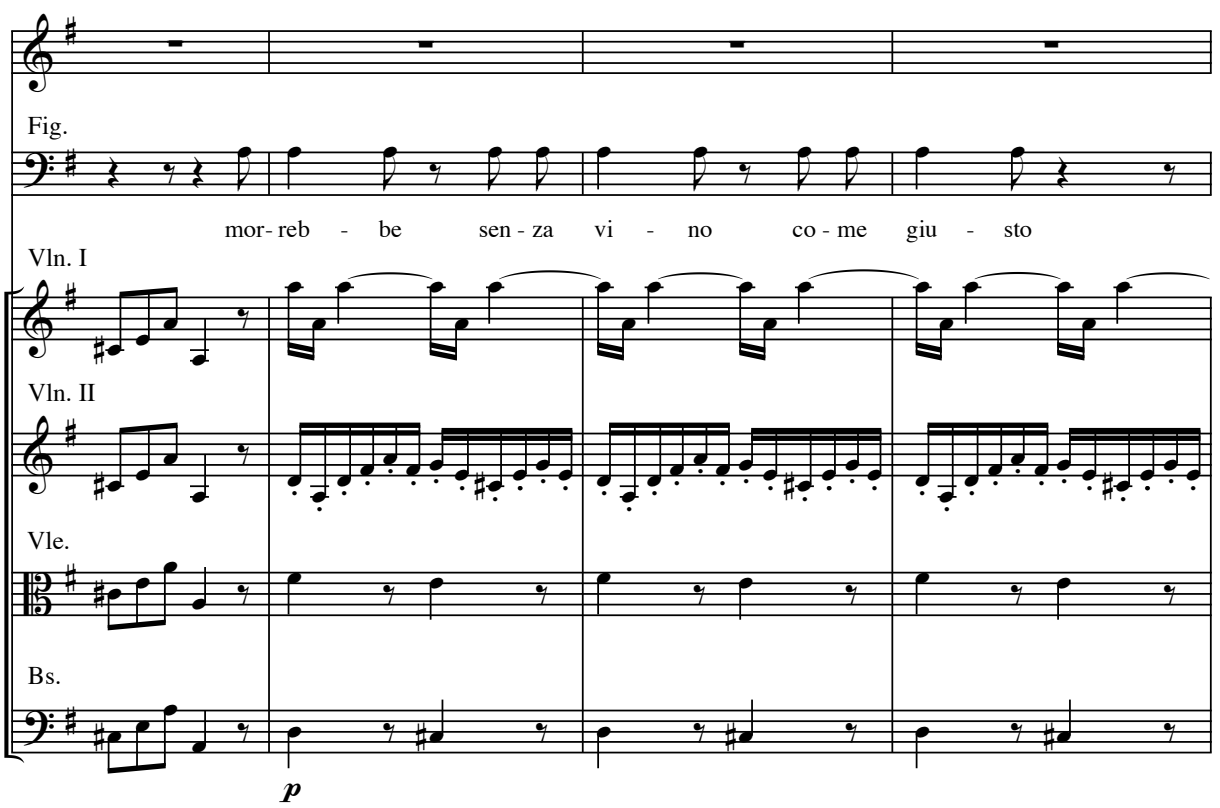



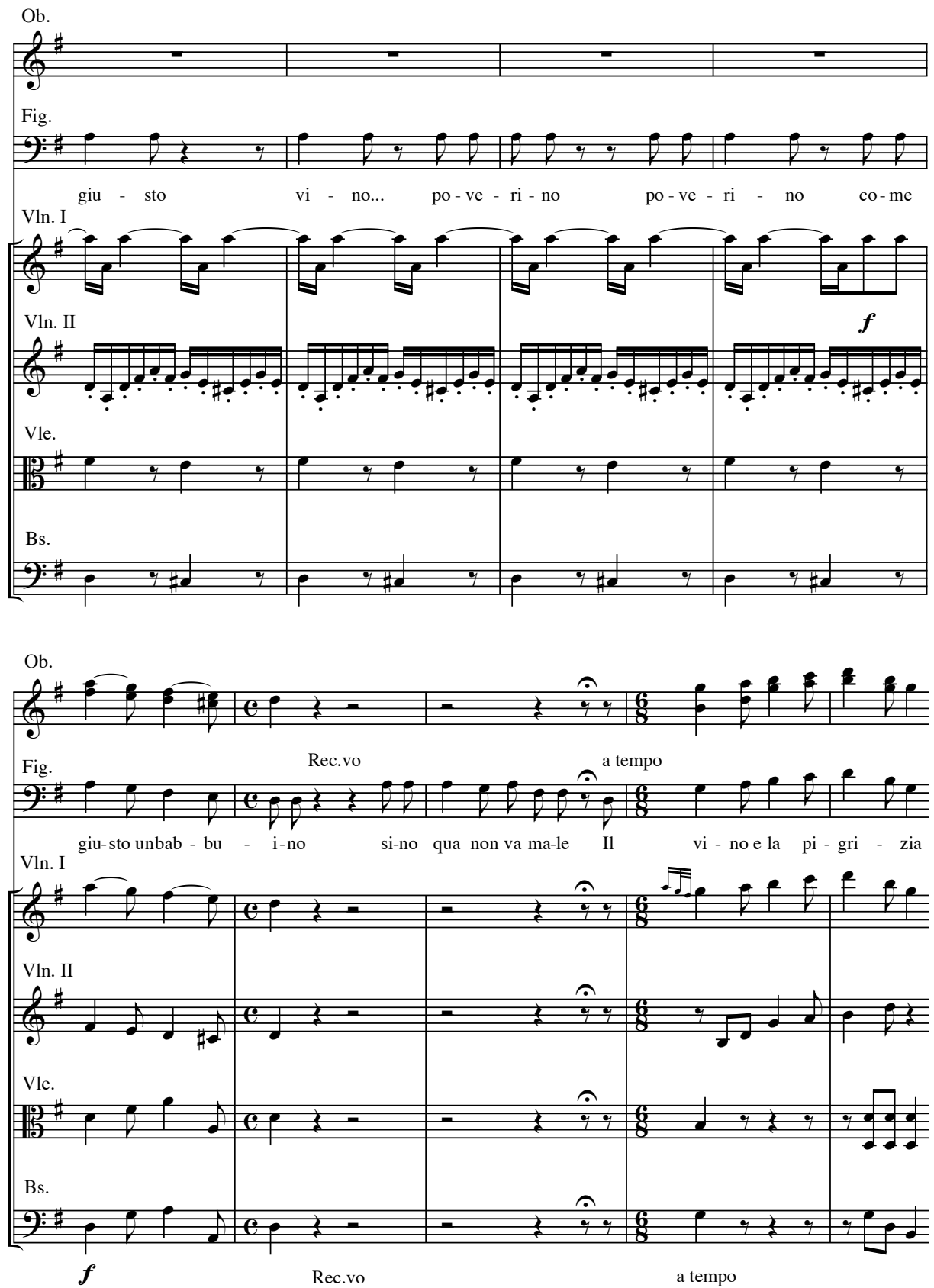

53 Paisiello/Petrosellini : Il barbiere di Siviglia. (I-Mc Part. Tr. Ms. 300) 
Ein weiterer Hinweis dafür, dass es sich um die realitätsnahe Darstellung eines kreativen Schaffensprozesses handelt, ist das Stocken und auskomponierte Überlegen, als ihm kein passendes Wort einfällt und er die Wörter wiederholt, mit denen es sich reimen muss.

Figaros Bemerkungen zum gerade komponierten Weinlied - beispielsweise „Sino a qui non va male“ oder „quando ci saranno gl'istromenti / Con quest'aria farò certo portenti“ - können als die von Scheuerl erwähnten "Spielphasen“ innerhalb eines Schaffensprozesses aufgefasst werden, in denen ein „virtuelles Spielen mit den vorweggenommenen Wirkungen des erstrebten Werks“781 erfolgt. In dieser fröhlichen Kompositionsszene wird meines Erachtens das von Scheuerl genannte Kriterium für das „spielende Schaffen“, nämlich das grenzenlose Ineinander-Übergehen von Spielund Schaffensphasen, ${ }^{782}$ erfüllt. Auch Scheuerls Aussage, die „Inspiration“ sei „der Gipfel des spielenden Schaffens“, ${ }^{783}$ findet in dieser Szene eine Bestätigung, denn als Figaro beschließt, die Ariette „con un qual cosa di bello“ zu beenden, hat er nach kurzem Überlegen geradezu einen Geistesblitz, als ihm die rhetorische Figur der Antithese in den Sinn kommt. Die etwas sentenziöse Äußerung bezüglich der Theorie der Vertonung von Versen („Quel che va male in versi / In musica si mette / E così si compongon le Burlette“) könnte als „Spielregel“ gedeutet werden. Vor allem aber sind es der glückliche Moment des zufälligen „Findens“ („Cospetto! l'ho trovata“), also des Einfalls, sowie die auskomponierte Spontaneität und die Fröhlichkeit der gesamten Szene, die generell den Eindruck eines „spielenden Schaffens“ bzw. eines kreativen „Gestaltungsspiels“ vermitteln.

\subsection{Musikspiel und Tanz als "therapeutische Spiele“ in "Li sposi in commedia"}

Musikspiel und Tanz können generell als Mimicry- oder Gestaltungsspiele verstanden werden. Auf der Bühne kommen sie in der Opera buffa häufig vor, sind aber meistens in Festszenen eingebettet oder dienen dem allgemeinen Ausdruck der Freude und Fröhlichkeit. Auf diese Zusammenhänge wird im Kapitel über das Fest genauer eingegangen, während hier der - in den untersuchten Werken einzigartige - Fall eines therapeutischen Einsatzes dieser "Spiele“ besprochen wird, der im ersten Finale von Giuseppe Palomba und Luigi Carusos „Li sposi in commedia“ in folgender Situation stattfindet: Doktor Don Ipocrate will Sofonisba heiraten, die in seinem Haus wohnt. Diese hat sich aber in den Cavalier Gelsomino verliebt, der ihre Liebe erwidert. Um ihren Liebhaber in der Nähe zu behalten, hat Sofonisba ihn überredet, sich krank zu stel-

781 Hans Scheuerl: Das Spiel. S. 156.

782 Vgl. ebd. S. 153.

783 Ebd. 
len und sich vom Arzt behandeln zu lassen. Die Diagnose „pazzia che vien d'amore“784 scheint einen Anklang an einen aus dem „Orlando furioso“ von Ariosto stammenden Topos zu enthalten. Nach diversen Heilungsversuchen mit höchst fragwürdigen Methoden und absurden, wenn nicht giftigen Rezepten kommt Don Ipocrate schließlich auf die Idee, die gespielte Verrücktheit des Cavaliere durch Musiktherapie zu heilen.

Ipo. La Musica dovrebbe esser specifico

Da fare un grande effetto. ${ }^{785}$

Und später :

Ipo. Il suono, ed il canto

Dilegua il furore

E il pazzo d'Amore

Tornar lo fa in sè. ${ }^{786}$

Ipocrate preist die Wirkung von Musik, Klängen und Gesang und empfiehlt sie als für einen „pazzo d'amore“ geeignete Arznei. Es werden Musiker bestellt und die Therapie-Szene (I, I3) bildet als besonders kreativer Einfall den Höhepunkt dieses ersten Finales. Hier wird nicht nur das beliebte Mittel der diegetischen Musik, also der Musikeinlage auf der Bühne, eingesetzt, sondern es werden auch - wie im Topos der Instrumentenarien üblich - die einzelnen Musikinstrumente genau dann im Orchester solistisch eingesetzt, wenn sie im Text genannt werden, wodurch die Aufmerksamkeit der Zuschauer stark auf das Orchester und die Musik gelenkt wird. Eine Besonderheit dieser Szene besteht darin, dass bei der Nennung der einzelnen Instrumente jeweils ihre heilende Wirkung beschrieben wird. Diese Idee wirkt für die zweite Hälfte des I 8. Jahrhunderts sehr fortschrittlich und scheint in den untersuchten Libretti ein Einzelfall zu sein, ist aber vermutlich durchaus als Mode bzw. als ein Phänomen der Zeit aufzufassen, wenn man bedenkt, dass ein Jahr nach der venezianischen Aufführung von Carusos „Li sposi in commedia“ gerade in Venedig ein discorso eines gewissen Giovanni Francesco Zulatti mit dem Titel Della forza della musica nelle passioni, nei costumi, e nelle malattie, e dell'uso medico del ballo ${ }^{787}$ veröffentlicht wurde, in dem ausgehend von der Theorie der alten Griechen die Wirkung der Musik, ihre Heilkraft

784 Palomba/Caruso: Li sposi in commedia. Venedig 1786 (I,9).

785 Ebd.

786 Ebd. (I,10).

787 Für den Hinweis auf Zulattis discorso und das Borgen des Mikrofilms möchte ich mich bei Andrea Korenjak herzlich bedanken. 
und ihr medizinischer Einsatz besprochen werden. Die hier der Musik zugeschriebenen Eigenschaften bestehen wesentlich darin, „di affettare la nostr'Anima, e di scuoterla, di svegliare, e reprimere le nostre passioni, di modificare i nostri costumi, e di curare alcune infermità. “788 Insbesondere gelte dies für die „malattie nervose, che si temperano dalla Musica, perch'essa può reprimere la passione dominante, calmarla, e farle succedere a poco a poco una disposizione contraria. "789

Don Ipocrate wendet im Prinzip genau diese Theorie an. Fröhliche, angenehme Klänge und die Harmonie der Musik sollen den Kranken beruhigen.

Ipo. $\quad$ Suonin pure gl'istrumenti
Con piacere, ed allegria,
Che il concerto, e l'armonia
Lo dovran tosto quietar. ${ }^{790}$

Die daraufhin erklingende rein instrumentale Musik wirkt tatsächlich beruhigend, denn das Tempo ist gemächlich (Larghetto) und der reine Streichersatz ist klar und durchsichtig: Die schöne Melodie einer konzertierenden Solo-Geige wird durch eine einfache und zurückhaltende Streicherbegleitung unterstützt und hervorgehoben. Die Klarheit des Ganzen wird durch die reinste Tonart, C-Dur, hervorgehoben.

Larghetto

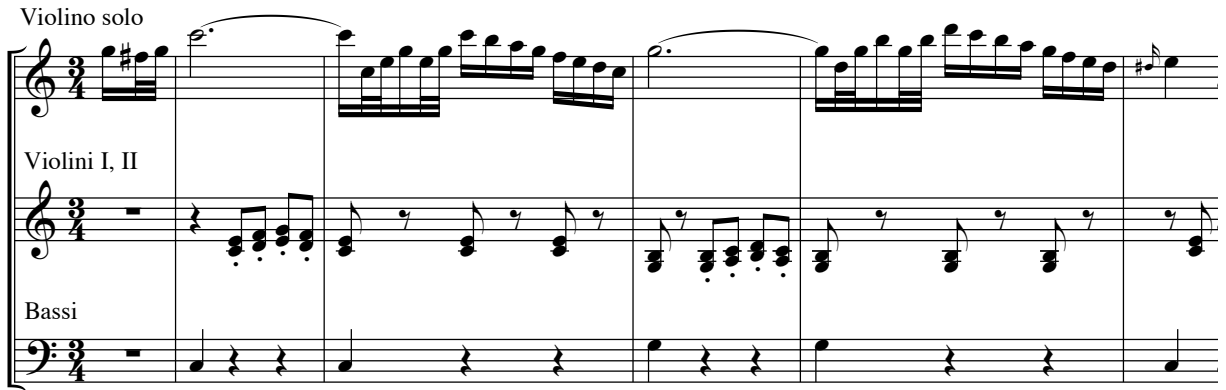

54 Caruso/Palomba: Il matrimonio in commedia. (F-Pn D 1865-1866)

Die wunderbare Wirkung dieser Geigenmelodie wird von den beteiligten Personen sofort bemerkt.

788 Zulatti, S. 40.

789 Ebd. S. 43.

790 Palomba/Caruso: Li sposi in commedia. Venedig 1786 (I,13). 
Ire. Che portento, ch'è il Violino!

Lo fa docile ballar. ${ }^{791}$

Diesem Kommentar ist trotz seiner Kürze ein eigenständiger Abschnitt gewidmet, dessen Takt (C) und Tempo (Allegro) einen Kontrast zum vorhergehenden melodiösen Abschnitt bilden, so dass der Bruch zwischen der „echten“, diegetischen Musik auf der Bühne und dem „,in Musik gesprochenen“ Kommentar der Außenstehenden das Sprechen wird dabei „realistisch“ im Buffo-Parlando vertont - deutlich hörbar wird.

Der langsame wiegende 3/4-Takt hat den verrückten Cavaliere zum Tanzen verlockt, wie aus dem als indirekte Regieanweisung dienenden Kommentar der Donna Irene hervorgeht. In diesem Zusammenhang erscheint Zulattis discorso interessant, in dem vorgegeben wird, dass die Heilkraft der Musik durch den Tanz noch stärker wirke: „i buoni effetti della Musica nelle malattie si accresce allora quando si unisce al ballo. "792 Bemerkenswert ist außerdem, dass in mehreren Fallbeispielen, die im discorso angeführt werden, gerade die von einem Geiger gespielte Tanzmusik eine sichere Heilung bewirke, wie Zulatti in seiner Beschreibung des Tarantismus behauptet: „La Musica guarisce una spezie di affezione ipocondriaca frequente in estate nelle parti meridionali del Regno di Napoli malamente attribuita al morso della Tarantola. I presidj medici sono inutili. Un Suonatore di Violino va provando alla loro presenza molte arie da ballo finché ne abbia trovata una che faccia impressione; allora il malato si avviva a poco a poco, danza talora per molte ore di seguito; e questo esercizio ripetuto più, o meno spesso non manca giammai di guarire gl'infermi."793 Im ersten Finale von „Li sposi in commedia“ haben wir es zwar weder mit einer tarantella noch mit dem Phänomen des Tarantismus zu tun, aber die Elemente des Tanzes und der Geigenmusik spielen als therapeutische Mittel eine Rolle. Zulatti nennt außerdem einen gewissen Herrn Pomme, dessen Therapie für einen „strano Isterismo“ gerade in der „armonia del Violino" bestanden habe. ${ }^{794}$

Das darauffolgende Musikstück, das die Musiker auf der Bühne spielen, ist ebenfalls durch einen Tempo- und Taktwechsel (Andantino sostenuto, 2/4-Takt) deutlich vom vorhergehenden Stück sowie von dem auf einer anderen Ebene stattfindenden Kommentar abgehoben. Dieses Musikstück ist zwar wie schon das erste von einem ruhigen Duktus geprägt und klar in Melodie und Begleitung unterteilt, das Tempo ist

791 Ebd.

792 Zulatti, S. 49.

793 Ebd. S. 33.

794 Vgl. ebd. 
aber etwas schneller, die Begleitung etwas bewegter und voller, weil mehrere Instrumente mit differenzierteren Figuren beteiligt sind. Die Melodie wird hier nicht mehr von der Solo-Oboe, sondern von einer voce umana ${ }^{795}$ vorgetragen, wie auch Don Tritemio in seinem anschließenden Kommentar bemerkt.

Trit. Quanto puol la voce umana,

Che lo fa sì ben cantar! ${ }^{796}$

Die voce umana im Orchester wurde in Neapel und Rom in den I $760 e r$ und I 770er Jahren gelegentlich verwendet; Paisiello gilt als der erste Komponist, der sie in der Opera buffa einsetzte. ${ }^{797}$ Welches Instrument in der venezianischen Aufführung dieser in Rom uraufgeführten Oper ${ }^{798}$ an dieser Stelle eingesetzt wurde, ist unbekannt, ${ }^{799}$ seine Melodie und sein (wie der Name voce umana suggeriert) der menschlichen Stimme (oder dem gleichnamigen Orgelregister) ähnelnder Klang veranlassen jedenfalls den Kranken zu singen. Dieser wiederholt zunächst die zu Beginn von der voce umana vorgetragene Melodie, um seinen Gesang dann selbständig weiterzugestalten. Dabei entsteht der Eindruck, als würde die voce umana ihn sanft in eine Art Spiel verwickeln. Das dialogische Wechselspiel zwischen den beiden Stimmen entspricht nämlich der typischen Hin-und-Her-Bewegung, der Grunddynamik des Spiels. Dieses Wechselspiel zwischen zwei solistischen Stimmen, das in anderen Kontexten als Wettstreit interpretiert werden konnte, ${ }^{800}$ trägt hier entspanntere, keineswegs agonale Züge, denn als der Gesang des Cavaliere beginnt, weicht die voce umana in eine ergänzende und somit eher untergeordnete Rolle aus und überlässt die Führung dem zu heilenden Mann (s. Notenbeispiel 55, S. 3 I If.). Das aktive Musizieren und die mimetische Teilnahme an einem harmonischen Zusammenspiel scheinen zusehends heilend und beruhigend zu wirken.

Den weiteren genannten Instrumenten entsprechen keine eigenen musikalischen Abschnitte mehr, sondern das Allegro (C-Dur, C) des Kommentars wird beibehalten, während die Flöten, Bratschen und Hörner bei ihrer jeweiligen Nennung im Text wie in den typischen Instrumentenarien kurz solistisch auftreten.

795 Der Terminus voce umana bezeichnet üblicherweise eine wie das Englischhorn in F gestimmte TenorOboe. Allerdings ist sie in der verwendeten Partitur (F-Pn D 1865-1866) über der Orchesteroboe und im Violinschlüssel notiert und scheint - wie die Oboe - in C gestimmt zu sein.

796 Palomba/Caruso: Li sposi in commedia. Venedig 1786 (I,13).

797 Vgl. Villinger, S. 51.

7981782 wurde diese Oper im römischen Teatro Capranica unter dem Titel „I matrimoni in commedia“ uraufgeführt. Für die venezianische Aufführung wurde der Titel in „Li sposi in commedia“ umgeändert.

799 In Venedig scheint die voce umana nicht gebräuchlich gewesen zu sein. (Vgl. Villinger, S. 83).

800 Siehe Kapitel „Agon“. 
Mad. Delli flauti il suono grato.

Lo fa immobile restar.

Ipo. Più di ognun Viole e Cetre ${ }^{801}$

Lo fan quasi addormentar. ${ }^{802}$

Die letztgenannten Instrumente üben auf den Verrückten insgesamt eine einschläfernde Wirkung aus. Schließlich kommt es zu einem „Gemeinschaftsspiel“ aller Instrumente, das zu einem eigenständigen, rein instrumentalen Abschnitt überleitet.
a 4 .
Su facciamo insieme uniti
Gl'istrumenti ora suonar. ${ }^{803}$

Andantino sostenuto

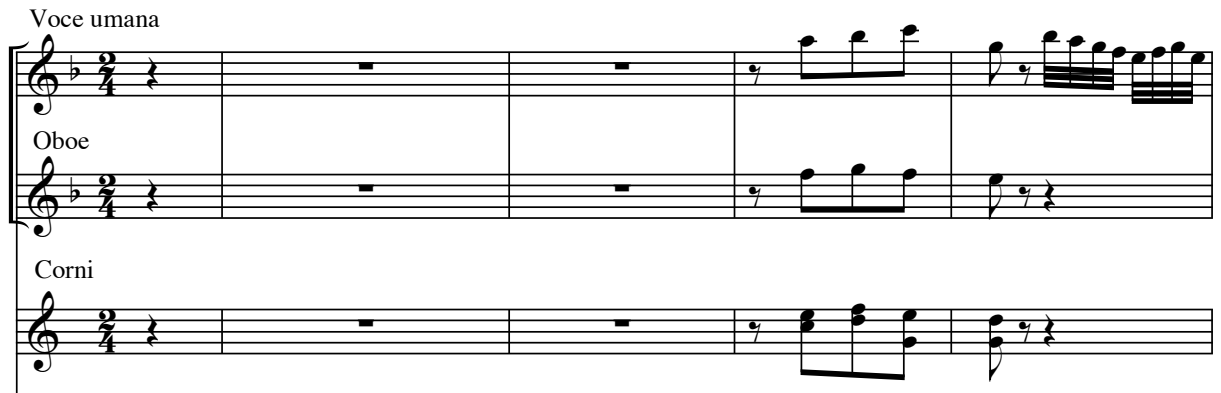

Cavaliere
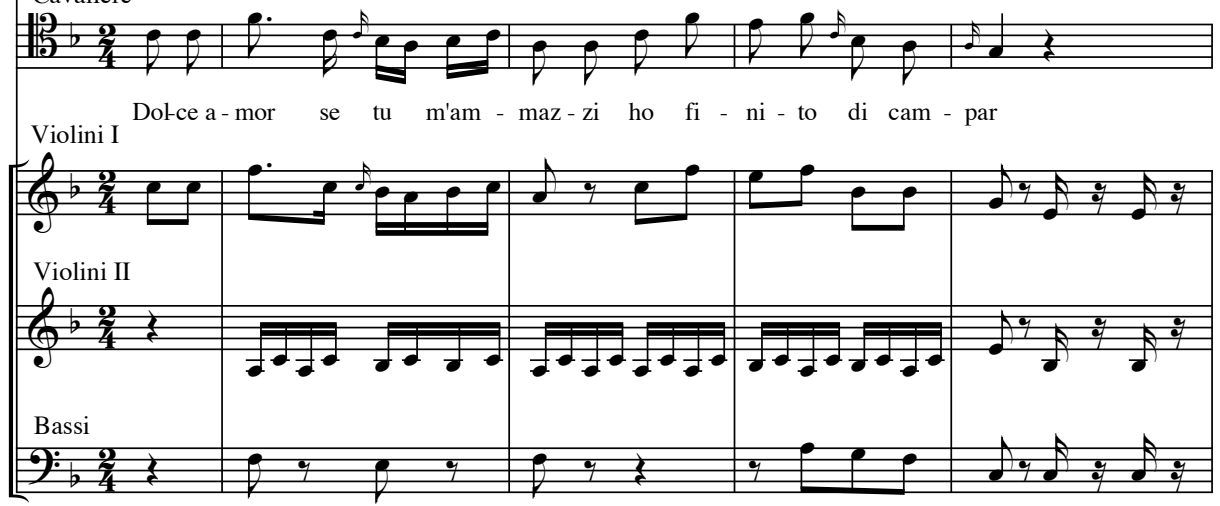

801 In der verwendeten Partitur (F-Pn D 1865-1866) „Corni“ statt „Cetre“ im Text.

802 Palomba/Caruso: Li sposi in commedia. Venedig $1786(\mathrm{I}, 13)$.

803 Ebd. 


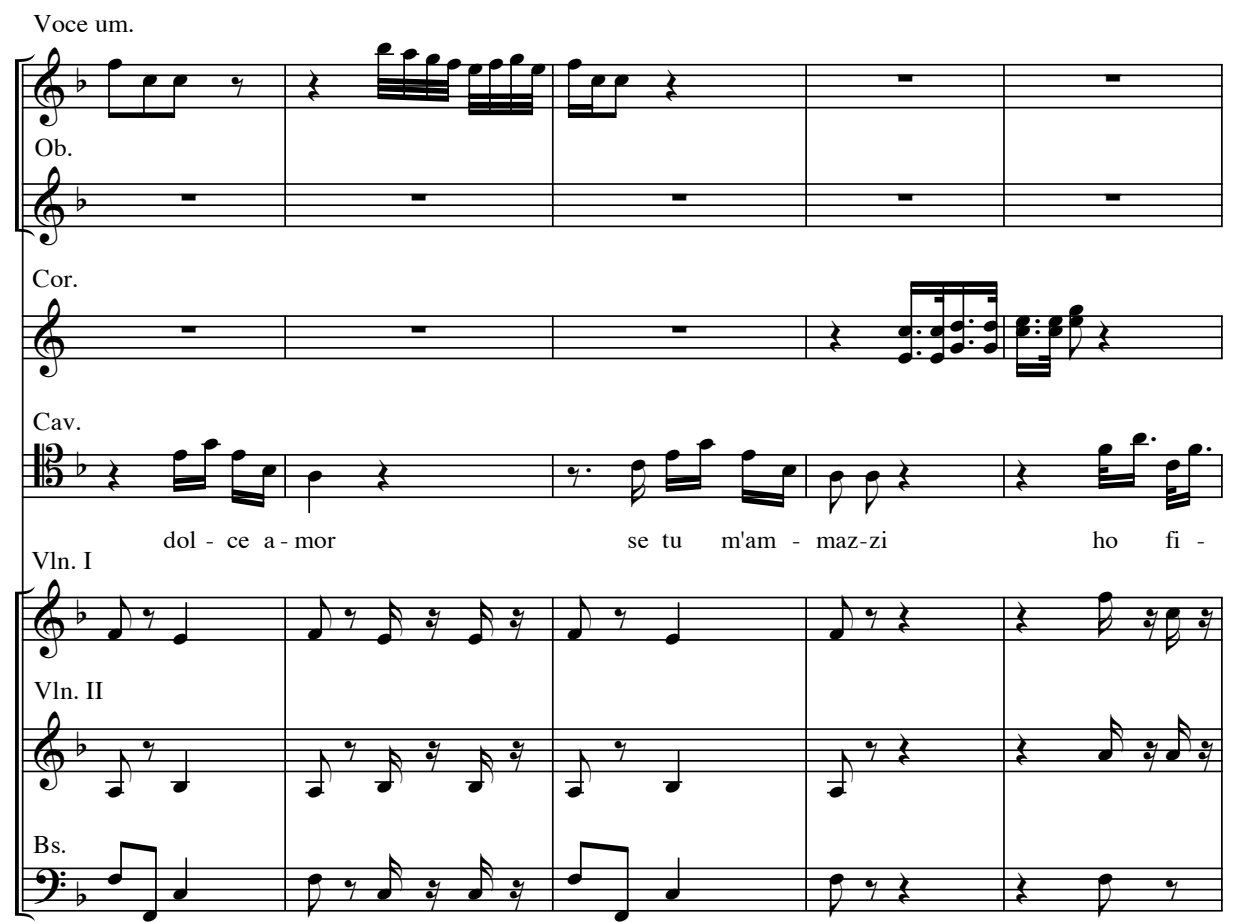

55 Caruso/Palomba: Il matrimonio in commedia. (F-Pn D 1865-1866)

Dabei wird auf der Bühne das schon zitierte „giuoco degli istrumenti“ vorgeführt sowie ihr „maraviglioso effetto“, 804 in diesem Fall die Heilung des vermeintlich kranken Cavaliere. Die Solo-Geige stimmt eine ähnliche Melodie wie in dem ihr gewidmeten ersten Abschnitt an, worauf alle im Text erwähnten solistisch auftretenden Instrumente sich nacheinander in imitatorischen Einsätzen an dem großen, zunächst additiv, dann eher abwechselnd verlaufenden Nachahmungsspiel beteiligen, aus dem dieses rein instrumentale "therapeutische“ Musikstück besteht (Notenbeispiel 56, S. 3 I 3 f.).

Die Wirkung der Musiktherapie besteht zunächst im Tanzen und Singen und dann im Einschlafen des vermeintlichen Verrückten. Die Ruhe hält aber - wahrscheinlich aus Gründen der Einhaltung der dramaturgischen und musikalischen Konvention - nicht lange an, denn der Cavaliere wacht gleich wieder auf und spielt wieder den Verrückten. Zwischen gespielter Verrücktheit und echter Gereiztheit ist an dieser Stelle nicht mehr klar zu unterscheiden. Der Cavaliere möchte dem „Fiktionsspiel“ 
ein Ende setzen, indem er allen die Wahrheit erzählt („Or vuò tutto raccontar“), aber niemand hört ihm zu, was ihn zum Rasen bringt - vermutlich ein dramaturgischer Griff, um das Finale in Durcheinander und Erregtheit enden zu lassen.

Die therapeutische Wirkung der Musik und des Tanzes scheint in dieser Szene einerseits auf dem „mimetischen Spiel“ zu beruhen, aufgrund dessen der Verrückte sich in die ruhige, harmonische Musik einfühlt und sich beruhigt. Diese Art von „heilenden Spielen“ würde also, wie die Musik im Allgemeinen, Friedrich Georg Jüngers Kategorie der „auf Ahmung abgestellten vorahmend-nachahmenden Spiele“805 angehören.
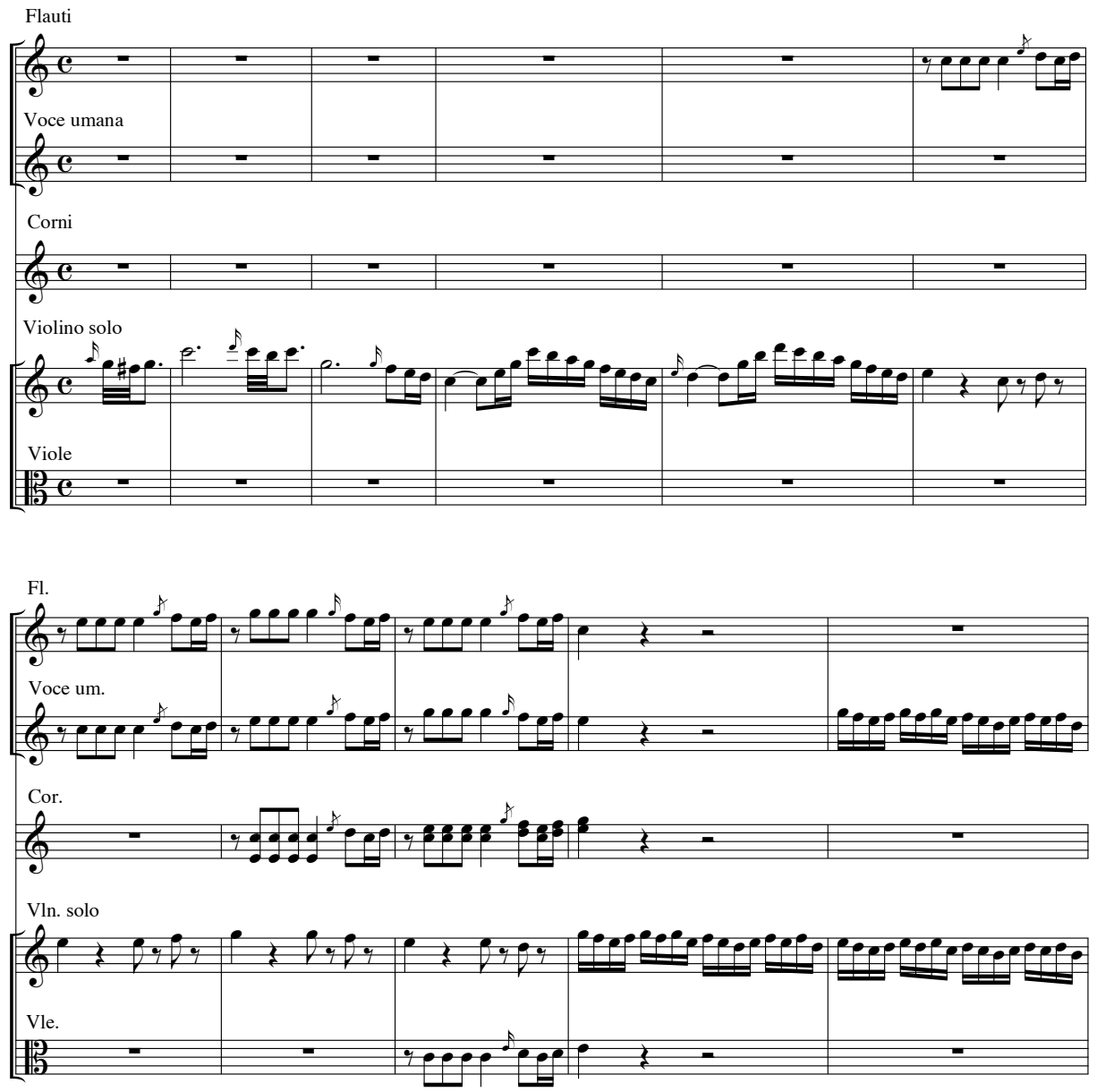

805 Jünger, S. 47. 


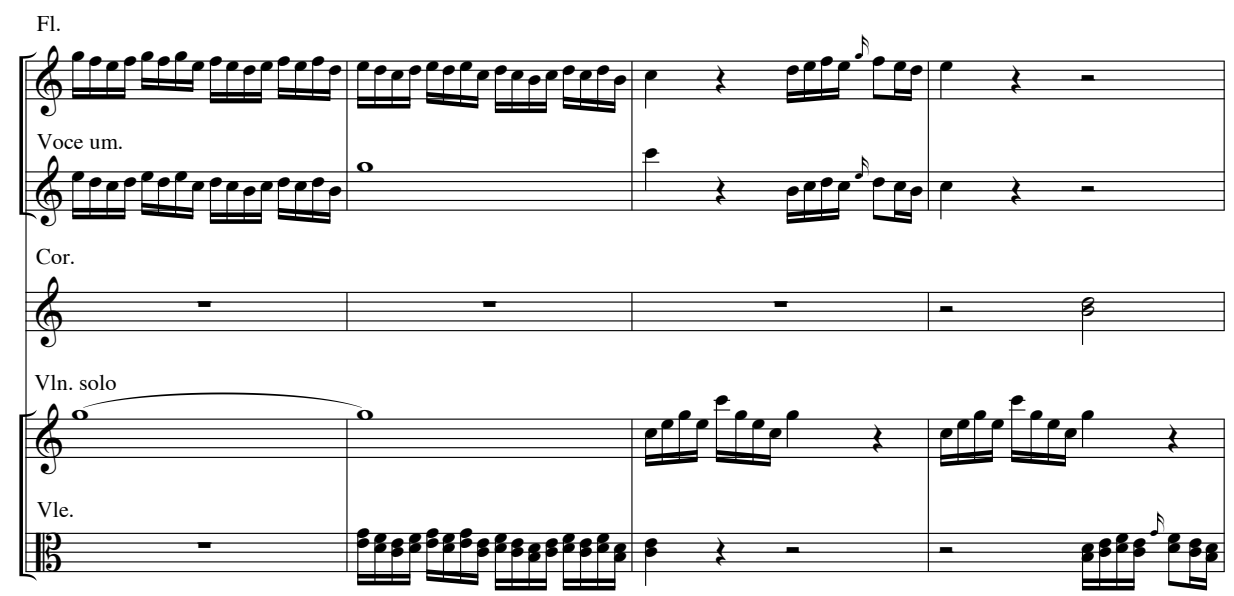

56 Caruso/Palomba: Il matrimonio in commedia. (F-Pn D 1865-1866)

Andererseits wird der vermeintliche Kranke durch die vorgetragene Musik zur aktiven Teilnahme - Singen und Tanzen - verlockt, beides unter die Gestaltungsspiele einzuordnende Tätigkeiten. Die spontane kreative Mitgestaltung, zu der der vermeintlich Verrückte indirekt veranlasst wird, kann gewissermaßen als der gemeinsame Nenner zwischen Musik- und Spieltherapie gelten. Nach Wolfgang Mastnak „scheint das eigentlich therapeutische des Spiels in den Künsten gerade darin zu liegen, daß das Leben im ästhetischen Prozeß spürbar präsent wird, daß durch den künstlerischen Akt hindurch im Spiel das transzendente Moment des Seins erfahrbar wird und sich zur spirituellen Lust am, ich bin` entfalten kann. Künstlerisches Spiel (...) fordert das ästhetische Maximum an Authentizität ein und gibt dem Leben, gibt uns, ein Maximum an vitaler Erfahrung zurück." ${ }^{806}$ Ähnliches behauptet Bilstein im Zusammenhang mit dem Spiel im Allgemeinen: „Vielmehr finden die Menschen im Spiel eine Verbindung sowohl zu sich selbst und ihren innersten Regungen als auch zum Großen Ganzen, das sie als Kosmos umgibt." ${ }^{807}$ Beide Äußerungen erinnern deutlich an Schillers häufig zitierte Behauptung, der Mensch sei „nur da ganz Mensch, wo er spielt." 808

806 Wolfgang Mastnak: Das Spiel: mystische Brücke zwischen Mensch und Kunst. Aspekte von Musik- und Spieltherapie. In: Günther G. Bauer (Hg.): Homo ludens. Musik und Spiel. Bd. 10. Internationale Beiträge des Institutes für Spielforschung und Spielpädagogik an der Hochschule „Mozarteum“ Salzburg. München, Salzburg 2000, S. 282f.

807 Johannes Bilstein: Spiel-Glück und Glücks-Spiele. In: Krassimira Kruschkova und Arno Böhler (Hg.): Dies ist kein Spiel. Maske und Kothurn 54/4 (2008), S. 79.

808 Schiller: Fünfzehnter Brief. Zit. nach Scheuerl: Theorien des Spiels. S. 37. 
Der Musik und dem Tanz, die Huizinga als reinste und vollkommenste Formen des Spiels bezeichnet, ${ }^{809}$ wird in dieser Szene eine beinahe magische Wirkung zugeschrieben, die eine große Ähnlichkeit aufweist mit der „Enthebung aus der reellen Weltwirklichkeit, die bis zur Entrückung, bis zur Verzauberung gehen kann “, ${ }^{810}$ mit der Fink die Sphäre des Spiels umschreibt. Sobald die Musiker zu spielen aufhören, verfällt der Cavaliere wieder in seine Raserei, aber während des Verlaufs der „Musik- und Tanztherapie“ stimmt sein Zustand durchaus mit Finks Begriff der durch das Spiel bewirkten „Oase des Glücks“ überein, die er mit folgenden Worten kennzeichnet: „Spielend sind wir für eine Weile entlassen aus dem Lebensgetriebe - wie versetzt auf einen anderen Stern, wo das Leben leichter, schwebender, glückender scheint." 811

\subsection{Jahrmarktspiele: Geschicklichkeit und Schaukunst in "Lo sposo di tre e marito di nessuna"}

Filippo Livignis Libretto zur ersten (erhaltenen) Opera buffa des jungen Cherubini „Lo sposo di tre e marito di nessuna“ kreist zwar wie viele Buffe um das Thema „Wer heiratet wen?"“, allerdings erhält die ansonsten eher konventionelle Handlung durch die für die Gattung des dramma giocoso unübliche Einführung von zwei Gauklern in den Dramatis Personae einen jahrmarktähnlichen Rahmen, in dem besonders häufig spielhafte Elemente auftauchen. Obwohl in der gesamten Oper spielerische Momente eingestreut sind, wird hier nur die Introduzione unter die Lupe genommen, in der konkrete aktionsreiche Spiele auf der Bühne stattfinden.

Die Eingangsszene führt durch eine tableauartige scena in piazza mit der Vorführung von Kunststücken durch die beiden Jahrmarktskünstler in die leichte, „frische“ und spielerische Atmosphäre der Oper ein. Die Regieanweisung dazu lautet: „Folletto fra molti villani facendo giuochi ai Bussolotti, D. Simone a sedere guardandolo con meraviglia, e Bettina in atto di suonare il Salterio."

Die ersten vier Verse der Oper beschreiben die Situation vom Blickwinkel des Don Simone aus, der Follettos Spielen zuschaut.

D. Sim. Guardate quanti giochi

Che fa quel Ciarlatano!

809 Huizinga spricht von der Musik als „reinste und höchste Manifestation der menschlichen Facultas ludendi“ (Huizinga, S. 179) und vom Tanz als „eine der reinsten und vollkommensten Formen des Spiels." (Huizinga, S. 159).

810 Fink: Oase des Glücks. S. 39.

811 Ebd. S. $23 \mathrm{f}$. 


\section{È destro assai di mano, \\ Strasecolar mi fa. ${ }^{812}$}

Als Schlüsselbegriffe fallen dabei „giochi“, „ciarlatano“, „destro“ und „strasecolar“ auf: Schon im ersten Vers der Oper werden die Spiele („giochi“) explizit genannt. Der Spieler ist hier ein „ciarlatano“, also ein wandernder "Illusionsverkäufer“. Während üblicherweise damit ein Heilpraktiker gemeint ist, der Wundermittel verkauft, wird Folletto im Personenverzeichnis als „giocatore di bussolotti“, also als Taschenspieler bezeichnet. Er vollbringt Zaubertricks, die normalerweise mit einem Geldeinsatz verbunden sind und somit für die Zuschauer die Funktion von Glücks- bzw. Einsatzspielen übernehmen, während hier von Geld keine Rede ist.

Don Simone bewundert Folletto, weil er „destro assai di mano“ ist. „Destrezza“, also Geschicklichkeit, ist die Fertigkeit, die Folletto zur Schau stellt. Seine Spiele gehören zu den Geschicklichkeitsspielen, die einige Spieltheoretiker als eigene Kategorie des Spiels behandeln, beispielsweise Friedrich Georg Jünger, der sie als eine der drei Hauptkategorien des Spiels betrachtet, während dagegen Scheuerl die Geschicklichkeitsspiele zu der allgemeineren Kategorie der Leistungsspiele zählt. Hier handelt es sich aber um die Zurschaustellung von Fertigkeiten und Kunststücken, so dass zusätzlich eine performative Komponente hinzukommt, die Follettos Spiele in die Nähe der Spiele mit Darstellungscharakter und des Theaters rücken lässt.

Schließlich spricht Don Simone von seiner Reaktion auf Follettos Spiele - „strasecolar mi fa" - und äußert so seine Bewunderung und Verblüffung. Das Ziel solcher Schaukünste ist nämlich, bei den Passanten gerade durch Spiele Staunen, Begeisterung und Faszination hervorzurufen.

Die darauffolgenden Verse stammen aus Follettos Mund, der als ciarlatano „im Einsatz" dargestellt wird:

Fol. $\quad$ Passa sparisci, e vola,

In man non ci ho più niente,

Ecco la verità.

Or dunque dove sta?

E pur questa Figliuola (a Bettina che cava la palla di saccoccia)

L'ha in tasca, e non lo sa. ${ }^{813}$

812 Livigni/Cherubini: Lo sposo di tre e marito di nessuna. Venedig 1783 (I,1).

813 Ebd. 
Allegro

Folletto

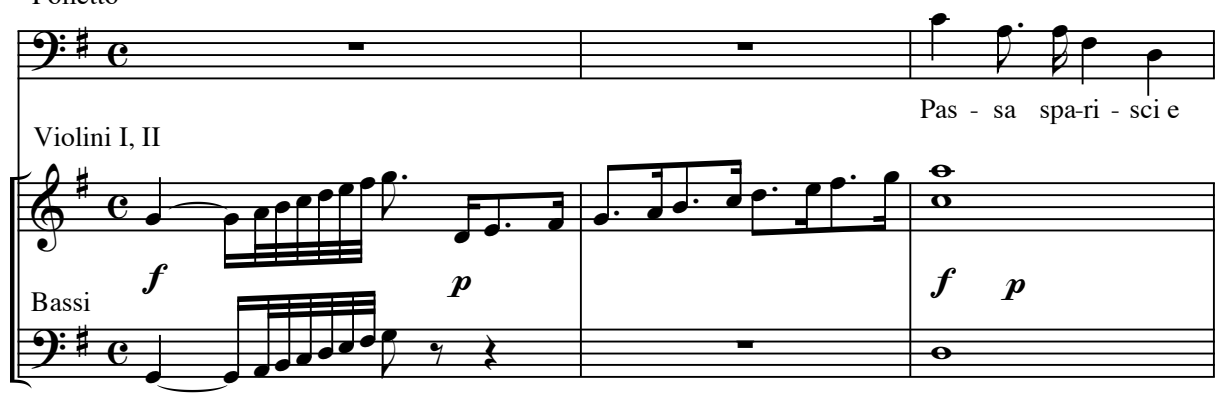

Fol.

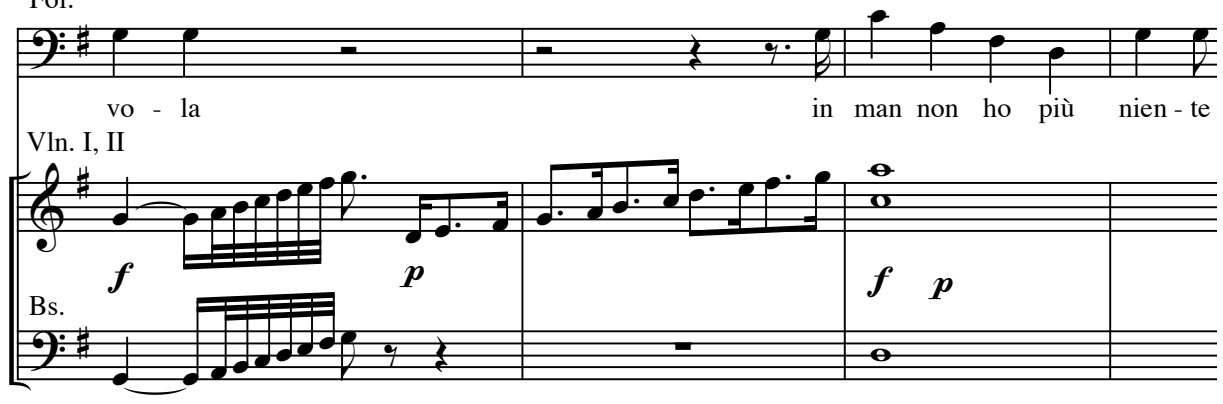

57 Cherubini/Livigni: Lo sposo di tre e marito di nessuna. Venezia 1783 (F-Pn D 2022-2023)

Folletto spielt hier ein Taschenspiel vor, nämlich das gioco dei bussolotti, ein altes Spiel, das üblicherweise mit drei bussolotti (Würfelbecher) und drei Bällchen oder Münzen gespielt wird. Hier werden offensichtlich Bällchen verwendet, da von einer palla die Rede ist. Die Spielmöglichkeiten sind dabei vielfältig. Eines der üblichsten Zaubertricks ist beispielsweise das „magische“ Durchgehen des Bällchens durch den Becherboden. Oft müssen die Zuschauer auch erraten, unter welchem Becher sich das Bällchen befindet, nachdem die Becher durch das Hin- und Herschieben mehrmals Platz gewechselt haben. In diesem Fall ist das Bällchen offensichtlich verschwunden und durch Zauber in Bettinas Tasche gelandet.

Follettos erste Worte „Passa sparisci e vola“ (passare = durchgehen, sparire = verschwinden, volare $=$ fliegen) klingen wie ein Zauberspruch. Die Tirata-Figur, die vor und nach dieser Phrase zu hören ist, könnte das Wort „vola“ (volare = fliegen) tonmalerisch darstellen, kann aber auch einfach die geschickte Geste des Taschenspielers unterstreichen, der den Zaubertrick vorführt. Das darauffolgende unbegleitete, 
punktierte Motiv der Geigen in plötzlichem Piano bewirkt eine witzig-unheimliche Stimmung, die die magische Sphäre des Zauberspiels ebenfalls gut trifft.

Die Frage nach der Lösung des Rätsels („Or dunque dove sta?“) ist, wie es häufig in der Opera buffa bei Fragen der Fall ist, rezitativisch vertont in einer typischen „fragenden" harmonischen Wendung, nämlich in Form eines verminderten Akkords (als Doppeldominante), dem ein Halbschluss auf der Dominante folgt. Schleiferfiguren in den Geigen betonen dabei den spielerischen Charakter der Situation. Durch Fragen entwickelt Folletto eine Art Gespräch mit seinem Publikum auf der Bühne, das er so ins Spiel mit einbezieht.

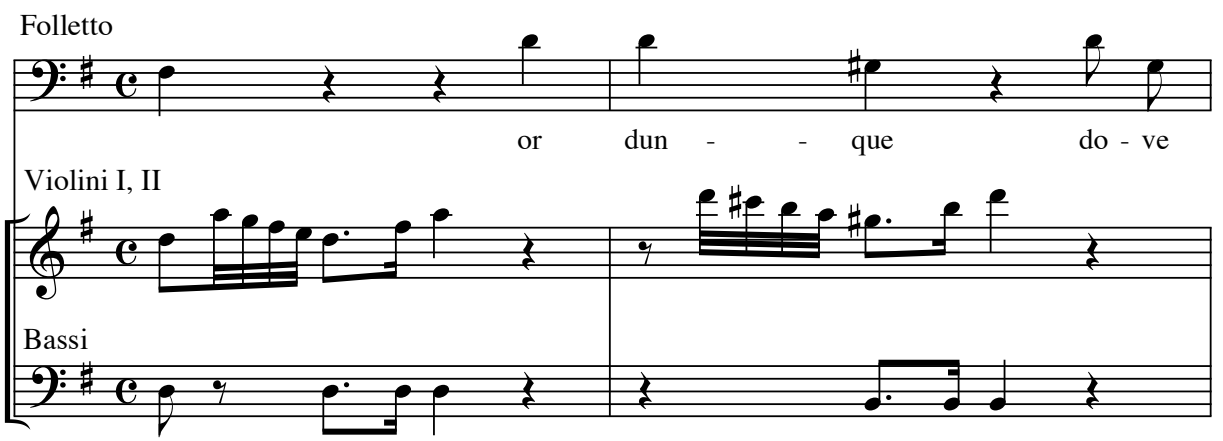

Fol.

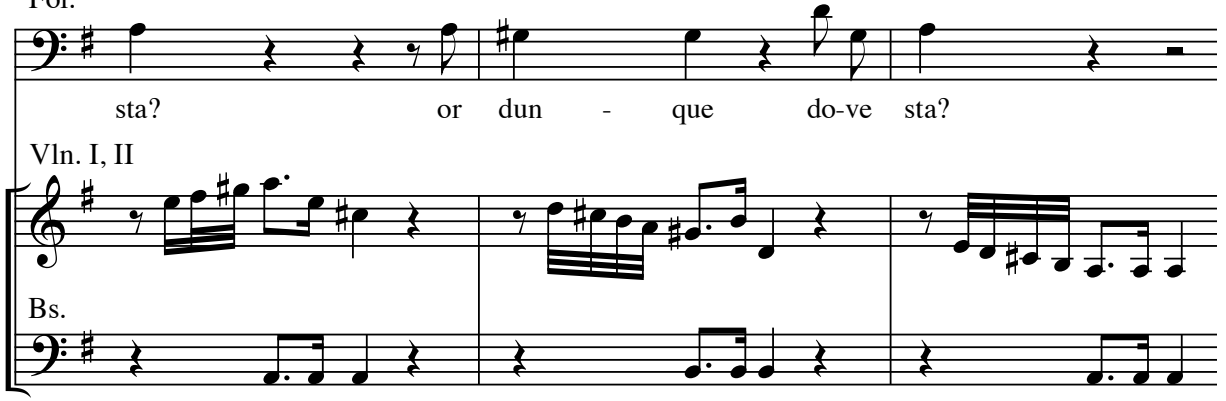

58 Cherubini/Livigni : Lo sposo di tre e marito di nessuna. Venezia 1783 (F-Pn D 2022-2023)

Die Reaktion auf die überraschende Lösung des Spiels - das Bällchen wird in der Tasche der scheinbar ahnungslosen Bettina gefunden - ist vonseiten aller Beteiligten ein herzhaftes Lachen, das nicht nur von den drei Stimmen gesungen, sondern auch tonmalerisch durch verzierte punktierte Figuren von den ersten Geigen dargestellt wird. 

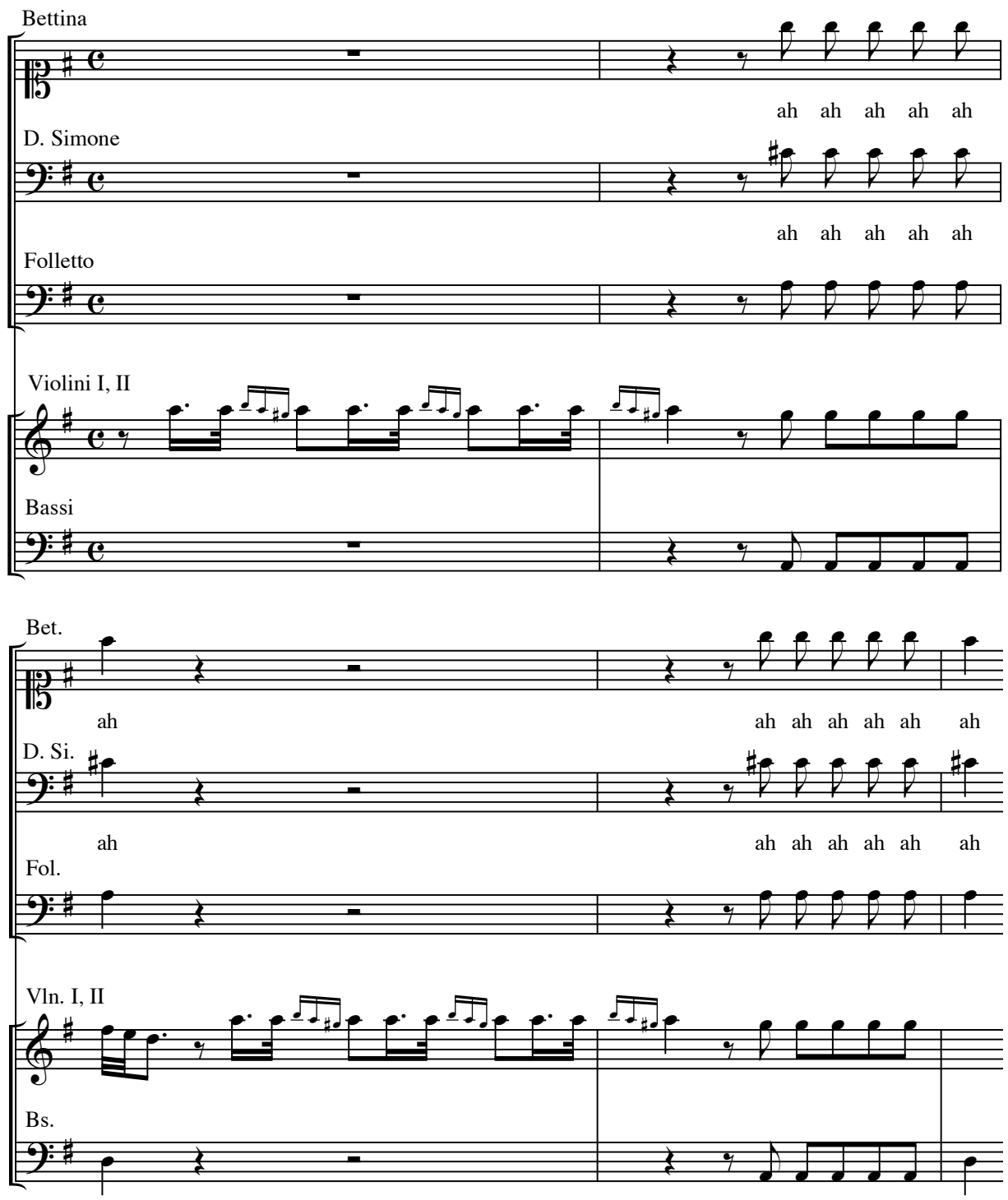

59 Cherubini/Livigni: Lo sposo di tre e marito di nessuna. Venezia 1783 (F-Pn D 2022-2023)

Die Achtelbewegung dieses Lachens wird imitatorisch weitergeführt, während im Text das Lachen in Zusammenhang mit dem Lob dieses "tollen“ Spiels thematisiert wird. 
a 3. Ah, ah, ah, ah, ah, ah.

Son cose da ridere,

Gran gioco è questo qua. ${ }^{814}$

Das Lachen, das nach Retemeyer „für die Scharlatane ein zentrales Mittel ist“815 und das Garvey als häufiges Signal einer Spielorientierung ansieht, ${ }^{816}$ während Plessner sogar von einem direkten Kausalitätsverhältnis zwischen Spielen und Lachen spricht, ${ }^{817}$ ist die Reaktion auf eine Überraschung und gleichzeitig ein Ausdruck der lustvollen Heiterkeit, die in dieser Szene auf dem Dorfplatz herrscht.

Kaum haben die Personen zu Ende gelacht, kündigt Bettina schon die nächste Unterhaltungsmöglichkeit an, nämlich ihre eigene Gesangsvorführung mit ZitherBegleitung. Die Ankündigung beginnt mit einer Aufforderung zur allegria, zur Fröhlichkeit. Die musikalische Darbietung wird hier in ihrer Fähigkeit zu spassare (unterhalten) dem Spiel gewissermaßen gleichgestellt.

Bet. Allegri, piazza piazza,

Che adesso col Salterio

Vi vuol questa ragazza

Spassare col cantar. ${ }^{818}$

Darauf folgt eine regelrechte Einlage, die - wie es in der Opera buffa üblich ist - musikalisch durch einen neuen Abschnitt mit neuer Takt- und Tonart gekennzeichnet und somit von der restlichen nicht-diegetischen Musik abgehoben ist. Besonders anmutig und spielerisch wirkt diese Einlage einerseits aufgrund des tänzerischen 3/8-Takts, andererseits aufgrund des Pizzicatos der Streicherbegleitung. Es handelt sich beim Pizzicato um einen Topos, der in vielen Serenaden, Ständchen und anderen einlageartigen Stücken immer wieder als Nachahmung eines Zupfinstruments - häufig der Gitarre, hier der Zither - eingesetzt wird. Das Pizzicato erfüllt hier zusätzlich auch eine textausdeutende Funktion, denn der erste Vers von Bettinas Lied lautet „Un certo pizzicore“. (Sowohl pizzicato als auch pizzicore stammen vom Verb pizzicare, das zupfen, aber auch

814 Ebd.

815 Kerstin Retemeyer: „das alle frömbde unnd landtstrychende artzet, salbenschryger, bruch-, steinund augenschnyder inn unnseren landen allerdings abgeschafft (...) werde“. Zum Agieren von Scharlatanen und Lachsnern in Zürich im 17.-18. Jahrhundert. In: Ludica. Annali di storia e civiltà del gioco. 5-6. Treviso 2000, S. 234.

816 Vgl. Garvey, S. 26.

817 Plessner: Lachen und Weinen. S. 285.

818 Livigni/Cherubini: Lo sposo di tre e marito di nessuna. Venedig 1783 (I,1). 
Flauto solo

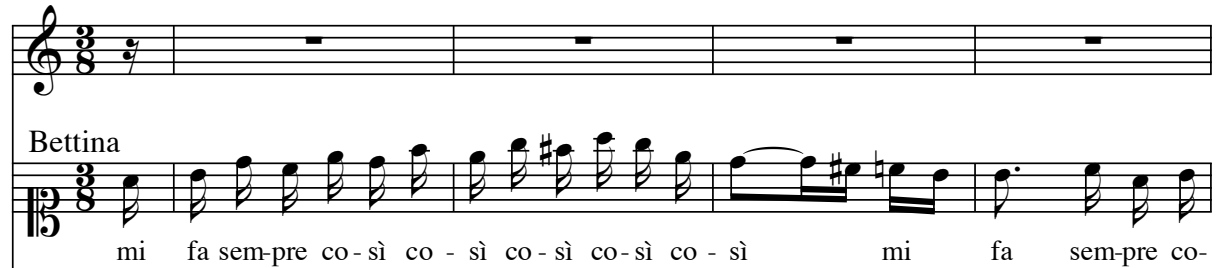

Violini I
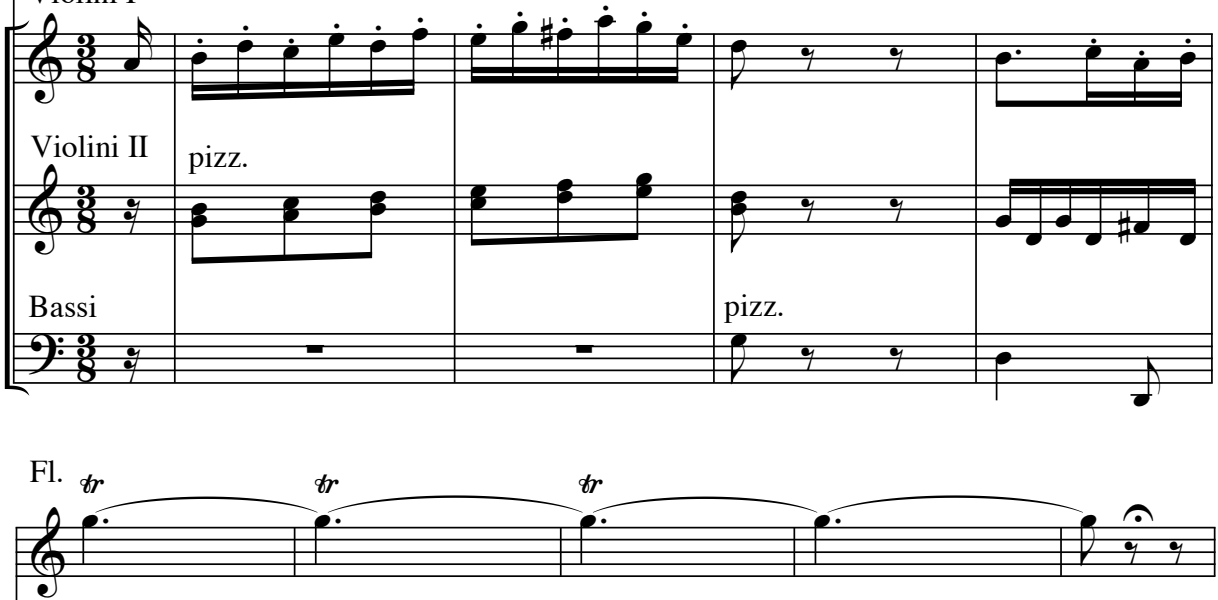

Bet.

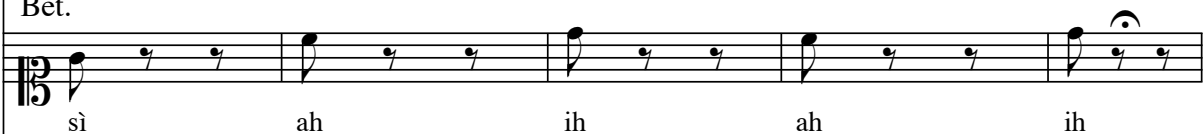

Vln. I

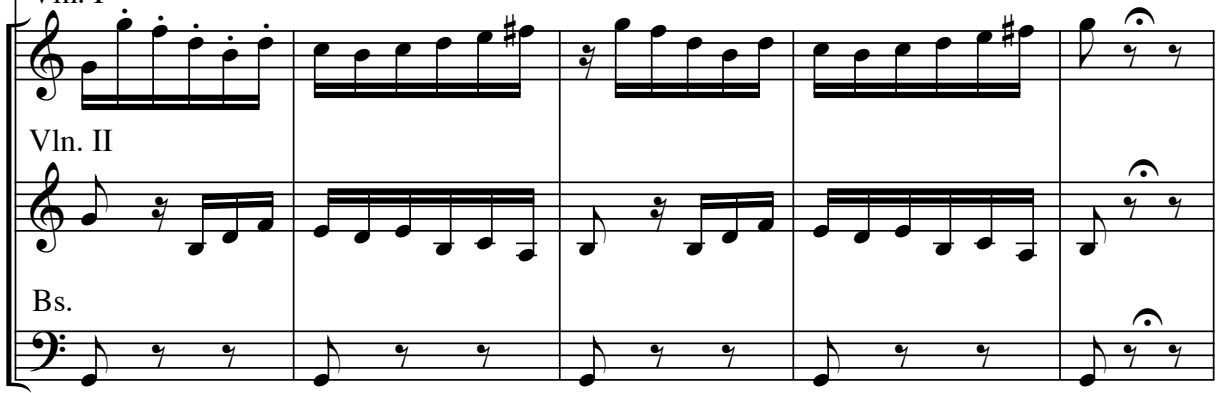

60 Cherubini/Livigni: Lo sposo di tre e marito di nessuna. Venezia 1783 (F-Pn D 2022-2023) 
zwicken, jucken oder kribbeln bedeutet.) Nicht nur das Pizzicato trägt zum naiven, beinahe niedlichen Charakter dieser Einlage bei, sondern auch das Vorwiegen des hohen Registers in Melodie und Begleitung sowie der Text, der zunächst nur in kurzen Motiven vertont ist und sich erst bei der mehrmaligen kindlich-spielerischen Wiederholung des Wortes „cosi“ zu einer etwas langatmigeren melodischen Linie öffnet. Der chromatische Durchgang gegen Ende deutet, in Anpassung an den Text („E sospirare Amore / Mi fa sempre cosi“), ein leichtes Schmachten an. Diese Worte geben außerdem erneut Anlass zu einem kleinen „Spiel“, nämlich zur spielerischen Nachahmung bzw. Darstellung des erwähnten Seufzens: „ah ih ah ih“. Die schon an sich performative Musikdarbietung enthält hier also zusätzlich ein schauspielerisches Moment, das die darstellerische Komponente des „Musikspiels“ und den ästhetischen Genuss erhöht.

Diese Einlage ist wie viele Musiknummern von Cherubinis Oper von einer großen Leichtigkeit und Frische geprägt, die sich hier vor allem aus dem tänzerisch schwingenden Rhythmus, dem hüpfenden Pizzicato der Streicher, den hohen Staccato-Tönen und Trillern der Flöte und dem sparsamen Einsatz von Bässen ergeben, woraus insgesamt der Eindruck des Spielerischen erweckt wird. Das hübsche Musikstück und Bettinas anmutiger Gesang wirken bezaubernd, wie auch das refrainartige Lob der beiden Männer („Che bella Canzoncina, / Mi piace, Signor sì“) nach jeder der beiden Strophen bestätigt.

Der letzte, im geschwinderen 2/4-Takt vertonte Abschnitt der Introduzione rundet schließlich die Jahrmarkt-Szene mit einem dreistimmigen, dem Spaß und der Fröhlichkeit gewidmeten Jubel ab.

a 3: Viva lo spasso, con l'allegria,

In festa, e giubilo qui si starà ${ }^{819}$

Ausgelassenheit und Jubel sind in der Opera buffa eher am Ende einer Oper oder eines Finales üblich, hier durchläuft die fröhliche festliche Stimmung angefangen von der Introduzione wie ein roter Faden beinahe die gesamte Oper und verleiht ihr dadurch einen heiteren und spielerischen Gesamtcharakter. Die Spielleute bewirken mit ihren Kunststücken bei den Zuschauern das von Groos für das Spiel theoretisierte gefühlsreiche „innere Miterleben“ und „Hineingerissenwerden in die dargestellten Begebenheiten“" ${ }^{820}$ Besonders für Bettinas musikalische Darbietung gilt Huizingas Aussage: „Musizieren (...) entrückt Zuhörer und Ausführende aus der ,gewöhnlichen“

819 Ebd.

820 Groos: Das Spiel. Zit. nach Scheuerl: Theorien des Spiels. S. 72. 
Sphäre in ein Gefühl der Heiterkeit“, 821 denn sie vermittelt die vielfach mit dem Spiel assoziierte Leichtigkeit und Anmut und bezaubert, wie auch der Taschenspieler mit seiner virtuosen Geschicklichkeit und seinen Zauberkünsten, das Publikum. Faszination und Vergnügen prägen diese „von Spiel durchtränkte“ Introduzione.

\section{Alea}

In den agonalen Spielen liegen der Verlauf und das Ergebnis des Spiels in den Händen der Teilnehmer, bei den Als-ob-Spielen sowie den zuletzt erwähnten „Gestaltungsspielen“ sind ebenfalls die Spieler „am Werk“, während hingegen bei den der Kategorie „Alea“ zugeordneten Spielen allein die „abstrakte und unberührbare Macht“822 des Zufalls die „gestaltende“ bzw. „entscheidende“ Kraft besitzt. Die Spieler haben in solchen Spielen keinerlei Einfluss auf den Ausgang des Spiels, der wie bei den agonalen Spielen für den einzelnen Spieler in Gewinn oder Verlust besteht; sie fordern gewissermaßen den Zufall heraus bzw. „spielen“ mit dem Zufall. Buland spricht dabei von „Einsatz-Spielen“, denn das Kennzeichen dieser Spiele ist, „daß der Spieler in irgendeiner Weise einen Einsatz leistet, und mit diesem Einsatz wird dann gespielt. Die Höhe des Einsatzes muß mathematisch genau bestimmt sein, ebenso die Gewinnchance. Auch das Ergebnis muß mathematisch genau (...) sein. "823 Dass es sich bei diesem Einsatz meistens um Geld handelt und dass der Anteil des Zufalls sich proportional zur Rolle des Geldes verhält, hat schon Caillois bemerkt. ${ }^{824}$ Dies ist unter anderem auch der Grund dafür, dass die in der Regel als Glücksspiele bezeichneten Spiele der Klasse „Alea“ im Gegensatz zu den Spielen der drei übrigen Kategorien Caillois' eher von Erwachsenen als von Kindern gespielt werden, weswegen sie in den meisten einer pädagogischer Perspektive entspringenden Spieleinteilungen (Piaget, Château) nicht berücksichtigt werden. Auch Huizingas Definition von Spiel als „eine freie Handlung, (...) an die kein materielles Interesse geknüpft ist und mit der kein Nutzen erworben wird“, 825 schließt Wett- und Glücksspiele aus der Sphäre des Spiels aus, während Caillois in seiner Definition des Spiels auch die Möglichkeit einer „Verschiebung des Eigentums“826 einbezieht. Buytendijk erklärt sehr genau „warum

821 Huizinga, S. 48.

822 Caillois, S. 26.

823 Buland: Die Einteilung der Spiele nach ihren Freiheitsaspekten. S. 272.

824 „Je größer der Anteil des Zufalls ist (...), desto bedeutender wird im Allgemeinen die Rolle des Geldes." (Caillois, S. 26).

825 Huizinga, S. 20.

826 Vgl. Caillois, S. 11 f. 
man die sogenannten Glücksspiele mit dem Namen ,Spiele‘ bezeichnet, und warum man bei Teilnahme an einer Lotterie oder am Roulette-Tisch tatsächlich spielt. Persönlich tut man dabei scheinbar nichts, aber der Ablauf des Geschehens - innerlich miterlebt - hat so ausgesprochen das Element der unberechenbaren Abwechslung, des Zufalls in sich, dass damit schon die Bezeichnung ,Spiel' begründet ist. Erlebnismäßig spielen wir mit dem Glück oder dem Zufall, mit einer Gottheit oder mit einem Dämon, jedenfalls mit einer unberechenbaren Macht, so dass die Spieltätigkeit die Überraschung eines abenteuerlichen Unternehmens mit sich bringt." 827

Das häufig genannte Merkmal der Folgenlosigkeit und der Probecharakter ${ }^{828}$ des Spiels treffen bei Alea-Spielen oft nicht zu: Man denke beispielsweise an die unter Umständen vernichtenden Konsequenzen eines großen Geldverlustes bei Wett- oder Glücksspielen. Es handelt sich auch um die Spielkategorie, die am ehesten (auch schwerwiegende) Suchterkrankungen verursachen kann.

In der Opera buffa wird das Glücksspiel - möglicherweise aus Gründen der Zensur - verhältnismäßig selten thematisiert, obwohl es in Venedig, der „europäischen Hauptstadt des öffentlichen Glücksspiels“, ${ }^{829}$ gewissermaßen zum Alltag gehörte. Neben den Masken- bzw. Identitätsspielen des Karnevals waren Glücks- und Hasardspiele die üblichste Art des Spiels, die überall - in Theater- und Opernhäuser, in Kaffeehäusern und den sogenannten botteghe da gioco - gespielt wurde.

Bei den gelegentlich in den Buffa-Handlungen vorkommenden Kartenspielen handelt es sich meistens um eine Mischform zwischen Agon- und Alea-Spielen, weswegen sie schon im Kapitel „Agon“ behandelt worden sind. In keinem Libretto kommt explizit zur Sprache, dass dabei um Geld gespielt wird. Das generell mit Spiel assoziierte Prinzip des Zufalls - Buytendijk nennt „die Möglichkeit, die Überraschung, den Zufall“ als „das wichtigste Merkmal, das die ganze Spielsphäre ausfüllt“ ${ }^{830}$ - spielt dagegen in der Opera buffa sehr wohl eine Rolle. Buffa-Figuren versuchen in der Regel durch Schlauheit, Geschicktheit, Burle und Strategiespiel ihr Glück (Heirat, Reichtum) zu verwirklichen und somit ihres eigenen Glückes Schmied zu sein, sind aber natürlich wie alle Menschen der „unberechenbaren Macht“831 des Zufalls unterworfen, die sich besonders dann bemerkbar macht, wenn sie unerwartete Situationen, vor allem zufällige Begegnungen, auch im Sinne von merkwürdigen Zusammentreffen von Umständen (coincidenze) und unwahrscheinlichen Begebenheiten und Ereignissen, herbeiführt. Das Spiel des Zufalls kommt in solchen Fällen gewissermaßen als

827 Buytendijk, S. $115 \mathrm{f}$.

828 Vgl. Rapp: Rolle, Interaktion, Spiel. S. $103 \mathrm{f}$.

829 Vgl. Zollinger u. Depaulis, S. 45.

830 Buytendijk, S. 162.

831 Ebd. S. 116. 
dramaturgisches Mittel zur Anwendung, um in die Handlung überraschende Wendungen, insbesondere regelrechte colpi di scena (Theatercoups), einzubringen. Dabei ergeben sich aus unglücklichen Zufällen häufig „handlungskatalysierende“ Hindernisse, die dann im weiteren Handlungsverlauf entweder durch menschliche Strategien überwunden oder durch das wiederum unerwartete Auftreten eines glücklichen Zufalls aufgelöst bzw. beseitigt werden. „Mimicry-Spiele“ wie Burle und bewusste Täuschungsmanöver stehen in der Opera buffa also in deutlichem Gegensatz zum "Alea-Prinzip“, übernehmen teilweise aber dieselbe dramaturgische Funktion. Der Zufall wird als dramaturgischer Griff einerseits zur Herstellung von Missverständnissen und imbrogli verwendet, auf die die ganze Handlung aufbaut, wie beispielsweise in „La finta giardiniera“ und in „I castellani burlati“, in denen ein Mann zufällig seine Geliebte einen fremden Mann umarmen sieht und unwissend, dass es sich um ihren Bruder handelt, sich betrogen fühlt und seine Geliebte verlässt oder sogar zu erschießen versucht. Andererseits üben zufällige Ereignisse und glückliche Umstände - wie u.a. aus einigen auf die Rolle des Glücks (fortuna) hinweisenden Titeln ersichtlich ist: „Le gelosie fortunate“, „La discordia fortunata“, „L'innocente fortunata“ - immer wieder auch die dramaturgische Funktion der Auflösung des Handlungsknotens aus. $\mathrm{Zu}$ demselben Schluss gelangt auch Martini in seinen allgemeinen Überlegungen zur Komödie: „Die Konflikte des Lustspiels sind Konflikte unter Menschen innerhalb der von ihnen geschaffenen und verwirrten Zuständen; Menschen verschulden sie, Menschen können sie auch wieder ausgleichen und entwirren. (...) Die einzige außermenschliche Macht, welche das Lustspiel in sich aufzunehmen vermag und auch geradezu ausbeutet, ist der Zufall. Denn in ihm wohnt die Qualität des Unerwarteten und Unberechenbaren (...). Er ist dann das Spielelement, das gleichsam das Leben selbst zur Verfügung stellt und mit dem es seine Überraschungen produziert und zurücknimmt." 832

Als Beispiel dafür, dass der Zufall in der Opera buffa häufig Überraschungen verursacht - allerdings ist ein Umkehrschluss nicht möglich, denn nicht jede Überraschung wird durch Zufall verursacht -, soll ein kurzer Ausschnitt aus dem ersten Finale von Livignis und Anfossis „I viaggiatori felici“ dienen: Hier besteht die Überraschung in der unerwarteten Begegnung von Vater (Pancrazio) und Sohn (Giannetto), während der Vater sich gerade anschickt, das Mädchen (Bettina) zu entführen, mit dem sein Sohn nach ihrer heimlichen Heirat geflohen ist. Alle sind verblüfft, und nach dem im Allegro vivace vertonten Überraschungsmoment folgt, wie es in der Opera buffa typisch ist, ein Moment des Stillstands, in dem jeder vom unerwarteten Ereignis beinahe gelähmt für sich da parte seine Verblüffung mit einem Gleichnis veranschaulicht.

832 Martini, S. 350. 
Eines der verschiedenen ideenreichen Gleichnisse basiert auf dem Vergleich der gerade erlebten Überraschung und Fassungslosigkeit mit der Reaktion eines abergläubischen Lottospielers, der fest mit der Ziehung der Zahl „eins“ rechnet, wogegen dann zu seiner Verblüffung die Zahl 38 gezogen wird.

D. Gas. (Sbalordito affè, qui resto

Come quel che crede al Lotto,

Gioca l'uno, e vien trent'otto,

Né si può capacitar. $)^{833}$

An diesem Gleichnis wird die naheliegende Assoziation zwischen Glücksspiel bzw. Zufall und Überraschung besonders deutlich. Dass dabei gerade das Lottospiel als Beispiel für ein Glücksspiel verwendet wird, ist nicht besonders verwunderlich: Das im I6. Jahrhundert in Genua entstandene und 1734 in Venedig importierte Zahlenlotto gewann in der „Hauptstadt des Vergnügens“ so rasch an Beliebtheit, dass es die schon I 522 offiziell eingeführte Staatslotterie, das sogenannte „loto alla veniziana“, sehr bald an Popularität übertraf. ${ }^{834}$ Die in Venedig für die Lotterie und später für das Lotto entbrannte Leidenschaft sowie die besondere Beliebtheit der Glücksspiele setzt Alberto Fiorin nicht nur mit dem allgemeinen „clima ludico“ der Stadt in Zusammenhang, sondern auch mit der Risikobereitschaft, die mit den in Venedig vorherrschenden Handelstätigkeiten verbunden war: „Altro elemento di grande interesse è l'enorme interesse suscitato dalle lotterie nei veneziani e questo può essere spiegato con il clima ludico che regnava in quei secoli a Venezia, città in cui l'aria doveva essere pregna di azzardo, di rischio, legato sia al gioco ,tout court' che all'esercizio di professioni ad alto rischio come quelle mercantili." 835

In mehreren Opern, Balletten, Theaterstücken und Romanen des i 8. Jahrhunderts werden Hasardspiele thematisiert, wobei vor allem die Figur des giocatore, des Spielsüchtigen, im Vordergrund steht. ${ }^{836}$ Von den in Venedig im untersuchten Zeitraum aufgeführten musiktheatralischen Werken ist in diesem Zusammenhang „La

833 Livigni/Anfossi : I viaggiatori felici. Venedig $1780(\mathrm{I}, 22)$.

834, „....) nel cuore degli scommettitori era subentrata ormai la nuova stella: l'Impresa del Lotto Pubblico ad uso di Genova e di Roma, instauratasi con continuità dal 1734 e destinata a fare la parte del leone nel mondo delle estrazioni." (Vgl. Alberto Fiorin: Nascita e sviluppo delle lotterie a Venezia. In: Günther G. Bauer (Hg.) : Homo ludens. Der spielende Mensch. Bd. 7. Internationale Beiträge des Institutes für Spielforschung und Spielpädagogik an der Hochschule „Mozarteum“ Salzburg. München, Salzburg 1997, S. 119).

835 Ebd. S. 120.

836 Siehe Zollinger u. Depaulis: Zwischen Allegorie und Realismus. Zur Thematisierung des Spiels in der Musik. In: Günther G. Bauer (Hg.): Homo ludens. Musik und Spiel. Bd. 10. S. 37-113. 
villeggiatura di Mestre“ zu nennen, eine farsa per musica aus dem Jahr I770, in der die Figur des giocatore als versessener Bassette-Spieler auftaucht. Zollinger spricht außerdem von einer privaten Aufführung des Intermezzo „Il giocatore amoroso“ von Dominicus Friggieri und Andrea Lucchesi in Venedig im Jahr I 769. Vor allem aber in der in Venedig uraufgeführten Opera buffa „L'astratto ovvero Il giocator fortunato“ von Giuseppe Petrosellini und Niccolò Piccinni spielt das Glücksspiel eine wesentliche Rolle, denn hier steht nicht nur ein giocatore im Mittelpunkt der gesamten Handlung, sondern es ist gerade sein Gewinn beim Lottospiel, der eine glückliche Wende herbeiführt und eine scheinbar ausweglose Situation schließlich einem lieto fine zuführt. Schon aus dem Titel ist die Thematisierung des Glücksspiels zu erahnen, denn ein „giocator fortunato “ ist ein vom Glück begünstigter Spieler und tatsächlich dreht sich die Handlung um einen bürgerlichen jungen Mann namens Leandro, auf dessen Versessenheit für das Lottospiel schon im Personenverzeichnis hingewiesen wird:

Primo buffo mezzo carattere

LEANDRO Giovane astratto, e giocator di Lotto Figlio di Timoteo

Eine weitere charakterisierende Eigenschaft von Leandro ist seine „Abstraktion“, d. h., seine beinahe krankhafte Zerstreutheit und Geistesabwesenheit, die durchaus mit der Spielversessenheit verbunden ist. Schon in der Introduzione, in der, wie es häufig der Fall ist, mehrere mit unterschiedlichen Dingen bzw. Tätigkeiten beschäftigte Personen gezeigt werden, sitzt Leandro an einem kleinen Tisch und schreibt, während eine seiner beiden Schwestern am Spinett singt und die andere frisiert wird. Vermutlich füllt Leandro gerade einen Tippschein aus, denn er erhofft sich von drei von ihm aus Kalenderrechnungen abgeleiteten Zahlen (2, 6, 23, wobei die erste der Epakte, d.h. der Zahl der Tage zwischen dem Neumond des vergangenen Jahres und dem I. Januar, und die zweite dem Mond entspricht) den Gewinn eines „Terno“.

Leandro: Due d'Epata, sei di Luna ...

E sfacciato il ventitre.

Si farò la mia fortuna

Qui ci è il Terno per mia fe.

(...)

Ah che il Lotto è un gran piacere! ${ }^{837}$

837 Petrosellini/Piccinni: L'astratto ovvero Il giocator fortunato. Venedig 1772 (I,1). 
Dass das Glücksspiel auch in Venedig als Unsitte, die gelegentlich damit assoziierte Zahlenmystik als Aberglaube und die Spielsucht als zu verdammende Schwäche oder Laster gesehen wurde, wird nicht nur durch den venezianischen Spruch „chi zoga al loto in rovina va de troto" 838 verdeutlicht, sondern auch durch die Worte des Vaters, der sich in der Introduzione über seine drei Kinder, besonders über seinen spielsüchtigen Sohn beklagt.

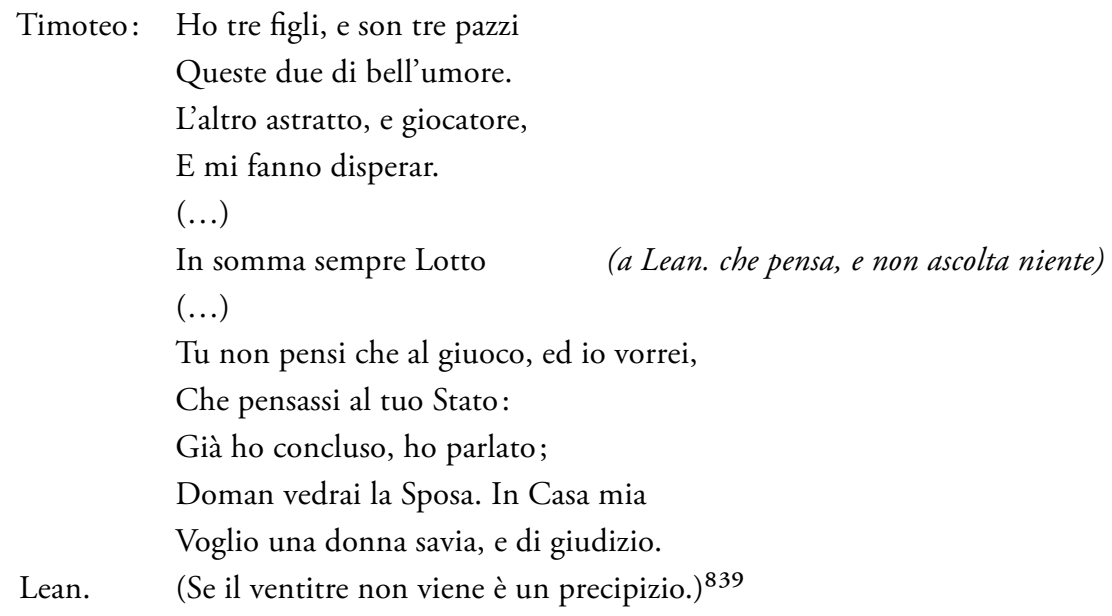

Der in Gedanken versunkene Leandro nimmt die Ankündigung seines Vaters über seine (Leandros) bevorstehende Hochzeit nicht wahr und denkt nur an die Zahl 23, auf die er gesetzt hat. Er ist „astratto“, spricht oft da parte für sich und nimmt von der Außenwelt keine Kenntnis. Das Thema des Glücks beschäftigt ihn ; der „Fortuna“ gibt er auch die Schuld, dass seine Geliebte, die Gärtnerin Laurina, nicht in demselben gesellschaftlichen Stand geboren ist wie er und über keine Mitgift verfügt, was anscheinend ein unüberwindbares Hindernis für ihre Hochzeit darstellt. Schon zu Beginn hofft er auf einen Lottogewinn, der dieses Problem lösen könnte.

Lean. (Ah Fortuna

Fortuna maledetta

A far nascer Laurina in basso stato!

Ma se vinco, se vinco. $)^{840}$

838 Vgl. Benvenuti, S. 727.

839 Ebd.

840 Ebd. (I,2). 
Während der gesamten Handlung denkt Leandro beinahe an nichts anderes als an das Lottospiel und kann das Ergebnis der Lottoziehung kaum erwarten.

Lean. Odi Giocondo (piano)

Va a veder, se la nuova

Del Lotto, è giunta ancora.

Gioc. E troppo presto:

Non vien prima di sera. ${ }^{841}$

Immer wieder kommt die Zahl 23 zur Sprache, die einen Gewinn bedeuten würde, der die fehlende Mitgift seiner Geliebten ersetzen könnte.

Lean. La Dote poi ... la dote ...

Sì sì senza la dote presto presto

Noi diventeremo ricchi ...

(Basta che il ventitre non me la ficchi.) ${ }^{842}$

Leandros Spielbesessenheit reicht soweit, dass er, als seine Schwester ihm von einer Neuigkeit erzählen will, sofort glaubt, sie wolle ihm das Ergebnis der Ziehung mitteilen und fragt, ob die 23 gezogen worden sei. Angelica meint natürlich etwas ganz anderes.

Ang. Leandro la sapete

La bella nuova?

Lean. E fatta l'estrazione? (con gran premura)

E uscito il ventitre?

Ang. Non volevo dir questo. ${ }^{843}$

Das Lottospiel ist eine derart fixe Idee, dass Leandro der Spielgewinn und die damit verbundene Verwirklichung seiner Hochzeit mit Laurina sogar im Traum erscheinen. Während er in einer Cavatina $\left(\mathrm{II}, \mathrm{I}_{3}\right)$ und den darauffolgenden rezitativischen Versen von diesem bedeutenden Traum erzählt und in seinen um das Lottospiel kreisenden Gedanken versunken ist, versucht sein Vater vergeblich, mit ihm zu sprechen.

Lean. In mezzo a mille affanni

Languiva questo core.

841 Ebd. (I,8).

842 Ebd. (II,3).

843 Ebd. (II,4). 
Ma con un sogno amore

Mi venne a consolar.

Mi parea d'aver vinto,

E che Laurina fosse mia Consorte,

Felice me, se avessi una tal sorte.

Tim. (Eccolo qui d'intorno alla Casetta

Della sua bella Diva ...

Vorrei persuaderlo a poco a poco.)

Lean. (Basteria che reggesse il capo gioco.)

Tim. Leandro. (chiamandolo)

Lean. (Il gioco è forte,

È caricato assai.)

Tim. Senti.

Lean. (La nuova, oh Dio! Non giunge mai.)

Tim. Ma Leandro, Leandro

Per carità. $\quad(\text { gridando })^{844}$

Leandros Verhalten weist die typischen Anzeichen einer Spielsucht auf, nämlich die andauernde gedankliche Beschäftigung mit dem Spiel, die auch mit Wunschvorstellungen verbunden ist, die Ruhelosigkeit, das Einsetzen von immer höheren Geldbeträgen und die Flucht aus der Realität sowie die Entfremdung von seinen Angehörigen. Leandro nimmt nicht wahr, dass sein Vater mehrmals nach ihm ruft, er bleibt in Gedanken in seiner eigenen Welt, nämlich der Welt des Spiels, befangen, verwendet Begriffe aus dem Lottojargon wie „capogioco“ (Bankzahl) ${ }^{845}$ und denkt über die hohe Geldsumme nach, die er eingesetzt hat („Il gioco è forte / È caricato assai“). Dass seine Zerstreutheit und Spielbesessenheit pathologische Züge annimmt, wird unter anderem deutlich, als er mit seiner geliebten Laurina zu sprechen glaubt, und nicht bemerkt, dass an ihrer Stelle sein Vater steht, dessen Hand er hält. Seine Versunkenheit im Spiel scheint also mit einer ausgesprochenen Realitätsflucht einherzugehen.

Als er endlich durch eine „nuova“" vom Ergebnis der Ziehung erfährt, zittert er vor Aufregung:

Gioc. Caro Signor Padrone, ecco la nuova. (gli dà una carta.)

Lean. La nuova ... ah tremo tutto.

844 Ebd. (II,13).

845 Die Bankzahl ist eine meist bei den Ziehungen schon lange nicht erschienene Zahl, die man in mehreren bzw. allen gespielten Zahlenkombinationen verwendet. 
La nuova ... presto ... oh Dio! Vediam ... dov'è:

Quattordeci ... sessanta ... ventitre ... (leggendo)

Cari, cari carissimi

Numeri amabilissimi. (bacia la Carta.)

Lau. Avete vinto?

Lean. Ho vinto.

Gioc. Evviva, evviva.

Lau. Ah voi mi consolate.

Lean. Quanti Terni ... guardate...

Questo è Terno sei mila:

Questo dodeci mila ... eccone un altro ...

Ecco il quarto ... Ecco il quinto ...

Ah Laurina, ah Giocondo

Più felice di me non v'è nel Mondo. ${ }^{846}$

Die Zahl 23, auf die Leandro offensichtlich als Bankzahl (capogioco) getippt hat, ist tatsächlich gezogen worden und Leandro hat fünf „terni“ im Wert von insgesamt 36000 scudi gewonnen. Er schickt den Diener, den Gewinn einzulösen, bleibt also mit Laurina allein, der er nun seine höchste Aufgeregtheit und Freude offen zeigen kann. Um den Erregungszustand des überglücklichen Leandro angemessen darzustellen, wählen die Autoren die in dieser Oper nur an dieser Stelle eingesetzte und dafür dramaturgisch umso wirksamere Form des Accompagnato-Rezitativs.

Lau. $\quad$ Caro sposo adorato

Molto più del denaro m'interessa

La tua felicità.

Lean. Che bella sorte!

Che gran sorte ... io sono ricco ...

Io sono Principe ... io sono ...

Che caldo ... che gran smania ... ah più non capo [sic]

Dentro il Giustacore (si sbottona e si fa vento.)

Son più grasso, più pingue, e son Signore.

„Voglio comprare un Feudo ...

„Voglio fare un viaggio ... una Carrozza,

„Una muta ... Ah Laurina

„Verrai tu nella muta? ... il sangue il sangue

846 Ebd. (II,17). 
„Mi bolle nelle vene ... fuma il Capo ...

„Il cor mi balza ... L'equinozio ... l'Anno

„Il giorno della Luna ...

„Oh che sorte, oh che sorte! O che fortuna! ${ }^{847}$

Leandro a tempo

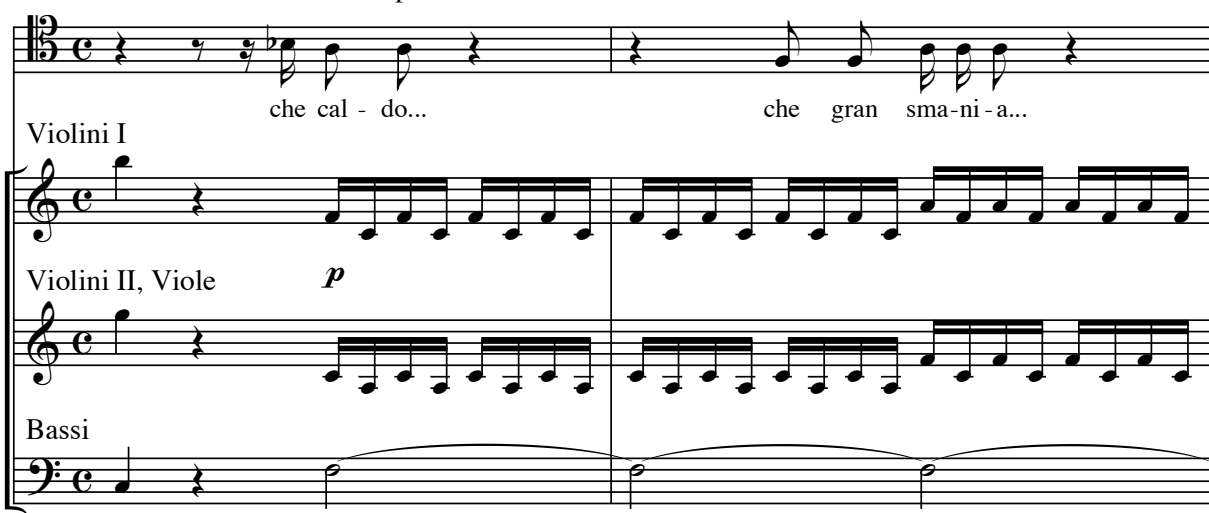

$\boldsymbol{p}$

Lea.

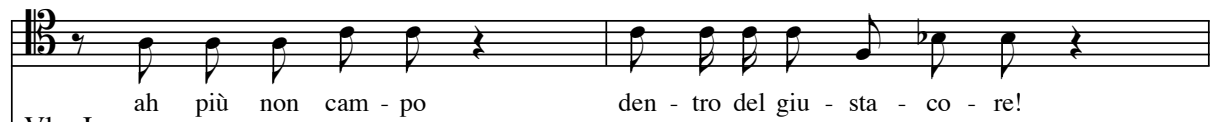

Vln. I

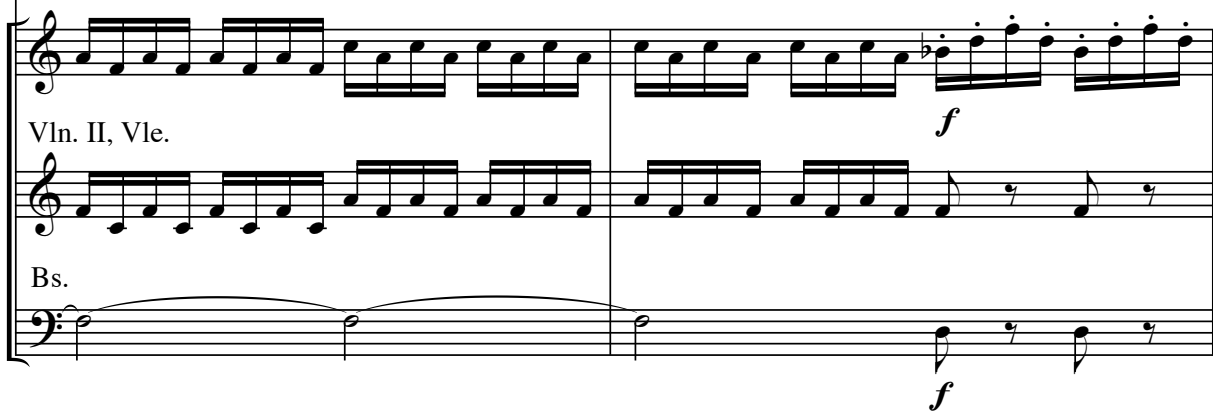

61 Piccinni/Petrosellini: L'astratto o Il giocatore fortunato. (F-Pn MS. 2372)

Leandros regelrechtes Spiel- bzw. „Gewinnfieber“ äußert sich in diesem dramatischen Höhepunkt nicht nur durch unvollständige, mit Fortführungspunkten endende Sätze, die in ebenso abgehackte musikalische Phrasen vertont werden, sondern auch - wie

847 Ebd. (II,18). 
es in der Opera buffa häufig der Fall ist - durch körperliche Symptome, vor allem das Gefühl der Hitze, bei dessen Nennung Geigen und Bratschen „Hitzewallungen“ als leise, aber rasche Sechzehntel-Figuren „malen“.

Die metaphorische Darstellung dieses Hitzegefühls als in den Adern siedendes Blut (,il sangue mi bolle nelle vene“) und als rauchender Kopf („fuma il capo") wird ebenfalls durch leise und rasch bebende Sechzehntel untermalt, während der beschleunigte Herzschlag (,il cor mi balza“) musikalisch durch laute, auf Akkordtönen „springende“ Achtelnoten umgesetzt wird.

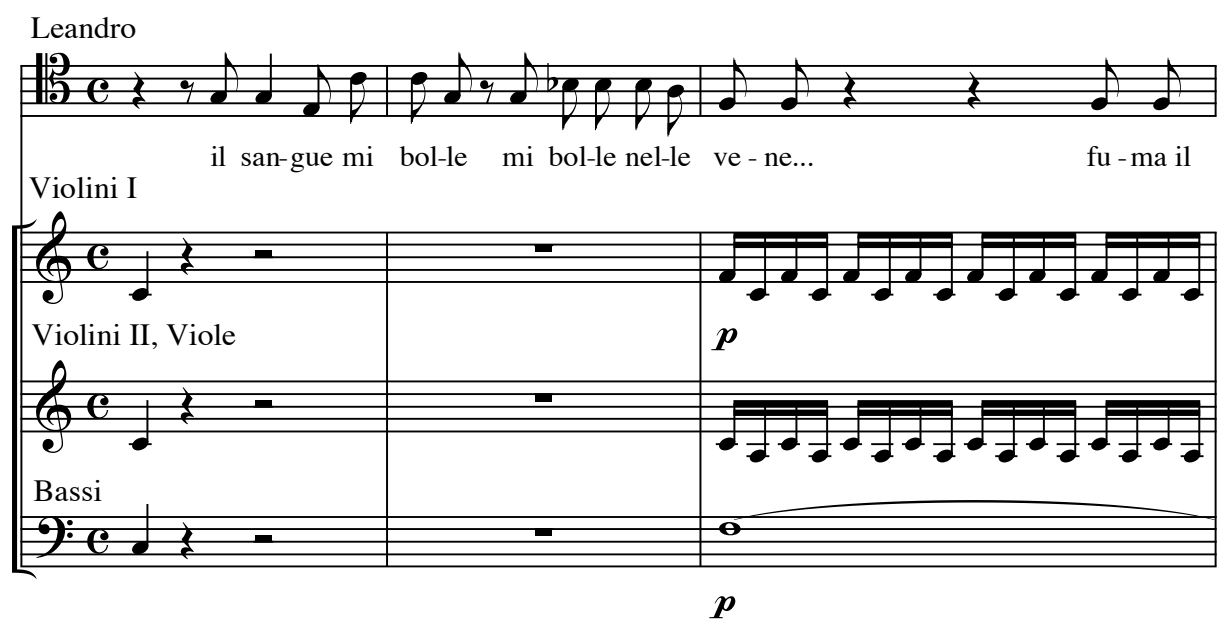

Lea.

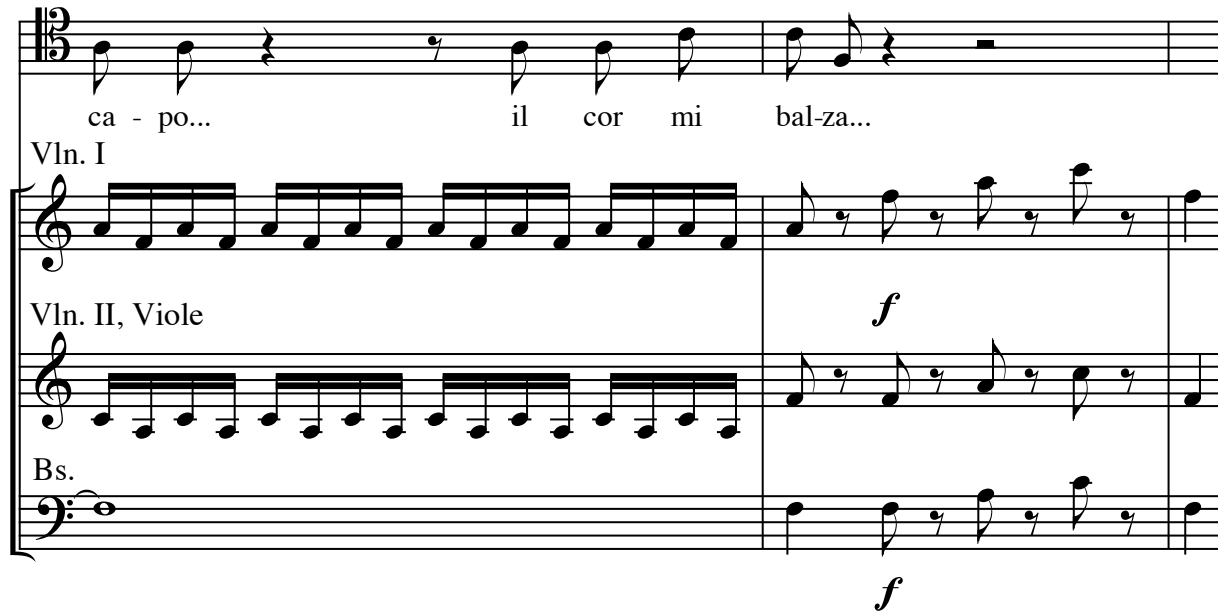

62 Piccinni/Petrosellini: L'astratto o Il giocatore fortunato. (F-Pn MS. 2372) 
Leandro erwähnt zum Schluss noch einmal die glückbringenden „magischen“ Elemente, die die gewinnenden Zahlen ergeben haben („L'equinozio ... l'Anno / Il giorno della Luna ..."), bevor er sich dem triumphierenden Jubel über sein Glück hingibt („Oh che sorte, oh che sorte! O che fortuna“), der musikalisch durch sich freudig hinaufschwingende melodische Linien umgesetzt wird.

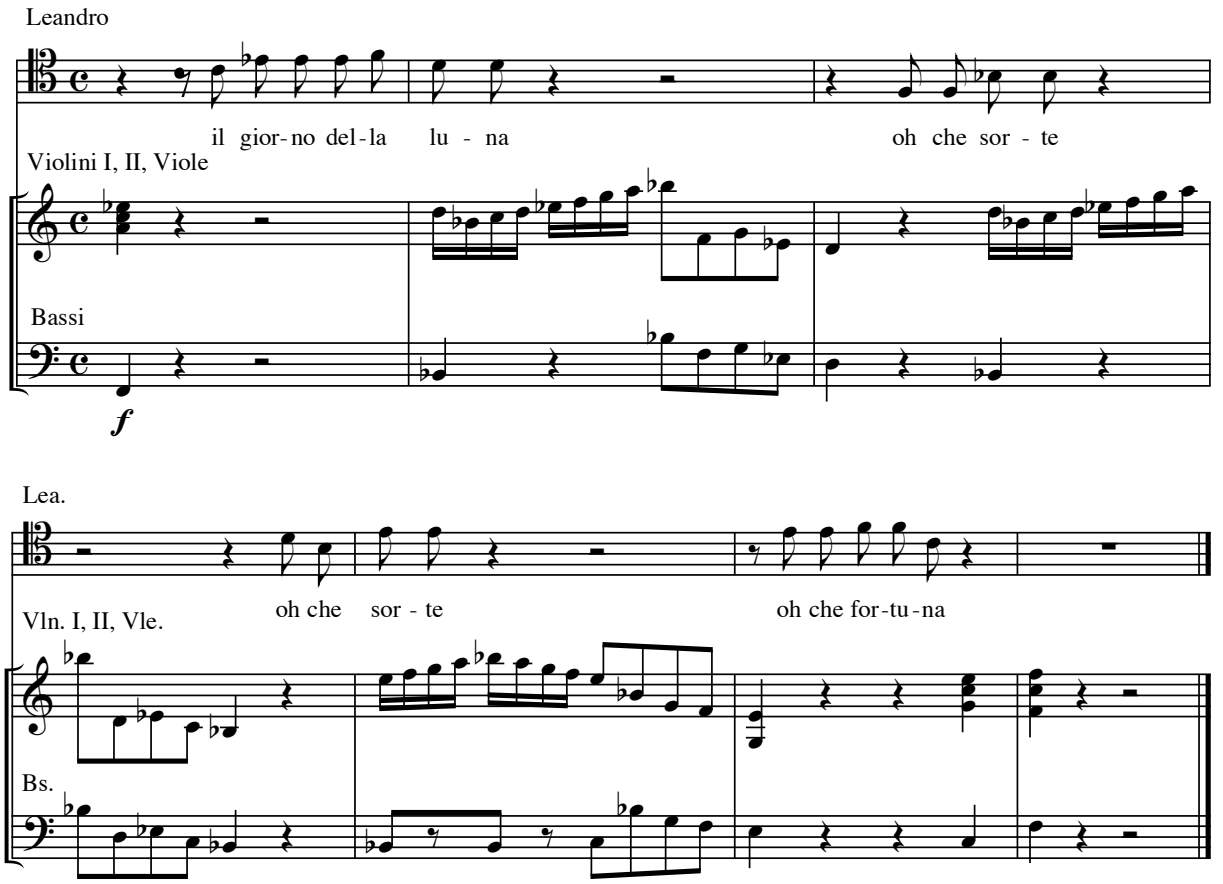

63 Piccinni/Petrosellini: L'astratto o Il giocatore fortunato. (F-Pn MS. 2372)

Die für das Spiel und besonders für den Moment des Sieges typische freudige Erregtheit, die Mitgerissenheit, also die höchste Emotionalität, aber auch Irrationalität des giocatore kommen in diesem Accompagnato-Rezitativ zum Ausdruck und bewirken einen dramatischen Höhepunkt. Hier entlädt sich die Spannung, die mit dem Risiko verbundene Erregung und der entsprechende Schwebezustand, die sich vom Beginn der Oper an, als Leandro durch Ausfüllen der Tippscheine das Schicksal herausgefordert hatte, und während des hoffnungsvollen, aber aufreibenden Wartens auf die Ziehung aufgestaut hatten. (Die darauffolgende Arie beginnt im Anschluss an den Siegestaumel kontrastreich im ruhigen Largo.) 
Am Ende des zweiten Finales wird das Los thematisiert, das von Fortuna, der Göttin mit verbundenen Augen, durch das Drehen des Glücksrades bestimmt wird. Den Anlass dafür bietet eine Burla des Capitano, der, um die von allen (außer von Leandro) schlecht behandelte Gärtnerin Laurina zu rächen, zunächst Angelica und Clarice die Hochzeit verspricht, dann so tut, als würde er sich in Laurina verlieben, die eigentlich seine Schwester ist.

$\begin{array}{lll}\text { Tim. Ang. Cla. } & \begin{array}{l}\text { La sorte maledetta } \\ \text { Contro di noi s'aggira. }\end{array} & \text { (inquietati) } \\ \text { Lean. Lau. Cap. } & \begin{array}{l}\text { La sorte favorevole } \\ \text { Per noi la ruota gira. }\end{array} & \text { (allegri) } \\ \text { Tim. Ang. Cla. } & \text { Fortuna istabilissima. } & \\ \text { Lean. Lau. Cap. } & \text { Fortuna amabilissima. } & \\ \text { Tutti. } & \text { Girando a poco a poco } & \\ & \text { Di noi ti prendi gioco } \\ & \text { Con farci delirar. }\end{array}$

Musikalisch teilen sich die Personen bzw. Stimmen in zwei Dreiergruppen, eine vom Schicksal benachteiligte (Angelica, Clarice und ihr Vater Don Timoteo) und eine vom Glück begünstigte (Leandro, Laurina, Capitano), wodurch es zu einem Ausgleich von Glück und Unglück kommt. Die beiden Gruppen singen nacheinander ungefähr denselben Satz; wenn es schließlich um das Drehen des Glücksrades geht, vereinen sich alle im Tutti. Die Drehbewegung des Rades und die Phrase „di noi ti prendi gioco" werden musikalisch durch eine von Oboen und Geigen unterstützte Pendelbewegung in den melodischen Linien der drei Frauenstimmen dargestellt, die daraufhin sequenziert und um eine Terz hinaufgerückt wird (s. Notenbeispiel 64, S. 336 f.).

Die einen loben die Göttin Fortuna, die anderen beklagen sich über ihre Unbeständigkeit, aber alle sind sich darüber einig, dass sie mit den Menschen ihr Spiel treibt („di noi ti prendi gioco“) und sie zum Narren hält, indem sie ihr Rad dreht und die Leute in den Wahnsinn treibt („Con farci delirar“). Der Begriff des Spiels dient hier also als Metapher für die „Funktionsweise“ der Welt schlechthin.

Im Schlusschor der scena ultima wird auch das Spiel - gemeint ist in diesem Fall das Glücksspiel - in das übliche Lob der Liebe miteinbezogen, denn beide verursachen Freude und Heiterkeit.

848 Ebd. (II,21). 
Allegro presto

Oboe

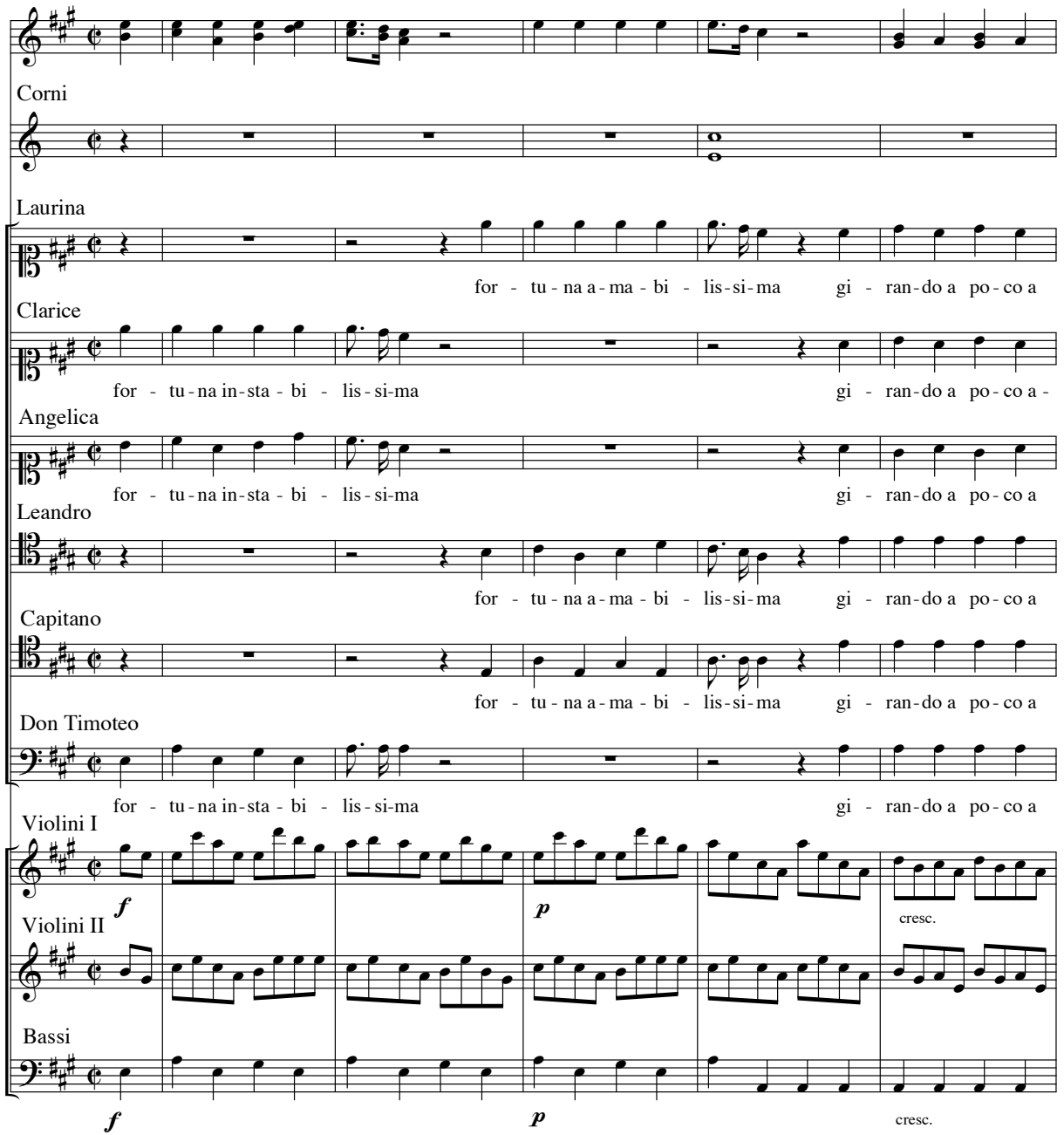

64a Piccinni/Petrosellini: L'astratto o Il giocatore fortunato. (F-Pn MS. 2372)

Tutti. Viva il gioco, e viva amore

Che fa tutti rallegrar. ${ }^{849}$

849 Ebd. (Scena ultima). 


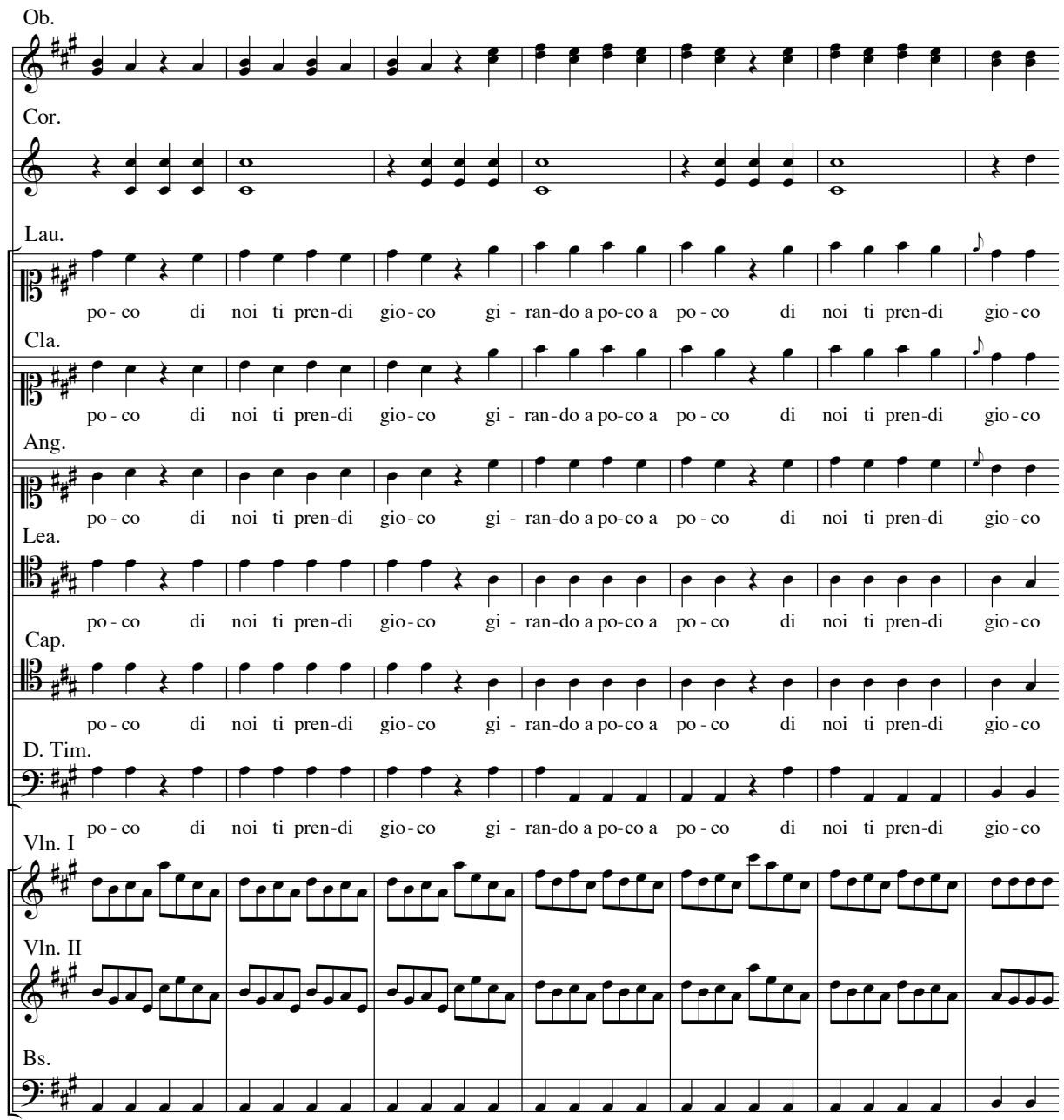

64b Piccinni/Petrosellini: L'astratto o Il giocatore fortunato. (F-Pn MS. 2372)

Nach dem Gewinn wird ein sehr positives Verständnis vom Spiel geäußert, während dieses zu Beginn der Handlung als etwas moralisch verwerflich angeprangert worden ist. Das sowohl mühelosen Gewinn als auch leichten Ruin ermöglichende Glücksspiel widerspricht nämlich den bürgerlichen Idealen von Arbeitsamkeit, Fleiß und Sparsamkeit; deshalb stellt der bürgerliche Vater Don Timoteo in den ersten zwei Akten der Oper seinen spielsüchtigen Sohn als verrückt hin und möchte ihn wegen seiner Liebe zur Gärtnerin sogar verkennen und enterben: 
Ma fuor di Casa, parti in quest' istante:

Figlio, Figlio birbante

T'odio, ti diseredo, ti slegitimo,

Ti scaccio, ti bastono,

Figlio più non mi sei, Padre non sono. ${ }^{850}$

Nach dem Gewinn hingegen tut er so, als wäre nichts geschehen, freut sich und lobt den spielsüchtigen Leandro, und ähnlich heuchlerisch verhalten sich die beiden Schwestern. Der ironische Kommentar des Dieners Giocondo lautet: „Quando uno è ricco, è il miglior Uom del Mondo." Dieses Umschwenken der Meinung über den Spielsüchtigen Leandro, aber vor allem über das Glücksspiel entspricht der üblichen Einstellung zum Spiel, die „Zwischen Verlockung und Unwürdigkeit“851 schwankt.

Dass der verschrobene, gesellschaftlich unangepasste Leandro nicht bloßgestellt, sondern als sympathische Figur dargestellt wird, scheint in der Opera buffa eher eine Seltenheit zu sein, die sich aber dadurch erklärt, dass die Bloßstellung sich hier auf die kleinbürgerliche Hypokrisie und Geldgier bezieht. Leandros hohe Risiko- und Spielbereitschaft wird dagegen „belohnt“, wobei erneut die Botschaft vermittelt wird: „Das Leben ist ein Spiel.“

Das auf Fortuna, die Göttin mit den verbundenen Augen, zurückgehende Missgeschick der unterschiedlichen Standeszugehörigkeit der Liebenden wird gewissermaßen durch den Gewinn beim Glücksspiel wieder gutgemacht. Das von den Spielern unbeeinflussbare Glücksspiel ermöglicht also eine zwar unstandesgemäße, aber aus Liebe eingegangene Ehe und stellt somit eine „Demokratie des Zufalls“ her. Über diesen Zusammenhang schreibt Imbucci: „Il gioco fondato sull'alea costruisce una vera e propria democrazia del caso perché ciascun giocatore deve avere probabilità di vincita assolutamente uguali e tutti allora sono uguali innanzi al caso."852 Spiel und Spielbereitschaft ermöglichen den Buffa-Figuren eine Verbesserung der eigenen Lebenssituation, wobei sich als Spiele nicht nur strategische Burle, sondern auch Glücksspiele eignen. In beiden Fällen muss eine gewisse Risikobereitschaft an den Tag gelegt werden, denn Ungewissheit und Unvorhersehbarkeit des Ausgangs müssen in Kauf genommen werden, wobei man sich vor allem bei Glücksspielen auf das unheimliche Spiel mit der unberechenbaren, außermenschlichen Macht des Zufalls einlassen muss.

850 Ebd. (II,7).

851 Vgl. Matuschek, S. 43.

852 Giuseppe Imbucci: Lotto, totocalcio, lotterie. Storia dei comportamenti sociali. Venedig 1997, S. 93. 


\section{ILINX}

Caillois wählt den Begriff ilinx ${ }^{853}$ im Sinne des Wirbels, des Schwindels, der Verwirrung für seine vierte Spielkategorie, die er folgendermaßen definiert: „Eine letzte Kategorie fasst jene Spiele zusammen, die auf dem Begehren nach Rausch beruhen und deren Reiz darin besteht, für einen Augenblick die Stabilität der Wahrnehmung zu stören und dem klaren Bewusstsein eine Art wollüstige Panik einzuflößen. Es geht hier stets darum, sich in einen tranceartigen Betäubungszustand zu versetzen, der mit kühner Überlegenheit die Wirklichkeit verleugnet. Die Verwirrung, die der Rausch hervorruft, wird zumeist lediglich um ihrer selbst willen gesucht." ${ }^{854}$

Die Idee des Wasserstrudels oder Wirbels als Metapher für die durch Drehbewegungen ein Schwindelgefühl erzeugenden Spiele scheint Caillois direkt von Buytendijk übernommen zu haben, in dessen (zwei Jahrzehnte vor Caillois formulierter) Spieltheorie Folgendes zu lesen ist: „Eine rasche, drehende Bewegung übt auf den Menschen eine sehr starke Wirkung aus. Nicht nur ein riesiger Schwung und ein mächtiger Wasserstrudel, sondern auch ein Kreisel und ein Karussell ergreift uns und ruft ein Gefühl hervor, das zwischen einem Angezogen-werden, Schwindel, Bewusstseinseinschränkung und einem Rauschzustand schwebt." 855

Buland kritisiert an Caillois' Einteilung der Spiele bei dieser Kategorie die Abweichung vom System, denn „bei alea, agôn und mimicry handelt es sich um Spielprinzipien, unter ilinx sind jene Spiele zusammengefasst, die ähnliche Wirkungen zeitigen. "856 Das Problem liege demnach in der Abgrenzung zwischen den verschiedenen Kategorien, „zumal besonders in agônalen Spielen der Rausch immer wieder beobachtet werden kann. " 857 Bulands Kritik scheint mir durchaus berechtigt zu sein, denn nicht nur in agonalen Spielen, sondern auch im besonders bei Glücksspielen auftretenden Spielfieber und im Taumel bei einem beträchtlichen Gewinn kann ein Spieler in einen rauschartigen Zustand verfallen, wie das obige Beispiel aus „L'astratto ovvero Il giocator fortunato“ verdeutlicht. Caillois' besonderes Interesse für Trance- und Rauschspiele ist vermutlich durch seine Tätigkeit als Anthropologe und Ethnologe bedingt, weshalb er die Art von Spielen hervorheben möchte, dessen einziger Beweggrund im Erleben eines lustvollen Schwindelgefühls besteht. In dieser Untersuchung der spielhaften Momente der Opera buffa, in der Caillois' Kate-

853 Etymologie: altgriechisch ilinx mit der Variante ilingos, neugriechisch nur ilingos in der Bedeutung von Wasserstrudel, Wirbel, Schwindel.

854 Caillois, S. 32.

855 Buytendijk, S. 134.

856 Buland: Die Einteilung der Spiele nach ihren Freiheitsaspekten. S. 263.

857 Ebd. 
gorisierung besonders im Hinblick auf die stets anfallenden Abgrenzungsprobleme zwischen den Kategorien ohnehin eher einen Anhaltspunkt als eine allumfassende Systematik abgeben soll, ist der Aspekt des Rausches und der Verwirrung auf jeden Fall wert angesprochen zu werden, zumal er in den untersuchten Opern häufig in Situationen auftaucht, die große Ähnlichkeiten zu den von Jean Château als jeux de désordre und jeux d'emportement ${ }^{858}$ bezeichneten Phänomenen aufweisen. Damit meint Château „kollektive Erregungszustände“, 859 die er auch als „Spiele des Hingerissenseins“ bzw. „Entladungsspiele“ 860 bezeichnet und in denen er „Vorformen der Rauschspiele der Erwachsenen“861 sieht. Sie „bedeuten keineswegs völlige Unordnung (...). Es wird zwar Unordnung gewollt, aber eine bestimmte Unordnung“, denn die Regel „besteht lediglich darin, ein bestimmtes Verhalten auf die Spitze zu treiben." 862

Dieses Charakteristikum der Erregung und der Unordnung ist auch als Wesensmerkmal der Opera buffa hingestellt worden. Hermann Abert behauptet, „der Hauptzweck“ der Opera buffa sei „der Eindruck eines möglichst drastischen Durcheinanders“. ${ }^{863}$ Meines Erachtens sind solche Momente der höchsten Verwirrung und Turbulenz, die Châteaus Beschreibung der „Tumult- und Erregungsspiele" weitgehend entsprechen, vorwiegend in den Buffa-Finali zu finden, bei zweiaktigen Opern vor allem im ersten Finale, das auch als Konfusionsfinale bezeichnet wird. Hier spitzt sich das imbroglio der durch Burle verursachten und/ oder im Dunkeln stattfindenden Verwechslungen und Missverständnisse zu; der Steigerung zur größtmöglichen Verwirrung in der Aktion entspricht musikalisch eine Tempo-Beschleunigung zum Ende hin, die konventionsmäßig in die typische Stretta finale mündet.

Das Finale, das Da Ponte in einer berühmten Passage aus seinen Memoiren als „una specie di commediola o di picciol dramma da sé" 864 bezeichnet, muss besonders effektvoll sein („In questo principalmente deve brillare (...) il più grande effetto del dramma"). ${ }^{865}$ Die Spannung muss eine maximale Steigerung erfahren, um schließlich den Applaus des Publikums auszulösen. Dazu dienen hauptsächlich die musikdramaturgischen Mittel der Abwechslung, der Repetition und der Steigerung, die durch

858 Vgl. Château, S. 57ff. und Scheuerl: Das Spiel. S. 141.

859 Château, S. 59.

860 Scheuerl: Das Spiel. S. 141.

861 Château, S. 59.

862 Ebd.

863 Hermann Abert: Paisiellos Buffokunst und ihre Beziehung zu Mozart. In: AfMw 1 (1918-19), S. 416.

864 Lorenzo Da Ponte: Memorie. Libretti mozartiani. Mailand 1991, S. 92.

865 Ebd. 
Vermehrung der Personen auf der Bühne und vor allem durch Beschleunigung des Tempos der verschiedenen musikalischen Abschnitte erzeugt wird: „trovar vi si deve ogni genere di canto. L'adagio, l'allegro, l'andante, l'amabile, l'armonioso, lo strepitoso, l'arcistrepitoso, lo strepitosissimo, con cui quasi sempre il sudetto finale si chiude; il che in voce musico-tecnica si chiama la ,chiusa' o la ,stretta', non so se perché in quella la forza del dramma si stringe, o perché dà generalmente non una stretta ma cento al povero cerebro del poeta che deve scrivere le parole. In questo finale devono per teatrale domma comparir in scena tutti i cantanti, se fossero trecento, a uno, a due, a tre, a sei, a dieci, a sessanta, per cavarvi de' soli, de' duetti, de' terzetti, de' sestetti, de' sessantetti." 866

In welch turbulentem Lärmen eine solche Steigerung endet, wird im Vorwort zu Lorenzis „Opere teatrali“ beschrieben: „si conchiude finalmente l'Atto primo con un finale di sette, o otto scene, quale poi deve terminarsi, con un ripieno, in cui tutti gli Attori diranno le stesse parole, siano o no confacenti al loro carattere, facendo colle voci, e strumenti una rumorosa sinfonia con imitazioni, canoni, fughe e strette, onde con grandi rumori, e grida si terminii l'Atto." 867

Das Durcheinander wird nicht nur durch die Unübersichtlichkeit und Verwirrung in der Handlung und die Tempobeschleunigung hervorgerufen - hohe Geschwindigkeit ist in Caillois' Definition neben Drehbewegungen die Hauptursache des Schwindelgefühls bei „Rauschspielen“ -, sondern beispielsweise auch in der Überlagerung mehrerer Texte, die aufgrund ihrer Gleichzeitigkeit nicht nur unverständlich bleiben, sondern gerade den erwünschten Effekt der Unordnung und des Durcheinanders herstellen.

Die hier verwendeten Notenbeispiele stammen aus dem zweiten Finale von Luigi Carusos Oper „Li sposi in commedia“, in vielen Finali sind aber ähnliche Passagen zu finden, denn gerade die Mittel, die in der Opera buffa bei „Schluss-Gestaltungen“ verwendet wurden, waren in besonders starkem Maße konventionell und standardisiert (s. Notenbeispiel 65, S. 342).

Die später von Rossini bis an äußerste Grenzen getriebenen „Crescendo-Anlagen“, die repetitiven Muster und das „Rotieren von Sechzehntel- und Zweiunddreißigstelfiguren des Vokal- und Instrumentalparts" ${ }^{868}$ sind als kompositorische Mittel schon in den Buffa-Finali enthalten. Dass diese „unaufhaltsame Rotation“869 für die riesige Steigerung, das Lärmen und das größtdenkbare Durcheinander sorgt, haben schon

866 Ebd.

867 Opere teatrali di Giambattista Lorenzi napolitano. Bd. 2. Zit. nach Villinger S. 271.

868 Gerd Rienäcker: Art. Finale. In: Die Musik in Geschichte und Gegenwart. 2., neubearb. Ausg. hg. von Ludwig Finscher. Sachteil Bd. 3. Kassel u. a. 1995, Sp. 481.

869 Ebd. 


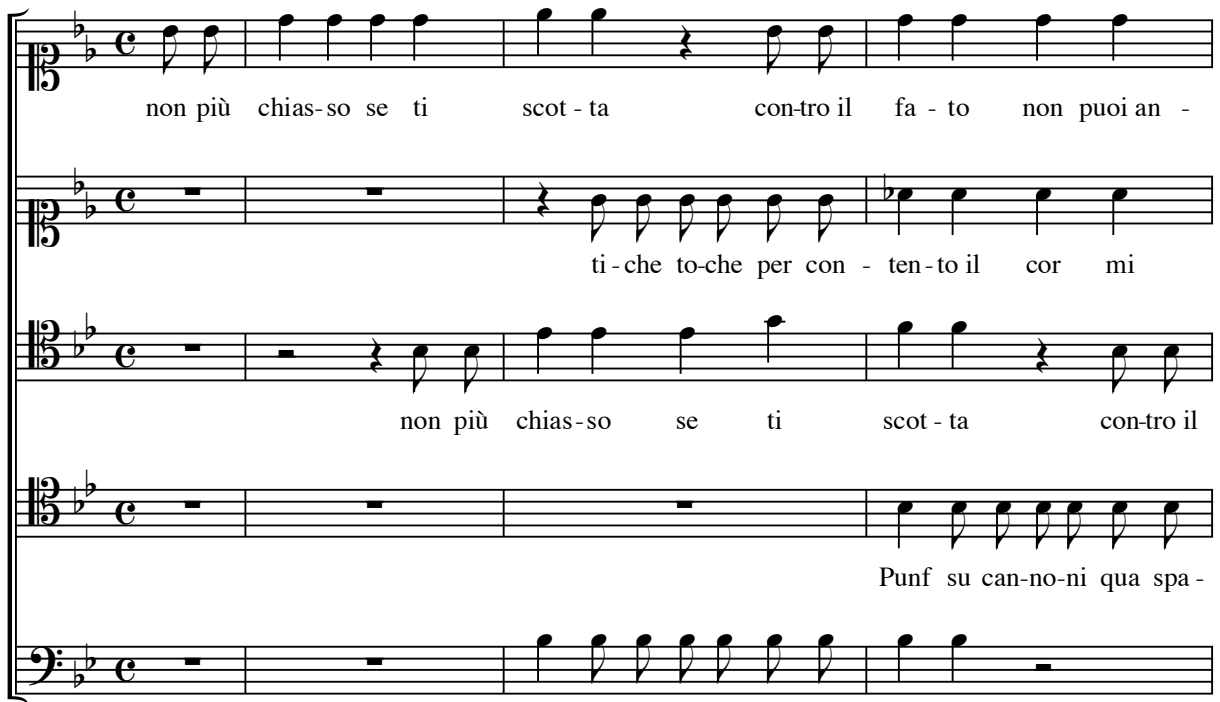

Punf su can-no-ni qua spa - ra - te

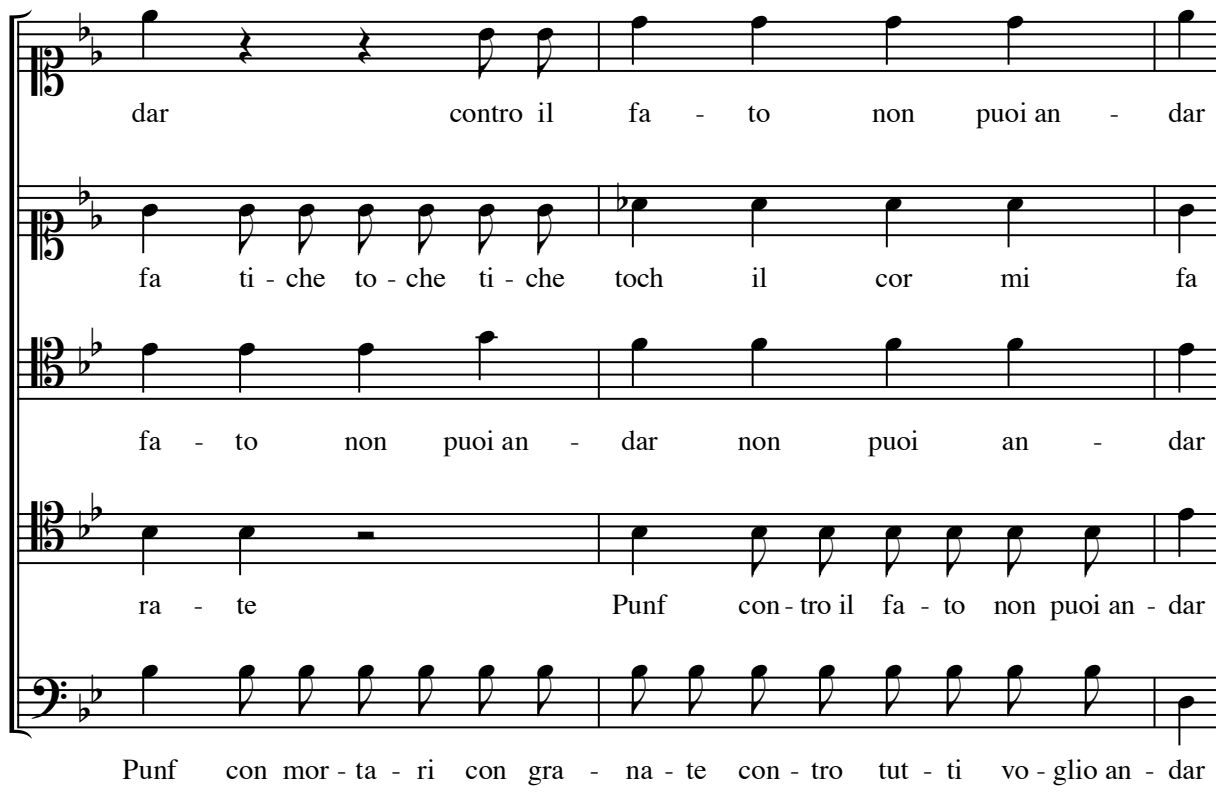

65 Caruso/Palomba: Il matrimonio in commedia. (F-Pn D 1865-1866) 
Theoretiker der Zeit aufgezeigt. Manfredini schreibt beispielsweise: „oggi moltissimi finali buffi si rassomigliano estremamente; terminando quasi tutti coll'imitazione della tempesta, o del molino, o della campana, o del martello; in somma con un tal strepito, e fracasso che talvolta (e l'ho veduto io stesso) ha spaventato infino i Cani. "870 Erstaunlich ähnlich äußert sich Arteagas fiktiver Impresario: „così non sarebbe male un finale dove tutti cantassero ad un tratto. Meglio poi se c'entra nelle parole un non so che di mulinello, di tempesta, di zuffa o di cosa, che apportasse un gran fracasso. Allora l'orchestra batterebbe fuoco, e gli uditori sguazzerebbero per l'allegrezza. Egli è vero, che codesti finali rassomigliano per lo più ad una sinagoga di ebrei anzi che ad un canto ben eseguito, ma nelle cose di gusto non bisogna essere cotanto sofistico." 871

Die von beiden Theoretikern erwähnte Drehbewegung („molino“, „mulinello“, wörtlich Wirbel oder Strudel) entspricht der Grunddynamik der von Caillois unter der Kategorie „Ilinx“ zusammengefassten Spiele, denn es ist gerade die „frenetisch ansteckende Rotation",872 die den Wirbel und das Schwindelgefühl

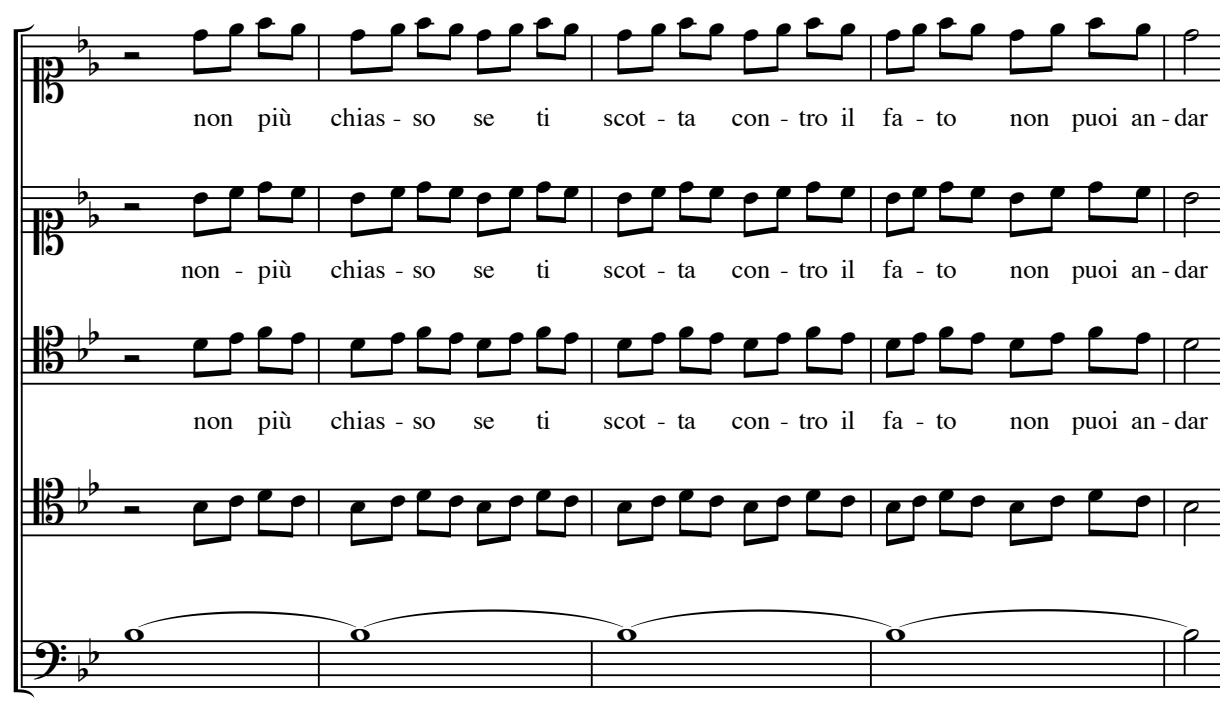

dar

66 Caruso/Palomba: Il matrimonio in commedia. (F-Pn D 1865-1866)

870 Manfredini, S. 121.

871 Arteaga, S. 149.

872 Caillois, S. 32. 
verursacht. Château spricht im Zusammenhang mit den Tumult- und Erregungsspielen ebenfalls von einer „zentrifugalen Bewegung" 873 bzw. von „Zirkular- und Wirbelbewegungen"874 sowie von der Tendenz, „unaufhörlich denselben Bewegungsablauf zu wiederholen". 875

Diesen Charakteristika entsprechen die in der Musik der Buffa-Finali häufig eingesetzten kreisenden melodischen Linien, die meist aus einem wiederholt aneinandergereihten Muster bestehen.

In den Schlussfinali verbinden sich die rotierenden Bewegungen in der Musik und der schwindelerregende Wirbel mit dem Jubel und dem Ausdruck höchster Freude.
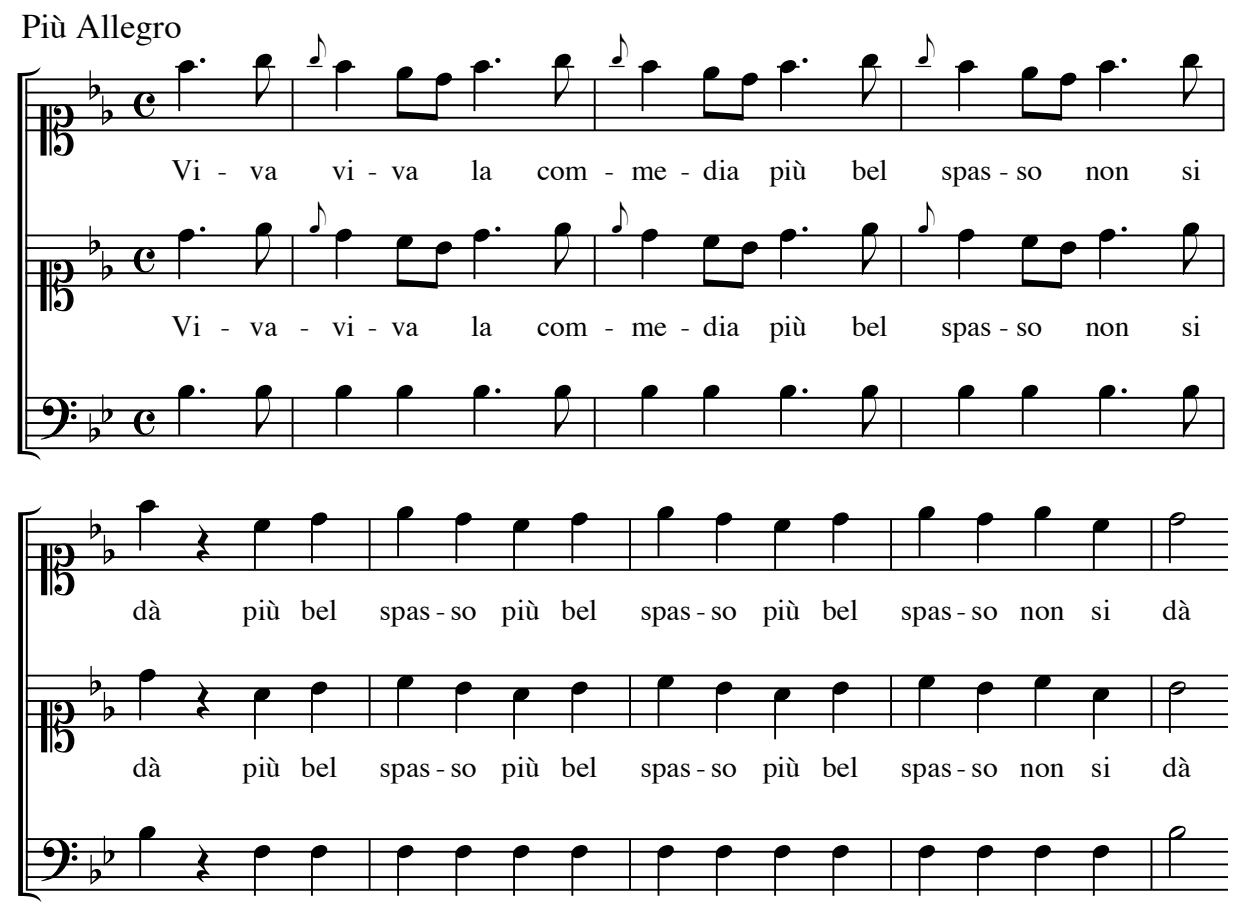

67 Caruso/Palomba: Il matrimonio in commedia. (F-Pn D 1865-1866)

873 Château, S. 18.

874 Ebd. S. 62.

875 Ebd. 
In diesem Zusammenhang ist Châteaus Begriff der turbulence zu nennen, der sowohl den Aspekt der „Drehung“ und des „Wirbels (tourbillon)“ als auch den der „Unordnung“, der „Menge“ und des „Gewühls“, aber auch den der Ausgelassenheit umfasst, denn es handelt sich um „eine Bewegung und sozusagen eine Explosion von Energie, was sich in Fröhlichkeit und Übermut zeigt, worin sich extremer Elan entlädt."876

Die turbulenten Finali der Opera buffa scheinen also ähnlichen Prinzipien zu gehorchen wie die von Caillois und Château beschriebenen Ilinx- bzw. „Tumult- und Erregungsspiele“: „Die Verwirrung“ wird „um ihrer selbst willen gesucht.“877 Beschleunigung und Rotation führen einen Höhepunkt an Bewegung und Erregung herbei, was ein lustvolles Gefühl des Schwindels, des Rausches und des Außer-sichSeins verursacht, das durch das kollektive Erleben umso mehr wirkt und sich auf das Publikum überträgt. Ilinx-Spiele und Buffa-Finali finden also im dionysischen Element, in der Ausgelassenheit, im Vergnügen am Durcheinander, am Lärm und an der Übertreibung einen gemeinsamen Nenner.

In den untersuchten Opere buffe werden die verschiedensten dramaturgischen Motivationen für den rauschartigen Erregungshöhepunkt in den Finali verwendet. In einigen Fällen - wie beispielsweise in den in Venedig uraufgeführten Opern "L'inimico delle donne“ (I 77 I), „La villanella incostante“ (I 773), „I viaggiatori felici“ (I780) und „Il serraglio di Osmano“878 (I785) - wird ein durch Weintrinken konkret herbeigeführter kollektiver Rausch dargestellt. In der erstgenannten, besonders erfolgreichen ${ }^{879}$ Oper von Giovanni Bertati und Baldassarre Galuppi geschieht dies in dem an Spielelementen reichen ersten Finale: Die Italienerin Agnesina und ihr Onkel Geminiano landen nach einem Schiffbruch in der chinesischen Stadt Kibin-Kin-Ka, wo sie vom Prinzen Zon-zon würdevoll mit einem großen Festmahl empfangen werden, das den Rahmen für das gesamte erste Finale bildet. Als Gastgeschenk bringen die Italiener den in China unbekannten Wein mit. Agnesina erkennt sofort an der anfänglichen Anrufung an die „spirti familiari“, dass es sich beim chinesischen Gastmahl um eine Zeremonie handelt („Questa qui è una cerimonia“). Tatsächlich erinnert diese an die Kategorie des streng geregelten ritualisierten Spiels, dessen typische Kennzeichen und formbildende Prinzipien die „kontrollierte Wiederholung“ und

876 Vgl. Château, S. 62.

877 Caillois, S. 32.

878 In dieser „Entführung-aus-dem-Serail“-Oper ist das kollektive Betrinken in einem Binnen-Ensemble eingebracht und bezweckt, Osmano und seine Diener von der Entführungsaktion abzulenken.

879 „L'inimico delle donne“ wurde nach der Uraufführung am Teatro San Samuele 1771 in Venedig zweimal (1773 und 1779) wiederaufgenommen, was auf eine besondere Beliebtheit hinweist, denn Wiederaufnahmen waren eine Seltenheit. 
die „Regelmäßigkeit des Tempos“ sind. ${ }^{880}$ Château spricht in demselben Zusammenhang von „Regelkult“ und „Heiligkeit der Regel“". ${ }^{81}$ Beim chinesischen Gastmahl besteht die erste „heilige“, als „usanza del paese“ unbedingt zu beachtende Spielregel bezeichnenderweise darin, dass man im Takt essen und trinken muss (Regieanweisung: „mangiano tutti a tempo di Musica con cerimonia“). Der Takt wird von einem Dirigenten angezeigt (Regieanweisung: "Si-sin che sta in piedi per misurar la battuta"), der für die von Garvey theoretisierte Kontrolliertheit und Regelmäßigkeit des Tempos sorgt. Wer wie der ahnungslose Geminiano die Regel nicht beachtet, wird zurechtgewiesen (Ly-lam: „State attento alla battuta / E mangiate con decor“), was die besagte „Heiligkeit“ der Regel zum Ausdruck bringt. Die zweite Spielregel beim Bankett besteht darin, dass jede Geste des Prinzen - wie bei einem Nachahmungsspiel - imitiert werden muss. Dieser ist vom Wein so begeistert, dass er immer wieder davon trinkt, während alle zwangsweise mitmachen müssen. Die Folge davon ist, dass alle an der Zeremonie Beteiligten vom vielen Wein auf leeren Magen sehr schnell betrunken werden. Die „Spielregeln“ des chinesischen Festmahls dienen in erster Linie der komischen Wirkung. Wenn Komik aus einer „Kollision mit irgendeiner Norm“882 resultiert, so ergibt sich hier die "Inkongruenz zwischen Sein und Sollen" 883 aus aufeinandertreffenden kulturellen Unterschieden und phantasievoll erfundenen chinesischen Gepflogenheiten: Belustigend ist zunächst die karikaturhaft übertriebene Kontrolliertheit des chinesischen Zeremoniells mit dem unerwarteten, zugleich absurden und lustigen, „rhythmischen Essen“. Umso kontrastreicher und witziger erscheint dann der Verstoß gegen die Norm der Selbstbeherrschung, die wiederum auf kulturellen Unterschieden beruht, denn die Chinesen wissen nichts von der Wirkung des Alkohols und lassen die wiederholten Warnungen der beiden Italiener unbeachtet. Es ist allerdings die obligatorische Regel der Nachahmung des Prinzen, die die Situation eskalieren lässt und den kollektiven Rausch sowie das unerwartete, der feierlichen Zeremonie nicht angemessene Benehmen der Höflinge verursacht.

Der ungewohnte Anblick von vielen betrunkenen Chinesen, die mit ihren Fächern herumfuchteln, um sich eine Erfrischung von der „Hitze“ des Alkohols zu verschaffen, wirkt nicht nur komisch, sondern auch besonders performativ und aktionsreich, genauso wie zuvor das „rhythmische Essen“, denn die gleichzeitige Bewegung mehrerer Menschen kann auf der Bühne einem Tanz ähneln und eine große szenische Wirkung hervorrufen. Galuppi erkennt das szenische und komische Potential des vom

880 Vgl. Garvey, S. 144.

881 Vgl. Château, S. 80 und 82.

882 Plessner: Lachen und Weinen. S. 299. Zit. nach Lamping, S. 61.

883 Lamping, S. 58. 
Dirigenten angeleiteten Essens und sieht dafür einen eigenen, rein instrumentalen Abschnitt vor, in dem übertrieben klare musikalische „Gesten“ in feierlichem Maestoso-Tempo das Karikaturhafte der Situation unterstreichen.

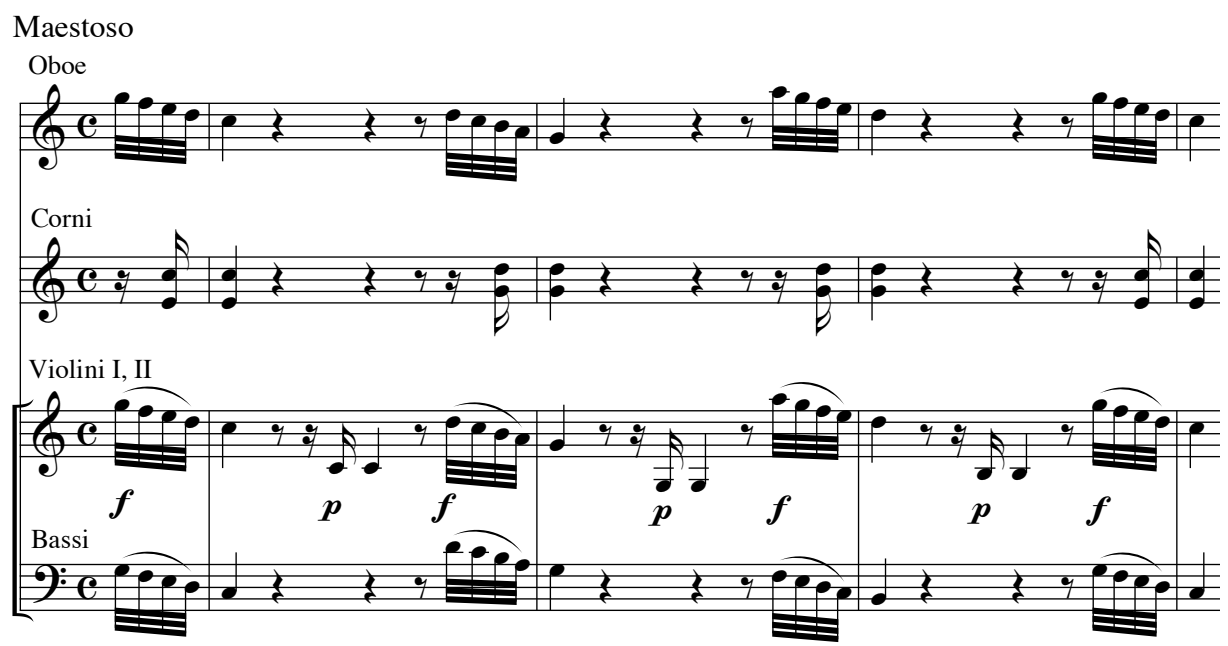

68 Galuppi/Bertati: L’inimico delle donne. Hg. von Helen Geyer-Kiefl. Mailand 1986

Der darauffolgende allgemeine Rauschzustand eignet sich dramaturgisch ganz besonders dafür, die von der Konvention vorgesehene Steigerung im Laufe des ersten Finales und ein unkontrolliertes Durcheinander am Ende des Ensembles zu rechtfertigen. Metaphern für das Gefühl des Betrunkenseins sind unerträgliche Hitze und Feuer,
Zon. Sento un caldo che mi toglie
L'appetito ed il piacere!
Ly. Oh qual foco in me s'accoglie!

die musikalisch durch als Leidsymbol dienende, größtenteils chromatisch absteigende Bewegungen in kurzatmigen seufzerähnlichen Phrasen dargestellt werden. Der Passus duriusculus wird dabei parodistisch eingesetzt.

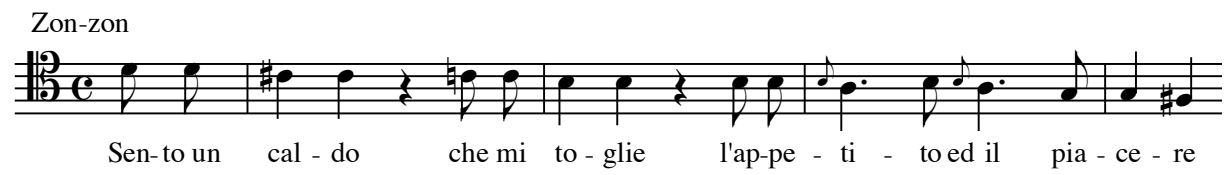

69 Galuppi/Bertati: L'inimico delle donne. Hg. von Helen Geyer-Kiefl. Mailand 1986 
Das Lechzen nach Erfrischung ist dagegen in einer von Oboen und Geigen unterstützten, eine ganze Oktave umfassenden aufsteigenden Bewegung der oberen Stimmen vertont, deren punktierter Rhythmus eine vorantreibende, hetzende Bewegung wiedergibt.

a 4. Presto, presto, a noi da bere,

Che n'abbrucia il grande ardor.

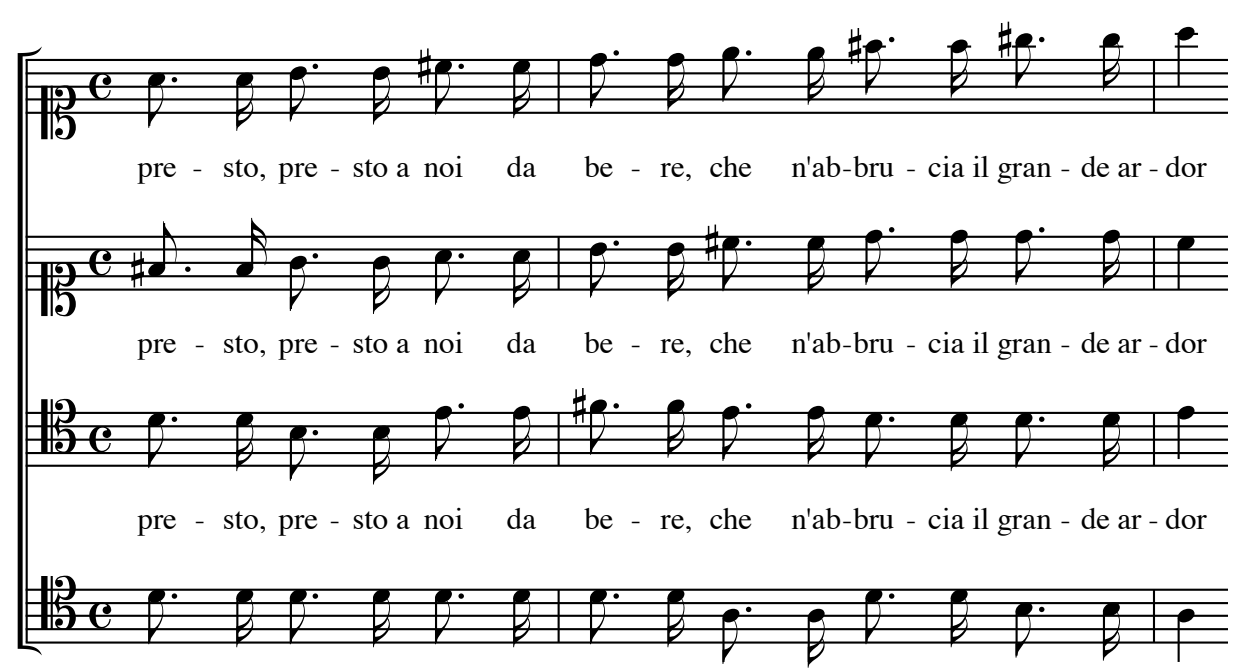

70 Galuppi/Bertati: L’inimico delle donne. Hg. von Helen Geyer-Kiefl. Mailand 1986

Im Text des Schluss-Tutti wird neben der Hitze und dem Wunsch nach frischem Wasser besonders das Schwindelgefühl und die Schwierigkeit, auf eigenen Beinen zu stehen, betont.

Tutti. Tutto, tutto mi va sopra, e sotto:

Il mio piede traballa a ogni passo ...

Oh che caldo! Oh che fiero fracasso,

Che nel petto sentire mi par!

Acqua fresca, acqua fresca recate.

State in piedi, no, no, non ballate.

Viva, viva, mi sento brillare!

E nuotare mi sembra nel mar! 
Während die Singstimmen konventionsgemäß in beinahe durchgehend homophonem Tutti-Blocksatz die schnelle Schluss-Stretta singen und von Trommelbässen, liegenden Tönen und anderen Figurationen begleitet werden, erwecken die Geigen mit ihren raschen Triolen und den typischen kreisenden Bewegungen (mulinelli) den Eindruck eines dahinrasenden Wirbels, der den Rauschzustand und das Durcheinander der Situation vermittelt.
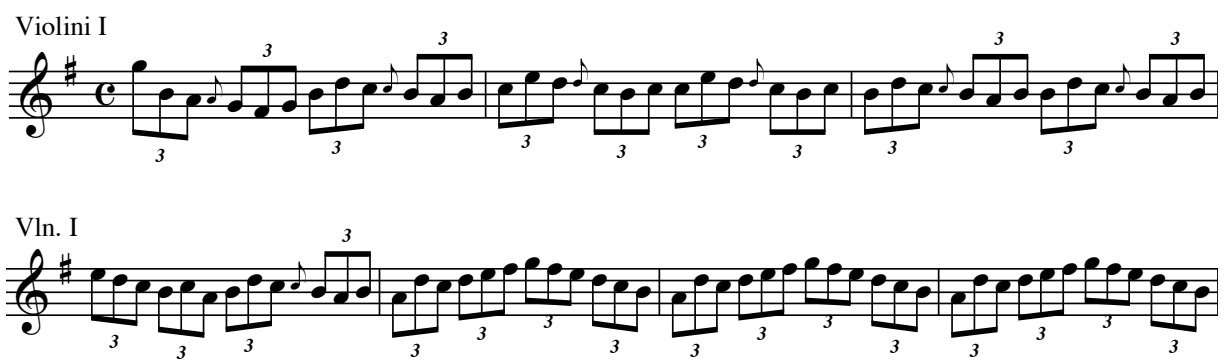

71 Galuppi/Bertati: Linimico delle donne. Hg. von Helen Geyer-Kiefl. Mailand 1986

Es handelt sich bei der durch Tempobeschleunigung und Drehbewegung erreichten Turbulenz und Erregung um eine Konvention, die allgemein in der Schluss-Gestaltung aller größeren Ensembles, vor allem der Finali, angewendet wird. Nachdem gerade die Ensembles die hauptsächliche musikalische Besonderheit im Vergleich zur Opera seria ausmachen und gewissermaßen als Markenzeichen der Opera buffa verstanden werden können, ${ }^{884}$ ist es wohl nicht zu gewagt, die genannten Gestaltungsmittel als für die Buffa besonders charakteristisch zu bezeichnen. Dass es in dieser Opernhandlung nicht nur in einem Finale, sondern auch gerade im Rahmen eines Festmahls zu einem kollektiven Erregungs- und Rauschzustand kommt, ist ebenfalls nicht untypisch, denn festliche Situationen eignen sich ganz besonders dazu, Ausgelassenheit auf der Bühne darzustellen bzw. dramaturgisch zu rechtfertigen und werden dementsprechend in der Opera buffa sehr häufig eingesetzt.

884 Im späten 18. Jahrhundert übernahm die Opera seria wiederum von der Buffa den Gebrauch von größeren Ensembles. Als erstes Beispiel für eine Seria mit umfangreichen Ensembles (Introduzione und Finali) gilt Giovanni Paisiellos 1787 uraufgeführte und im selben Jahr in Venedig erstaufgeführte Oper „Pirro“, die bezeichnenderweise aus der Feder eines Buffa-Komponisten stammte. 


\section{Festliches}

\section{I Das Fest}

Ausgelassenes Feiern kann als charakteristischer Topos der Opera buffa gelten, doch sollen der konkreten Untersuchung von in der Buffa vorkommenden Festszenen noch einige grundsätzliche Überlegungen zum Fest und zu seinem Verhältnis zum Spiel vorausgeschickt werden.

Einen Zusammenhang zwischen den beiden Phänomenen bringt Erhard Busek auf den Punkt: „Spiel ist keine Kulturerscheinung neben anderen, sondern Spiel ist etwas Vorkulturelles, das auch den Tieren eigen ist. Kultur entwickelt sich im Spiel, und erhält seine Überhöhung im Fest. "885 Huizinga bezieht sich wohl vorwiegend auf das menschliche Spiel, wenn er über die enge Verbindung zwischen Spiel und Fest schreibt: „Zwischen Fest und Spiel bestehen nun der Natur der Sache nach engste Beziehungen. Die Ausschaltung des gewöhnlichen Lebens, der überwiegend, wenn auch nicht notwendig fröhliche Ton der Handlung - auch das Fest kann ernst sein -, die zeitliche und räumliche Begrenztheit, das Zusammengehen von strenger Bestimmtheit und echter Freiheit, das sind die hauptsächlichsten gemeinsamen Züge von Spiel und Fest. Im Tanz scheinen die beiden Begriffe die innigste Verbindung einzugehen." 886

Während Huizinga das Spiel als ein dem Fest eher unter- oder nebengeordnetes Phänomen ansieht, ${ }^{887}$ äußert etwa zur selben Zeit der Religions- und Mythenforscher Karl Kerényi in seinem Aufsatz über das „Wesen des Festes“ den Gedanken, dass das Fest selbst als Spiel bezeichnet werden könne: „(...) jede Festhandlung ist gewissermaßen ein Spiel." 888 Auf denselben Schluss ist in jüngster Vergangenheit auch Buland gekommen, der Folgendes behauptet: „Ich denke, es ist durchaus möglich, das Fest als eine ganz bestimmte Form des Spiels zu begreifen. Das Fest ist gleichsam der engere Begriff, eine auf den Menschen eingeschränkte Form des Spiels. "889

Das Fest kann also gleichzeitig sowohl als eine eigenständige Form von Spiel betrachtet werden als auch als Rahmen, in dem viele verschiedene Arten von Spiel Raum

885 Erhard Busek: Feste und Festspiele heute. In: Günther G. Bauer (Hg.): Homo ludens. Fest und Spiel. Bd. 8. Internationale Beiträge des Institutes für Spielforschung und Spielpädagogik an der Hochschule „Mozarteum“ Salzburg. München, Salzburg 1998, S. 116.

886 Huizinga, S. $28 f$.

887 „Das menschliche Spiel gehört doch jedenfalls in all seinen höheren Formen, in denen es etwas bedeutet oder etwas feiert, der Sphäre des Festes (...) an." (Huizinga, S. 16).

888 Karl Kerényi: Vom Wesen des Festes (1938). In: Werke in Einzelausgaben: Antike Religion. Stuttgart 1995, S. 38.

889 Die Erneuerung und das Erleben der Fülle im Fest. Rainer Buland im Gespräch mit Rudolf zur Lippe. S. 121. In: Homo ludens. Fest und Spiel. Bd. 8, S. 121-134. 
finden, also gewissermaßen als Ort einer verdichteten Spiel-Präsenz. Als eigenes Spiel betrachtet, entspricht das Fest allen von Huizinga genannten Wesenskriterien des Spiels und kann mit verschiedenen Kategorien in Verbindung gebracht werden, die in dieser Arbeit der Übersichtlichkeit halber getrennt betrachtet wurden, aber in der Realität - auch in der fiktiven Realität des dramma giocoso - oft kaum auseinanderzuhalten sind.

Wie das eben beschriebene chinesische Festmahl in "L'inimico delle donne“ kann das Fest der Spielkategorie Ilinx zugeordnet werden, wenn der dionysische Aspekt des Rausches überwiegt. Buland bezeichnet Dionysos als den eigentlichen „Festgott“ 890 Besonders aufschlussreich ist in diesem Zusammenhang die Verbindung, die Mohammed Rassem in Bezug auf das Fest zwischen den Kategorien Ilinx und Mimicry aufzeigt: „Anthropologisch noch interessanter ist ein anderer Auslöser der festlichen ,vertige', der festlichen Ekstase. Es ist hier die Kostümierung und die Maskierung, die ja schon als ein Haupttypus des Spielens erwähnt wurde. Das Anlegen einer Maske verfremdet den Träger nicht nur dem Zuschauer, sondern auch sich selbst. Er identifiziert sich mit dem, was er darstellt, er ist verwandelt, gerät außer sich - auch ohne, daß er durch Drogen oder Drehen nachhelfen mußte. Dieses Phänomen tritt in verschiedenen Intensitätsgraden auf. (...) Aber jedenfalls sind Feste ohne Ablegen des Alltagsgewandes und der Alltagsmiene schwer zu feiern. " 891

Rauschartige Zustände können also auch durch „Mittel“ erzeugt werden, die eigentlich anderen Spielkategorien entsprechen, wie es sich schon aus Bulands Kritik an der unscharfen Abgrenzung der Spielklasse Ilinx zu den übrigen Kategorien in Caillois Systematik ergeben hatte. ${ }^{892}$ Als eigentliches Spielprinzip scheint demnach dem Fest die Mimicry zugrunde zu liegen, wie auch aus einer Aussage Huizingas über das Fest indirekt hervorgeht: „Mit dem echten Spiel ist abgesehen von seinen formalen Kennzeichen und seiner fröhlichen Stimmung noch ein wesentlicher Zug untrennbar verbunden: das Bewusstsein, wenn es auch noch so sehr in den Hintergrund gedrängt sein mag, daß man ,bloß so tut'. "893 Für ein derart facettenreiches Phänomen wie das des Festes - auf das an dieser Stelle nicht näher eingegangen wird, um den Rahmen der Arbeit nicht zu sprengen - eignet sich meines Erachtens am besten Bulands Zuordnung zur umfassenden, die Mimicry einschließenden Kategorie der Gestaltungsspiele. ${ }^{894}$

890 Vgl. ebd. S. 125.

891 Mohammed Rassem: Das Fest als Spiel - Spiele als Feste oder Festersatz. S. 85. In: Homo ludens. Fest und Spiel. Bd. 8, S. 77-88.

892 Vgl. Kapitel „Ilinx“.

893 Huizinga, S. 29.

894 „In der von mir vorgeschlagenen Einteilung der Spiele, die auch auf die Wesensmerkmale der unterschiedlichen Spielformen eingeht, gehört die Vorbereitung, Durchführung und das Begehen des 
Festliche Szenen kommen in der Opera buffa sehr häufig vor. Festlichkeit herrscht generell als Grundstimmung in den beinahe umungänglichen Hochzeiten am Ende der meisten Opern vor, wobei eine regelrechte „Festhandlung“ nicht immer konkret durchgeführt, sondern oft nur symbolisch angedeutet wird. Andere, auch weniger bedeutsame Anlässe können in den Opera buffa ebenfalls zu Momenten festlicher Geselligkeit führen, wie unter anderem im eben beschriebenen Bankett im ersten Finale von "L'inimico delle donne“ oder in den Jahrmarktszenen aus „Lo sposo di tre“ ersichtlich wurde. Das Festmahl bzw. der Empfang kann unabhängig von seinem Anlass als regelrechter Topos der Opera buffa bezeichnet werden, der häufig eine eher illustrative und rahmenbildende Funktion besitzt und sowohl den Bühnenfiguren als auch den Zuschauern Unterhaltung bieten bzw. Ausgelassenheit vermitteln soll. Zu diesem Topos gehört das ausgiebige Essen und Trinken sowie die Erwähnung der einzelnen Speisen und Getränke. Einen beinahe obligatorisch damit verbundenen, untergeordneten Topos bildet dabei das brindisi, der Toast, bei dem auf eine Person aus der Handlung angestoßen wird oder unter anderem allgemein die Frauen, die Liebe oder der Wein lobgepriesen werden. Manchmal wird der Trinkspruch an die Damen des jeweiligen Aufführungsorts gerichtet, wobei durch diese Art von Widmung eine Verbindung zur Aufführungssituation hergestellt und somit die Illusion durchbrochen wird. Gelegentlich werden Festmähler auch durch diegetische Musik auf der Bühne begleitet, allerdings erscheinen Musik und Tanz häufiger in Hochzeitsszenen, ${ }^{895}$ vor allem bei Bauernhochzeiten, die vielleicht als die charakteristischsten Arten von Festen in der Opera buffa angesehen werden können.

Bei den Festszenen der Opera buffa handelt es sich durchwegs um typische Momente des kollektiven Vergnügens und der Fröhlichkeit, aber wenn auf der Bühne Musik und Tanz dazukommen, steht nicht nur die Ausgelassenheit, sondern auch das Spielelement besonders stark im Vordergrund.

Als Beispiel dafür, wie eine Festszene als Gestaltungsspiel und gleichzeitig als Rahmen für viele verschiedene Arten von Spiel fungieren kann, mag das zweite Finale aus einer besonders erfolgreichen, I78 I in Venedig am Teatro San Samuele uraufgeführten Oper, nämlich „Giannina e Bernardone“ von Filippo Livigni und Domenico Cimarosa dienen. Dieses zweiaktige, in einer ländlichen Sphäre spie-

Festes zu den Gestaltungsspielen." (Rainer Buland: Fest-Spiel-Frieden. Zusammenhänge und Wesenszüge. S. 256. In: Homo ludens. Fest und Spiel. Bd. 8, S. 249-260).

895 Das Wort „Hochzeit“ beinhaltet schon an sich den Aspekt des Festes. Karl Kerényi macht in seinem Aufsatz über das Wesen des Festes auf die enge Verbindung zwischen „hohen Zeiten“ und Fest aufmerksam: „Der Ethnologe begegnet solchen verwandelten Zeiten - , hohen Zeiten “-, die immer noch etwas von der Wärme, Frische und Ursprünglichkeit des schöpferischen Augenblicks an sich haben. Sie sind durchwärmt von Leben (...). Man nennt solche Zeiten: Feste." (Kerényi, S. 35). 
lende dramma giocoso dreht sich um die Eifersucht des groben Bernardone auf seine junge liebenswürdige Ehefrau Giannina. Das Hauptpaar ist also schon verheiratet, allerdings formt sich im Laufe der Handlung ein zweites Liebespaar (Donna Aurora und Capitan Francone), für das im zweiten Finale ein großes Hochzeitsfest veranstaltet wird.

Verschiedene musikalische und spielhafte Einlagen machen die Höhepunkte des Festes aus. Sie unterscheiden sich voneinander unter anderem im jeweiligen Spontaneitätsgrad, der auch ihrer Reihenfolge beim Fest entspricht. Zur musikalischen Gestaltung des Festes hat der Vater der Braut, der ungarische Offizier Don Orlando, eigens „Suonatori del Reggimento“ bestellt, deren Auftritte also geplant und folglich vorhersehbar sind. Zur mit dem Beginn des Finales zusammenfallenden Festeröffnung spielt diese „Banda di suonatori militari“ eine oder mehrere „Sinfonie“, wobei der (mit deutschem Akzent sprechende) Don Orlando wie in den typischen Instrumentenarien unterschiedliche Musikinstrumente aufzählt, die aber nicht alle tatsächlich im Orchester erklingen.

D. O. Che grate melodie!

Che pelle Sinfonie!

Piacer fan Clarinetti,

Dan gusto Pifferetti,

Fagotti star famosi,

Star Corni buoni assai, $(\ldots)^{896}$

Am schönen Konzert erfreuen sich nicht nur Don Orlando, sondern auch das Hochzeitspaar, dessen wachsende Freude durch kreisende Figuren im Crescendo und das typische Bild des hüpfenden Herzen ausgedrückt wird. Alle drei betonen in ihren Äußerungen die durch das Konzert hergestellte fröhliche Stimmung.

Cap. D.A. a 2 Che amabile concerto!

Che suono ameno e grato!

(...)

Il core di piacere

Mi sento saltellar.

(...)

896 Livigni/Cimarosa: Giannina e Bernardone. Venedig 1781 (II,17). 

D. Or. D. A. Cap. a 3 La gioja, e l'allegrezza
Crescendo in sen mi va. ${ }^{897}$

In der Zwischenzeit werden die bei Festen unerlässlichen Erfrischungen, Limonade, Schokolade, Wein und Kekse serviert:
D. Or. Via presto, servitori, Portar qui Limonate, Piscotti, Cioccolate, Bottiglie in quantità. (Servi portano i Rinfreschi.) ${ }^{898}$

Als zweite Musikeinlage in diesem Hochzeitsfest dient ein von einigen Hochzeitsgästen zur Beglückwünschung organisiertes Ständchen. Der vor Beginn des Festes angedeutete Plan für eine Überraschungseinlage deutet auf einen vorbereiteten Auftritt hin, allerdings ist der Spontaneitätsgrad dabei trotzdem relativ hoch, denn weder das Hochzeitspaar noch Giannina sind eingeweiht und Letztere wird noch unwissend erst in letzter Minute einbezogen.

$\begin{array}{ll}\text { Lau. } & \text { Dimmi tu la Chitarra } \\ & \text { Non suoni a meraviglia? } \\ \text { Gia. } & \text { Qualche poco. } \\ \text { Lau. } & \text { O poco, o assai questo ci basta } \\ \text { Gia. } & \text { E cosa } \\ & \text { Di far pensato avete? } \\ \text { Lau. } & \text { Animo andiamo; }\end{array}$

Più tempo non perdiam ch'or lo saprai. ${ }^{899}$

Während des Finales wird klar, dass damit eine von den Bauern selbst vorgetragene volkstümliche Musikeinlage gemeint war. Wie es für ländliche Festszenen in der Opera buffa typisch ist, wird sie nicht nur gesungen, sondern auch mit den entsprechenden Instrumenten laut Libretto-Regieanweisung auf der Bühne gespielt: „Giannina, suonando il Chitarrino, Masino il Caliscione e Lauretta il Cemballo." Diese typischen, in der Partitur nicht aufscheinenden Volksmusikinstrumente tragen zum Lokalkolorit - die Handlung spielt im „Borgo di Gaeta“, einem Dorf zwischen Neapel und

897 Ebd.

898 Ebd.

899 Ebd. (II,16). 
Rom - bei, denn die "Caliscione“ oder colascione genannte Art von Langhalslaute war vor allem in der süditalienischen Volksmusik gebräuchlich. Mit „Cemballo“ ist vermutlich eine Schellen- oder Handtrommel gemeint, die gemeinsam mit dem muskalischen Satz der Einlage und dem charakteristischen \%/8-Takt ihren volkstümlichen, tarantellaartigen Charakter ausmacht und unterstreicht.

Das hurtige Tempo (Allegro con brio) und die zweimalige punktierte Figur mit kurzem Vorschlag zu jedem Phrasenbeginn in den Frauenstimmen tragen zur schwungvollen, tänzerischen Bewegung des Ständchens bei, mit dem die Bauern das Hochzeitspaar hochleben lassen.

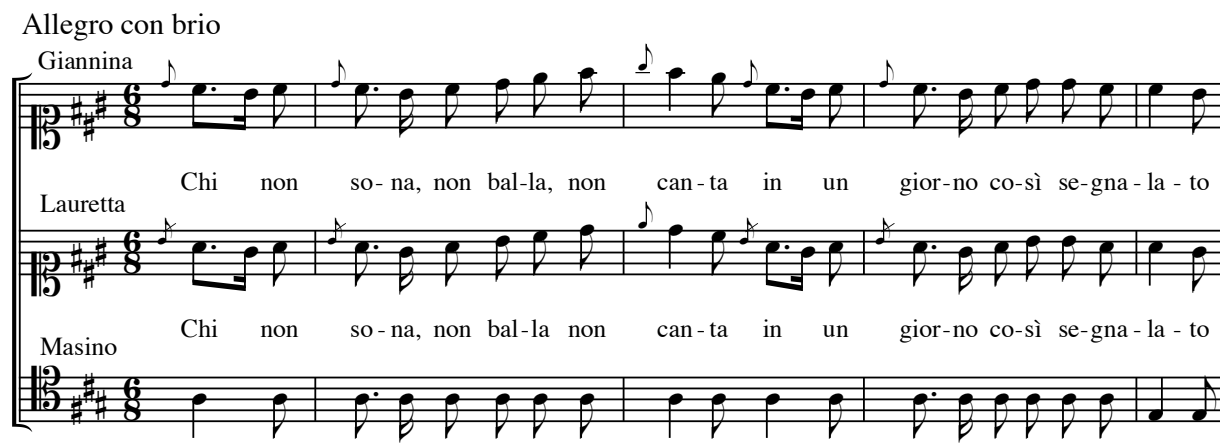

72 Cimarosa/Livigni: Giannina e Bernardone. (I-Mc Noseda E.1/I-II)

Schwung erzeugende punktierte Figuren tauchen immer wieder auf und lassen gemeinsam mit dem Abwechseln und Ineinanderspielen von solistischen und chorischen Phrasen die Einlage besonders lebendig erscheinen.

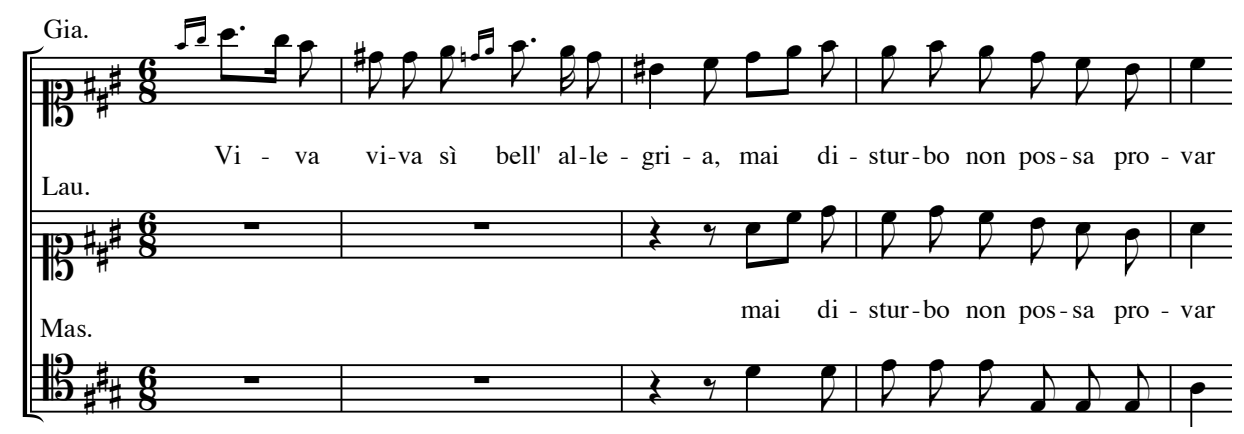

73 Cimarosa/Livigni: Giannina e Bernardone. (I-Mc Noseda E.1/I-II)

Wie typisch eine solche volkstümliche Musikeinlage in der Opera buffa ist, bestätigt Stefan Kunze in folgender Bemerkung in Bezug auf Gazzanigas ebenfalls in Venedig 
uraufgeführte Oper „Don Giovanni o sia Il convitato di pietra“ (I787): „Das Bild heiteren Landlebens wird musikalisch durch den $6 / 8$-Rhythmus von Tarantella und Siciliano vergegenwärtigt, die seit Beginn des i 8. Jahrhunderts musikalische Archetypen des volkstümlichen Elements in der Opera buffa geworden waren. "900

Direkt im Anschluss an dieses eher klischeehafte Ständchen folgt eine vollkommen unvorhergesehene Festeinlage, deren hoher Spontaneitätsgrad mit einer besonderen Spielhaftigkeit und Originalität einhergeht. Bernardone überrascht nämlich alle, indem er als Bänkelsänger verkleidet auftritt. Die Regieanweisung gibt über die charakteristischen Requisiten Auskunft: „Bernardone vestito da Cantastorie, con Chitarra, e Cesto sotto il braccio pieno di Storie." Alle halten ihn für einen echten Bänkelsänger und fragen sich, wer ihn bestellt habe; nur Giannina erkennt ihren Ehemann. Nicht nur die äußerliche Erscheinung, sondern auch Bernardones sprachliche und musikalische Ausdrucksweise, beispielsweise die Rezitation auf einem einzigen Ton und eine balladenartige, fragende Wendung bestehend aus einem aufsteigenden Dreiklang mit einer „offen lassenden“ Fermate am Schluss jeder Phrase, vermitteln den Eindruck eines echten cantastorie (s. Notenbeispiel 74, S. 357).

Wie geschickt Bernardone seine Zuhörer von der Spontaneität seines Auftritts überzeugt und wie kalkuliert in Wirklichkeit sein einfallsreiches Spiel ist, erkennt man unter anderem daran, dass er zu Beginn mehrere bekannte, insbesondere aus „Klassikern“ wie „Bertoldo, Bertoldino e Cacasenno“ oder „Don Chisciotte“ stammende Geschichten vorschlägt und am Schluss dieser typischerweise auf einem Ton rezitierten Auflistung eine neue und unbekannte Geschichte ankündigt, auf deren Vortrag die von der Neuigkeit verlockten Zuhörer („Questa è nuovissima / Questa è bizzarra") sogleich bestehen.

Bevor die eigentliche Erzählung beginnt, stimmt Bernardone seine Gitarre - ein beliebter, die Inszenierung einer Musikdarbietung ankündigender Topos der „realistischen“ Darstellung des Stimmens. Hier wird eher die Idee des Stimmens vermittelt, denn statt einer Gitarre werden mehrere Streichinstrumente im Orchester mit gestrichenen statt gezupften Saiten gestimmt. Die Bemühung um Realitätsnähe ist trotzdem vorhanden und am Detail des wiederholten Auftretens eines Halbtonschritts $(\mathrm{g}-\mathrm{as})$ in den zweiten Geigen ersichtlich, der einen typischen, sich im Stimmvorgang ergebenden Klang wiedergibt (s. Notenbeispiel 75, S. 358).

900 Kunze Stefan: Don Giovanni vor Mozart. München 1972, S. 102f. Die große Häufigkeit von volkstümlich anmutenden Musiknummern legt die Vermutung nahe, dass folkloristische Momente einen besonderen Reiz ausgemacht haben. Bemerkenswert ist dabei der Zusammenhang mit dem Wertsystem der Zeit, in dem Natürlichkeit, Einfachheit und bonté naturelle eine vorrangige Stellung einnahmen, sowie mit der in der Opera buffa häufig vorkommenden Gegenüberstellung von Stadt als Sinnbild der Unsittlichkeit und Land als Inbegriff von Ehrlichkeit der Gefühle, Treue und Naivität. 
Larghetto con moto
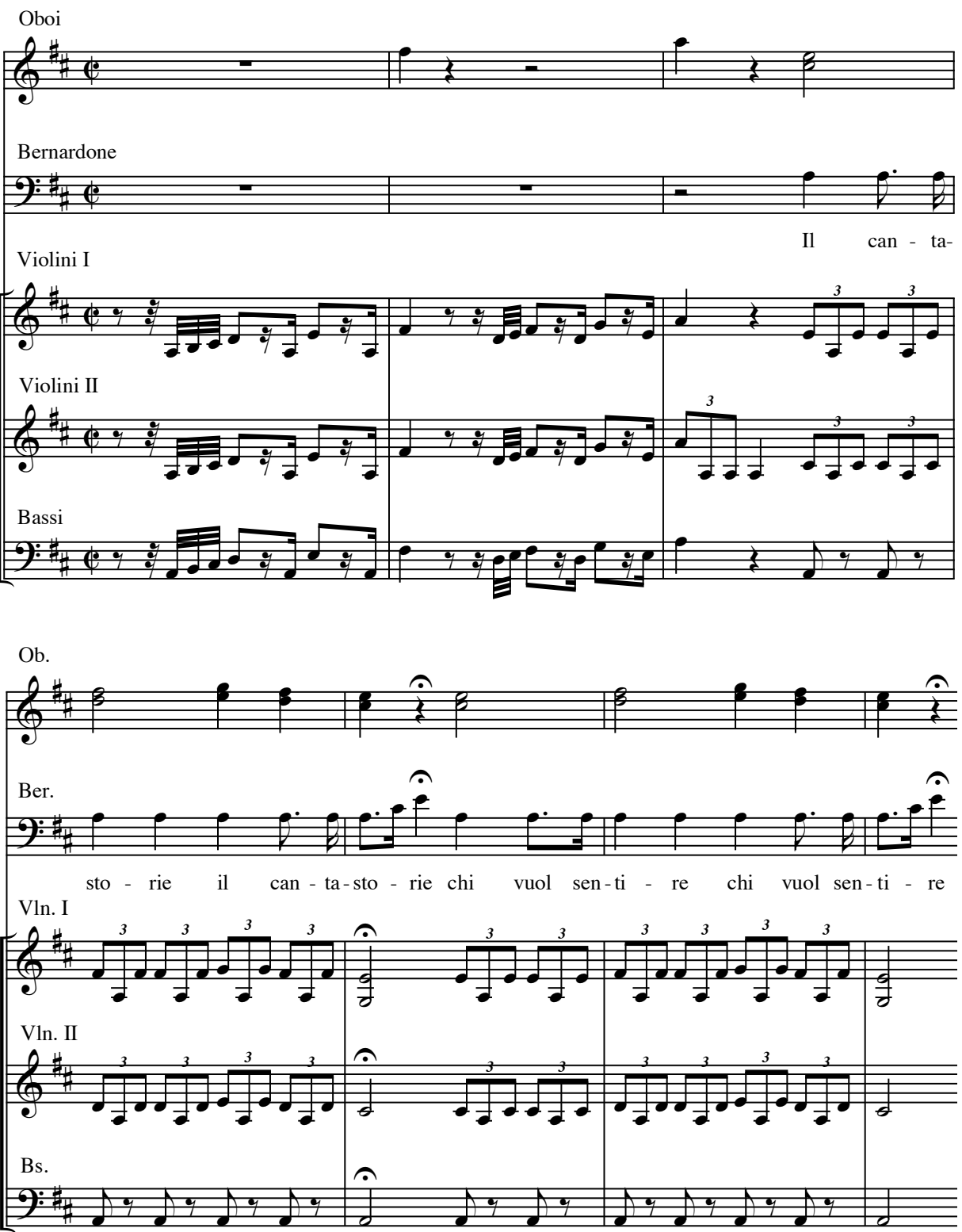

74 Cimarosa/Livigni: Giannina e Bernardone. (I-Mc Noseda E.1/I-II) 


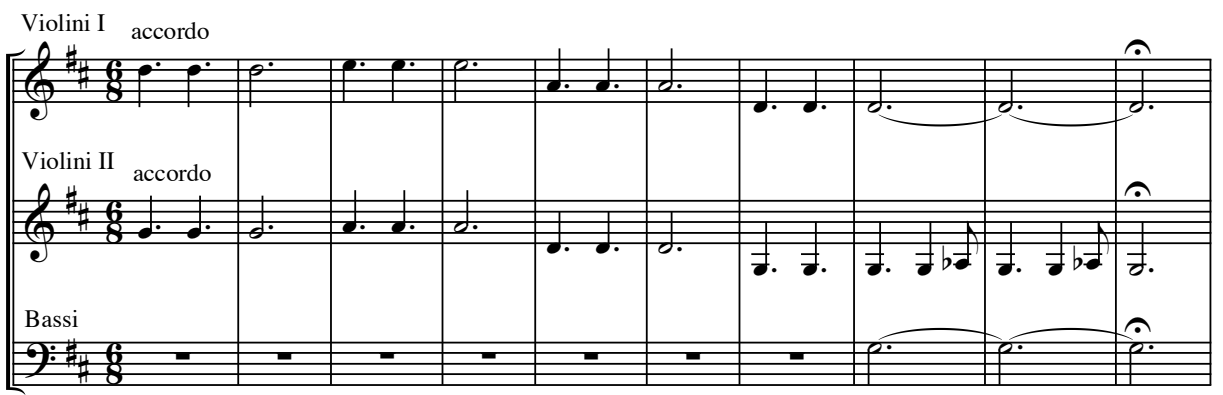

75 Cimarosa/Livigni: Giannina e Bernardone. (I-Mc Noseda E.1/I-II)

Der eigentliche Vortrag beginnt mit einer pathetischen instrumentalen Einleitung in g-Moll (Andante 6/8), auf die die Erzählung in klagendem Ton folgt.

Es ist kein Zufall, dass für die gesungene Erzählung Cimarosa die Form des Accompagnato-Rezitativs (Largo ad libitum) wählt, die der Deklamation des Textes große Freiheiten lässt und so den improvisierten Vortrag des cantastorie anschaulich darstellt. Auch eignet sich das Accompagnato besonders zum Aufbau einer dramatischen Spannung, die in den Schilderungen der cantastorie häufig mit einer tragischen Note gekoppelt war, die hier ebenfalls durch das Moll-Geschlecht und den klagenden Gesang wiedergegeben wird.

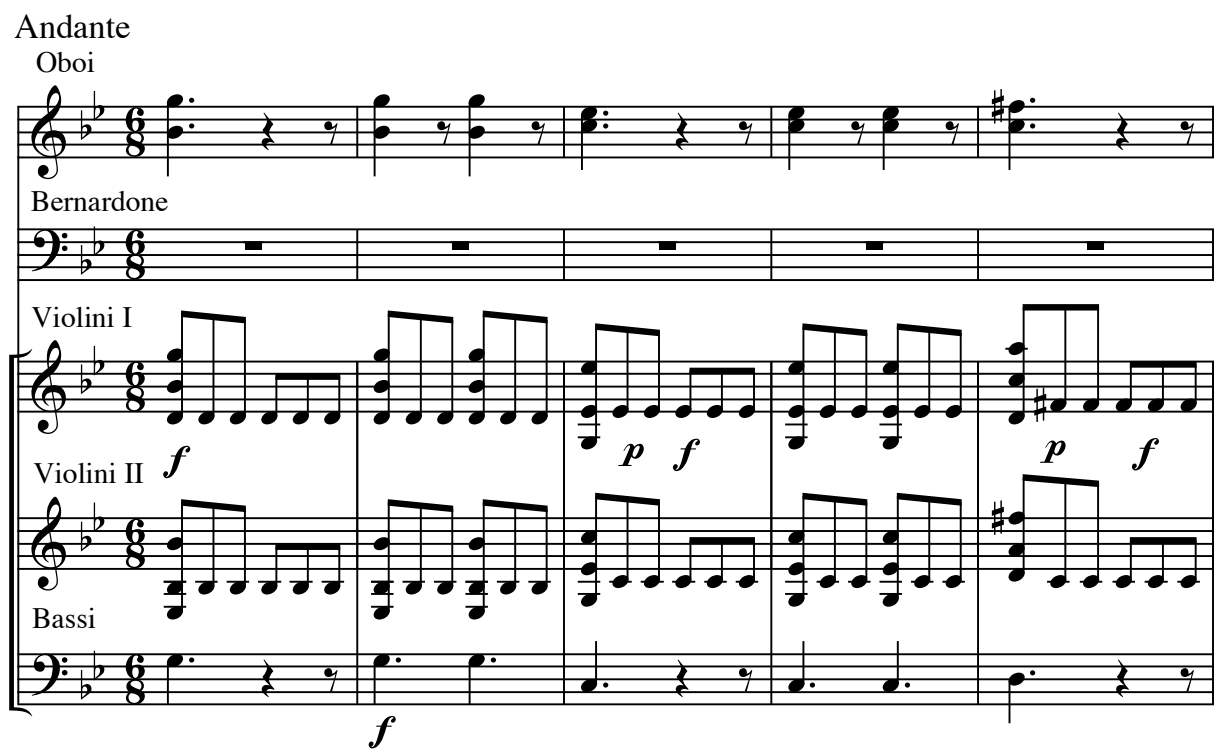



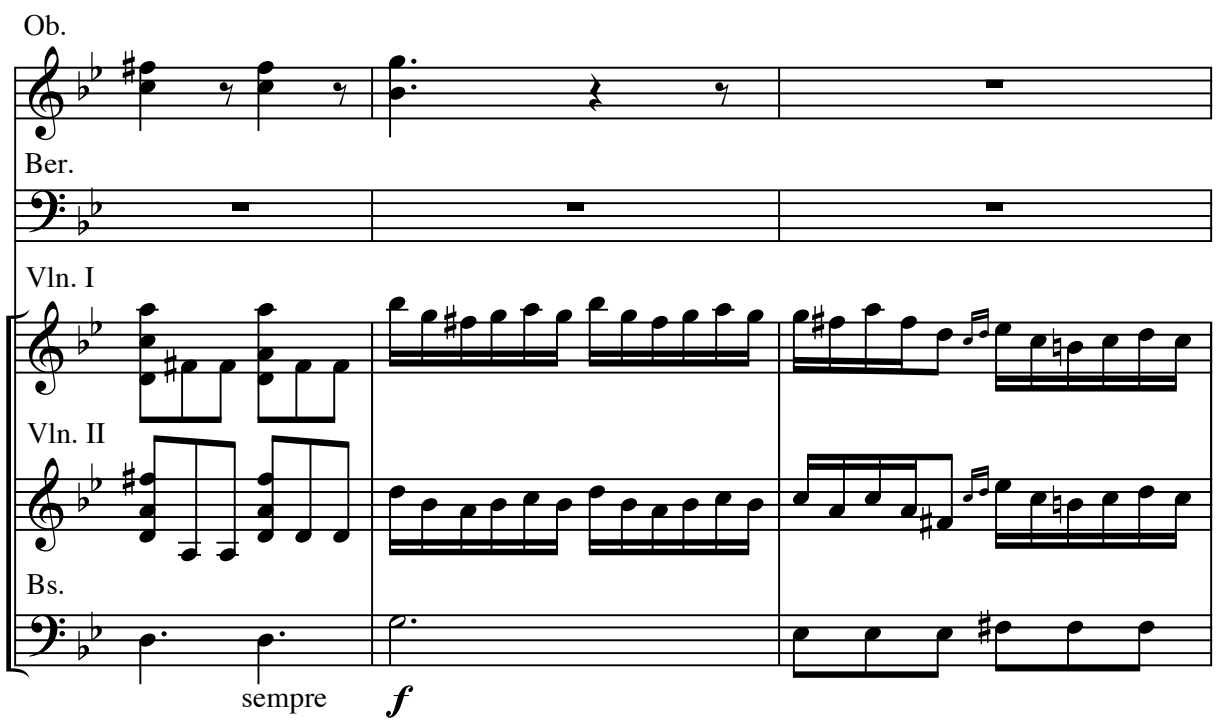

$\mathrm{Ob}$.
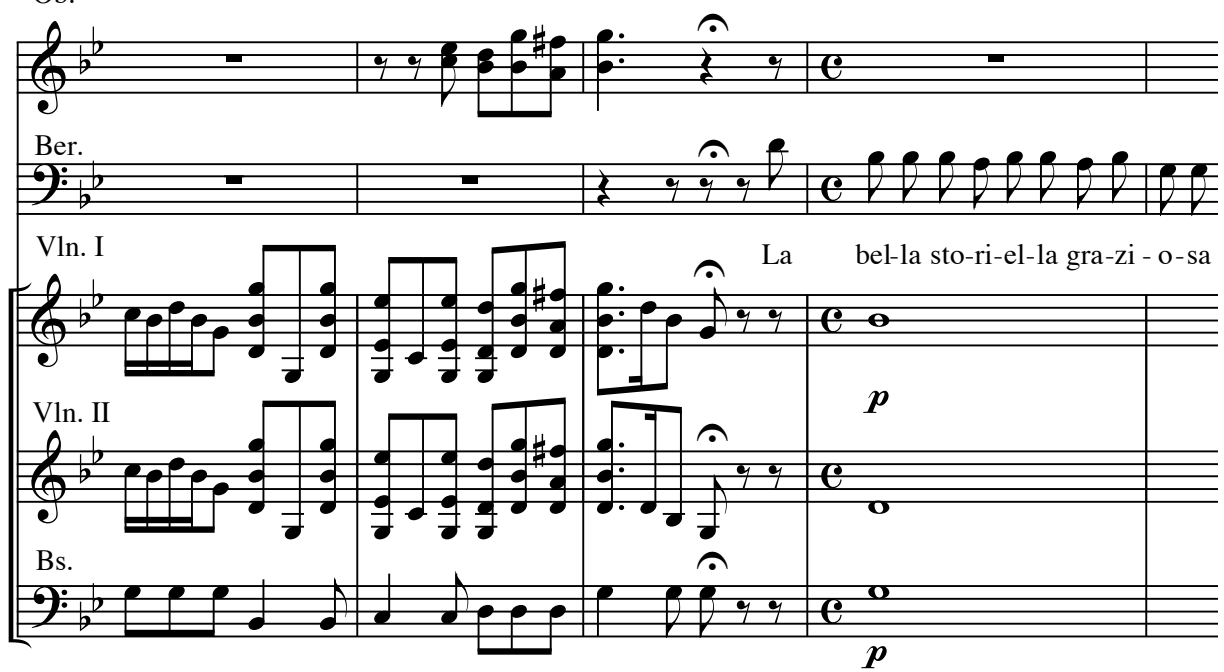

76 Cimarosa/Livigni: Giannina e Bernardone. (I-Mc Noseda E.1/I-II)

Vor der eigentlichen Erzählung fasst Bernardone in (für die volkstümlichen narrativen Formen, die mittel- und süditalienischen storie und ballate) typischen Elfsilblern ${ }^{901}$ die Geschichte kurz zusammen.

901 Vgl. Roberto Leydi: La canzone popolare. In: Ruggiero Romano und Corrado Vivanti (Hg.): Storia d'Italia. Bd. 5/2. Turin 1973, S. 1211. 
Ber. La bella Storiella, e graziosa
D'un povero Marito io vuò cantare,
Che per aver amata la sua Sposa
Questa lo fece un matto diventare.
Nobiltà riverita, attenzione,
Ch'io canto di Giannina, e Bernardone.

Als Bernardone im letzten Vers die mit dem Titel der Oper identische Überschrift seiner Erzählung nennt, fühlt sich Giannina angesprochen und will die Geschichte, die zugleich ihre eigene ist, selbst erzählen.

Musikalisch wird Gianninas spontanes Eingreifen durch einen plötzlichen Wechsel in ein rascheres Allegretto und durch die Aufhellung von g-Moll nach G-Dur umgesetzt. Im Gegensatz zu Bernardones Deklamation in erzählendem Ton (Accompagnato-Rezitativ) drückt sich Giannina in „normalem“ Sprechton aus, wobei man bedenken muss, dass in der Oper das Sprechen in Gesang umgesetzt ist und in der Opera buffa insbesondere das spontane Sprechen einer Buffo-Figur als rascher, syllabischer Buffo-Gesang dargestellt wird. Der Ebenenwechsel wird besonders deutlich, als Giannina die Geschichte aus ihrer eigenen Perspektive zu erzählen beginnt und zu einem „narrativen Modus“ - musikalisch dementsprechend zu einem Accompagnato-Rezitativ - übergeht. Über die Sichtweise seiner Ehefrau empört, unterbricht Bernardone ihre Erzählung. Seine Spontaneität wird hier durch rasches, diesmal echtes Sprechen - die Anweisung in der Partitur (I-Mc Noseda E.I/I-II) lautet „Tutto questo periodo và detto in fretta, e senza Musica“ - zum Ausdruck gebracht, ein Mittel, das nach den untersuchten Quellen zu urteilen in der Opera buffa sonst nie verwendet wurde. Bernardone erzählt die Geschichte in seiner Version weiter und wird wiederum von Giannina unterbrochen. So entsteht einerseits ein sehr abwechslungsreicher, immer wieder zwischen rezitativischen, gesungenen und gesprochenen Passagen wechselnder Vortrag, andererseits durch das ständige Alternieren des Erzählers und die miteinander konstrastierenden Versionen der Geschichte eine Art „agonales Spiel“, das sehr stark an einen contrasto erinnert, eine Art von volkstümlichem, dialogischem Streitgedicht, das in Italien vor allem vom I3. bis zum I6. Jahrhundert verbreitet war und meist aus einem Streitgespräch zwischen zwei Liebenden bestand.

Giannina und Bernardone erzählen also abwechselnd ihre gemeinsame Geschichte, jeder aus seiner eigenen Perspektive. Die Vertonung verdeutlicht jeweils, ob es sich um einen bewussten Vortrag handelt, der meistens in der Versform der endecasillabi und im Accompagnato-Rezitativ gehalten ist, oder um eine spontane Reaktion, die in der Regel in rascher Prosa gesprochen wird. Das für das Spiel typische Hin und Her drückt sich im Alternieren der verschiedenen „Modi“ sowie der beiden Erzähler aus, 
die sich gegenseitig ins Wort fallen oder einen vom Partner angefangenen Satz in einer Weise beenden, die nicht der Absicht des anderen entspricht.

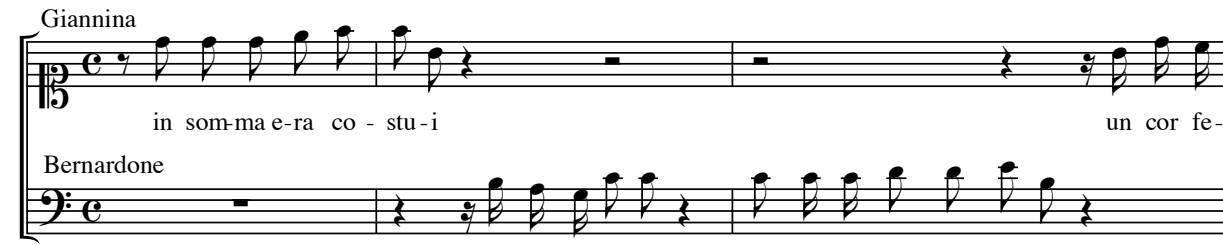

un uom d'o-no-re. Ma la sua mo-glie a-ve - a

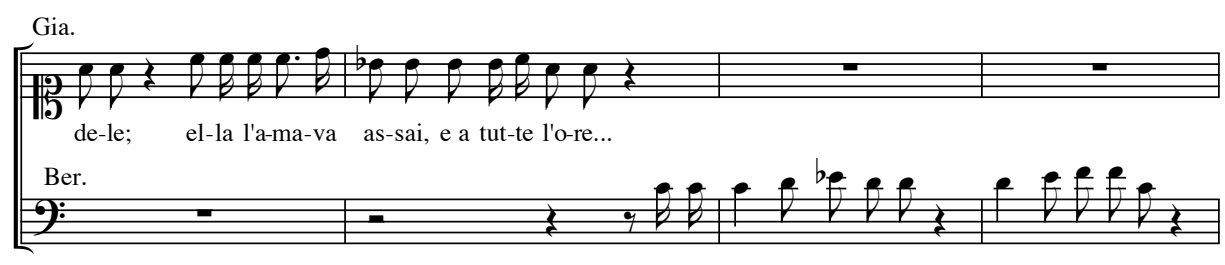

a Cor-ne-to il man-da-va, a gon-fie ve-le.

77 Cimarosa/Livigni: Giannina e Bernardone. (I-Mc Noseda E.1/I-II)

Der Replikenwechsel der beiden Erzähler wird immer gedrängter, bis er schließlich in ein regelrechtes Streitduett mündet, dem ein neuer musikalischer Abschnitt gewidmet ist (Tempo giusto non tanto presto, $\%$, F-Dur).

Tempo giusto non tanto presto

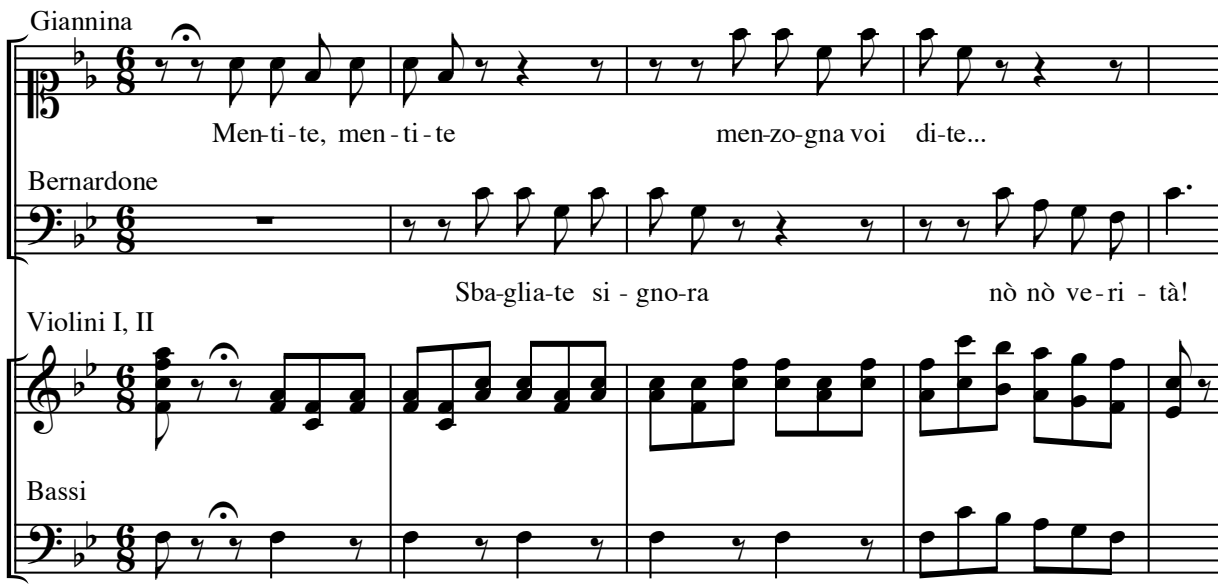

78 Cimarosa/Livigni: Giannina e Bernardone. (I-Mc Noseda E.1/I-II) 
Von diesem Punkt an wird die Erzählebene - und damit das Accompagnato-Rezitativ - endgültig aufgegeben. Der sich ergebende Streit ist keine beabsichtigte Performance, in der die metakommunikative Mitteilung „Dies ist ein Spiel“ im Sinne Batesons mitschwingt, sondern (auf der Bühne) gelebte Wirklichkeit und ist dementsprechend im typischen Parlando, im schnellen, syllabischen Buffo-Gesang vertont. Das Hin und Her der Repliken geht weiter, bis schließlich Don Orlando eingreift und den Streit beendet.

Im „Erzählspiel“ vor dem Streitduett konzentrieren sich auffällig viele Spielelemente. Neben der schon erwähnten charakteristischen Hin- und Herbewegung auf verschiedenen Ebenen überlagern und verknüpfen sich in dieser besonders originellen Festeinlage zwei grundlegende Spielprinzipien. Nach Huizinga scheinen es die beiden konstitutiven Prinzipien zu sein, die dem Spiel zugrunde liegen: „Das Spiel ist ein Kampf um etwas oder eine Darstellung von etwas. Diese beiden Funktionen können sich auch vereinigen (...)."902 Gianninas und Bernardones Schilderung kann tatsächlich als ein Darstellungsspiel angesehen werden: Bernardone tritt als cantastorie verkleidet auf und durch Gianninas spontanes Eingreifen ergibt sich ein performativer Erzähl-Wettstreit, der schließlich in einen echten Streit ausartet. Diese Verknüpfung der Spielkategorien Agon und Mimicry sowie der hohe Spontaneitätsgrad tragen zur ausgesprochenen Spielhaftigkeit dieser Festeinlage bei. Einerseits ist der Auftritt eines cantastorie für alle Anwesenden überraschend und wirkt spontan, obwohl Bernardone dabei die Rolle des cantastorie sehr bewusst spielt und somit „eine Illusion von Spontaneität"903 und Natürlichkeit - zwei Ideale der damaligen Zeit - kreiert. Seine Worte und sein Gesang wirken improvisiert; es handelt sich jedoch eher um eine gespielte Spontaneität. Echte Spontaneität kommt auf der Bühne zum Ausdruck, als Giannina, die als einzige Zuschauerin das Spiel durchschaut, spontan in Bernardones Vortrag eingreift. Giannina hatte schon in der vorherigen, nur zum Teil geplanten Einlage eine große Spielbereitschaft bewiesen, als sie eingesprungen war, ohne den genauen Plan zu kennen. Hier mischt sie sich spontan und unaufgefordert in die vollkommen unvorhergesehene Performance ein und spielt mit, indem sie „miterzählt“. Ihr spontanes Eingreifen zwingt Bernardone zur Improvisation und somit zur Spontaneität, denn er muss auf Gianninas Herausforderung eingehen und von seinem eigentlichen Vorhaben abweichen, wobei er ebenfalls eine typisch buffomäßige Spielbereitschaft an den Tag legt.

902 Huizinga, S. 20.

903 Zum Begriff der „Illusion von Spontaneität“ und der „komponierten Spontaneität“ siehe Gernot Gruber: Komponierte Spontanität und die Idee der Improvisation. In: Dieter Borchmeyer und Gernot Gruber (Hg.): Mozarts Opern. Laaber 2007 (Das Mozart Handbuch 3), S. 19-27. 
Den Spielcharakter dieser Hochzeitsfest-Einlage hebt ein weiterer Aspekt hervor: das Spiel im Spiel bzw. die Geschichte in der Geschichte. Dabei kommt es zu einer Spiegelung zwischen der ersten und der durch die Erzählung eingebrachten zweiten Fiktionsebene. Giannina und Bernardone erzählen nämlich ihre gemeinsame Geschichte, dieselbe, die als Haupthandlung unter demselben Titel („Giannina e Bernardone“) gespielt wird, betrachten sich also gewissermaßen von außen und tun so, als seien die Geschehnisse um ihren realen Ehekonflikt in der cantastorie-Einlage fiktiv. Dadurch, dass es sich aber um die Lebenswelt der beiden Betroffenen handelt und ihre Sichtweisen sich nicht decken, geraten sie miteinander in Streit, spielen also trotz des performativen Rahmens ihre eigenen Rollen und lassen durch ihre Spontaneität ihre wahre Persönlichkeit durchscheinen. ${ }^{904}$ Die Identität von Erzählungsinhalt und Realität der ersten Fiktionsebene ermöglicht - wie schon am Beispiel von Paisiellos „Don Anchise Campanone“ erläutert wurde - ein reizvolles Kipp-Spiel zwischen den beiden Ebenen, das die Grenzen zwischen dem „gewöhnlichen Leben“ und der „Spielsphäre“ bzw. zwischen Realität und Illusion verwischt. Dabei entsteht nicht nur ein wirksamer Spiegeleffekt, sondern eine regelrechte matrioschkaartige Verschachtelung, die Da Pontes Forderung, ein Finale solle „una specie di commediola“905 enthalten, gewissermaßen wörtlich umsetzt.

Nach dieser besonders spontanen, spielerischen und reizvollen Einlage, die den Höhepunkt des Hochzeitsfestes und des zweiten Finales ausmacht, spielen die „Suonatori del Reggimento“, die das Fest eröffnet hatten, zum Tanz auf. Anfang und Ende des Festes sind also durch offizielle, im Voraus organisierte Musikeinlagen gekennzeichnet, die von Berufsmusikern zur Unterhaltung der tanzfreudigen Hochzeitsgäste gespielt werden. Die Geste der spontanen Laienmusiker, die ihre Instrumente weglegen, um sich den Feiernden anzuschließen, wird ausdrücklich in einer Regieanweisung vorgegeben und erfolgt in dem Moment, als die Banda zum Tanz aufspielt: „Qui la Banda de' Suonatori si alza, e principia di nuovo a suonare. Bernardone, Giannina, Masino e Lauretta pongono i loro strumenti sopra un sedile.“ Das Verhältnis zwischen den eigens beauftragten „Suonatori“ und den tanzenden und „spielenden“ Gästen entspricht gewissermaßen der Konstellation einer Opernaufführung, in der professionelle Spieler, also Darsteller und Musiker, deren Spieltätigkeit eigentlich Arbeit, also Nicht-Spiel ist, den Zuschauern durch ihr Spiel ein „Mitspielen“ ermöglichen. Der dabei von den Festteilnehmern erlebte „Spielgeist“ geht mit einer besonders freudigen

904 Diese besondere Spontaneität und die dabei durchblitzende Menschlichkeit sind nicht nur charakteristische Begleiterscheinungen des Spiels, sondern entsprechen auch den für das 18. Jahrhundert typischen Idealen der Natürlichkeit, der Ursprünglichkeit und der Wahrhaftigkeit.

905 Da Ponte: Memorie. Libretti mozartiani. S. 92. 
und ausgelassenen Stimmung einher, die die Hochzeitsgäste am Schluss des Festes im gemeinsamen Tanzen und Singen ausdrücken. Wie in der Gattung des dramma giocoso üblich, schließt die Oper im allgemeinen Jubel.

Viva viva l'allegria

Viva ancor la Compagnia;

Che piacere, che contento,

Giubilare il cor mi sento;

Via saltiamo, via balliamo,

Là, là laira là là là là

Oh che gran felicità.

Typische Freude- und Hochrufe auf die Heiterkeit und die Gesellschaft, Musik auf der Bühne und kollektives Singen auf Trällersilben prägen diese bunte und ausgelassene Tanzszene, die musikalisch konventionell als rasche und schwungvolle SchlussStretta vertont ist. Die unter "Ilinx“ beschriebenen Gestaltungsmittel der Finali, wie die hohe Geschwindigkeit bzw. Beschleunigung - das vorgeschriebene Tempo ist "Stretto di molto“ - und die kreisenden mulinello-Bewegungen tragen zur typischen Schluss-Steigerung bei. Musik und Tanz, die Huizinga als reinste und vollkommenste Formen des Spiels schlechthin bezeichnet, ${ }^{906}$ werden durch zusätzliche „Spiele“ ergänzt, wie beispielsweise das Hin und Her der abwechselnd singenden (und möglicherweise tanzenden) Frauen- und Männergruppe.

Stretto di molto

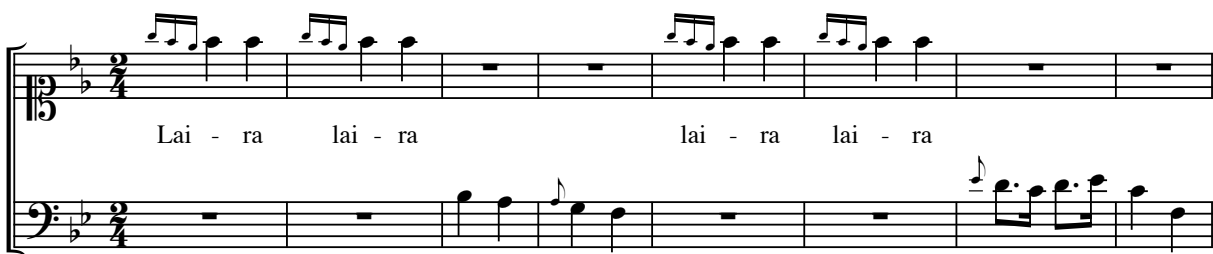

lal-lal - le-ra

lai-ra-li -ral - là

79 Cimarosa/Livigni: Giannina e Bernardone. (I-Mc Noseda E.1/I-II)

Volkstümliche Einfachheit prägt die vergnügte und fröhliche Festszene, die als Gestaltungsspiel mit dionysischen Ilinx-Anteilen klassifiziert werden könnte. Das Fest ist hier insofern ein Gestaltungsspiel, als es einen durch unterschiedliche Vergnügun-

906 Huizinga, S. 159 und 179. 
gen - vorwiegend Inszenierungen verschiedener Einlagen - gestalteten Zeitrahmen bildet. Die darin enthaltenen für die Bühnenfiguren wie auch für das Opernpublikum besonders reizvollen und unterhaltsamen Einlagen können selbst als Gestaltungsspiele bezeichnet werden. Der sich aus der Mischung von spontanen und geplanten Festeinlagen ergebende Spielraum ist für das Gelingen des Festes entscheidend, denn „wäre ein Fest eine genaue Festlegung, wer, wie, wann und wo, was zu tun hat, dann wäre zwischen einem Fest und einem Zeremoniell kein Unterschied. Das aber ist der Unterschied, daß das Fest, wenn es auch einen äußeren Rahmen vorgibt, den Feiernden Raum zur Entfaltung lässt. (...) Das Fest muß sehr gut vorbereitet sein, um Spontanität und Improvisation zulassen zu können. So sollen auch die Festgäste in einer spielenden Haltung am Fest teilnehmen, bereit zu konversieren, zu improvisieren, zu genießen. Während eines Zeremoniells sind die Rollen genau verteilt. Jeder und jede versucht seine und ihre Rolle zu erfüllen, nicht aus der Rolle zu fallen. Wie langweilig sind aber solche Feste, wenn alle bemüht sind, ihre Rollen zu spielen und möglichst nicht aus der Rolle zu fallen. (...) Zum Fest gehört, wie beim Spiel, das Wagnis."907

\subsection{Exkurs: Der Tanz}

Der Tanz als typischer Bestandteil eines Festes - nach Groos bildet er „neben dem Mahl die ursprünglichste Form der Festlichkeit" Zusammenhangs mit dem Spiel eine gesonderte Behandlung. Auf der Suche nach Gemeinsamkeiten zwischen Spiel und Fest hatte Huizinga festgestellt: „Im Tanz scheinen die beiden Begriffe die innigste Verbindung einzugehen." ${ }^{909}$ Der Tanz scheint also einen grundlegenden gemeinsamen Nenner beider Phänomene zu bilden. Sein Verhältnis zum Spiel ist durch vielerlei gemeinsame Elemente geprägt: Die beiden als Urphänomene definierbaren Erscheinungen sind schon durch die ursprüngliche etymologische Bedeutung des Wortes Spiel als „tänzerischer Bewegung “910 miteinander verknüpft, die vermutlich auf dem Bewegungsdrang junger Menschen (und Tiere) ${ }^{911}$

907 Rainer Buland: Fest-Spiel-Frieden. Zusammenhänge und Wesenszüge. S. 256. In: Homo ludens. Fest und Spiel. Bd. 8, S. 249-260. In Jean Châteaus Systematik erscheinen Tänze und Zeremonien als zwei unterschiedliche Untergruppen der Kategorie der jeux à régulation stricte.

908 Groos: Die Spiele der Menschen. S. 456.

909 Huizinga, S. 28f.

910 Vgl. Duden Etymologie. S. 659. Siehe Kapitel „Begriffsbestimmung“.

911 Buytendijk bezeichnet den „Bewegungsdrang“ als „Wesenseigenschaft der jugendlichen Dynamik“ und schreibt: „Der jugendliche Organismus zeigt diesen ursprünglichen spontanen Bewegungsdrang im höchsten Maße. Das Kind zappelt mit Armen und Beinen, das junge Tier tummelt sich herum, springt und hüpft, rollt und rennt." (Buytendijk, S. 28). 
beruht. Darüber hinaus werden beide vielfach als vergnügliche und fröhliche Tätigkeiten aufgefasst; Böhme bezeichnet den Tanz sogar als einen „durch Takt geregelten Ausbruch der Lebensfreude." ${ }^{12}$ Allerdings stellt Buytendijk, der sich besonders eingehend mit dem Aspekt der Bewegung und der Spieldynamik beschäftigt, in diesem Zusammenhang Folgendes fest: „Besonders schwierig ist es, die Grenze zwischen Spielen und lustbetonten Tätigkeiten, sowie auch zwischen diesen beiden und reinen Ausdrucksbewegungen zu finden." ${ }^{13}$ Diese Abgrenzungen hängen ausschließlich von der jeweiligen Definition des Spiels und des Tanzes ab; so erklärt sich, dass Huizinga den Tanz als ,eine der reinsten und vollkommensten Formen des Spiels “914 ansieht, weil er den von ihm formulierten Spielmerkmalen entspricht, während Buytendijk eine entgegengesetzte Meinung vertritt: „Auch das Tanzen und so viele von Menschen und Tieren ausgeführte lustbetonte Bewegungen, insofern dabei keine Bindung an irgend einen Gegenstand (auch nicht an einen Artgenossen wie bei den Kampfspielen) auftritt, sind keine Spiele. Daß das Spielen eine lustbetonte Handlung ist, soll noch kein Grund sein, alle lustbetonten Handlungen Spiele zu nennen." formale Begründung dieser Aussage führt Buytendijk allerdings nur die Nicht-Erfüllung seiner Maxime „Das Spielen ist immer ein Spielen mit etwas"916 an, wogegen eingewendet werden könnte, dass man beim Tanzen sehr wohl „mit etwas“ spielt, nämlich - entsprechend dem „Musikspielen“, als dessen Gegenstand Buytendijk „die Musik, die akustische Materie selbst“917 betrachtet, oder der Musik, deren „tönend bewegte Formen" als Spiel der Töne angesehen werden können - mit den Bewegungen bzw. Formen des eigenen Körpers. Dementsprechend kann der Tanz genauso wie die Musik oder das Fest als Spiel angesehen werden und gehört je nach Einteilung zu den Bewegungs- oder den Mimicry- bzw. Gestaltungsspielen.

Der Tanz findet nicht nur als wesentlicher Bestandteil von Festen seinen Weg in die Opera buffa, sondern tritt darin bei genauer Betrachtung als performatives Element in unterschiedlichen Erscheinungsformen und Kontexten auf. Brandenburg beschreibt den Tanz als eines der „Ausdrucksmittel, die sich in der Buffa bis zu ihren Anfängen, d.h. bis zum Stegreiftheater, zurückverfolgen lassen "918 und vermutet,

912 Franz M. Böhme: Geschichte des Tanzes in Deutschland. Leipzig 1886, S. 1.

913 Buytendijk, S. 40.

914 Huizinga, S. 159.

915 Buytendijk, S. 45.

916 Ebd. S. 44.

917 „Musikspielen ist mit Musik spielen. Das Klavier oder die Geige ist Instrument, nicht eigentliches Spielobjekt. Das ist die Musik, die akustische Materie selbst." (Buytendijk, S. 128).

918 Daniel Brandenburg: Zu Tanz- und Bewegungsphänomenen in der Opera buffa des 18. Jahrhunderts. S. 160. 
„daß Tanzbewegungen eine viel größere Rolle gespielt haben als heute auf den ersten Blick aus Partitur und Libretto erkennbar ist." 119 Abgesehen davon, dass die $\mathrm{Mu}$ siknummern der Opera buffa, wie generell viele Musikformen des I 8. Jahrhunderts, häufig aus der Tanzmusik abgeleitet zu sein scheinen, ${ }^{920}$ können in den Libretti immer wieder implizite Regieanweisungen für Tanz aufgefunden werden. Allein unter den schon besprochenen Beispielen, finden sich etliche, die ein Potenzial für Tanzszenen bergen: Man denke nur an die kleinen imaginierten Szenen, wie die Barbarinas aus „La forza delle donne“, die in ihrer Vorstellung mit einem imaginären Soldaten die „Alemanna“ tanzt, wobei die Sängerin höchstwahrscheinlich einige Tanzschritte angedeutet haben wird. Dasselbe gilt für Don Perichettos imaginierte Katzenszene aus „Il geloso in cimento“, die ein "con la voce del gatto" gesungenes Menuett enthält, das der Interpret vermutlich auch getanzt haben wird. Auch in der besprochenen Musik- und Tanztherapie-Szene und in der mit „balli“ versehenen Unterweltszene aus der Orfeo-Parodie "Le spose ricuperate" wurde sicherlich getanzt, möglicherweise in grotesk-komischem Stil. In den häufigen, auf einen Topos der Commedia dell'arte zurückgehenden Tanzunterrichtsszenen mit einem französischen Tanzmeister wurden mit höchster Wahrscheinlichkeit Tanzschritte aus modischen Gesellschaftstänzen der Zeit ausgeführt. Als Beispiele dafür wurde Canziano („Lo sposo disperato“), der zur Verfeinerung seiner bäuerlichen Manieren in den Tanzunterricht geschickt wurde, erwähnt sowie „I viaggiatori felici“, wo sich Giannetto als ein Tanzmeister namens „Monsiù Ballonè“ und Bettina als seine Schülerin „Mamsella Tortigliè" verkleideten.

Buffo-Figuren drücken im Allgemeinen ihre Freude auf sehr direkte Art durch Freudensprünge, Tanz und Gesang aus; so singt Martino in „Lo sposo di tre“ aus Freude über eine gelungene Burla eine Arie, die folgenden Textabschnitt enthält:

\footnotetext{
Da bravi, ancora noi

Balliamo in buona tresca

Un Taici alla Tedesca

Vogliamo adesso far.

La laira, che diletto,

La laira, che spassetto,

La laira, via girate,
}

919 Ebd. S. 172

920 Vgl. dazu Wye J. Allanbrook: Rhythmic Gesture in Mozart's „Le nozze di Figaro“ \& „Don Giovanni“. Chicago 1983. „The repertory of conventional music for social dance (...) naturally become one of the most important sources of topoi in the affective language of both Baroque and Classic music." (Allanbrook, S. 16). 
La laira, via saltate,

La laira, che allegria

$(\ldots)^{921}$

Ausdruck von Martinos Freude ist unter anderem sein Wunsch, einen „Taici alla tedesca“, also einen Deutschen Tanz zu tanzen, worauf ab dem ersten „La laira“ tatsächlich ein tänzerischer, einlageartiger Abschnitt folgt, der sich musikalisch deutlich vom Rest der Arie abhebt. Die Ausgelassenheit wird hier zusätzlich durch das Mitsingen des Tanzstückes (auf „La laira“) betont; die verwendeten Worte beschreiben die fröhliche Stimmung (diletto, spassetto, allegria) sowie die Tanzbewegungen (girare, saltare). Die hier eingesetzte Tanzmusik entspricht in ihrem schnellen Tempo (Allegro) und im Dreiertakt (3/8) tatsächlich dem in der zweiten Hälfte des I 8. Jahrhunderts vor allem im süddeutschen Raum und in Österreich gebräuchlichen und als besonders heiter empfundenen Deutschen Tanz. ${ }^{922}$

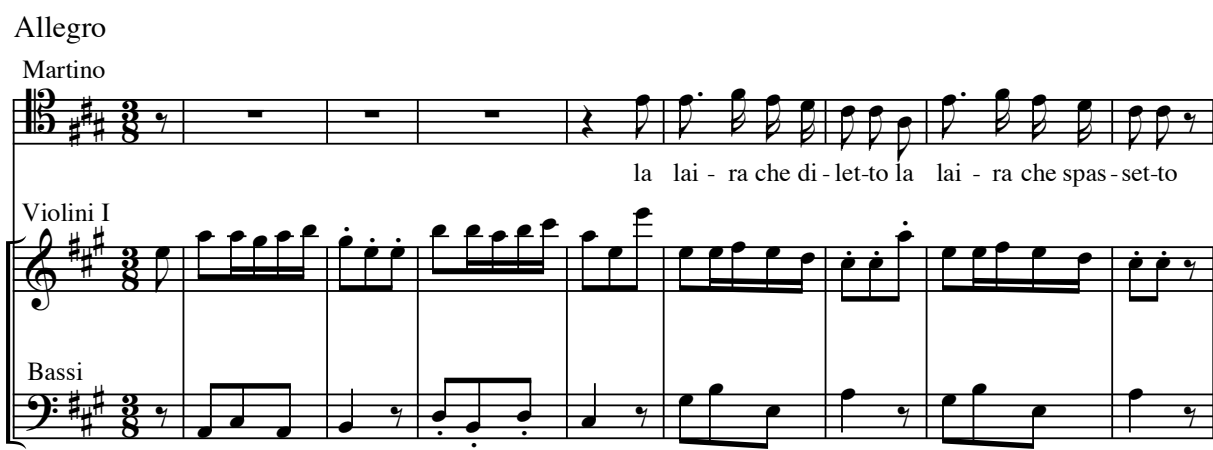

80 Cherubini/Livigni: Lo sposo di tre e marito di nessuna. Venezia 1783 (F-Pn D 2022-2023)

Martino wird von Don Pistacchio unterbrochen, der ihn nachäfft: „La laira, Vussignoria / Si vada a far squartar." Aus einem späteren Kommentar von Don Pistacchio („Col suo ballar m’ha tutto stroppiato“ - stroppiare bedeutet wörtlich verkrüppeln) geht hervor, dass Martino ihn gegen seinen Willen in einen wilden Tanz verwickelt hat, womöglich haben die beiden Männer sich auf der Bühne tatsächlich einem ausgelassenen Deutschen Tanz hingegeben, der ja als Paartanz ausgeführt wurde.

921 Livigni/Cherubini: Lo sposo di tre e marito di nessuna. Venedig 1783 (I,3).

922 „The affect of the contredance is the most lighthearted of all, especially in its $3 / 4$ German version; a common phrase used to express the triple allemande's distinctive gaiety is ,skipping joy', or hüpfende Freude (gaiezza saltante in the Italian)." (Allanbrook, S. 63). 
In derselben Oper singt Don Simone aus Freude über seine bevorstehende Hochzeit eine Arie, in der er sein freudiges Herzklopfen mit der furlana, einem raschen und wilden Volkstanz aus Venetien bzw. Friaul gleichsetzt.

\author{
Vezzosa cara Sposa \\ Voi rimbambir mi fate; \\ Il cor mi consolate, \\ Lo sento a saltellar. \\ Ballando d'allegrezza \\ Già fa la furlanetta; ${ }^{923}$ \\ Per voi, o mia diletta, \\ Gran festa voglio far. ${ }^{924}$
}

Ob der Sänger bei der Beschreibung seines hüpfenden, tanzenden Herzen tatsächlich Tanzbewegungen durchgeführt hat, ist unbekannt. Der letzte Vers bestätigt jedenfalls den Eindruck, dass Tanz in der Opera buffa meist mit einer freudigen und festlichen Stimmung assoziiert wird. Brandenburg hat diesbezüglich eine treffende Bemerkung formuliert: „Im Bereich der italienischen Buffa werden Tanzmotive nicht nur für getanzte Szenen benutzt, vielmehr können sie dem Sänger auch als Aufhänger für die schauspielerische Gestaltung einer komischen Szene dienen und damit gleichzeitig eine Pointe setzen."925

Der Tanz hat in der Opera buffa wahrscheinlich als unverzichtbares performatives Mittel fungiert, wobei die ihm (an sich schon) eigene Spielhaftigkeit vermutlich zusätzlich durch die Tatsache gesteigert wurde, dass es sich in den meisten Fällen wohl um improvisierte, spontane, spielerische Tanzbewegungen gehandelt hat.

Über die genannten Erscheinungsformen innerhalb der Opera buffa hinaus hatte der Tanz in einem „Opernabend“ eine erhebliche Präsenz, denn in den Zwischenaktpausen wurden in Venedig während des gesamten I8. Jahrhunderts meistens „balli“ (Ballette) aufgeführt.

923 Unter der Verkleinerungsform furlanetta ist hier wahrscheinlich die eigentliche furlana gemeint, ein generell als lebhaft und wild geltender Tanz. Der Vollständigkeit halber sei trotzdem erwähnt, dass Furlanette nach Benedetto Marcellos Beschreibung in „Il teatro alla moda“ (1720) auch von Sängerinnen ausgeführte Theatertänze genannt wurden bzw. die von ihnen gesungenen Melodien. (Vgl. Art. Furlana. In: Die Musik in Geschichte und Gegenwart. 2., neubearb. Ausg. hg. von Ludwig Finscher. Sachteil Bd. 3. Kassel u. a. 1995, Sp. 964).

924 Livigni/Cherubini: Lo sposo di tre e marito di nessuna. Venedig 1783 (II,5).

925 Brandenburg, S. 159 f. 


\section{SCHLUSSBEMERKUNGEN}

Der Tanz auf der Opernbühne, den Brandenburg „als belebendes szenisches und mu-

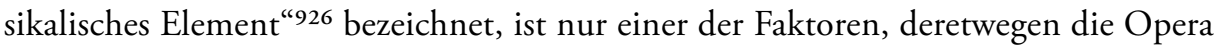
buffa „zu den vitalsten Phänomenen der Musikgeschichte des I8. Jahrhunderts“927 gehört. Dieselbe besondere Lebendigkeit ist auch häufig als typische Eigenschaft des Spiels allgemein definiert worden, nicht zuletzt auch wegen ihrer engen Verbindung mit der vielfach mit dem Spiel assoziierten Bewegung und dem „Bewegungsdrang“, der nach Buytendijk „dem Jugendlichen den Ausdruck der Vitalität, der Aktivität“"928 verleiht, wobei davon ausgegangen wird, ,dass gerade die Jugendzeit die Spielperiode par excellence ist. " ${ }^{29}$ Ebenso beobachtet Jean Château beim Spiel der Kinder einen ausgesprochenen „Elan“, den er auch mit den Begriffen „Lebenslust, vitale Energie oder Daseinsfreude“ 930 umschreibt. „Diesen Elan meint man, wenn man von einem Kind sagt, es stecke voller Leben. "931 Dementsprechend wird das Spiel beispielsweise von Eugen Fink „als verjüngende, lebenserneuernde Kraft" ${ }^{932}$ angesehen und von Gadamer als „Bewegung, die sozusagen ein Phänomen des Überschusses, der Selbstdarstellung des Lebendigseins meint",, 33 bestimmt.

Es liegt folglich nahe zu behaupten, die vitale Qualität und belebende Wirkung der Opera buffa beruhe zum Großteil auf den vielfältigen Elementen des Spiels und des Spielerischen - und somit auch des Tanzes -, die auf verschiedenen Ebenen und in unterschiedlichen Facetten im Inneren der Werke sowie in deren Aufführungskontext eine ausschlaggebende Rolle spielen.

Da mein Anliegen vornehmlich darin bestand, eine möglichst umfassende und differenzierte Betrachtung des Phänomens der Opera buffa anzustreben und zugleich dem Begriff des Spiels als „Begriff mit verschwommenen Rändern“934 gerecht zu werden, wurde in dieser Untersuchung nicht nur die Bevorzugung einer oder weniger Theorien des Spiels vermieden, sondern auch auf eine scharfe Abgrenzung zwischen „eigentlichen“ Spielen und lustbetonten bzw. spielerischen Handlungen sowie zwi-

926 Brandenburg, S. 164.

927 Ebd. S. 173.

928 Buytendijk, S. 28.

929 Groos: Die Spiele der Menschen. S. 4.

930 Vgl. Château, S. 14.

931 Ebd.

932 Fink: Oase des Glücks. S. 5.

933 Gadamer: Die Aktualität des Schönen. S. 30.

934 Wittgenstein: Philosophische Untersuchungen. S. 50. 
schen dem Spiel als konkreter Tätigkeit und als der sich daraus auf einer Metaebene ergebenden Hin- und Herbewegung verzichtet.

Unter Anwendung unterschiedlicher Spieltheorien ergibt sich aus der eingehenden Untersuchung des venezianischen Buffa-Repertoires und seines Aufführungskontexts das Bild einer auf vielen unterschiedlichen Ebenen „von Spiel durchtränkten“ Opernveranstaltung innerhalb eines optimal als „Spielraum“ geeigneten, räumlich und zeitlich abgeschlossenen Rahmens, der einem feierfreudigen, ja geradezu vergnügungssüchtigen Publikum vielfältige Gelegenheiten zum Spiel im weitesten Sinne bot.

Schon das zentrale Ereignis der Opernaufführung an sich, das für einen Großteil des Publikums möglicherweise lediglich einen Anlass zur gesellschaftlichen Zusammenkunft darstellte, vereinigt alle Spielmerkmale, die Theater und Musikaufführungen in sich bergen. Die Fiktivität der dargestellten Handlung sowie die durch die Musik ausgedrückten Emotionen und Stimmungen ermöglichen den Zuschauern ein „spielendes Durchkosten von Lebensmöglichkeiten“935 im Zustand der bewussten Illusion sowie das damit einhergehende „ästhetische Genießen“, das Groos als „die höchste und feinste Form des Spiels“936 bezeichnet. In der Opera buffa als einer komischen Gattung äußert sich dies im Wechselspiel zwischen dem durch die Darstellung einer Handlung und durch die Musik bewirkten „mimetischen Spiel“937 des empathischen „inneren Miterlebens“938 und einer vor allem durch die dramaturgischen Mittel der theatralischen Perspektive bewirkten Distanzierung, die den Zuschauern den Spielcharakter der Theatersituation bewusst macht. Durch diese und weitere unterschiedliche Arten von „Illusionsspielen“ - wie beispielsweise die immer wieder aufs Neue geschürte Hoffnung bei den im Opernhaus üblichen Glücksspielen sowie das bewusste Rollen- bzw. Als-ob-Spiel der konversierenden und flirtenden maskierten Zuschauer - scheint sich eine „zeitweilige Aufhebung der ,gewöhnlichen Welt“"939 einzustellen, die unter anderem den „Spielraum Opernhaus“ gleichsam zum idealen „Biotop“ des homo ludens macht. Bei diesem gesellschaftlichen Ereignis spiegelt sich die im Theatersaal herrschende festlich-heitere Stimmung gewissermaßen im Inhalt der aufgeführten Opern wider, denn die drammi giocosi vermitteln durch ihre leichten, spielerischen Handlungen, ihre Verkleidungs- und Festszenen, ihre Burle, Überraschungen und lieti fini sowie die dazu erklingende lebendige, fröhliche Musik ein besonders leichtes, sorgenlos schwebendes Lebensgefühl, das mit der in Bezug auf

935 Vgl. Groos: Das Spiel. Zit. nach Scheuerl: Theorien des Spiels. S. 72.

936 Scheuerl: Theorien des Spiels. S. 67.

937 Vgl. Rapp: Rolle, Interaktion, Spiel. S. 103.

938 Groos: Das Spiel. Zit. nach Scheuerl: Theorien des Spiels. S. 72.

939 Huizinga, S. 78. 
das Spiel festgestellten „Aufhebung aller Schwere des Lebens, Denkens, Handelns“940 eng zusammenhängt. Nicht nur geben die meisten Buffa-Handlungen die im Zuschauerraum herrschende Feierlaune wieder, indem sie allerlei Vergnügungen und Zeitvertreib auf der Bühne zeigen, wie Karten- und andere Gesellschaftsspiele, Karneval-, Theater- oder Opernszenen, Verkleidungs-Burle, aber auch Feste, insbesondere Hochzeitsfeste, mit Musik und Tanz; vielmehr animieren die dargestellten Gegebenheiten das Publikum zu einer lebensfrohen und spielerischen Haltung, denn in der Regel werden die spiel- und risikobereiten, schlauen, spontanen und quicklebendigen Jugendlichen als "Gewinner", die sich auf ihre Ideen und Absichten versteifenden, habgierigen, autoritären Alten hingegen als „Verlierer“ hingestellt. Die Gewinner weisen meist eine lockere, spielerische Einstellung gegenüber dem Leben auf, einen gewissen Leichtsinn, im Sinne einer „positiven Neigung zu der Gefahr, zum Abenteuer“ sowie der „Bejahung des Leichten, Beweglichen, des Scherzes und der Freude“. ${ }^{941}$ All dem entspricht, dass in jeder Oper raffinierte strategische Burle organisiert oder spontan erfunden sowie auf leichte, spielerische Weise Ehen geschlossen werden, dass die spielerisch mit der drohenden Gefahr umgehenden Frauen in "La forza delle donne“ die kriegerische Strategie der Männer schlagen oder die hohe Spiel- und Risikobereitschaft des zerstreuten Lottospielers und vieler anderen Buffa-Figuren „belohnt“ wird.

Der Aspekt des Jugendlich- bzw. Kindlich-Spielerischen kommt in den BuffaHandlungen unter anderem in den typisch kindlichen Sprach- und Lautspielen, vom Imitieren von Geräuschen und Lauten bis zum phantasievollen Sprachen-Erfinden, sowie auch in regelrechten kindlichen Als-ob-Spielen, wie den genannten Kriegsspielen oder dem fiktiven Flötenspiel auf einem Stock im spontanen Ständchen des Capitano in „Giannina e Bernardone“, zum Vorschein. Ob es sich dabei um Anzeichen rokokohafter Verspieltheit ${ }^{942}$ handelt, sei dahingestellt. Die dabei stets auffallende Umdeutungs- und Imaginationsfreiheit, die auch in den vielen untersuchten Arten von Als-ob-Spielen, von den beliebten Verkleidungs- und Komödien-Spielen bis zu den Imaginations- und Sprachspielen festzustellen ist, weist auf die schon erwähnte spielerische Einstellung der Buffa-Figuren gegenüber dem Leben hin, die Buytendijks Deutung von „Spielen“ als „eine bei allen Tieren und Menschen mögliche Beziehungsform zu Gegenständen“ bzw. „zur Umwelt“943 weitgehend entspricht. Aus einer distanzierteren Zuschauer-Perspektive heraus scheint - abgesehen von der „Spielhaftigkeit" der stark typisierten, beinahe marionettenhaft wirkenden Bühnenfiguren -

940 Ebd.

941 Buytendijk, S. 20.

942 Zum Rokokostil hat Huizinga Folgendes bemerkt: „Als das wesenhafte Kennzeichen dieses Stils ist von alters her die Spielqualität hingestellt worden." (Huizinga, S. 177).

943 Ebd. S. 47 und 160. 
immer wieder die Botschaft durch, dass das Leben ein Spiel sei, bzw. die „Moral“, dass im Leben die geschickten, in jeder Lebenssituation zum Spielen bereiten Personen "gewinnen".

Der in dieser Untersuchung auf den spielerischen Aspekt der Opera buffa als gesamtheitlich betrachtetes Kulturphänomen gelegte Nachdruck soll nicht besagen, dass diese Gattung ernster Facetten entbehrt. Amurs allgemein auf die Komödie bezogene Behauptung - „Der Glaube, ,die Komödie habe es mit der leichteren Seite des Lebens' zu tun, läßt uns häufig die Tatsache übersehen, daß der ,Ernst' nicht aus der Komödie ausgeschlossen ist. “944 - trifft gleichermaßen auch auf die Opera buffa zu. Allein die Tatsache, dass in Buffa-Handlungen neben den reinen parti buffe und den bufficaricati auch parti serie und parti di mezzo carattere auftreten, beweist, dass diese Gattung eine breite Palette an unterschiedlichen Facetten umfasst, die unter anderem die dramaturgische Funktion des chiaro-scuro, der gegenseitigen Hervorhebung durch Kontrastwirkung, ausüben. Bei einer genaueren Betrachtung vieler wegen ihres Spielcharakters angeführten Beispiele kommt außerdem eine für das Spiel typische Ambivalenz zum Vorschein, die die Grenze zwischen Spiel und Ernst häufig sehr labil erscheinen lässt, wie beispielsweise im Falle der Verstellungsspiele der Frascatana, bei denen oft echte oder gespielte Ehrlichkeit und Naivität nicht zu unterscheiden sind, oder im Falle der untersuchten Liebesduette, bei denen auf ausgesprochen spielerische Weise ernste und bindende Ehen geschlossen werden.

Eine gewisse Ambivalenz wohnt auch den als „Höhepunkt des Spielerischen“ bezeichneten Burle inne. Dabei handelt es sich um die vielleicht charakteristischsten Elemente der Opera buffa, die als harmlose spielerisch-strategische Streiche oder einfallsreiche Scherze zwar als Spiel angesehen werden können, aber vom betroffenen "Opfer" aufgrund ihres verbindlichen Ergebnisses ernst genommen und als Betrug oder Bloßstellung empfunden werden.

$\mathrm{Zu}$ einem regelrechten Kippen vom Ernst ins Spiel kommt es beispielsweise in der Oper „Don Anchise Campanone“ durch die wiederholt angewandte Verstellungsbzw. Verheimlichungsstrategie, wobei die beiden innamorati so tun, als wären ihre ernsten Liebeserklärungen nur gespielt. Dieses immer auf einem labilen Gleichgewicht beruhende Schwanken zwischen Fiktion und Realität, Spielwelt und gewöhnlichem Leben, Komik und Ernst ist in der Opera buffa allgegenwärtig. Vor allem die in dieser Gattung häufig auftretenden satirischen und parodistischen Momente beruhen auf diesem „Ins-Komische-Kippen“; Wolfgang Iser definiert sogar das Komische allgemein als „Kipp-Phänomen“. Die Auffassung, dass dieses kaum greifbare, faszinierende Kippen auch als ein charakteristisches Element des Spiels verstanden

944 Amur, S. 282. 
werden kann, wird nicht nur durch Scheuerls Kriterium der „labilen Ambivalenz“ bekräftigt, sondern auch durch Batesons Feststellung, dass die Labilität komplexerer Formen des Spiels nicht so sehr ,auf der Prämisse ,Dies ist ein Spiel' gegründet ist, sondern sich eher um die Frage ,Ist das Spiel?" dreht." 945 Aus demselben Grund stellt Huizinga fest, „der Gegensatz Spiel-Ernst“ bleibe „stets schwebend.“946 In diesem Zusammenhang ist Gadamers These erwähnenswert, laut der als Gegenbegriff zum Spiel weder Ernst noch Arbeit zu verstehen seien, sondern das „Nichtdabeisein “, 947 denn „die echte Erfahrung des Spieles“ sei „das Hineingezogensein “, 948 „dabei sein “949 und „das Miteinandersein“.950 Somit rückt die „verwirrende Unauflösbarkeit des Problems Spiel oder Ernst"951 in den Hintergrund und der Fokus wird auf einen Aspekt des Spiels gelegt, den Gadamer selbst folgendermaßen umschreibt: „Das große Geheimnis des Spiels ist das Einander. Man spielt nie für sich allein. Selbst wenn man für sich alleine spielt, imaginiert man ein Gegenüber. "952 Auffallend ähnlich hatte sich wenige Jahre zuvor Fink geäußert: „Spielen ist Zusammenspiel, ist Miteinanderspielen, eine innige Form der menschlichen Gemeinschaft."953

Der gemeinschaftsstiftende ${ }^{954}$ Charakter, den die beiden letztgenannten Theoretiker dem Spiel und dem Fest ${ }^{955}$ beimessen, wird auch in der gesamten Veranstaltung einer Buffa-Aufführung augenscheinlich. Das besagte „Miteinander“ drückt sich nämlich einerseits in der Opera buffa selbst aus, die von Osthoff als „Gattung der

945 Bateson. In: Uri Rapp: Rolle. Interaktion. Spiel. S. 118.

946 Vgl. Huizinga, S. 16.

947 Jean Grondin: Spiel, Fest und Ritual bei Gadamer. Zum Motiv des Unvordenklichen in seinem Spätwerk. In: Günther G. Bauer (Hg.): Homo ludens. Fest und Spiel. Bd. 8. Internationale Beiträge des Institutes für Spielforschung und Spielpädagogik an der Hochschule „Mozarteum“ Salzburg. München, Salzburg 1998, S. 45.

948 Ebd.

949 Ebd. S. 44.

950 Ebd. S. 45.

951 Huizinga, S. 200.

952 Über den Ernst des Fehlens von Festen. Hans-Georg Gadamer im Gespräch mit Rainer Buland. In: Günther G. Bauer (Hg.): Homo ludens. Fest und Spiel. Bd. 8. Internationale Beiträge des Institutes für Spielforschung und Spielpädagogik an der Hochschule „Mozarteum“ Salzburg. München, Salzburg 1998, S. 23.

953 Fink: Oase des Glücks. S. 30. Finks Begründung für diese Aussage deckt sich beinahe vollständig mit der Gadamers: „Es bedeutet keinen Einwand, wenn man darauf hinweist, daß vielfach doch Spielende ,ganz allein', abseits von anderen Mitmenschen, ihre eigenen Spiele treiben. Denn erstens ist die Offenheit für mögliche Mitspieler im Sinn des Spiels schon eingeschlossen, und zweitens spielt ein solcher Einsamer oft mit imaginären Partnern." (Fink: Oase des Glücks. S. 30).

954 Fink: Oase des Glücks. S. 41.

955 „Das Fest ist Gemeinsamkeit und die Darstellung von Gemeinsamkeit selbst in ihrer vollendeten Form." (Gadamer: Die Aktualität des Schönen. S. 52). 


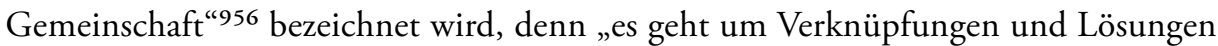
innerhalb der Gemeinschaft." "957 Strohm stellt in diesem Zusammenhang fest, dass „im komischen Musiktheater (...) das Verhältnis von Individuum und Gemeinschaft bewußt gemacht "958 wird. Entscheidend ist dabei, dass am Ende die Gemeinschaft fast immer über die gesellschaftlich Unangepassten, die „Anormalen“ siegt. Musikalisch manifestieren sich diese stark präsente Gemeinschaft sowie das „Zusammenspiel“ oder „Miteinanderspielen“ zwischen ihren Mitgliedern besonders durch die Anwesenheit von Ensembles, vor allem von Finali, die vielleicht das bedeutendste musikalische Charakteristikum der Gattung darstellen und sie in musikalischer Hinsicht von der Opera seria abheben, die von wenigen Schlussakt-Duetten abgesehen grundsätzlich aus einer Reihe von Sologesängen bestand. Andererseits stellt das kollektive, gemeinschaftliche Moment sowohl für die Produktion als auch für die Rezeption einer Oper eine wichtige Voraussetzung dar. Der gesamte Kontext einer Opernaufführung war geradezu durchdrungen von diesem „Miteinander“, das nicht nur die Intensität der Rezeption im Sinne des Miterlebens der Zuschauer verstärkte, sondern auch für viele der maskierten und sich selbst inszenierenden Zuschauer den nahezu wichtigsten Anlass eines Opernbesuchs bildete, denn der gesellschaftliche Aspekt, das „Dabeisein“ stand besonders im Vordergrund. Die Unterhaltung nahm vor dem Hintergrund der galanten Lebensweise der Rokoko-Gesellschaft in der gesellschaftlichen Werteskala einen sehr hohen Stellenwert ein.

Eine soziale, gemeinschaftsstiftende Funktion hatten Theater oder Opernhäuser als zentrale mondäne Vergnügungsstätten selbstverständlich auch bei der Aufführung von ernsten Werken, allerdings spiegelten diese keineswegs die vergnüglich-spielerische Atmosphäre des Aufführungskontexts auf eine ebenso eindrucksvolle Weise wider wie die Opera buffa und eignen sich dementsprechend aufgrund ihrer ernsten Stimmung und ihres „spielarmen“ Inhalts kaum für eine Assoziation mit dem Begriff des Spiels. Ausschlaggebend dafür sind nämlich in erster Linie die heiteren, burlesken, spielhaften bzw. spielerischen Handlungen des dramma giocoso und die darin vermittelte Lebensleichtigkeit sowie das besagte, für diese Operngattung kennzeichnende, eng mit dem Phänomen des Spiels und des Festes verbundene Gemeinschaftsgefühl. Entscheidend für das reizvolle „Spiegelspiel“ zwischen Bühne und Zuschauerraum waren vor allem die auf der Buffa-Bühne gespielten Spiele, ausgeheckten Burle und gefeierten Feste, die Komik und der ergreifende Taumel der Aktschlüsse, durch die dem Publikum Heiterkeit und Ausgelassenheit „vorgelebt“ wurde und die es mit Le-

956 Osthoff: Die Opera buffa. S. 683.

957 Ebd. S. 681.

958 Strohm, S. 249. 
bens- und Spielfreude ansteckten. Es waren höchstwahrscheinlich die unter anderem auf spielhaften und spielerischen Elementen beruhende Unterhaltsamkeit der Opera buffa - Mary Hunter spricht zu Recht von einer der gesamten Gattung zugrunde liegenden "poetics of entertainment" - und die ebenfalls mit dem Spiel verbundene Lebendigkeit der Werke, die ihre außerordentliche Beliebtheit ausgemacht haben müssen, wenn 1773 Giammaria Ortes in einem an Johann Adolph Hasse gerichteten Brief die Opera seria als „stucchevole al maggior segno e tediosa al solito“ beschreibt und im Hinblick auf die Opera buffa behauptet, diese stelle in Venedig die einzige wirklich lebendige theatrale Vergnügungsmöglichkeit dar: „Ciò fa che il solo divertimento teatrale che qui ne resti sia l'opera burlesca in $S$. Moisè, la quale à molto incontro a motivo della musica, ch'è veramente vivace, nuova ed espressiva. “959 Die Frische und Lebendigkeit der in den I770er Jahren vor allem aufgrund ihrer Musik noch immer als „neu“ empfundenen Gattung beruhte wohl nicht zuletzt auf ihrem belebend und unterhaltsam wirkenden, vielschichtigen spielerischen Charakter, der das Publikum nicht nur aufheiterte, sondern es womöglich zum „Spielen“ bzw. zu einer spielerischen Haltung animierte oder sogar in ein reizvolles, zum „Mitspielen“ anregendes "Spiel“ einbezog, was mit Buytendijks Definition - „Spielen ist also nicht nur, dass einer mit etwas spielt, sondern auch, dass etwas mit dem Spieler spielt. "“60 durchaus übereinstimmen würde.

Die Opera buffa, die Wiel als „forma d'arte fresca, vitale, umana“ bezeichnet, deren Ziel besonders im „divertire e muovere al riso"961 bestand, war selbstverständlich kein ausschließlich venezianisches Phänomen. Allerdings wies die in Venedig besonders starke Produktion von Opere buffe im Kontext einer über alle Maßen „spielenden“ und feiernden „Hauptstadt des Vergnügens“ im Vergleich zu anderen italienischen und europäischen Städten einen deutlichen Quantitäts- bzw. Intensitätsunterschied auf, der mit der in Venedig im I8. Jahrhundert herrschenden ökonomisch-politischen Situation in Zusammenhang gebracht werden könnte. Was wenigstens potentiell jedem Feiern, jedem Fest implizit anhaftet, ist der Versuch eines Festhaltens des Vergänglichen, das Feiern des Lebens, wobei zugleich die Negation des Todes mitschwingt. Dazu schreibt in Gadamers Gefolge Jean Grondin: „Ein Fest feiert immer das Bleibende im Vergehenden, aber so, daß beide Momente, sowohl das Bleibende als auch das Vergängliche zugleich mitgedacht werden. (...) Jedem Fest haftet somit ein Bewusstsein der menschlichen Gebrechlichkeit an. Jede Festfreude, ja jede Freude

959 Museo Civico e Raccolta Correr. Mss. Cicogna, Cod. MDXCV (2658) - Let. 235 (2 gennaio 1773). Zit nach Wiel, S. XXXVII.

960 Buytendijk, S. 117.

961 Manfredini, S. 131. 
ist vielleicht die Kehrseite eines Unsagbaren, Unsäglichen."962 Dieser Gedanke könnte generell auf das exzessive Spielen und Feiern in der dem Untergang geweihten Republik Venedig und insbesondere auf den riesigen Erfolg der Opera buffa übertragen werden, der aufgrund der besonderen Lebensfreude und Vitalität der Gattung als Symptom eines aus einer Krisensituation entstandenen Kompensationsbedarfs interpretiert werden könnte. ${ }^{963}$ In dieser Hinsicht könnte vor dem Hintergrund des Spielcharakters der Opera buffa und ihres entsprechenden Aufführungskontexts zur Aufschlüsselung vor allem Groos' Kompensationstheorie als Beschreibungs- und Erklärungsmodell in Frage kommen. Für Gumbrecht scheint aus theaterwissenschaftlicher Sicht selbstverständlich zu sein, dass das Theater, das er auch zu den „institutionalisierten Nischen des Spiels“ zählt, typischerweise zu den „sozialen Orten zum Vollzug“ einer „Kompensationsbewegung“ gehört. ${ }^{964}$

Weitere, aus unterschiedlichen Spieltheorien stammende Aspekte des Spiels könnten ebenfalls auf die venezianische Situation des I 8. Jahrhundert und auf deren verdichtete Spiel-Präsenz bezogen werden. In diesem Sinne könnten Erscheinungen wie beispielsweise eine „zeitweilige Aufhebung der gewöhnlichen Welt“965 bzw. eine Schaffung von parallelen ,zeitweiligen Welten innerhalb der gewöhnlichen Welt“966 festgestellt und als Alltags- und Realitätsflucht verstanden werden. Imbucci bezieht sich zwar ausschließlich auf das Glücksspiel, spricht aber ebenfalls von einer charakteristischen Distanzierung von der Realität, die er aber nicht als Flucht, sondern positiv als Möglichkeit eines besseren Zurechtkommens mit der Realität bewertet: "Col gioco si prende distanza dalla realtà per vivere meglio con essa. Esso è un artificio vitale che compensa frustrazioni sociali. " ${ }^{967}$ Auch in dieser Aussage spielen die Vitalität und der kompensatorische Aspekt des Spiels eine Rolle. Imbuccis Feststellung zum Verhältnis zwischen Ausmaß des Glücksspielphänomens und ökonomischer Krise bzw. Lebendigkeit und Reaktionsfähigkeit der Betroffenen - „Il volume del gioco $(\ldots)$ denunciando in filigrana le crisi economiche, rivela la vitalità e reattività

962 Grondin, S. $48 f$.

963 Der Zusammenhang zwischen Krise und exzessivem Spielbedürfnis ist in vielen verschiedenen historischen Kontexten festgestellt worden. Über die „roaring twenties“ schreibt beispielsweise Reck: „Je stärker die ludischen Exzesse in die verschiedenen sozialen und ökonomischen Sphären eindringen, umso ernster scheint das Leben ebendort geworden zu sein." (Hans Ulrich Reck: Terrain und Entwurf-Zur Bedeutung von Theorien über, Spiel' für Ästhetik und bildende Kunst. In: Kunst und Spiel I. Kunstforum International. Bd. 176 (2005), S. 70).

964 Hans Ulrich Gumbrecht: Anmut und Spiel: Warum man Tanz nicht verstehen muss. In: „Dies ist kein Spiel. "Maske und Kothurn 54/4 (2008), S. 60.

965 Huizinga, S. 20.

966 Ebd. S. 17.

967 Imbucci, S. 90. 
di quell'ambiente." ${ }^{968}$ - könnte ebenfalls auf das Spiel im Allgemeinen und auf die Niedergangszeit der Republik Venedig übertragen werden. Die damals herrschende Spiel- und Vergnügungssucht wäre demnach als eine höchst vitale Reaktion auf die herrschende Untergangsstimmung zu bewerten und somit die besondere Beliebtheit einer lebensbejahenden, leichten und spielerischen Operngattung als eine Form der Realitätsbewältigung, was einer typischen Funktion des Spiels entsprechen würde. ${ }^{969}$

Ähnliche Erklärungen für die besondere Unterhaltungssucht der Venezianer während des Untergangs der Republik führt Benvenuti an, der ihre Vergnügungen als Daseinsweise und einzige Möglichkeit, sich lebendig zu fühlen, bezeichnet: „Il crollo avviene mentre sono accese le luminarie e avviene nel più assoluto disinteresse per ciò che sta accadendo. La Repubblica è morta da molto tempo; le sopravvivono ancora dei piaceri che furono le sue ultime panacee, perché il piacere era diventato il modo di esistere, anzi l'unico modo di essere vivi e presenti. "970 In diesem Zusammenhang kommt das in den erwähnten Vergnügungen anfallende Spiel „als verjüngende, lebenserneuernde Kraft“, ${ }^{971}$ als ein Ergebnis von "Lebenslust, vitaler Energie oder Daseinsfreude“972 zum Tragen, kann allerdings je nach Blickwinkel auch als eine Art Genuss-, Rausch- oder Betäubungsmittel, als Zerstreuung, Alltagsflucht oder Realitätsbewältigung betrachtet werden. Keine der genannten Facetten schließt die anderen vollkommen aus, jede trägt dazu bei, ein vielschichtiges Phänomen möglichst umfassend zu beschreiben.

Festzuhalten ist dabei jedenfalls, dass keine Krise als Anlass erforderlich ist, um Feste zu feiern und Spiele zu spielen. Deren Universalität, die zugleich ein Wesensmerkmal der Opera buffa ${ }^{973}$ als Produkt einer hochentwickelten Spielkultur darstellt, kann eine Erklärung dafür abgeben, dass diese „spieldurchtränkte“ Operngattung nicht nur in Venedig, der spielbesessenen und sich selbst zelebrierenden „Hauptstadt des Vergnügens“, sondern in jedem Opernhaus der Zeit ihre bezaubernde Frische und spielerische Lebendigkeit ausstrahlen und dementsprechend in ganz Europa einen enormen Erfolg haben konnte.

\footnotetext{
968 Ebd. S. 47.

969 Vgl. Groos, Freud, Sutton-Smith, Stepina, u. a.

970 Benvenuti, S. 744.

971 Fink: Oase des Glücks. S. 5.

972 Château, S. 14.

973 „Die opera buffa ist in Venedig entstanden, und sie bildet zusammen mit dem Sprechtheater Goldonis vielleicht den letzten spezifisch venezianischen Beitrag zur europäischen Kultur. Dabei hat sie etwas Universales (nicht unbezeichnend für das venezianische Settecento), indem sie Entwicklungslinien aus verschiedenen Richtungen bündelt." (Strohm, S. 251).
} 


\section{ANHANG}

1. Verzeichnis der untersuchten Werke (Chronologisch nach Datum der venezianischen Aufführung)

1770

BORONI, Antonio; CHIARI, Pietro: Il carnovale.

I77 I

GALUPPI, Baldassarre; BERTATI, Giovanni: L'inimico delle donne. GAZZANIGA, Giuseppe; BERTATI, Giovanni: Calandrano.

PAISIELLO, Giovanni; BERTATI, Giovanni: La locanda.

1772

ASTARITA, Gennaro; Bertati, Giovanni: I visionari.

GALUPPI, Baldassarre; PETROSELLINI, Giuseppe: Gl'intrighi amorosi.

GAZZANIGA, Giuseppe; BERTATI, Giovanni: L'isola d'Alcina.

PICCINNI, Niccolò; PETROSELLINI, Giuseppe: L'astratto o Il giocatore fortunato.

I773

PAISIELLO, Giovanni; BERTATI, Giovanni: Il tamburo notturno.

PAISIELLO, Giovanni; LIVIGNI, Filippo: L'innocente fortunata.

PAISIELLO, Giovanni; LORENZI, Giambattista: Don Anchise Campanone.

I 774

ANFOSSI, Pasquale; BERTATI, Giovanni: Il geloso in cimento.

PAISIELLO, Giovanni; LIVIGNI, Filippo: La frascatana.

I775

ALESSANDRI, Felice; BERTATI, Giovanni: La novità.

ALESSANDRI, Felice; BERTATI, Giovanni: L'Italiano a Parigi.

ANFOSSI, Pasquale; BERTATI, Giovanni: L'avaro.

ANFOSSI, Pasquale; TASSI, Niccolò: La contadina incivilita.

ASTARITA, Gennaro; CALZABIGI, Ranieri de': La critica teatrale.

PAISIELLO, Giovanni; ANON.: La discordia fortunata.

I 776

ANFOSSI, Pasquale; BERTATI, Giovanni: Isabella e Rodrigo o La costanza in amore.

ANFOSSI, Pasquale; PUTTINI, Francesco: La pescatrice fedele.

BERTONI, Ferdinando; CALZABIGI, Ranieri de': Orfeo ed Euridice.

BORGHI, Giovanni Battista; BERTATI, Giovanni: La donna instabile. 
RUST, Giacomo; ANON.: Il Giove di Creta.

SARTI, Giuseppe; GRANDI, Tommaso: Le gelosie villane.

I 777

ANFOSSI, Pasquale; BERTATI, Giovanni (?); PETROSELLINI, Giuseppe (?): Il curioso indiscreto.

ANFOSSI, Pasquale; BERTATI, Giovanni: Lo sposo disperato.

CALEGARI, Giuseppe; PARIATI, Pietro: Il convitato di pietra.

PAISIELLO, Giovanni; PETROSELLINI, Giuseppe: Le due contesse.

I 778

ANFOSSI, Pasquale; BERTATI, Giovanni: La forza delle donne.

ANFOSSI, Pasquale; PETROSELLINI, Giuseppe: L'incognita perseguitata.

GAZZANIGA, Giuseppe; BERTATI, Giovanni: La vendemmia.

SARTI, Giuseppe; PORTA, Nunziato: I contratempi.

TRAETTA, Tommaso; BERTATI, Giovanni: Il cavaliere errante.

I779

ASTARITA, Gennaro; ANON.: Il francese bizzarro.

PICCINNI, Niccolò; ANON.: L'americano.

SACCHINI, Antonio; ANON.: L'isola d'amore.

SALIERI, Antonio; MAZZOLÀ, Caterino: La scuola dé gelosi.

1780

ANFOSSI, Pasquale; LIVIGNI, Filippo: I viaggiatori felici.

CARUSO, Luigi; PALOMBA, Giuseppe: L'albergatrice vivace.

CIMAROSA, Domenico; PETROSELLINI, Giuseppe: Litaliana in Londra.

CIMAROSA, Domenico; PETROSELLINI, Giuseppe (?): Le donne rivali.

RUST, Giacomo; MAZZOLÀ, Caterino: L'isola capricciosa.

I78 I

ANFOSSI, Pasquale; BERTATI, Giovanni: Il matrimonio per inganno.

ANFOSSI, Pasquale; PETROSELLINI, Giuseppe: La finta giardiniera.

CARUSO, Luigi; BERTATI, Giovanni: Il marito geloso.

CIMAROSA, Domenico; LIVIGNI, Filippo: Giannina e Bernardone.

VALENTINI, Giovanni; BERTATI, Giovanni: La statua matematica.

1782

ALESSANDRI, Felice; LIVIGNI, Filippo: La finta principessa.

CIMAROSA, Domenico; LIVIGNI, Filippo: Il convito.

PAISIELLO, Giovanni; BERTATI, Giovanni: I filosofi immaginari.

SARTI, Giuseppe; ANON.: I pretendenti delusi. (= Fra i due litiganti il terzo gode) 
1783

BIANCHI, Francesco; BERTATI, Giovanni: La villanella rapita.

CARUSO, Luigi; PALOMBA, Giuseppe: Il vecchio burlato.

CHERUBINI, Luigi; LIVIGNI, Filippo: Lo sposo di tre e marito di nessuna.

CIMAROSA, Domenico; PETROSELLINI, Giuseppe: Il pittore parigino.

PICCINNI, Niccolò; PETROSELLINI, Giuseppe: Le due finte gemelle. (= Le finte gemelle)

1784

CIMAROSA, Domenico; PALOMBA, Giuseppe: Il falegname.

PAISIELLO, Giovanni; ANON.: Il matrimonio inaspettato.

VALENTINI, Giovanni; LIVIGNI, Filippo: I castellani burlati.

I785

BIANCHI, Francesco; GREPPI, Giovanni (Florimondo Ermioneo): Lo stravagante inglese.

CARUSO, Luigi; BERTATI, Giovanni: Le spose ricuperate.

CIMAROSA, Domenico; ANELLI, Angelo: I due supposti conti.

GAZZANIGA, Giuseppe; BERTATI, Giovanni: Il serraglio di Osmano.

GAZZANIGA, Giuseppe; LIVIGNI, Filippo: La moglie capricciosa.

I786

ANFOSSI, Pasquale; LIVIGNI, Filippo: Le gelosie fortunate.

CARUSO, Luigi; PALOMBA, Giuseppe: Li sposi in commedia.

1787

ANFOSSI, Pasquale; BERTATI, Giovanni: L'orfanella americana.

BERNARDINI, Marcello; ANON.: Li tre Orfei.

GARDI, Francesco; ANON.: Il nuovo convitato di pietra.

GAZZANIGA, Giuseppe; BERTATI, Giovanni: L'amore costante.

GAZZANIGA, Giuseppe; BERTATI, Giovanni: Il capriccio drammatico.

GAZZANIGA, Giuseppe; BERTATI, Giovanni: Il convitato di pietra.

PAISIELLO, Giovanni; PETROSELLINI, Giuseppe: L'inutile precauzione. (= Il barbiere di

Siviglia)

ROBUSCHI, Ferdinando; GREPPI, Giovanni (Florimondo Ermioneo): Castrini padre e figlio.

I 788

GUGLIELMI, Pietro Alessandro; ANON.: L'impostore punito.

GUGLIELMI, Pietro Alessandro; PALOMBA, Giuseppe: Le nozze disturbate.

MARTÍN Y SOLER, Vincente; DA PONTE, Lorenzo: L'arbore di Diana.

MARTÍN Y SOLER, Vincente; DA PONTE, Lorenzo: Bellezza ed onestà. 
1789

MARTÍN Y SOLER, Vincente; DA PONTE, Lorenzo: Il burbero di buon cuore.

PAISIELLO, Giovanni; PALOMBA, Giuseppe: L'amor contrastato.

\section{Alphabetisches Titelverzeichnis der untersuchten Werke}

L'albergatrice vivace (CARUSO, Luigi; PALOMBA, Giuseppe)

L'americano (PICCINNI, Niccolò; ANON.)

L'amor contrastato (PAISIELLO, Giovanni; PALOMBA, Giuseppe)

L'amore costante (GAZZANIGA, Giuseppe; BERTATI, Giovanni)

L'arbore di Diana (MARTÍN Y SOLER, Vincente; DA PONTE, Lorenzo)

L'astratto o Il giocatore fortunato (PICCINNI, Niccolò; PETROSELLINI, Giuseppe)

L'avaro (ANFOSSI, Pasquale; BERTATI, Giovanni)

Bellezza ed onestà (MARTÍN Y SOLER, Vincente; DA PONTE, Lorenzo)

Il burbero di buon cuore (MARTÍN Y SOLER, Vincente; DA PONTE, Lorenzo)

Calandrano (GAZZANIGA, Giuseppe; BERTATI, Giovanni)

Il capriccio drammatico (GAZZANIGA, Giuseppe; BERTATI, Giovanni)

Il carnovale (BORONI, Antonio; CHIARI, Pietro)

I castellani burlati (VALENTINI, Giovanni; LIVIGNI, Filippo)

Castrini padre e figlio (ROBUSCHI, Ferdinando; GREPPI, Giovanni (Florimondo Ermioneo))

Il cavaliere errante (TRAETTA, Tommaso; BERTATI, Giovanni)

La contadina incivilita (ANFOSSI, Pasquale; TASSI, Niccolò)

I contratempi (SARTI, Giuseppe; PORTA, Nunziato)

Il convitato di pietra (CALEGARI, Giuseppe; PARIATI, Pietro)

Il convitato di pietra (GAZZANIGA, Giuseppe; BERTATI, Giovanni)

Il convito (CIMAROSA, Domenico; LIVIGNI, Filippo)

La critica teatrale (ASTARITA, Gennaro; CALZABIGI, Ranieri de')

Il curioso indiscreto (ANFOSSI, Pasquale; BERTATI, Giovanni (?); PETROSELLINI, Giuseppe (?))

La discordia fortunata (PAISIELLO, Giovanni; ANON.)

Don Anchise Campanone (PAISIELLO, Giovanni; LORENZI, Giambattista)

La donna instabile (BORGHI, Giovanni Battista; BERTATI, Giovanni)

Le donne rivali (CIMAROSA, Domenico; PETROSELLINI, Giuseppe (?))

Le due contesse (PAISIELLO, Giovanni; PETROSELLINI, Giuseppe)

Le due finte gemelle (= Le finte gemelle) (PICCINNI, Niccolò; PETROSELLINI, Giuseppe)

I due supposti conti (CIMAROSA, Domenico; ANELLI, Angelo)

Il falegname (CIMAROSA, Domenico; PALOMBA, Giuseppe)

I filosofi immaginari (PAISIELLO, Giovanni; BERTATI, Giovanni)

La finta giardiniera (ANFOSSI, Pasquale; PETROSELLINI, Giuseppe) 
La finta principessa (ALESSANDRI, Felice; LIVIGNI, Filippo)

La forza delle donne (ANFOSSI, Pasquale; BERTATI, Giovanni)

Il francese bizzarro (ASTARITA, Gennaro; ANON.)

La frascatana (PAISIELLO, Giovanni; LIVIGNI, Filippo)

Le gelosie fortunate (ANFOSSI, Pasquale; LIVIGNI, Filippo)

Le gelosie villane (SARTI, Giuseppe; GRANDI, Tommaso)

Il geloso in cimento (ANFOSSI, Pasquale; BERTATI, Giovanni)

Giannina e Bernardone (CIMAROSA, Domenico; LIVIGNI, Filippo)

Il Giove di Creta (RUST, Giacomo; ANON.)

L'impostore punito (GUGLIELMI, Pietro Alessandro; ANON.)

L'incognita perseguitata (ANFOSSI, Pasquale; PETROSELLINI, Giuseppe)

L'inimico delle donne (GALUPPI, Baldassarre; BERTATI, Giovanni)

L'innocente fortunata (PAISIELLO, Giovanni; LIVIGNI, Filippo)

Gl'intrighi amorosi (GALUPPI, Baldassarre; PETROSELLINI, Giuseppe)

L'inutile precauzione (= Il barbiere di Siviglia) (PAISIELLO, Giovanni; PETROSELLINI,

Giuseppe)

Isabella e Rodrigo o La costanza in amore (ANFOSSI, Pasquale; BERTATI, Giovanni)

L'isola capricciosa (RUST, Giacomo; MAZZOLÀ, Caterino)

L'isola d'Alcina (GAZZANIGA, Giuseppe; BERTATI, Giovanni)

Lisola d'amore (SACCHINI, Antonio; ANON.)

L'italiana in Londra (CIMAROSA, Domenico; PETROSELLINI, Giuseppe)

L'Italiano a Parigi (ALESSANDRI, Felice; BERTATI, Giovanni)

La locanda (PAISIELLO, Giovanni; BERTATI, Giovanni)

Il marito geloso (CARUSO, Luigi; BERTATI, Giovanni)

Il matrimonio inaspettato (PAISIELLO, Giovanni; ANON.)

Il matrimonio per inganno (ANFOSSI, Pasquale; BERTATI, Giovanni)

La moglie capricciosa (GAZZANIGA, Giuseppe; LIVIGNI, Filippo)

La novità (ALESSANDRI, Felice; BERTATI, Giovanni)

Le nozze disturbate (GUGLIELMI, Pietro Alessandro; PALOMBA, Giuseppe)

Il nuovo convitato di pietra (GARDI, Francesco; ANON.)

L'orfanella americana (ANFOSSI, Pasquale; BERTATI, Giovanni)

Orfeo ed Euridice (BERTONI, Ferdinando; CALZABIGI, Ranieri de')

La pescatrice fedele (ANFOSSI, Pasquale; PUTTINI, Francesco)

Il pittore parigino (CIMAROSA, Domenico; PETROSELLINI, Giuseppe)

I pretendenti delusi (= Fra i due litiganti il terzo gode) (SARTI, Giuseppe; ANON.)

La scola dé gelosi (SALIERI, Antonio; MAZZOLÀ, Caterino)

Il serraglio di Osmano (GAZZANIGA, Giuseppe; BERTATI, Giovanni)

Le spose ricuperate (CARUSO, Luigi; BERTATI, Giovanni)

Li sposi in commedia (CARUSO, Luigi; PALOMBA, Giuseppe)

Lo sposo disperato (ANFOSSI, Pasquale; BERTATI, Giovanni)

Lo sposo di tre e marito di nessuna (CHERUBINI, Luigi; LIVIGNI, Filippo) 
La statua matematica (VALENTINI, Giovanni; BERTATI, Giovanni)

Lo stravagante inglese (BIANCHI, Francesco; GREPPI, Giovanni (Florimondo Ermioneo)

Il tamburo notturno (PAISIELLO, Giovanni; BERTATI, Giovanni)

Li tre Orfei (BERNARDINI, Marcello; ANON.)

Il vecchio burlato (CARUSO, Luigi; PALOMBA, Giuseppe)

La vendemmia (GAZZANIGA, Giuseppe; BERTATI, Giovanni)

I viaggiatori felici (ANFOSSI, Pasquale; LIVIGNI, Filippo)

La villanella rapita (BIANCHI, Francesco; BERTATI, Giovanni)

I visionari (ASTARITA, Gennaro; Bertati, Giovanni) 


\title{
BibLIOGRAPHIE
}

\author{
i. Primärliteratur
}

I.I Libretti

ANELLI, Angelo: I due supposti conti. Venezia 1785

ANON.: L'americano. Venezia 1779

ANON.: La discordia fortunata. Venezia I775

ANON.: Il francese bizzarro. Venezia 1779

ANON.: Il Giove di Creta. Venezia 1776

ANON.: L'impostore punito. Venezia I 788

ANON.: L'isola d'amore. Venezia I779

ANON.: Il matrimonio inaspettato. Venezia 1784

ANON.: Il nuovo convitato di pietra. Venezia 1787

ANON.: I pretendenti delusi. Venezia 1782

ANON.: Li tre Orfei. Venezia 1787

BERTATI, Giovanni: L'avaro. Venezia 1775

BERTATI, Giovanni: Calandrano. Venezia I77I

BERTATI, Giovanni: La locanda. Venezia I77 I

BERTATI, Giovanni: L'inimico delle donne. Venezia I77 I

BERTATI, Giovanni: L'isola d'Alcina. Venezia 1772

BERTATI, Giovanni: I visionari. Venezia 1772

BERTATI, Giovanni: L'inimico delle donne. Venezia I773

BERTATI, Giovanni: Il tamburo notturno. Venezia I773

BERTATI, Giovanni: Il geloso in cimento. Venezia 1774

BERTATI, Giovanni: L'Italiano a Parigi. Venezia 1775

BERTATI, Giovanni: La novità. Venezia I775

BERTATI, Giovanni: Isabella e Rodrigo o La costanza in amore. Venezia 1776

BERTATI, Giovanni (?); PETROSELLINI, Giuseppe (?): Il curioso indiscreto. Venezia I777

BERTATI, Giovanni: Lo sposo disperato. Venezia I 777

BERTATI, Giovanni: L'avaro. Venezia 1778

BERTATI, Giovanni: Il cavaliere errante. Venezia 1778

BERTATI, Giovanni: La forza delle donne. Venezia 1778

BERTATI, Giovanni: La vendemmia. Venezia 1778

BERTATI, Giovanni: L'inimico delle donne. Venezia 1779

BERTATI, Giovanni: Il marito geloso. Venezia I78 I

BERTATI, Giovanni: Il matrimonio per inganno. Venezia $178 \mathrm{I}$

BERTATI, Giovanni: La statua matematica. Venezia $178 \mathrm{I}$

BERTATI, Giovanni: I filosofi immaginari. Venezia 1782 
BERTATI, Giovanni: La villanella rapita. Venezia 1783

BERTATI, Giovanni: Il geloso in cimento. Venezia 1784

BERTATI, Giovanni: Il serraglio di Osmano. Venezia 1785

BERTATI, Giovanni: Le spose ricuperate. Venezia I 785

BERTATI, Giovanni: L'amore costante. Venezia I 787

BERTATI, Giovanni: Il capriccio drammatico. Venezia 1787

BERTATI, Giovanni: Il convitato di pietra. Venezia 1787

BERTATI, Giovanni: L'orfanella americana. Venezia 1787

BERTATI, Giovanni: La donna instabile. Venezia I 776

CALZABIGI, Ranieri de': La critica teatrale. Venezia I 775

CALZABIGI, Ranieri de': Orfeo ed Euridice. Venezia 1776

CHIARI, Pietro: Il carnovale. Venezia I770

DA PONTE, Lorenzo: L'arbore di Diana. Venezia I 788

DA PONTE, Lorenzo: Bellezza ed onestà. Venezia I 788

DA PONTE, Lorenzo: Il burbero di buon cuore. Venezia 1789

GRANDI, Tommaso: Le gelosie villane. Venezia 1776

GREPPI, Giovanni (Florimondo Ermioneo): Lo stravagante inglese. Venezia 1785

GREPPI, Giovanni (Florimondo Ermioneo): Castrini padre e figlio. Venezia 1787

LIVIGNI, Filippo: L'innocente fortunata. Venezia I773

LIVIGNI, Filippo: La frascatana. Venezia I774

LIVIGNI, Filippo: I viaggiatori felici. Venezia 1780

LIVIGNI, Filippo: Giannina e Bernardone. Venezia I78 I

LIVIGNI, Filippo: La finta principessa. Venezia I 782

LIVIGNI, Filippo: La frascatana. Venezia 1782

LIVIGNI, Filippo: Il convito. Venezia I 782

LIVIGNI, Filippo: Lo sposo di tre e marito di nessuna. Venezia 1783

LIVIGNI, Filippo: I castellani burlati. Venezia I 784

LIVIGNI, Filippo: La moglie capricciosa. Venezia 1785

LIVIGNI, Filippo: Le gelosie fortunate. Venezia 1786

LIVIGNI, Filippo: Il villano geloso. Venezia I 786

LORENZI, Giambattista: Don Anchise Campanone. Venezia 1773

MAZZOLÀ, Caterino: La scola dé gelosi. Venezia 1779

MAZZOLÀ, Caterino: L'isola capricciosa. Venezia 1780

MAZZOLÀ, Caterino: La scuola de gelosi. Venezia 1783

PALOMBA, Giuseppe: L'albergatrice vivace. Venezia 1780

PALOMBA, Giuseppe: L'amor contrastato. Venezia 1789

PALOMBA, Giuseppe: Il falegname. Venezia I 784

PALOMBA, Giuseppe: Le nozze disturbate. Venezia 1788

PALOMBA, Giuseppe: Li sposi in commedia. Venezia 1786

PALOMBA, Giuseppe: Il vecchio burlato. Venezia I 783

PARIATI, Pietro: Il convitato di pietra. Venezia I 777 
PETROSELLINI, Giuseppe: L'astratto o Il giocatore fortunato. Venezia 1772

PETROSELLINI, Giuseppe: Gl'intrighi amorosi. Venezia 1772

PETROSELLINI, Giuseppe: Le due contesse. Venezia I 777

PETROSELLINI, Giuseppe: L'incognita perseguitata. Venezia I 778

PETROSELLINI, Giuseppe: La finta giardiniera. Venezia I78 I

PETROSELLINI, Giuseppe: L'italiana in Londra. Venezia 1780

PETROSELLINI, Giuseppe (?): Le donne rivali. Venezia I 780

PETROSELLINI, Giuseppe: Le due finte gemelle. Venezia 1783 (= Le finte gemelle)

PETROSELLINI, Giuseppe: Il pittore parigino. Venezia 1783

PETROSELLINI, Giuseppe: L'inutile precauzione. Venezia 1787

PORTA, Nunziato: I contratempi. Venezia I778

PUTTINI, Francesco: La pescatrice fedele. Venezia I 776

PUTTINI, Francesco: La pescatrice fedele o La vera costanza. Venezia 1783

TASSI, Niccolò: La contadina incivilita. Venezia I775

\section{I.2 Partituren}

ALESSANDRI, Felice; LIVIGNI, Filippo: La finta principessa. (I-Mc Part. Tr. Ms. 6I)

ALESSANDRI, Felice; BERTATI, Giovanni: Litaliano a Parigi. Venezia 1775 (I-Mc Part. Tr. Ms. 2)

ALESSANDRI, Felice; BERTATI, Giovanni: La novità. Venezia I775 (I-Mc Part. Tr. Ms. 2) ANFOSSI, Pasquale; BERTATI, Giovanni: L'avaro. Venezia i775 (F-Pn D ro5-106)

ANFOSSI, Pasquale; TASSI, Niccolò: La contadina incivilita. Venezia I 775 (F-Pn D Io8-I09)

ANFOSSI, Pasquale; BERTATI, Giovanni (?); PETROSELLINI, Giuseppe (?): Il curioso indiscreto. (F-Pn D I I 5-I I6)

ANFOSSI, Pasquale; PETROSELLINI, Giuseppe: La finta giardiniera. I774 (I-Mc Part. Tr. Ms. 4)

ANFOSSI, Pasquale; BERTATI, Giovanni: La forza delle donne. 1778 (I-BGc C.2.23/I-2)

ANFOSSI, Pasquale; LIVIGNI, Filippo: Le gelosie fortunate. (F-Pn MS 1974 (I-2))

ANFOSSI, Pasquale; BERTATI, Giovanni: Il geloso in cimento. Venezia I774 (I-Gi B.7.7/8 (C.7.13/14))

ANFOSSI, Pasquale; PETROSELLINI, Giuseppe: L'incognita perseguitata. 1773 (I-Mc Part. Tr. Ms. 5)

ANFOSSI, Pasquale; BERTATI, Giovanni: Isabella e Rodrigo o La costanza in amore. 1776 (I-Mc Part. Tr. Ms. 3)

ANFOSSI, Pasquale; BERTATI, Giovanni: Il matrimonio per inganno. (F-Pn D I34-I 35)

ANFOSSI, Pasquale; BERTATI, Giovanni: L'orfanella americana. Venezia I790 (I-Gi B.7.I 3. (L.8.2)

ANFOSSI, Pasquale; BERTATI, Giovanni: Lo sposo disperato. Venezia I 778 (F-Pn D 205-206)

ANFOSSI, Pasquale; PUTTINI, Francesco: La vera costanza. (F-Pn D 208-209) (= La pescatrice fedele) 
ANFOSSI, Pasquale; LIVIGNI, Filippo: I viaggiatori felici. (F-Pn D 2 I $0-2$ I I-2 I 2-2 I 3 )

BERNARDINI, Marcello; ANON.: Li tre Orfei. (I-Mc Part. Tr. Ms. 322bis)

BERTONI, Ferdinando; CALZABIGI, Ranieri de' : Orfeo ed Euridice. (I-Mc Part. Tr. Ms. 23)

BIANCHI, Francesco; GREPPI, Giovanni (Florimondo Ermioneo): Lo stravagante inglese. (I-Bz,Toggenburg C/IV,I)

BIANCHI, Francesco; BERTATI, Giovanni: La villanella rapita. I784 (I-Tf)

BORGHI, Giovanni Battista; ANON.: La donna instabile. Venezia 1776 (F-Pn D I388I3899)

CALEGARI, Giuseppe; PARIATI, Pietro: Il convitato di pietra. Venezia I777 (F-Pn D I793)

CARUSO, Luigi; PALOMBA, Giuseppe: L'albergatrice vivace. (F-Pn D I 859-I 860)

CARUSO, Luigi; BERTATI, Giovanni: Il marito geloso. (I-Tf)

CARUSO, Luigi; PALOMBA, Giuseppe: Il matrimonio in commedia. (F-Pn D I865-1866)

CARUSO, Luigi; BERTATI, Giovanni: Le spose ricuperate. (F-Pn D I87I-I872)

CARUSO, Luigi; PALOMBA, Giuseppe: Il vecchio burlato. Venezia 1783 (F-Pn D 1873-1874)

CHERUBINI, Luigi; LIVIGNI, Filippo: Lo sposo di tre e marito di nessuna. Venezia I 783 (F-Pn D 2022-2023)

CIMAROSA, Domenico; LIVIGNI, Filippo: Il Convito. Venezia I782 (I-OS Mss. Mus. B 95/I-2)

CIMAROSA, Domenico; PETROSELLINI, Giuseppe (?): Le donne rivali. (I-Mc Part. Tr. Ms. 69)

CIMAROSA, Domenico; ANELLI, Angelo: I due supposti conti. (F-Pn D 2 I03-2 I04)

CIMAROSA, Domenico; PALOMBA, Giuseppe: Il falegname. I780 (I-R,Massimo)

CIMAROSA, Domenico; LIVIGNI, Filippo: Giannina e Bernardone. (I-Mc Noseda E. I/I-II)

CIMAROSA, Domenico; PETROSELLINI, Giuseppe: L'italiana in Londra. (I-Rsc G. Mss. 609-6Iо)

CIMAROSA, Domenico; PETROSELLINI, Giuseppe: Il pittor parigino. (I-Gi B.7b.37 (M.7.I0))

GALUPPI, Baldassarre; BERTATI, Giovanni: Linimico delle donne. (Faksimile) Hg. von Helen Geyer-Kiefl. Milano I 986 (Drammaturgia musicale veneta 2I)

GALUPPI, Baldassarre; PETROSELLINI, Giuseppe: Gl'intrighi amorosi. (B-Bc)

GARDI, Francesco; ANON.: Il convitato. Venezia I 787 (I-Bc FF 92)

GAZZANIGA, Giuseppe; BERTATI, Giovanni: L'amore costante. (F-Pn D 4373)

GAZZANIGA, Giuseppe; BERTATI, Giovanni: Calandrano. Venezia I77I (F-Pn D 43764377)

GAZZANIGA, Giuseppe; BERTATI, Giovanni: Don Giovanni o sia Il convitato di pietra. Hg. von Stefan Kunze. Kassel u. a. I974

GAZZANIGA, Giuseppe; BERTATI, Giovanni: L'isola d'Alcina. (A-Wn Mus. Hs. I7777)

GAZZANIGA, Giuseppe; LIVIGNI, Filippo: La moglie capricciosa. (I-Gi M.6.23/24 (M.8.5/6))

GAZZANIGA, Giuseppe; BERTATI, Giovanni: Il serraglio di Osmano. Venezia I78 5 (F-Pn D 4386-4387) 
GAZZANIGA, Giuseppe; BERTATI, Giovanni: La vendemmia. (F-Pn D 4388-4389)

GUGLIELMI, Pietro Alessandro; PALOMBA, Giuseppe: Le due gemelle. (I-Gi B.6b.28 $(\mathrm{M.8.3}))$ (= Le nozze disturbate)

GUGLIELMI, Pietro Alessandro; ANON.: Limpostore punito. (I-Gi B.6b.3 I/32 (M.7.2 I/22))

MARTÍN Y SOLER, Vincente; DA PONTE, Lorenzo: L'arbore di Diana. (I-Gi B.5.19/20 $(\mathrm{L} .8 .6 / 7))$

MARTÍN Y SOLER, Vincente; DA PONTE, Lorenzo: Bellezza ed onestà. I786 (I-Mc Part. Tr. Ms. 203)

MARTÍN Y SOLER, Vincente; DA PONTE, Lorenzo: Il burbero di buon cuore. Hg. von Leonardo J. Waisman. Madrid 2003

PAISIELLO, Giovanni; PALOMBA, Giuseppe: L'amor contrastato. (I-Mc Noseda G 39/I-II)

PAISIELLO, Giovanni; PETROSELLINI, Giuseppe: Il barbiere di Siviglia. (I-Mc Part. Tr. Ms. 300) (= L'inutile precauzione)

PAISIELLO, Giovanni; LORENZI, Giambattista: Gli amanti comici o sia Don Anchise Campanone. (I-Nc I6.8.I-2)

PAISIELLO, Giovanni; ANON.: La discordia fortunata. (I-Mc Part. Tr. Ms. 2)

PAISIELLO, Giovanni; PETROSELLINI, Giuseppe: Le due contesse. 1786 (I-OS Mss. Mus. B $63 / \mathrm{I}-2)$

PAISIELLO, Giovanni; BERTATI, Giovanni: I filosofi immaginari. (I-Pi ATVa 6o/I-II)

PAISIELLO, Giovanni; LIVIGNI, Filippo: La frascatana. (I-Mc Part. Tr. Ms. 308)

PAISIELLO, Giovanni; LIVIGNI, Filippo: L'innocente fortunata. Venezia I773 (I-Fc D. I. $464-465-466)$

PAISIELLO, Giovanni; BERTATI, Giovanni: La locanda. (F-Pn D- 4383-4384)

PAISIELLO, Giovanni; ANON.: Il matrimonio inaspettato. (I-Mc Part. Tr. Ms. 297)

PAISIELLO, Giovanni; BERTATI, Giovanni: Il tamburo notturno. (I-Nc Rari 3.4.27-28)

PICCINNI, Niccolò; ANON.: L'americano. (A-Wn Mus. Hs. I7825)

PICCINNI, Niccolò; PETROSELLINI, Giuseppe: L'astratto o Il giocatore fortunato. (F-Pn MS. 2372)

PICCINNI, Niccolò; PETROSELLINI, Giuseppe: Le finte gemelle. (A-Wn Mus. Hs. I7828) ROBUSCHI, Ferdinando; GREPPI, Giovanni (Florimondo Ermioneo): Castrini padre e figlio.

(I-PAc Borb.3045.i/I-II)

RUST, Giacomo; ANON.: Il Giove di Creta. (I-Gi B.4.19/20 (L.7.9/10))

RUST, Giacomo; MAZZOLÀ, Caterino: L'isola capricciosa. (I-Rsc G. Mss. 0485)

SACCHINI, Antonio; ANON.: L'isola d'amore. I 766 (I-Mc Part. Tr. Ms. 39I)

SALIERI, Antonio; MAZZOLÀ, Caterino: La scuola dé gelosi. Venezia I778 (A-Wn Mus. Hs. I6615)

SARTI, Giuseppe; PORTA, Nunziato: I contratempi. (A-Wn KT. 93)

SARTI, Giuseppe; ANON.: Fra i due litiganti il terzo gode. I782 (I-Tf) (= Ipretendenti delusi)

SARTI, Giuseppe; GRANDI, Tommaso: Le gelosie villane. (I-Pi ATVa 28/I-II)

TRAETTA, Tommaso; BERTATI, Giovanni: Il cavaliere errante. I778 (I-Mc Part. Tr. Ms. 4I9) 
VALENTINI, Giovanni; LIVIGNI, Filippo: I castellani burlati. (I-Gi B.3.27/28 (C.7.20/2 I)) VALENTINI, Giovanni; BERTATI, Giovanni: La statua matematica. (I-Tf)

\section{SEKundërLiteratur}

ABERT, Hermann: Paisiellos Buffokunst und ihre Beziehung zu Mozart. In: BLUME, Friedrich (Hg.): Gesammelte Schriften und Vorträge von Hermann Abert. Halle I929, S. 365-96

ABERT, Hermann: Piccinni als Buffokomponist. In: BLUME, Friedrich (Hg.): Gesammelte Schriften und Vorträge von Hermann Abert. Halle I 929, S. 346-364

AGAWU, Kofi V.: Playing with signs. Princeton I991

ALBERTI, Luciano: Note per la riproposta di una sintomatica opera buffa: ,Il convitato di pietra di Gazzaniga. In: Chigiana 29-30, Nr. 9-10, 1975, S. I 8 5-1 87

ALGAROTTI, Francesco: Saggio sopra l'opera in musica. Venezia 1755

ALLANBROOK, Wye J.: Rhythmic Gesture in Mozart's „Le nozze di Figaro“ \& „Don Giovanni“. Chicago 1983

AMUR, Gururaja S.: Der Geist der Komödie. In: GRIMM, Reinhold; BERGHAHN, Klaus L. (Hg.): Wesen und Formen des Komischen im Drama. Darmstadt I975, S. 272-302

ANGELINI, Franca: „In maschera voi siete / Senza maschera in volto?" Le regole del gioco teatrale nei primi intermezzi goldoniani (1730-36). In: Studi goldoniani 6 (I982), S. I I 4-I 27

ANZ, Thomas: Literatur und Lust. Glück und Unglück beim Lesen. München 1998

ANZ, Thomas; KAULEN, Heinrich (Hg.) : Literatur als Spiel. Evolutionsbiologische, ästhetische und pädagogische Konzepte. Berlin 2009

ARTEAGA, Stefano: Le rivoluzioni del teatro musicale italiano dalla sua origine fino al presente. Venezia 1785

AVEDON, Elliot M.; SUTTON-SMITH, Brian (Hg.): The study of games. New York I 97 I

BACHTIN, Michail: Rabelais und seine Welt. (1965). Hg. und mit einem Vorwort versehen von Renate Lachmann. Frankfurt am Main 1987

BARNETT, Dene: Die Schauspielkunst in der Oper des I8. Jahrhunderts. In: Hamburger Jahrbuch für Musikwissenschaft. 3, I978, S. 289-304

BATESON, Gregory: Eine Theorie des Spiels und der Phantasie (1955). In: RAPP, Uri: Rolle. Interaktion. Spiel. Eine Einführung in die Theatersoziologie. Wien, Köln, Weimar 1993, S. $113-122$

BAUER, Günther G. (Hg.): Homo ludens. Der spielende Mensch. Bd. I. Internationale Beiträge des Institutes für Spielforschung und Spielpädagogik an der Hochschule „Mozarteum“ Salzburg. München, Salzburg I99 I

BAUER, Günther G. (Hg.): Homo ludens. Lotto und Lotterie. Bd. 7. Internationale Beiträge des Institutes für Spielforschung und Spielpädagogik an der Hochschule „Mozarteum“ Salzburg. München, Salzburg 1997

BAUER, Günther G. (Hg.) : Homo ludens. Fest und Spiel. Bd. 8. Internationale Beiträge des Institutes für Spielforschung und Spielpädagogik an der Hochschule „Mozarteum“ Salzburg. 
München, Salzburg 1998

BAUER, Günther G. (Hg.): Homo ludens. Musik und Spiel. Bd. Io. Internationale Beiträge des Institutes für Spielforschung und Spielpädagogik an der Hochschule „Mozarteum“ Salzburg. München, Salzburg 2000

BELLINA, Anna Laura: Cenni sulla presenza della commedia dell'arte nel libretto comico settecentesco. In: MURARO, Maria Teresa (Hg.): Venezia e il melodramma nel settecento. Bd. I. Firenze 1978 (Studi di musica veneta 6), S. I 3 I-I 47

BENISCELLI, Alberto: Naturale e artificiale in scena nel secondo settecento. Roma 1997

BENVENUTI, Feliciano: La città dei "piaseri“. In: DEL NEGRO, Piero; PRETO, Paolo

(Hg.): Storia di Venezia. Dalle origini alla caduta della Serenissima. Bd. 8. Roma I998, S. $705-744$

BERENGO, Marino: La società veneta alla fine del settecento. Firenze 1956

BERENGO, Marino: Il problema politico-sociale di Venezia e della sua terraferma. In: BRANCA, Vittore (Hg.): Storia della civiltà veneziana. Bd. 6. La civiltà veneziana del Settecento. Firenze I 960

BIANCONI, Lorenzo (Hg.) : La drammaturgia musicale. Bologna 1986

BIANCONI, Lorenzo: Il teatro d'opera in Italia. Bologna I993

BILSTEIN, Johannes: Spiel-Glück und Glücks-Spiele. In: KRUSCHKOVA, Krassimira; BÖHLER, Arno: Dies ist kein Spiel. Maske und Kothurn 54/4 (2008), S. 63-79

BLANCHETTI, Francesco: Tipologia musicale dei concertati nell'opera buffa di Giovanni Paisiello. In: RIM I9 I984, S. 234-60

BRANDENBURG, Daniel: $Z u$ Tanz-und Bewegungsphänomenen in der Opera buffa des I8. Jahrhunderts. In: DAHMS, Sibylle; SCHROETER, Stephanie (Hg.): Tanz und Bewegung in der barocken Oper. Kongressbericht Salzburg I994. Innsbruck, Wien 1996 (Derra de Moroda Dance Archives 3), S. I 59-I73

BROWN, John: Letters upon the Poetry and Music of the Italian Opera adressed to a Friend. Edinburgh 1789

BUCHHART, Dieter; FUCHS, Mathias (Hg.): Kunst und Spiel I. In: Kunstforum International. Bd. I76 (2005)

BULAND, Rainer: Die Einteilung der Spiele nach ihren Freiheitsaspekten. In: BAUER, Günther G. (Hg.) : Homo ludens. Lotto und Lotterie. Bd. 7. Internationale Beiträge des Institutes für Spielforschung und Spielpädagogik an der Hochschule „Mozarteum“ Salzburg. München, Salzburg I997, S. 259-280

BULAND, Rainer: Fest-Spiel-Frieden. Zusammenhänge und Wesenszüge. In: BAUER, Günther G. (Hg.): Homo ludens. Fest und Spiel. Bd. 8. Internationale Beiträge des Institutes für Spielforschung und Spielpädagogik an der Hochschule „Mozarteum“ Salzburg. München, Salzburg I998, S. 249-260

BURNEY, Charles: The Present State of Music in France and Italy. A facsimile of the 1773 London edition. New York 1969

BUSTICO, Guido: Venezia e i melodrammi di Carlo Goldoni. In: Pagine libere: Rivista quindicinale di Politica, Scienza ed Arte, anno V, I 5 gennaio i9 I I, S. 88-92 
BUYTENDIJK, Frederik Jacobus Johannes: Wesen und Sinn des Spiels. Das Spielen des Menschen und der Tiere als Erscheinungsform der Lebenstriebe. Berlin 1933

CAILLOIS, Roger: Die Spiele und die Menschen. Maske und Rausch. Stuttgart 1960

CAPLIN, William E.: On the Relation of Musical Topoi to Formal Function. In: EighteenCentury Music 2/I (2005), S. I I3-I 24

CAPONE, Stefano: Piccinni e l'opera buffa: modelli e varianti di un genere alla moda. Foggia 2002

CHÂTEAU, Jean: Spiele des Kindes. Stuttgart 1974

CICALI, Gianni: Attori e ruoli nell'opera buffa italiana del settecento. Firenze 2005

COLOZZA, Giovanni Antonio: Psychologie und Pädagogik des Kinderspiels. Altenburg I 900

COMISSO, Giovanni (Hg.): Agenti segreti di Venezia I707-1797. Milano I94I

DA PONTE, Lorenzo: Memorie. Libretti mozartiani. Milano I99I

DELLA CORTE, Andrea: Paisiello. Torino 1922

DELLA CORTE, Andrea: L'opera comica italiana nel '70o. Bari 1923

DELLA CORTE, Andrea: Piccinni (settecento italiano). Con frammenti musicali inediti e due ritratti. Bari 1928

DEL NEGRO, Piero; PRETO, Paolo (Hg.): Storia di Venezia. Dalle origini alla caduta della Serenissima. Bd. 8. Roma 1998

DE NATALE, Marco: La Musica come Gioco. Il dentro e il fuori della Teoria. Bern 2004

DENT, Edward J.: Ensembles and Finales in I8th Century Italian Opera. (part I) SIMG I I ( I 909-10), S. 543-69, (part II) I 2 (I910-I I), S. I I 2-38

EGGEBRECHT, Hans Heinrich: Der Begriff des Komischen in der Musikästhetik des I8. Jahrhunderts. Mf 4 , I95 I, S. I44-I 52

EIGEN, Manfred; WINKLER, Ruthild: Das Spiel. Naturgesetze steuern den Zufall. München I975

EMERY, Ted: Goldoni as librettist: Theatrical Reform and the Drammi Giocosi per Musica. New York I99I

FELDMAN, Martha: Magic Mirrors and the Seria Stage. Thoughts toward a Ritual View. In: Journal of the American Musicological Society 48 (I995), S. 423-484

FELDMAN, Martha: Opera and Sovereignty. Chicago 2007

FERRONI, Giulio: L'opera in commedia. Una immagine del melodramma nella cultura veneziana del settecento. In: MURARO, Maria Teresa (Hg.): Venezia e il melodramma nel settecento. Bd. I. Firenze 1978 (Studi di musica veneta 6), S. 63-78

FIDO, Franco: Guida a Goldoni. Teatro e società nel Settecento. Torino 1977

FIDO, Franco: La serietà del gioco. Svaghi letterari e teatrali nel Settecento. Lucca 1998

FIGDOR, Helmuth: Die Gefühle und das Musizieren: Musik als überlebendes Symbolsystem sensomotorischen Erlebens. In: FIGDOR, Helmuth; RÖBKE Peter: Das Musizieren und die Gefühle. Instrumentalpädagogik und Psychoanalyse im Dialog. Mainz 2008, S. I I 4-1 49

FINK, Eugen: Oase des Glücks. Gedanken zu einer Ontologie des Spiels. Freiburg, München 1957 FINK, Eugen: Spiel als Weltsymbol. Stuttgart I960

FIORIN, Alberto: Nascita e sviluppo delle lotterie a Venezia. In: BAUER, Günther G. (Hg.): Homo ludens. Lotto und Lotterie. Bd. 7. Internationale Beiträge des Institutes für Spielfor- 
schung und Spielpädagogik an der Hochschule „Mozarteum“ Salzburg. München, Salzburg I997, S. IOI-I 25

FISCHER-LICHTE, Erika: Semiotik des Theaters. Bd. I. Das System der theatralischen Zeichen. Tübingen 1983

FISCHER-LICHTE, Erika; WULF, Christoph (Hg.): Theorien des Performativen. Berlin $200 \mathrm{I}$ FOLENA, Gianfranco: Goldoni librettista comico. In: MURARO, Maria Teresa (Hg.) : Venezia e il melodramma nel settecento. Bd. 2. Firenze I98 I (Studi di musica veneta 7), S. 2 I-32

FOLENA, Gianfranco: Litaliano in Europa. Esperienze linguistiche del Settecento. Torino 1983

FRÖBEL, Friedrich Wilhelm August: Die Menschenerziehung, die Erziehungs-, Unterrichtsund Lehrkunst, angestrebt in der allgemeinen deutschen Erziehungsanstalt zu Keilhau. Bd. I. Leipzig I 826

FUCHS, Mathias; STROUHAL, Ernst (Hg.): Das Spiel und seine Grenzen. Wien, New York 2010

GADAMER, Hans-Georg: Wahrheit und Methode. Grundzüge einer philosophischen Hermeneutik. Tübingen 1960

GADAMER, Hans-Georg: Die Aktualität des Schönen. Stuttgart 1977

GALEAZZI, Francesco: Elementi teorico-pratici di musica con un saggio sopra l'arte di suonare il violino. Roma I79I-1 796

GALLARATI, Paolo: Musica e maschera. Il libretto italiano del Settecento. Torino I984

GARVEY, Catherine: Spielen. Stuttgart 1978

GIER, Albert: Oper als Text. Romanistische Beiträge zur Libretto-Forschung. Heidelberg 1986

GIER, Albert: Das Libretto. Theorie und Geschichte einer musikoliterarischen Gattung. Darmstadt 1998

GINGUENÉ, Pierre-Louis: Niccolò Piccinni. Vita e Opere. Bari 1999

GOLDIN, Daniela: Aspetti della librettistica italiana fra I770 e I830. In: LIPPMANN, Friedrich (Hg.): Colloquium „Die stilistische Entwicklung in der italienischen Musik zwischen 1770 und I830 und ihre Beziehung zum Norden" (Rom I978). Laaber I 982 (Analecta musicologica 2I), S. I28-I9I

GOLDONI, Carlo: Tutte le Opere di Carlo Goldoni. Hg. von Giuseppe Ortolani. Milano 1935

GOLDONI, Carlo: Memorie. Con un'appendice di scritti goldoniani. Übers. von Eugenio Levi, hg. von Guido Davico Bonino. Torino 1967

GRIMM, Reinhold; BERGHAHN, Klaus L. (Hg.): Wesen und Formen des Komischen im Drama. Darmstadt I975

GRONDIN, Jean: Spiel, Fest und Ritual bei Gadamer. Zum Motiv des Unvordenklichen in seinem Spätwerk. In: BAUER, Günther G. (Hg.) : Homo ludens. Fest und Spiel. Bd. 8. Internationale Beiträge des Institutes für Spielforschung und Spielpädagogik an der Hochschule „Mozarteum“ Salzburg. München, Salzburg 1998, S. 43-52

GROOS, Karl: Die Spiele der Menschen. Jena I 899

GRUBER, Gernot: Komponierte Spontanität und die Idee der Improvisation. In: BORCHMEYER, Dieter; GRUBER, Gernot (Hg.): Mozarts Opern. Laaber 2007 (Das Mozart Handbuch 3), S. I9-27 
HAGER, Manuela: Die Opernprobe als Theateraufführung: Eine Studie zum Libretto in Wien des I8. Jahrhunderts. In: GIER, Albert (Hg.): Oper als Text: Romanische Beiträge zur Libretto-Forschung. Heidelberg I986, S. I I-24

HANSELL, Sven H.: Ferdinando Bertoni's setting of Calzabigi’s „Orfeo ed Euridice“. In: MURARO, Maria Teresa (Hg.): Venezia e il melodramma del settecento. Bd. 2. Firenze I98 I (Studi di musica veneta 7), S. I85-2 I I

HEARTZ, Daniel: The Creation of the Buffo Finale in Italian Opera. In: Proceedings of the Royal Musical Association 104 (1977-78), S. 67-78

HEARTZ, Daniel: Goldoni, Don Giovanni and the dramma giocoso. In: Musical Times I 20, I 979, S. 993-998

HEARTZ, Daniel: Vis comica: Goldoni, Galuppi and "L'Arcadia in Brenta“ (Venice I749). In: MURARO, Maria Teresa (Hg.) : Venezia e il melodramma nel settecento. Bd. 2. Firenze I98 I (Studi di musica veneta 7), S. 33-73

HELLMANN, Manfred: Grundzüge der Geschichte Venedigs. Darmstadt 1976

HENZE-DÖHRING, Sabine: Opera seria, Opera buffa und Mozarts „Don Giovanni“. Regensburg 1986

HUIZINGA, Johan: Homo ludens. Vom Ursprung der Kultur im Spiel. Hamburg 1956

HUNTER, Mary: The Culture of Opera Buffa in Mozart's Vienna. A Poetics of Entertainment. Princeton 1999

IACONO, Alfonso M.: L'illusione e il sostituto. Milano 20 Iо

IGLHAUT, Stefan; RÖTZER, Florian; SCHWEEGER, Elisabeth (Hg.): Illusion und Simulation. Begegnung mit der Realität. Ostfildern 1995

IMBUCCI, Giuseppe: Lotto, totocalcio, lotterie. Storia dei comportamenti sociali. Venezia I 997

ISER, Wolfgang: Das Komische: ein Kipp-Phänomen. In: PREISENDANZ, Wolfgang; WARNING, Rainer (Hg.): Poetik und Hermeneutik VII. S. 398-402

JACOBSHAGEN, Arnold: Farsa sentimentale - Melodramma eroicomico - Opera semiseria. Zur Gattungskonvergenz in der venezianischen Oper um I80o. In: HAUK, Franz; WINKLER, Iris (Hg.): Johann Simon Mayr und Venedig. Beiträge des Internationalen musikwissenschaftlichen Johann-Simon-Mayr-Symposiums Ingolstadt 1998. München, Salzburg I999 (Mayr-Studien 2), S. 95-I04

JACOBSHAGEN, Arnold: Opera semiseria. Gattungskonvergenz und Kulturtransfer im Musiktheater. Stuttgart 2005 (Archiv für Musikwissenschaft, Beiheft 57)

JASCHKE, Regina: Formen der Selbstbezüglichkeit in der frühen Oper. Diss. Universität Wien 2005

JÜNGER, Friedrich Georg: Die Spiele. Ein Schlüssel zu Ihrer Bedeutung. Frankfurt a. M. I953

KELLY-BYRNE, Diana; SUTTON-SMITH, Brian: The masks of play. New York 1984

KERÉNYI, Karl: Vom Wesen des Festes (1938). In: KERÉNYI, Karl: Werke in Einzelausgaben: Antike Religion. Stuttgart I995, S. 33-5 I

KIPPER, Christian: Musikalische Aktion in der Opera buffa. "Il mercato di Malmantile" von Carlo Goldoni. Frankfurt a. M. 2003 (Perspektiven der Opernforschung, Bd. Io)

KONRAD, Ulrich: Bearbeitungspraxis in der Oper des späten I8. Jahrhunderts. Bericht über die 
Internationale wissenschaftliche Tagung vom I8. bis 20. Februar 2005 in Würzburg. Tutzing 2007

KREUZER, Karl Josef (Hg.): Handbuch der Spielpädagogik. Düsseldorf I 983

KRUSCHKOVA, Krassimira; BÖHLER, Arno (Hg.): Dies ist kein Spiel. Maske und Kothurn $54 / 4(2008)$

KUNZE, Stefan: Don Giovanni vor Mozart. München 1972

KUNZE, Stefan: Per una descrizione tipologica della introduzione nell'opera buffa del settecento e particolarmente nei drammi giocosi di Carlo Goldoni e Baldassarre Galuppi. In: MURARO, Maria Teresa (Hg.): Galuppiana I985: Studi e ricerche. Firenze 1986, S. I65-78

KUNZE, Stefan: Su alcune farse di Giuseppe Foppa musicate da Francesco Gardi. In: MURARO, Maria Teresa (Hg.): I vicini di Mozart. Firenze 1989, Bd. 2, S. 479-488

KUNZE, Stefan: Die Sinfonie im I8. Jahrhundert. Von der Opernsinfonie zur Konzertsinfonie. Laaber I 993

LAMPING, Dieter: Ist Komik harmlos? Zu einer Theorie der literarischen Komik und der komischen Literatur. In: Literatur für Leser (1994), S. 53-65

LAZAREVICH, Gordana: Transformation of an Intermezzo. Cimarosas "Il pittore parigino" as a Reflection of I 8th Century Operatic Performance Practices. In: ANTOLINI, Bianca Maria; WITZENMANN, Wolfgang (Hg.): Napoli e il teatro musicale in Europa tra Sette e Ottocento. Firenze I993, S. I75-189

LEOPOLD, Silke: Einige Gedanken zum Thema Komische Oper in Venedig vor Goldoni. In: MAHLING, Christoph-Hellmut; WIESMANN, Sigrid (Hg.): Bericht über den internationalen musikwissenschaftlichen Kongress Bayreuth I98I. Kassel I984, S. 85-93

LINK, Dorothea: The Da Ponte Operas of Martin y Soler. Ph. D. Dissertation, University of Toronto I99I

LIPPMANN, Friedrich: Il mio ben quando verrà. Paisiello creatore di una nuova semplicità. In: Studi musicali XIX (1990/92), S. 385-405

LIPPMANN Friedrich: Das „Große“ Finale in Opera buffa und Opera seria. Paisiello und Rossini. In: HORTSCHANSKY, Klaus (Hg.): Traditionen - Neuansätze. Für Amalie Abert (1906-1996). Tutzing 1997, S. 377-398

LÜHNING, Helga: Die Rondo-Arie im späten I8. Jahrhundert. Dramatischer Gehalt und musikalischer Bau. In: Hamburger Jahrbuch für Musikwissenschaft 5 (I98I), S. 2 I 9-246

LÜHNING, Helga: Die Cavatina in der italienischen Oper um I80o. In: LIPPMANN, Friedrich (Hg.): Colloquium „Die stilistische Entwicklung in der italienischen Musik zwischen 1770 und I 830 und ihre Beziehung zum Norden "(Rom I978). Laaber 1982 (Analecta musicologica 2I), S. 333-368

MANFREDINI, Vincenzo: Dello stile buffo. In: Ders.: Regole armoniche o sieno precetti ragionati per apprendere la musica. 2. Ausg., Venezia I797, S. I 3 I-I 37

MANGINI, Nicola: I teatri di Venezia. Milano I974

MANGINI, Nicola: Sulla diffusione dell'opera comica nei teatri veneziani. In: MURARO, Maria Teresa (Hg.): Venezia e il melodramma nel settecento. Bd. I. Firenze I 978 (Studi di musica veneta 6$)$, S. I75-I 84 
MARCELLO, Benedetto: Il teatro alla moda. Venezia I 720

MARTINI, Fritz: Johann Elias Schlegel: Die stumme Schönheit. Spiel und Sprache im Lustspiel. Mit einem Anhang: „Einige Überlegungen zur Poetik des Lustspiels“. In: GRIMM, Reinhold; BERGHAHN, Klaus L. (Hg.): Wesen und Formen des Komischen im Drama. Darmstadt I975, S. 303-365

MASTNAK, Wolfgang: Das Spiel: mystische Brücke zwischen Mensch und Kunst. Aspekte von Musik- und Spieltherapie. In: BAUER, Günther G. (Hg.): Homo ludens. Musik und Spiel. Bd. Io. Internationale Beiträge des Institutes für Spielforschung und Spielpädagogik an der Hochschule „Mozarteum“ Salzburg.. München, Salzburg 2000, S. 275-286

MATTERN, Volker: Das Dramma giocoso La finta giardiniera: Ein Vergleich der Vertonungen von Pasquale Anfossi und Wolfgang Amadeus Mozart. Laaber 1989

MATUSCHEK, Stefan: Literarische Spieltheorie. Von Petrarca bis zu den Brüdern Schlegel. Heidelberg I 998

MATZAT, Wolfgang: Dramenstruktur und Zuschauerrolle. Theater in der französischen Klassik. München 1982

MAZZOLA, Alessandro: Giocatori e spie. Note e segnalazioni in materia di ludicità veneziana del XVIII secolo. In: Ludica. Annali di storia e civiltà del gioco. 5-6, Treviso 2000, S. $265-269$

METZELTIN, Michele: Appunti sulla poetica dei drammi giocosi goldoniani. In: GIER, Albert (Hg.): Oper als Text. Romanistische Beiträge zur Libretto-Forschung. Heidelberg 1986, S. $55-64$

MIGGIANI, Maria Giovanna: Il teatro di San Moisè (1793-1818). Bollettino del centro Rossiniano di Studi. Anno XXX (1990) n. I-3. Urbino I99 I

MILIZIA, Francesco: Trattato completo, formale e materiale del teatro. Venezia 1794

MILLAR, Susanna: Psychologie des Spiels. Ravensburg 1973

MÜLLER-LINDENBERG, Ruth: Weinen und Lachen. Dramaturgie und musikalisches Idiom der Opéra-comique im Vergleich zur Opera buffa (1750-1790). Berlin 2006

MURARO, Maria Teresa (Hg.): Venezia e il melodramma nel settecento. Firenze 1978-I98 I (Studi di musica veneta 6-7)

MURARO, Maria Teresa (Hg.) : I vicini di Mozart. Il teatro musicale tra Sette e Ottocento. Firenze 1989

NATALI, Giulio: La vita italiana del Settecento. In: Rivista d'Italia. Bd. I/4, I 922

NICASTRO, Guido: Goldoni e il teatro del secondo Settecento. Rom, Bari 1974

OERTER, Rolf: Psychologie des Spiels. Weinheim I 997

OERTER, Rolf; MONTADA, Leo (Hg.) : Entwicklungspsychologie. 4. Aufl. Weinheim I 998

OSTHOFF, Wolfgang: Mozarts Cavatinen und ihre Tradition. In: STAUDER, Wilhelm; AARBURG, Ursula; CAHN, Peter (Hg.): Frankfurter musikhistorische Studien: Helmuth Osthoff zu seinem siebzigsten Geburtstag. Tutzing I 969, S. I39-77

OSTHOFF, Wolfgang: Die Opera buffa. In: Gattungen der Musik in Einzeldarstellungen. Gedenkschrift Leo Schrade. Bern, München 1973, S. 678-743

OSTHOFF, Wolfgang: Gli endecasillabi villottistici in „Don Giovanni“ e „Nozze di Figaro“. In: 
MURARO, Maria Teresa (Hg.): Venezia e il melodramma nel settecento. Bd. 2. Firenze I98 I (Studi di musica veneta 7), S. 293-3 I I

OSTHOFF, Wolfgang; WIESEND, Reinhard (Hg.): Mozart e la drammaturgia veneta. Tutzing 1996 (Mozart Studien 6)

PALADINI VOLTERRA, Angela: Verso una moderna produzione teatrale. Appendice I: il repertorio a Venezia dal 1759 al I797. Appendice II: cenni critici per una bibliografia sul dramma borghese in Italia. In: Quaderni di teatro, V, Nr. 20, maggio I983, S. 87-I 44

PASSADORE, Francesco; ROSSI, Franco: Il Teatro San Benedetto di Venezia. Cronologia degli spettacoli I755-I8I0. Venezia 2003

PFISTER, Manfred: Das Drama. Theorie und Analyse. I I. Aufl. München 200 I

PIPERNO, Franco: L'opera in Italia nel secolo XVIII. In: BASSO, Alberto (Hg.): Musica in scena. Storia dello spettacolo musicale. Bd. 2. Gli italiani all'estero. L'opera in Italia e in Francia. Torino 1996, S. 97-199

PIPERNO, Franco: „La mia cara Cecchina è baronessa“. Livelli stilistici e assetto drammaturgico ne la buona figliuola di Goldoni-Piccinni. In: LIPPMANN, Friedrich (Hg.): Studien zur italienischen Musikgeschichte XV. Laaber 1998 (Analecta musicologica 30/II), S. 523-542

PIRROTTA, Nino: Commedia dell'arte and Opera. In: Musical Quarterly 4I, I955, S. 305-324

PIRROTTA, Nino: Don Giovanni in musica. Venezia I99 I

PIRROTTA, Nino: Divagazioni su Goldoni e il dramma giocoso. In: Rivista italiana di musicologia XXXII (1997), S. гоo-1o8

PLANELLI, Antonio: Dell'opera in musica. Napoli 1772

PLATOFF, John: Musical and Dramatic Structure in the Opera Buffa Finale. In: JM 7 (I989), S. I9I-230

PLATOFF, John: A New History for Martin's, Una cosa rara: In: JM I 2 I 994, S. 85-I I 5

PLATOFF, John: Catalogue Arias and the ,Catalogue Aria: In: SADIE, Stanley (Hg.): Wolfgang Amadé Mozart. Essay on his life and music. Oxford I996, S. 296-3 I I

PLESSNER, Helmuth: Lachen und Weinen. Eine Untersuchung der Grenzen menschlichen Verhaltens. (194I). In: Ders.: Gesammelte Schriften VII. Ausdruck und menschliche Natur. Hg. von Günter Dux, Odo Marquard, Elisabeth Ströker. Frankfurt a. M. I982, S. 20I-387

PLESSNER, Helmuth: Zur Anthropologie des Schauspielers. In: RAPP, Uri: Rolle. Interaktion. Spiel. Eine Einführung in die Theatersoziologie. Wien, Köln, Weimar I993, S. I36-I 48

POLIN, Giovanni: Introduzione. In: Carlo Goldoni: Drammi comici per musica (I748-I75I). Hg. von Silvia Urbani. Venezia 2007, S. 9-i I 9

POLIN, Giovanni : „Il mondo della luna“ di Goldoni-Galuppi: uno studio sulla tradizione settecentesca. In: Fonti musicali italiane I 3 (2008), S. 7-60

POLZONETTI, Pierpaolo: Italian Opera in the Age of the American Revolution. Cambridge $201 \mathrm{I}$

RAPP, Uri: Handeln und Zuschauen. Untersuchungen über den theatersoziologischen Aspekt in der menschlichen Interaktion. Darmstadt 1973

RAPP, Uri: Rolle, Interaktion, Spiel. Eine Einführung in die Theatersoziologie. Wien, Köln, Weimar 1993 
RASSEM, Mohammed: Das Fest als Spiel - Spiele als Feste oder Festersatz. In: BAUER, Günther G. (Hg.): Homo ludens. Fest und Spiel. Bd. 8. Internationale Beiträge des Institutes für Spielforschung und Spielpädagogik an der Hochschule „Mozarteum“ Salzburg. München, Salzburg 1998, S. 77-88

RICHTER, Christoph: Musik als Spiel. Orientierung des Musikunterrichts an einem fachübergreifenden Begriff. Ein didaktisches Modell. Wolfenbüttel, Zürich, I975

ROBINSON, Michael F.: Opera before Mozart. New York 1967

ROBINSON, Michael F.: Giovanni Paisiello. A Thematic Catalogue of his Works. Stuyvesant N. Y. I99I-I 994

ROLANDI, Ulderico: Il librettista del „Matrimonio segreto“ Giovanni Bertati. Tricase 1926

ROMMEL, Otto: Komik und Lustspieltheorie. In: GRIMM, Reinhold; BERGHAHN, Klaus

L. (Hg.): Wesen und Formen des Komischen im Drama. Darmstadt I975, S. 39-76

ROSSELLI, John: L'impresario d'opera. Arte e affari nel teatro musicale dell'Ottocento. Torino I 985

RUSSO, Francesco Paolo (Hg.): Giovanni Paisiello e la cultura europea del suo tempo. (Convegno internazionale di studi. Taranto 20-23 giugno 2002) Lucca 2007

SARTORI, Claudio: I libretti italiani a stampa dalle origini al I800. Cuneo I990-1994

SCHEUERL, Hans: Theorien des Spiels. Weinheim, Basel 1975

SCHEUERL, Hans: Das Spiel. Bd. I. Untersuchungen über sein Wesen, seine pädagogischen Möglichkeiten und Grenzen. Weinheim, Basel I 990

SCHÖPFLIN, Karin: Theater im Theater. Formen und Funktionen eines dramatischen Phänomens im Wandel. Frankfurt a. M. I993

SLOTERDIJK, Peter: Für eine Philosophie des Spiels. In: Ders.: Der ästhetische Imperativ. Schriften zur Kunst. Hg. von Peter Weibel. Hamburg 2007

SONNECK, Oscar G.: Catalogue of Opera Librettos Printed before I80o. Washington D.C. I 9 I 4 STEPINA, Clemens: Systematische Handlungstheorie. Wien 2007

STILLE, Michael: Möglichkeiten des Komischen in der Musik. Frankfurt a. M. I990

STROHM, Reinhard: Die italienische Oper im I8. Jh. Wilhelmshaven 1979

SUTTON-SMITH, Brian: The ambiguity of play. Cambridge 1997

TAMASSIA MAZZAROTTO, Bianca: Le feste veneziane. I giochi popolari, le cerimonie religiose e di governo. Firenze I96I

TIBALDI CHIESA, Mary: Cimarosa e il suo tempo. Milano I939

TRINCANATO, Egle; FRANZOI, Umberto: Venise au fil du temps. Paris I97I

VALERI, Diego: Il mito del Settecento veneziano. In: BRANCA, Vittore (Hg.): Storia della civiltà veneziana. Bd. 3. Dall'età barocca all'Italia contemporanea. Firenze 1979

VALENTE, Mario: L'inafferrabile felicità e il senso del tragico. L'Olimpiade, Metastasio e Cimarosa. (Atti del convegno Venezia 2001). Roma 2003

VAN BAEST, Arjan: A semiotics of opera. Delft, 2000

VILLINGER, Christine: Mi vuoi tu corbellar. Die opere buffe von Giovanni Paisiello. Tutzing 2000 (Mainzer Studien zur Musikwissenschaft 40)

WALTON, Kendall L.: Mimesis as Make-Believe. On the Foundation of the representational Arts. Cambridge, London 1993 
WEBER, Horst: Der Serva-padrona-Topos in der Oper. Komik als Spiel mit musikalischen und sozialen Normen. In: Archiv für Musikwissenschaft 65 (I988), S. 87-I Io

WEBSTER, James: Understanding Opera buffa. Analysis = Interpretation. In: HUNTER, Mary; WEBSTER, James (Hg.): Opera Buffa in Mozart's Vienna. Cambridge 1997, S. 340-77

WEISS, Piero: La diffusione del repertorio operistico nell'Italia del Settecento. Il caso dell'opera buffa. In: DAVOLI, Susi (Hg.): Civiltà teatrale e Settecento emiliano. Bologna I986, S. $24 \mathrm{I}-56$

WETZEL, Tanja: Art. Spiel. In: BARCK, Karlheinz u. a. (Hg.): Ästhetische Grundbegriffe. Historisches Wörterbuch in sieben Bänden. Bd. 5. Stuttgart 2010, S. 577-61 8

WIEL, Taddeo: I teatri musicali veneziani del settecento. Catalogo delle opere in musica rappresentate nel secolo XVIII in Venezia (I70I-I800). Venezia I 897

WIESEND, Reinhard: Art. Opera buffa. In: FINSCHER, Ludwig (Hg.): Die Musik in Geschichte und Gegenwart. 2., neubearb. Ausg. Sachteil Bd. 7/1. Kassel u. a. I 995

WIESEND, Reinhard: Exkurs zur Geschichte der Rollenbezeichnungen. In: OSTHOFF, Wolfgang; WIESEND, Reinhard (Hg.): Mozart e la Drammaturgia Veneta. Tutzing I 996 (Mozart Studien 6), S. 9I-93

WIESEND, Reinhard; SCHNEIDER, Herbert: Oper im I8. Jahrhundert. Laaber $200 \mathrm{I}$ (Handbuch der musikalischen Gattungen I 2)

WINNICOTT, Donald W.: Vom Spiel zur Kreativität. Stuttgart 1985

WITTGENSTEIN, Ludwig: Philosophische Untersuchungen. Frankfurt a. M. I977

WITZENMANN, Wolfgang: Grundzüge der Instrumentation in ltalienischen Opern von 1770 bis I830. In: LIPPMANN, Friedrich (Hg.): Colloquium „Die stilistische Entwicklung in der italienischen Musik zwischen 1770 und I830 und ihre Beziehung zum Norden" (Rom I978). Laaber 1982 (Analecta musicologica 21), S. 276-332

ZOLLINGER, Manfred: Der „König der Spiele“ im Theater des I8. Jahrhunderts. In: Ludica. Annali di storia e civiltà del gioco. 2. Treviso 1996, S. 237-250

ZOLLINGER, Manfred; DEPAULIS Thierry: Zwischen Allegorie und Realismus. Zur Thematisierung des Spiels in der Musik. In: BAUER, Günther G. (Hg.): Homo ludens. Musik und Spiel. Bd. Io. Internationale Beiträge des Institutes für Spielforschung und Spielpädagogik an der Hochschule „Mozarteum“ Salzburg. München, Salzburg 2000, S. 37-I I 3

ZULATTI, Giovanni Francesco: Della forza della musica nelle passioni, nei costumi, e nelle malattie, e dell'uso medico del ballo. Discorso. Venezia 1787 


\section{DANKSAGUNG}

Diesem Buch liegt eine im Juni 20 I 2 am Institut für Musikwissenschaft der Universität Wien approbierte Dissertation zugrunde. Meinem Betreuer, Herrn Prof. Dr. Gernot Gruber, danke ich besonders herzlich für die anregenden Gespräche und die Offenheit, die er mir bei der Themenfindung entgegengebracht hat, sowie für die Aufnahme meiner Arbeit in seine Schriftenreihe Wiener Musikwissenschaftliche Beiträge.

Mein Dank gilt auch der Österreichischen Akademie der Wissenschaften für ein Doktoratsstipendium (DOC) und dem Historischen Institut beim Österreichischen Kulturforum in Rom für ein Forschungsstipendium (ROM), durch die mein Dissertationsprojekt wirksam gefördert wurde. Die Einsicht in viele, in verschiedenen europäischen Bibliotheken verstreute Partituren bzw. ihre Beschaffung wäre ohne diese finanzielle Unterstützung gewiss schwieriger gewesen.

Für die Möglichkeit, Libretti und Partituren einzusehen und zu fotografieren, möchte ich mich an dieser Stelle bei Donna Isabella Massimo di Carpegna Falconieri (Rom) und Graf Ulrich Toggenburg (Bozen) bedanken sowie beim Don Juan Archiv Wien und den Bibliothekaren folgender Bibliotheken:

Biblioteca del Conservatorio di Musica „Arrigo Boito“ di Parma (Sezione musicale della Biblioteca Palatina di Parma), Biblioteca del Conservatorio di Musica "Cesare Pollini“ (Padua), Biblioteca del Conservatorio di Musica "Giuseppe Verdi“ di Milano, Biblioteca del Conservatorio di Musica „Niccolò Paganini“ di Genova, Biblioteca del Conservatorio di Musica San Pietro a Majella di Napoli, Biblioteca „Gianni Milner“, Fondazione Ugo e Olga Levi (Venedig), Biblioteca Musicale Governativa del Conservatorio di Musica Santa Cecilia (Rom), Biblioteca Musicale dell'Accademia Filarmonica di Torino, Biblioteca Musicale „Giuseppe Greggiati“ (Ostiglia), Bibliothèque de France (Paris), Casa di Carlo Goldoni (Venedig), Civica Biblioteca „Angelo Mai“ (Bergamo).

Die Drucklegung dieses Buches wurde dankenswerterweise vom Wissenschaftsfonds FWF unterstützt. 


\section{REgISTER}

Abert, Hermann 340

Alessandri, Felice 26, 287

Algarotti, Francesco 68

Amur, Gururaja S. 65, 373

Anfossi, Pasquale 25, I I 3 , I 32, I42, I 52, I 54 f., 2 I6, 2 I gf., 224, 240, 242, 248, 253, 259, 292, 325

Anz, Thomas 46, 49

Aristoteles 3 Iff., 44, 50, 66f., I I I

Arteaga, Stefano 68, 72f., 79, i I If., I I 5 f., i I $8 f$., I7I, 246f., 343

Astarita, Gennaro 25

Augustinus 3I

Bachtin, Michail 74, 254, 263

Bally, Gustav ${ }_{42} \mathrm{f}$.

Baretti, Giuseppe I I 4 ff.

Bargagli, Girolamo $32 \mathrm{ff}$.

Bateson, Gregory 37, 50, 88, I 42, 255, 300, 362, 374

Bender, Marylka I03

Benvenuti, Feliciano 17, 20, 378

Bertati, Giovanni 23, 25 f., I 32, I 49, I 52 , I 55 , I $80,254,287,292,296,300,345$

Bertoni, Ferdinando 297, 299

Bianchi, Francesco 26

Bilstein, Johannes 3 I 4

Böhme, Franz Magnus 366

Borges, Jorge Luis 199

Borghi, Giovanni Battista 262

Boroni, Antonio 244

Borsa, Matteo 64, I 22

Brandenburg, Daniel 366, $369 f$.

Brown, John I2 I

Bühler, Charlotte 55

Bühler, Karl 44

Buland, Rainer 57, 174, 302, 323, 339, 35 of.

Burney, Charles 7If., 90

Busek, Erhard 350

Buytendijk, Frederik Jacobus Johannes 35, 39, 43f., 89, гог, I 48, I76, I78, I 82, 323f., 339,

$366,370,372,376$

Caillois, Roger 39, 4I, 44, 48ff., 55, 57ff., 62, 70, 74, 76, I04, I25f., I $28 \mathrm{fff}$., I 55, I76, I98, 200, $302,323,339,34 \mathrm{I}, 343,345,35 \mathrm{I}$

Calegari, Giuseppe I39ff., 300

Calzabigi, Ranieri de’ 297

Caruso, Luigi I7I, 243, 247, 249, 252, 296f., 306f., 34I

Château, Jean 48, 55, I98, 323, 340, 344ff., 370

Cherubini, Luigi 26, 208, 261, 31 5, 322

Chiari, Pietro 25, 244

Cimarosa, Domenico 25, 64, 68, 21 2, 250, 26I, $267,280,294,352,358$

Claparède, Edouard $52 \mathrm{f}$.

Coleridge, Samuel Taylor 87

Colozza, Giovanni Antonio 55

Coltellini, Celeste 80

Csikszentmihalyi, Mihaly 47

Da Ponte, Lorenzo 25, I35, I38, I61, 340, 363

Derrida, Jacques 40

De Rossi, Giovanni Gherardo I I 8

Diderot, Denis 90

Du Bos, Jean-Baptiste 90

Duni, Egidio Romualdo I 17

Eibl, Karl 38, 49

Eigen, Manfred 30, 34, 40, 96

Erasmus von Rotterdam 32

Feldman, Martha 78, 89

Figdor, Helmuth iosf.

Fink, Eugen 30, 35, 39, 43f., 48, 5 Iff., 70, 85 f., 88, 92, 96f., 106, 282, 31 5, 370, 374

Fiorin, Alberto 326

Folena, Gianfranco 247

Freud, Sigmund 38, 46, 52

Fröbel, Friedrich Wilhelm August 55 
Fuchs, Mathias I 30

Gadamer, Hans-Georg 40, 43f., 53, 62, 76, 89, I 75, 370, 374, 376

Galeazzi, Francesco 68, I70

Galuppi, Baldassarre 2 I, 26, I80, 27 I, 345f.

Gardi, Francesco $299 f$.

Garvey, Catherine 213, 246, 257ff., 320, 346

Gazzaniga, Giuseppe 26, I39, I4I, I49, I 52 , 290, 30of., 355

Gluck, Christoph Willibald 297, 299

Goldoni, Carlo 2 I, 25f., 79, 8 If., 95, 98, ro9ff., I I 4 ff., I 32, 252

Gozzi, Gasparo 23

Grandi, Tommaso 25

Greppi, Giovanni (= Florimondo Ermioneo) I 86

Grondin, Jean 376

Groos, Karl 37, 46, 49, 53ff., 60, 62, 66, 93, 97, IoI, I05f., I77, 322, 365, 37I, 377

Guglielmi, Pietro Alessandro 25, 26I

Gumbrecht, Hans Ulrich 377

Guts Muths, Johann Christoph Friedrich 45, 55

Hanslick, Eduard Ioo

Heidegger, Martin 39

Heraklit 30, 39, 96

Huizinga, Johan 3I, 38f., 4If., 44, 47f., 50, $52 \mathrm{ff}$., 59f., 62, 70, 74, 76f., 85 ff., 92, 99ff., 109, I $27 f f .$, I 34, I 37 ff., I 49, I 5 I, I 57, I74, I76, I98, 229, 257, 279, 302, 31 5, 322f., 35of., 362, $364 \mathrm{ff} ., 374$

Hunter, Mary I I, 82, 89, 240, 376

Iacono, Alfonso 87

Imbucci, Giuseppe 338, 377

Iser, Wolfgang $\mathrm{I} 43,373$

Jablonski, Johann Theodor 73

Jünger, Friedrich Georg 47, I o2ff., 31 3, 3 I 6

Kant, Immanuel 35f., 46

Kerényi, Karl 350

Kipper, Christian I 23, 233

Klee, Paul 87
Kunze, Stefan 355

Lamping, Dieter 66

Lange, Konrad 54

Lazarus, Moritz 35, 37, 43, 60, 85

Leopold, Silke I 27

Link, Dorothea I 68

Livigni, Filippo 25, 21 2, 229, 290, 31 5, 325, 352

Locke, John 34, 45

Lorenzi, Giambattista 25, 282, 34I

Manfredini, Vincenzo 64, 68, I I6, 343

Mangini, Nicola I7, 20, 22

Martini, Fritz 67, 92f., 95, 200, 325

Martín y Soler, Vincente 26, I38, I40, I6I, I66, I 68

Mastnak, Wolfgang 3 I 4

Mattei, Saverio 68

Matuschek, Stefan 30, 33

Matzat, Wolfgang 9if., 95, I 38

Mazzolà, Caterino I 35

McCollom, William 96, I27f.

Metastasio, Pietro I I

Milizia, Francesco 70

Montada, Leo 20I, $30 \mathrm{I}$

Morgenstern, Oskar 40

Morichelli, Anna 80

Mortellari, Michele 25

Müller-Lindenberg, Ruth I23, I 29, I 37

Natale, Marco de IO4

Naumann, Johann Gottlieb 26

Neumann, John von 40

Nietzsche, Friedrich 39

Oerter, Rolf 99, I04, 20I, $30 \mathrm{I}$

Osthoff, Wolfgang 21, 374

Paisiello, Giovanni 25, 64, 68, I44, I47, I69f., 229, 25I, 259, 265,277, 282, 288, 302, 310, 363

Palomba, Giuseppe 25, 306

Petrosellini, Giuseppe 25, I I9, I 82, 327

Pfister, Manfred I 48, 228f., 280 
Piaget, Jean 55, 20I, 323

Piccinni, Niccolò 25, I I7, I I9, I82, I87, I90, I95, 20I, 327

Pisoni, Giuseppe Pietro 24

Planelli, Antonio 98

Platon 30, 45, 96, 98

Plessner, Helmuth 65f., 93, I06, 320

Quintilian 32

Rabelais, François 32

Rapp, Uri 38, 62, 85, 88, 90ff., 97, I05, I 37, I99

Rassem, Mohammed 35 I

Retemeyer, Kerstin 320

Richardson, Samuel I 7

Ringhieri, Innocentio 32

Robuschi, Ferdinando I 86

Rossi, Giovanni I6, 23

Rousseau, Jean-Jacques 35, 42, 45, I90

Rust, Giacomo 26, I32

Salieri, Antonio 26, I $34 \mathrm{f}$.

Sarti, Giuseppe 26, 68, I I 3, I 34, I 43, I 46

Scaino, Antonio 32

Schaller, Julius 38, 49f., 52, 60, 84

Scheuerl, Hans 35, 39, 4Iff., 47, 5I, 53, 55f., 6of., 7I, 75, 83ff., 89, Iо I, I43, I99, 258, 306, 3 I 6,374
Schiller, Friedrich 34, 36, 42, 5I, 54f., 3 I 4

Schöpflin, Karin 287

Schuster, Joseph 26

See, Max 301

Sorel, Charles 34

Speroni, Sperone 33

Stepina, Clemens 38, 43f., 46, 50

Steptun, Fedor 97

Stern, William 49

Strohm, Reinhard 375

Sutton-Smith, Brian 34, 38, 46, 48, I 3 I

Tasso, Torquato 33, 94

Valentini, Giovanni 25

Valla, Lorenzo 32

Waisman, Leonardo J. 164

Walton, Kendall L. I98, 2 I 3, 227

Wiel, Taddeo I9, 7of., 74, 376

Wiesend, Reinhard I 2

Winkler, Ruthild 30, 34, 40, 96

Winnicott, Donald W. 86f., ros

Witt, Sigrun IO2

Wittgenstein, Ludwig 28, $56 f$.

Zollinger, Manfred 72, 327

Zulatti, Giovanni Francesco 64, 98, 307, 309 
WIENER MUSIKWISSENSCHAFTLICHE BEITRÄGE

HERAUSGEGEBEN VON GERNOT GRUBER UND

THEOPHIL ANTONICEK

EINE AUSWAHL

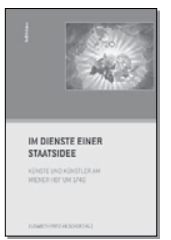

BD. 24 | ELISABETH FRITZ-HILSCHER (HG.) IM DIENSTE EINER STAATSIDEE KÜNSTE UND KÜNSTLER AM WIENER HOF UM 1740

2013. 244 S. 21 S/W-ABB. UND 8 TAB. GB. $€ 39,90$ | ISBN 978-3-205-78927-7

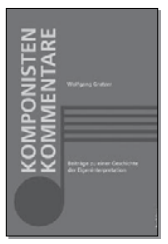

BD. 22 | WOLFGANG GRATZER

KOMPONISTENKOMMENTARE

BEITRÄGE ZU EINER GESCHICHTE DER

EIGENINTERPRETATION

2003. 384 S. 46 FAKS. GB.

$€ 45,00$ (UVP) | ISBN 978-3-205-77055-8

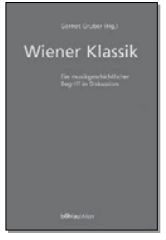

BD. 21 | GERNOT GRUBER (HG.) WIENER KLASSIK

EIN MUSIKGESCHICHTLICHER BEGRIFF IN DISKUSSION

2002. 198 S. 10 NOTENBSP. BR.

$€ 29,90$ | ISBN 978-3-205-99383-4

BD. 20/1,2 | JOSEPH RIEPEL

SÄMTLICHE SCHRIFTEN ZUR MUSIKTHEORIE

1996. 1093 S. ZAHLR. FAKS. GB.

$€ 255,80 \mid$ ISBN 978-3-205-98618-8

BD. 19 | JOSEF-HORST LEDERER

VERISMO AUF DER DEUTSCH-

SPRACHIGEN OPERNBÜHNE 1891-1926

EINE UNTERSUCHUNG SEINER

REZEPTION DURCH DIE ZEITGENÖS-

SISCHE MUSIKALISCHE FACHPRESSE

1992. 316 S. BR.

$€ 43,70$ | ISBN 978-3-205-05506-8

BÖHLAU VERLAG, WIESINGERSTRASSE I, A-IOIO WIEN, T: + 43 I 33024 27-O INFO@BOEHLAU-VERLAG.COM, WWW.BOEHLAU-VERLAG.COM | WIEN KÖLN WEIMAR 


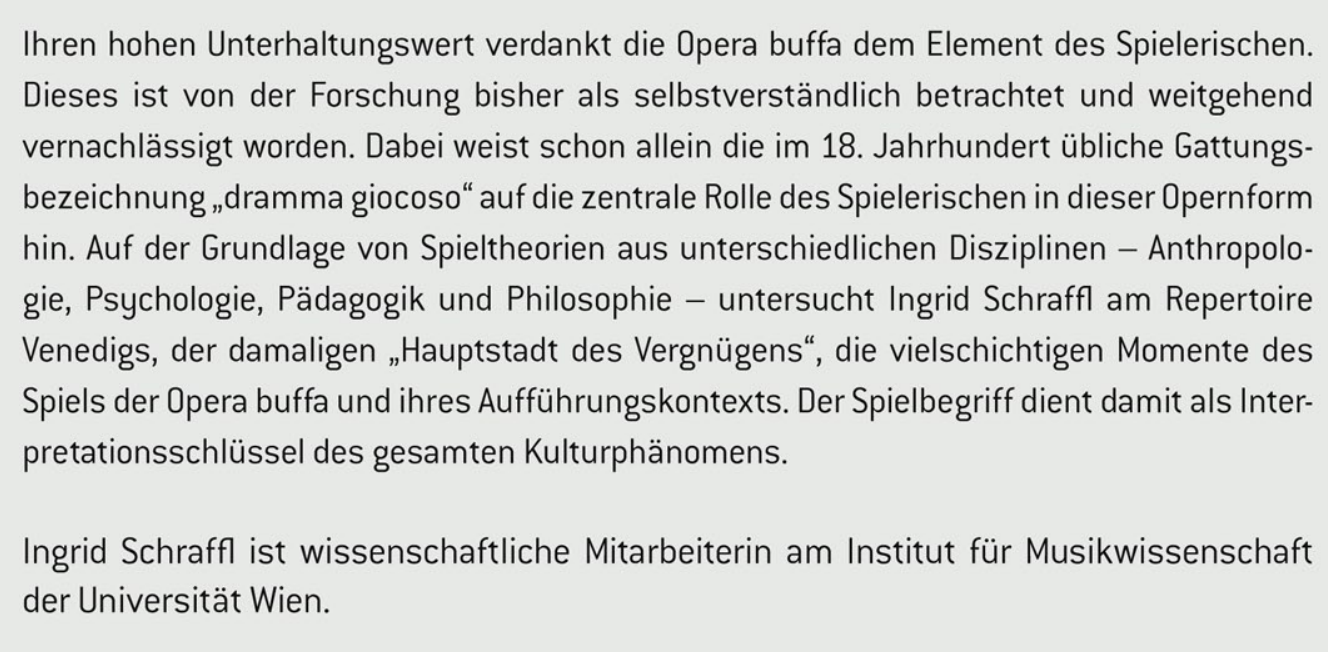

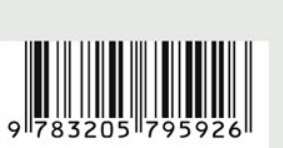

